\title{
International Energy Agency Building Energy Simulation Test (BESTEST) and Diagnostic Method
}

Click Here for

[- Supporting Files

\author{
R. Judkoff \\ J. Neymark
}
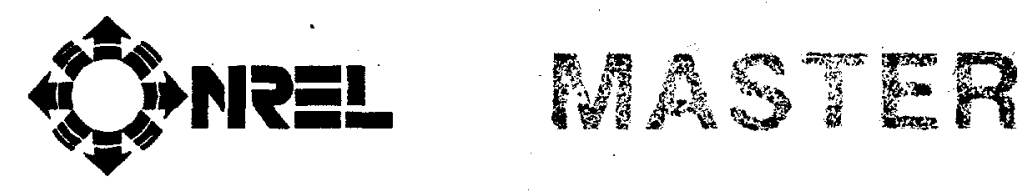

National Renewable Energy Laboratory

1617 Cole Boulevard

Golden, Colorado 80401-3393

A national laboratory of the
U.S. Department of Energy
managed by Midwest Research Institute
for the U.S. Department of Energy
under Contract No. DE-AC36-83CH10093

DISTRIBUTION OF THIS DOCUMENT IS UNLIMITED February 1995

A cooperative project between IEA Solar Heating and Cooling Task 12B and IEA Energy Conservation in Buildings and Community Systems Annex 21C

IEA SHC Task 12: $\quad$ Building Energy Analysis and Design Tools for Solar Applications

Subtask B: Model Evaluation and Improvement

IEA BCS Annex 21: Calculation of Energy and Environmental Performance of Buildings

Subtask C: $\quad$ Reference Cases and Evaluation Procedures 


\section{DISCLAIMER}

This report was prepared as an account of work sponsored by an agency of the United States Government. Neither the United States Government nor any agency thereof, nor any of their employees, make any warranty, express or implied, or assumes any legal liability or responsibility for the accuracy, completeness, or usefulness of any information, apparatus, product, or process disclosed, or represents that its use would not infringe privately owned rights. Reference herein to any specific commercial product, process, or service by trade name, trademark, manufacturer, or otherwise does not necessarily constitute or imply its endorsement, recommendation, or favoring by the United States Government or any agency thereof. The views and opinions of authors expressed herein do not necessarily state or reflect those of the United States Government or any agency thereof. 


\section{DISCLAIMER}

Portions of this document may be illegible in electronic image products. Images are produced from the best available original document. 
The International Energy Agency (IEA), headquartered in Paris, was formed in November 1974 as an autonomous body within the framework of the Organization for Economic Cooperation and Development to establish cooperation in the area of energy policy. Twenty-one countries are presently members, with the Commission of the European Communities participating under a special arrangement.

Collaboration in the research, development, and demonstration of new energy technologies has been an important part of the agency's programme. The IEA R\&D activities are headed by the Committee on Research and Technology (CERT), which is supported by a small secretariat staff. In addition, four Working Parties (in Conservation, Fossil Fuels, Renewable Energy, and Fusion) are charged with monitoring the various collaborative energy agreements, identifying new areas for cooperation, and advising the CERT on policy matters.

The work reported here resulted from a cooperative effort between the IEA Solar Heating and Cooling Programme Task 12B and the IEA Energy Conservation in Buildings and Community Systems Programme Annex 21C.

\section{Solar Heating and Cooling Programme}

Initiated in 1977, the Solar Heating and Cooling Programme was one of the first IEA R\&D agreements. Its objective is to conduct joint projects to advance solar technologies for buildings. The twenty members of the programme are

$\begin{array}{lll}\text { Australia } & \text { France } & \text { Spain } \\ \text { Austria } & \text { Germany } & \text { Sweden } \\ \text { Belgium } & \text { Italy } & \text { Switzerland } \\ \text { Canada } & \text { Japan } & \text { Turkey } \\ \text { Denmark } & \text { The Netherlands } & \text { United Kingdom } \\ \text { European Community } & \text { New Zealand } & \text { United States } \\ \text { Finland } & \text { Norway } & \end{array}$

A total of 18 projects or "tasks" have been undertaken since the beginning of the programme. The overall programme is managed by an Executive Committee composed of one representative from each of the member countries, while the leadership and management of the individual tasks is the responsibility of operating agents. These tasks and their respective operating agents are.

*Task 1: Investigation of the Performance of Solar Heating and Cooling Systems - Denmark

*Task 2: Coordination of Research and Development on Solar Heating and Cooling - Japan

*Task 3: Performance Testing of Solar Collectors - United Kingdom

*Task 4: Development of an Insulation Handbook and Instrument Package - United States

*Task 5: Use of Existing Meteorological Information for Solar Energy Application - Sweden

*Task 6: Solar Heating, Cooling, and Hot Water Systems Using Evacuated Collectors - United States

*Task 7: Central Solar Heating Plants with Seasonal Storage - Sweden

*Task 8: $\quad$ Passive and Hybrid Solar Low Energy Buildings - United States

*Task 9: Solar Radiation and Pyranometry Studies - Federal Republic of Germany

*Task 10: Material Research and Testing - Japan

*Task 11: Passive and Hybrid Solar Commercial Buildings - Switzerland

Task 12: Building Energy Analysis and Design Tools for Solar Applications - United States

Task 13: Advanced Solar Low Energy Buildings - Norway

Task 14: Advanced Active Solar Systems - Canada

Task 15: (Not Initiated)

Task 16: Photovoltaics in Buildings - Germany

Task 17: Measuring and Modeling Spectral Radiation - Germany

Task 18: Advanced Glazing Materials - United Kingdom

Task 19: Solar Air Systems - Sweden

Task 20: Solar Retrofit Systems - Sweden

* Completed task 


\section{Energy Conservation in Bulldings and Community Systems Programme}

The IEA sponsors research and development in a number of areas related to energy. In one of these areas, energy conservation in buildings, the IEA is sponsoring various exercises to predict more accurately the energy use of buildings, including the comparison of existing computer programs, building monitoring, the comparison of calculation methods, and studies of occupancy and air quality. Seventeen countries have elected to participate in this area and have designated contracting parties to the Implementing Agreement covering collaborative research in this area. The designation by governments of a number of private organizations, as well as universities and government laboratories, as contracting parties has provided a broader range of expertise to tackle the projects in the different technology areas than would have been the case if participation were restricted to governments. The importance of associating industry with government-sponsored energy research and development is recognized in the IEA, and every effort is made to encourage this trend.

Overall control of the programme is maintained by an Executive Committee, which not only monitors existing projects, but identifies new areas where collaborative effort may be beneficial. The Executive Committee ensures that all projects fit into a predetermined strategy, without unnecessary overlap or duplication but with effective liaison and communication. The Executive Committee has initiated the following projects to date:

*Annex 1: Load energy determination of buildings

*Annex 2: $\quad$ Ekistics and advanced community energy systems

*Annex 3: Energy conservation in residential buildings

*Annex 4: Glasgow commercial building monitoring

Annex 5: Air infiltration and ventilation center

*Annex 6: Energy systems and design of communities

*Annex 7: Local government energy planning

*Annex 8: Inhabitants' behavior with regard to ventilation

*Annex 9: Minimum ventilation rates

*Annex 10: Building heating, ventilating, and air conditioning (HVAC) system simulation

*Annex 11: Energy auditing

*Annex 12: Windows and fenestration

*Annex 13: Energy management in hospitals

*Annex 14: Condensation and energy

*Annex 15: Energy efficiency of schools

Annex 16: BEMS 1-User interfaces and system integration

Annex 17: BEMS 2-Evaluation and emulation techniques

Annex 18: Demand controlled ventilating systems

Annex 19: Low slope roofs systems

Annex 20: Air flow patterns within buildings

Annex 21: Calculation of energy and environmental performance of buildings

Annex 22: Energy efficient communities

Annex 23: Multizone air flow modeling

Annex 24: Heat, air, and moisture transport in new and retrofitted insulated envelope parts

Annex 25: Real time simulation of HVAC systems and fault detection

Annex 26: Energy-efficient ventilation of large enclosures

Annex 27: Evaluation and demonstration of domestic ventilation systems

Annex 28: Low-energy cooling systems

* Completed project

\section{Tasks}

\section{Solar Task 12: Building Energy Analysis and Design Tools for Solar Applications}

The scope of Task 12 includes: (1) selecting and developing appropriate algorithms for modeling the interaction of solar energy-related materials, components, and systems with the building in which these solar elements are integrated; (2) selecting analysis and design tools, and evaluating the algorithms as to their ability to model the dynamic performance of the solar elements in respect to accuracy and ease of use; and (3) improving the usability of the analysis and design tools, by preparing common formats and procedures and by standardizing specifications for input/output, default values, and other user-related factors. 
The subtasks of this project are

Subtask A-Model Development

Subtask B-Model Evaluation and Improvement

Subtask C-Model Use.

The participants in this task are Denmark, Finland, the Federal Republic of Germany, Norway, Spain, Sweden, Switzerland, and the United States. However, for Subtask B, the following countries participate as a collaborative research activity of Annex 21 of the IEA Energy Conservation in Building and Community Systems Programme: Belgium, France, Italy, and the United Kingdom.

Architectural Energy Corporation serves on behalf of the U.S. Department of Energy as Operating Agent of Task 12.

Bulldings and Community Systems Annex 21: Calculation of Energy and Environmental Performance of Bulldings

The objectives of Annex 21 are to

1. Develop quality assurance procedures for calculating the energy and environmental performance of buildings by producing guidance on

- Program and modeling assumptions

- The appropriate use of calculation methods for a range of design applications

- The evaluation of calculation methods

2. Establish requirements and market needs for calculation procedures in building and environmental services design

3. Propose policy and strategic direction for the development of calculation procedures

4. Propose means to effect the technology transfer of calculation procedures into the building and environmental services design profession.

The subtasks of this project are

Subtask 21A-Documentation of Existing Methods

Subtask 21B-Appropriate Use of Models

Subtask 21C-Reference Cases and Evaluation Procedures

Subtask 21D-Design Support Environment.

The participants in this task are Belgium, France, the Federal Republic of Germany, Italy, The Netherlands, Switzerland, and the United Kingdom. Canada, Finland, and Sweden also participated in the early part of the project. For Subtask $\mathrm{C}$, the following countries participate as a collaborative research activity of Task 12 of the IEA Solar Heating and Cooling Programme: Finland, Spain, Sweden, and the United States.

This report documents work on intermodel comparisons carried out by the Model Evaluation and Improvement Group from Solar Task 12, Subtask B, and Conservation Annex 21, Subtask C. Other work on model evaluation performed by this group is published in separate documents. The Combined Experts Group is chaired by the National Renewable Energy Laboratory under auspices of the IEA Solar and Conservation Executive Committees, with support from the U.S. Department of Energy Office of Building Technology Passive Solar Program. 


\section{Acknowledgments}

This work was a cooperative effort involving the members of the International Energy Agency (IEA) Model Evaluation and Improvement Experts Group. The group was composed of experts from the IEA Solar Heating and Cooling Programme, Task 12B, and the IEA Energy Conservation in Buildings and Community Systems Programme, Annex 21C. The group was chaired by R. Judkoff of the National Renewable Energy Laboratory on behalf of the U.S. Department of Energy (DOE). Contributions from the modelers and the authors of sections on each of the computer programs used in this effort are gratefully acknowledged as follows:

- BLAST 3.0 Level 193 V.1-J. Neymark and R. Judkoff, modelers and authors; National Renewable Energy Laboratory (NREL), United States

- BLAST 3.0 Level 193 V.1-V. Bocchio and A. Mazza, modelers; Politecnico di Torinó, Italy

- CLIM 2000-P. Dalicieux, modeler and author; Electricite de France

- DEROB-LTH-P. Wallenten, modeler and author; University of Lund, Sweden

- DOE2.1D Level 14-J. Neymark and R. Judkoff, modelers and authors; NREL, United States

- ESP-RV8-H. Eppel and K. Lomas, modelers and authors; De Montfort University, Leicester, United Kingdom, for the Building Research Establishment (BRE), United Kingdom

- SERIRES/SUNCODE-J. Neymark and R. Judkoff, modelers and authors; NREL, United States

- SERIRES1.2 (ETSU version)—S.R. Hammond, modeler and author; Building Research Establishment, (BRE), United Kingdom

- S3PAS_S. Alvarez and E. Rodriguez, modelers and authors; Universidad de Sevilla, Spain

- TASE-S. Kataja, T. Kalema, and T. Haapala, modelers and authors; Tempere University, Finland

- TRNSYS 13.1-P. Verstraete and R. Van De Perre, modelers and authors; Vrije Universiteit, Brussels, Belgium

- TRNSYS 13.1-F. Parand, modeler and author; BRE, United Kingdom

Also, we appreciate the efforts of Michael Holtz and David Bloomfield, operating agents for Task 12 and Annex 21, respectively; Mary Margaret Jenior, DOE Program Manager for Task 12; and Theodore Kapus, DOE Representative to the IEA Solar Heating and Cooling Programme Executive Committee. 


\section{Executive Summary}

This is a report on the Building Energy Simulation Test (BESTEST) project conducted by the Model Evaluation and Improvement International Energy Agency (IEA) Experts Group. The group was composed of experts from the Solar Heating and Cooling (SHC) Programme, Task 12 Subtask B, and the Energy Conservation in Buildings and Community Systems (BCS) Programme, Annex 21 Subtask C. Recognizing that the needs for model evaluation were similar in both IEA programmes, the combined Experts Group was approved by the Executive Committees in 1990. This is the first joint group organized by the respective IEA Executive Committees, and it has resulted in significant cost savings for all participating countries.

The objective of this subtask has been to develop practical implementation procedures and data for an overall IEA validation methodology which has been under development by NREL since 1981, with refinements contributed by the United Kingdom. The methodology consists of a combination of empirical validation, analytical verification, and comparative analysis techniques. This report documents a comparative testing and diagnostic procedure for thermal models related to the architectural fabric of the building. Other projects (reported elsewhere) conducted by this group include work on empirical validation, analytical verification, and comparative test cases for commercial buildings.

In the BESTEST project, a method was developed for systematically testing whole-building energy simulation programs and diagnosing the sources of predictive disagreement. Field trials of the method were conducted with a number of "reference" programs selected by the participants to represent the best state-of-the-art detailed simulation capability available in the United States and Europe. These included BLAST, DOE2, ESP; SERIRES, S3PAS, TASE, and TRNSYS. Also, several programs from countries that joined the project late were tested against the reference programs and included CLIM2000 and DEROB. The method consists of a series of carefully specified test case buildings that progress systematically from the extremely simple to the relatively realistic. Output values for the cases, such as annual loads, annual maximum and minimum temperatures, annual peak loads, and some hourly data are compared, and used in conjunction with diagnostic logic to determine the algorithms responsible for predictive differences. The more realistic cases, although geometrically simple, test the ability of the programs to model effects such as thermal mass, direct solar gain windows, window-shading devices, internally generated heat, infiltration, sunspaces, earth coupling, and deadband and setback thermostat control. The more simplified cases facilitate diagnosis by allowing excitation of certain heat-transfer mechanisms.

The results generated with the reference programs are intended to be useful for evaluating other detailed or simplified building energy prediction tools. The collective experience of the group has shown that when a program exhibits major disagreement with the reference programs, the underlying cause is usually a bug, faulty algorithm, or documentation problem.

The field trials revealed a large amount of disagreement among the participating programs even after all problems found via the diagnostics were repaired. The differences ranged from approximately $20 \%$ for prediction of peak loads in test cases with low thermal capacitance to about $66 \%$ for prediction of annual cooling loads in the high thermal capacitance test cases. Disagreements were particularly large in the peak heating predictions for thermostat setback cases. These ranges of disagreement were generally consistent with those observed in a concurrent empirical validation study (reported elsewhere), also conducted by our Experts Group. Despite these differences, the diagnostic methodology was successful at exposing bugs, faulty algorithms, and input errors in every one of the building energy simulation programs tested. Notable examples were: 
- Isolation and correction of a bug in the transfer function (BID) module of TRNSYS Version 12.2 causing insensitivity to thermal capacitance effects (TRNSYS is the main program for active solar systems analysis supported by the U.S. Department of Energy)

- Isolation and correction of an error in the algorithm for calculating absorptance of solar energy on interior surfaces in ESPsim v6.18a (ESP is the building energy reference program selected by the research arm of the Commission of European Communities)

- Isolation and correction of an error in the algorithm for calculating absorptance of solar energy on exterior surfaces defined as doors in DOE-2.1D Version 14 (DOE2 is the main building energy analysis program sponsored by the U.S. Department of Energy)

- Isolation of a documentation problem concerning the detailed algorithm for calculating exterior surface infrared radiation exchange in BLAST3.0 level 193 v.1. (BLAST is the main building energy analysis program sponsored by the U.S. Department of Defense.)

The test cases presented here augment the work conducted in IEA SHC Task 8, "Passive Low Energy Buildings," by including a well-developed diagnostic method. The range of disagreement among the participating programs in this study was larger than in that previous study because the test cases were designed to be more sensitive to the effects of solar energy, and because modelers were directed to use the most detailed level of modeling available in their programs. In Task 8 , a common denominator approach to modeling was used.

An advantage of BESTEST is that a program is examined over a broad range of parametric interactions based on a variety of output types, minimizing the possibility for concealment of problems by compensating errors. Performance of the BESTEST resulted in quality improvements to all 8 of the building energy simulation programs used in this study. The majority of errors found in the reference programs during this project stemmed from incorrect code implementation. Some of the bugs may well have been present for many years. The fact that they have just now been uncovered shows the power of the BESTEST and also suggests that validation is not given a high enough priority by code developers and national research programs.

Checking a building energy simulation program with BESTEST requires about 2 to 5 days. The major programs have taken many years to produce. BESTEST provides a very cost-effective way of evaluating them.

The BESTEST method may be used in a number of different ways by architects, engineers, program developers, and researchers including:

- Comparing the predictions from other building energy simulation programs to the reference results presented in this report

- Comparing several building energy simulation programs to determine the amount of disagreement among them

- Diagnosing the algorithmic sources of differences in predictions among building energy simulation programs

- Checking a program against a previous version of itself, after internal code modifications, to ensure that only the intended changes actually resulted 
- Checking a program against itself, after a single algorithmic change, to understand the sensitivity between algorithms.

In general, the current generation of programs appear most reliable when modeling diffusion of sensible heat in solid media assuming one-dimensional heat transfer and constant properties. Prediction inaccuracy and intermodel disagreement increase as solar excitations become stronger, and the solid conduction heattransfer mode becomes dominated by other more complex energy transfer mechanisms. The predominant sources of disagreement in the prediction of building fabric response to the external and internal environment appear to be in those algorithms related to the calculation of:

- Interior and exterior surface convection and infrared radiation exchange

- Interior and exterior solar radiation distribution including shading effects

- Ground heat transfer.

Algorithms that we have not yet tested, but which we believe may contribute to major predictive uncertainties, are:

- 2- and 3-dimensional conduction

- Interzone and intrazone natural convection, and stratification

- Latent loads, moisture migration, and moisture adsorption/desorption

- Variation of thermal properties due to temperature and moisture content.

After working on this project for more than 3 years, the experts (a group of model developers and users) unanimously recommended that no building energy simulation program be used until it is at least checked with the BESTEST procedure. They also recognized the need for increased national efforts to further develop and validate whole-building energy simulation programs. Such an effort should contain all the elements of an overall validation methodology including analytical verification, empirical validation, and comparative testing and diagnostics.

Future work should therefore encompass:

- Production of a standard set of analytical tests

- Development of a sequentially ordered set of high-quality data sets for empirical validation

- Development of a set of comparative tests which emphasize the modeling issues important in large commercial buildings such as zoning and heating, ventilation, and air-conditioning systems.

Continued support of model development and validation activities is essential because buildings are not amenable to classical controlled, repeatable experiments. The energy, comfort, and lighting performance of buildings depends on the interactions between a large number of energy transfer mechanisms, components, and systems. Simulation is the only practical way to bring a systems integration problem of this magnitude within the grasp of designers. Radically reducing the energy intensity of buildings through better design is possible with the use of such simulation tools. However, widespread use of building energy simulation programs will not occur unless the design and engineering communities have confidence in these programs. Confidence can best be encouraged by a rigorous development and validation effort, combined with friendly user interfaces to minimize human error and effort.

This report is divided into three parts. The first part is a user's manual that provides instructions on how to apply the BESTEST procedure. The second part describes the development, field testing, and production of data for the procedure. The third part presents the output of the reference programs in tables and graphs. 


\section{Table of Contents}

$\underline{\text { Page }}$

Executive Summary $\ldots \ldots \ldots \ldots \ldots \ldots \ldots \ldots \ldots \ldots \ldots \ldots \ldots \ldots \ldots \ldots$

Introduction $\ldots \ldots \ldots \ldots \ldots \ldots \ldots \ldots \ldots \ldots \ldots \ldots \ldots \ldots \ldots \ldots \ldots$



1.0 Part I: BESTEST User's Manual: Procedure and Specification $\ldots \ldots \ldots \ldots \ldots \ldots$

1.1 General Description of Test Cases $\ldots \ldots \ldots \ldots \ldots \ldots \ldots \ldots \ldots \ldots \ldots$

1.2 Modeling Approach: Rules for Performing the Tests $\ldots \ldots \ldots \ldots \ldots \ldots \ldots$

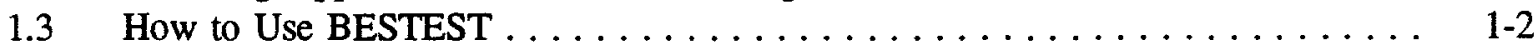

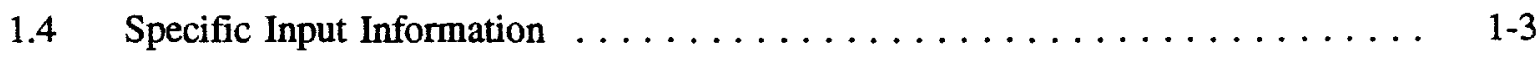

1.4.1 Weather .......................... 1-3

1.4.2 Ground Coupling $\ldots \ldots \ldots \ldots \ldots \ldots \ldots \ldots \ldots \ldots \ldots \ldots$

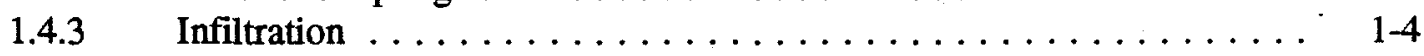

1.4.4 Internally Generated Heat (Casual Gains) $\ldots \ldots \ldots \ldots \ldots$ 1-5

1.4.5 Exterior Combined Radiative and Convective

1.4.6 Interior Combined Radiative and Convective

1.4.7 High-Conductance Wall/Opaque Window $\ldots \ldots \ldots \ldots \ldots \ldots$. $\ldots \ldots$

1.4.8 Transparent Window . . . . . . . . . . . . . . . . . . 1-7

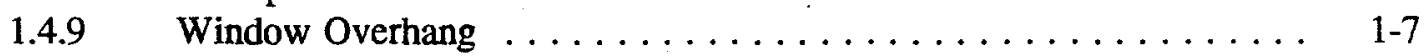

1.4.10 Interior Solar Distribution $\ldots \ldots \ldots \ldots \ldots \ldots \ldots \ldots \ldots \ldots \ldots$ 1-7

1.4.11 Mechanical System . . . . . . . . . . . . . . . . 1-10

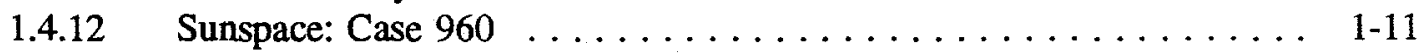

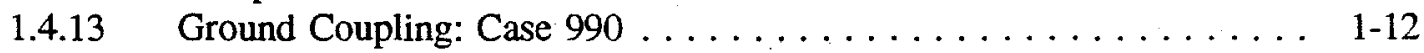

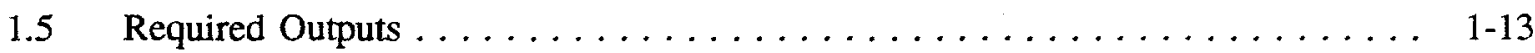

1.5.1 Annual Outputs . . . . . . . . . . . . . . . . . 1-13

1.5.2 Daily Hourly Outputs . . . . . . . . . . . . . . . . .

1.6 Specification Figures and Tables $\ldots \ldots \ldots \ldots \ldots \ldots \ldots \ldots \ldots \ldots \ldots \ldots$



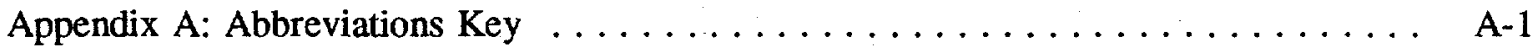

Appendix B: Infiltration and Fan Adjustments for Altitude $\ldots \ldots \ldots \ldots \ldots \ldots$ B-1

Appendix C: Exterior Combined Radiative and Convective

Surface Coefficients . . . . . . . . . . . . . . . . . . . . . C-1

Appendix D: Infrared Portion of Film Coefficients $\ldots \ldots \ldots \ldots \ldots \ldots \ldots \ldots \ldots \ldots$ D-1

Appendix E: Window Transmittance Equations and Glazing Tables . . . . . . . . . E-1

Appendix F: Detailed Calculation of Solar Fractions $\ldots \ldots \ldots \ldots \ldots \ldots \ldots \ldots \ldots$ F-1

Appendix G: TMY Weather Data Format Description $\ldots \ldots \ldots \ldots \ldots \ldots$. . $\ldots \ldots$ 


\section{Table of Contents (Concluded)}

Appendix H: LOTUS-123 Output Spreadsheet Instructions $\ldots \ldots \ldots \ldots \ldots \ldots \ldots$ H-1

Appendix I: Temperature Bin Conversion Program . . . . . . . . . . . . I-1

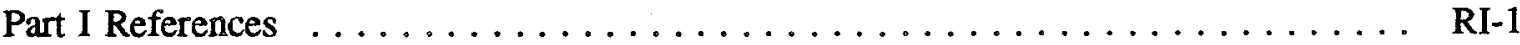

$2.0 \quad$ Part II: Production of Example Results $\ldots \ldots \ldots \ldots \ldots \ldots \ldots \ldots \ldots \ldots \ldots \ldots \ldots$



2.2 Selection of Reference Programs and Range Settings . . . . . . . . . . . . 2-2

2.3 Modeling Rules for Reference Programs . . . . . . . . . . . . . . . . . . . 2-3

2.4 Examples of Error Trapping with BESTEST Diagnostics . . . . . . . . . 2-4

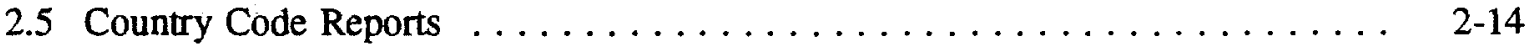

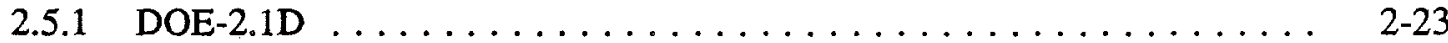

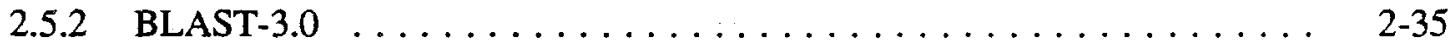

2.5 .3 SERIRES/SUNCODE $\ldots \ldots \ldots \ldots \ldots \ldots \ldots \ldots \ldots \ldots \ldots \ldots \ldots \ldots \ldots$

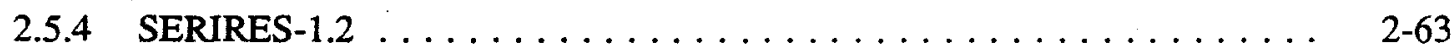

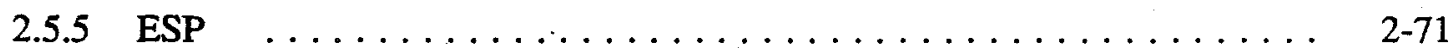

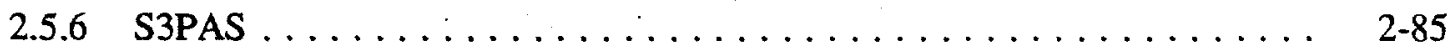

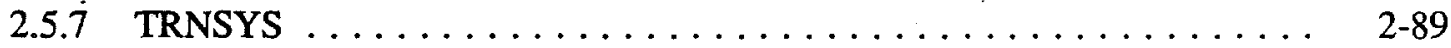

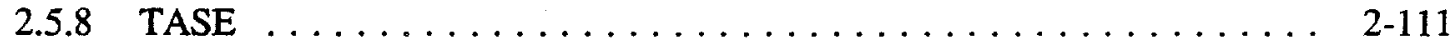

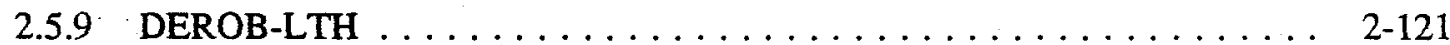

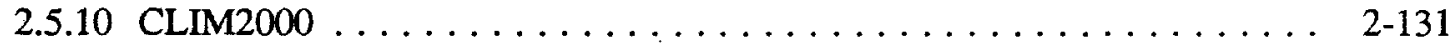

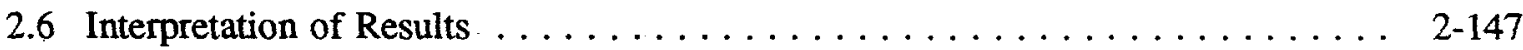

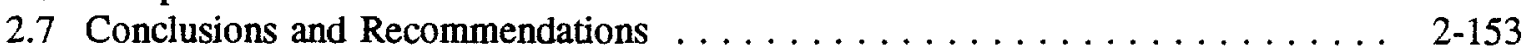

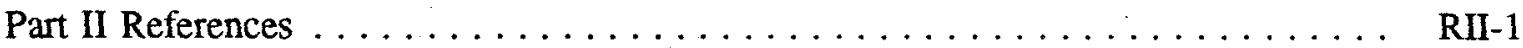

3.0 Part III: Final Results from Reference Programs:

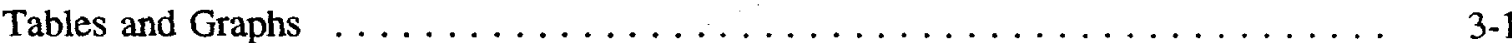




\section{List of Figures}

$\underline{\text { Page }}$

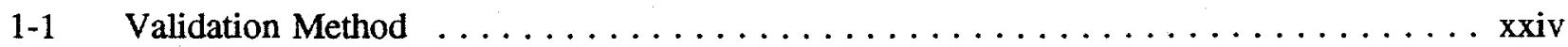

1-2 BESTEST: isometric south windows-unshaded $\ldots \ldots \ldots \ldots \ldots \ldots \ldots \ldots \ldots$

1-3 BESTEST: section of south window overhang $\ldots \ldots \ldots \ldots \ldots \ldots \ldots \ldots \ldots \ldots$

1-4 BESTEST: east and west window shading $\ldots \ldots \ldots \ldots \ldots \ldots \ldots \ldots$

1-5. BESTEST: isometric east and west window shading $\ldots \ldots \ldots \ldots \ldots \ldots \ldots$

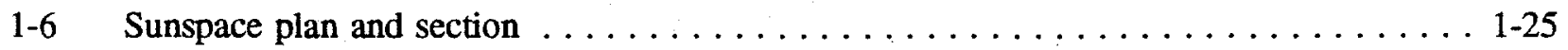

1-7 BESTEST: low-mass qualification flow diagram $\ldots \ldots \ldots \ldots \ldots \ldots \ldots \ldots \ldots$

1-8 BESTEST: low-mass diagnostics flow diagram . . . . . . . . . . . . . . . . . . . 1-29

1-9 BESTEST: high-mass qualification flow diagram $\ldots \ldots \ldots \ldots \ldots \ldots$

1-10 BESTEST: high-mass diagnostics flow diagram $\ldots \ldots \ldots \ldots \ldots \ldots \ldots \ldots \ldots$

1-11 Shape factor for adjacent rectangles in perpendicular planes sharing



1-12 Shape factor for directly opposed rectangles $\ldots \ldots \ldots \ldots \ldots \ldots \ldots \ldots$

2-1 BESTEST: qualification high-mass annual heating $\ldots \ldots \ldots \ldots \ldots \ldots$

$2-2 \quad$ High-mass qualification flow diagram $\ldots \ldots \ldots \ldots \ldots \ldots \ldots \ldots \ldots \ldots \ldots \ldots$

2-3 Mass diagnostics flow diagram $\ldots \ldots \ldots \ldots \ldots \ldots \ldots \ldots \ldots \ldots \ldots \ldots \ldots$

2-4 BESTEST qualification mass effect (delta) annual heating and cooling $\ldots \ldots \ldots \ldots$

2-5 BESTEST case $900 \mathrm{FF}$ annual hourly temperature frequency $\ldots \ldots \ldots \ldots$

2-6 BESTEST qualification high-mass annual heating $\ldots \ldots \ldots \ldots \ldots \ldots \ldots$

2-7 BESTEST qualification mass effect (delta) annual heating and cooling $\ldots \ldots \ldots \ldots$

2-8 BESTEST case $900 \mathrm{FF}$ annual hourly temperature frequency $\ldots \ldots \ldots \ldots \ldots$

2-9 East and west shaded window (delta) annual heating and cooling . . . . . . . 2-10

$2-10$ Annual overhang and fin shading coefficients $\ldots \ldots \ldots \ldots \ldots \ldots \ldots$

2-11 Exterior SW absorptivity effect annual cooling load cases $250,220 \ldots \ldots \ldots \ldots$ 


\section{List of Figures (Continued)}

2-12 Exterior IR emissivity effect annual heating load

2-13 Interior solar absorptance effect annual cooling load $2-13$

2-14 Monthly summed heating/cooling load GROUNDCODE case 990: ground coupling . . 2-50

2-15 SUNCODE interior film coefficient parametric study case 940 : setback $\ldots \ldots \ldots 2-53$

2-16 East-West window shading schemes with SERIRES $1-2 \ldots \ldots \ldots \ldots \ldots \ldots$

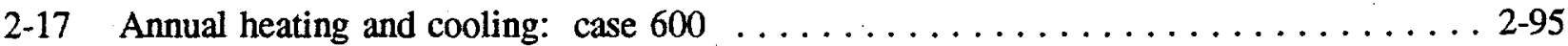

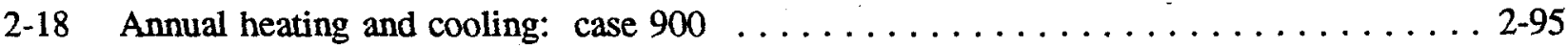

2-19 Peak heating and cooling: case $600 \ldots \ldots \ldots \ldots \ldots \ldots \ldots \ldots \ldots \ldots$

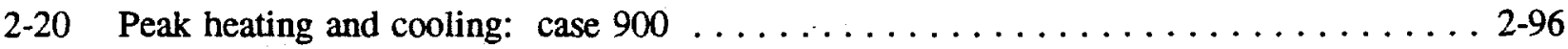

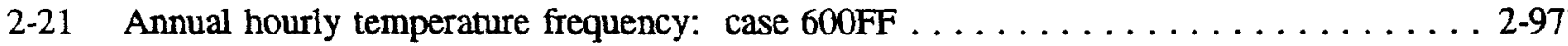

2-22 Annual hourly temperature frequency: case $900 \mathrm{FF} \ldots \ldots \ldots \ldots \ldots . \ldots \ldots 7$

2-23 Variation of outdoor air temperature $\ldots \ldots \ldots \ldots \ldots \ldots \ldots \ldots \ldots \ldots \ldots \ldots \ldots \ldots$

2-24 Variable convective heat-transfer coefficients $\ldots \ldots \ldots \ldots \ldots \ldots \ldots \ldots \ldots \ldots \ldots .113$

2-25 Annual heating consumption: low-mass (light) building $\ldots \ldots \ldots \ldots \ldots \ldots \ldots \ldots$

2-26 Peak heating demand: low-mass building $\ldots \ldots \ldots \ldots \ldots \ldots \ldots \ldots \ldots \ldots \ldots \ldots$

2-27 Annual cooling consumption: low-mass building $\ldots \ldots \ldots \ldots \ldots \ldots \ldots \ldots \ldots$

2-28 Peak cooling demand: low-mass building $\ldots \ldots \ldots \ldots \ldots \ldots \ldots \ldots \ldots \ldots \ldots \ldots \ldots$

2-29 Annual heating and cooling consumptions, January 4: case $600 \ldots \ldots \ldots \ldots \ldots$

2-30 Annual heating and cooling consumptions, January 4: case $900 \ldots \ldots \ldots \ldots . \ldots .2-138$

2-31 Minimum hourly temperatures: free-float case $\ldots \ldots \ldots \ldots \ldots \ldots \ldots \ldots \ldots \ldots$

$2-32$ Annual solar flux incident on the five walls $\ldots \ldots \ldots \ldots \ldots \ldots \ldots \ldots \ldots \ldots \ldots \ldots$

2-33 Global flux incident on south wall, March $5 \ldots \ldots \ldots \ldots \ldots \ldots \ldots \ldots \ldots$

2-34 Global flux incident on west wall, March $5 \ldots \ldots \ldots \ldots \ldots \ldots \ldots \ldots \ldots \ldots$

2-35 Global flux incident on south wall, July $27 \ldots \ldots \ldots \ldots \ldots \ldots \ldots \ldots$ 


\section{List of Figures (Concluded)}

$\underline{\text { Page }}$

2-36 Global flux incident on west wall, July $27 \ldots \ldots \ldots \ldots \ldots \ldots \ldots \ldots \ldots$

2-37 Annual solar flux transmitted by south and west windows $\ldots \ldots \ldots \ldots \ldots \ldots \ldots$

2-38 Transmission coefficient of windows (annual transmitted flux/annual incident flux) $\ldots .2-140$

2-39 Annual heating consumption: elementary cases (195 through 220$) \ldots \ldots \ldots \ldots \ldots$

2-40 Annual heating consumption: elementary cases (230 through 320$) \ldots \ldots \ldots \ldots$. . . . . . . . .

2-41 Annual cooling consumption: elementary cases $(195$ through 220$) \ldots \ldots \ldots \ldots . . \ldots .141$

2-42 Annual cooling consumption: elementary cases (230 through 320$) \ldots \ldots \ldots \ldots . . \ldots .141$

243 Peak heating demand: elementary cases $(195$ through 220$) \ldots \ldots \ldots \ldots \ldots \ldots$. . . . . . . .

2-44 Peak heating demand: elementary cases $(230$ through 320$) \ldots \ldots \ldots \ldots \ldots \ldots$. . . . . . . .

2-45 Peak cooling demand: elementary cases $(195$ through 220$) \ldots \ldots \ldots \ldots \ldots \ldots$. . . . . . . . .

2-46 Peak cooling demand: elementary cases $(230$ through 320$) \ldots \ldots \ldots \ldots$. . . . . . 2-142

2-47 Annual heating consumption: series A1 through A6 . . . . . . . . . . . 2-142

2-48 Annual cooling consumption: series A1 through A6 . . . . . . . . . . . 2-142

2-49 Peak heating demand: series A1 through A6 . . . . . . . . . . . . 243

2-50 Peak cooling demand: series A1 through A6 . . . . . . . . . $\ldots \ldots \ldots$

2-51 Annual heating consumption: high-mass (heavy) building $\ldots \ldots \ldots \ldots \ldots \ldots \ldots . . \ldots 24$

2-52 Peak heating demand: high-mass building $\ldots \ldots \ldots \ldots \ldots \ldots \ldots \ldots \ldots \ldots$

2-53 Annual heating and cooling consumptions: influence of window orientation $\ldots \ldots \ldots .2-144$

2-54 Peak heating and cooling demands: influence of window orientation $\ldots \ldots \ldots \ldots .2-144$

2-55 Peak heating demand: influence of ventilation $\ldots \ldots \ldots \ldots \ldots \ldots \ldots \ldots \ldots \ldots$

2-56 Maximal hourly temperatures: free-float case $\ldots \ldots \ldots \ldots \ldots \ldots \ldots \ldots \ldots \ldots .144$

2-57 Average hourly temperatures: free-float case $\ldots \ldots \ldots \ldots \ldots \ldots \ldots \ldots \ldots \ldots .245$

2-58 Interior temperature change, January 4 , case $600 \mathrm{FF} \ldots \ldots \ldots \ldots \ldots \ldots \ldots \ldots$

2-59 Interior temperature change, January 4 , case $900 \mathrm{FF} \ldots \ldots \ldots \ldots \ldots \ldots \ldots \ldots \ldots$

2-60 Frequency of hourly temperatures: case $900 \mathrm{FF} \ldots \ldots \ldots \ldots \ldots \ldots \ldots \ldots \ldots \ldots$ 


\section{List of Tables}

$\underline{\text { Page }}$

1-1 Validation Techniques $\ldots \ldots \ldots \ldots \ldots \ldots \ldots \ldots \ldots \ldots \ldots \ldots \ldots \ldots \ldots$

1-2 Types of Extrapolation $\ldots \ldots \ldots \ldots \ldots \ldots \ldots \ldots \ldots \ldots \ldots \ldots \ldots \ldots \ldots \ldots \ldots \ldots \ldots i i$

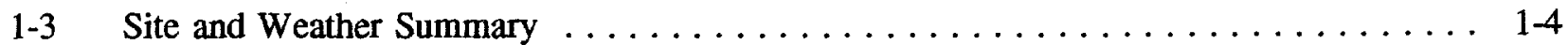

1-4 Infiltration Rates Depending on the Presence of Automatic

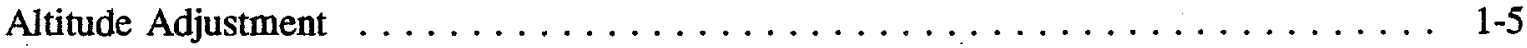

1-5 Exterior Combined Surface Coefficient Versus Surface Orientation



1-6 Interior Combined Surface Coefficient Versus Surface Orientation

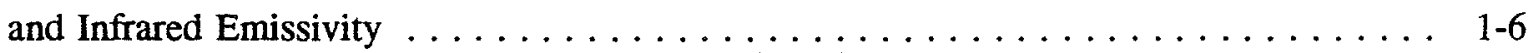

1-7 Window Properties $\ldots \ldots \ldots \ldots \ldots \ldots \ldots \ldots \ldots \ldots \ldots \ldots \ldots$

1-8 Angular Dependence of Direct-Beam Transmittance for Double-

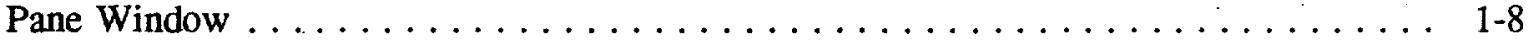

1-9 Interior Solar Distribution Fractions Versus Window Orientation and Interior Shortwave Absorptance $\ldots \ldots \ldots \ldots \ldots \ldots \ldots \ldots \ldots \ldots$

1-10 Vent Fan Capacity Depending on the Presence of Automatic

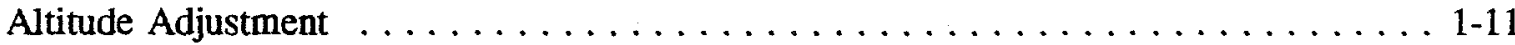

1-11 Thermal and Physical Properties of Sun Zone/Back Zone Common Wall $\ldots \ldots \ldots$ 1-11

1-12 Hourly Output Requirements $\ldots \ldots \ldots \ldots \ldots \ldots \ldots \ldots \ldots \ldots \ldots \ldots \ldots$

1-13 BESTEST Case Descriptions: Low-Mass Diagnostics . . . . . . . . . . . 1-16

1-14 BESTEST Qualification Case Descriptions and Realistic Diagnostics . . . . . . . 1-17

1-1.5 Material Specifications: Lightweight Case (Metric) $\ldots \ldots \ldots \ldots \ldots \ldots \ldots \ldots \ldots$

1-16 Material Specifications: Lightweight Case (English) . . . . . . . . . . . . . . 1-19

1-17 Material Specifications: Heavyweight Case (Metric) $\ldots \ldots \ldots \ldots \ldots \ldots \ldots \ldots$

1-18 Material Specifications: Heavyweight Case (English) $\ldots \ldots \ldots \ldots \ldots \ldots \ldots \ldots \ldots$ 1-21

1-19 Polynomial Coefficients for Describing Exterior Surface Conductance

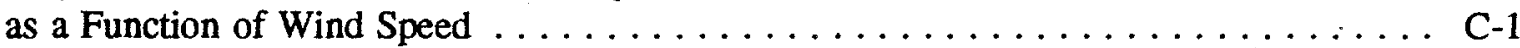

1-20 Disaggregation of Film Coefficients Versus Surface Emissivity for Various Surface Types $\ldots \ldots \ldots \ldots \ldots \ldots \ldots \ldots \ldots \ldots \ldots \ldots \ldots$ 


\section{List of Tables (Continued)}

$\underline{\text { Page }}$

1-21 Glazing Properties as a Function of Incidence Angle $\ldots \ldots \ldots \ldots \ldots \ldots \ldots$

1-22 Angular Dependence of Solar Heat Gain Coefficient . . . . . . . . . . . . E-3

1-23 Typical Meteorological Year Data Format $\ldots \ldots \ldots \ldots \ldots \ldots \ldots \ldots \ldots$

2-1 Participating Organizations and Computer Programs $\ldots \ldots \ldots \ldots \ldots \ldots \ldots$

2-2 Ability of Participating Computer Programs to Explicitly Model Diagnostic

Cases That Vary Selected Radiative Properties . . . . . . . . . . . . . . 2-4

2-3 Pro Forma Summary of Participating Programs $\ldots \ldots \ldots \ldots \ldots \ldots \ldots$

2-4 Comparison of DOE2 Double-Pane Glass Type 1 Transmissivities to

BESTEST Specification Glazing Transmissivities $\ldots \ldots \ldots \ldots \ldots \ldots \ldots \ldots \ldots$

2-5 Design Temperature Parametric Results for Case $960 \ldots \ldots \ldots \ldots$. . . . . . . . 2-27

2-6 DOE2 Solar Distribution Fractions Versus Window Orientation for

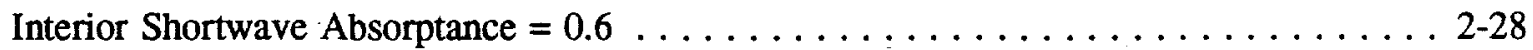

2-7 BLAST "Heat Balance" Setting Sensitivity Using

Case 250

2-8 Comparison of BLAST-Calculated Transmissivities to BESTEST Specification

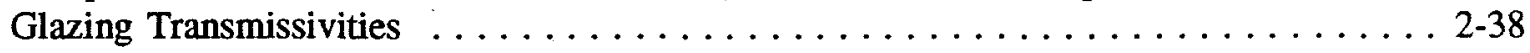

2-9 Number of Nodes for High-Mass Shell Elements $\ldots \ldots \ldots \ldots \ldots \ldots \ldots \ldots$

2-10 Building-Shell Insulation Conductivities Used with SUNCODE $\ldots \ldots \ldots \ldots \ldots . . \ldots 2-51$

2-11 Building-Shell Insulation R-Values Used with SUNCODE $\ldots \ldots \ldots \ldots \ldots \ldots$

2-12 BESTEST East and West Shading Effectiveness Comparisons:

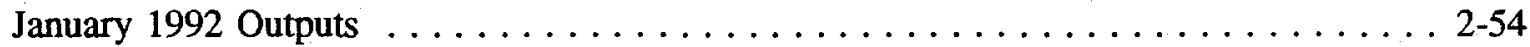

2-13 Cavity Albedo for Various Methods and Interior Shortwave Absorptances . . . . . . 2-56

2-14 SERIRES/SUNCODE Cooling Loads Versus Cavity Albedo Algorithm:

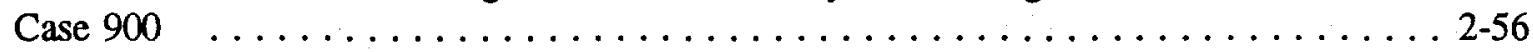

2-15 SERIRES/SUNCODE Annual Cooling Load Sensitivity Versus Cavity Albedo

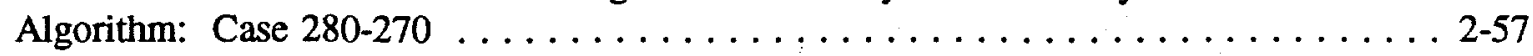

2-16 Monthly Ground Temperatures for SERIRES $1.2 \ldots \ldots \ldots \ldots \ldots \ldots \ldots$ 


\section{List of Tables (Continued)}

2-17 SERIRES 1.2 Interior Solar Distribution Fractions for Case $990 \ldots \ldots \ldots \ldots \ldots$

2-18 Case 940 Sensitivity to Equipment Capability $\ldots \ldots \ldots \ldots \ldots \ldots \ldots$

2-19 SERIRES 1.2 Ground Coupling Sensitivity Tests . . . . . . . . . . . . . 2-68

2-20 SERIRES 1.2 Annual and Peak Load Sensitivity to Interior Surface Coefficient $\ldots \ldots \ldots \ldots \ldots \ldots \ldots \ldots \ldots \ldots \ldots \ldots \ldots \ldots$

2-21 SERIRES 1.2 Maximum and Minimum Zone Temperature Sensitivity to Interior Surface Coefficient ... . . . . . . . . . . . . . . . . . . . . . . . . 2-69

2-22 Case 200: Window Type Sensitivity . . . . . . . . . . . . . . . 2-74

2-23 Case $600:$ Window Type Sensitivity . . . . . . . . . . . . . . . 2-74

2-24 Case 195: Sensitivity to External Infrared Emissivity . . . . . . . . . . . . . 2-74

2-25 Case $600:$ View Factor Sensitivity $\ldots \ldots \ldots \ldots \ldots \ldots \ldots \ldots \ldots \ldots \ldots \ldots$

2-26 Example of Error Trapping through BESTEST Diagnostics $\ldots \ldots \ldots \ldots \ldots \ldots \ldots$

2-27 Time-Invariant Wall Surface Coefficients Suggested in the BESTEST Specification $\left(\mathrm{Wm}^{-2} \mathrm{~K}^{-1}\right)$

2-28 Example of Hourly Varying ESP-r Surface Coefficients . . . . . . . . . . . 2-78

2-29 Comparison of Case 600 Results Using Fixed and Variable Surface Coefficients . . . . . . . . . . . . . . . . . . . . . . . . . 2-79

2-30 Incidence-Angle-Dependent Direct-Beam Transmittance for Double-Pane Glazing Using Various Methods . . . . . . . . . . . . . . . . . . 2-92

2-31 TRNSYS Case 990 Sensitivity to Soil Thickness . . . . . . . . . . . . 2-93

2-32 Transfer Function Coefficient File Generated by BID 12.2 v1 . . . . . . . . . 2-98

2-33 Transfer Function Coefficient File Generated by BID 12.2 v2 $\ldots \ldots \ldots \ldots$

2-34 TRNSYS BID Source Code Comparison . . . . . . . . . . . . . . . 2-99

2-35 TRNSYS Sensitivity to Cavity Albedo, Cases 600 and $900 \ldots \ldots \ldots \ldots$

2-36 TRNSYS Sensitivity to Timestep $\ldots \ldots \ldots \ldots \ldots \ldots \ldots \ldots \ldots \ldots \ldots \ldots \ldots \ldots$

2-37 TRNSYS Sensitivity to Cavity Albedo, Cases 900 and $960 \ldots \ldots \ldots \ldots \ldots 2$ 


\section{List of Tables (Concluded)}

$\underline{\text { Page }}$

2-38 Wall Conduction Validation Test Matrix . . . . . . . . . . . . . . . . . .2-104

2-39 Comparison of Indoor Air Temperatures $\left({ }^{\circ} \mathrm{C}\right) \ldots \ldots \ldots \ldots \ldots \ldots \ldots \ldots \ldots$

2-40 DEROB-LTH Annual and Peak Heating and Cooling Load Results $\ldots \ldots \ldots \ldots$. . . . . . . .

2-41 DEROB-LTH Low-Mass Qualification Tests $\ldots \ldots \ldots \ldots \ldots \ldots \ldots \ldots \ldots \ldots$

2-42 DEROB-LTH Low-Mass Primitive Diagnostic Tests . . . . . . . . . . . . . . . 2-127

2-43 DEROB-LTH Low-Mass Realistic Diagnostic Tests . . . . . . . . . . . . . . . . 2-127

$2-44$ DEROB-LTH High-Mass Qualification Tests $\ldots \ldots \ldots \ldots \ldots \ldots \ldots \ldots \ldots \ldots \ldots \ldots$

2-45 DEROB-LTH High-Mass Diagnostic Tests $\ldots \ldots \ldots \ldots \ldots \ldots \ldots \ldots \ldots \ldots \ldots$

2-46 DEROB-LTH Free-Float Temperature Output $\ldots \ldots \ldots \ldots \ldots \ldots \ldots \ldots \ldots \ldots \ldots$

2-47 DEROB-LTH Annual Incident and Transmitted Solar Radiation . . . . . . . . . . . . 2-129

2-48 Interior (Global) and Exterior (Convection) Exchange Coefficients for the Different Partitions . . . . . . . . . . . . . . . . . . . . . . . 2-133

2-49 BESTEST Reference Results Summary . . . . . . . . . . . . . . . . . 2-147

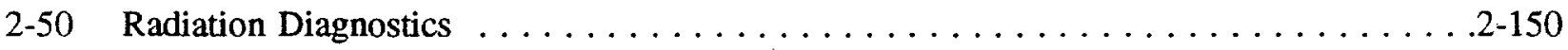

$2-51 \quad$ BESTEST Case Descriptions Proposed New Cases $\ldots \ldots \ldots \ldots \ldots \ldots \ldots \ldots \ldots \ldots$ 


\section{Introduction}

This is a report on the Building Energy Simulation Test (BESTEST) project conducted by the Model Evaluation and Improvement International Energy Agency (IEA) Experts Group. The group was composed of experts from the Solar Heating and Cooling (SHC) Programme, Task 12 Subtask B and the Energy Conservation in Buildings and Community Systems (BCS) Programme, Annex 21 Subtask C. Recognizing that the needs for model evaluation were similar in both IEA programmes, the combined Experts Group was approved by the Executive Committees in 1990. This is the first joint group organized by the respective IEA Executive Committees, and it has resulted in significant cost savings for all participating countries.

The objective of the Model Evaluation and Improvement subtask has been to develop practical implementation procedures and data for an overall IEA validation methodology which has been under development by NREL since 1981 (Judkoff et al. 1983a; Judkoff 1988), with refinements contributed by the United Kingdom (Lomas 1991; Bloomfield 1989). The methodology consists of a combination of empirical validation, analytical verification, and comparative analysis techniques. This report documents a comparative analysis and diagnostic procedure for testing the ability of whole building simulation programs to thermally model the building fabric. Other projects, conducted by this group and reported elsewhere, include work on empirical validation (Lomas et al. 1994), analytical verification (Van De Perre and Verstraete 1994; Rodriguez and Alvarez 1991), and comparative test cases for commercial buildings (Kataja and Kalema 1993).

In this project, a method-BESTEST - was developed for systematically testing whole-building energy simulation models and diagnosing the sources of predictive disagreement. Field trials of the method were conducted with a number of detailed state-of-the-art programs from the United States and Europe. The technique consists of a series of carefully specified test case buildings that progress systematically from the extremely simple to the relatively realistic. Output values for the cases, such as annual loads, annual maximum and minimum temperatures, peak loads, and some hourly data are compared and used in conjunction with diagnostic logic to determine the algorithms responsible for predictive differences. The more realistic cases, although geometrically simple, test the ability of the programs to model such combined effects as thermal mass, direct solar gain windows, window-shading devices, internally generated heat, infiltration, sunspaces, earth coupling, and deadband and setback thermostat control. The more simplified cases facilitate diagnosis by allowing excitation of particular heat-transfer mechanisms.

This report is divided into three parts. The first part is a user's manual that provides instructions on how to apply the BESTEST procedure. The second part describes what the working group members did to develop the procedure, field test it, and produce a set of reference results using several state-of-the-art, public domain, detailed whole-building energy simulation programs with time steps of one hour or less. The second part will be useful to those wanting to understand the theory and logic behind the procedure. However, it is not necessary to read the second part to use the procedure described in Part I.

Part III presents the reference results in tables and graphs. These data can be used to compare the results from other programs to the reference results, and to observe the range of disagreement among the reference programs. A diskette is also provided that contains the weather data, some utility programs to assist users in formatting their output data, all of the reference data in a common spreadsheet format, and a "help" file.

The BESTEST procedure presented here emphasizes the testing of a program's modeling capabilities with respect to the architectural fabric of the building. In other work, the Model Evaluation and Improvement 
Group is also investigating test cases aimed at the special zoning issues associated with commercial buildings (Kataja and Kalema 1993). Related work by the American Society of Heating, Refrigerating, and Air-Conditioning Engineers (ASHRAE) is also under way to develop tests related to the mechanical equipment in commercial buildings (Haberl and Yuill 1993). 


\section{Background}

This section summarizes some of the work that preceded this BESTEST effort and describes the overall methodological and historical context for BESTEST.

Increasing power and attractive pricing of personal computers has encouraged a proliferation of building energy software. A survey among International Energy Agency (IEA) countries found 215 tools, 156 of which were developed in the United States (Rittelmann and Ahmed 1985). There is little if any objective quality control of this software. An evaluation of a number of design tools conducted in IEA SHC Task 8, "Passive Low Energy Buildings," showed large unexplained predictive differences between these tools, even when run by experts (Rittelmann 1985). Also, there is little information available to assist designers in selecting programs that are appropriate for a particular purpose. Obviously, vendors have little incentive to reveal limitations, simplifications, or inaccuracies in the algorithms that underlie their models, and in many cases may not be aware of them. It is imperative that the design industry not become disillusioned with these tools because their use offers a great potential for energy savings and comfort improvements.

In recognition of this problem, an effort was begun under IEA SHC Task 8, and continued in SHC Task 12 Subtask B and BCS Annex 21 Subtask C, to develop a quantitative procedure for evaluating and diagnosing building energy software (Judkoff et al. 1988; Bloomfield 1989). The procedure that resulted from that effort is called the Building Energy Simulation Test (BESTEST) and Diagnostic Method.

Prior to the inception of IEA SHC Task 8, NREL (then the Solar Energy Research Institute) had begun working on a comprehensive validation methodology for building energy simulation programs (Judkoff et al. 1983a). This effort was precipitated by two comparative studies that showed considerable disagreement between four simulation programs-DOE-2, BLAST, DEROB, and SUNCAT—when given equivalent input for a simple direct-gain solar building with a high and low heat capacitance parametric option (Judkoff et al. 1980, 1981). The need for a validation effort based on a sound methodological approach was clearly indicated by these studies.

\section{Validation Methodology}

A typical building energy simulation program contains hundreds of variables and parameters. The number of possible cases that can be simulated by varying each of these parameters in combination is astronomical and cannot practically be fully tested. For this reason the NREL validation methodology required three different kinds of tests (Judkoff et al. 1983a):

- Analytical verification-in which the output from a program, subroutine, or algorithm is compared to the result from a known analytical solution for isolated heat transfer mechanisms, under very simple boundary conditions

- Empirical validation-in which calculated results from a program, subroutine, or algorithm are compared to monitored data from a real structure, test cell, or laboratory experiment

- Comparative testing-in which a program is compared to itself or to other programs. The comparative approach includes "sensitivity testing" and "intermodel comparisons."

The advantages and disadvantages of these three techniques are shown in Table 1-1. 
Table 1-1. Validation Techniques

\begin{tabular}{||l|l|l||}
\hline \multicolumn{1}{|c|}{ Technique } & \multicolumn{1}{|c||}{ Advantages } & \multicolumn{1}{c||}{ Disadvantages } \\
\hline $\begin{array}{l}\text { Comparative } \\
\text { Relative test of model and } \\
\text { solution process }\end{array}$ & $\begin{array}{l}\text { No input uncertainty } \\
\text { Any level of complexity } \\
\text { Inexpensive } \\
\text { Quick, many comparisons possible }\end{array}$ & No truth standard \\
\hline $\begin{array}{l}\text { Analytical } \\
\text { Test of numerical } \\
\text { solution }\end{array}$ & $\begin{array}{l}\text { No input uncertainty } \\
\text { Exact truth standard given the } \\
\text { simplicity of the model } \\
\text { Inexpensive }\end{array}$ & $\begin{array}{l}\text { No test of model } \\
\text { Limited to cases for which } \\
\text { analytical solutions can be } \\
\text { derived }\end{array}$ \\
\hline $\begin{array}{l}\text { Empirical } \\
\text { Test of model and solution } \\
\text { process }\end{array}$ & $\begin{array}{l}\text { Approximate truth standard within } \\
\text { experimental accuracy } \\
\text { Any level of complexity }\end{array}$ & $\begin{array}{l}\text { Measurement involves some } \\
\text { degree of input uncertainty } \\
\text { Detailed measurements of high } \\
\text { quality are expensive and } \\
\text { time-consuming } \\
\text { A limited number of data sites } \\
\text { are economically practical }\end{array}$ \\
\hline \hline
\end{tabular}

The NREL methodology subdivided empirical validation into different levels. This was necessary because many of the empirical validation efforts conducted prior to that time produced results that could not support definitive conclusions despite considerable expenditure of resources.

\section{Empirical Validation Levels}

The levels of validation depend on the degree of control exercised over the possible sources of error in a simulation. These error sources consist of seven types divided into two groups.

\section{External Error Types}

1. Differences between the actual microclimate affecting the building, and the weather input used by the program

2. Differences between the actual schedules, control strategies, and effects of occupant behavior and those assumed by the program user

3. User error in deriving building input files

4. Differences between the actual thermal and physical properties of the building and those input by the user.

\section{Internal Error Types}

5. Differences between the actual thermal transfer mechanisms taking place in the real building and the simplified model of those physical processes in the simulation 
6. Errors or inaccuracies in the mathematical solution of the models

\section{Coding errors.}

At the most simplistic level, the actual long-term energy use of a building is compared to that calculated by a computer program, with no attempt to eliminate sources of discrepancy. This level is similar to how a simulation tool would actually be used in practice and is therefore favored by many representatives of the building industry. However, it is difficult to interpret the results of this kind of validation exercise because all possible error sources are simultaneously operative. Even if good agreement is obtained between measured and calculated performance, the possibility of offsetting errors prevents a definitive conclusion about the accuracy of the model. More informative levels of validation are achieved by controlling or eliminating various combinations of error types. At the most detailed level, all known sources of error are controlled to identify and quantify unknown error sources, and to reveal cause and effect relationships associated with the error sources.

This same general principle applies to comparative and analytical methods of validation. The more realistic the test case, the more difficult it is to establish cause and effect, and to diagnose problems. The simpler and more controlled the test case, the easier it is to pinpoint the source(s) of error or inaccuracy. Realistic cases are useful for testing the interaction between algorithms that model linked mechanisms.

Each comparison between measured and calculated performance represents a small region in an immense $\mathrm{N}$-dimensional parameter space. We are constrained to exploring relatively few regions within this space, yet we would like to be assured that the results are not coincidental and do represent the validity of the simulation elsewhere in the parameter space. The analytical and comparative techniques minimize the uncertainty of the extrapolations we must make around the limited number of empirical domains it is possible to sample. These extrapolations are classified in Table 1-2.

Table 1-2. Types of Extrapolation

\begin{tabular}{||l|l|}
\hline \multicolumn{1}{|c|}{ Obtainable Data Points } & \multicolumn{1}{c|}{ Extrapolation } \\
\hline \hline A few climates & Many climates \\
\hline Short-term total energy usage & Long-term total energy usage \\
\hline Short-term (hourly) temperatures and/or fluxes & Long-term total energy usage \\
\hline $\begin{array}{l}\text { A few buildings representing a few sets of variable } \\
\text { mixes }\end{array}$ & $\begin{array}{l}\text { Many buildings representing many sets of variable } \\
\text { mixes }\end{array}$ \\
\hline $\begin{array}{l}\text { Small-scale, simple test cells and buildings, and } \\
\text { laboratory experiments }\end{array}$ & Large-scale complex buildings \\
\hline
\end{tabular}

Figure 1-1 shows one process by which we may use the analytical, empirical, and comparative techniques together. In actual fact these three techniques may be used together in a number of ways. For example, intermodel comparisons may be done in advance of an empirical validation exercise to better define the experiment and to help estimate experimental uncertainty by propagating all known sources of uncertainty through one or several whole-building energy simulation programs (Hunn et al. 1982; Martin 1991; Lomas et al. 1994). 


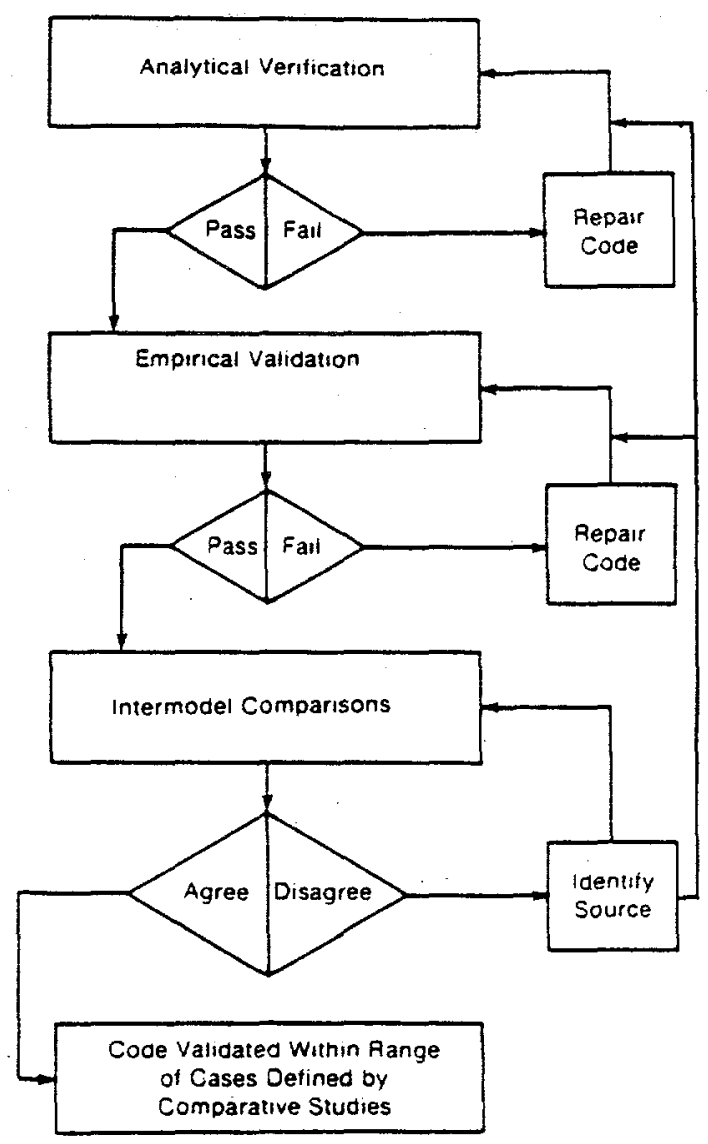

Figure 1-1. Validation method

For the path shown in Figure 1-1, the first step is to run the code against analytical test cases. This checks the mathematical solution of major heat transfer models in the code. If a discrepancy occurs, the source of the difference must be corrected before any further validation is done.

The second step is to run the code against empirical validation data and to correct errors. However, diagnosis of error sources can be quite difficult. Comparative techniques can be used to create diagnostic procedures (Judkoff et al. 1983b; Judkoff 1985a, 1985b, 1988; Judkoff and Wortman 1984; Morck 1986) and to better define the empirical experiments.

The third step involves checking the agreement of several different programs with different thermal solution and modeling approaches (which have passed through steps 1 and 2 ) in a variety of representative cases. Cases for which the program predictions diverge indicate areas for further investigation. This utilizes the comparative technique as an extrapolation tool. When programs have successfully completed these three stages, then we consider them to be validated for the domains in which acceptable agreement was achieved. That is, the codes are considered validated for the range of building and climate types represented by the test cases.

Once several detailed simulation programs have satisfactorily passed through the procedure, then other programs and simplified design tools can be tested against them. A validated code does not necessarily represent truth. It does represent a set of algorithms that have been shown, through a repeatable procedure, to perform according to the current state of the art. 
The NREL methodology for validation of building energy simulation programs has been generally accepted by the IEA (Irving 1988) with a number of methodological refinements suggested by subsequent researchers (Bowman and Lomas 1985b; Lomas and Bowman 1987; Lomas 1991; Lomas and Eppel 1992; Bloomfield 1985, 1988; Bloomfield et al. 1992; Allen et al. 1985; Irving 1988; Bland and Bloomfield 1986; Bland 1992). Additionally, considerable work has been conducted by the Commission of European Communities under the PASSYS program. However, this work is not generally available to U.S. citizens.

\section{Summary of Previous NREL and IEA-Related Validation Work}

Beginning in 1980, several analytical, empirical, and comparative studies were conducted at NREL in support of the validation methodology.

\section{Analytical Verification}

A number of analytical tests were derived and implemented including:

- Wall conduction

- Mass charging and decay due to a change in temperature

- Glazing heat transfer

- Mass charging and decay due to solar radiation

- Infiltration heat transfer.

These tests and several comparative studies facilitated the detection and diagnosis of a convergence problem in the DEROB-3 program which was then corrected in DEROB-4 (Wortman et al. 1981; Burch 1980; Judkoff et al. 1980, 1981). These studies also showed DOE2.1, BLAST-3, SUNCAT-2.4, and DEROB 4 to be in good agreement with the analytical solutions even though considerable disagreement was observed among them in some of the comparative studies. This confirmed the need for both analytical and comparative tests as part of the overall validation methodology.

Further development of the analytical testing approach has occurred in Europe with work on conduction tests (Bland and Bloomfield 1986; Bland 1992), infrared radiation tests (Stefanizzi and Wilson 1988), and solar shading tests (Rodriguez and Alvarez 1991).

\section{Empirical Validation}

Several empirical validation studies were conducted including:

- NREL (formerly SERI) Direct Gain Test House in Denver, Colorado

- National Research Council of Canada Test House in Ottawa, Canada

- Los Alamos National Laboratory Sunspace Test Cell in Los Alamos, New Mexico.

Data were collected from the NREL Test House during the winters of 1982 and 1983, and two studies were conducted using the DOE-2.1A, BLAST-3.0, and SERIRES computer programs (Burch et al. 1985). In the first study, based on the 1982 data, 9 cases were run, beginning with a basecase (case 1) in which only "handbook" input values were used, and ending with a final case (case 9) in which measured input values were used for infiltration, ground temperature, ground albedo, set point, and opaque envelope and window conductances (Judkoff et al. 1983b). Code heating energy predictions were high by 59\%-66\% for the handbook case. Code heating energy predictions were low by $10 \%-17 \%$ when input inaccuracies were eliminated using measured values. However, root mean square (rms) temperature prediction errors were actually greater for case 9 indicating the existence of compensating errors in some of the programs. 
In the second study, based on the 1983 data, a comparative diagnostic approach was used to determine the sources of disagreement among the computer programs (25\%) and between the programs and the measured data $( \pm 13 \%)$ (Judkoff and Wortman 1984). The diagnostics showed that most of the disagreement was caused by the solar and ground-coupling algorithms. Also, the change in the range of disagreement caused by the difference between the 1982 and 1983 weather periods confirmed the existence of compensating errors.

The Canadian direct gain study and the Los Alamos Sunspace study were both done in the context of IEA SHC Task 8 (Judkoff 1985a, 1985b, 1986; Barakat 1983; Morck 1986; McFarland 1982). In these studies a combination of empirical, comparative, and analytical techniques were used to diagnose the sources of difference among code predictions, and between code predictions and measurements. These studies showed that disagreement increases in cases where the solar forcing function is greater, and decreases in cases where one-dimensional conduction is the dominant heat-transfer mechanism.

In general, the studies demonstrated the importance of designing validation studies with a very high degree of control over the previously mentioned external error sources. Thus the NREL methodology emphasized the following points for empirical validation:

- start with very simple test objects, before progressing to more complex buildings

- use a detailed mechanism level approach to monitoring

- use a diversity of climates, building types, and modes of operation to sample a variety of domains within the parameter space

- compare measured data to calculated outputs at a variety of time scales, and on the basis of both intermediate and final outputs including temperature and power values.

The studies also showed the diagnostic power of using comparative techniques in conjunction with empirical validation methods. These are especially useful for identifying compensating errors in a program.

European work on empirical validation included a comprehensive review of empirical validation data sets (Lomas 1986; Lomas and Bowman 1986), a critical review of previous validation studies (Bowman and Lomas 1985a), the construction and monitoring of a group of test cells, several validation studies using the test cell data (Martin 1991), and methodological work on sensitivity analysis techniques (Lomas and Eppel 1992).

\section{Comparative Testing: The BESTEST Approach}

The objective of IEA Task $12 \mathrm{~B} / 21 \mathrm{C}$ has been to develop practical implementation procedures and data for the overall validation methodology. The task has therefore proceeded on three tracks, with the analytical validation approach lead by Belgium, the empirical validation approach lead by the United Kingdom, and the comparative validation approach lead by the United States. The United States has also served as the chair for the IEA SHC 12B and IEA BCS 21C, "Model Evaluation and Improvement" Experts Group.

The procedures presented in this report take the "comparative testing" approach. A set of carefully specified cases is described so that equivalent input files can be easily defined for a variety of detailed and simplified whole-building energy simulation programs. A range of results from a number of detailed public domain models, considered to be state-of-the-art in the United States and Europe, is provided as 
the basis for comparison. These reference model results do not necessarily represent "truth"; however, they are representative of what is commonly accepted as the current state-of-the-art in whole-building energy simulation. A program which disagrees with the reference data in this report may not be incorrect, but it does merit scrutiny. Experience from previous studies has shown that the underlying cause of such discrepancies is usually a bug or faulty algorithm (Judkoff et al. 1988; Bloomfield 1989). While not a perfect solution to the validation problem, we hope that these cases and the accompanying set of results will be useful to software developers and to designers attempting to determine the appropriateness of a program for a particular application. Such an approach is certainly better than the current situation in which computer programs are used or misused on blind faith.

The test cases presented here augment the work conducted in IEA SHC Task 8 by including a welldeveloped diagnostic method (Judkoff 1988; Bloomfield 1989). The range of disagreement among the participating programs in this study was larger than in previous studies because the test cases were designed to be more sensitive to solar energy and because modelers were directed to use the most detailed level of modeling available in their programs. In Task 8 , a common-denominator approach to modeling was used.

We hope that as this test procedure becomes better known, all software developers will use it as part of their standard quality control program. We also hope that they will include the input and output files for the tests as sample problems with their software packages.

The next section, Part I, is a User's Manual that fully describes the test cases, how to use them, and how to use the diagnostic procedures. 
Xxviii 


\subsection{Part I: BESTEST User's Manual: Procedure and Specification}

\subsection{General Description of Test Cases}

The purpose of this specification is to create a uniform set of unambiguous test cases for software-tosoftware comparisons, and program diagnostics. No two programs require exactly the same input information. Therefore, we have tried to describe the test cases in a fashion that allows many different building simulation programs (representing different degrees of modeling complexity) to be tested. There are 36 cases in all (plus 4 free-floating variants of cases $600,650,900$, and 950). However, a user who is not interested in performing diagnostics need run only 14 qualification tests. The remaining cases are for diagnostic purposes. The sequencing in the case numbering is from simple to complex. Thus, case 195 (lowest number) represents a very primitive diagnostic case. Case 990 (highest number) represents a relatively realistic, thermally complex ground-coupled case. The 600 and 900 series consist of the qualification cases, and are therefore run first. All other cases are for diagnostics, and are run according to the logic presented in a series of flow diagrams in Section 1.6. As an alternative approach, a user may perform all the tests at once, and analyze the results according to the diagnostic logic.

Qualification cases 600 to 650 and 900 to 990 represent a set of lightweight and heavyweight buildings that are relatively realistic with respect to their thermal characteristics. These cases test a program's ability to model such features as windows at different orientations, horizontal and vertical external shading devices, set-back thermostats, night ventilation economizer cooling, a passive solar sunspace, and ground coupling.

Diagnostic cases 195 to 320 represent an attempt to isolate the effects of individual algorithms by varying a single parameter from case to case. These cases are relatively primitive, to minimize the number of interacting heat transfer phenomena that can confound attempts at diagnosis. Some programs will not be able to model some of these cases for the very reason that they are not realistic. That is, programs that include simplified algorithms or fixed assumptions may not be capable of explicitly modeling some of the primitive diagnostic cases. Diagnostic cases 395 to 440 attempt to solve this problem by presenting an alternative set of diagnostic tests that are slightly more realistic than the primitive cases. Although these tests do not provide as precise a diagnosis because of interactive effects, more programs will be able to use them.

The qualification cases themselves also provide some diagnostic information-based on the results from individual cases, the sequencing of the tests, and the differences in results between certain cases. These differences can be thought of as the sensitivity of a program to the presence or absence of a certain feature of the building. For example, the difference in cooling load between a case with shading devices and without such devices may be thought of as the sensitivity of the program's cooling load predictions to shading devices. Implementation and interpretation of the tests are discussed in later sections.

The basic geometry of the test case building is a rectangular single zone with no interior partitions (except for a two-zone sunspace case). The geometric and materials specifications are purposely kept as simple as possible to minimize the opportunity for input errors on the part of the user. A complete description for the cases is provided in Sections 1.4 to 1.6 . 


\subsection{Modeling Approach: Rules for Performing the Tests}

These are the rules for performing the tests:

- Use the most detailed level of modeling your program will allow. For example, do not use a shading coefficient input for windows if your program calculates the incident angle dependent transmittance of glass.

- Do not use constant combined convective and radiative film coefficients if your program can calculate surface radiation and convection in a more detailed, or physically correct manner.

- If your program allows for initialization or preconditioning (iterative simulation of an initial time period until temperatures and/or fluxes stabilize at initial values), then use that capability.

- If your program includes the thickness of walls in a three-dimensional definition of the building geometry, then wall, roof, and floor thicknesses should be defined such that the interior air volume of the building remains as specified $\left(6 \mathrm{~m} \times 8 \mathrm{~m} \times 2.7 \mathrm{~m}=129.6 \mathrm{~m}^{3}\right)$. Make the thicknesses extend exterior to the currently defined internal volume.

- All references to time in this specification are to solar time, and assume that hour $1=$ the interval from midnight to 1 a.m. Do not use daylight savings time or holidays for scheduling.

- In some instances, the specification will include input values that do not apply to the input structure of your program. For example, your program may not allow adjustment of infrared emissivities. When this occurs, either use approximation methods suggested in your users manual, or simply disregard the nonapplicable inputs, and continue. Such inputs are in the specification for those programs that may need them.

\subsection{How to Use BESTEST}

The following text describes the most parsimonious (least work) way to use BESTEST. This path follows a sequential "go or no go" branching logical structure and will probably be favored by those not needing to use the diagnostics. Program authors and researchers may wish to use an alternate approach that yields more diagnostic information. This alternate approach involves performing all the tests, and then using the BESTEST flow logic to assist in analyzing the results.

Input data for the various cases are included in Sections 1.4 and 1.6. Tables 1-13 and 1-14 cover case descriptions and diagnostics. Tables 1-15 to 1-18 cover material specifications for lightweight and heavyweight cases (in English and metric). Tables 1-13 and 1-14 contain information on those building parameters that change from case to case. Tables 1-15 to 1-18 contain nonvarying material properties for the components of a low- and high-mass building. Figures 1-2 to 1-5 (Section 1.6) show the geometry of the base building, and the window overhang and sidefin geometries for those cases that have window shading. Figure 1-6 shows the geometry of the sunspace case for 960 . Figures 1-7 to 1-10 (Section 1.7) consist of qualification flow diagrams and diagnostic flow diagrams that guide you through the cases, summarize the logic behind them, and describe what may be learned by running the cases. Abbreviations used in the tables, figures, and text are defined in Appendix A.

Begin with case 600 (Table 1-14), which is the start of the low-mass qualification series. These tests include cases 600 to 650 . The sequence and meaning of these cases is shown on the low-mass cases flow chart (Figure 1-7). Input case 600 to your program using the information on the material specification sheets (Tables 1-15 and 1-16), and on the case description sheet (Table 1-14). Once you have developed 
an accurate input description for case 600 , the remaining low-mass cases may be input by slightly modifying case 600 , as indicated on the case description sheet (Table 1-14). When the low-mass series has been completed, proceed to case 900 , which is the start of the high-mass qualification series. However, do not proceed until anomalous results have been corrected. If the results appear reasonable, input case 900 using the materials specification sheets (Table 1-17 and 1-18) and the case description (Table 1-14). Then input the rest of the high-mass qualification cases ( 900 to 990 ), according to the case description sheet (Table 1-14). The additional four free-floating cases-600FF, 650FF, 900FF, and 950FF-should also be run as qualification cases if your program has the ability to calculate and output hourly temperatures. This will involve modifying the mechanical systems so that there is no mechanical heating or cooling of the building (mechanical venting is still required in cases $650 \mathrm{FF}$ and $950 \mathrm{FF}$ ).

A program may be thought of as having passed successfully through the qualification series when its results compare favorably with the reference program output for both the qualification cases (600 and 900 series) and the qualification sensitivity cases (e.g., case 610-600).

If anomalous results are observed, then follow the diagnostic paths indicated on the flow diagrams (Figures 1-7 to 1-10). The logic is sequential. It is therefore important to interpret results from both the diagnostic and qualification cases according to the flow diagrams. We provide no exact definition for "anomalous results" here. In general, any result very different from the example results presented later in this report should be scrutinized. We expect that, in the future, other organizations will set error bands according to their individual accuracy requirements.

The diagnostic cases contain several alternative paths because not all programs will be capable of modeling all diagnostic cases. For example, cases 195 to 310 require that the heating and cooling sét points be effectively equal. No diagnostic information will be obtained from running a simplified design tool with fixed assumptions about the thermostat set points on these cases. If your program cannot explicitly model, implicitly model, or approximate an effect in a diagnostic case, don't run that case, but look for an alternative diagnostic path on the flow diagrams. For example, programs not able to use path $A$ on Figure 1-8 will probably be able to use path $B$. The path $B$ diagnostics are not as clean as those in path $\mathrm{A}$ because more effects are interacting; however, they are still useful in detecting the probable sources of differences.

To summarize, only do those diagnostic cases that you can model in at least some approximate fashion.

\subsection{Specific Input Information}

\subsubsection{Weather}

Use the weather diskette supplied in your packet. See Appendix $G$ for details about the typical meteorological year (TMY) weather data file format. Site and weather characteristics are summarized in Table 1-3.

\subsubsection{Ground Coupling}

The state-of-the-art in ground modeling is not very good even in detailed building energy simulation programs. The floor insulation has therefore been made very thick to effectively decouple the floor thermally from the ground. Assume that the underfloor insulation has the minimum density and specific heat your program will allow. Case 990 is defined to specifically test the modeling of heat transfer between the building and the ground. This case will be described in detail later in the specification. 
Table 1-3. Site and Weather Summary

\begin{tabular}{||l|l|}
\hline Weather type & Cold clear winters/Hot dry summers \\
\hline Weather format & TMY \\
\hline Latitude & $39.8^{\circ}$ north \\
\hline Longitude & $104.9^{\circ}$ west \\
\hline Altitude & $1609 \mathrm{~m}$ \\
\hline Time zone & 7 \\
\hline Ground reflectivity & 0.2 \\
\hline Site & Flat, unobstructed, located exactly at weather \\
& station \\
\hline Mean annual wind speed & $4.02 \mathrm{~m} / \mathrm{s}$ \\
\hline Ground temperature & $10^{\circ} \mathrm{C}$ \\
\hline Mean annual ambient dry-bulb temperature & $9.71^{\circ} \mathrm{C}$ \\
\hline Minimum annual dry-bulb temperature & $-24.39^{\circ} \mathrm{C}$ \\
\hline Maximum annual dry-bulb temperature & $35.00^{\circ} \mathrm{C}$ \\
\hline Maximum annual wind speed & $14.89 \mathrm{~m} / \mathrm{s}$ \\
\hline Heating degree days (base $18.3^{\circ} \mathrm{C}$ ) & $3636.2^{\circ} \mathrm{C}-$ days \\
\hline Cooling degree days (base $18.3^{\circ} \mathrm{C}$ ) & $487.1^{\circ} \mathrm{C}-$ days \\
\hline Mean annual dew point temperature & $-1.44^{\circ} \mathrm{C}$ \\
\hline Mean annual humidity ratio & 0.0047 \\
\hline $\begin{array}{l}\text { Global horizontal solar radiation } \\
\text { annual total }\end{array}$ & $1831.82 \mathrm{kWh} / \mathrm{m}^{2}-\mathrm{y}$ \\
\hline Direct normal solar radiation \\
annual total & $2353.58 \mathrm{kWh} / \mathrm{m}^{2}-\mathrm{y}$ \\
\hline Direct horizontal solar radiation & $1339.48 \mathrm{kWh} / \mathrm{m}^{2}-\mathrm{y}$ \\
\hline Diffuse horizontal solar radiation & $492.34 \mathrm{kWh} / \mathrm{m}^{2}-\mathrm{y}$ \\
\hline & \\
\hline & \\
\hline
\end{tabular}

\subsubsection{Infiltration}

This is a high-altitude site, so the density of air is roughly $80 \%$ of that at sea level. If your program does not use barometric pressure from the weather data, or otherwise automatically correct for the change in air density due to altitude, then adjust the specified infiltration rates to yield mass flows equivalent to what would occur at the specified altitude, as shown in Table 1-4. 
Table 1-4. Infiltration Rates Depending on the Presence of Automatic Altitude Adjustment

\begin{tabular}{|l|c|c|}
\hline Altitude adjustment algorithm & $\begin{array}{l}\text { Input air changes } \\
\text { per hour } \mathbf{A C H}\end{array}$ & Adjustment factor \\
\hline $\begin{array}{l}\text { Programs with automatic } \\
\text { altitude adjustment }\end{array}$ & $\begin{array}{l}0.5 \text { or } 1 \text { depending } \\
\text { on case number }\end{array}$ & 1 \\
\hline $\begin{array}{l}\text { Programs with fixed assumption that site is } \\
\text { at sea level (no automatic adjustment) }\end{array}$ & 0.41 or 0.822 & $0.822^{\mathrm{a}}$ \\
\hline
\end{tabular}

${ }^{2}($ Specified rate $) \times 0.822=($ altitude adjusted rate $)$

Note: For further discussion of this input, see Appendix B.

\subsubsection{Internally Generated Heat (Casual Gains)}

These are internally generated sources of heat from equipment, lights, people, animals, etc., that are not related to heating, ventilating, and air conditioning (HVAC). The cases with internally generated sensible heat (no latent) are specified in Section 1.6 (Tables 1-13 and 1-14), and assume a constant value of $200 \mathrm{~W}$ ( $60 \%$ radiative, $40 \%$ convective; $100 \%$ sensible, $0 \%$ latent).

\subsubsection{Exterior Combined Radiative and Convective Surface Coefficients}

If your program calculates exterior surface radiation and convection automatically, then you may disregard this section. If your program does not calculate this effect, then use the information given in Table 1-5.

Table 1-5: Exterior Combined Surface Coefficient Versus Surface Orientation and Infrared Emissivity

\begin{tabular}{||l|l|l||}
\hline Surface texture & \multicolumn{1}{|c|}{$\begin{array}{c}\text { Specified emissivity } \\
\varepsilon=\mathbf{0 . 9}\end{array}$} & \multicolumn{1}{|c|}{$\begin{array}{c}\text { Specified emissivity } \\
\varepsilon=\mathbf{0 . 1}\end{array}$} \\
\hline \hline Brick or rough plaster & $\begin{array}{l}29.3 \mathrm{~W} / \mathrm{m}^{2} \mathrm{~K} \\
\text { (all walls and roofs) }\end{array}$ & $\begin{array}{l}25.2 \mathrm{~W} / \mathrm{m}^{2} \mathrm{~K} \\
\text { (all walls and roofs) }\end{array}$ \\
\hline $\begin{array}{l}\text { Glass or very smooth } \\
\text { surface }\end{array}$ & $\begin{array}{l}21.0 \mathrm{~W} / \mathrm{m}^{2} \mathrm{~K} \\
\text { (window and high-conductive } \\
\text { wall) }\end{array}$ & $\begin{array}{l}16.9 \mathrm{~W} / \mathrm{m}^{2} \mathrm{~K} \\
\text { (window and high-conductive } \\
\text { wall) }\end{array}$ \\
\hline
\end{tabular}

Note: All values in table are based on a mean annual wind speed of $4.02 \mathrm{~m} / \mathrm{s}$.

The exterior combined radiative and convective surface conductance for the glass and very smooth opaque surfaces are specified as equivalent for the convenience of input, even though the infrared emissivity for common window glass is usually 0.84 .

If your program adjusts glass surface coefficients according to window overhang and fin structure-use that capability, and provide documentation. 
Rain causes the surface temperature to rapidly approach the water temperature. Provide documentation if your program treats rain as a special case.

See Appendices $C$ and $D$ if you need more information on exterior film coefficients.

\subsubsection{Interior Combined Radiative and Convective Surface Coefficients}

If your program calculates interior surface radiation and convection,then you may disregard this section. If your program does not calculate these effects, then use the following American Society of Heating, Refrigerating, and Air-Conditioning Engineers (ASHRAE) constant combined radiative and convective coefficients as shown in Table 1-6 (the ASHRAE values are not exactly the same as the Chartered Institution of Building Services Engineers [CIBSE] values).

Table 1-6. Interior Combined Surface Coefficient Versus Surface Orientation and Infrared Emissivity

\begin{tabular}{|l|l|l|}
\hline Orientation of surface and heat flow & \multicolumn{1}{|c|}{$\begin{array}{c}\text { Specified } \\
\text { emissivity } \\
\varepsilon=\mathbf{0 . 9}\end{array}$} & $\begin{array}{c}\text { Specified } \\
\text { emissivity } \\
\varepsilon=\mathbf{0 . 1}\end{array}$ \\
\hline \hline Horizontal heat transfer on vertical surfaces & $8.29 \mathrm{~W} / \mathrm{m}^{2} \mathrm{~K}$ & $3.73 \mathrm{~W} / \mathrm{m}^{2} \mathrm{~K}$ \\
\hline Upward heat transfer on horizontal surfaces & $9.26 \mathrm{~W} / \mathrm{m}^{2} \mathrm{~K}$ & $4.70 \mathrm{~W} / \mathrm{m}^{2} \mathrm{~K}$ \\
\hline Downward heat transfer on horizontal surfaces & $6.13 \mathrm{~W} / \mathrm{m}^{2} \mathrm{~K}$ & $1.57 \mathrm{~W} / \mathrm{m}^{2} \mathrm{~K}$ \\
\hline Upward heat transfer on $45^{\circ}$ surfaces & $9.09 \mathrm{~W} / \mathrm{m}^{2} \mathrm{~K}$ & $4.53 \mathrm{~W} / \mathrm{m}^{2} \mathrm{~K}$ \\
\hline Downward heat transfer on $45^{\circ}$ surfaces & $7.50 \mathrm{~W} / \mathrm{m}^{2} \mathrm{~K}$ & $2.94 \mathrm{~W} / \mathrm{m}^{2} \mathrm{~K}$ \\
\hline
\end{tabular}

The radiative portion of these combined coefficients may be taken as: $5.13 \mathrm{~W} / \mathrm{m}^{2} \mathrm{~K}$ for cases with an infrared emissivity of 0.9 . For those diagnostic cases where the infrared emissivity is 0.1 , the radiative portion decreases to $0.57 \mathrm{~W} / \mathrm{m}^{2} \mathrm{~K}$. Thus the coefficients listed under $\varepsilon=0.9$ in Table $1-6$ are reduced by $4.56 \mathrm{~W} / \mathrm{m}^{2} \mathrm{~K}$ to produce the values listed under $\varepsilon=0.1$.

If your program does not allow scheduling of these coefficients, then use $8.29 \mathrm{~W} / \mathrm{m}^{2} \mathrm{~K}$ for all horizontal surfaces when infrared emissivity is 0.9 , and $3.73 \mathrm{~W} / \mathrm{m}^{2} \mathrm{~K}$ when infrared emissivity is 0.1 . Document any reasons you have for using different values.

See Appendix D if you need more information on interior combined radiative and convective film coefficients.

\subsubsection{High-Conductance Wall/Opaque Window}

An element that may be thought of as a highly conductive wall or an opaque window, replaces the $12 \mathrm{~m}^{2}$ transparent window on the south wall for all cases with 0.0 glass area (except for cases 195 and 395, where the transparent window is replaced by the normally insulated wall). 
The properties of the high-conductance wall are as follows:

- Short wave transmittance $=0$.

- Interior and exterior infrared emissivity is the same as for the normally insulated wall in each test case.

- Interior combined surface coefficient is $8.29 \mathrm{~W} / \mathrm{m}^{2} \mathrm{~K}$, and the exterior combined surface coefficient is $21 \mathrm{~W} / \mathrm{m}^{2} \mathrm{~K}$ for cases where the infrared emissivity is 0.9 . For cases where the infrared emissivity is 0.1 , the exterior surface coefficient is $16.9 \mathrm{~W} / \mathrm{m}^{2} \mathrm{~K}$, and the interior surface coefficient is 3.73 $\mathrm{W} / \mathrm{m}^{2} \mathrm{~K}$.

- Exterior solar absorptance is the same as for the normally insulated wall in each test case.

- Conductance, density, specific heat, and surface texture (very smooth) are the same as for the transparent window (see Section 1.4.8).

\subsubsection{Transparent Window}

Many programs use different algorithms to calculate window transmittance, and therefore require different inputs. For example, SERIRES calculates the transmittance, absorptance, and reflectance for each hourly incidence angle-given the index of refraction, extinction coefficient, glazing thickness, and number of panes in the window assembly. BLAST calculates the extinction coefficient, absorptance, reflectance, and angle dependent transmittance-given the direct normal transmittance of a single pane in air, glass thickness, index of refraction, and number of panes. A great deal of information about the window properties has therefore been provided so that equivalent input for the window will be possible for many programs. The basic properties of the window are provided in Table 1-7. The angular dependence of direct beam transmittance is given in Table 1-8. Additional information can be found in the glazing tables that were derived from Snell's Law, Bouger's Law, and the Fresnel Equations (Appendix E). For programs that need transmittance or reflectance at other angles of incidence, calculate them using the equations given with the glazing tables, or interpolate between the values in the glazing tables. Where other unspecified data is needed, then values that are consistent with those quoted will have to be calculated.

If you need more information on glazing optical properties, refer to Appendix E.

\subsubsection{Window Overhang}

The horizontal overhang for the south facing windows (see Figure 1-3) is assumed to travel the entire length of the south wall. All other dimensions for shading devices are shown in the drawings (Figures 1-4 to 1-5). Include the shading effect on adjacent opaque surfaces, if possible, with your program. Also, modifications to longwave interchange due to the shading device should be modeled, if your program has that capability.

\subsubsection{Interior Solar Distribution}

Use your program at its greatest level of detail.

If your program does not calculate this effect internally, but requires distribution fractions from the user, then assume that $100 \%$ of the incoming radiation strikes the floor first, and that all reflections are diffuse. Table 1-9 presents an approximate calculation of solar distribution fractions. Only use these approximations if your program does not provide a more detailed approach. 
Table 1-7. Window Properties

\begin{tabular}{|c|c|}
\hline Property & Value \\
\hline Extinction coefficient & $0.0196 / \mathrm{mm}$ \\
\hline Number of panes & 2 \\
\hline $\begin{array}{l}\text { Pane thickness } \\
\text { (standard } 1 / 8 " \text { glass under the inch-pound [IP] } \\
\text { system) }\end{array}$ & $3.175 \mathrm{~mm}$ \\
\hline Air-gap thickness & $13 \mathrm{~mm}$ \\
\hline Index of refraction & 1.526 \\
\hline $\begin{array}{l}\text { Normal direct-beam transmittance through one } \\
\text { pane in air }\end{array}$ & 0.86156 \\
\hline Conductivity of glass & $1.06 \mathrm{~W} / \mathrm{mK}$ \\
\hline Conductance of each glass pane & $\left(\mathrm{R}-.003 \mathrm{~m}^{2} \mathrm{~K} / \mathrm{W}\right)$ \\
\hline $\begin{array}{l}\text { Combined radiative and convective coefficient } \\
\text { of air gap }\left(\mathrm{h}_{\mathrm{S}}\right)\end{array}$ & $6.297 \mathrm{~W} / \mathrm{m}^{2} \mathrm{~K} \quad\left(\mathrm{R}-1588 \mathrm{~m}^{2} \mathrm{~K} / \mathrm{W}\right)$ \\
\hline Exterior combined surface coefficient $\left(\mathrm{h}_{\mathrm{o}}\right)$ & $\left(\mathrm{R}-.0476 \mathrm{~m}^{2} \mathrm{~K} / \mathrm{W}\right)$ \\
\hline Interior combined surface coefficient $\left(h_{i}\right)$ & $\left(\mathrm{R}-.1206 \mathrm{~m}^{2} \mathrm{~K} / \mathrm{W}\right)$ \\
\hline U-value from interior air to ambient air & $\left(\mathrm{R}-.3333 \mathrm{~m}^{2} \mathrm{~K} / \mathrm{W}\right)$ \\
\hline $\begin{array}{l}\text { Hemispherical infrared emittance of ordinary } \\
\text { uncoated glass }\end{array}$ & $\begin{array}{l}0.84 \text { (Use } 0.9 \text { for simplicity of input. If your } \\
\text { program must use } 0.84 \text {, this is acceptable } \\
\text { because the effect on outputs will be less than } \\
0.5 \% \text {.) }\end{array}$ \\
\hline Density of glass & $2500 \mathrm{~kg} / \mathrm{m}^{3}$ \\
\hline Specific heat of glass & $750 \mathrm{~J} / \mathrm{kgK}$ \\
\hline $\begin{array}{l}\text { Curtains, blinds, frames, spacers, mullions, } \\
\text { obstructions inside the window }\end{array}$ & None \\
\hline $\begin{array}{l}\text { Double-pane shading coefficient (at normal } \\
\text { incidence) }\end{array}$ & 0.916 \\
\hline $\begin{array}{l}\text { Double-pane solar heat gain coefficient (at } \\
\text { normal incidence) }\end{array}$ & 0.787 \\
\hline
\end{tabular}

Table 1-8. Angular Dependence of Direct-Beam Transmittance ${ }^{a}$ for Double-Pane Window

\begin{tabular}{|l|c|c|c|c|c|c|c|c|c|}
\hline Angle of incidence & 0 & 10 & 20 & 30 & 40 & 50 & 60 & 70 & 80 \\
\hline Transmittance & 0.74745 & 0.74682 & 0.74465 & 0.73989 & 0.72983 & 0.70733 & 0.65233 & 0.51675 & 0.26301 \\
\hline
\end{tabular}

${ }^{\text {a }}$ Transmittance is defined as total direct-beam transmittance through the window assembly (no other solar absorptance or reflectance, or transmission of radiation reflected from the room back out the window is included in these values). 
Table 1-9. Interior Solar Distribution Fractions Versus Window Orientation and Interior Shortwave Absorptance

\begin{tabular}{|c|c|c|c|c|c|c|}
\hline Surface & $\begin{array}{c}\text { South window } \\
\text { cases } \\
\alpha=0.6\end{array}$ & $\begin{array}{c}\text { East/West } \\
\text { window cases } \\
\alpha=0.6\end{array}$ & $\begin{array}{c}\text { South } \\
\text { window cases } \\
\alpha=0.9\end{array}$ & $\begin{array}{c}\text { East/West } \\
\text { window cases } \\
\alpha=0.9\end{array}$ & $\begin{array}{c}\text { South window } \\
\text { cases } \\
\alpha=0.1\end{array}$ & $\begin{array}{l}\text { Sun- } \\
\text { space } \\
\text { case }\end{array}$ \\
\hline Floor & 0.642 & 0.642 & 0.651 & 0.651 & 0.244 & 0.6 \\
\hline Ceiling & 0.168 & 0.168 & 0.177 & 0.177 & 0.191 & 0.06 \\
\hline East wall & 0.038 & 0.025 & 0.041 & 0.027 & $\quad 0.057$ & 0.02 \\
\hline West wall & 0.038 & 0.025 & 0.041 & 0.027 & 0.057 & 0.02 \\
\hline North wall & 0.053 & 0.0525 & 0.056 & 0.056 & 0.082 & 0.2 \\
\hline South wall & 0.026 & 0.0525 & 0.028 & 0.056 & 0.065 & 0.03 \\
\hline $\begin{array}{l}\text { Solar lost } \\
\text { through window }\end{array}$ & 0.035 & 0.035 & 0.006 & 0.006 & 0.304 & 0.07 \\
\hline
\end{tabular}

Note: Interior solar absorptivity is denoted as $\alpha$.

Appendix $\mathrm{F}$ has a detailed description of the algorithm used for calculating these solar fractions. Briefly, the calculations assume that

- No solar radiation is directly absorbed by the zone air.

- All incident solar radiation initially hits the floor.

- The fraction of radiation initially absorbed by the floor is the interior shortwave absorptance.

- The remaining solar radiation is diffusely reflected such that it is distributed over the other surfaces in proportion to their shape factors (Kreith and Bohn 1993).

- The fraction of radiation absorbed by these surfaces is the interior shortwave absorptance.

- The remaining amount of the original sunlight (after the second "bounce") is then assumed to be absorbed by all the surfaces in proportion to their area-absorptance products.

Fractional values for the walls with windows include the portion of the solar radiation absorbed by the glass (as it passes back out the window) and conducted into the zone. Solar radiation absorbed by the glass (and conducted inward) as it passes into the building is treated by most programs in their window transmissivity algorithms, and is therefore not included in the values in Table 1-9.

For the cases with windows oriented east and west, everything is assumed to be the same as for the southoriented cases, except that the fractions are adjusted in proportion to the change in the opaque areas of the east, west, and south walls caused by moving the windows.

For case 960 (sunspace) we calculated solar lost using the same assumptions as for the south window orientation cases, with some adjustments because of the shallow $2-\mathrm{m}$ depth of the sun zone. The tabulated values assume a solar fraction of 0.6 for the floor and 0.2 for the common wall. The remaining solar fractions were distributed in proportion to the area-absorptance products of the remaining surfaces. The solar-lost fraction was rounded to 0.07 . 


\subsubsection{Mechanical System}

Assume the following conditions:

- $100 \%$ convective air system

- The thermostat sensing only the air temperature

- Nonproportional-type thermostat

- No latent loads.

\subsubsection{Thermostat Control Strategies}

The thermostat is nonproportional in the sense that when the air temperature exceeds the thermostat cooling set point, the heat extraction rate is assumed to equal the maximum capacity of the cooling equipment. Likewise, when the air temperature drops below the thermostat heating set point, the heat addition rate equals the maximum capacity of the heating equipment. A proportional thermostat model can be made to approximate a nonproportional thermostat model by setting a very small throttling range (the minimum allowed by your program). Various thermostat control strategies specified in the case descriptions in Section 1.6 (Tables 1-13 and 1-14) are defined below.

20,20 or BANG-BANG

Heat $=$ on if temp $<20^{\circ} \mathrm{C}$

$\mathrm{Cool}=$ on if temp $>20^{\circ}$

20,27 or DEADBAND

Heat $=$ on if temp $<20^{\circ} \mathrm{C}$

Cool $=$ on if temp $>27^{\circ} \mathrm{C}$

\section{SETBACK}

From 2300 hours to 0700 hours, heat $=$ on if temp $<10^{\circ} \mathrm{C}$ From 0700 hours to 2300 hours, heat $=$ on if temp $<20^{\circ} \mathrm{C}$ All hours, $\mathrm{cool}=$ on if temp $>27^{\circ} \mathrm{C}$

\section{VENTING}

From 1800 hours to 0700 hours, vent fan $=$ on From 0700 hours to 1800 hours, vent fan $=$ off Heating = always off From 0700 hours to 1800 hours, $\mathrm{cool}=$ on if temp $>27^{\circ} \mathrm{C}$ From 1800 hours to 0700 hours, cool $=$ off

\subsubsection{Equipment Characteristics}

Heating capacity $=1000 \mathrm{~kW}$ (effectively infinite)

Effective efficiency $=100 \%$

Cooling capacity $=1000 \mathrm{~kW}$ (effectively infinite)

Effective efficiency $=100 \%$

Sensible cooling only; no latent load calculation 
Vent fan capacity $=1703.16$ standard $\mathrm{m}^{3} / \mathrm{h}$ (in addition to specified infiltration rate)

Waste heat from fan $=0$

If your program does not automatically correct for the reduced density of air at altitude, then adjust your inputs for the fan capacity as noted in Table 1-10.

Table 1-10. Vent Fan Capacity Depending on the Presence of Automatic Altitude Adjustment

\begin{tabular}{|l|c|c||}
\hline $\begin{array}{l}\text { Vent fan capacity specification } \\
\text { (in addition to specified infiltration rate) }\end{array}$ & $\begin{array}{c}\text { Air changes } \\
\text { per hour } \\
\text { (ACH) }\end{array}$ \\
\hline $\begin{array}{l}\text { Input for programs that automatically correct vent fan mass } \\
\text { flow for altitude }\end{array}$ & 1703.16 & 13.14 \\
\hline $\begin{array}{l}\text { Input for programs with fixed assumption that site is at sea } \\
\text { level (no automatic correction of fan mass flow) }\end{array}$ & 1400 & 10.8 \\
\hline
\end{tabular}

\subsubsection{Sunspace: Case 960}

The sunspace consists of two zones (back zone and sun zone) separated by a common wall (Figure 1-6). The back zone is of lightweight construction, and the sun zone is of heavyweight construction.

\subsubsection{Back Zone}

The geometric and thermal properties of the back zone are exactly the same as for case 600 except that the south wall and windows are replaced with the common wall. Infiltration in the back zone $=0.5 \mathrm{ACH}$ (with the same altitude adjustment as for case 600). Internal heat generation (casual gains) in the back zone $=200 \mathrm{~W}$ (as in case 600$)$.

\subsubsection{Sun Zone/Back Zone Common Wall}

Properties of the sun zone/back zone common wall are specified in Table 1-11.

Table 1-11. Thermal and Physical Properties of Sun Zone/Back Zone Common Wall

\begin{tabular}{|c|c|c|c|c|c|c||}
\hline $\begin{array}{c}\mathbf{k} \\
(\mathbf{W} / \mathbf{m K})\end{array}$ & $\begin{array}{c}\text { Thickness } \\
(\mathbf{m})\end{array}$ & $\begin{array}{c}\mathbf{U} \\
\left(\mathbf{W} / \mathbf{m}^{2} \mathbf{K}\right)\end{array}$ & $\begin{array}{c}\mathbf{R} \\
\left(\mathbf{m}^{2} \mathbf{K} / \mathbf{W}\right)\end{array}$ & $\begin{array}{c}\text { Density } \\
\left(\mathbf{k g} / \mathbf{m}^{\mathbf{3}}\right)\end{array}$ & $\begin{array}{c}\text { Specific heat } \\
(\mathbf{J} / \mathbf{k g K})\end{array}$ & $\begin{array}{c}\text { Shortwave } \\
\text { absorptance }\end{array}$ \\
\hline \hline 0.510 & 0.20 & 2.55 & 0.392 & 1400 & 1000 & $\alpha=0.6$ \\
\hline
\end{tabular}

\subsubsection{Sun Zone}

The sun zone is $2 \mathrm{~m}$ deep by $8 \mathrm{~m}$ wide by $2.7 \mathrm{~m}$ high. The back (north) wall of the sun zone is the common wall. The south wall of the sun zone contains two $6-\mathrm{m}^{2}$ windows that are the same as the windows in case 900 , except that they are raised $0.3-\mathrm{m}$ higher on the south wall than in case 900 (see Figure 1-6). The thermal and physical properties of the sun zone are the same as those in case 900 , except for the following exceptions: 
- They changed in depth from $6 \mathrm{~m}$ to $2 \mathrm{~m}$.

- The north wall has been replaced by the common wall.

- The south wall has been replaced with two $3-\mathrm{m} \times 2-\mathrm{m}$ windows raised $0.3-\mathrm{m}$ higher on the south wall than in case 900 . These windows are double pane and have the same properties as the windows in case 900 .

- The east and west walls of the sun zone (end walls) are $5.4 \mathrm{~m}^{2}$ each.

- The air volume of the sun zone is $43.2 \mathrm{~m}^{3}$.

- Infiltration in the sun zone is $\mathbf{0 . 5}$ air changes per hour (with the same altitude adjustment as for all other cases).

- Internal heat generation (casual gains) in the sun zone $=0$.

The exact geometric details are shown in Figure 1-6.

\subsubsection{Solar Distribution in Sun Zone}

If your program requires manual input of the distribution of solar energy onto the various interior surfaces of the sun zone, assume the following:

- $60 \%$ absorbed in the floor

- $20 \%$ absorbed in the common wall

- $7 \%$ lost back out of the window

- $13 \%$ absorbed in proportion to the remaining side wall and ceiling area.

See Table 1-9 in Section 1.4.10 for further details.

\subsubsection{Heating and Cooling Control Strategies}

- The sun zone has no space conditioning system (i.e., it is allowed to free-float).

- The back zone is controlled the same as for case 600 .

\subsubsection{Interzone Mass Transfer}

There is no mechanical or natural interzone air exchange.

\subsubsection{Ground Coupling: Case 990}

This case is somewhat different in philosophy than other cases in that no simplifying boundary conditions are given. The $10^{\circ} \mathrm{C}$ ground temperature specified earlier should not automatically be applied in this case. Ground temperature is some function of the meteorological data, the soil properties, and the heat exchange between the building and the ground. It is up to the modeler to simulate the case as accurately as possible with the program being tested.

The ground close to a house takes about a year to come to thermal stability with respect to the house. Thus ground temperatures will be different the first year after a house is built and its environmental 
control systems activated, than in subsequent years. For this case, assume that the house was built just prior to the start of the simulation run.

Case 990 is the same as case 900 , except that

- The building has sunk $1.35 \mathrm{~m}$ into the ground.

- The nonmasonry layers have been stripped from the floor and the sub-grade portion of the walls.

- The above-grade portions of the walls are exactly the same as for case 900.

- The south window is reduced in area to $10.8 \mathrm{~m}^{2}$ and completely fills the above-grade portion of the south wall.

- The roof is the same as for case 900 .

- The ground temperature is not specified for this case.

- The house has just been built.

The ground in the vicinity of the building is dry packed soil with the following characteristics:

Soil conductivity $(\mathrm{k})=1.3 \mathrm{~W} / \mathrm{mK}$

Soil density $\quad=1500 \mathrm{~kg} / \mathrm{m}^{3}$

Soil specific heat $\quad=800 \mathrm{~J} / \mathrm{kgK}$

Ground temperature Not specified for this case.

\subsection{Required Outputs}

Enter all your output data into the pre-formatted LOTUS-123 spreadsheet with the file name BESTOUT4.WK1 on the enclosed diskette. Instructions for using the spreadsheet are included at the top of the spreadsheet and in Appendix $\mathrm{H}$. The data already entered in the spreadsheet represent a range of results based on the predictions from the example programs run in IEA Task 12B and Annex 21C.

\subsubsection{Annual Outputs}

The annual outputs are as follows:

- Annual heating and cooling loads for all nonfree-float cases (MWh)

- Annual hourly-integrated peak heating and cooling loads $(\mathrm{kW})$ with the date and hour for all nonfreefloat cases

- Annual hourly-integrated maximum, and minimum, temperature $\left({ }^{\circ} \mathrm{C}\right)$ with date and hour for all freefloat cases, and for the sun zone in case 960 (case 960 is not a free-floating case, but the sun zone is free-floating); annual mean temperature $\left({ }^{\circ} \mathrm{C}\right)$ for all free-float cases, and for the sun zone in case 960

- Annual hourly $1^{\circ} \mathrm{C}$ temperature bin frequencies from $-20^{\circ} \mathrm{C}$ to $70^{\circ} \mathrm{C}$ for case $900 \mathrm{FF}$. A computer program is provided on the enclosed diskette that converts annual hourly temperature data to this form (see Appendix I). 
- Annual incident unshaded total solar radiation (diffuse and direct) on north, east, west, south, and horizontal surfaces $\left(\mathrm{kWh} / \mathrm{m}^{2}\right)$ for case 600 or 900

- Unshaded annual transmitted solar radiation (diffuse and direct) through west and south windows $\left(\mathrm{kWh} / \mathrm{m}^{2}\right)$. This quantity does not include radiation that is absorbed in the glass and conducted inward as heat. This quantity may be taken as the optically transmitted solar radiation through a window that is backed by a perfectly absorbing black cavity (for case 600 or 900 )

- Annual transmitted solar radiation through the shaded south window with a horizontal overhang, as in case 610 or 910 , and through the shaded west window, as in case 630 or $930\left(\mathrm{kWh} / \mathrm{m}^{2}\right)$.

\subsubsection{Daily Hourly Outputs}

If your program can produce hourly outputs, then produce the hourly values for the specified days as shown in Table 1-12. To produce this output, run the program for a normal annual run. Do not just run the required days because your results could contain temperature history errors.

Table 1-12. Hourly Output Requirements

\begin{tabular}{|l|c|c|}
\hline Hourly outputs $^{2}$ & Case number & Day \\
\hline \hline Hourly free-floating temperature $\left({ }^{\circ} \mathrm{C}\right)$ & $600 \mathrm{FF}$ and $900 \mathrm{FF}$ & Jan. 4 \\
\hline $\begin{array}{l}\text { Hourly heating }(+) \text { and cooling }(-)(\mathrm{kWh}) \text { (designate cooling with a } \\
(-) \text { sign) }\end{array}$ & 600 and 900 & Jan. 4 \\
\hline Hourly free-floating temperature $\left({ }^{\circ} \mathrm{C}\right)$ & $650 \mathrm{FF}$ and $950 \mathrm{FF}^{\mathrm{b}}$ & July 27 \\
\hline $\begin{array}{l}\text { Hourly unshaded incident solar radiation on south and west surfaces } \\
\left(\mathrm{Wh} / \mathrm{m}^{2}\right)\end{array}$ & 600 or 900 & July 27 \\
\hline $\begin{array}{l}\text { Hourly unshaded incident solar radiation on south and west surfaces } \\
\left(\mathrm{Wh} / \mathrm{m}^{2}\right)\end{array}$ & 600 or 900 & Mar. 5 \\
\hline
\end{tabular}

${ }^{a}$ Hourly data to consist of 24 values for each day. The first hour (hour 1 ) is defined to run from 0000 to 0100 hours.

${ }^{b}$ Cases $650 \mathrm{FF}$ and $950 \mathrm{FF}$ designate cases where the vent fan operates according to the specified schedule, but the heating and cooling systems are always off.

\subsection{Specification Figures and Tables}

The following tables include the summary case descriptions and building envelope material descriptions. Figures presented in this section give isometric, plan, elevation, and section views for various window orientations and shading configurations. For convenience, these tables and figures are listed below in order of their appearance within this section.

Table 1-13. BESTEST Case Descriptions: Low-Mass Diagnostics

Table 1-14. BESTEST Qualification Case Descriptions and Realistic Diagnostics

Table 1-15. Material Specifications: Lightweight Case (Metric)

Table 1-16. Material Specifications: Lightweight Case (English)

Table 1-17. Material Specifications: Heavyweight Case (Metric)

Table 1-18. Material Specifications: Heavyweight Case (English) 
Figure 1-2. BESTEST: isometric south windows-unshaded

Figure 1-3. BESTEST: section of south window overhang

Figure 1-4. BESTEST: east and west window shading

Figure 1-5. BESTEST: isometric east and west window shading

Figure 1-6. Sunspace plan and section

Figure 1-7. BESTEST: low-mass qualification flow diagram

Figure 1-8. BESTEST: low-mass diagnostics flow diagram

Figure 1-9. BESTEST: high-mass qualification flow diagram

Figure 1-10. BESTEST: high-mass diagnostics flow diagram 
Table 1-13. BESTEST Case Descriptions: Low-Mass Diagnostics

\begin{tabular}{|c|c|c|c|c|c|c|c|c|c|c|c|c|}
\hline \multirow{3}{*}{ CASE: } & \multirow{2}{*}{$\begin{array}{l}\text { SETPOINTS } \\
\text { (c) } \\
\mathrm{H}, \mathrm{C}, \mathrm{V}\end{array}$} & \multirow{2}{*}{ MASS } & \multirow[b]{2}{*}{$\begin{array}{l}(w) \\
\text { INTGEN }\end{array}$} & \multirow[b]{2}{*}{$\begin{array}{l}\text { ACH } \\
\text { INFILTR }\end{array}$} & \multicolumn{2}{|c|}{ OPAQUE SUAFACE } & \multicolumn{2}{|c|}{ OPAQUE SUAFACE } & \multirow[b]{2}{*}{$\mid \begin{array}{l}\text { (m2) } \\
\text { GLASS }\end{array}$} & \multirow[b]{2}{*}{ ORIENT } & \multirow[b]{2}{*}{$\left.\right|_{\text {SHADE }} ^{(m)}$} & \multirow[b]{2}{*}{ COMMENTS (see note 3) } \\
\hline & & & & & $\begin{array}{l}\text { INT IR } \\
\text { EMISSIV } \\
\end{array}$ & $\begin{array}{l}\text { EXT IR } \\
\text { EMISSIV }\end{array}$ & $\mid \begin{array}{l}\text { INT SW } \\
\text { ABSORPT }\end{array}$ & $\begin{array}{l}\text { EXT SW } \\
\text { ABSORPT }\end{array}$ & & & & \\
\hline & 20,20 & $\mathrm{~L}$ & 0 & 10 & $\begin{array}{l}1 \\
\text { see note } 1\end{array}$ & $\begin{array}{l}1 \\
\text { see note } 1\end{array}$ & $\begin{array}{l}\text { NA } \\
\text { see note } 4\end{array}$ & .1 & $\begin{array}{l}\text { see note } 1 \\
\text { see note } 2\end{array}$ & $\mathbf{s}$ & NO & Case 195 tests solid conduction \\
\hline 200 & 20,20 & $\mathrm{~L}$ & to & to & .1 & .1 & &.$\overline{1}$ & 0 & s & NO & $\begin{array}{l}\text { Do cases } 200 \text { thru } 215 \text { only if you can explicitly } \\
\text { adjust Infra-red emissivity in your code. } \\
\text { Cases } 200,195 \text { test film convection algorithms. } \\
\text { The major portion of the change in results } \\
\text { between } 200 \& 195 \text { will be from the opaque } \\
\text { window. Increased differences between codes } \\
\text { will be from the different film algorithms. }\end{array}$ \\
\hline 210 & 20,20 & $L$ & 0 & 0 & .1 & .9 & NA & .1 & 0 & s & NO & Cases 210,200 lest ext ir with int ir off \\
\hline 215 & 20,20 & $L$ & 0 & 0 & .9 & .1 & NA & .1 & 0 & s & NO & $\begin{array}{l}\text { Cases 220,215 test ext ir with int ir on. } \\
\text { Case 215,200 test int ir with ext ir off. }\end{array}$ \\
\hline 220 & 20,20 & $\mathrm{~L}$ & 0 & 0 & .9 & .9 & $\overline{N A}$ & .1 & 0 & $\mathbf{S}$ & NO & $\begin{array}{l}\text { Case } 220,210 \text { test int ir with ext ir on. } \\
\text { Case } 220 \text { is Base for } 230-270 \text {. }\end{array}$ \\
\hline 230 & 20,20 & $L$ & 0 & 1 & .9 & .9 & $\overline{\mathrm{NA}}$ & .1 & 0 & $\mathrm{~s}$ & NO & Cases 230,220 test infiltration. \\
\hline 240 & 20,20 & $L$ & 200 & 0 & .9 & .9 & NA & .1 & 0 & s & No & Cases 240,220 test internal gains. \\
\hline 250 & 20,20 & L & 0 & 0 & .9 & .9 & NA & .9 & 0 & s & NO & $\begin{array}{l}\text { Cases } 250,220 \text { test exterior solar } \\
\text { absorptance/incident solar. }\end{array}$ \\
\hline 270 & 20,20 & $L$ & to & 0 & .9 & .9 & .9 & 1 & 12 & $\mathbf{s}$ & NO & $\begin{array}{l}\text { Cases } 270,220 \text { test South solar transmittance/ } \\
\text { incident solar. }\end{array}$ \\
\hline 280 & 20,20 & $\mathrm{~L}$ & 0 & 0 & .9 & .9 & .1 & .1 & 12 & $\mathrm{~s}$ & NO & Cases 280,270 test cavity albedo. \\
\hline 290 & 20,20 & L & 0 & 0 & .9 & .9 & .9 & .1 & 12 & $s$ & $1.0 \mathrm{mH}$ & Cases 290,270 test south horizontal overhang. \\
\hline 300 & 20,20 & L & 0 & 0 & .9 & .9 & .9 & .1 & 6,6 & $E, W$ & No & $\begin{array}{l}\text { Cases } 300,270 \text { test East \& West } \\
\text { solar transmittance \& incidence. }\end{array}$ \\
\hline 310 & 20,20 & L & 0 & 0 & .9 & .9 & .9 & .1 & 6,6 & $E, W$ & 1.0mHV & $\begin{array}{l}\text { Cases } 310,300 \text { test East \& West } \\
\text { overhang \& fins. }\end{array}$ \\
\hline 320 & 20,27 & L & 10 & 10 & .9 & 1.9 & .9 & 1.1 & 12 & s & NO & Cases 320,270 test thermostat deadband. \\
\hline \multicolumn{8}{|c|}{$\begin{array}{l}\text { Note1: Cases with o glass area (except case } 1958395 \text { ) have a "High Conductance Wall" } \\
\text { in place of the window and with the same area as the window. } \\
\text { Case } 195 \text { has neither a window, nor a "High Conductance Wall", but } \\
\text { consists of } 100 \% \text { normally insulated wall as specified for the light-weight case. }\end{array}$} & \multicolumn{5}{|c|}{ 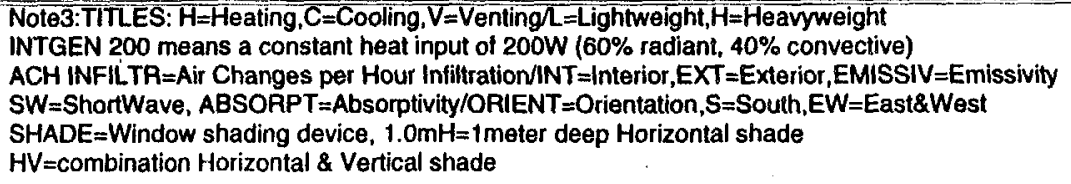 } \\
\hline
\end{tabular}


Table 1-14. BESTEST Qualification Case Descriptions and Realistic Diagnostics




Table 1-15. Material Specifications: Lightweight Case (Metric)

\begin{tabular}{|c|c|c|c|c|c|c|}
\hline & & & & & $\begin{array}{c}\text { CSPECL.3.WK3 } \\
\text { Mar } 13 / 93 \\
\end{array}$ & \\
\hline LIGHTWEIGHT CASE: E & EXTERIOF & WALL (insic & de to outside & & & \\
\hline ELEMENT & $\begin{array}{c}k \\
\left(W / m^{*} K\right)\end{array}$ & $\begin{array}{c}\text { Thickness } \\
\text { (m) }\end{array}$ & $\begin{array}{c}U \\
\left(W / m 2^{*} \mathrm{~K}\right)\end{array}$ & $\begin{array}{c}R \\
\left(m 2^{*} K N\right)\end{array}$ & $\begin{array}{l}\text { DENSITY } \\
(\mathrm{kg} / \mathrm{m} 3)\end{array}$ & $\begin{array}{c}\mathrm{Cp} \\
\left(\mathrm{J} / \mathrm{kg}^{*} \mathrm{~K}\right)\end{array}$ \\
\hline Int Surf Coef (see note 2) & & & 8.290 & 0.121 & & \\
\hline Plasterboard & 0.160 & 0.012 & 13.333 & 0.075 & 950.000 & 840.000 \\
\hline Fibreglas quilt & 0.040 & 0.066 & 0.606 & 1.650 & 12.000 & 840.000 \\
\hline $\begin{array}{l}\text { Wood Siding } \\
\text { Ext Surt Coef }\end{array}$ & 0.140 & 0.009 & $\begin{array}{l}15.556 \\
29.300\end{array}$ & $\begin{array}{l}0.064 \\
0.034\end{array}$ & 530.000 & 900.000 \\
\hline $\begin{array}{l}\text { Total air - air } \\
\text { Total surf - surf }\end{array}$ & & & $\begin{array}{l}0.514 \\
0.559\end{array}$ & $\begin{array}{l}1.944 \\
1.789\end{array}$ & & \\
\hline LIGHTWEIGHT CASE: $F$ & LOOR (ins) & ide to outsid & & & & \\
\hline ELEMENT & $\begin{array}{c}k \\
\left(W / m^{*} K\right)\end{array}$ & $\begin{array}{l}\text { Thickness } \\
(\mathrm{m})\end{array}$ & $\begin{array}{c}U \\
\left(W / \mathrm{m}^{*} \mathrm{~K}\right)\end{array}$ & $\begin{array}{c}R \\
\left(m 2^{*} K / W\right)\end{array}$ & $\begin{array}{c}\text { DENSITY } \\
(\mathrm{kg} / \mathrm{m} 3)\end{array}$ & $\begin{array}{c}\mathrm{Cp} \\
\left(\mathrm{J} / \mathrm{kg}^{*} \mathrm{~K}\right)\end{array}$ \\
\hline Int Surf Coef & & & 8.290 & 0.121 & & \\
\hline Timber flooring & 0.140 & 0.025 & 5.600 & 0.179 & 650.000 & 1200.000 \\
\hline Insulation & 0.040 & 1.003 & 0.040 & 25.075 & & \\
\hline & & & & & & \\
\hline Total air - air & & & 0.039 & 25.374 & & \\
\hline Total surf - surf & & & 0.040 & 25.254 & & \\
\hline LIGHTWEIGHT CASE: R & ROOF (insid & le to outside & & & & \\
\hline ELEMENT & $\begin{array}{c}k \\
\left(W / m^{*} K\right)\end{array}$ & $\begin{array}{l}\text { Thickness } \\
(\mathrm{m})\end{array}$ & $\underset{\left(W / m^{*} K\right.}{U}$ & $\begin{array}{c}R \\
\left(m 2^{*} \mathrm{~K} M\right)\end{array}$ & $\begin{array}{l}\text { DENSITY } \\
(\mathrm{kg} / \mathrm{m} 3)\end{array}$ & $\begin{array}{c}\mathrm{Cp} \\
\left(\mathrm{J} / \mathrm{kg}^{* \mathrm{~K}}\right)\end{array}$ \\
\hline Int Surf Coef & & & 8.290 & 0.121 & & \\
\hline Plasterboard & 0.160 & 0.010 & 16.000 & 0.063 & 950.000 & 840.000 \\
\hline Fibreglas quilt & 0.040 & 0.1118 & 0.358 & 2.794 & 12.000 & 840.000 \\
\hline Roofdeck & 0.140 & 0.019 & 7.368 & 0.136 & 530.000 & 900.000 \\
\hline Ext Surt Coef & & & 29.300 & 0.034 & & \\
\hline Total air - air & & & 0.318 & 3.147 & & \\
\hline Total surf - surt & & & 0.334 & 2.992 & & \\
\hline SUMMARY: LIGHTWEIG & ATT CASE & & & & & \\
\hline COMPONENT & $\begin{array}{l}\text { AREA } \\
\mathrm{m} 2\end{array}$ & $\begin{array}{l}\text { UA } \\
W / K\end{array}$ & & & & \\
\hline Wall & 63.600 & 32.715 & & & & \\
\hline Floor & 48.000 & 1.892 & & & & \\
\hline Roof & 48.000 & 15.253 & & & & \\
\hline S.window & 12.000 & 36.000 & & & & \\
\hline Infiltration & & 18.440 & (see note 1) & & & \\
\hline Total UA (wf S.Glass) & & 104.300 & & & & \\
\hline Total UA (No S.Glass) & & 68.300 & & & & \\
\hline & $\overline{\mathrm{ACH}}$ & $\begin{array}{l}\text { VOLUME } \\
\text { m3 }\end{array}$ & $\underset{\mathrm{m}}{\overline{\text { ALTITUDE }}}$ & . & & \\
\hline & 0.500 & 129.600 & 1609.000 & & & \\
\hline $\begin{array}{l}\text { NOTE 1: Infiltration derive } \\
\text { ACH*Volume**(specific he } \\
\text { NOTE 2: The interior film }\end{array}$ & $\begin{array}{l}\text { ed from: } \\
\text { coefficient }\end{array}$ & $\begin{array}{l}\text { lensity of air } \\
\text { for floors an }\end{array}$ & $\begin{array}{l}\text { at specified } \\
d \text { ceilings is }\end{array}$ & altitude) & & \\
\hline
\end{tabular}


Table 1-16. Material Specifications: Lightweight Case (English)

\begin{tabular}{|c|c|c|c|c|c|c|}
\hline & & & & & $\begin{array}{l}\text { CSPECL3.WX3 } \\
\text { (auroconverts SI LE }\end{array}$ & $\begin{array}{l}\text { Mar 13/93 } \\
\text { English) }\end{array}$ \\
\hline LIGHTWEIGHT CASE: & XTERIOR & WALL (inside & de to outside & & & \\
\hline ELEMENT & $\begin{array}{c}k \\
\text { Btw } \\
h^{*} f t * F\end{array}$ & Thickness & $\underset{\substack{\text { Btw } \\
h^{*} \mathrm{ft} \mathbf{2}^{*} \mathrm{~F}}}{\mathrm{U}}$ & $\begin{array}{c}R \\
h^{*} f t 2^{*} F / \\
B+u\end{array}$ & $\begin{array}{c}\text { DENSITY } \\
\mathrm{lb} / \mathrm{ft} 3\end{array}$ & $\begin{array}{c}C p \\
B t u / l b^{\star} F\end{array}$ \\
\hline Int Surf Coef & & & 1.461 & 0.685 & & \\
\hline Plasterboard & 0.093 & 0.039 & 2.350 & 0.426 & 59.307 & 0.201 \\
\hline Fibreglas quilt & 0.023 & 0.217 & 0.107 & 9.363 & 0.749 & 0.201 \\
\hline $\begin{array}{l}\text { Wood Siding } \\
\text { Ext Surf Coef }\end{array}$ & 0.081 & 0.030 & $\begin{array}{l}2.741 \\
5.163\end{array}$ & $\begin{array}{l}0.365 \\
0.194\end{array}$ & 33.087 & 0.215 \\
\hline & & & & & & HCAP/A \\
\hline Total air - àir & & & 0.091 & 11.031 & & Btu/ft2*F \\
\hline Total surf - surf & & & 0.098 & 10.153 & & 0.469 \\
\hline LIGHTWEIGHT CASE: & -OOR (insi & ide to outside & & & & \\
\hline ELEMENT & $\begin{array}{c}k \\
B t w \\
h^{*} t^{*} F\end{array}$ & $\begin{array}{c}\text { Thickness } \\
\text { ft }\end{array}$ & $\underset{\substack{\text { Btw } \\
h^{*} \mathrm{ft} 2^{*} F}}{U}$ & $\begin{array}{c}R \\
h^{\star} f t 2^{\star} F / \\
\text { Btu }\end{array}$ & $\begin{array}{c}\text { DENSITY } \\
\mathrm{lb} / \mathrm{ft} 3\end{array}$ & $\begin{array}{c}C p \\
B t u / b^{*} F\end{array}$ \\
\hline Int Surf Coef & & & 1.461 & 0.684 & & \\
\hline Timber flooring & 0.081 & 0.082 & 0.987 & 1.013 & 40.578 & 0.287 \\
\hline Insulation & 0.023 & 3.291 & 0.007 & 142.287 & 0.000 & 0.000 \\
\hline $\begin{array}{l}\text { Total air - air } \\
\text { Total surf - surf }\end{array}$ & & - & $\begin{array}{l}0.007 \\
0.007\end{array}$ & $\begin{array}{l}143.985 \\
143.301\end{array}$ & & $\begin{array}{r}\text { HCAP/A } \\
\text { Btu/ft2*F } \\
0.955\end{array}$ \\
\hline LIGHTWEIGHT CASE: & OOF (insid & de to outside) & & & & \\
\hline ELEMENT & $\begin{array}{c}k \\
\mathrm{Btw} \\
\mathrm{h}^{*} \mathrm{ft}^{*} \mathrm{~F} \\
\end{array}$ & $\begin{array}{c}\text { Thickness } \\
\mathrm{tt}\end{array}$ & $\begin{array}{c}U \\
\text { Btw } \\
h^{*} f t 2^{*} F\end{array}$ & $\begin{array}{c}R \\
h^{*} f 2^{*} F / \\
\text { Btu }\end{array}$ & $\begin{array}{c}\text { DENSITY } \\
\text { Ib/tt3 }\end{array}$ & $\begin{array}{c}\mathrm{Cp} \\
\text { Btu/lb*F }\end{array}$ \\
\hline Int Surf Coef & & & 1.461 & 0.684 & & \\
\hline Plasterboard & 0.093 & 0.033 & 2.820 & 0.355 & 59.307 & 0.201 \\
\hline Fibreglas quilt & 0.023 & 0.367 & 0.063 & 15.854 & 0.749 & 0.201 \\
\hline Roofdeck & 0.081 & 0.062 & 1.299 & 0.770 & 33.087 & 0.215 \\
\hline Ext Surt Coef & & & 5.163 & 0.194 & & \\
\hline & & & & & & HCAP/A \\
\hline Total air - air & & & 0.056 & 17.857 & & Btu/ft2*F \\
\hline Total surf - surf & & & 0.059 & 16.979 & & 0.391 \\
\hline SUMMARY: LIGHTWE & HT CASE & & & & & \\
\hline COMPONENT & $\begin{array}{l}\text { AREA } \\
\text { ft2 }\end{array}$ & $\begin{array}{l}\text { UA } \\
\text { Btu/h*F }\end{array}$ & $\begin{array}{l}\text { HEATCAP } \\
\text { Btu/F }\end{array}$ & $\begin{array}{c}\text { HEATCAPI } \\
\text { S.GL.A } \\
\text { Btw/tt2/F }\end{array}$ & $\begin{array}{l}\text { MASS A } \\
\text { S.GL.A }\end{array}$ & LCR \\
\hline Wall & 684.585 & 62.058 & 320.903 & & & \\
\hline Floor & 516.668 & 3.588 & 493.183 & & & \\
\hline Roof & 516.668 & 28.933 & 201.826 & & & \\
\hline $\begin{array}{l}\text { S.window } \\
\text { Infittration }\end{array}$ & 129.167 & 68.288 & & & & \\
\hline & & & & & & \\
\hline $\begin{array}{l}\text { Total UA (wf S.Glass) } \\
\text { Total UA (No S.Glass) }\end{array}$ & & $\begin{array}{l}197.846 \\
129.558\end{array}$ & 1015.912 & 7.865 & 13.300 & 24.073 \\
\hline - & $\overline{\mathrm{ACH}}$ & $\begin{array}{l}\text { VOLUME } \\
\mathrm{ft3}\end{array}$ & $\begin{array}{c}\text { ALTITUDE } \\
\mathrm{ft}\end{array}$ & $\begin{array}{l}\text { UAinf } \\
\text { Btu/h* } F\end{array}$ & & \\
\hline & 0.500 & 4576.788 & 5278.872 & & & \\
\hline INFILTRATION & & & & 34.979 & & \\
\hline
\end{tabular}


Table 1-17. Material Specifications: Heavyweight Case (Metric)

CSPECH3.WK3

Mar 18/93




Table 1-18. Material Specifications: Heavyweight Case (English)

\begin{tabular}{|c|c|c|c|c|c|c|}
\hline & & & & & $\begin{array}{l}\text { CSPECH3.WK3 } \\
\text { (auroconverts SI to }\end{array}$ & $\begin{array}{l}\text { Mar } 18993 \\
\text { english) }\end{array}$ \\
\hline HEAVYWEIGHT CASE & EXTERIOP & 7WALL (insic & ide to outsid & & & \\
\hline ELEMENT & $\begin{array}{c}k \\
B t w \\
h^{*} f^{\star} F\end{array}$ & $\begin{array}{c}\text { Thickness } \\
\mathrm{ft}\end{array}$ & $\begin{array}{c}U \\
B t w \\
h^{*} f t 2^{*} F\end{array}$ & $\begin{array}{c}R \\
h^{*} f t 2^{*} F / \\
\text { Btu }\end{array}$ & $\begin{array}{c}\text { DENSITY } \\
\text { Ib/tt3 }\end{array}$ & $\begin{array}{c}\mathrm{Cp} \\
\text { Btu/lb*F}\end{array}$ \\
\hline Int Surf Coef & & & $\frac{11.461}{1.46}$ & $\frac{D l u}{0.685}$ & & \\
\hline Concrete Block & 0.295 & 0.328 & 0.899 & 1.113 & 87.399 & 0.239 \\
\hline Foam Insulation & 0.023 & 0.202 & 0.115 & 8.722 & 0.624 & 0.335 \\
\hline Wood Siding & 0.081 & 0.030 & 2.741 & 0.365 & 33.087 & 0.215 \\
\hline Ext Surf Coef & & & 5.163 & 0.194 & & \\
\hline & & & & & & HCAP/A \\
\hline Total air = air & & & 0.090 & 11.077 & & Btu/ft2*F \\
\hline Total surf - surf & & & 0.098 & 10.199 & & 6.853 \\
\hline HEAVYWEIGHT CASE & LOOR (ins & side to outsic & ide) & & & \\
\hline & k & Thickness & $U$ & $R$ & DENSITY & $C p$ \\
\hline ELEMENT & $\begin{array}{c}\text { Btw } \\
h^{\star} f^{*} F\end{array}$ & $\mathrm{ft}$ & $\begin{array}{c}\text { Btud } \\
h^{*} \mathrm{ft}^{*} \mathrm{~F}\end{array}$ & $\begin{array}{c}h^{*} f t 2^{\star} F / \\
\text { Btu }\end{array}$ & $\mathrm{lb} / \mathrm{ft3}$ & $B t u / / b^{\star} F$ \\
\hline Int Surf Coef & & & 1.461 & 0.684 & & \\
\hline Concrete Slab & 0.653 & 0.262 & 2.489 & 0.402 & 87.399 & 0.239 \\
\hline Insulation & 0.023 & 3.304 & 0.007 & 142.855 & 0.000 & 0.000 \\
\hline Total air - air & & & 0.007 & 143941 & & $\begin{array}{l}\mathrm{HCAP} / \mathrm{A} \\
\mathrm{Btw} / \mathrm{At} 2^{*} \mathrm{~F}\end{array}$ \\
\hline Total surf - surf & & & 0.007 & 143.256 & & 5.483 \\
\hline HEAVYWEIGHT CASE & OOF (insi & ide to outside & & & & \\
\hline & $\underset{\substack{k \\
\text { Btw }}}{k}$ & Thickness & $\underset{\text { Btw }}{U}$ & $\begin{array}{c}R \\
h^{*} f 2^{*} F /\end{array}$ & & \\
\hline ELEMENT & $h^{*} f t^{*} F$ & $\mathrm{ft}$ & $h^{*} t 2^{*} F$ & Btu & $\mathrm{lb} / \mathrm{ft} 3$ & Btu/lb*F \\
\hline Int Surf Coef & & & 1.461 & 0.684 & & \\
\hline Plasterboard & 0.093 & 0.033 & 2.820 & 0.355 & 59.307 & 0.201 \\
\hline Fibreglas quilt & 0.023 & 0.367 & 0.063 & 15.854 & 0.749 & 0.201 \\
\hline Roofdeck & 0.081 & 0.062 & 1.299 & 0.770 & 33.087 & 0.215 \\
\hline Ext Surf Coef & & & 5.163 & 0.194 & & \\
\hline & & & & & & HCAP/A \\
\hline Total air - air & & & 0.056 & 17.857 & & Btu/ft2*F \\
\hline Total surf - surf & & & 0.059 & 16.979 & & 0.391 \\
\hline HEAVYWEIGHT CASE & SUMMARY & & & & & \\
\hline COMPONENT & $\begin{array}{l}\text { AREA } \\
\mathrm{ft} 2\end{array}$ & $\underset{B t u / h{ }^{\star f}}{U A}$ & $\begin{array}{l}\text { HEATCAP } \\
\text { BtwF }\end{array}$ & $\begin{array}{l}\text { HEATCAP/ } \\
\text { S.GL.A } \\
\text { Btw/ft2/F }\end{array}$ & $\begin{array}{c}\text { MASS A } \\
\text { S.GL.A }\end{array}$ & LCR \\
\hline Wall & 684.585 & 61.801 & 4691.566 & & & \\
\hline Fioor & 516.668 & 3.589 & 2832.643 & & & \\
\hline Roof & 516.668 & 28.933 & 201.826 & & & \\
\hline S.window & 129.167 & 68.288 & & & & \\
\hline Infiltration & & 34.979 & & & & \\
\hline Total UA (wf S.Glass) & & 197.591 & 7726.03 & 59.814 & 9.300 & 24.025 \\
\hline Total UA (No S.Glass) & & 129.303 & & & & \\
\hline & $\mathrm{ACH}$ & $\begin{array}{l}\text { VOLUME } \\
\text { ft3 }\end{array}$ & $\begin{array}{l}\text { ALTITUDE } \\
\mathrm{ft}\end{array}$ & $\begin{array}{c}\text { UA } \\
\text { Btu/h*F }\end{array}$ & & \\
\hline & 0.500 & 4576.788 & 5278.872 & & & \\
\hline INFILTRATION & & & & 34.979 & & \\
\hline
\end{tabular}




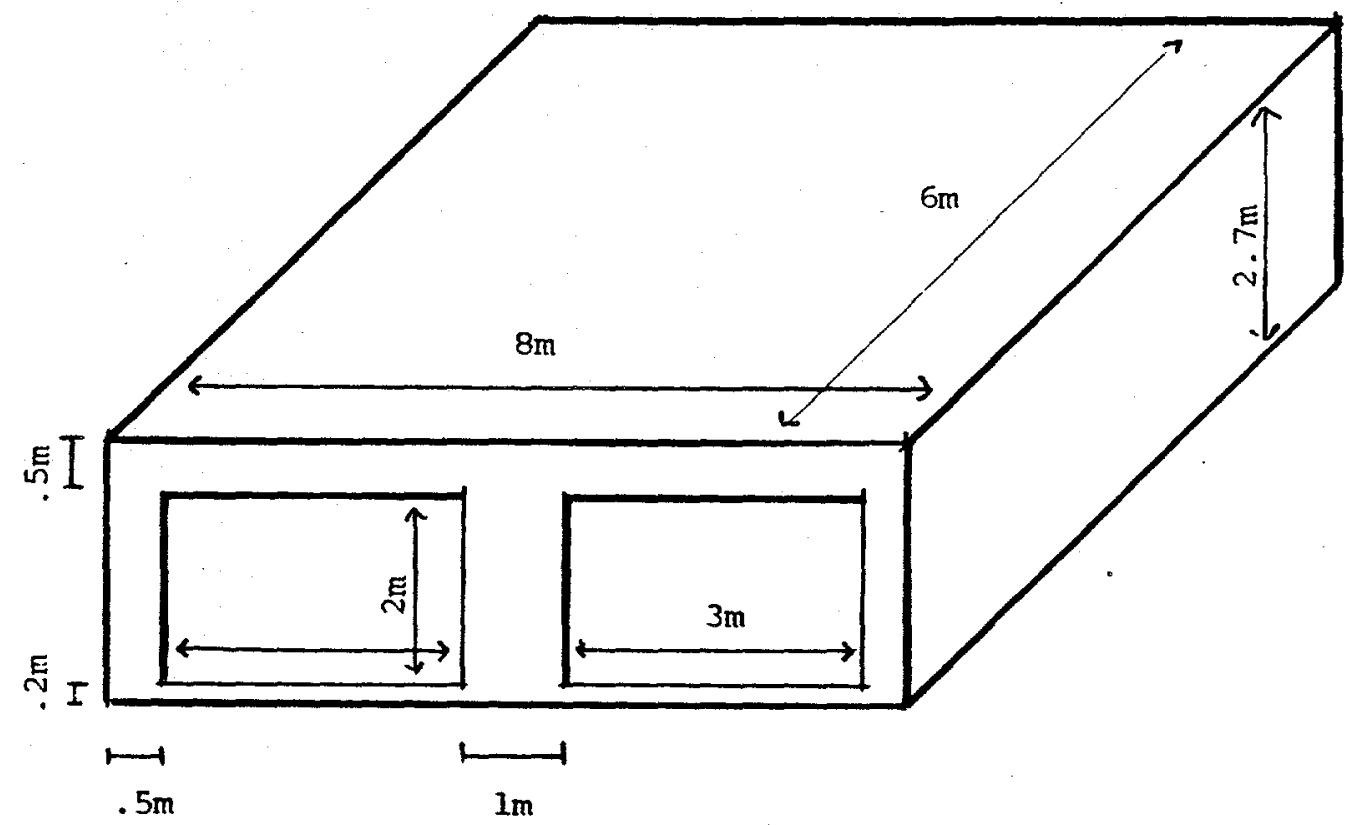

Figure 1-2. BESTEST: isometric south windows-unshaded

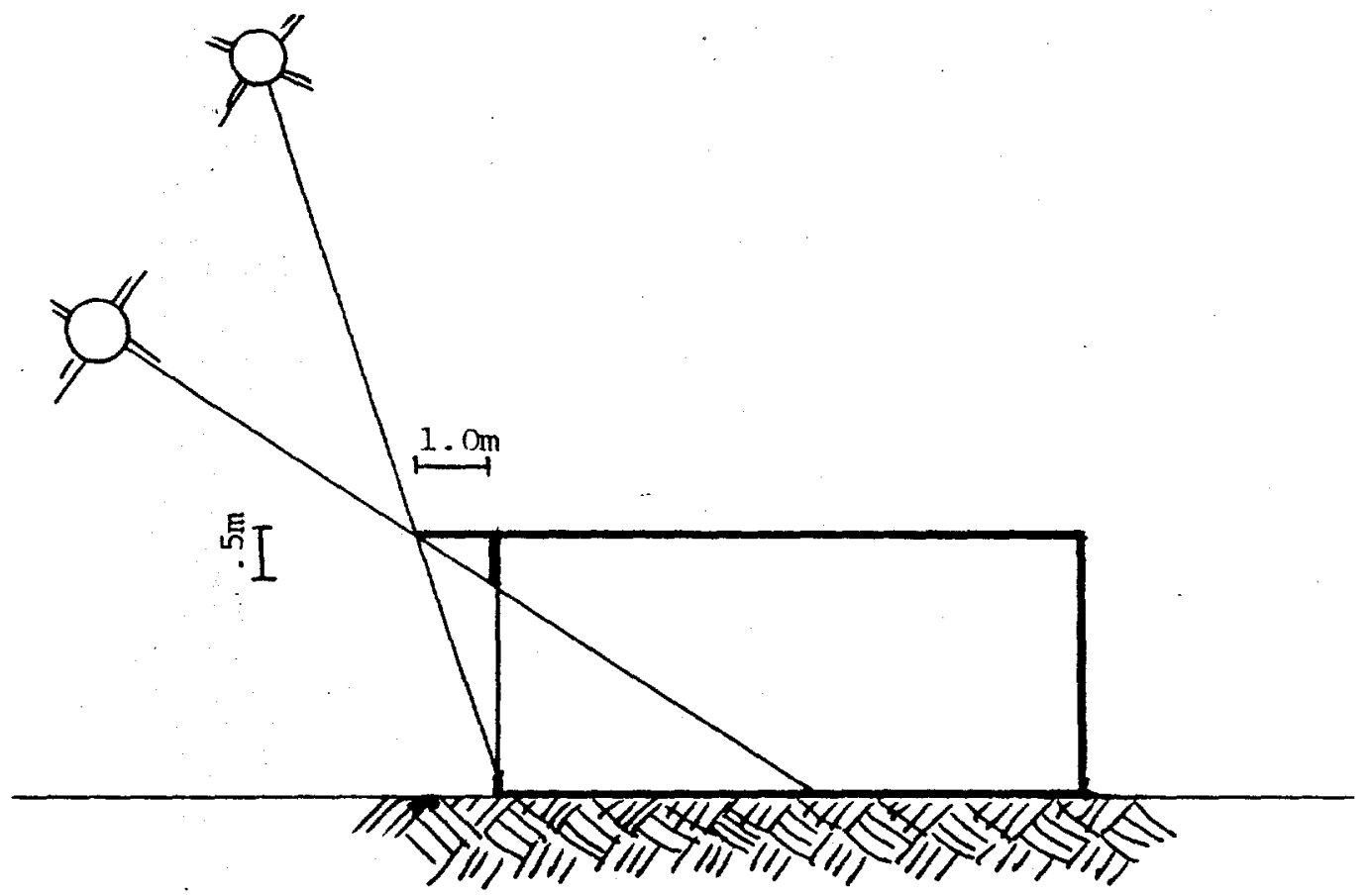

Figure 1-3. BESTEST: section of south window overhang 

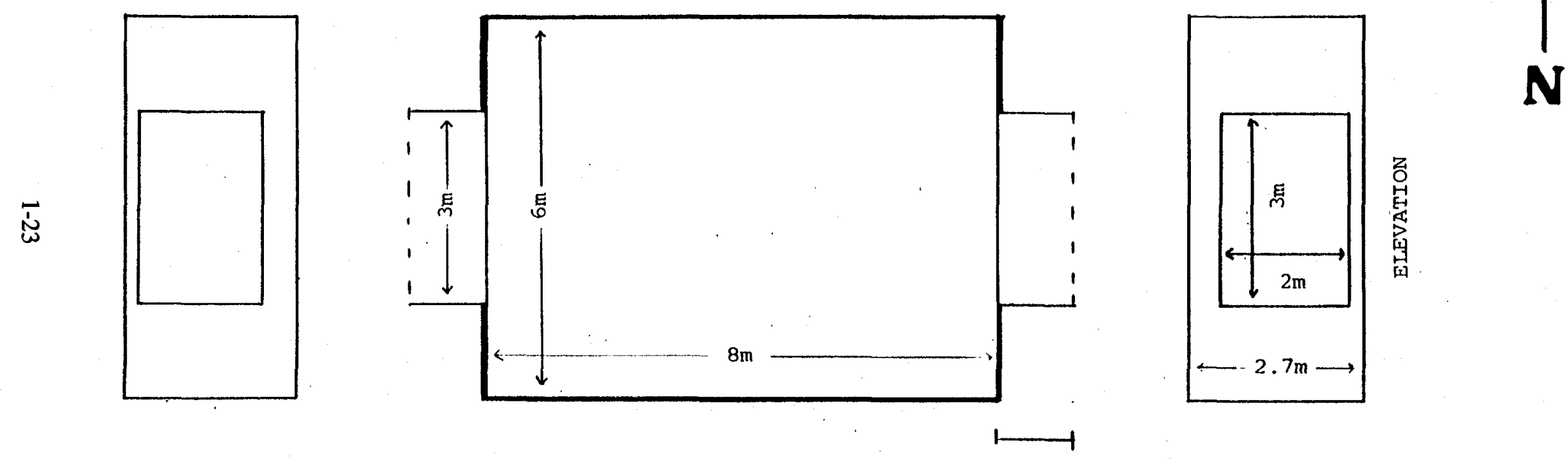

PIAAN VIEW

Figure 1-4. BESTEST: east and west window shading 


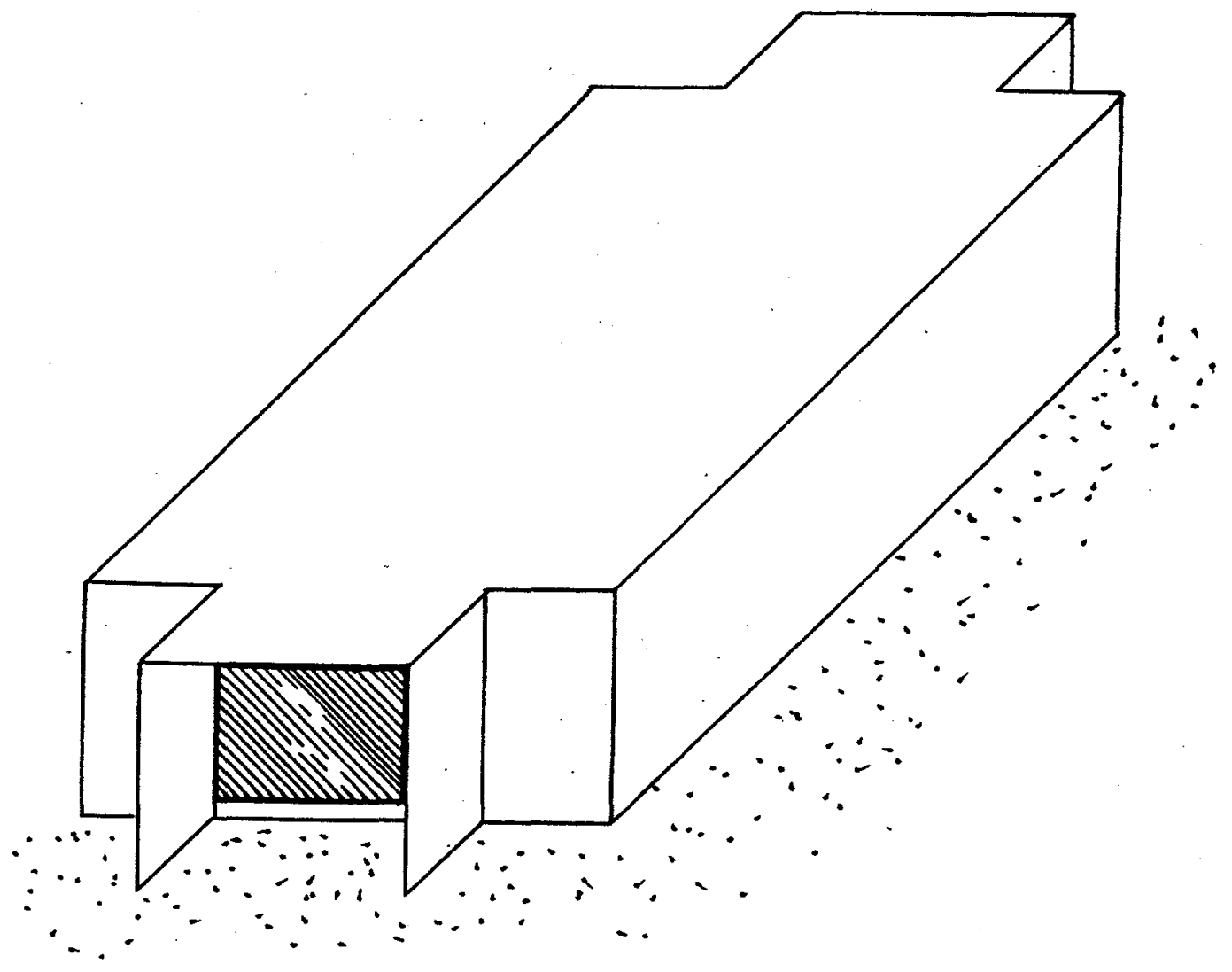

Figure 1-5. BESTEST: isometric east and west window shading 
PLAN

$\mathrm{Icm}=1 \mathrm{~m}$

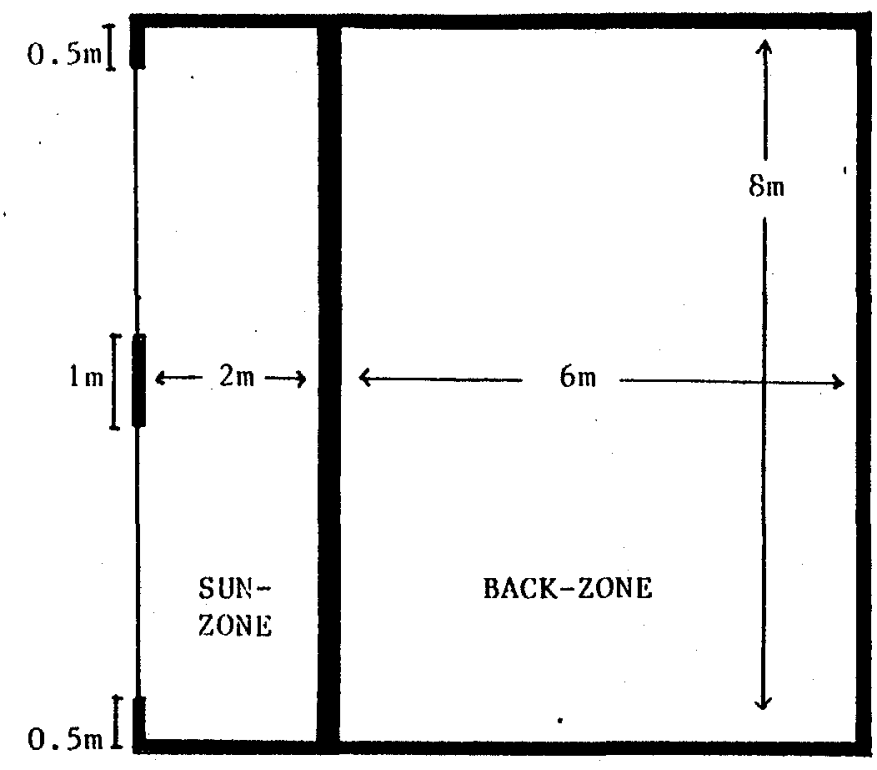

$\bar{u}$

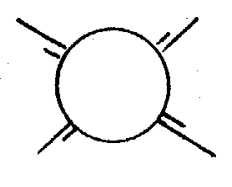

SECTION $2 \mathrm{~cm}=1 \mathrm{~m}$

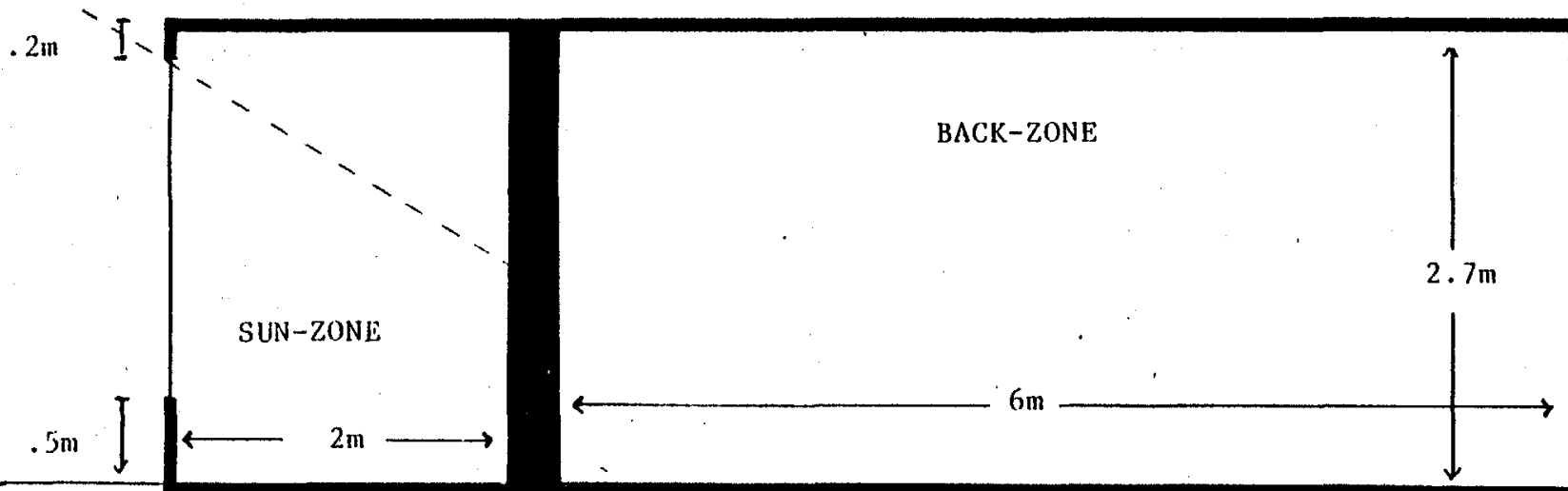

Figure 1-6. Sunspace plan and section 


\subsection{The Flow Diagrams}

The flow diagrams can be used in two ways. The most powerful, but time consuming way is to perform all of the tests, and then use the diagnostic logic in the flow diagrams to analyze the results. The least time consuming way is to perform the tests in sequence according to the flow diagrams, as described below.

Figures 1-7 to 1-10, at the end of this section, contain a set of qualification and diagnostic flow diagrams. These flow diagrams show the sequence for running the test cases, give a brief explanation of the feature(s) being tested, and indicate where to enter the diagnostics if problems are encountered. The first flow diagram (Figure 1-7) covers cases 600 to 650 . Begin with case 600 , which is a simple insulated lightweight room with a large south-facing window. If your program output agrees satisfactorily with the ranges presented in the results tables and figures in Part III, then proceed through the cases sequentially according to the flow diagram. Once the low-mass cases have been successfully completed, proceed with the high-mass qualification cases (Figure 1-9 and 1-10).

To "pass" a test, a program must show reasonable agreement with the reference programs for both the absolute results and the sensitivity results. For example, to pass case $610-600$ in the low-mass qualification diagram (Figure 1-7), the program results must compare well with both the case 610 reference range resuits and the case 610-600 reference sensitivity results. The term "pass" as used in this report means to show reasonable agreement with the reference program result ranges. "Fail" means to show substantial disagreement with the reference program result ranges.

There are some cases where it is possible to proceed even if problems were uncovered in the previous case. For example, in case 610, inability to model a shading overhang would not affect the usefulness of the program for modeling buildings with unshaded windows. Thus the flow diagram has an extra arrow connecting case 610 and case 620 , which denotes that you may proceed regardless of the results for case 610 . Where cases are connected by a single arrow, a satisfactory result is required in order to proceed to the next case. For example, in case 620 , the inability to model transmitted radiation through an unshaded east window renders the program practically useless for whole building energy analysis. Thus, there is no sense in proceeding until the problem is fixed.

Be sure to compare all available output types produced by your program because it is possible for your results to compare well with all but one of the output types. A major disagreement with even a single output type may be cause for concern. The output types are

- Annual heating and cooling loads

- Peak hourly integrated heating and cooling loads for the year

- Maximum, minimum, and average annual hourly integrated temperatures

- Annual incident solar radiation

- Annual transmitted solar radiation (shaded and unshaded)

- Annual hourly $1^{\circ} \mathrm{C}$ temperature bin frequencies

- Hourly temperatures for selected cases and time periods

- Hourly heating and cooling loads for selected cases and time periods

- Hourly incident solar radiation for selected orientations and time periods.

If your program shows major disagreement with the result ranges, then re-check your inputs against the specified values. Even a small input error can sometimes lead to large output errors. If this doesn't help, consult the vendor or user support representative for the program. Request that they run the tests. If your vendor can't help you obtain satisfactory results, consider selecting a different program. 
Some individuals will be interested in running the diagnostic cases to try and isolate the problem. We recommend this only for software developers, user support consultants, building energy specialists, and scientists. To use the diagnostics, follow the flow diagrams through the diagnostic cases. For example, an unsatisfactory result from case 600 indicates a fairly basic heat transfer problem. The flow diagram indicates two possible diagnostic paths, A1 to A11 or B1 to B10. These paths are further described in the low-mass diagnostic flow diagram (Figure 1-8). Selection of path A versus path B depends on the capabilities of your program. Path $A$ is the preferable diagnostic path. If your model is literal enough in its treatment of building physics to allow input of the A cases, then do so. If not, path B will still help to identify the algorithmic source of problems, but less definitively-because of interacting effects.

The diagnostic capability of the flow diagrams depends, to some extent, on observing the difference between cases that may be thought of as the sensitivity to a parametric change or a set of parametric changes. Diagnostic information is also contained in the absolute results for each individual case. The flow diagrams are useful in helping to organize the diagnostic process. However, all available output information for diagnosing problems should be used, including

- Absolute results from qualification and diagnostic cases

- Sensitivity results from qualification and diagnostic cases

- Hourly results (if the program has this capability)

- Incident, transmitted, and shaded solar radiation outputs (if the program has this capability).

\section{Example}

A program passes case 600 , but shows large disagreement with the reference program annual cooling load predictions for case 610. The low-mass qualification flow diagram (Figure 1-7) suggests a potential problem with the shading algorithm and directs the user to look at the sensitivity results for shading as represented by the difference between the output values from cases 600 and 610 . The qualification flow diagrams (Figures 1-7 and 1-9) not only show in what order to run the cases, but also serve as a kind of expert system to interpret the results and diagnose the source of problems. Thus, if a program shows improper sensitivity to the shading device, the flow diagram indicates a potential problem in the shading algorithm and directs the user to diagnostic A12. Diagnostic A12 will either confirm shading as the problem, or direct the user to additional diagnostics if the shading algorithm is okay. The logic is sequential in that to fail 610-600 and to pass A12 indicates compensating errors in some of the basic heat transfer algorithms. To fail both 610-600 and A12 confirms a shading algorithm problem.

Several examples of how the BESTEST diagnostics were used to trace and correct specific algorithmic and input problems in the reference programs are given in Part II of this report. 


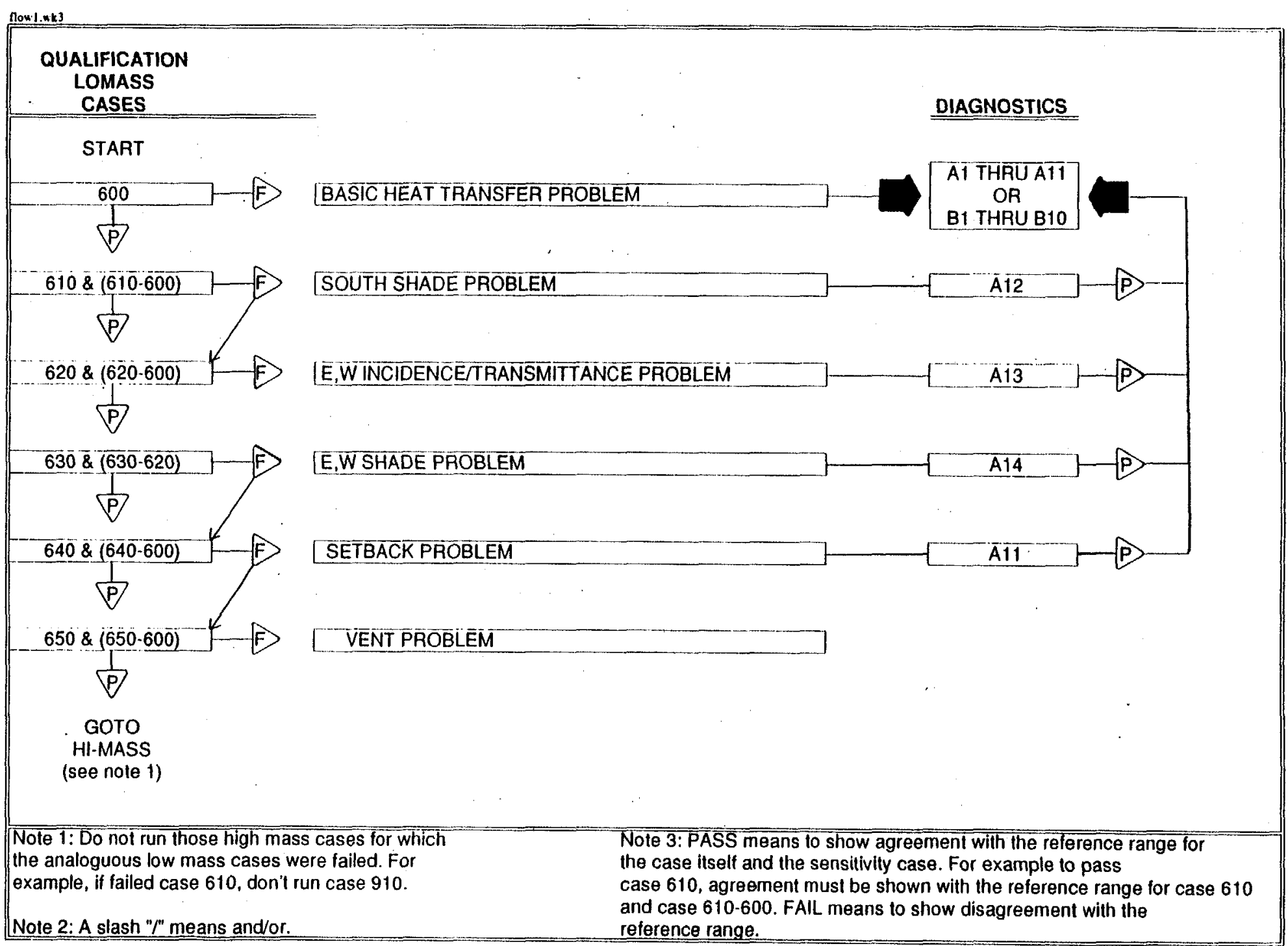

Figure 1-7. BESTEST: low-mass qualification flow diagram 


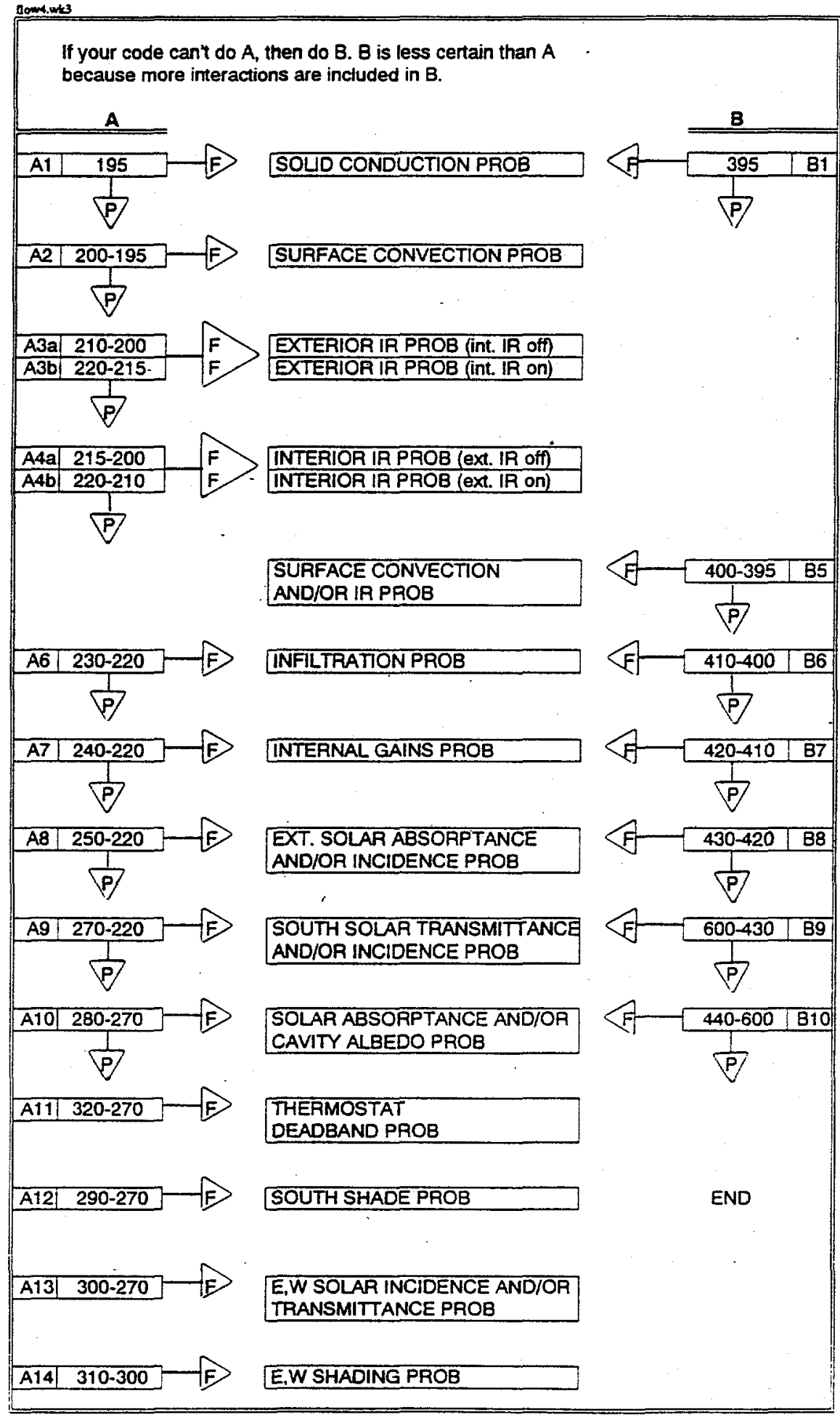

Figure 1-8. BESTEST: low-mass diagnostics flow diagram 


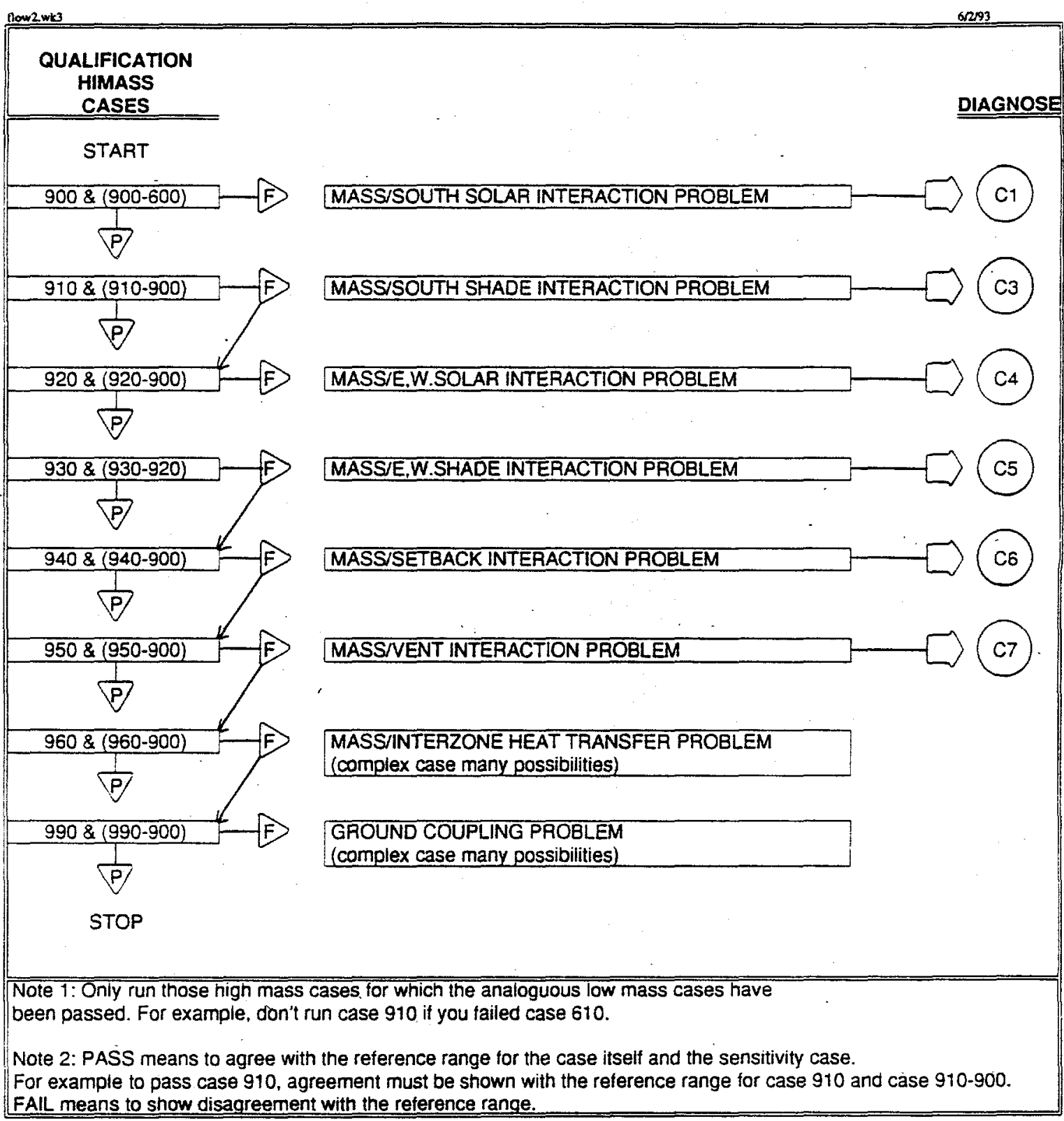

Figure 1-9. BESTEST: high-mass qualification flow diagram 


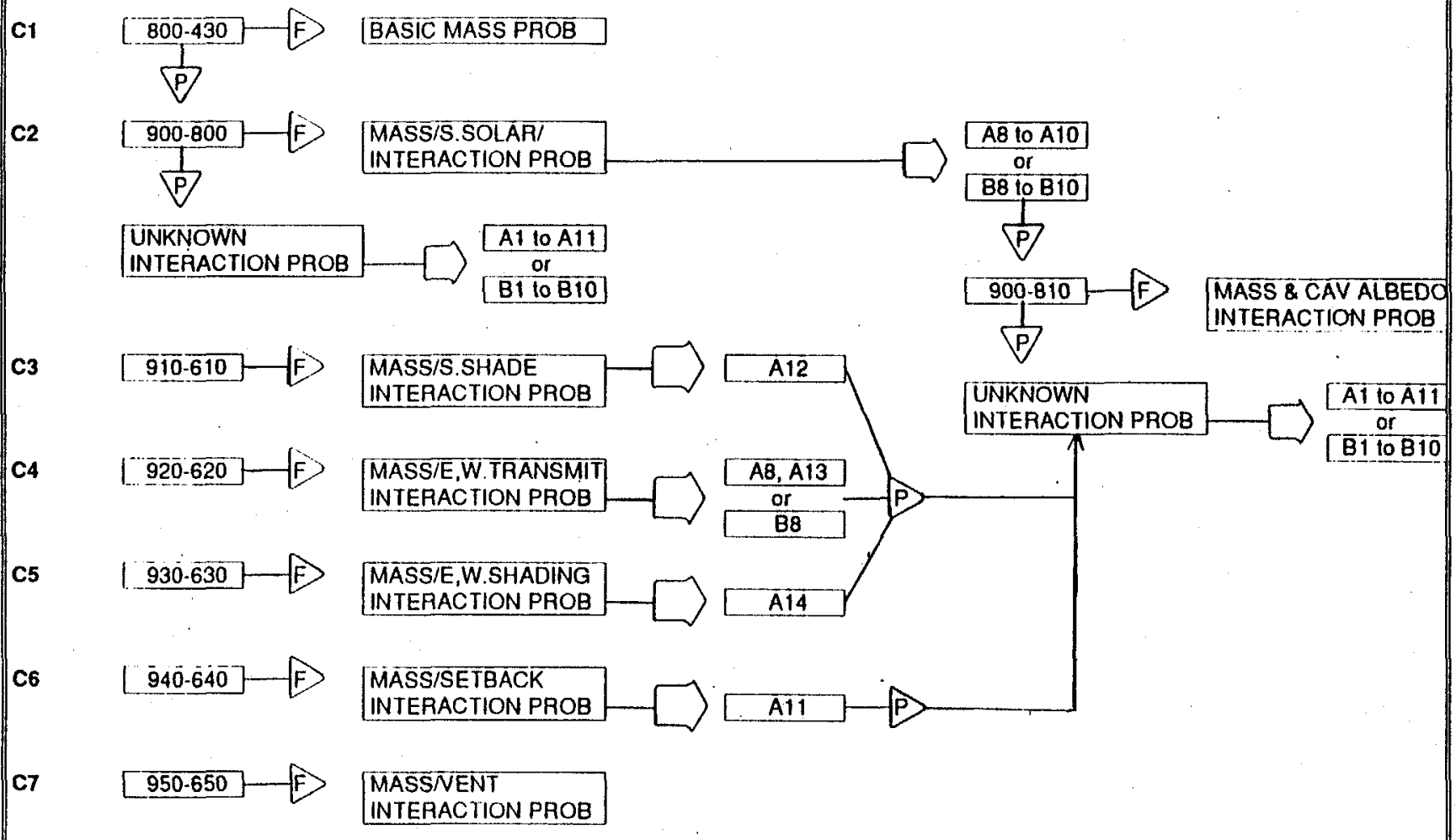

Nole 1: A slash " $f$ " means "and/or"

Note 2: The reason we sometimes return to low mass diagnostics, even though the program may have already passed the low mass

qualification tests, is that the high mass cases may reveal problems that the low mass cases did not expose because

a) the eflect is more readily delectable when mass is present, or

b) the elfect was not previously delectable because of compensating errors, or

c) the elfect was not previously detectable because of other unknown interactions.

Figure 1-10. BESTEST: high-mass diagnostics flow diagram 
APPENDICES 


\section{Appendix A}

\section{Abbreviations Key}

$\begin{array}{ll}1.0 \mathrm{mH} & \begin{array}{l}\text { Horizontal overhang projecting } \\ 1 \text { meter perpendicular to } \\ \text { window surface }\end{array} \\ 1.0 \mathrm{mHV} & \begin{array}{l}\text { Horizontal overhang and } \\ \text { vertical fins projecting } 1 \text { meter } \\ \text { perpendicular to } \\ \text { window surface }\end{array} \\ 20,20 \quad \begin{array}{l}\text { A single temperature } \\ \text { thermostat control strategy } \\ \text { (heat on below } 20^{\circ} \mathrm{C}, \text { cooling } \\ \text { on above } 20^{\circ} \mathrm{C} \text { ) }\end{array}\end{array}$

20,27

A deadband thermostat control strategy (heat on below $20^{\circ} \mathrm{C}$, cooling on above $27^{\circ} \mathrm{C}$ )

$\begin{array}{ll}\text { Absorpt } & \text { Absorptance } \\ \mathrm{A} / \mathrm{C} & \text { Air conditioning } \\ \mathrm{ACH} & \text { Air changes per hour } \\ \mathrm{C}_{\mathrm{p}} & \text { Specific heat } \\ \mathrm{E}, \mathrm{W}, \mathrm{N}, \mathrm{S} & \text { East, west, north, south } \\ \text { Emissiv } & \text { Emissivity } \\ \text { Ext } & \text { Exterior } \\ \text { FF } & \begin{array}{l}\text { Free-Floating thermostat } \\ \text { control strategy (no heating or } \\ \text { cooling) }\end{array} \\ \text { H } & \text { Heavy mass } \\ \text { Heatcap } & \text { Heat capacity } \\ \text { High-mass } & \text { Heavy mass } \\ \text { Infiltr } & \text { Infiltration (natural ventilation) } \\ \text { Int } & \text { Interior }\end{array}$

$\begin{array}{ll}\text { Intgen } & \begin{array}{l}\text { Internally generated heat } \\ \text { (casual gains) }\end{array} \\ \text { IR } & \text { Infrared radiation } \\ \mathrm{k} & \text { Thermal conductivity } \\ \mathrm{L} & \text { Light mass } \\ \text { LCR } & \text { Load to collector area ratio } \\ \text { Low-mass } & \text { Light mass }\end{array}$

Mass A Mass surface area

Mass A Mass surface area to

S.GL.A south glazing area ratio

NA Not applicable

Orient Orientation

Prob Problem

R Unit thermal resistance

S.GL.A South glazing area

Shade Window shading device. Horizontal overhang and/or vertical fins

SS Sunspace

SW Shortwave (solar spectrum) radiation

U Unit thermal conductance or overall heat transfer coefficient

UA Thermal conductance

V Forced ventilation cooling

XFER Transfer 


\section{Appendix B}

\section{Infiltration and Fan Adjustments for Altitude}

The decline in air density with altitude may be expressed according to the following exponential curve fit:

$$
P_{\text {air,u }}=P_{\text {air, } 0} \times \mathrm{e}^{(\mathrm{a})(\mathrm{elev})}
$$

where:

$\mathrm{P}_{\mathrm{air}, \mathrm{u}} \quad=$ air density at specified elevation

$\mathrm{P}_{\text {air,0 }}=$ air density at sea level

$\mathrm{e}^{=} \quad$ inverse $\mathrm{Ln}$

$\mathrm{a} \quad=-1.219755 \times 10^{-4} / \mathrm{m}$

elev $=$ elevation in meters $(\mathrm{m})$.

Air density at sea level $=1.201385 \mathrm{~kg} / \mathrm{m}^{3}$.

Air density at $1609 \mathrm{~m}=0.987298 \mathrm{~kg} / \mathrm{m}^{3}$.

The corrected infiltration rate for $1609 \mathrm{~m}$ altitude $=($ specified rate $) \times(0.987298 / 1.201385)$.

(For example, $0.5 \mathrm{ACH}$ becomes $0.41 \mathrm{ACH}$, and $1 \mathrm{ACH}$ becomes $0.822 \mathrm{ACH}$.)

The corrected vent-fan capacity for $1609 \mathrm{~m}$ altitude $=$ (specified capacity under standard conditions at sealevel) $\times(0.987298 / 1.201385){ }^{*}$ (For example, $1703.16 \mathrm{Sm}^{3} / \mathrm{h}$ becomes $\left.1400 \mathrm{~m}^{3} / \mathrm{h}.\right)^{* *}$

* Standard conditions $(S)=$ U.S. Standard Atmospheric Conditions: dry air behaving as a perfect gas, $15^{\circ} \mathrm{C}, 101.321 \mathrm{kPa}$ (ASHRAE Handbook Fundamentals 1993, p. 6.1).

${ }^{* *} \mathrm{Sm}^{3} / \mathrm{h}=$ standard cubic meters per hour. 


\section{Appendix C}

\section{Exterior Combined Radiative and Convective Surface Coefficients}

If your program does not automatically calculate these values internally, then use the information given below.

ASHRAE and several widely used programs such as DOE2 and BLAST calculate the exterior combined radiative and convective surface coefficient as a second order polynomial in wind speed of the form:

$$
h=a_{1}+a_{2} V+a_{3} v^{2}
$$

where the units of $\mathrm{h}$ are $\mathrm{W} / \mathrm{m}^{2} \mathrm{~K}$, and the " $\mathrm{a}$ " coefficients are dependent on the surface texture. Assuming a surface texture of brick or rough plaster, and a mean annual wind speed of $4.02 \mathrm{~m} / \mathrm{s}$, then the information in Table 1-19 (Walton 1983, p. 71) is applicable.

Table 1-19. Polynomial Coefficients for Describing Exterior Surface Conductance as a Function of Wind Speed

\begin{tabular}{||l|c|c|c|}
\hline Material & $\mathbf{a}_{\mathbf{1}}$ & $\mathbf{a}_{\mathbf{2}}$ & $\mathbf{a}_{\mathbf{3}}$ \\
\hline \hline Stucco & 11.58 & 5.894 & 0.0 \\
\hline Brick/rough plaster & 12.49 & 4.065 & 0.028 \\
\hline Concrete & 10.79 & 4.192 & 0.0 \\
\hline Clear pine & 8.23 & 4.0 & -0.057 \\
\hline Smooth plaster & 10.22 & 3.1 & 0.0 \\
\hline Glass & 8.23 & 3.33 & -0.036 \\
\hline
\end{tabular}

For cases where the exterior infrared emissive $=0.9$, the exterior combined surface coefficient for all walls and roofs will be $29.3 \mathrm{~W} / \mathrm{m}^{2} \mathrm{~K}$, and the exterior combined surface coefficient for glass and high conductance walls/opaque windows will be $21.0 \mathrm{~W} / \mathrm{m}^{2} \mathrm{~K}$.

For these diagnostic cases where the exterior infrared emissivity is 0.1 , use $16.9 \mathrm{~W} / \mathrm{m}^{2} \mathrm{~K}$.

For convenience of input, the exterior combined radiative and convective surface conductance for the transparent window and the opaque window are assumed to be the same, even though the hemispherical infrared emissivity of ordinary uncoated window glass is usually 0.84 . This is equivalent to assuming that the emissivity of the glass is 0.9 .

If your program adjusts glass surface coefficients according to window overhang and fin structure, use that capability, and provide documentation.

Rain causes the surface temperature to rapidly approach the water temperature. Provide documentation if your program treats rain as a special case. 


\section{Appendix D}

\section{Infrared Portion of Film Coefficients}

The infrared portion of film coefficients is based on the linearized gray-body radiation equation (Duffie and Beckman 1974):

where:

$$
h_{i}=4 \varepsilon \sigma T^{3},
$$

$\varepsilon=$ Infrared emissivity

$\sigma=5.67 * 10^{-8} \mathrm{~W} / \mathrm{m}^{2} \mathrm{~K}^{4}$ (Stefan-Boltzmann constant)

$T=$ Average temperature of surrounding surfaces [assumed $10^{\circ} \mathrm{C}(283 \mathrm{~K})$ for outside, $20^{\circ} \mathrm{C}(293 \mathrm{~K})$ for inside]

$\mathrm{K}=\operatorname{Kelvin}\left(\right.$ absolute $0=-273.16^{\circ} \mathrm{C}$ )

$\mathrm{h}_{\mathrm{i}}=$ Infrared radiation portion of surface coefficient

$h_{c}=$ Convective portion of surface coefficient

$h_{s}=$ Total combined interior surface coefficient

$h_{0}=$ Total combined outside surface coefficient.

Table 1-20. Disaggregation of Film Coefficients Versus Surface Emissivity for Various Surface Types

\begin{tabular}{|c|c|c|c|}
\hline $\begin{array}{l}\text { Very smooth surface } \\
\text { outside }^{\mathrm{a}}\left(\mathrm{T}=10^{\circ} \mathrm{C}\right)(283 \mathrm{~K})\end{array}$ & $\varepsilon=0.9$ & $\varepsilon=0.84$ & $\varepsilon=0.1$ \\
\hline$h_{\cdot}\left(W / m^{2} K\right)$ & 4.63 & 4.32 & .51 \\
\hline$h_{a}\left(W / \dot{m}^{2} K\right)$ & 21 & 20.69 & 16.88 \\
\hline$h_{c}\left(W / m^{2} K\right)=h_{0}-h_{i}$ & 16.37 & 16.37 & 16.37 \\
\hline \multicolumn{4}{|l|}{$\begin{array}{l}\text { Inside surface } \\
\left(\mathrm{T}=20^{\circ} \mathrm{C}\right)(293 \mathrm{~K})\end{array}$} \\
\hline $\mathrm{h}_{\mathrm{i}}\left(\mathrm{W} / \mathrm{m}^{2} \mathrm{~K}\right)$ & 5.13 & 4.79 & .57 \\
\hline $\mathrm{h}_{\mathrm{s}}\left(\mathrm{W} / \mathrm{m}^{2} \mathrm{~K}\right)$ & 8.29 & 7.95 & 3.73 \\
\hline $\mathrm{h}_{\mathrm{c}}\left(\mathrm{W} / \mathrm{m}^{2} \mathrm{~K}\right)=\mathrm{h}_{\mathrm{s}}-\mathrm{h}_{\mathrm{j}}$ & 3.16 & 3.16 & 3.16 \\
\hline \multicolumn{4}{|l|}{$\begin{array}{l}\text { Brick/Rough plaster } \\
\text { outside }^{\mathrm{a}}\left(\mathrm{T}=10^{\circ} \mathrm{C}\right)(283 \mathrm{~K}) \\
\end{array}$} \\
\hline$h_{i}\left(W / m^{2} K\right)$ & 4.63 & & .51 \\
\hline$h_{0}\left(W / m^{2} K\right)$ & 29.3 & & 25.18 \\
\hline $\mathrm{h}_{\mathrm{c}}\left(\mathrm{W} / \mathrm{m}^{2} \mathrm{~K}\right)$ & 24.67 & & 24.67 \\
\hline
\end{tabular}

${ }^{a}$ Based on a mean annual wind speed of $4.02 \mathrm{~m} / \mathrm{s}$ for outside surfaces.

For convenience of input, the interior combined radiative and convective surface conductance for the opaque window and the transparent window are assumed the same, even though the hemispherical infrared emissivity of ordinary uncoated window glass is usually 0.84 . This is equivalent to assuming that the emissivity of the glass is 0.9 . 


\section{Appendix E}

\section{Window Transmittance Equations and Glazing Tables}

Snell's Law, Fresnel Equations, and Bouger's Law for Transmittance of Glass in Air

\section{Nomenclature}
AOI
Angle of incidence
AOR
Angle of refraction
INDRA
Index of refraction for air $=1.0$
INDRG
Index of refraction for glass $=1.526$ (for this case)
RPERP
Perpendicular reflectance (component of polarization)
RPAR
Parallel reflectance (component of polarization)
R
Reflectance - (RPERP + RPAR $) / 2$
n
Number of panes of glass $=2$ (for this case)
$\operatorname{Tr}$
Tabs Transmittance due to reflectance
losses and no absorptance losses)
Transmittance due to absorptance losses (transmittance if there were just absorptance
$\mathrm{T} \quad$ Total transmittance $-\operatorname{Tr} \times$ Tabs losses and noreflectance losses)
K Extinction coefficient $=0.0196 / \mathrm{mm}$ (for this case)
TH Thickness of glass $=3.175 \mathrm{~mm}$ (for this case)
L . Path length $=\mathrm{TH} /(\cos$ AOR $)$
ARCSIN . INVSIN
e
INV Ln $=$ EXP (value)

\section{Snell's Law}

INDRA/INDRG $=\sin A O R / \sin A O I$

$\mathrm{AOR}=\mathrm{ARCSIN}[(\sin \mathrm{API}) / \mathrm{INDRG}]$

Fresnel Equations (reflectance at 1 air to glass interface)

$\mathrm{RPERP}=\left[\sin ^{2}(\mathrm{AOR}-\mathrm{AOI})\right] /\left[\sin ^{2}(\mathrm{AOR}+\mathrm{AOI})\right]$

$\operatorname{RPAR}=\left[\tan ^{2}(A O R-A O I)\right] /\left[\tan ^{2}(A O R+A O I)\right]$

$\mathrm{R}=(\mathrm{RPERP}+\mathrm{RPAR}) / 2$

Fresnel Equations (transmittance due to reflectance with several panes)

$\operatorname{Tr}, \mathrm{n}=0.5\{[(1-\mathrm{RPERP}) /(1+(2 \mathrm{n}-1) \mathrm{RPERP})]+[(1-\operatorname{RPAR}) /(1+(2 \mathrm{n}-1) \operatorname{RPAR})]\}$

Bouger's Law (transmittance due to absorptance)

Tabs $=\mathrm{e}^{[\mathrm{n}(-\mathrm{KL})]}$

$T=\operatorname{Tr} \times$ Tabs 
Table 1-21. Glazing Properties as a Function of Incidence Angle

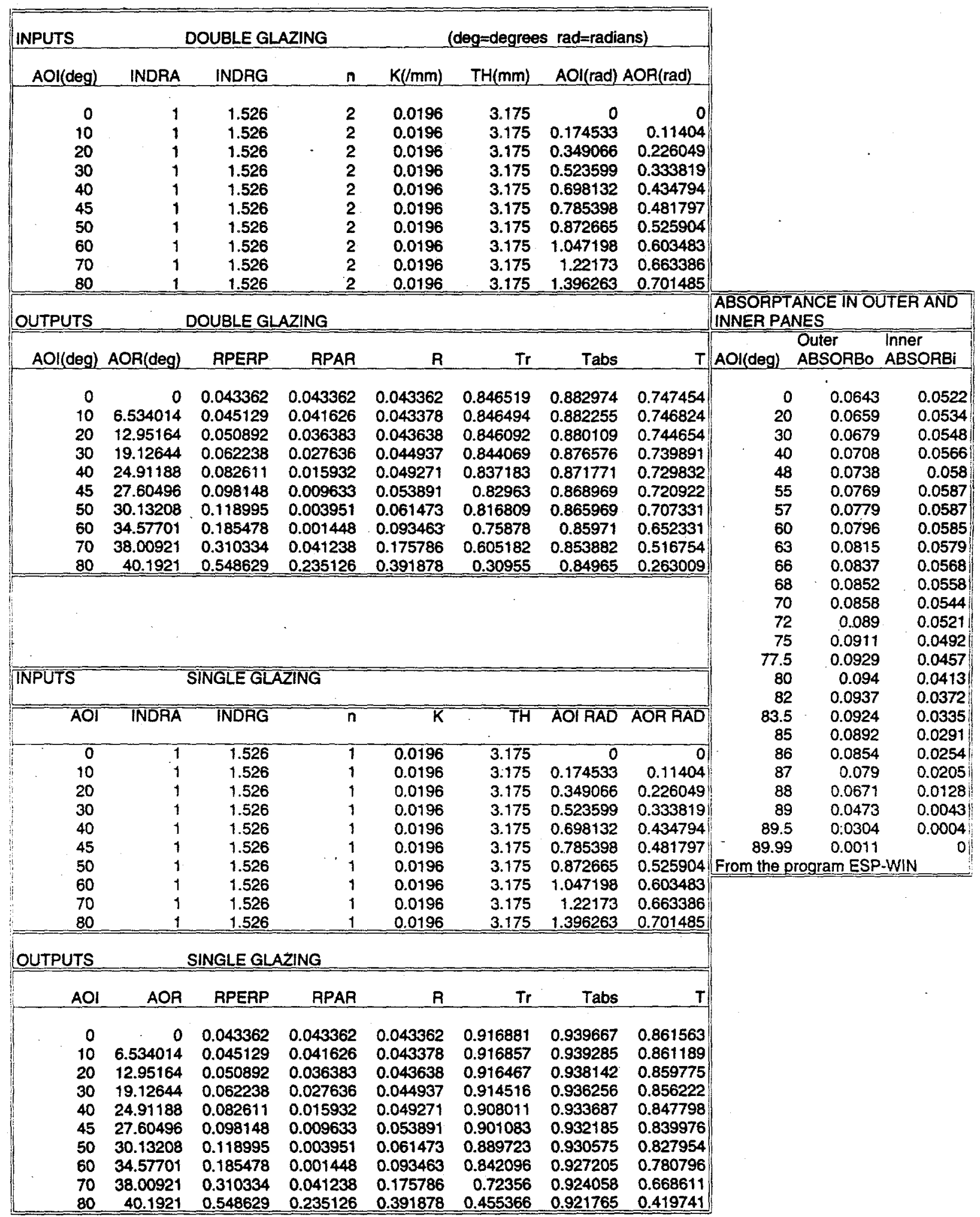


Angular Dependent Solar Heat Gain Coefficients (SHGC) shown in Table 1-22 were evaluated with WINDOW 4.0 (WINDOW 4.0 1992) using appropriate BESTEST inputs. The direct normal shading coefficient of 0.916 was also determined from WINDOW 4.0.

Table 1-22. Angular Dependence of Solar Heat Gain Coefficient

\begin{tabular}{|c|c|}
\hline Angle & SHGC \\
\hline 0 & 0.787 \\
\hline 10 & 0.786 \\
\hline 20 & 0.785 \\
\hline 30 & 0.780 \\
\hline 40 & 0.767 \\
\hline 50 & 0.737 \\
\hline 60 & 0.666 \\
\hline 70 & 0.518 \\
\hline 80 & 0.266 \\
\hline 90 & 0.000 \\
\hline Hemispherical & 0.686 \\
\hline
\end{tabular}




\section{Appendix F}

\section{Detailed Calculation of Solar Fractions}

The BESTEST solar fraction approximations are calculated from

$$
S F_{n}=B 1_{n}+B 2_{n}+B 3_{n}+B R_{n} \text {, }
$$

where:

$\mathrm{n}=\mathrm{a}$ particular surface

$\mathrm{SF}=$ total solar fraction.

B1 describes the first "bounce" of incident shortwave radiation assuming all of it initially hits the floor.

$B 1_{\text {floor }}=\alpha$

$B 1_{\text {all other }}=0$

$\alpha=$ interior shortwave absorptance of opaque surfaces (all interior surfaces have the same absorptance except for the window, which is denoted as $\alpha_{w}$ ).

B2 describes the second "bounce" such that shortwave radiation diffusely reflected by the floor is distributed over other surfaces in proportion to their view factor-absorptance product.

$B 2_{\text {floor-floor }}=0$

$B 2_{\text {floor-other opaque }}=(1-\alpha)\left(F F_{i}\right)(\alpha)$

$B 2_{\text {floor-window lost }}=(1-\alpha)\left(\mathrm{FF}_{\mathrm{i}}\right)\left\{1-\left[\rho_{\mathrm{w}}+\left(\alpha_{\mathrm{w}} / 2\right)\right]\right\}$

$B 2_{\text {floor-window absorbed }}=(1-\alpha)\left(\mathrm{FF}_{\mathrm{i}}\right)\left(\alpha_{\mathrm{w}} / 2\right)$,

where:

$\mathrm{FF}=$ view factor from Figures 1-11 and 1-12

$i=$ particular surface which the floor "sees"

$\rho_{\mathrm{w}}=1-\tau_{\mathrm{r}}, \tau_{\mathrm{r}}=0.76$ from Appendix $\mathrm{E}$ for double glazing, $60^{\circ}$ incidence angle to approximate properties of diffuse radiation

$\alpha_{\mathrm{w}}=1-\tau_{\mathrm{abs}}, \tau_{\mathrm{abs}}=0.86$ from Appendix $\mathrm{E}$ for double glazing, $60^{\circ}$ incidence angle to approximate properties of diffuse radiation. 
Use of $\left(\alpha_{w} / 2\right)$ assumes half of the interior reflected radiation absorbed by the double-pane window is conducted back out to ambient; the other half remains as heat in the zone.

B3 describes the third bounce such that the remaining nonabsorbed shortwave radiation is distributed over each surface in proportion to its area-absorptance product.

$B 3_{\text {opaque-opaque }}=\left[1-\alpha-\Sigma\left(B 2_{n}\right)\right]\left(A_{n} / A_{\text {total }}\right)(\alpha)$

$B 3_{\text {opaque-window lost }}=\left[1-\alpha-\Sigma\left(B 2_{n}\right)\right]\left(A_{n} / A_{\text {total }}\right)\left\{1-\left[\rho_{w}+\left(\alpha_{w} / 2\right)\right]\right\}$

$B 3_{\text {opaque-window absorbed }}=\left[1-\alpha-\Sigma\left(B 2_{\mathrm{p}}\right)\right]\left(\dot{A}_{\mathrm{p}} / \mathrm{A}_{\text {total }}\right)\left(\alpha_{\mathrm{w}} / 2\right)$.

BR describes the distribution of all remaining bounces based on distribution fractions from calculations for $\mathrm{B3}_{\mathrm{n}}$ above.

$B R_{n}=\left[1-\alpha-\Sigma\left(B 2_{n}\right)-\Sigma\left(B 3_{n}\right)\right]\left[B 3_{n} / \Sigma\left(B 3_{n}\right)\right]$. 


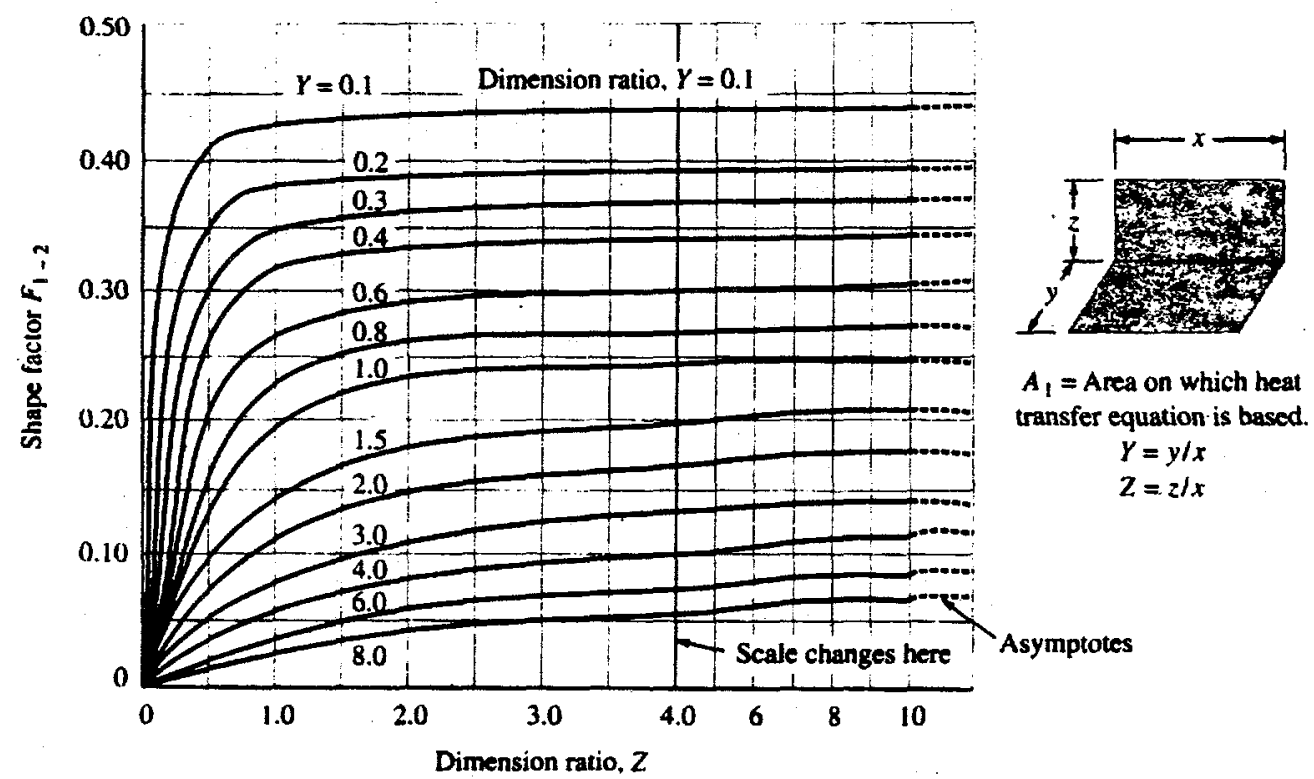

Figure 1-11. Shape factor for adjacent rectangles in perpendicular planes sharing a common edge Reprint permission pending from the American Society of Mechanical Engineers

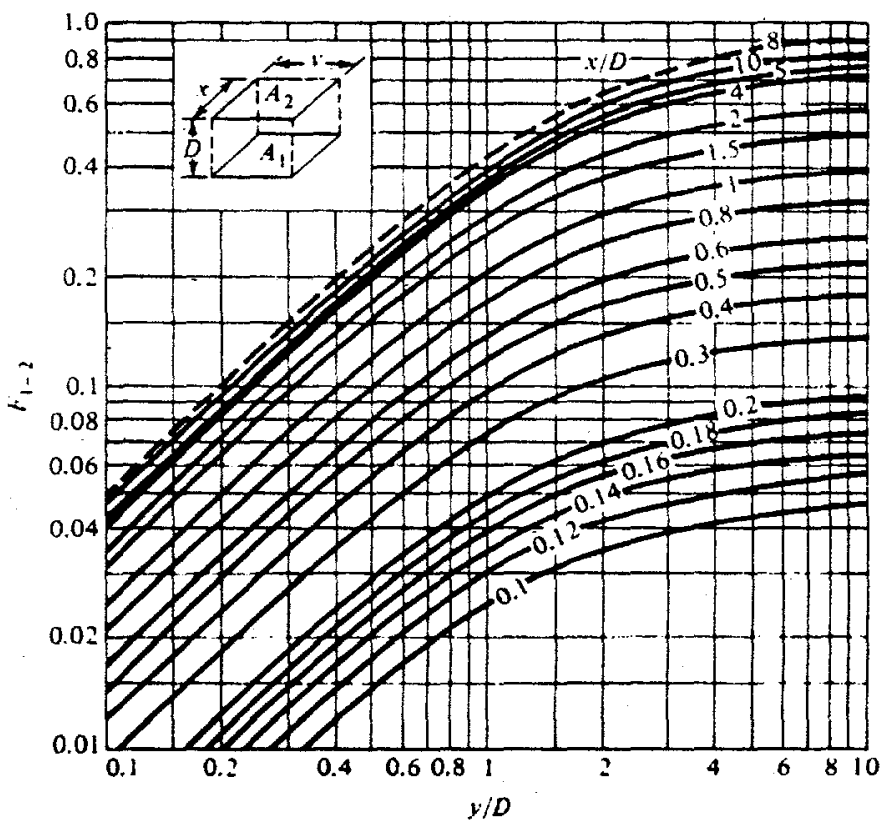

Figure 1-12. Shape factor for directly opposed rectangles

Reprinted by permission from Principles of Heat Transfer, Fifth Edition by Frank Kreith and Mark S. Bohn, CopyrightO 1993 by West Publishing Company. All rights reserved. 


\section{Appendix G}

\section{Typical Meteorological Year (TMY) Weather Data Format Description}

For convenience we have reprinted the following discussion from the documentation for DOE2.1A Reference Manual, (p. VIII-31), and tables (Table 1-23) from "Typical Meteorological Year" (National Climatic Center 1981). The reprint of tables from "Typical Meteorological Year" also includes some additional notes from our experience with TMY data. If this summary is insufficient for your weather processing needs, the complete documentation on TMY weather data can be obtained from the National Climatic Center (NCC) in Asheville, North Carolina. Their address is Federal Bldg., Asheville, NC 28801-2733, telephone 704-271-4800.

Solar radiation and surface meteorological data recorded on an hourly ${ }^{1}$ basis are maintained at the NCC. These data cover recording periods from January 1953 through December 1975 for 26 data rehabilitation stations, although the recording periods for some stations may differ. The data are available in blocked (compressed) form on magnetic tape (SOLMET) for the entire recording period for the station of interest.

Contractors desiring to use a data base for simulation or system studies for a particular geographic area require a data base that is more tractable than these, and also one that is representative of the area. Sandia National Laboratory has used statistical techniques to develop a method for producing a typical meteorological year (TMY) for each of the 26 rehabilitation stations. This section describes the use of these magnetic tapes.

The TMY tapes comprise specific calendar months selected from the entire recorded span for a given station as the most representative, or typical, for that station and month. For example, a single January is chosen from the 23 Januarys for which data are recorded from 1953 through 1975 on the basis of its being most nearly like the composite of all 23 Januarys. Thus, for a given station, January of 1967 might be selected as the typical meteorological month (TMM) after a statistical comparison with all of the other 22 Januarys. This process is pursued for each of the other calendar months, and the twelve months chosen then constitute the TMY.

Although the data have been rehabilitated by NCC, some recording gaps do occur in the SOLMET tapes. Moreover, there are data gaps because of the change from one-hour to three-hour meteorological data recording in 1965. Consequently, as TMY tapes were being constituted from the SOLMET data, the variables data for barometric pressure, temperature, and wind velocity and direction were scanned on a month-by-month basis, and missing data were replaced by linear interpolation. Missing data in the leading and trailing positions of each monthly segment are replaced with the earliest/latest legitimate observation.

Also, since the TMMs were selected from different calendar years, discontinuities occurred at the month interfaces for the above continuous variables. Hence, after the monthly segments were rearranged in calendar order, the discontinuities at the month interfaces were ameliorated by cubic spline smoothing covering the six-hourly points on either side of the interface.

\footnotetext{
${ }^{1}$ Hourly readings for meteorological data are available through 1964 ; subsequent readings are on a three-hour basis.
} 


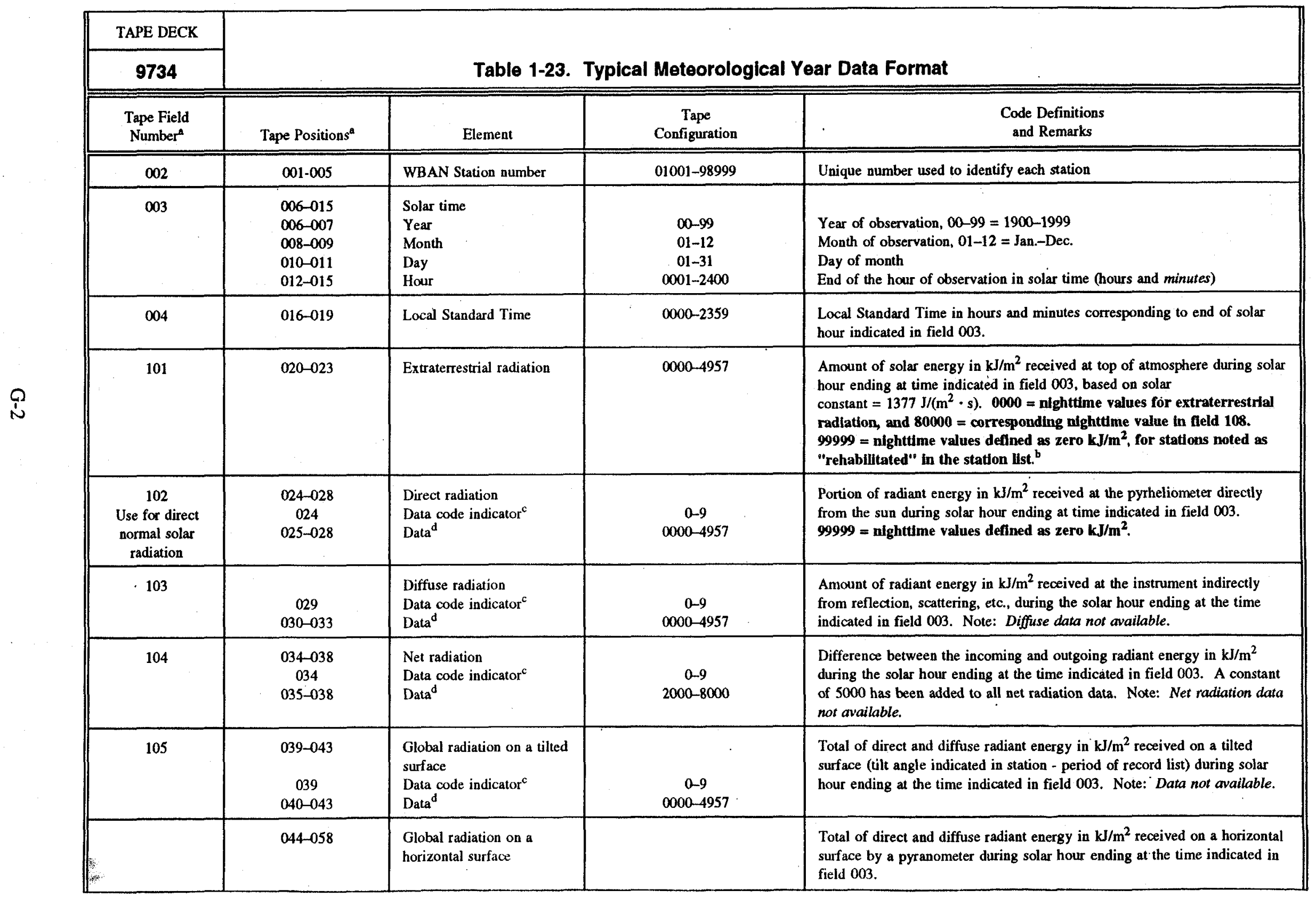




\begin{tabular}{|c|c|c|c|c|}
\hline \multirow{2}{*}{$\frac{\text { TAPE DECK }}{9734}$} & \multirow{2}{*}{\multicolumn{4}{|c|}{ Table 1-23. Typical Meteorological Year Data Format (Continued) }} \\
\hline & & & & \\
\hline $\begin{array}{l}\text { Tape Field } \\
\text { Number }^{\mathrm{a}}\end{array}$ & Tape Positions ${ }^{\mathrm{a}}$ & Element & $\begin{array}{c}\text { Tape } \\
\text { Configuration }\end{array}$ & $\begin{array}{l}\text { Code Definitions } \\
\text { and Remarks }\end{array}$ \\
\hline 106 & $\begin{array}{c}044-048 \\
044 \\
045-048\end{array}$ & $\begin{array}{l}\text { Observed data } \\
\text { Data code indicator }^{c} \\
\text { Data }^{\mathrm{d}}\end{array}$ & $\begin{array}{c}0-9 \\
0000-4957\end{array}$ & $\begin{array}{l}\text { Observed value. Note: These data are not corrected. Recommend use of } \\
\text { data in field } 108 \text {. }\end{array}$ \\
\hline 107 & $\begin{array}{c}049-053 \\
049 \\
050-053\end{array}$ & $\begin{array}{l}\text { Engineering corrected } \\
\text { data } \\
\text { Data code indicator } \\
\text { Data }^{\mathrm{c}}\end{array}$ & $\begin{array}{c}0-9 \\
0000-4957\end{array}$ & $\begin{array}{l}\text { Note: Recommend use of data in field } 108 \text {. } \\
\text { Observed value corrected for known scale changes, station moves, recorder } \\
\text { and sensor calibration changes, etc. }\end{array}$ \\
\hline $\begin{array}{l}108 \\
\text { Use for total } \\
\text { horizontal } \\
\text { solar radiation }\end{array}$ & $\begin{array}{c}054-058 \\
054 \\
055-058\end{array}$ & $\begin{array}{l}\text { Standard year } \\
\text { Corrected data } \\
\text { Data code indicator }^{\mathrm{c}} \\
\text { Data }^{\mathrm{d}}\end{array}$ & $\begin{array}{c}0-9 \\
000-4957\end{array}$ & $\begin{array}{l}\text { Observed value adjusted to Standard Year Model. This model yields } \\
\text { expected sky irradiance received on a horizontal surface at the elevation of } \\
\text { the station. The value includes the effects of clouds. Note: All nighttime } \\
\text { values coded as } 80000 \text { except stations noted as rehabilitated in the station } \\
\text { list; for those stations, nighttime values are coded } 99999^{b}\end{array}$ \\
\hline 109,110 & $\begin{array}{l}059-068 \\
059-064 \\
060-063 \\
065-068\end{array}$ & $\begin{array}{l}\text { Additional radiation } \\
\text { measurements } \\
\text { Data code indicators } \\
\text { Data }^{\mathrm{d}} \\
\text { Data }^{\mathrm{d}}\end{array}$ & $0-9$ & $\begin{array}{l}\text { Supplemental fields A and B for additional radiation measurements: type } \\
\text { of measurement specified in station-period of record list. }\end{array}$ \\
\hline 111 & $069-070$ & Minutes of sunshine & $00-60$ & $\begin{array}{l}\text { For Local Standard Hour most closely matching solar hour. Note: Data } \\
\text { available only for when observations were made. }\end{array}$ \\
\hline 201 & $071-072$ & $\begin{array}{l}\text { Time of TD } 1440 \\
\text { Observations }\end{array}$ & $00-23$ & $\begin{array}{l}\text { Local Standard Hour of TD } 1440 \text { Meteorological Observation that comes } \\
\text { closest to midpoint of the solar hour for which solar data are recorded. }\end{array}$ \\
\hline 202 & 073-076 & Ceiling height & $\begin{array}{l}0000-3000 \\
7777 \\
8888\end{array}$ & $\begin{array}{l}\text { Ceiling height in dekameters }\left(\mathrm{dam}=\mathrm{m} \times 10^{1}\right) \text {; ceiling is defined as opaque } \\
\text { sky cover of } 0.6 \text { or greater. } \\
0000-3000=0 \text { to } 30,000 \text { meters } \\
7777=\text { unlimited; clear } \\
8888 \text { = unknown height of cirroform ceiling }\end{array}$ \\
\hline
\end{tabular}




\begin{tabular}{|c|c|c|c|c|}
\hline TAPE DECK & \multirow{2}{*}{\multicolumn{4}{|c|}{ Table 1-23. Typical Meteorological Year Data Format (Continued) }} \\
\hline 9734 & & & & \\
\hline $\begin{array}{c}\text { Tape Field } \\
\text { Number }^{\mathrm{a}}\end{array}$ & Tape Positions ${ }^{\mathrm{a}}$ & Element & $\begin{array}{c}\text { Tape } \\
\text { Configuration }\end{array}$ & $\begin{array}{l}\text { Code Definitions } \\
\text { and Remarks }\end{array}$ \\
\hline 203 & $\begin{array}{c}077-081 \\
077 \\
078-081\end{array}$ & $\begin{array}{l}\text { Sky condition } \\
\text { Indicator } \\
\text { Sky condition }\end{array}$ & $\begin{array}{c}0 \\
0000-8888\end{array}$ & $\begin{array}{l}\text { Identifies observation after June } 1,1951 . \\
\text { Coded by layer in ascending order; four layers are described; if fewer than } \\
\text { four layers are present the remaining positions are coded } 0 . \text { The code for } \\
\text { each layer is: } \\
\qquad \begin{aligned} 0 & =\text { Clear or less than } 0.1 \text { cover } \\
1 & =\text { Thin scattered }(0.1-0.5 \text { cover }) \\
2 & =\text { Opaque scattered }(0.1-0.5 \text { cover }) \\
3 & =\text { Thin broken }(0.6-0.9 \text { cover }) \\
4 & =\text { Opaque broken }(0.6-0.9 \text { cover }) \\
5 & =\text { Thin overcast }(1.0 \text { cover }) \\
6 & =\text { Opaque overcast }(1.0 \text { cover }) \\
7 & =\text { Obscuration } \\
8 & =\text { Partial obscuration }\end{aligned}\end{array}$ \\
\hline 204 & $082-085$ & Visibility & $\begin{array}{c}0000-1600 \\
8888\end{array}$ & $\begin{array}{l}\text { Prevailing horizontal visibility in hectometers }\left(\mathrm{hm}=\mathrm{m} \times 10^{2}\right) \\
0000-1600=0 \text { to } 160 \text { kilometers } \\
8888=\text { unlimited }\end{array}$ \\
\hline \multirow[t]{2}{*}{205} & $\begin{array}{c}086-093 \\
086\end{array}$ & $\begin{array}{l}\text { Weather } \\
\text { Occurrence of thunder- } \\
\text { storm, tornado, or squall }\end{array}$ & $0-4$ & 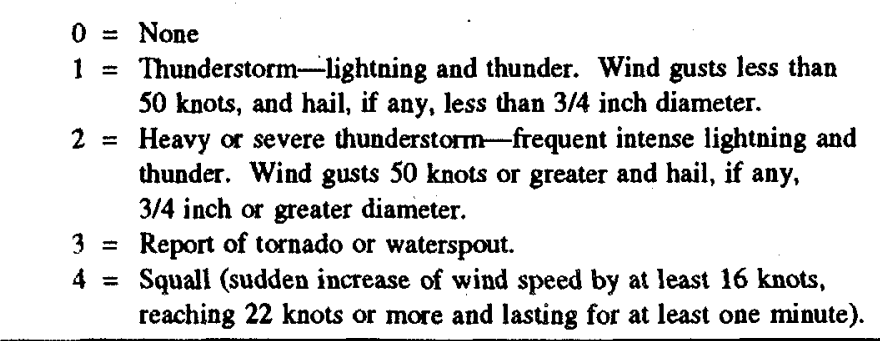 \\
\hline & 087 & $\begin{array}{l}\text { Occurrence of rain, rain } \\
\text { showers, or freezing rain }\end{array}$ & $0-8$ & $\begin{array}{l}0=\text { None } \\
1=\text { Light rain } \\
2=\text { Moderate rain } \\
3=\text { Heavy rain } \\
4=\text { Light rain showers } \\
5=\text { Moderate rain showers } \\
6=\text { Heavy rain showers } \\
7=\text { Light freezing rain } \\
8=\text { Moderate or heavy freezing rain }\end{array}$ \\
\hline
\end{tabular}




\begin{tabular}{|c|c|c|c|c|}
\hline TAPE DECK & \multirow{2}{*}{\multicolumn{4}{|c|}{ Table 1-23. Typical Meteorological Year Data Format (Continued) }} \\
\hline 9734 & & & & \\
\hline $\begin{array}{l}\text { Tape Field } \\
\text { Number }\end{array}$ & Tape Positions $^{a}$ & Element & $\begin{array}{c}\text { Tape } \\
\text { Configuration }\end{array}$ & $\begin{array}{c}\text { Code Definitions } \\
\text { and Remarks }\end{array}$ \\
\hline \multirow[t]{3}{*}{205 (cont'd) } & 088 & $\begin{array}{l}\text { Occurrence of drizzle, } \\
\text { freezing drizzle }\end{array}$ & $0-6$ & $\begin{array}{l}0=\text { None } \\
1=\text { Light drizzle } \\
2=\text { Moderate drizzle } \\
3=\text { Heavy drizzle } \\
4=\text { Light freezing drizzle } \\
5=\text { Moderate freezing drizzle } \\
6=\text { Heavy freezing drizzle }\end{array}$ \\
\hline & 089 & $\begin{array}{l}\text { Occurrence of snow, snow } \\
\text { pellets, or ice crystals }\end{array}$ & $0-8$ & 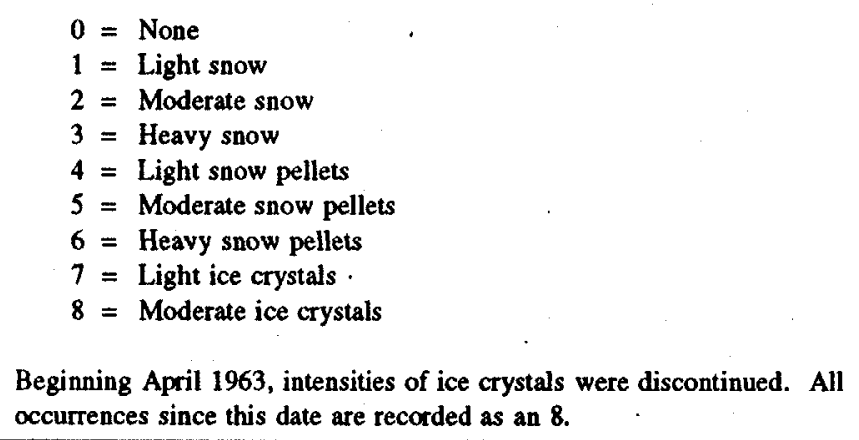 \\
\hline & 090 & $\begin{array}{l}\text { Occurrence of snow } \\
\text { showers or snow grains }\end{array}$ & $0-6$ & $\begin{aligned} 0 & =\text { None } \\
1 & =\text { Light snow showers } \\
2 & =\text { Moderate snow showers } \\
3 & =\text { Heavy snow showers } \\
4 & =\text { Light snow grains } \\
5 & =\text { Moderate snow grains } \\
6 & =\text { Heavy snow grains }\end{aligned}$ \\
\hline
\end{tabular}




\begin{tabular}{|c|c|c|c|c|}
\hline TAPE DECK & \multirow{2}{*}{\multicolumn{4}{|c|}{ Table 1-23. Typical Meteorological Year Data Format (Continued) }} \\
\hline 9734 & & & & \\
\hline $\begin{array}{l}\text { Tape Field } \\
\text { Number }\end{array}$ & Tape Positions & Element & $\begin{array}{c}\text { Tape } \\
\text { Configuration }\end{array}$ & $\begin{array}{l}\text { Code Definitions } \\
\text { and Remarks }\end{array}$ \\
\hline \multirow[t]{3}{*}{205 (Cont'd) } & 091 & $\begin{array}{l}\text { Occurrence of sleet (iee } \\
\text { pellets), sleet showers, or } \\
\text { hail }\end{array}$ & $0-8$ & $\begin{aligned} & 0=\text { None } \\
& 1=\text { Light sleet or sleet showers (iee pellets) } \\
& 2=\text { Moderate sleet or sletet showers (ile pellets) } \\
& 3=\text { Heavy sleet or sleet showers (ice pellets) } \\
& 4=\text { Light hail } \\
& 5=\text { Moderate hail } \\
& 6=\text { Heavy hail } \\
& 7=\text { Light small hail } \\
& 8=\text { Moderate or heavy small hail } \\
& \text { Prior to April } 1970, \text { ice pellets were coded as sleet. Begining April } 1970, \\
& \text { sleet and small hail were redefined as ice pellets and are coded as a } 1,2,2 \text { or } \\
& 3 \text { in this position. Beginning September 1956, intensities of hail were no } \\
& \text { longer reported and all occurrences were recorded as a } 5 .\end{aligned}$ \\
\hline & 092 & $\begin{array}{l}\text { Occurrence of fog, blowing } \\
\text { dust, or blowing sand }\end{array}$ & $0-5$ & $\begin{aligned} & 0=\text { None } \\
& 1=\text { Fog } \\
& 2=\text { Ice fog } \\
& 3=\text { Ground fog } \\
& 4=\text { Blowing dust } \\
& 5=\text { Blowing sand } \\
& \text { These values recorded only when visibility less than } 7 \text { miles. }\end{aligned}$ \\
\hline & 093 & $\begin{array}{l}\text { Occurnence of smoke, haze, } \\
\text { dust, blowing snow, or } \\
\text { blowing spray }\end{array}$ & $0-6$ & 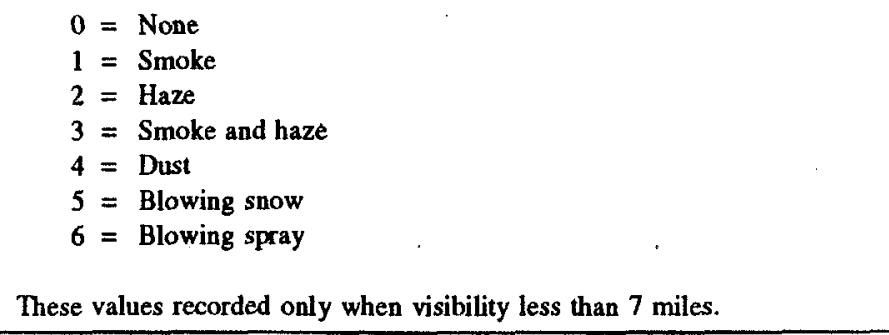 \\
\hline 206 & $\begin{array}{l}094-103 \\
094-098 \\
099-103\end{array}$ & $\begin{array}{l}\text { Pressure } \\
\text { Sea level pressure } \\
\text { Station pressure }\end{array}$ & $\begin{array}{l}08000-10999 \\
08000-10999\end{array}$ & $\begin{array}{l}\text { Pressure, reduced to sea level, in kilopascals }(\mathrm{kPa}) \text { and hundredths. } \\
\text { Pressure at station level in kilopascals }(\mathrm{kPa}) \text { and hundredths. } \\
08000-10999=80 \text { to } 109.99 \mathrm{kPa}\end{array}$ \\
\hline 207 & $\begin{array}{l}104-111 \\
104-107 \\
108-111\end{array}$ & $\begin{array}{l}\text { Temperature } \\
\text { Dry bult } \\
\text { Dew poist }\end{array}$ & $\begin{array}{l}-700 \text { to } 0600 \\
-700 \text { to } 0600\end{array}$ & $\begin{array}{l}{ }^{\circ} \mathrm{C} \text { and tenths } \\
-700 \text { to } 0600=-70.0 \text { to }+60.0^{\circ} \mathrm{C}\end{array}$ \\
\hline
\end{tabular}




\begin{tabular}{|c|c|c|c|c|}
\hline \multirow{2}{*}{$\frac{\text { TAPE DECK }}{9734}$} & \multirow{2}{*}{\multicolumn{4}{|c|}{ Table 1-23. Typical Meteorological Year Data Format (Concluded) }} \\
\hline & & & & \\
\hline \multirow[t]{2}{*}{$\begin{array}{l}\text { Tape Field } \\
\text { Number }^{\mathbf{A}}\end{array}$} & Tape Positions ${ }^{\mathrm{a}}$ & Element & $\begin{array}{c}\text { Tape } \\
\text { Configuration }\end{array}$ & $\begin{array}{l}\text { Code Definitions } \\
\text { and Remarks }\end{array}$ \\
\hline & $\begin{array}{l}112-118 \\
112-114 \\
115-118\end{array}$ & $\begin{array}{l}\text { Wind } \\
\text { Wind direction } \\
\text { Wind speed }\end{array}$ & $\begin{array}{c}000-360 \\
0000-1500\end{array}$ & $\begin{array}{l}\text { Degrees } \\
\mathrm{m} / \mathrm{s} \text { and tenths; } 0000 \text { with } 000 \text { direction indicates calm. } \\
000-1500=0 \text { to } 150.0 \mathrm{~m} / \mathrm{s}\end{array}$ \\
\hline 209 & $\begin{array}{l}119-122 \\
119-120 \\
121-122\end{array}$ & $\begin{array}{l}\text { Clouds } \\
\text { Total sky cover } \\
\text { Total opaque sky cover }\end{array}$ & $\begin{array}{l}00-10 \\
00-10\end{array}$ & $\begin{array}{l}\text { Amount of celestial dome in tenths covered by clouds or obscuring } \\
\text { phenomena. Opaque means clouds or obscuration through which the sky of } \\
\text { higher cloud layers cannot be seen. }\end{array}$ \\
\hline 210 & 123 & $\begin{array}{l}\text { Snow cover } \\
\text { Indicator }\end{array}$ & $0-1$ & $\begin{array}{l}0 \text { indicates no snow or trace of snow. } \\
1 \text { indicates more than a trace of snow on the ground. }\end{array}$ \\
\hline 211 & $124-132$ & Blank & & \\
\hline
\end{tabular}

at Tape positions are the precise column locations of data. Tape Field Numbers are ranges representing topical groups of tape positions.

DDRCOLD.TMY is not defined as a "rehabilitated" station.

'Note for Fields 102-110: Data code indicators are:

$0=$ Observed data, 1=Estimated from model using sunshine and cloud data, 2=Estimated from model using cloud data, 3=Estimated from model using sunshine data, 4=Estimated from model using sky condition data, 5=Estimated from linear interpolation, $6=$ Reserved for future use, 7=Estimated from other model (see individual station notes in SOLMET: Volume 1), 8=Estimated without use of a model, 9=Missing data follows (See model description in SOLMET: Volume 2).

d"9s" may represent zeros or missing data or the quantity nine depending on the positions in which they occur. Except for tape positions 001-023 in fields 002-101, elements with a tape configuration of 9 's indicate missing or unknown data. 


\title{
Appendix H
}

\section{LOTUS-123 Output Spreadsheet Instructions}

\author{
BESTEST Output Form $\quad$ BESTOUT4.WK1 SEP 17, 1992
}

Instructions:

1. Please use specified units.

2. All radiation data is for sum of direct and diffuse solar radiation.

3. Please format dates using the appropriate two-digit date followed by a three-digit month code and two-digit hour code (24-hour clock) as shown below.

Month Codes:

\begin{tabular}{ll} 
Month & Code \\
\cline { 2 - 2 } January & Jan \\
February & Feb \\
March & Mar \\
April & Apr \\
May & May \\
June & Jun \\
July & Jul \\
August & Aug \\
September & Sep \\
October & Oct \\
November & Nov \\
December & Dec
\end{tabular}

For example, a peak occurring on Jan 4 during the 15 th hour interval ( 2 to 3 p.m.) should be input as:

$$
\frac{\text { Date }}{\text { 04-Jan }} \quad \frac{\text { Hour }}{15}
$$

When dates are input in this format, they are converted to a five-digit date code (04-Jan = 33607) which appears in the data cell. (This code is also recognized by some other spreadsheet software.) To convert this five-digit code back into a date, the cell must have an appropriate format. Thus, for BESTOUT4.WK1 we have already applied the format command "/ Worksheet Range Format Date 2" to the cells that require the entry of dates.

4. For the 960 case, please leave the south zone (sunspace) as free floating and the north zone as controlled to get both the required load and free-float temperature outputs. This case is the only 900 series case that will not require a change to the input deck to produce free-float outputs. 
5. Data entry is restricted to column B or columns B, C, D. This worksheet extends down to row 981. Note that we have used the protection option in this worksheet to help assure that data is input in the correct cells. This was done to help ease data handling on our end. If you think we have accidentally left an area protected that should have been unprotected, then disable the worksheet protection to input your data. 


\section{Appendix 1}

\section{Temperature Bin Conversion Program}

\section{Program User Notes}

This program sorts hourly temperature output data into bins of $1^{\circ} \mathrm{C}$.

Enclosed is the source code and executable program (written in MS-Fortran) for sorting annual hourly temperature output into bins of $1^{\circ} \mathrm{C}$. The bins range from $-50^{\circ} \mathrm{C}$ to $99^{\circ} \mathrm{C}$. The program will abort if temperatures outside this range are encountered.

The annual hourly temperature file must be sequential, and each line must not contain more than one occurrence of the temperature of interest. The program reads either free format, or formatted data. In freeformat mode, the number of the column in which the data resides is needed (the program interactively explains this input). No alpha characters are allowed in the data columns in free-format mode. A line with alpha characters in the data column will be escaped.

It is advisable to use the formatted option in which alphanumeric characters prior to the data of interest are skipped over, using $\mathrm{X}$ format. The limitation is that the format has to be in either " $F$ " or " $E$ " FORTRAN formats. Even if the temperature data in the file were integers, the format has to be for a "REAL" type number. In such cases, integers must be read in " $F "$ format with 0 digits (F3.0):-

Output from the bin program is written into a file with the same name as the temperature data file, but with the extension ".BND".

The program will prompt the user for input with some explanatory remarks. It displays dots after each 10 lines processed to show it is running. When finished, it will show the number of lines processed, and the number of lines that contained errors or unreadable characters. If the number of errors is substantial, then the input file and format should be corrected. Run and error information is stored in a file with the same name as the input data file, but with the extension ".INF".

Support for the program is available from F. Parand, Building Research Establishment, United Kingdom, at +44923664842 . 


\section{Part I References}

ASHRAE Handbook Fundamentals. (1989). Atlanta, GA: American Society of Heating, Refrigerating and Air-Conditioning Engineers.

ASHRAE Handbook Fundamentals. (1993). Atlanta, GA: American Society of Heating, Refrigerating, and Air-Conditioning Engineers.

Allen, E.J. et al. (August 1985). "Analytical and Empirical Validation of Dynamic Thermal Building Models." Proc. First Building Energy Simulation Conference, Seattle, WA; pp. 274-280.

Barakat, S.A. (May 1983). Passive Solar Heating Studies at the Division of Building Research, ISSN 0701-5232, Building Research Note \#181, Ottawa, Canada.

Bland, B.H. (1992). "Conduction in Dynamic Thermal Models: Analytical Tests for Validation." BSER\&T (13) 4; pp. 197-208.

Bland, B.H. and D.P. Bloomfield. (1986). "Validation of Conduction Algorithms in Dynamic Thermal Models." Proc. CIBSE 5th Int. Symp. on the Use of Computers for Environmental Engineering Related to Buildings, Bath, UK.

Bloomfield, D. (1985). "Appraisal Techniques for Methods of Calculating the Thermal Performance of Buildings." Build. Serv. Eng. Res. Technol., 6(1); pp. 13-20.

Bloomfield, D.P. (1988). An Investigation into Analytical and Empirical Validation Techniques for Dynamic Thermal Models of Buildings: Executive Summary, 25 pp., Vol. 1, SERC/BRE final report, BRE Garston.

Bloomfield, D., ed. (November 1989). Design Tool Evaluation: Benchmark Cases. IEA T8B4. Solar Heating and Cooling Program, Task VIII: Passive and Hybrid Solar Low-Energy Buildings. Building Research Establishment. Garston, UK: International Energy Agency.

Bloomfield, D.P., K.J. Lomas, and C.J. Martin. (1992). Assessing Programs which Predict the Thermal Performance of Buildings. BRE Information Paper, IP7/92, 3 pp.

Bowman, N.T. and K.J. Lomas. (July 1985a). "Building Energy Evaluation." Proc. CICA Conf. on Computers in Building Services Design, Nottingham, UK, Construction Industry Computer Association; pp. 99-110.

Bowman, N.T. and K.J. Lomas. (1985b). "Empirical Validation of Dynamic Thermal Computer Models of Buildings." Build. Serv. Eng. Res. Technol., 6(4); pp. 153-162.

Burch, J.D. (1980). Analytical Validation for Transfer Mechanisms in Passive Simulation Codes. Solar Energy Research Institute (now NREL), Golden, CO, internal report.

Burch, J.D., D. Wortman, R. Judkoff, and B.D. Hunn. (May 1985). Solar Energy Research Institute Validation Test House Site Handbook. LA-10333-MS and SERI/PR-254-2028, joint SERI/LANL publication. 
Duffie, J.A. and W.A. Beckman. (1980). Solar Engineering of Thermal Processes. New York, NY: John Wiley \& Sons.

Haberl, J. and G. Yuill. (June 1993). ASHRAE TC-4.7/SPC-140. Working document. Atlanta, GA: American Society of Heating, Refrigerating, and Air-Conditioning Engineers.

Hunn, B. et al. (1982). Validation of Passive Solar Analysis/Design Tools Using Class A Performance Evaluation Data. LA-UR-82-1732, Los Alamos, NM: Los Alamos National Laboratory.

Irving, A. (January 1988). Validation of Dynamic Thermal Models, Energy, and Buildings, ISSN 0378-7788, Lausanne, Switzerland: Elsevier Sequoia, S.A.

Judkoff, R.D. (January 1985a). A Comparative Validation Study of the BLAST-3.0, SERIRES-1.0, and DOE-2.1 A Computer Programs Using the Canadian Direct Gain Test Building (draft). SERI/TR-253-2652, Golden, CO: Solar Energy Research Institute (now NREL).

Judkoff, R.D. (August 1985b). International Energy Agency Building Simulation Comparison and Validation Study. Proc. Building Energy.Simulation Conference, August 21-22, 1985, Seattle, WA, Pleasant Hill, CA: Brown and Caldwell.

Judkoff, R.D. (April 1986). International Energy Agency Sunspace Intermodel Comparison (draft). SERI/TR-254-2977, Golden, CO: Solar Energy Research Institute (now NREL).

Judkoff, R. (1988). Validation of Building Energy Analysis Simulation Programs at the Solar Energy Research Institute. Energy and Buildings, Vol. 10, No. 3, p. 235 . Lausanne, Switzerland: Elsevier Sequoia.

Judkoff, R. (March 18, 1993). Building Energy Simulation Test and Diagnostic Method (draft revision). Golden, CO: National Renewable Energy Laboratory.

Judkoff, R.D. and D.N. Wortman. (April 1984). Validation of Building Energy Analysis Simulations Using 1983 Data from the SERI Class A Test House (draft). SERITR-253-2806, Golden, CO: Solar Energy Research Institute (now NREL).

Judkoff, R., D. Wortman, and C. Christensen (October 1980). A Comparative Study of Four Building Energy Simulations: DOE-2.1, BLAST, SUNCAT-2.4, DEROB-III. SERI/TP-721-837. UL-59c. Golden, CO: Solar Energy Research Institute (now NREL).

Judkoff, R., D. Wortman, and B. O'Doherty. (1981). A Comparative Study of Four Building Energy Simulations Phase II: DOE-2.1, BLAST-3.0, SUNCAT-2.4, and DEROB-4. Golden, CO: Solar Energy Research Institute (now NREL).

Judkoff, R., D. Wortman, B. O'Doherty, and J. Burch. (1983a). A Methodology for Validating Building Energy Analysis Simulations. SERI/TR-254-1508. Golden, CO: Solar Energy Research Institute (now NREL).

Judkoff, R.D., D.N. Wortman, and J.D. Burch. (1983b). Measured versus Predicted Performance of the SERI Test House: A Validation Study. SERITP-254-1953, Golden, CO: Solar Energy Research Institute (nOW NREL). 
Judkoff, R., S. Barakat, D. Bloomfield, B. Poel, R. Stricker, P. van Haaster, and D. Wortman. (1988). International Energy Agency Design Tool Evaluation Procedure. SERI/TP-254-3371, Golden, CO: Solar Energy Research Institute (now NREL).

Kataja, S. and T. Kalema. (1993). Energy Analysis Tests for Commercial Buildings (Commercial Benchmarks). IEA 12B/21C. Tampere University of Technology. Tampere, Finland: International Energy Agency.

Kreith, F. and M. Bohn. (1986). Principles of Heat Transfer. Fourth edition. St. Paul, MN: West Publishing Company.

Kreith, F. and M. Bohn. (1993). Principles of Heat Transfer. Fifth edition. St. Paul, MN: West Publishing Company.

Lomas, K.J. (1986). A Compilation and Evaluation of Data Sets for Validating Dynamic Thermal Models of Buildings. SERC/BRE Validation Group Working Report.

Lomas, K.J. (1991). "Dynamic Thermal Simulation Models of Buildings: New Method of Empirical Validation." BSER\&T 12 (1); pp. 25-37.

Lomas, K.J. and N.T. Bowman. (1986). "The Evaluation and Use of Existing Data Sets for Validating Dynamic Thermal Models of Buildings." Proc. CIBSE Sth Int. Symp. on the Use of Computers for Environmental Engineering Related to Buildings, Bath, UK.

Lomas, K.J. and N.T. Bowman. (1987). "Developing and testing tools for empirical validation," Ch. 14, Vol. IV of SERC/BRE final report, An Investigation in Analytical and Empirical Validation Techniques for Dynamic Thermal Models of Buildings, BRE Garston, 79 pp.

Lomas, K.J. and H. Eppel. (1992). "Sensitivity Analysis Techniques for Building Thermal Simulation Programs." Energy and Building (19) 1; pp. 21-44.

Lomas, K., H. Eppel, C. Martin, and D. Bloomfield. (1994). Empirical Validation of Thermal Building Simulation Programs Using Test Room Data. Volume 1, Final Report. International Energy Agency Report \#IEA21RN399/94. Volume 2, Empirical Validation Package (1993), IEA21RR5/93. Volume 3, Working Reports (1993), IEA21RN375/93. De Montfort University, Leicester, UK.

Martin, C. (1991). Detailed Model Comparisons: An Empirical Validation Exercise Using SERI-RES. Contractor Report from Energy Monitoring Company to U.K. Department of Energy, ETSU S 1197-p9, $141 \mathrm{pp}$.

McFarland, R.D. (May 1982). Passive Test Cell Data for the Solar Laboratory Winter 1980-81. LA-9300-MS, Los Alamos, NM: Los Alamos National Laboratory.

Morck, O. (June 1986). Simulation Model Validation Using Test Cell Data. IEA SHC Task VIII, Report \#176, Thermal Insulation Laboratory, Technical University of Denmark.

National Climatic Center (May 1981). Typical Meteorological Year User's Manual. TD-9734. Asheville, NC: National Climatic Center.

Rittelmann, P.R. (1985). Design Tool Comparison. International Energy Agency Task VII working document. Butler, PA: Burt Hill Kosar Rittelmann Associates. 
Rittelmann, P.R. and S.F. Ahmed. (1985). Design Tool Survey. International Energy Agency Task VIII. Butler, PA: Burt Hill Kosar Rittelmann Associates.

Rodriguez, E. and S. Alvarez. (November 1991). Solar Shading Analytical Tests (I). Universidad de Savilla, Seville, Spain.

Stefanizzi, P. and A. Wilson. (1988). The Intermal Longwave Radiation Exchange in Thermal Models, BRE draft document, Building Research Establishment, UK.

Van De Perre, R. and P. Verstraete. (1994). A Proposal for Analytic Tests. (IEA 12B/21C working document). Vrije. University. Brussels, Belgium: International Energy Agency.

Walton, G. (March 1983). Thermal Analysis Research Program Reference Manual (TARP). NBSIR 83-2655. Washington, D.C.: National Bureau of Standards. (Note that this software is based on BLAST and the manual has a high level of technical detail. Since the BLAST Support Office does not supply an engineer's manual, the TARP manual is used as a substitute.) A reprint of this document can be obtained through the BLAST Support Office, Department of Mechanical and Industrial Engineering, University of Illinois, Urbana, $\mathbb{L}$.

WINDOW 4.0 (March 1992). LBL-32091, UC-350. Berkeley, CA: Lawrence Berkeley Laboratory.

Wortman, D., B. O'Doherty, and R. Judkoff. (January 1981). The Implementation of an Analytical Verification Technique on Three Building Energy Analysis Codes: SUNCAT 2.4, DOE 2.1, and DEROB III. SERI/TP-721-1008, UL-59c. Golden, CO: Solar Energy Research Institute (now NREL). 


\subsection{Part II: Production of Example Results}

\subsection{Introduction}

In this section we describe what the working group members did to produce example results with several detailed programs that were considered to represent the state-of-the-art for building energy simulation in Europe and the United States. The effort took about two years; it involved several revisions to the BESTEST specifications and subsequent re-execution of the computer simulations. The process was iterative in that the execution of the simulations lead to refinement of BESTEST, and the results of BESTEST lead to the improvement and debugging of the programs. The modeling rules for reference programs were somewhat different (more stringent) than for a given program to be subjected to the BESTEST procedure. These differences will be described in Section 2.3.

The programs used to generate the example results are described in Table 2-1. Under the "computer program" column, the first entry in each cell is the proper program name and version number. The entries in parentheses are the various names and abbreviations for the programs used for labeling in some of the figures, tables, and text in this report.

Table 2-1. Participating Organizations and Computer Programs

\begin{tabular}{|c|c|c|}
\hline Computer program & Authoring organization & Implemented by \\
\hline $\begin{array}{l}\text { BLAST-3.0 level } 193 \text { v. } 1 \\
\text { (BLAST-US/TT) }\end{array}$ & CERL, ${ }^{\mathbf{a}}$ United States (U.S.) & $\begin{array}{l}\text { NREL, }{ }^{b} \text { U.S. } \\
\text { Politecnico Torino, Italy }\end{array}$ \\
\hline $\begin{array}{l}\text { DOE2.1D } 14 \\
\text { (DOE2) }\end{array}$ & LANL/LBL, ${ }^{c}$ U.S. & NREL, U.S. \\
\hline $\begin{array}{l}\text { ESP-RV8 } \\
\text { (ESP-DMU) }\end{array}$ & $\begin{array}{l}\text { Strathclyde University, } \\
\text { United Kingdom (U.K.) }\end{array}$ & De Montfort University; U.K. \\
\hline $\begin{array}{l}\text { SERIRES/SUNCODE } 5.7 \\
\text { (SRES/SUN) }\end{array}$ & NREL/Ecotope, U.S. & NREL, U.S. \\
\hline $\begin{array}{l}\text { SERIRES } 1.2 \\
\text { (SRES-BRE) }\end{array}$ & NREL/BRE, ${ }^{\mathrm{d}}$ U.S./U.K. & BRE, U.K. \\
\hline S3PAS & University of Sevilla, Spain & University of Sevilla, Spain \\
\hline TASE & Tampere University, Finland & Tampere University, Finland \\
\hline $\begin{array}{l}\text { TRNSYS } 13.1 \\
\text { (TSYS-BEL/BRE) }\end{array}$ & University of Wisconsin, U.S. & $\begin{array}{l}\text { BRE, U.K. } \\
\text { Vrije Universiteit (VUB) } \\
\text { Brussels, Belgium }\end{array}$ \\
\hline
\end{tabular}

${ }^{2}$ CERL-Civil Engineering Research Laboratory

- NREL - National Renewable Energy Laboratory

'LANL/LBL-Los Alamos National Laboratory/Lawrence Berkeley Laboratory

${ }^{\mathrm{d}} \mathrm{BRE}-$ Building Research Establishment 


\subsection{Selection of Reference Programs and Range Settings}

The initial selections of the programs used in this study were made by the countries participating in this International Energy Agency (IEA) Task. The criteria for selection required that

- A program be representative of the state-of-the-art in whole building energy simulation as defined by the country making the selection

- A program be public domain in the sense that a large portion of its development was government sponsored and that source code be available

- A program be a true simulation based on hourly weather data and calculational time increments of one hour or less.

The tables and graphs in Part III present all of the results from all of the programs used in this study. Additionally, a range has been superimposed over the results from the qualification cases. This range is referred to as the reference range. Ranges were not set for the diagnostic cases because we expect that diagnostics will be performed by specialists for whom the simplification represented by the ranges would not be necessary. The reference range is denoted by a maximum and minimum horizontal line. In many cases, the maximum and minimum borders of the range correspond with the maximum and minimum predictions from among the eight programs in the study. However, in some cases the range is narrower than the spread in results from the eight programs. The ranges were set according to a specific set of rules developed by the participants as follows:

1. Where there is known to be a specific, identifiable, documented deficiency in a program that impacts the results for specific cases, and not for any other cases, the results for those cases will be excluded from the data ranges. These deficiencies must be referenced and explained in the modeler's code report for that program.

2. If a fundamental bug or algorithmic error is suspected that effects many of the results from a particular program, then all the results from that program will be excluded from the data ranges. An explanation of the problem (if known) will be included in the modeler's code report.

3. A very odd result for a particular case must be explained or justified by the modeler, or corrected by the modeler with an explanation of the physical basis for the correction; otherwise, it will not be used for setting the range in that case.

Application of these rules resulted in the elimination of SERIRES/SUNCODE and SERIRES/BRE for setting ranges related to peak loads. This was because these programs could not explicitly model a pure convective thermostat. A convective thermostat is one that responds to pure interior air temperature (does not respond directly to infrared radiation from interior surfaces). In physical terms, such a thermostat may be thought of as a silver-coated aspirated sensor. A mean radiant temperature thermostat is one that responds exclusively to the infrared radiation from interior surfaces. In physical terms, such a thermostat may be thought of as a globe thermometer. A real thermostat actually behaves somewhere between these two extremes-responding to both the air temperature and the radiant environment-which is also similar to the manner in which a human occupant perceives comfort. The mathematical representation of the thermostat control temperature in SERIRES is closer to a radiant temperature than an air temperature. This can have a significant effect on peak load prediction in certain cases. The convective thermostat defined in BESTEST could not be modeled by SERIRES as specified, and so the peak load results from that program are not used for setting reference ranges (see code reports, Section 2.5, for further discussion). 
TASE results related to east and west shading devices (cases 630 and 930) were also eliminated from range setting, based on communications with the modeler.

ESP results were used for range setting despite some cases in which they were substantially lower than all other program results. This was because the modelers successfully demonstrated that these differences could largely be explained by the algorithms for the convective heat transfer coefficients. When used at its most sophisticated level of modeling for this effect (in this case, the default mode for the program), ESP produced the results shown in Part III of this report. This algorithm is based on what the code authors considered to be the best available empirical data for this effect. Results much closer to the other programs' results were produced when two simpler options were used (ESP allows three options for the exterior convective film coefficient; see ESP code report, Section 2.5.5, for more detail). It is evident that the spread in results is quite sensitive to this phenomenon in buildings with relatively large window-toopaque wall-area ratios. Further study of interior and exterior surface radiative and convective heat transfer is probably necessary to reduce the predictive spread in the current crop of state-of-the-art building energy simulation programs.

The ESP modelers also corrected all bugs uncovered by the BESTEST diagnostics.

\subsection{Modeling Rules for Reference Programs}

The modeling rules were somewhat different for the reference programs than for a given program to be tested (see Sections 1.2 and 1.3). For the reference programs, we allowed a variety of explicit and implicit modeling approaches for qualification cases 600 to 650 and 900 to 990 . However, we required that these cases be modeled in the most detailed way possible for each reference program. For diagnostic cases 195 to 440 and 800 to 810 , we used results only from those reference programs capable of explicitly modeling the effect in question. The most difficult cases were those that required variation of exterior and/or interior infrared emissivity $(\varepsilon)$, and those that required variation of interior shortwave absorptivity $(\alpha)$. Thus, for cases that specified interior $\varepsilon=0.1$, exterior $\varepsilon=0.1$, or interior $\alpha=0.1$ (cases $195,200,210,220,280$, 440 , and 810 ), the decision to include the results in the output graphs was based on the modeling approach described in the code report produced by each modeler. Where explicit modeling of the effect was internal to the program, or where the modeler documented a credible method equivalent to explicit modeling of the effect, the results were graphed. Table 2-2 shows those effects responsible for eliminating some of the programs (no = eliminated).

For case 210 , we required at least some sort of interior radiosity network and the ability to explicitly vary interior emissivity. ESP, BLAST, TRNSYS, and TASE were the only programs able to meet these requirements. The TRNSYS modelers were able to do case 210 (interior $\varepsilon=0.1$ ) by varying the StefanBoltzmann Constant within the context of a simplified radiosity network. The SERIRES modelers were able to do cases 280,440 , and 810 (cavity albedo) by externally calculating the fraction of shortwave radiation absorbed by interior surfaces based on shape factors and absorptivities (SERIRES/SUNCODE), or area weighting and absorptivities (SERIRES/BRE). Most of the programs were capable of explicitly modeling the remainder of the diagnostic cases.

To minimize the potential for user error, we encouraged more than one modeler to develop input files for each program. This was done for BLAST (U.S./taly), SERIRES (U.S./U.K.), and TRNSYS (Belgium/U.K.). Where disagreement in the inputs or results was found, we requested the two modelers to resolve the differences. Where only a single modeler was involved, we strongly recommended that inputs be carefully checked by another modeler familiar with the program. 
Table 2-2. Ability of Participating Computer Programs to Explicitly Model Diagnostic Cases That Vary Selected Radiative Properties

\begin{tabular}{|l|c|c|c|}
\hline Computer program & Exterior $\varepsilon=\mathbf{0 . 1}$ & Interior $\varepsilon=\mathbf{0 . 1}$ & Interior $\alpha=0.1$ \\
\hline \hline $\begin{array}{l}\text { BLAST-3.0 level 193 } \\
\text { v.1 }\end{array}$ & No* & Yes & Yes \\
\hline DOE2.1D14 & No & No & No \\
\hline $\begin{array}{l}\text { SERIRES/SUN- } \\
\text { CODE 5.7 }\end{array}$ & No & No & Yes \\
\hline SERIRES1.2 & No & No & Yes \\
\hline ESP-RV8 & Yes & Yes & Yes \\
\hline S3PAS & No & No & No \\
\hline TRNSYS 13.1 & No & Yes & Yes \\
\hline TASE & No & Yes & Yes \\
\hline
\end{tabular}

*Just prior to final publication of this report, the BLAST Support Office notified us of the undocumented commands for invoking BLAST's most detailed algorithm for handling of exterior surface infrared radiation exchange. This information was not available in time to revise the reference results of Part III. Further discussion of this issue is included in Section 2.5.2.

\subsection{Examples of Error Trapping with BESTEST Diagnostics}

This section summarizes a few examples that demonstrate how the BESTEST diagnostics presented in Section 1.3 were used to isolate and correct bugs in the reference programs. Further description may be found in the individual code reports presented in the next section.

Simulations were performed for each test case with the participating computer programs using annual hourly Typical Meteorological Year (TMY) weather data from a climate characterized by cold clear winters $\left(3600^{\circ} \mathrm{KDD}\right)$, hot dry summers, and large diurnal temperature variations throughout the year. This climate was chosen because it provides a robust test of all the weather sensitive algorithms of a program except those related to humidity. At each stage of the exercise, output data from the simulations were compared to each other according to the diagnostic logic of the test cases. The diagnostics revealed, and lead to the correction of, bugs, faulty algorithms, and/or input errors in every one of the programs tested. Several examples follow.

\section{TRNSYS}

TRNSYS is considered to be the most advanced program for simulation of active solar systems sponsored by the U.S. Department of Energy. Early in the study, the results from the program TRNSYS 12.2v1 as implemented by Belgium disagreed markedly from those of the other programs for many of the qualification cases involving high thermal capacitance (Figure 2-1) (Klein 1990). The diagnostic flow logic, as illustrated in Figures 2-2 and 2-3, confirmed that the algorithm causing the problem was related to the calculation of the thermal mass effect (Figures 2-4 and 2-5). It was then relatively easy to trace the problem to the TRNSYS "BID" module which contains the transfer function coefficients (Mitalas and Arsenault 1971). Inspection of the module revealed that two sets of wall ccefficients were transposed. Rearranging the coefficients eliminated the discrepancies (Figures 2-6, 2-7, and 2-8). This problem has 
been corrected in all subsequent versions of TRNSYS, and in fact did not exist in all copies of TRNSYS $12.2 \mathrm{v} 1$.

Note that this problem would neither have been detected in any of the lightweight cases, nor in case 930 (Figure 2-1) where compensating errors between the handling of thermal mass and the shading of east and west windows conceals the problem. The power of this procedure is that a program is tested over a broad range of parametric interactions, and inspected on the basis of a number of different output types.

\section{TASE}

TASE was the program selected by Finland to participate in this study (Aittomaki and Kalema 1976). It was developed with the support of the Finnish government (Kalema 1992). Early results from TASE showed large disagreement with the other programs for the thermostat set-back case (640), and the South shading case (610). This lead to an improvement in the room temperature evaluation algorithm, and modification of a shading algorithm by the author. These changes are included in the current set of results. Note that Figure 2-9 indicates a problem remaining in TASE's ability to model east and west shading. It is curious that this problem does not show up in the annual shading coefficient results for east and west windows (Figure 2-10). This suggests either the presence of combined errors in TASE or the presence of output from an inconsistent set of runs.

\section{DOE2}

The DOE2 program is considered to be the most advanced of the programs sponsored by the U.S. Department of Energy, and is the technical basis for setting national building energy codes and standards in the United States. The tests in the "low-mass" diagnostic flow diagram (Figure 1-8, diagnostic A-8) revealed a problem in DOE2.1D014 concerning treatment of solar absorptivity on exterior surfaces (DOE2 Manuals, 1981-1989). This is shown in Figure 2-11, case 250 and case 250-220 where the annual cooling load output from DOE2 appears less sensitive to a change in exterior solar absorptivity (0.1 to 0.9$)$ than the other programs'. This was traced to a bug in the solar absorptance algorithm associated with surfaces defined as doors. The bug has been repaired in DOE2.1D017 (Figure 2-11) and in DOE2.1E, and now yields results comparable to the other programs (Winkelmann 1991-1993; Hirsch 1992-1993).

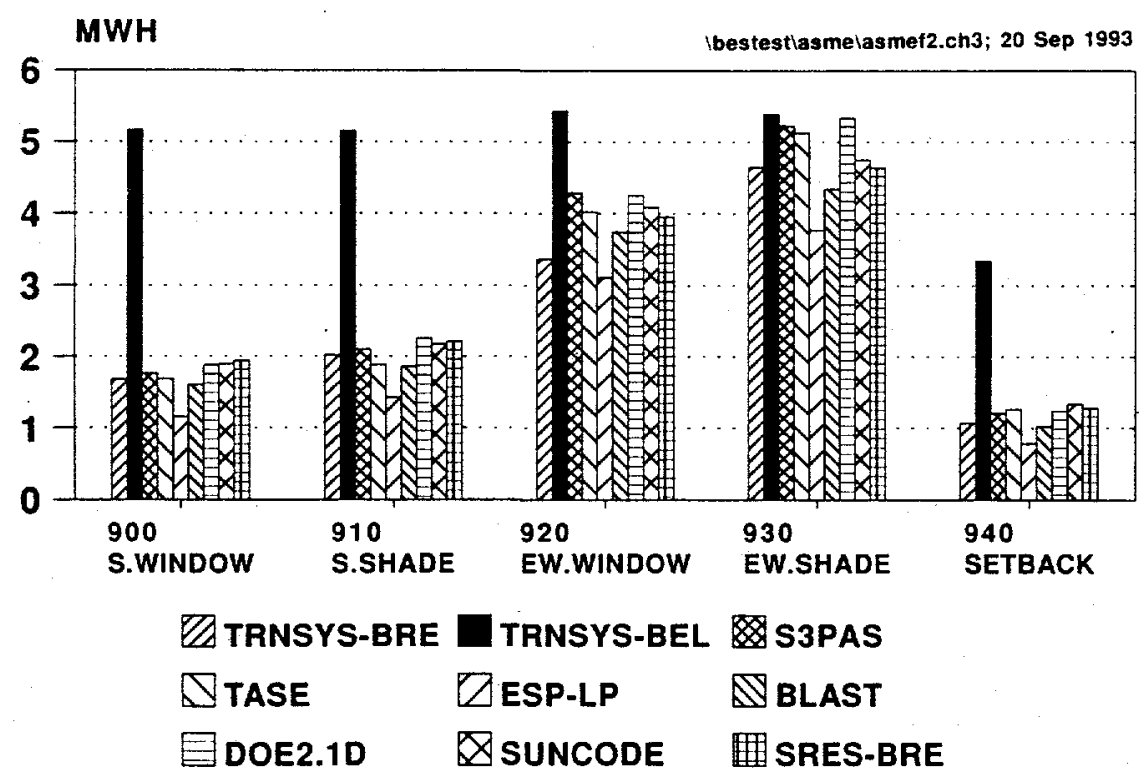

Figure 2-1. BESTEST: qualification high-mass annual heating 


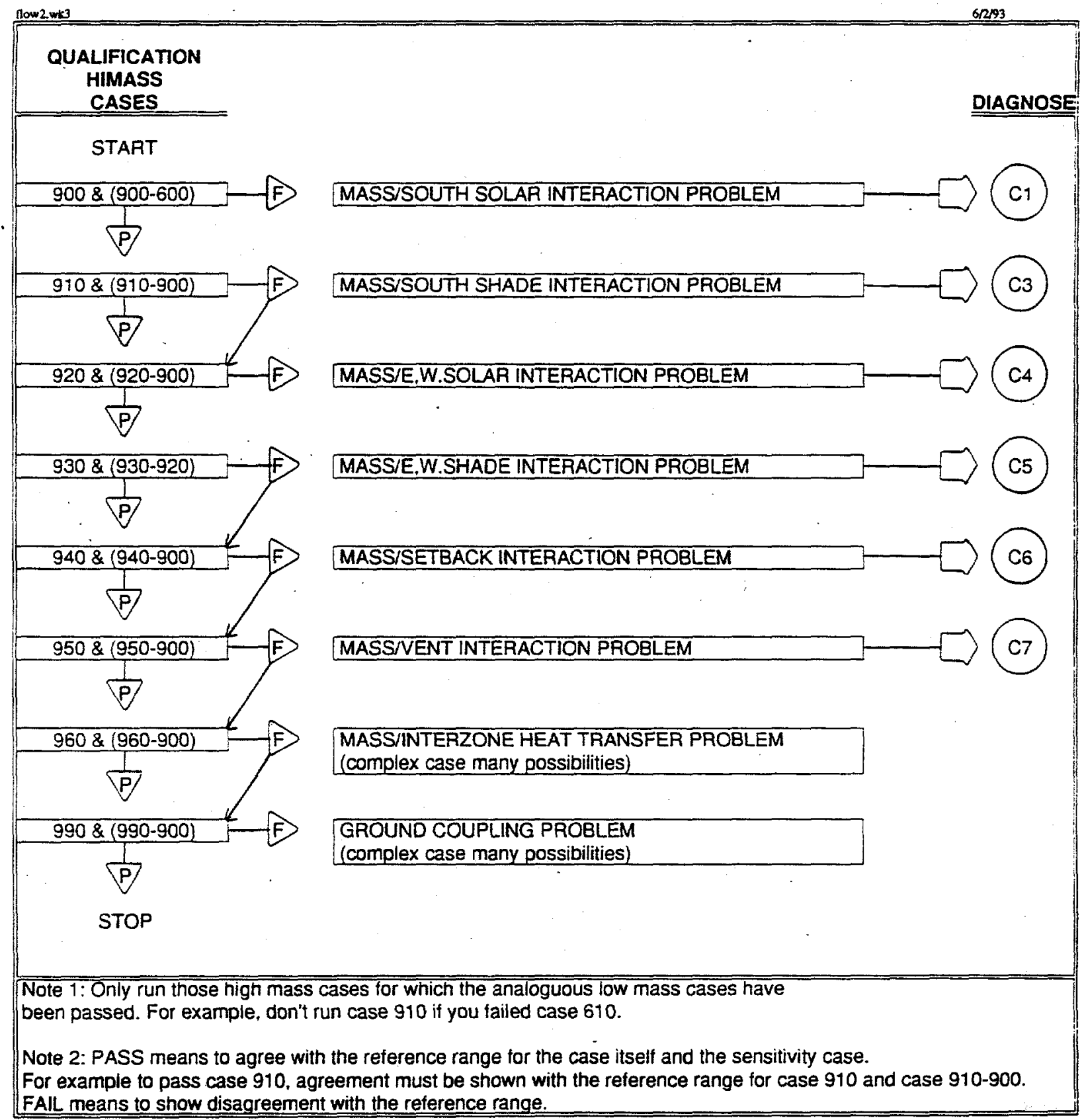

Figure 2-2. High-mass qualification flow diagram 
(2)

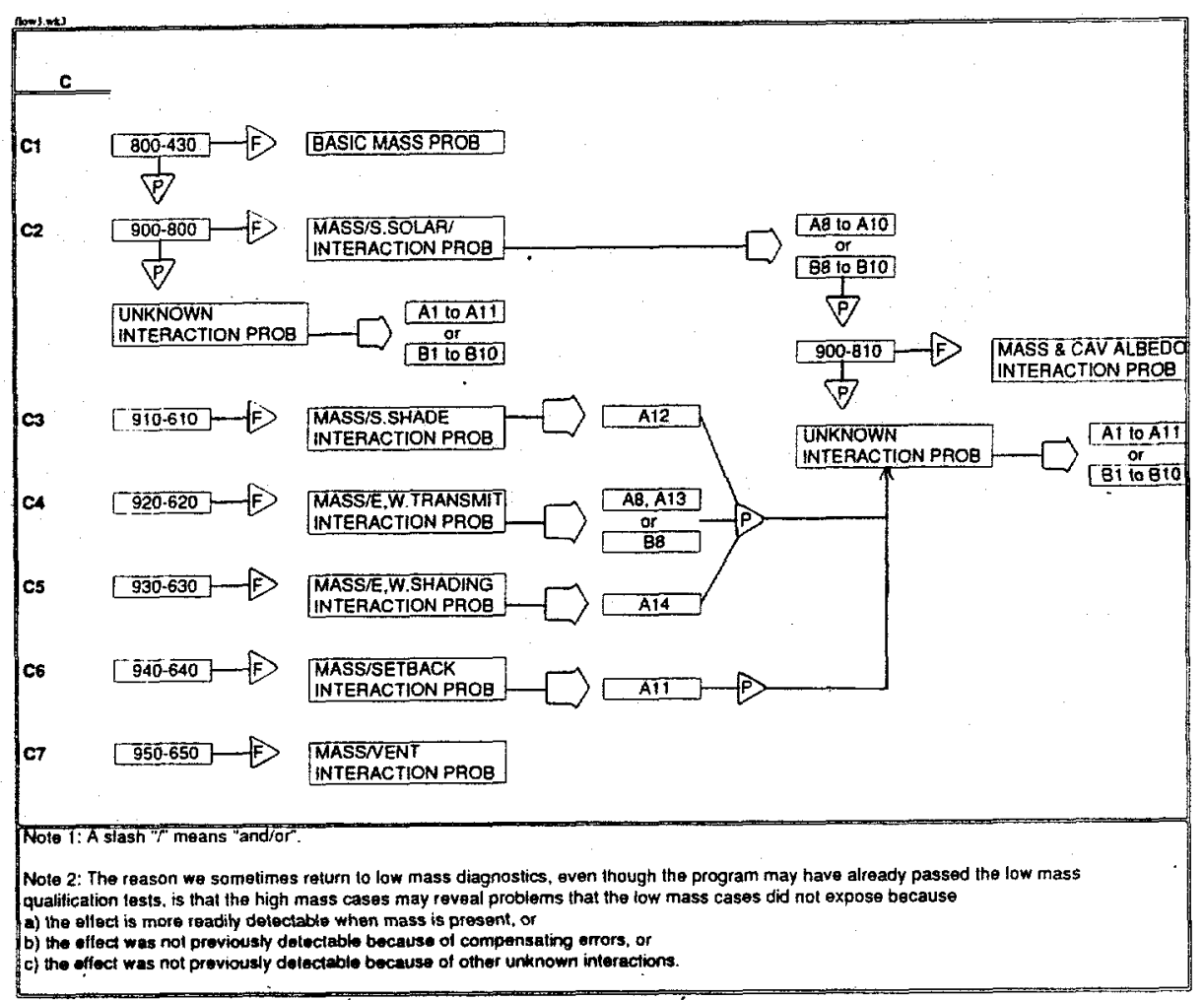

Figure 2-3. Mass diagnostics flow diagram



Ibestestlasmelasmet5.ch3; 20 Sep 1993

Figure 2-4. BESTEST qualification mass effect (delta) annual heating and cooling 


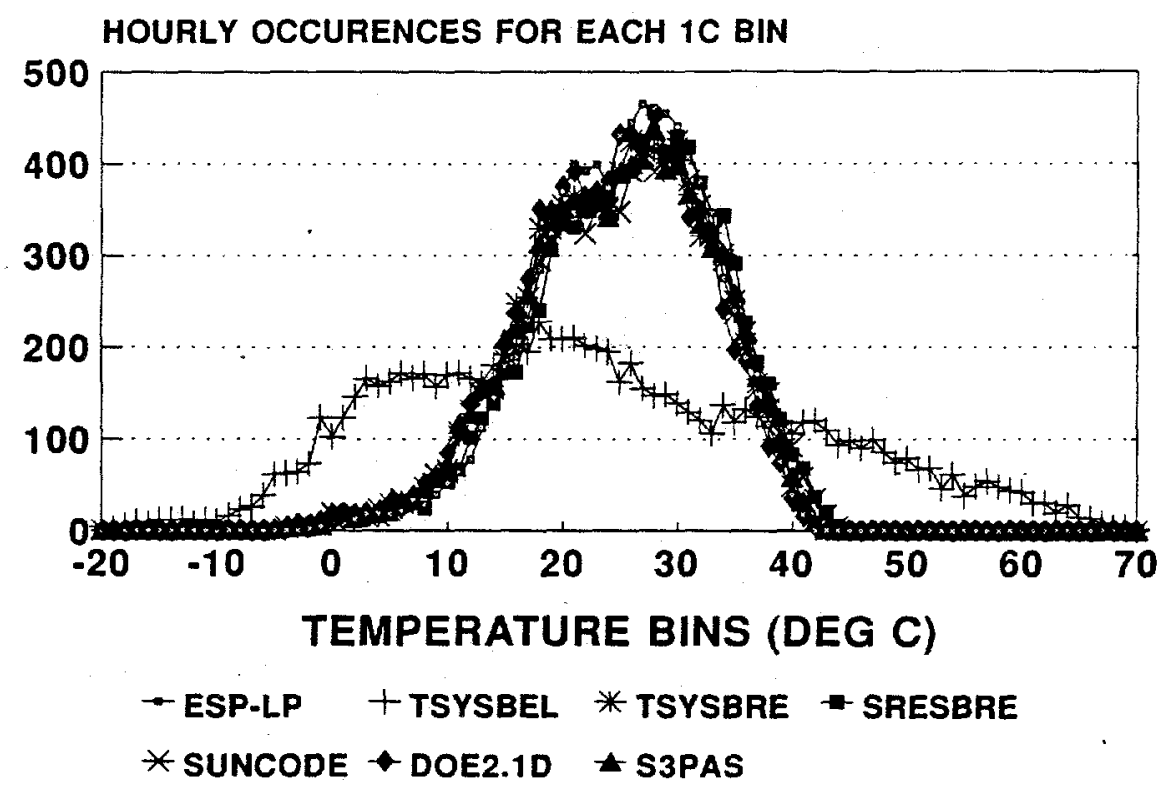

HIMASS/S. WINDOW

Figure 2-5. BESTEST case 900FF annual hourly temperature frequency

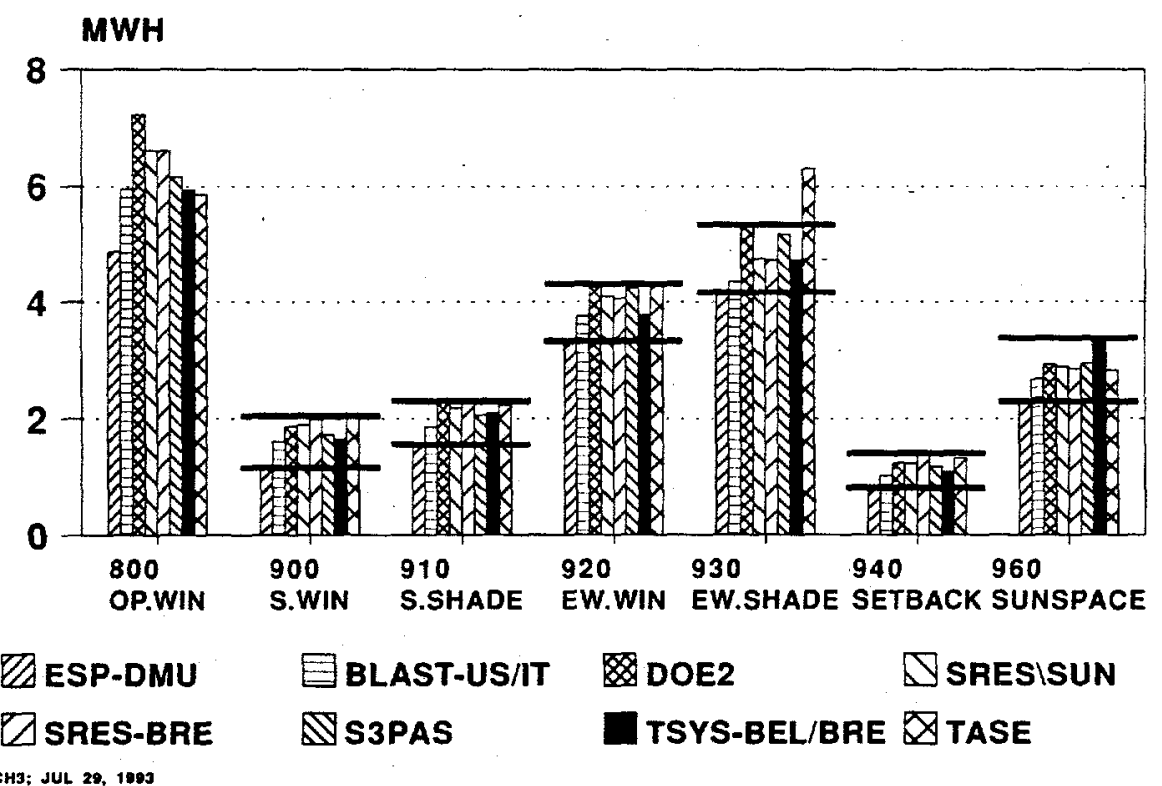

Figure 2-6. BESTEST qualification high-mass annual heating 


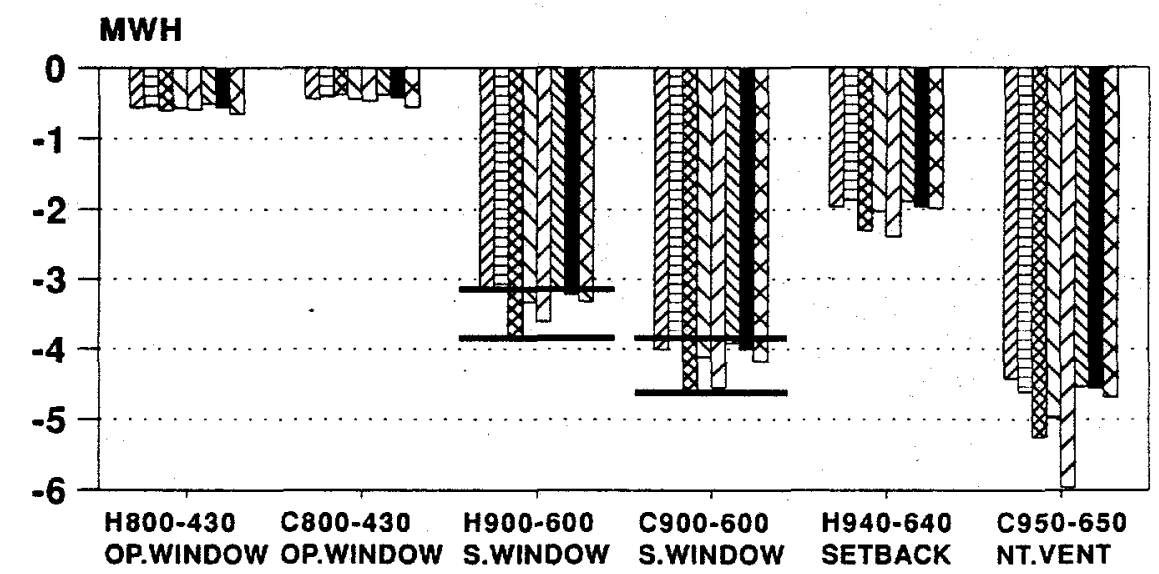

ZESP-DMU 目BLAST-US/TT DOE2 DSRES/SUN

$\square$ SRES-BRE DSPPAS DTSYBEL/BRE

DAMXX.CH3; AUG 2. 1003

Figure 2-7. BESTEST qualification mass effect (delta) annual heating and cooling



Figure 2-8. BESTEST case 900FF annual hourly temperature frequency 


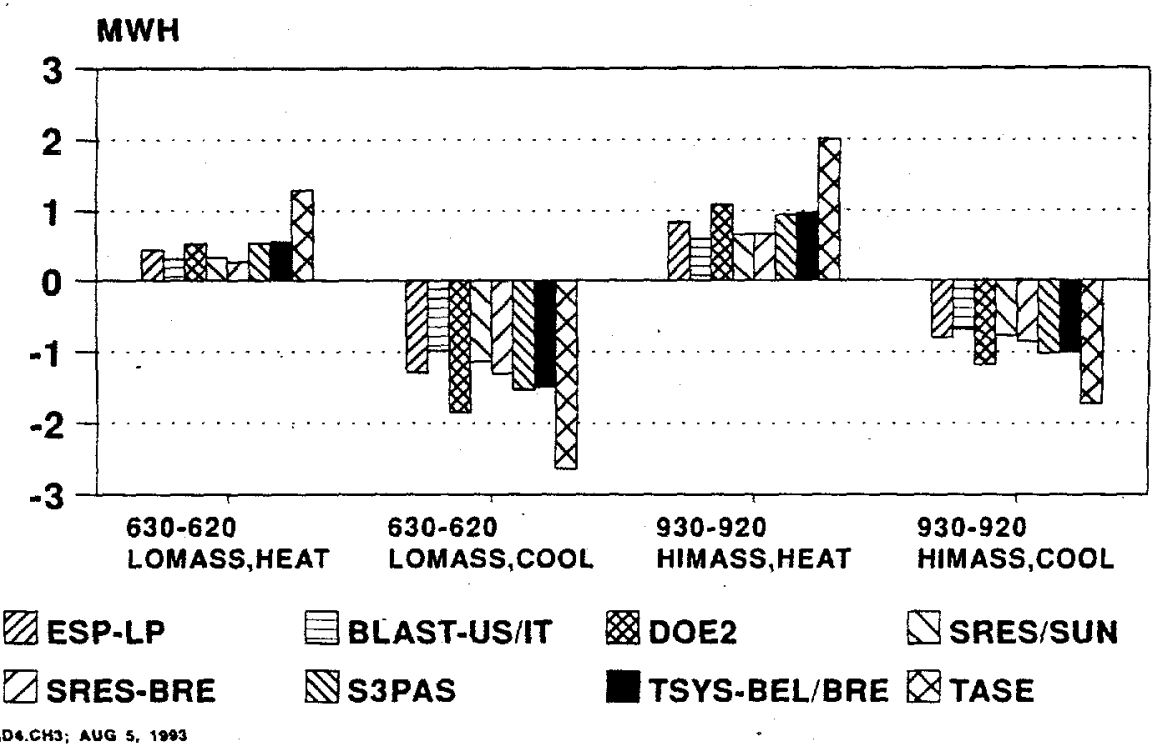

Figure 2-9. East and west shaded window (delta) annual heating and cooling

\section{(1-(SHADED)/(UNSHADED)) TRANSMITTED SOLRAD}



Figure 2-10. Annual overhang and fin shading coefficients 


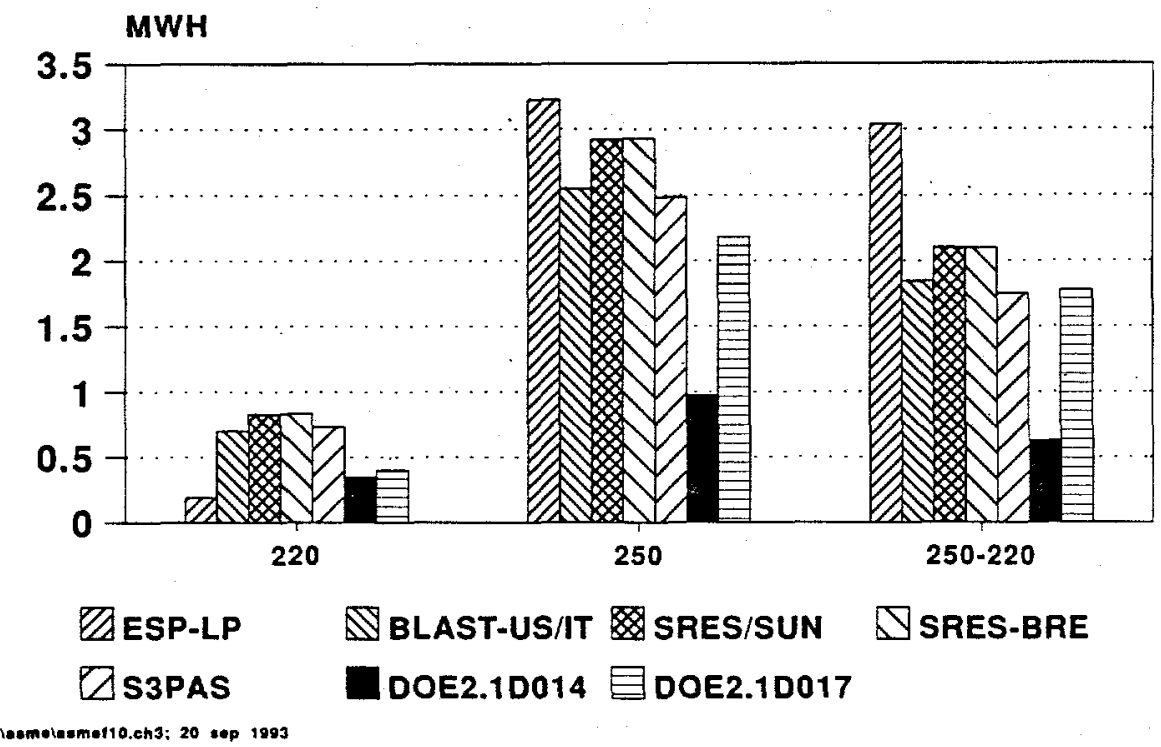

Figure 2-11. Exterior SW absorptivity effect annual cooling load cases 250, 220

\section{BLAST}

BLAST is the program used by the U.S. Department of Defense for energy efficiency improvements to their buildings. BLAST explicitly allows the infrared emissivity of all materials to be varied (BLAST Manuals, 1986-1992). It is therefore commonly believed that BLAST contains a fairly detailed model for exterior surface radiation exchange. This is supported by the TARP Manual (Walton 1983) which in the absence of a BLAST Engineer's Manual describes most, but not all of the BLAST algorithms. The TARP Manual states that the command "HEAT BALANCE $=2$ ", invokes an algorithm which separately accounts for radiative exchange between the exterior surface and the sky, ground and ambient air, as well as convective interchange between the exterior surface and ambient air. The diagnostic test for exterior infrared (IR) radiation (Figure 1-8, diagnostic A-3) revealed no sensitivity to a change in exterior IR emissivity from 0.1 to 0.9 (Figure 2-12). This has been confirmed in a follow up test by one of the original BLAST authors (Hittle 1993). The faulty algorithm has been reported to the BLAST support office.

Just prior to final publication of this report, the BLAST Support Office (BSO) notified us of the undocumented commands for invoking BLAST's most detailed algorithms for handling of surface infrared radiation exchange through the use of the commands: "OUTSIDE CONVECTION $=2$ " and "INSIDE CONVECTION $=2$ " (Chorpening 1995). The results for BLAST with the proper commands have been added to Figure 2-12 and show sensitivity to exterior surface infrared radiative exchange similar to ESP and DOE2.1E.

This example indicates that proper documentation is as important as good algorithms; even sophisticated software users are fully dependent on documentation and technical support to properly implement buildingenergy simulation software. 
ESP is the program that has been selected by the research arm of the Commission of European Communities (CEC) as their reference program for building energy research. ESP predicted relatively low annual heating loads for the qualification test cases (600 and 900 series). A similar trend was observed in the empirical validation study conducted under this task (Lomas et al. 1994). This trend was also observed in the PASSYS empirical validation study conducted by the CEC (Jensen 1993), although Jensen concluded that the discrepancies could be explained by input and measurement uncertainties. BESTEST diagnostic A-10 (Figure 1-8), case 280-270 (Figure 2-13) revealed a problem with interior solar absorptance or cavity albedo. Based on this information the ESP development group at Strathclyde was able to locate and correct the responsible algorithm. De Montfort University then re-executed all the test cases with the corrected and latest version of ESP, "ESP-R". The correction moved the ESP results somewhat closer to the others'. De Montfort University conducted a sensitivity study demonstrating that the remainder of the differences could mostly be explained by the algorithms that calculate the surface convective coefficients in ESP (see Section 2.5.5). Since there are no definitive algorithms for this effect, the ESP results were used for the setting of reference ranges later in this report.



『ESP 目BLAST1 \BLAST2 DOE21D014 \DOE21E

BLAST1: results based on old discussions with BSO BLAST2: with commands "OUTSIDE CONVECTION = 2" and "INSIDE CONVECTION = 2" (per new info. from BSO) 


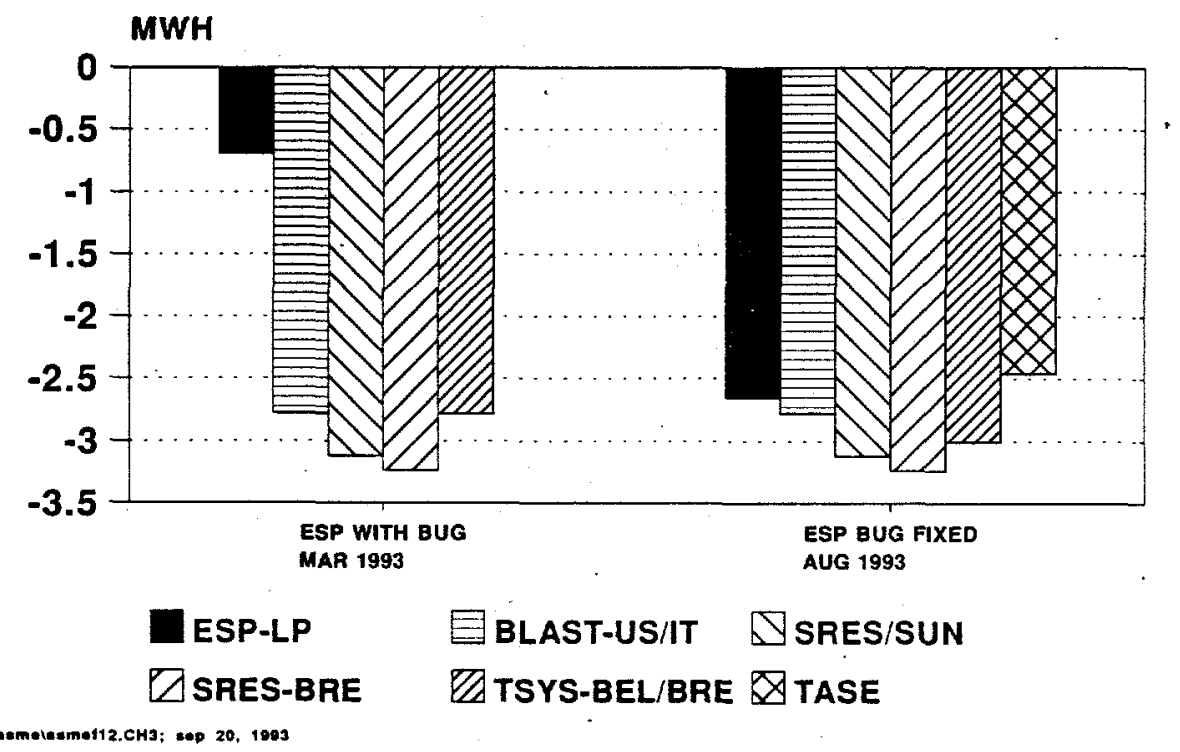

Figure 2-13. Interior solar absorptance effect annual cooling load 


\subsection{Country Code Reports}

In this section we present a brief report for each program written by the modeler. Here the modelers were asked to document

- Any difficulties experienced in developing input files for the test cases with their program

- Any bugs, faulty algorithms, or input errors uncovered using the BESTEST diagnostics

- Any source code, or input modifications made because of the diagnostic results

- Any odd results obtained with their programs

- Any sensitivity studies conducted to further understand the sources of differences between their programs and the others.

Modelers also filled out a pro forma description that defines many of the algorithms within their programs. The pro forma description is presented at the end of each individual code report. A pro forma summary that facilitates the comparison of algorithms is presented in this section (Table 2-3). The individual code reports are presented immediately after the pro forma summary, in Sections 2.5.1 to 2.5.8. Additionally, code reports for DEROB-LTH and CLIM2000 are included in Sections 2.5.9 and 2.5.10 respectively. These programs could not be considered for use in producing the reference data because Lund University, Sweden, and Electricite de France joined the project too late. However, the experience of using BESTEST by researchers who were not part of designing BESTEST was considered worth documenting in code reports. 
Table 2-3. Pro Forma Summary of Particlpating Programs

Key: $\mathrm{x}=$ used in BESTEST; $\mathrm{o}=$ possible to use; $\mathrm{n} \#=$ note

\begin{tabular}{|c|c|c|c|c|c|c|c|c|}
\hline & ESP & BLAST & DOE2 & SERIRES & S3PAS & TRNSYS & TASE & DEROB \\
\hline $\begin{array}{l}\text { Program Status } \\
\text { Public domain } \\
\text { Commercial } \\
\text { Research } \\
\text { Other }\end{array}$ & $\mathrm{x}$ & $\mathbf{x}$ & $\mathbf{x}$ & $\begin{array}{c}x \\
x(n l)\end{array}$ & $\begin{array}{l}\mathbf{x} \\
\mathbf{x}\end{array}$ & $\mathrm{x}$ & $\mathbf{x}$ & $\begin{array}{l}\mathrm{x} \\
\mathrm{x}\end{array}$ \\
\hline $\begin{array}{l}\text { Solution Method } \\
\text { Explicit fin diff } \\
\text { Implicit fin diff } \\
\text { Weighting factors } \\
\text { Response factors } \\
\text { Transfer functions } \\
\text { Other }\end{array}$ & $\begin{array}{l}\mathrm{x} \\
\mathrm{x}\end{array}$ & $\begin{array}{l}\mathbf{x} \\
\mathbf{x}\end{array}$ & $\begin{array}{l}x \\
x \\
x\end{array}$ & $\mathbf{x}$ & $\begin{array}{l}\mathbf{0} \\
\mathbf{0} \\
\mathbf{0} \\
\mathbf{0} \\
\mathbf{x} \\
\mathrm{nl}\end{array}$ & $\begin{array}{c}\mathrm{x} \\
\mathrm{nl}\end{array}$ & $\mathbf{x}$ & $\mathbf{x}$ \\
\hline $\begin{array}{l}\text { Timestep } \\
\text { Timestep (h) } \\
\text { Fixed within code } \\
\text { User specified } \\
\text { Other }\end{array}$ & $\mathbf{x}$ & $\begin{array}{c}1.00 \\
\mathrm{x}\end{array}$ & $\begin{array}{c}1.00 \\
x\end{array}$ & $x(n 2)$ & 1.00 & $\begin{array}{r}0.50 \\
\mathrm{x}\end{array}$ & $\begin{array}{l}1.00 \\
x\end{array}$ & $\begin{array}{c}1.00 \\
\mathrm{x}\end{array}$ \\
\hline \multicolumn{9}{|l|}{$\begin{array}{l}\text { Meteorological data } \\
\text { reconstruction scheme }\end{array}$} \\
\hline $\begin{array}{l}\text { Treated as spot measurement } \\
\text { Treated as average over previous hour } \\
\text { Treated as average } \pm-30 \mathrm{~min} \\
\text { Linear interpolation over hour }\end{array}$ & $\begin{array}{l}\mathbf{0} \\
\mathrm{x}\end{array}$ & $\mathrm{x}(\mathrm{nl})$ & $\mathbf{x}$ & $\mathbf{x}$ & $\mathbf{x}$ & $\begin{array}{l}x(n 2) \\
x(n 2)\end{array}$ & $\mathbf{x}$ & $\mathrm{x}$ \\
\hline \multicolumn{9}{|l|}{ Output timing conventions for each hour } \\
\hline $\begin{array}{l}\text { Spot pred at end of hour } \\
\text { Average over previous hour } \\
\text { Average over }+/-30 \text { min } \\
\text { Average over previous timestep } \\
\text { Average over }+/ \text { - half timestep } \\
\text { Other }\end{array}$ & $\begin{array}{l}\mathbf{o} \\
\mathbf{x}\end{array}$ & $\begin{array}{l}x \\
0\end{array}$ & $\mathbf{x}$ & $\mathrm{x}$ & $\mathrm{n} 2$ & $\begin{array}{l}\mathrm{x} \\
\mathrm{o}\end{array}$ & $\mathbf{x}$ & $\mathrm{x}$ \\
\hline
\end{tabular}


Table 2-3. Pro Forma Summary of Particlpating Programs (Continued)

Key: $x=$ used in BESTEST; $0=$ possible to use; $n \#=$ note

\begin{tabular}{|c|c|c|c|c|c|c|c|c|}
\hline & ESP & BLAST & DOE2 & SERIRES & S3PAS & TRNSYS & TASE & DEROB \\
\hline \multicolumn{9}{|l|}{ Treatment of zone air } \\
\hline $\begin{array}{l}\text { Single temp } \\
\text { Other }\end{array}$ & $\mathrm{x}$ & $x$ & $x$ & $\mathrm{x}$ & $\mathrm{x}$ & $x$ & $\mathrm{x}$ & $\mathbf{x}$ \\
\hline \multicolumn{9}{|l|}{ Heaters: Dynamics } \\
\hline $\begin{array}{l}\text { No dynamics } \\
\text { Detailed }\end{array}$ & $\begin{array}{l}x \\
0\end{array}$ & $\mathbf{x}$ & $\mathbf{x}$ & $\mathrm{x}$ & $\mathrm{x}$ & $x$ & $\begin{array}{l}\mathbf{x} \\
\mathbf{0}\end{array}$ & $\mathrm{x}$ \\
\hline \multicolumn{9}{|l|}{ Heater: Output } \\
\hline $\begin{array}{l}\text { To air node } \\
\text { To combined air and radiation node } \\
\text { Radiative/convective split fixed in code } \\
\text { Radiative/convective split user spec } \\
\text { Detailed }\end{array}$ & $\begin{array}{l}0 \\
0 \\
\end{array}$ & $\mathrm{x}$ & $\mathrm{x}$ & $\mathrm{x}$ & $\mathrm{x}$ & $\mathbf{x}$ & o & $\mathrm{x}$ \\
\hline \multicolumn{9}{|l|}{ Heater: Control temperature } \\
\hline $\begin{array}{l}\text { Air temperature node } \\
\text { Combined air and radiation node } \\
\text { Combined air and radiation fixed in code } \\
\text { Combined air and radiation user spec } \\
\text { User spec construction surface temp } \\
\text { User spec temp within construction } \\
\end{array}$ & $\begin{array}{l}0 \\
0 \\
0\end{array}$ & $x$ & $\mathrm{x}$ & $\mathbf{x}$ & $\mathrm{x}$ & $\mathrm{x}$ & $x$ & $\mathrm{x}$ \\
\hline \multicolumn{9}{|l|}{ Heater: Control laws } \\
\hline $\begin{array}{l}\text { Perfect control } \\
\text { On/Off thermostat } \\
\text { On/Off with deadband } \\
\text { On/Off with accelerator } \\
\text { Proportional control } \\
\text { Other }\end{array}$ & $\begin{array}{l}\mathrm{x} \\
\mathrm{o} \\
\mathrm{o} \\
\mathrm{o}\end{array}$ & $\begin{array}{c}0 \\
x \\
0 \\
x(n 2) \\
\end{array}$ & $\mathbf{x}$ & $\mathbf{x}$ & $\mathrm{x}$ & $x$ & $\mathrm{x}$ & $x$ \\
\hline $\begin{array}{l}\text { Cooling } \\
\text { Treated as heating } \\
\text { Other }\end{array}$ & $\mathrm{x}$ & $\mathrm{x}$ & $\mathbf{x}$ & $\mathrm{x}$ & $\mathrm{x}$ & $\mathrm{x}$ & $\mathbf{x}$ & $\mathrm{x}$ \\
\hline
\end{tabular}


Table 2-3. Pro Forma Summary of Participating Programs (Continued) Key: $\mathrm{x}=$ used in BESTEST; $\mathrm{o}=$ possible to use; $\mathrm{n \#}=$ note

\begin{tabular}{|c|c|c|c|c|c|c|c|c|}
\hline & ESP & BLAST & DOE2 & SERIRES & S3PAS & TRNSYS & TASE & DEROB \\
\hline \multicolumn{9}{|l|}{ Heat transfer within zones } \\
\hline $\begin{array}{l}\text { Rad and conv combined } \\
\text { Rad and conv separately }\end{array}$ & $\mathrm{x}$ & $\mathbf{x}$ & $\mathrm{x}$ & $\mathrm{x}$ & $\mathbf{x}$ & $\mathbf{x}$ & $x$ & $x$ \\
\hline \multicolumn{9}{|l|}{ Convective heat transfer within zones } \\
\hline $\begin{array}{l}\text { Coeff spec by user } \\
\text { Coeff calc as function of surf orient } \\
\text { Coeff calc as func of temp diff } \\
\text { Coeff calc as func of surf finish } \\
\text { Value at dT-3K vertical } \\
\text { smooth surface }\left(\mathrm{W} / \mathrm{m}^{20} \mathrm{C}\right)\end{array}$ & $\begin{array}{l}\mathbf{0} \\
\mathbf{x} \\
\mathrm{x}\end{array}$ & $\mathbf{x}$ & 3.06 & 3.16 & $\begin{array}{l}\mathbf{x} \\
\mathbf{0} \\
\mathbf{0}\end{array}$ & 3.16 & $\begin{array}{c}\mathrm{o} \\
\mathrm{x} \\
\mathrm{x} \\
2.50\end{array}$ & $\begin{array}{l}\mathbf{0} \\
\mathbf{x} \\
\mathbf{x}\end{array}$ \\
\hline \multicolumn{9}{|l|}{$\begin{array}{l}\text { Longwave radiative heat transfer within } \\
\text { zones }\end{array}$} \\
\hline $\begin{array}{l}\text { Constant linearized coeff } \\
\text { Lin coeff based on area or viewfact } \\
\text { Linearized coeff based on surf } \mathrm{cm} \\
\text { Nonlinear treatment }\end{array}$ & $\begin{array}{l}\mathrm{x} \\
\mathrm{x}\end{array}$ & $\begin{array}{l}\mathbf{x} \\
\mathbf{x}\end{array}$ & $\mathbf{x}$ & $\mathbf{x}$ & & $\mathbf{x}$ & $\mathbf{x}$ & $\begin{array}{l}\mathbf{x} \\
\mathrm{x}\end{array}$ \\
\hline $\begin{array}{l}\text { Coupled to mean radiation temp } \\
\text { Coupled to combined air and rad node } \\
\text { Detailed surface to surface } \\
\text { Other }\end{array}$ & & $x$ & & $\mathbf{x}$ & $\mathrm{x}$ & $\mathrm{x}(\mathrm{n} 3)$ & $\mathbf{x}$ & $\mathrm{x}$ \\
\hline \multicolumn{9}{|l|}{ Windows: Heat loss } \\
\hline $\begin{array}{l}\text { Max number of nodes per window } \\
\text { One node per pane } \\
\text { Dynamic treatment } \\
\text { User defined resistance } \\
\text { Compensation for frame }\end{array}$ & $\begin{array}{l}3.00 \\
\mathrm{x} \\
\mathrm{o}\end{array}$ & $\begin{array}{l}\mathrm{x} \\
\mathrm{o}\end{array}$ & $\mathrm{x}$ & $\mathrm{x}$ & $\mathrm{x}$ & 2.00 & $\begin{array}{l}1.00 \\
\mathrm{x}\end{array}$ & 2.00 \\
\hline
\end{tabular}


Table 2-3. Pro Forma Summary of Participating Programs (Continued) Key: $x=$ used in BESTEST; $0=$ possible to use; $n \#=$ note

\begin{tabular}{|c|c|c|c|c|c|c|c|c|}
\hline & ESP & BLAST & DOE2 & SERIRES & S3PAS & TRNSYS & TASE & DEROB \\
\hline \multicolumn{9}{|l|}{ Airgaps within windows } \\
\hline $\begin{array}{l}\text { User spec const res } \\
\text { Res calc as func of orient } \\
\text { Res calc as func of temp diff } \\
\text { Rad and con separately } \\
\text { Treated as zone } \\
\text { Other }\end{array}$ & $\mathrm{x}$ & n3 & nl & n3 & $\mathbf{x}$ & $\mathrm{x}$ & $\cdot$ & $\mathrm{x}$ \\
\hline \multicolumn{9}{|l|}{ Windows: Transmission of direct rad } \\
\hline $\begin{array}{l}\text { Fixed transmission used } \\
\text { Detailed calc as func of incident angle } \\
\text { Polynomial fit as func of incident angle }\end{array}$ & $\mathbf{x}$ & $\mathbf{x}$ & $\mathbf{x}$ & $\mathrm{x}$ & $\begin{array}{l}\mathbf{x} \\
\mathbf{x}\end{array}$ & $\stackrel{\cdot}{\mathbf{x}}$ & $\mathbf{x}$ & $\mathbf{x}$ \\
\hline \multicolumn{9}{|l|}{ Windows: Shading of direct radiation } \\
\hline $\begin{array}{l}\text { Calculated from raytracing } \\
\text { Geometric calculation of shades } \\
\text { User spec coefficient } \\
\text { Calculated from viewfactors }\end{array}$ & $\begin{array}{l}x \\
x\end{array}$ & $\mathbf{x}$ & $\mathbf{x}$ & $\mathbf{x}$ & $\mathbf{x}$ & $\mathbf{x}$ & $\mathrm{x}$ & $\mathbf{x}$ \\
\hline \multicolumn{9}{|l|}{ Windows: Transmission of diffuse rad } \\
\hline $\begin{array}{l}\text { Calculated from raytracing } \\
\text { Geometric calculation of shades } \\
\text { User spec coefficient } \\
\text { Calculated from viewfactors }\end{array}$ & $\begin{array}{l}x \\
x\end{array}$ & $\mathbf{x}$ & $\mathbf{x}$ & $\mathbf{x}$ & $\mathbf{x}$ & $\mathbf{x}$ & $\mathbf{x}$ & $\mathrm{x}$ \\
\hline \multicolumn{9}{|l|}{ Windows: Transmission of diffuse rad } \\
\hline $\begin{array}{l}\text { As direct from fixed incident angle }\left(^{\circ}\right) \\
\text { Mult of direct rad at normal inc }(\%) \\
\text { User-spec trans } \\
\text { Hemisph integral }\end{array}$ & 51.00 & $\mathbf{x}$ & $\mathbf{x}$ & 60.00 & $\mathbf{x}$ & 60.00 & $\mathrm{x}$ & 80.00 \\
\hline
\end{tabular}


Table 2-3. Pro Forma Summary of Participating Programs (Continued) Key: $\mathrm{x}=$ used in BESTEST; $0=$ possible to use; $\mathrm{n \#}=$ note

\begin{tabular}{|c|c|c|c|c|c|c|c|c|}
\hline & ESP & BLAST & DOE2 & SERIRES & S3PAS & TRNSYS & TASE & DEROB \\
\hline \multicolumn{9}{|l|}{ Windows: Shading of diffuse radiation } \\
\hline $\begin{array}{l}\text { Geometric calculation of shades } \\
\text { User spec coefficient } \\
\text { Calc from viewfactors to obstructions } \\
\text { No }\end{array}$ & o & $\mathbf{x}$ & $\begin{array}{l}\mathbf{0} \\
\mathrm{x}\end{array}$ & $\mathrm{x}$ & $\mathbf{x}$ & $\mathrm{x}$ & $x$ & $x$ \\
\hline \multicolumn{9}{|l|}{ Distribution of solar rad within zones } \\
\hline $\begin{array}{l}\text { Direct and diffuse rad treated separately } \\
\text { Direct and diffuse treated combined } \\
\text { Rad out through windows included }\end{array}$ & $\begin{array}{l}\mathbf{x} \\
\mathbf{x}\end{array}$ & $\begin{array}{l}\mathbf{x} \\
\mathbf{x}\end{array}$ & $\begin{array}{l}x \\
x \\
\end{array}$ & $\begin{array}{l}x \\
x \\
\end{array}$ & $\mathrm{x}$ & $\begin{array}{l}x \\
x \\
\end{array}$ & $\begin{array}{l}\mathbf{x} \\
\mathbf{x}\end{array}$ & $\mathbf{x}$ \\
\hline \multicolumn{9}{|l|}{ Direct rad } \\
\hline $\begin{array}{l}\text { Fixed within code } \\
\text { Const user spec distribution } \\
\text { Calc from area or view factors } \\
\text { Calc from raytracing } \\
\text { To floor } \\
\text { Other }\end{array}$ & $\mathbf{x}$ & $\begin{array}{c}\mathbf{x} \\
\mathrm{o}(\mathbf{n} 4)\end{array}$ & $\mathbf{x}$ & $\mathbf{x}$ & $\begin{array}{l}\mathbf{0} \\
\mathbf{o} \\
\mathbf{x} \\
.\end{array}$ & $\mathrm{x}$ & $\mathbf{n l}$ & $\mathrm{x}$ \\
\hline \multicolumn{9}{|l|}{ Diffuse rad } \\
\hline $\begin{array}{l}\text { Fixed within code } \\
\text { Const user spec distribution } \\
\text { Calc from area or view factors } \\
\text { To floor } \\
\text { Other }\end{array}$ & $\mathrm{x}(\mathrm{nl})$ & $\mathbf{x}$ & $\mathbf{x}$ & $\mathrm{x}$ & $\mathbf{x}$ & $\begin{array}{l}x \\
0\end{array}$ & $\begin{array}{c}\mathrm{nl} \\
\mathrm{x}\end{array}$ & $\mathbf{x}$ \\
\hline \multicolumn{9}{|l|}{$\begin{array}{l}\text { Heat transfer between external surfaces } \\
\text { and surrounding environment }\end{array}$} \\
\hline $\begin{array}{l}\text { Rad and con combined } \\
\text { Rad and con separately }\end{array}$ & $\mathrm{x}$ & $\begin{array}{l}\mathbf{0} \\
\mathrm{x}\end{array}$ & $\mathbf{x}$ & $\mathrm{x}$ & $\mathbf{x}$ & $\mathrm{x}$ & $x$ & $\begin{array}{l}\mathrm{x} \\
\mathrm{o}\end{array}$ \\
\hline
\end{tabular}


Table 2-3. Pro Forma Summary of Participating Programs (Continued) Key: $\mathrm{x}=$ used in BESTEST; $\mathrm{o}=$ possible to use; $\mathrm{n} \#=$ note

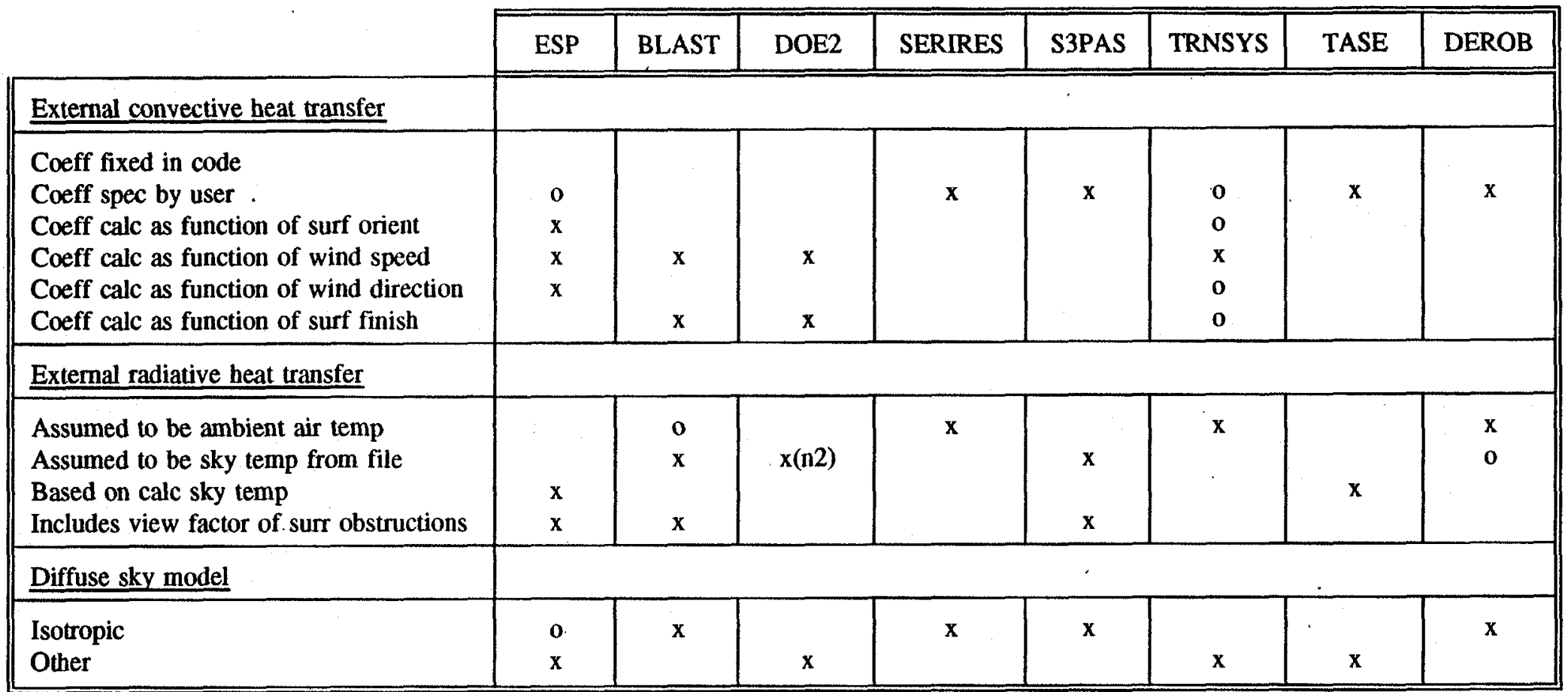

ESP

BLAST

DOE2

SERIRES

Note 1: Applied to every surface except window and outer wall.

Note 1: Treated as average over previous timestep where timestep is defined by interval in weather file.

Note 2: User specified.

Note 3: An air gap could have a dynamic material.

Note 4: All direct beam radiation initially hits the floor. Radiation not absorbed by the floor is added to diffuse radiation transmitted to the zone. Diffuse radiation is absorbed by all surfaces in proportion to their area absorption product.

Note 1: Window airgaps are not treated separately from the resistance of the entire window.

Note 2: Sky emissivity is determined from humidity data in the weather file.

Note 1: The original SERIRES is public domain. The PC version is commercially available from Ecotope, Seattle, WA.

Note 2: There are multiple timesteps for each hour. The minimum number of timesteps per hour is established from the input deck. For example, case 600 is run with a number of 15 steps per hour, while case 900 is run with a minimum of 14 timesteps per hour.

Note 3: Window airgaps are not treated separately from the resistance of the entire window. 
Table 2-3. Pro Forma Summary of Participating Programs (Concluded)

Key: $\mathrm{x}=$ used in BESTEST; $\mathrm{o}=$ possible to use; $\mathrm{n} \#=$ note

S3PAS

TRNSYS

TASE

Note 1: Eigen systems.

Note 2: Linear variation between two predictions.

Note 1: Transfer functions with use of Laplace and z-transform theory.

Note 2: Interpolation of solar radiation data using the ratio of extraterrestrial radiation every timestep to extraterrestrial radiation over period which corresponds to data.

Note 3: Longwave radiation is modeled by a network coupling all surfaces with resistances. Function of Boltzman constant, surface area and temperature.

Note 1: The diffuse and direct radiation hits the floor. The part that is not absorbed is distributed to all other surfaces, depending on area and absorption. 


\subsubsection{DOE-2.1D}

National Renewable Energy Laboratory (NREL)

United States

June 1993 


\subsubsection{1 introduction}

This report describes the modeling strategy used for the BESTEST simulations carried out at NREL with DOE2.1D. Modeling assumptions made in addition to the BESTEST specification, and modeling difficulties that occurred are noted. Input files and output in BESTEST spreadsheet format are on electronic files. The program version used is 2.1Di014 (DOE-2 Supplement 1989).

DOE2 uses an anisotropic sky model for diffuse radiation. This model gives greater incident solar gain on south-facing surfaces than does the isotropic model used in some other codes. For preconditioning, the program is run for three days on the first day's weather and schedules (DOE-2 Engineer's Manual 1981, p. III.5). Timesteps of one hour are used. Midnight to $1 \mathrm{a} . \mathrm{m}$. is defined as hour 1 in the DOE2 scheduling routines, and in the weather routines. All time is local time, with no daylight savings. The thermostat control temperature is the zone air temperature.

When DOE2 was first conceived-before the prevalence of relatively fast and inexpensive personal computers-reducing the computer time associated with detailed building energy simulations was a major issue. Thus, DOE2 contains a number of algorithms that reduce simulation time, but also cause results to deviate from those that would be obtained from modeling building physics more exactly. For example, rather than incorporating thermal mass directly into hourly heat balance calculations, DOE2 uses a "weighting factor method" (DOE-2 Reference Manual 1981; ASHRAE 1989, p. 28.21). In the weighting factor method, room weighting factors are developed from the material mass properties for the space; the weighting factors are than used to determine a time delay that is applied to what would otherwise be an instantaneous load that DOE2 calculates for the space. DOE2 custom weighting factors (as opposed to pre-calculated library weighting factors) were used, as this is the most detailed level of simulation.

Another computer time-saving feature is the use of "response factors" as part of the hourly heat balances to model heat flow through the building shell. Response factors incorporate material properties of the various elements of the building shell construction. These response factors are calculated during the compilation (Building Description Language Program) portion of the simulation. A series of response factors are obtained by sampling the response function to a triangular excitation at hourly time intervals (DOE-2 Engineer's Manual 1981). Response factors are also discussed in the 1977 American Society of Heating, Refrigerating, and Air-Conditioning Engineers (ASHRAE) Handbook of Fundamentals. The response factor approach as implemented in DOE2 has several limitations:

- Loads are calculated based on a fixed internal temperature that must be chosen by the user. Actual interior temperatures are then calculated in the systems portion of the program. Thus, component loads outputs are only meaningful if the room temperature is always constant at the user-defined design temperature. Also, in spaces that have free-floating temperatures or large deadband control strategies and that are also strongly solar driven, this had been shown to lead to large uncertainties in temperature and equipment energy predictions in previous versions of the program (Bloomfield 1989, p. 41). The DOE2 support office staff report that this has been corrected in the current version.

- A limited amount of thermal capacitance can be handled, restricting modeling of earth-sheltered buildings.

Some of the other time-saving algorithms used by DOE2 that are discussed topically below involve glazing radiative properties, shading exterior and interior surface infrared emissivity, and interior solar absorptivity. 


\subsubsection{Building Specification}

Case 990, ground coupling. Simulation inputs for case 990 are based on heat transfer path lengths through the ground to ambient air, as described in the 1989 ASHRAE Handbook of Fundamentals. The primary advantage of this method is that heat transfer from the upper portion of the underground walls can be modeled separately from the more deeply buried portions of the wall and floor slab.

In our initial run-where the upper portion of underground walls and neighboring soil was coupled with ambient air temperature-we obtained results quite different from our simulations with SERIRES/SUNCODE and BLAST using similar methods. When we coupled the same shell element to seasonal ground temperatures, we obtained results that were closer to the other programs; we used these results in the BESTOUT spreadsheet. Simulation of ground coupling is potentially an area for further study.

A small problem occurs because DOE2 crashes when a window is specified that fills an entire wall, such as BESTEST has specified in case 990 . To get around this problem, the south wall width was increased to $8.0001 \mathrm{~m}$.

Cases that could not be simulated. Cases 195 to 215 were not done because exterior infrared emissivity cannot be varied in DOE2, and interior infrared emissivity cannot be modeled with a simple wall construction in a single zone case. See Section 2.5.1.6.

Cases 270 to 320,440 , and 810 were not done because interior shortwave absorptance cannot be varied from 0.6 as assumed in DOE2, and cavity albedo cannot be altered with DOE2's solar fractions. See Section 2.5.1.6.

\subsubsection{Construction}

Exterior surface properties. For defining exterior film coefficients, the roof is assumed to have the same roughness as the brick or rough plaster. Based on surface roughness, windspeed, and sky emissivity determined from humidity data in the weather file, DOE2 automatically calculates the combined radiative and convective surface coefficient (DOE-2 Engineer's Manual 1981).

DOE2 does not allow variation of exterior surface emissivity. According to the documentation (DOE-2 Supplement 1989, p. 2.87), the exterior infrared loss calculation has been improved. However, the documentation appears to claim that a decrease in sky emissivity results in an increase in heat load; this seems counterintuitive and should be checked.

For windows GLASS-CONDUCTANCE-which includes the interior film coefficient but not the exterior film coefficient-was set at 3.5 per BESTEST. DOE's exterior film equation for windows as a function of windspeed (DOE-2 Supplement 1989, p. 2.79) gives the BESTEST value of $21.0 \mathrm{~W} /\left(\mathrm{m}^{2} \mathrm{~K}\right.$ ) for a windspeed of $4.02 \mathrm{~m} / \mathrm{s}$.

Glazing transmittance. DOE2 solar heat gain through windows is expressed by writing transmission and absorption coefficients as polynomials in the cosine of the solar incidence angle (DOE-2 Engineer's Manual 1981, p. III.71) avoiding exact hourly calculations. DOE2 provides polynomial coefficients for evaluating transmittance and absorptance for a number of predefined glass types. Table 2-4 shows the resulting angular variation of transmittance associated with DOE2's double pane glass type 1 versus the transmittances that result from glazing material properties specified by BESTEST. 
Table 2-4. Comparison of DOE2 Double Pane Glass Type 1 Transmissivities to BESTEST Specification Glazing Transmissivities

\begin{tabular}{|l|c|c|c|c|c|c|c|c|c|}
\hline $\begin{array}{l}\text { Incidence angle } \\
\text { (degrees) }\end{array}$ & 0 & 10 & 20 & 30 & 40 & 50 & 60 & 70 & 80 \\
\hline \hline $\begin{array}{l}\text { BESTEST trans- } \\
\text { mittances }\end{array}$ & 0.7475 & 0.7468 & 0.7447 & 0.7399 & 0.7298 & 0.7073 & 0.6523 & 0.5168 & 0.2630 \\
\hline $\begin{array}{l}\text { DOE2 trans- } \\
\text { mittances }\end{array}$ & 0.7506 & 0.7540 & 0.7624 & 0.7693 & 0.7641 & 0.7319 & 0.6540 & 0.5101 & 0.2812 \\
\hline$\%$ difference & 0.42 & 0.97 & 2.38 & 3.97 & 4.70 & 3.47 & 0.25 & -1.29 & 6.92 \\
\hline
\end{tabular}

High-conductance wall. When trying to model the opaque glass panes as given in the specification, DOE2 gives an error message requesting a U-value construction because the material is too thin or too light. Thus, a resistance corresponding to the BESTEST conductance of each glass pane was supplied.

Infiltration. In DOE2, infiltration air density automatically varies with atmospheric pressure from weather data and the calculated zone temperature. (DOE-2 Engineer's Manual 1981, p. III.90-91) Since the specified infiltration rate is independent of windspeed, INF-FLOW/AREA $=1.35$ was used to describe the infiltration rate.

\subsubsection{Shading}

For shading calculations, DOE2 divides walls into a specified number of segments-with a greater number of segments providing more exact results. These shading calculations are done only once per month to save computer time (DOE-2 Engineer's Manual 1981). The maximum allowable number of segments (40) was specified. DOE2 automatically calculates shading of diffuse radiation by obstructions (DOE-2 Supplement 1989 , p. 2.68). This may be why DOE2 shows more sensitivity to overhangs and fins in the annual and peak energy results, than the other programs.

In DOE2 there are two ways to describe shading. One method describes shading devices with respect to the building coordinates and the other method describes overhangs and fins with respect to specific windows. Providing the equivalent shading devices with the two different methods produced the same results for case 610 . The only problem with using overhangs instead of building shades is that DOE doesn't appear to verify the presence of overhangs in the loads verification output report.

\subsubsection{Building Operation}

Mechanical systems model. DOE2's SYSTEMS routine comes with a variety of mechanical system types for modeling various HVAC systems. For this work, we used SYSTEM-TYPE = SUM. The SUM system allows loads to be evaluated by simulating user-supplied thermostat schedules without simulating any other characteristics of mechanical equipment.

Thermostat control. DOE2 does not allow for a strict BANG-BANG type of thermostat control. DOE's on-off thermostat is "... simulated as a very narrow fixed throttling range around each set point." (DOE-2 Reference Manual 1981, p. IV.195). A throttling range of $0.1^{\circ} \mathrm{C}$ was specified; this is the minimum throttling range allowed: 
Design temperature sensitivity studies. When operating the buildings in setback mode (cases 640 and 940), the issue of appropriate design temperature for initial load calculation specified under SPACECONDITIONS was raised. Varying the design temperature from $23.5^{\circ} \mathrm{C}$ to $18.5^{\circ} \mathrm{C}$ was considered insignificant, as it produced only a $0.8 \%$ change in annual heating load. Changes in annual cooling and peak loads were about $0.2 \%$ or less.

In a free-floating sunspace with a $45^{\circ} \mathrm{C}$ temperature range, selecting the appropriate design temperature is more difficult. In previous work, we reported considerable sensitivity of outputs to the design temperature input (Judkoff 1988a), especially in sunspaces. We therefore did a sensitivity test of the design temperature for the sunspace zone in case 960 . The base case value of design temperature for this test was $23.5^{\circ} \mathrm{C}$, with parametric runs of $10^{\circ} \mathrm{C}$ and $40^{\circ} \mathrm{C}$. Table $2-5$ shows the results from the base case and the parametric cases.

Table 2-5: Design Temperature Parametric Results for Case 960

\begin{tabular}{|c||c|c|c|c||c|c|c||}
\hline \multicolumn{1}{|c|}{} & \multicolumn{4}{|c||}{ Back zone } & \multicolumn{3}{c|}{ Sunspace } \\
\cline { 2 - 8 } $\begin{array}{l}\text { Design } \\
\text { temperature } \\
\left({ }^{\circ} \mathbf{C}\right)\end{array}$ & $\begin{array}{c}\text { Q HEAT } \\
(\mathbf{M W H})\end{array}$ & $\begin{array}{c}\mathbf{Q} \text { COOL } \\
(\mathbf{M W H})\end{array}$ & $\begin{array}{c}\text { Peak } \\
\text { heating } \\
(\mathbf{k W})\end{array}$ & $\begin{array}{c}\text { Peak } \\
\text { cooling } \\
(\mathbf{k W})\end{array}$ & $\begin{array}{c}\text { Maximum } \\
\text { temperature } \\
\left({ }^{\circ} \mathbf{C}\right)\end{array}$ & $\begin{array}{c}\text { Minimum } \\
\text { temperature } \\
\left({ }^{\circ} \mathbf{C}\right)\end{array}$ & $\begin{array}{c}\text { Mean } \\
\text { tem- } \\
\text { perature } \\
\left({ }^{\circ} \mathbf{C}\right)\end{array}$ \\
\hline \hline 23.5 & 2.928 & 0.478 & 2.727 & 1.057 & 49.0 & 3.9 & 28.0 \\
\hline 40 & 2.800 & 0.471 & 2.694 & 1.085 & 49.8 & 4.8 & 28.8 \\
\hline 10 & 3.021 & 0.400 & 2.751 & 1.037 & 48.4 & 3.3 & 27.4 \\
\hline
\end{tabular}

The increase in design temperature from $23.5^{\circ} \mathrm{C}$ to $40^{\circ} \mathrm{C}$ results in a $10 \%$ increase in cooling load and a $4 \%$ reduction in heating.load; the peak hourly cooling demand increases by $3 \%$, while the peak hourly heating demand decreases by. $1 \%$. The decrease in design temperature from $23.5^{\circ} \mathrm{C}$ to $10^{\circ} \mathrm{C}$ results in a $7 \%$ decrease in cooling load and a $3 \%$ increase in heating load; the peak hourly cooling demand decreases by $2 \%$, while the peak hourly heating demand increases by $1 \%$. Maximum, minimum, and mean annual temperatures vary by $0.6^{\circ} \mathrm{C}$ to $0.9^{\circ} \mathrm{C}$. The space calculation temperature in this case is a sensitive input. The users' manuals do not adequately deal with this input in the context of passive solar building design. LBL has reported correcting this problem in DOE-2.1E (Winkelmann 1991) which is not yet available.

Ventilation control. The ventilation cases (650 and 950$)$ were more easily performed by modeling ventilation as scheduled infiltration. DOE2 automatically adjusts infiltration air density for atmospheric pressure from weather data and calculated zone temperature, so that the scheduled 13.14 air changes per hour $(\mathrm{ACH})$ for ventilation is added to the 0.5 constantly occurring $\mathrm{ACH}$.

\subsubsection{Internal Radiation Distribution}

DOE2 uses SOLAR-FRACTION to describe the fraction of solar radiation that is absorbed by each interior surface. Total solar fractions for a space which do not include solar lost back out the window(s) (see Cavity Albedo below), should be roughly 1, or DOE2 will adjust them to be 1 (DOE-2 Reference Manual 1981, p. III.103). For the south window cases, these fractions were calculated by assuming: 
- All incident solar radiation initially hits the floor.

- $60 \%$ of this radiation is absorbed by the floor.

- The remaining $40 \%$ is diffusely reflected such that it is distributed over the other surfaces in proportion to their areas.

- $60 \%$ of this remaining $40 \%$ is then absorbed by those surfaces.

- The remaining $16 \%$ of the original sunlight is then assumed to be absorbed by all the surfaces in proportion to their areas.

The resulting fractions for interior shortwave absorptance of 0.6 are shown in Table 2-6.

Table 2-6. DOE2 Solar Distribution Fractions Versus Window Orientation for Interior Shortwave Absorptance $=0.6$

\begin{tabular}{||l|c|c|c|}
\hline Surface & South window & East/West window & Case 960 \\
\hline \hline Floor & 0.648 & 0.648 & 0.6 \\
\hline Ceiling & 0.151 & 0.151 & 0.06 \\
\hline East wall & 0.051 & 0.032 & 0.02 \\
\hline West wall & 0.051 & 0.032 & 0.02 \\
\hline North wall & 0.068 & 0.068 & 0.2 \\
\hline South wall & 0.031 & 0.068 & 0.03 \\
\hline
\end{tabular}

For cases with windows oriented east and west, everything is assumed to be the same as for the southoriented cases, except that the fractions are adjusted in proportion to the change in the opaque areas of the east, west, and south walls that is caused by moving the windows. For case 960 , the solar fraction inputs are as recommended in Section 1.4.12; DOE2 automatically adjusts the fractions so that their sum is one.

\section{Cavity Albedo}

DOE2 accounts for cavity albedo by summing the amount of radiation reflected back out the window for each reflection. (DOE-2 Engineer's Manual 1981, pp. II.79-81) The amount of energy reflected back out the window on the first bounce is

$$
\text { (1- a) } \mathrm{n} \mathrm{T} \text {, }
$$

where:

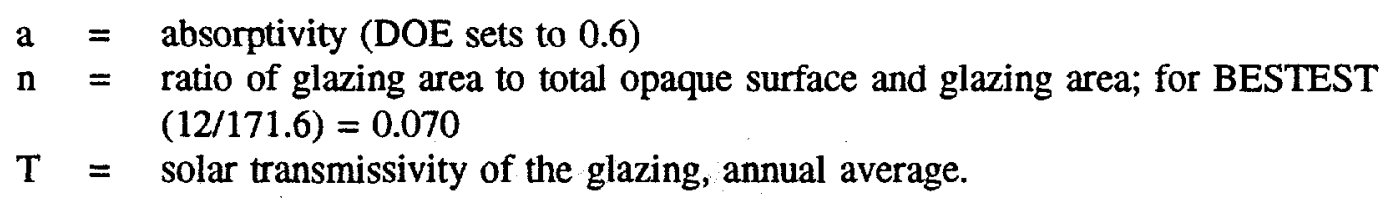


Applying an infinite series solution for geometric series based on the BESTEST geometry results in a 0.0303 fraction of initial transmitted solar radiation reflected back out the window when an average glazing transmissivity of 0.65 for $60^{\circ}$ average incidence is assumed.

The inside surface film coefficient is a user-defined constant, the radiative portion of which is determined internally via a one-time calculation (DOE-2 Engineer's Manual 1981, p 59).

\section{Modeling Difficulties}

DOE2.1D has the capacity to incorporate interior wall shortwave absorptance into heat transfer calculations (DOE-2 Supplement 1989 , p. 2.10 ). However, this feature only works for an interior wall which separates two zones (Winkelmann 1991). Some other simulation codes, such as BLAST and SERIRES/SUNCODE, allow the variation of the interior solar absorptance for the interior side of exterior walls in single zone models. Runs performed with those simulations show that varying interior shortwave absorptance has a large impact on the results for some of the BESTEST cases. Therefore, we recommend that DOE2 be changed to allow easier modification of interior shortwave absorptance.

DOE2 does not allow the variation of interior surface infrared wall emissivity for EXTERIOR-WALLs. However, an input for emissivity of interior walls and trombe walls is provided. Only one trombe wall can be input to each zone (DOE-2 Supplement 1989, pp. 2.60-2.61), so this option was not used.

\subsubsection{Output}

The output of SYSTEMS ZONE 31 was much different than expected for case 600; we expected an average zone temperature (DOE-2 Supplement 1989, p. A.18) and instead got $-17.8^{\circ} \mathrm{C}$ for the entire year.

The Systems program interprets metric input values as english units and converts them to metric even when INPUT-UNITS = METRIC. Therefore, INPUT-UNITS=ENGLISH is specified and english units are used for the Systems inputs. OUTPUT-UNITS=METRIC operates correctly.

\subsubsection{Use of BESTEST Diagnostics and Error Trapping}

The discussion in the DOE-2 Supplement (Version 2.1D) on infrared radiation seems counterintuitive and should be checked. Decreased sky emissivity (resulting from clouds) should result in decreased heat loads, not increased heat loads as the documentation claims. This was discovered in the process of thinking about why DOE2 gives generally higher annual heating loads in the 600 series cases than BLAST and SERIRES/SUNCODE.

A radiative heat transfer problem also appeared when comparing annual cooling loads for case 250 (see Section 2.4, Figure 2-11). In this case, cooling loads given by DOE2 (version 014) were much smaller than for the other codes. However, DOE2 still showed some sensitivity to solar absorptivity (compare case 250 , ext. abs. $=0.9$, and case 220, ext. abs. $=0.1$ for DOE2.1D014). The diagnostic logic for cases 250 and 220 indicated that the algorithm for exterior solar absorptivity should be checked. After communicating our results to LBL, they replied that DOE2's doors (which we used to describe high conductance wall sections for ease of input) did not absorb solar radiation. This bug has now been fixed in DOE2.1D version 017 (DOE2.1D017 in Section 2.4, Figure 2-11) and in DOE2.1E beta version (this was not a problem in DOE2.1C).

The annual heating loads for case 395 are $0.6 \mathrm{MWh}$ greater than the nearest program (about $14 \%$ higher than the average for all codes). Since case 395 is a very basic case with no windows or high conductance walls, a difference of this magnitude was somewhat unexpected. This difference is consistent throughout 
the 400 series cases and the high-mass case 800 with opaque windows. In general, DOE2's annual heating results for all cases either set or are near the high end of the range of results. It appears that the cause of this difference is not related to solar gains within the zone.

Additionally, the annual heating load sensitivity in the $800-430$ diagnostic is similar to that for other programs, so the higher annual heating loads previously noted for the 400 series cases are probably not related to a basic mass problem. Also note that $900-800$ annual heating sensitivity is $0.6 \mathrm{MWh}$ greater than the nearest program. This indicates offsetting differences in DOE2 because results from the more primitive case 800 (no interior solar gains) are different, while results from case 900 (with transmissive windows) are in better agreement with the other programs. Thus, DOE2 may have some difference in the way solar is incorporated into interior mass which offsets the difference noted in the opaque window and nonwindow cases. The 600-430 annual heating results are consistent with the $900-800$ results.

Due to the inability of DOE2 to run the primitive diagnostic series, we are not able to draw any more detailed conclusions concerning these differences with other program results.

\section{Correction of Problems}

A description of problems was sent to the simulation research group at LBL. LBL is implementing a number of improvements to DOE2.1D which will appear in the new version DOE2.1E. As noted above, some of these improvements have already been implemented in 2.1D. The improvements include

- Solar radiation-absorbing doors

- Replacing the Berdahl-Martin sky infrared calculation with the TARP Reference Manual (Walton 1983) correlation in DOE2.1D, and adding variable emissivity in DOE2.1E

- Correcting the operation of INPUT-UNITS = METRIC in systems

- Adding a new window library that allows more precise modeling of window properties.

\subsubsection{Recommendations}

- DOE2 should be modified to allow varying interior shortwave absorptance on the interior surface of exterior walls.

- Variable interior infrared emissivity should be made available. This effect will become more important as materials with spectrally selective properties become available.

- The documentation discussion on exterior infrared radiation (DOE-2 Supplement 1989, p. 2.87) seems counterintuitive and should be checked.

- DOE2 doesn't verify the presence of overhangs in the loads verification output report. We recommend that this be added.

- The response factor method as implemented in DOE2 limits the ability of the program to handle large amounts of mass. We would like to see greater mass handling ability for more realistic simulation of strongly earth-coupled buildings. 


\subsubsection{Pro Forma}

Program name (please include version number)

DOE2.1D V.014 and V.017

possible to use

used in BESTEST

Your name and organization

Joel Neymark, NREL

Program status

- Public domain

$\square$ Commercial

$\square \quad$ Other (please specify)

\section{Solution method}
$\square \quad$ Explicit finite difference
$\square \quad$ Implicit finite difference
- Weighting factors
- Response factor
$\square$ Other (please specify)

Timing convention for meteorological data: sampling interval

E Fixed within code (please specify interval) One hour

$\square \quad$ User-specified

Timing convention for meteorological data: period covered by first record

- Fixed within code (please specify period or time which meteorological record covers) 0:00-1:00

$\square \quad$ User-specified

\section{Meteorological data reconstruction scheme}

- Climate assumed stepwise constant over sampling interval

$\square \quad$ Linear interpolation used over climate sampling interval

$\square \quad$ Other (please specify)

\section{Output timing conventions}

$\square$ Produces spot predictions at the end of each timestep

- Produces spot output at end of each hour

$\square$ Produces average outputs for each hour (please specify period to which value relates) 
Treatment of zone air

- Single temperature (i.e., good mixing assumed)

$\square \quad$ Stratified model

$\square \quad$ Simplified distribution model

$\square \quad$ Full CFD model

$\square$ Other (please specify)

\section{Heaters (dynamics)}

- No dynamics assumed (output is instantaneous)

$\square$ Simple first order dynamics

$\square$ Detailed modeling of heat source dynamics

\section{Heaters (output characteristics)}

- Purely convective

$\square \quad$ Radiative/Convective split fixed within code

$\square$ Radiative/Convective split specified by user

$\square$ Detailed modeling of heat source output

\section{Control temperature}

\section{- Air temperature}

$\square$ Combination of air and radiant temperatures fixed within the code

$\square$ User-specified combination of air and radiant temperatures

$\square$ User-specified temperatures within construction

$\square \quad$ Other (please specify)

\section{Control laws}

$\square$ Perfect control

$\square \quad$ On/Off thermostatic control

$\square \quad$ On/Off thermostatic control with deadband

$\square$ On/Off thermostatic control with accelerator heater

- Proportional control

$\square \quad$ More comprehensive control laws (please specify)

\section{Heat transfer within zones}

- Radiation and convection combined

$\square \quad$ Radiation and convection treated separately

\section{Convective heat transfer within zones}

$\square$ Coefficients fixed within code

- Coefficients specified by user (Combined radiative and convective)

$\square$ Coefficients calculated by code as a function of surface orientation

$\square$ Coefficients calculated by code as a function of temperature difference

$\square$ Coefficients calculated by code as a function of surface finishes

$\square$ Other (please specify)

\section{Longwave radiative heat transfer within zones}

$\square$ Constant linearized coefficients

- Linearized coefficients based on viewfactors

$\square \quad$ Linearized coefficients based on surface emissivities

$\square$ Nonlinear treatment of radiation heat exchange

$\square \quad$ Other (please specify) 
Number of nodes placed within each layer of walls and slabs

Not applicable for this solution method

$\square \quad$ Fixed number of nodes per layer (please specify)

$\square$ User-specified number of nodes per layer

$\square \quad$ Other (please specify
Airgaps within walls and slabs
$\square \quad$ Resistance fixed within code
User-specified constant resistance
$\square$ Resistance calculated within code as a function of orientation
$\square \quad$ Radiation and convection treated separately across airgaps
$\square \quad$ Treated as additional zones
$\square \quad$ Other (please specify)

\section{Windows (heat loss)}

$\square \quad$ Fixed resistance used for window element

$\square$ Dynamic treatment of window heat loss using same scheme as for opaque elements

- Other (please specify) Fixed resistance, except exterior film coefficient varies with windspeed. Individual elements (panes, airgaps, etc.) are not disaggregated in DOE2.1D.

\section{Airgaps within windows}

$\square \quad$ Resistance fixed within code

- User-specified constant resistance

$\square$ Resistance calculated within code as a function of orientation

$\square \quad$ Radiation and convection treated separately across airgaps

$\square \quad$ Airgaps treated as additional zones

- Other (please specify) Window air gaps are not treated separately from the resistance of the entire window.

\section{Windows (transmission of direct shortwave radiation)}

$\square \quad$ Fixed transmission used

$\square \quad$ ASHRAE solar heat coefficients used

- Calculated by code as a function of incidence angle

$\square$ Calculated by code from user-specified function of incidence angle

$\square \quad$ Other (please specify)

Windows (transmission of diffuse radiation)

$\square \quad$ Diffuse radiation treated as direct from fixed altitude (please specify)

- Other (please specify) Constant based on a library of window types. The method used to determine those constants is not discussed in the DOE2 Engineer's Manual.

\section{Distribution of solar radiation within zones}

$\square \quad$ Fixed within the code

- Constant user-specified distribution

$\square \quad$ Calculated once by code and used throughout (please describe algorithm)

$\square$ Calculated as a function of solar position (please describe algorithm) 
Heat transfer between external surfaces and surrounding environment

$\square \quad$ Radiation and convection combined

- Radiation and convection treated separately

External convection

$\square$ Coefficients fixed within code

$\square$ User-specified constant coefficients

$\square$ Calculated within code as a function of orientation

- Calculated within code as a function of surface finish

- Calculated within code as a function of wind speed

$\square$ Calculated within code as a function of wind speed and direction

$\square \quad$ Other (please specify)

\section{External radiative heat transfer}

$\square \quad$ Assumed to be to ambient air temperature

- Assumed to be to sky temperature read from met file Sky emissivity is determined from humidity data in the weather file.

$\square$ Based on calculated sky temperature (please specify algorithm and requirements)

$\square$ Includes view factor of surrounding obstruction

\section{Diffuse sky model}

$\square \quad$ Isotropic

- Other (please specify model used) Anisotropic, see DOE2 Engineer's Manual, Section III.2.3 (pp. III.21-III.33). 
2.5.2 BLAST-3.0

National Renewable Energy Laboratory

United States

and

Politecnico di Torino

Italy

August 1993 


\subsubsection{Introduction}

General description. This report describes the modeling strategy used for the BESTEST simulations carried out at NREL with BLAST. Modeling assumptions that were made in addition to the BESTEST specification and modeling difficulties that occurred are noted. Input files and output in BESTEST spreadsheet format are on electronic files. The program version used is 3.0 Level 193 (BLAST Vol. 1 1991), which was released in late 1991 just after our initial work with BLAST was completed. A sensitivity test of this version versus the previous version (BLAST 1986) for case 600 showed identical annual and peak heating and cooling loads for the two versions.

BLAST uses an isotropic sky model for diffuse radiation (Walton 1983, p. 37). For preconditioning, temperature and flux histories are initialized by starting from a steady state and repeatedly calculating the building thermal performance for the first day of the simulation period until essentially equal results are achieved (Walton 1983, p. 26). Time steps of one hour are used. Midnight to 1 a.m. is defined as hour 1 in the BLAST scheduling routines, and in the weather routines. Temperatures are for the midpoint of the hour (Walton 1983, p. 16). BLAST automatically applies the U.S. daylight savings time clock adjustment to user-defined schedules (BLAST Support Office 1992). During the period that daylight savings time is in effect, ventilation and setback case schedules were set for one hour later than the designated time to compensate for BLAST's automatic schedule adjustment. The thermostat control temperature is a user-specified combination of the zone air and the mean radiant temperatures; a radiant fraction of zero was used for the control temperature.

Heat flow through massive elements is calculated on an hourly basis using conduction transfer functions (modified response factors that incorporate material properties of the various elements of the building shell construction) (Walton 1983, p. 26). Response factors are also discussed in the 1981 ASHRAE Handbook of Fundamentals, pp. 23.9-23.10, The main problem associated with conduction transfer functions as implemented in BLAST is that there is a limit to the amount of thermal capacitance that can be input, restricting modeling of earth-sheltered buildings. This is not an inherent limitation of response factors, but is caused by the truncation of terms for calculation speed. The film coefficients are calculated at each time step, with values being a function of surface orientation and temperatures, and other relevant factors. The interior surfaces were connected through the interior film coefficients to a central air node. A radiation heat flow path, parallel to the convection heat flow path, modeled surface radiation heat flow via a mean radiant temperature node (Bloomfield 1989, p. 38). Window optical properties are modeled by specifying their normal transmissivity, thickness, and index of refraction (BLAST 1986, p. 3-8). For conduction, BLAST will accept inputs for window pane density, specific heat, conductivity, and thickness, but if the material is too thin or too light BLAST will default to a steady state calculation (Walton 1983, pp. 26-27).

Heat balance solution methods and sensitivity tests. Initial contacts with the BLAST Support Office (BSO) indicated that the TARP manual properly documented the algorithms and commands in BLAST related to detailed modeling of exterior infrared radiation. Just prior to final publication, the BSO informed us that proper documentation for this effect should actually have been taken from Passive Solar Extension of BLAST Documentation (Walton 1981).

BLAST allows the user to select one of three levels of detail for heat networks. We used the most detailed method by specifying HEAT BALANCE $=2$. BLAST's heat balance methods as described in the TARP manual (Walton 1983) are as follows.

HEAT BALANCE $=0$ is the simplest solution method. In this case, the outside surface thermal network balances wall conduction, exterior surface coefficient, and solar gains. The exterior surface coefficient "... considers convective and thermal interchange between the surface and the environment in a single coefficient ..." (Walton 1983, pp. 68-69, 74, 79-80). The inside thermal network balances wall conduction, 
solar gains, interior radiation exchange, and interior convection; the interior convection coefficient is based on ASHRAE values for combined convection and radiation coefficients, with the radiation component subtracted out. The interior radiation exchange component is determined by using the balanced mean radiant temperature method.

HEAT BALANCE $=1$ is the same as HEAT BALANCE $=0$ except that detailed natural convection coefficients are based on natural convection theory, and are a function of the cube root of the temperature difference between the wall and the zone.

HEAT BALANCE $=2$ is the same as HEAT BALANCE $=1$ except that a more detailed outside surface coefficient is used that separately accounts for radiative exchange between the exterior surface and the sky, ground and ambient air, as well as convective interchange between the exterior surface and ambient air (Walton 1983, pp. 68-85; BLAST Support Office 1991).

Heat balance sensitivity tests were run for case 250 because radiant heat transfer effects are maximized by the high interior/exterior emissivity and exterior absorptance values, and the presence of the high conductance wall. The results are shown in Table 2-7. Note there is only a slight change in output when going from HEAT BALANCE $=1$ to HEAT BALANCE $=2$.

Table 2-7. BLAST "Heat Balance" Setting Sensitivity Using Case 250

\begin{tabular}{|l|c|c|c|c|}
\hline \multicolumn{1}{|c|}{$\begin{array}{c}\text { Heat balance } \\
\text { (HB) setting }\end{array}$} & $\begin{array}{c}\text { Annual heating } \\
(\mathbf{M W h})\end{array}$ & $\begin{array}{c}\text { Annual cooling } \\
(\mathbf{M W h})\end{array}$ & $\begin{array}{c}\text { Peak heating } \\
(\mathbf{k W})\end{array}$ & $\begin{array}{c}\text { Peak cooling } \\
(\mathbf{k W})\end{array}$ \\
\hline $\mathrm{HB}=0$ & 5.809 & 2.569 & 3.312 & 3.177 \\
\hline $\mathrm{HB}=1$ & 5.738 & 2.544 & 3.279 & 3.025 \\
\hline $\mathrm{HB}=2$ & 5.739 & 2.545 & 3.279 & 3.037 \\
\hline $\begin{array}{l}\text { HB }=2, \\
\text { OUTSIDE CONVECTION }=2\end{array}$ & 5.933 & 3.786 & 3.314 & 3.023 \\
\hline $\begin{array}{l}\text { HB }=2, \\
\text { INSIDE CONVECTION }=2\end{array}$ & 5.415 & 3.477 & 3.284 & 2.950 \\
\hline
\end{tabular}

The document Passive Solar Extension of BLAST Documentation (Walton 1981) and communications with BSO (Chorpening 1995) indicate the following: The command OUTSIDE CONVECTION $=2$ activates a more detailed algorithm for the convective and radiative portion of the exterior surface coefficient. The command INSIDE CONVECTION $=2$ activates a more detailed algorithm for the interior surface coefficient. Sensitivity to this variation of these algorithms is also shown above in Table 2-7.

\subsubsection{Building Specification}

Case 990, ground coupling. Simulation inputs for case 990 are based on heat transfer path lengths through the ground to ambient air as described in the 1989 ASHRAE Handbook of Fundamentals (pp. 25.5-25.6). The primary advantage of this method is that heat transfer from the upper portion of the 
underground walls can be modeled separately from the more deeply buried portions of the wall and floor slab.

BLAST's use of conduction transfer functions limits the thickness of soil next to the below-grade walls and floor that can be coupled directly to air such that only the upper $0.91 \mathrm{~m}$ of the below-grade wall could be modeled as desired; the exterior surface of this portion of the wall is specified with no solar gains. The remaining lower $0.44 \mathrm{~m}$ of below-grade wall and the floor were coupled to seasonally averaged ground temperatures using as much soil thickness as BLAST would allow for the thermal resistance corresponding to the heat transfer path length from ASHRAE (BLAST Vol. 2, pp. 858-859). In addition, seasonal ground temperatures were adjusted to account for heat from the building flowing into the ground and causing the ground temperature to increase to the average between the seasonal ground temperature and the building heating set point by September of the simulation year (BLAST Vol. 2, 1991, pp. 1335, 1338). Simulation of ground coupling is potentially an area for further study.

Window dimensions. A small problem occurs because BLAST does not allow a window to fill an entire wall, as BESTEST has specified for case 990 . To get around this problem, window dimensions were decreased to $7.9999 \mathrm{~m} \times 1.3499 \mathrm{~m}$.

\subsubsection{Construction}

Glazing transmittance. BLAST solar heat gain through windows is expressed by writing transmission and absorption coefficients as polynomials in the cosine of the solar incidence angle. The coefficients are computed from user inputs of normal incidence transmittance, index of refraction, and thickness. For greater accuracy, separate polynomials are developed for cosine (incidence angle) $>0.5$ and cosine (incidence angle) $<0.5$ (Walton 1983, pp. 29-33). Table 2-8 shows the resulting angular variation of BLAST's transmittances (based on BESTEST specified index of refraction, thickness and normal transmittance) versus the tabulated values in BESTEST.

Table 2-8. Comparison of BLAST-Calculated Transmissivities to BESTEST Specification Glazing Transmissivitios

\begin{tabular}{|l|l|l|l|l|l|l|l|l|}
\hline Cosine (Incidence angle) & 1.000 & 0.875 & 0.750 & 0.625 & 0.500 & 0.375 & 0.250 & 0.125 \\
\hline Incidence angle & 0.0 & 29.0 & 41.4 & 51.3 & 60.0 & 68.0 & 75.5 & 82.8 \\
\hline BESTEST transmittances & 0.7475 & 0.7406 & 0.7277 & 0.7026 & 0.6523 & 0.5538 & 0.3884 & 0.1819 \\
\hline BLAST transmittances & 0.7469 & 0.7399 & 0.7264 & 0.7002 & 0.6477 & 0.5458 & 0.3741 & 0.1571 \\
\hline \% difference & -0.07 & -0.09 & -0.18 & -0.34 & -0.71 & -1.44 & -3.68 & -13.6 \\
\hline
\end{tabular}

Interior combined radiative and convective surface coefficients. BLAST automatically adjusts inside film resistances hourly; no user input is required (BLAST 1986, p. 3-7). This calculation is independent of inside surface roughness (Walton 1983, pp. 79,80).

High conductance wall. For simulating wall conduction, BLAST will accept inputs for window pane density, specific heat, conductivity, and thickness. However, if the material is too thin or too light, BLAST will default to a steady state calculation (Walton 1983, pp. 26-27).

Infiltration. Since the specified infiltration rate is independent of climate (windspeed, temperature, etc.), the infiltration command uses WITH COEFFICIENTS $(1,0,0,0)$. BLAST varies the air density hourly, 
as a function of barometric pressure and outside dry bulb temperature from weather data (BLAST Support Office 1992).

Common wall (case 960). To properly model an interior wall between two zones in BLAST, the real dimensions of the wall must be input to each of the zones as an internal partition (BLAST Support Office 1992).

\subsubsection{Shading}

BLAST allows for overhangs and wings affixed directly to windows, or detached shading structures described relative to the building coordinates to simulate overhangs and fins. Overhangs and wings are used because they are easier to describe.

\subsubsection{Building Operation}

Thermostat control. In BLAST, the user defines the fraction of mean radiant temperature used to control the thermostat; the default value of zero was used. BLAST accepts a throttling range of zero for strict on/off control.

Ventilation control. The ventilation cases were modeled using BLAST's ventilation command, rather than modifying the existing infiltration command. BLAST varies the air density hourly, as a function of barometric pressure and outside dry bulb temperature from weather data.

Ventilation sensitivity studies. A sensitivity test was run to compare the annual cooling load for modeling the specified ventilation rate as infiltration (adding it to the base infiltration rate for the specified times) versus running it as ventilation. A negligible $0.1 \%$ difference in annual cooling loads resulted. Possibly the results are not exactly the same because of a small ramp that BLAST creates at the ventilation control temperature for stability of heat balance iterations (Walton 1983, p. 86).

\subsubsection{Internal Radiation Distribution}

BLAST allows three levels of detail for internal solar radiation distribution. The most detailed level calculates the amount of beam radiation falling on each surface in the zone by projecting the sun's rays through the windows. (BLAST 1986, p. 4-4). Beam radiation not directly absorbed by any surface, incoming diffuse radiation, and shortwave radiation from lights are combined and distributed over the surfaces of the zone according to an absorptance-weighted area ratio. Interior-reflected radiation on the window that is neither reflected nor absorbed by the window is transmitted back outside, and lost (Walton 1983, p. 59).

BLAST also accounts for interior infrared radiation exchange by using the balanced mean radiant temperature method (Walton 1983, p. 69). The sensitivity of BLAST to varying interior emissivity is comparable to that for other codes, as shown in the graphed output for diagnostic cases 210 and 220 .

\subsubsection{Output}

In the recent Level 190 release, BLAST's reporting capabilities have been greatly improved. Hourly zone loads and temperatures are now easy to extract. However, the hourly incident solar radiation and window transmitted radiation outputs required for BESTEST are not currently available as formatted output from BLAST. 


\subsubsection{Use of BESTEST Diagnostics and Error Trapping}

As noted in Figure 2-12 (Section 2.4), Cases 215 and 220 were used to show that there is no sensitivity to varying exterior emissivity in BLAST. Doug Hittle, a BLAST expert at Colorado State University, confirmed these results with an independent followup test (Hittle 1993).

A description of problems was sent to the Blast Support Office group at the University of Illinois. Just prior to publication, the BSO notified us of two commands that did activate sensitivity to this effect. We confirmed this by re-executing cases 215 and 220 (see Figure 2-12).

\subsubsection{Recommendations}

- The conduction transfer function method as implemented in BLAST limits the ability of the program to handle large amounts of mass. We would like to see greater mass handling ability for more realistic simulation of ground coupling.

- Documentation of the commands for activation of detailed interior and exterior surface models should be provided in the basic set of user's manuals.

- The report writer should be improved to include hourly outputs for incident solar gains on surfaces and solar energy transmission through windows.

- An engineer's manual is needed for BLAST. Use of the TARP manual for this function is not completely accurate. 


\subsubsection{Pro-Forma}

Program name (please include version number)

BLAST 3.0, Level 193

$\triangle$ possible to use

used in BESTEST

Your name and organization

Vittorio Bocchio-Politecnico di Torino, Joel Neymark-NREL

\section{Program status}

- Public domain

$\square$ Commercial

- Other (please specify) Costs cover documentation production and technical support from BSO. BSO is a nonprofit operation.

\section{Solution method}

$\square$ Explicit finite difference

$\square$ Implicit finite difference

$\square$ Weighting factors

Response factor

Other (please specify)

Timing convention for meteorological data: sampling interval

- Fixed within code (please specify interval)

$\square$ User-specified

Timing convention for meteorological data: period covered by first record

- Fixed within code (please specify period or time which meteorological record covers)

$\square$ User-specified

\section{Meteorological data reconstruction scheme}

a Climate assumed stepwise constant over sampling interval

$\square$ Linear interpolation used over climate sampling interval

Other (please specify)

\section{Output timing conventions}

$\square$ Produces spot predictions at the end of each timestep

$\square$ Produces spot output at end of each hour

Produces average outputs for each hour (please specify period to which value relates) Per BSO (7/12/93), the hour interval corresponding to the timestep period of the weather data. 


\section{Treatment of zone air}

- Single temperature (i.e., good mixing assumed)

Stratified model

Simplified distribution model

Full CFD model

Other (please specify)

\section{Heaters (dynamics)}

- No dynamics assumed (output is instantaneous)

Simple first order dynamics

$\square$ Detailed modeling of heat source dynamics

\section{Heaters (output characteristics)}

- Purely convective

Radiative/Convective split fixed within code

- Radiative/Convective split specified by user

Detailed modeling of heat source output

\section{Control temperature}

$\square$ Air temperature

Combination of air and radiant temperatures fixed within the code

User-specified combination of air and radiant temperatures

$\square$ User-specified temperatures within construction

$\square$ Other (please specify)

\section{Control laws}

\section{Perfect control}

On/Off thermostatic control

On/Off thermostatic control with deadband

$\square$ On/Off thermostatic control with accelerator heater

$\Delta$ Proportional control

- More comprehensive control laws (please specify) User specified

\section{Heat transfer within zones}

Radiation and convection combined

Radiation and convection treated separately

\section{Convective heat transfer within zones}

$\square$ Coefficients fixed within code

Coefficients specified by user

$\boldsymbol{\otimes}$ Coefficients calculated by code as a function of surface orientation

- Coefficients calculated by code as a function of temperature difference

$\square$ Coefficients calculated by code as a function of surface finishes

$\square$ Other (please specify) 
Longwave radiative heat transfer within zones

$\square$ Constant linearized coefficients

$\square$ Linearized coefficients based on viewfactors

$\square$ Linearized coefficients based on surface emissivities

Non-linear treatment of radiation heat exchange

- Other (please specify) See Note 1

Number of nodes placed within each layer of walls and slabs

Not applicable for this solution method

$\square$ Fixed number of nodes per layer (please specify)

User-specified number of nodes per layer

Other (please specify

\section{Airgaps within walls and slabs}

$\square$ Resistance fixed within code

U User-specified constant resistance

$\square$ Resistance calculated within code as a function of orientation

$\square$ Radiation and convection treated separately across airgaps

$\square$ Treated as additional zones

$\square$ Other (please specify)

Windows (heat loss)

Fixed resistance used for window element

Dynamic treatment of window heat loss using same scheme as for opaque elements

Other (please specify)

\section{Airgaps within windows}

$\square$ Resistance fixed within code

- User-specified constant resistance

Resistance calculated within code as a function of orientation

Radiation and convection treated separately across airgaps

Airgaps treated as additional zones

\ Other (please specify) An air gap could have a dynamic material.

Windows (transmission of direct shortwave radiation)

$\square$ Fixed transmission used

ASHRAE solar heat coefficients used

- Calculated by code as a function of incidence angle

$\square$ Calculated by code from user-specified function of incidence angle

Other (please specify)

Windows (transmission of diffuse radiation)

Diffuse radiation treated as direct from fixed altitude (please specify)

Other (please specify) See Note 2 


\section{Distribution of solar radiation within zones}

$\square$ Fixed within the code

$\square$ Constant user-specified distribution

Calculated once by code and used throughout (please describe algorithm) See Note 3

- Calculated as a function of solar position (please describe algorithm) See Note 4

\section{Heat transfer between external surfaces and surrounding environment}

Radiation and convection combined

- Radiation and convection treated separately

\section{External convection}

$\square$ Coefficients fixed within code

$\square$ User-specified constant coefficients

- Calculated within code as a function of orientation - natural convection component

- Calculated within code as a function of surface finish

$\square$ Calculated within code as a function of wind speed

Calculated within code as a function of wind speed and direction

$\square$ Other (please specify)

\section{External radiative heat transfer}

Assumed to be to ambient air temperature

- Assumed to be to sky temperature read from met file

$\square$ Based on calculated sky temperature (please specify algorithm and requirements)

Includes view factor of surrounding obstruction

\section{Diffuse sky model}

$\square$ Isotropic

Other (please specify model used)

\section{Note 1:}

Each surface in a zone is assumed to exchange heat radiatively with a fictitious surface which is an areaemissivity-temperature average of the other surfaces. The law is:

$$
\mathrm{q}_{\mathrm{rad}}=4 \sigma \varepsilon\left(\frac{\mathrm{T}_{\mathrm{mrad}}+\mathrm{T}_{\text {surf }, \mathrm{i}}}{2}\right)^{3}\left(\mathrm{~T}_{\mathrm{mrad}}-\mathrm{T}_{\text {surf }, \mathrm{i}}\right)
$$

\section{Note 2:}

Diffuse radiation is handled separately from direct. It's not assumed to be directed from a fixed angle. Properties are derived from integration over all possible wave lengths and directions.

\section{Note 3:}

All radiation initially hits the floor. Radiation not absorbed by the floor is added to diffuse radiation transmitted to the zone. Diffuse radiation is absorbed by all surfaces in proportion to their areaabsorptance products. 
Note 4:

Beam radiation is projected onto the appropriate interior surfaces. Radiation not absorbed by those surfaces is added to transmitted diffuse radiation and absorbed by all surfaces in proportion to their areaabsorptance products. 


\subsubsection{SERIRES/SUNCODE}

(U.S. Version)

National Renewable Energy Laboratory

United States

June 1993 


\subsubsection{Introduction}

This report describes the modeling strategy used for the BESTEST simulations carried out at the National Renewable Energy Laboratory (NREL) with SUNCODE/SERIRES. Modeling assumptions that were made in addition to the BESTEST specification and the modeling difficulties that occurred are noted. Input files and output in BESTEST spreadsheet format are on electronic files.

SUNCODE-PC is supported by Ecotope, Inc. (Seattle, WA), and is the microcomputer version of SERIRES. The specification for SERIRES was devised by the Solar Energy Research Institute (now called NREL), and the coding was produced by Kennedy, Palmiter, and Wheeling. The program version used is SUNCODE-PC 5.7 (Kennedy et al. 1992) which was released in early 1992, and includes an update to a shading algorithm that was required to fix a program bug detected by this study.

SUNCODE/SERIRES uses an isotropic sky model for diffuse radiation (Kennedy et al. 1992, p. 6-5). For preconditioning, SUNCODE runs the first day of weather data for 10 days or until thermal variables converge, whichever comes first (Kennedy 1992). Timesteps of one hour are used for input and output. Heat balance calculations are performed for timesteps within the hour (Kennedy et al. 1992, p. 6-2). The number of timesteps per hour is automatically calculated by SUNCODE based on the input, but can be overridden by the user; we used the default number of timesteps in this study. Output temperatures are the average for the hour. SUNCODE/SERIRES does not automatically adjust for daylight savings time.

Heat flow through massive elements is calculated hourly using nodal thermal networks (Kennedy et al. 1992, p. 1-1). With this method, one dimensional thermal diffusion through large amounts of thermal mass can be modeled.

The major analytical simplification in SUNCODE is the use of a zero thermal capacitance zonetemperature node with no direct radiation heat transfer between walls of a zone. The thermostat control temperature is the zone air node temperature evaluated with no heating or cooling equipment operating. The central zone air temperature is derived from an energy balance of internal gains, window conduction, infiltration, interior wall film conduction, etc. The interior wall heat transfer to this central zone node is described by a constant combined convective/radiative heat transfer coefficient (Kennedy et al. 1992, pp. 6-1, 6-16, 6-21 to 6-27). Because the zone air has no thermal capacitance, and because there is no direct radiant interchange between walls, the zone thermostat is effectively a combined radiant and air temperature sensor. Since BESTEST requires the thermostat to sense only air temperature, the interior film coefficient was modified, as noted in Section 2.5.3.3.

Exterior combined radiative and convective film coefficients are user input constants (independent of climate conditions). SUNCODE/SERIRES does not explicitly model either interior or exterior infrared emissivities. Glazing optical properties are modeled by specifying the number of glazing layers, layer thickness, index of refraction, extinction coefficient, and shading coefficient. (Kennedy et al. 1992, p. 2-13)

\subsubsection{Building specification}

Case 990, ground coupling. Simulation inputs for case 990 are based on heat transfer path lengths through the ground to the ambient air, as described in ASHRAE 1989. The primary advantage of this method is that heat transfer from the upper portion of the underground walls can be modeled separately from the more deeply buried portions of the wall and floor slab. 
The thermal network algorithm of SUNCODE/SERIRES allows the detailed modeling of massive buildingshell layers. Increments of heat transfer path lengths are modeled as increments of soil thickness adjacent to basement walls and floors. The documentation (Kennedy et al. 1992, p. 2-10) suggests a denser thermal network node spacing for massive construction elements near the zone interior surface.' For this reason, the soil elements attached to the walls and floor were divided into layers so that a larger density of nodes occurs near concrete wall and floor elements. Also, solar incidence on the exterior surface of the soil elements is neglected (set to zero) for this case.

A version of SUNCODE called GROUNDCODE is available which allows the same year of weather data to be rerun for several years. This allows the evaluation of the effect on building loads of charging the ground with heat from the building. For the first year of analysis, GROUNDCODE output matches SUNCODE output. Monthly summed heating and cooling loads for the first and second years of analysis with GROUNDCODE are shown in Figure 2-14. This output indicates that the ground near the building will reach equilibrium within 3 months after the building has begun to operate. Another researcher, who has modeled ground coupling with GROUNDCODE using a two-dimensional array of interconnected nodes and a deep ground temperature equal to the average air temperature (Kennedy 1991), notes that 18 months after building start up is a more reasonable time for ground equilibrium temperature to occur. Simulation of ground coupling is an area for further study.

Cases that could not be simulated. Cases 200 to 215 were not done because interior and exterior infrared emissivity cannot be explicitly varied in SUNCODE/SERIRES. The effect of varying emissivity could be accounted for by varying the interior and/or exterior film coefficients, but this was not done because the data generated by this work is meant as a reference for other codes.

\subsubsection{Construction}

High-mass materials. For massive constructions SUNCODE/SERIRES recommends including a thermal network node for every 4 in. of mass (Kennedy et al. 1992, p. 2-10). Most materials were modeled with one node; the multinode shell elements are tabulated in Table 2-9.

Glazing transmittance. Glazing optical properties are modeled by specifying the number of glazing layers, layer thickness, index of refraction, extinction coefficient, and shading coefficient. SUNCODE uses the same algorithm as BESTEST to evaluate glazing transmissivity as a function of solar incidence angle. This algorithm is based on the Fresnel Equations, Snell's Law, and Bouger's Law (Duffie and Beckman 1974, p. 108-113). Window conduction is modeled using steady-state conductance between the inside air temperature and the outside air temperature; it includes interior and exterior film coefficients (Kennedy et al. 1992, p. 2-13).

Interior combined radiative and convective surface coefficients. BESTEST calls for thermostat control to be based on pure air temperature (no radiative transfer to the thermostat). In previous work, it has been shown that the best way to model air thermostat control in SERIRES/SUNCODE is to suppress the radiant portion of the interior combined surface coefficient (Judkoff 1988b). The reason for this is that the zone air temperature node (which is also used for thermostat control) has no thermal capacitance, and there is no direct radiant interchange between walls. Additionally, the central zone air node is connected to the interior wall temperatures via a convective/radiative interior film coefficient. Thus, when the normal ASHRAE combined film coefficients are used, the control temperature in SERIRES is more like a radiant temperature. This would be analogous to painting the thermostat black instead of silver. Actually, real thermostats respond to both the radiant and convective environment. 


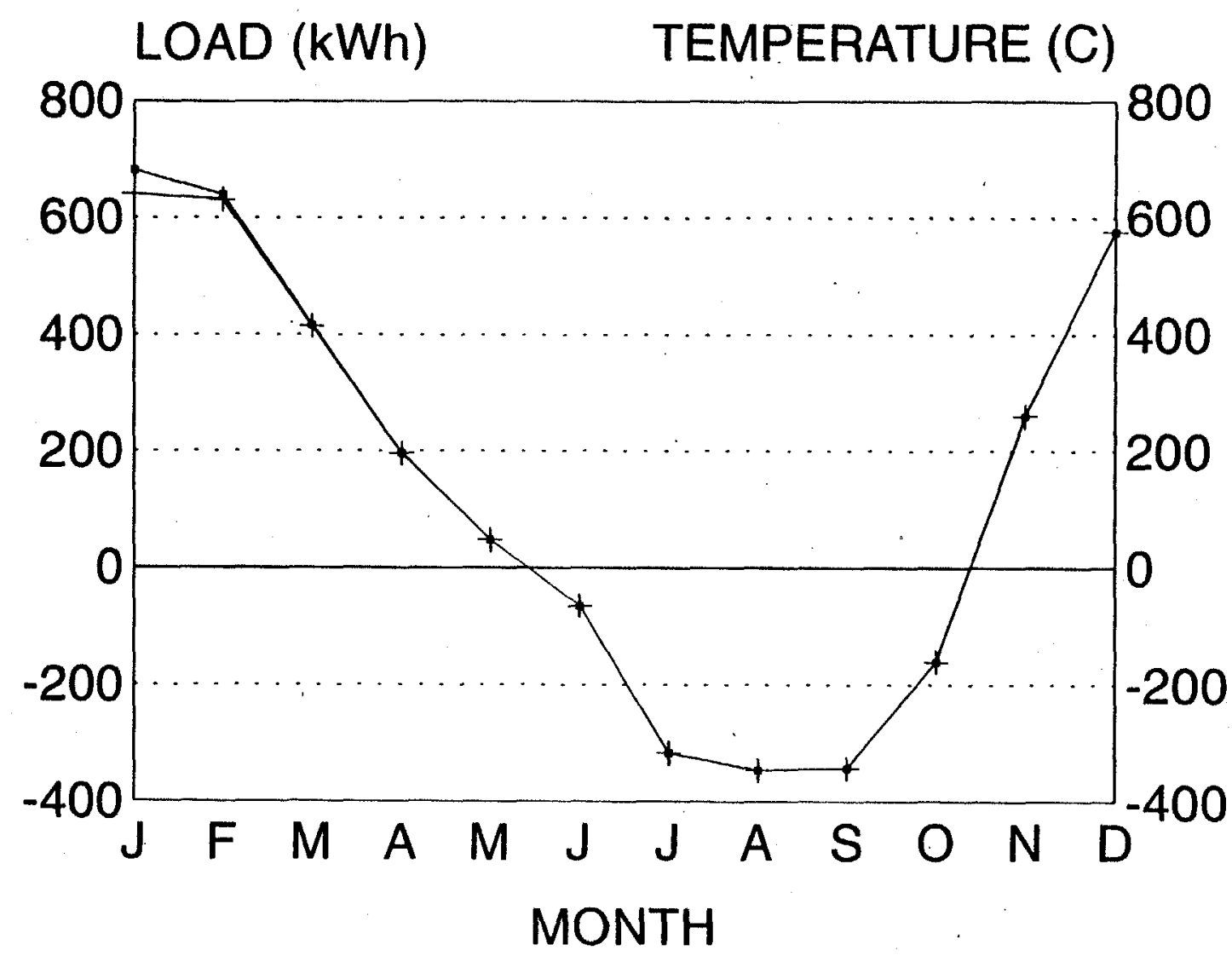

\section{- 1ST YEAR + 2ND YEAR}

C:IHG3IRONIGC990.CH3 MAR 18, 1993 
Table 2-9. Number of Nodes for High-Mass Shell Elements

\begin{tabular}{|l|c|c|}
\hline Material section & $\begin{array}{c}\text { Thickness } \\
(\mathbf{m})\end{array}$ & $\begin{array}{c}\text { Number of } \\
\text { nodes }\end{array}$ \\
\hline \hline Concrete block & 0.1 & 3 \\
\hline Concrete slab & 0.1 & 3 \\
\hline Concrete block, (case 960) & 0.2 & 5 \\
\hline Soil from interior/exterior surface & 6.65 & 20 \\
\hline Soil near interior/exterior surface & 0.207 & 6 \\
\hline Soil away from interior/exterior surface & 0.278 & 3 \\
\hline Soil away from interior/exterior surface & 0.213 & 1 \\
\hline Soil away from interior/exterior surface & 0.712 & 2 \\
\hline Soil away from interior/exterior surface & 1.03 & 3 \\
\hline
\end{tabular}

In comparison, the thermostat control temperature for BLAST and DOE2 is modeled more like an air temperature where both BLAST and DOE2 calculate the interior surface radiation hourly, based on their. specific algorithms: This implies that the standard combined coefficient when used in SERIRES, couples the building mass to the thermostat control node more closely than when used in DOE2 or BLAST (Judkoff et al. 1988b). In most instances, these somewhat subtle distinctions have very little effect on thermal performance predictions. However, under certain conditions, such as the "setup" hour after night thermostat setback, the effect can be significant. In this case, peak loads will be higher during the setup hour in SERIRES, because the heating system must work harder to bring the control temperature up to the new thermostat setting (since the interior walls must be warmed as well as the zone air). Reducing the interior film coefficient decreases the coupling between the walls and the zone temperature, and reduces the amount of wall heating that is required in order to maintain the thermostat setting.

Therefore, to compensate for the radiative thermostat in SERIRES, we reduced the combined radiative/convective interior film coefficient from $8.29 \mathrm{~W} / \mathrm{m}^{2} \mathrm{~K}$ to a convection-only film coefficient of $3.16 \mathrm{~W} / \mathrm{m}^{2} \mathrm{~K}$. We then slightly increased the conductivity of the wall and roof insulation materials, and increased the resistance of the floor insulation materials so that the building air-to-air heat transmission coefficient remained equivalent to that specified by BESTEST (See Tables 2-10 and 2-11). This was done exactly according to a method developed in previous work (Judkoff et al. 1988b).

Table 2-10. Building-Shell Insulation Conductivities Used with SUNCODE

\begin{tabular}{|l|c|c||}
\hline Shell element & $\begin{array}{c}\text { BESTEST conductivity } \\
\text { (W/mK) }\end{array}$ & $\begin{array}{c}\text { SUNCODE/SERIRES } \\
\text { conductivity } \\
\text { (W/mK) }\end{array}$ \\
\hline \hline Low-mass wall insulation & 0.040 & 0.0453 \\
\hline Low/High-mass roof insulation & 0.040 & 0.0430 \\
\hline High-mass wall insulation & 0.040 & 0.0458 \\
\hline Common wall (case 960) & 0.510 & 1.0187 \\
\hline
\end{tabular}


Table 2-11: Building-Shell Insulation R-Values Used with SUNCODE

\begin{tabular}{|l|c|c|}
\hline Shell element & $\begin{array}{c}\text { BESTEST R-value } \\
\left(\mathbf{m}^{\mathbf{2}} \mathbf{K} / \mathbf{W}\right)\end{array}$ & $\begin{array}{c}\text { SUNCODE/SERIRES } \\
\mathbf{R} \text {-value }\left(\mathbf{m}^{\mathbf{2}} \mathbf{K} / \mathbf{W}\right)\end{array}$ \\
\hline \hline Low-mass floor insulation & 25.075 & 24.879 \\
\hline High-mass floor insulation & 25.175 & 24.979 \\
\hline
\end{tabular}

Since the sunspace of case 960 has no thermostat, no interior film coefficient adjustment is necessary for any of the surfaces in that zone. Therefore, for case 960, BESTEST-specified conductivities and resistances were applied to all the sunspace building shell materials except the common wall. For the common wall, the conductivity of the concrete block was changed as noted in Table 2-10 to compensate for the reduced interior film conductance on the conditioned-zone side of the common wall. Interior film coefficients for all surfaces in the conditioned space have the radiative portion suppressed with low-mass material insulating values as shown in Tables 2-10 and 2-11; this is consistent with the conditioned zone in all the other cases.

Variations of annual and peak heating and cooling loads due to the revised interior film coefficient; and building-shell conductivities and R-values for the high-mass setback case (case 940) are shown in Figure 2-15. In this figure, labels for the SUNCODE runs represent the following set of inputs:

- SUNCODE, SPEC FILM/INS uses interior film and building-shell conduction properties of the BESTEST specification.

- SUNCODE, SPEC INS uses an interior film coefficient of $3.16 \mathrm{~W} / \mathrm{m}^{2} \mathrm{~K}$, and BESTEST-specified building-shell properties.

- SUNCODE uses an interior film coefficient of $3.16 \mathrm{~W} / \mathrm{m}^{2} \mathrm{~K}$, but uses the conductivities and resistances tabulated in the SUNCODE/SERIRES-labeled columns of Tables 2-10 and 2-11-this is the final run used in producing the example (reference) results.

This sensitivity study reconfirms the strategy of suppressing the interior radiant coefficient to model a convective thermostat controller with SERIRES. This is evident from comparing the SUNCODE SPEC FILM/INS output to the SUNCODE, SPEC INS output where the radiative portion of the interior combined film coefficient has been removed. For SUNCODE, SPEC INS the results are closer to those of BLAST, DOE2, and ESP; this is most noticeable in the peak heating load. The effect of varying air-toair wall resistance on annual and peak heating and cooling loads (SUNCODE, SPEC INS versus SUNCODE) is small compared to the effect of varying the film coefficient on the peak heating load.

High-conductance wall. To account for exterior surface solar absorptivity, the high conductance wall was modeled as a steady-state resistance wall instead of as a zero shading coefficient window. One modeling complication arose from our modified interior film coefficient noted above. In SERIRES/SUNCODE, window conduction is described with a total air-to-air glazing U-value; no interior or exterior film coefficients are applied. To model the high conductance wall with the same air-to-air U-value as the windows, requires an interior film coefficient of $8.29 \mathrm{~W} / \mathrm{m}^{2} \mathrm{~K}$ rather than the modified value that is used for the more massive walls (as noted above). Per BESTEST, an exterior film coefficient of $21.0 \mathrm{~W} / \mathrm{m}^{2} \mathrm{~K}$ was applied, leaving a high-conductance wall resistance of $0.16509 \mathrm{~m}^{2} \mathrm{~K} / \mathrm{W}$ to get the total air-to-air U-value of $3.0 \mathrm{~W} / \mathrm{m}^{2} \mathrm{~K}$. 

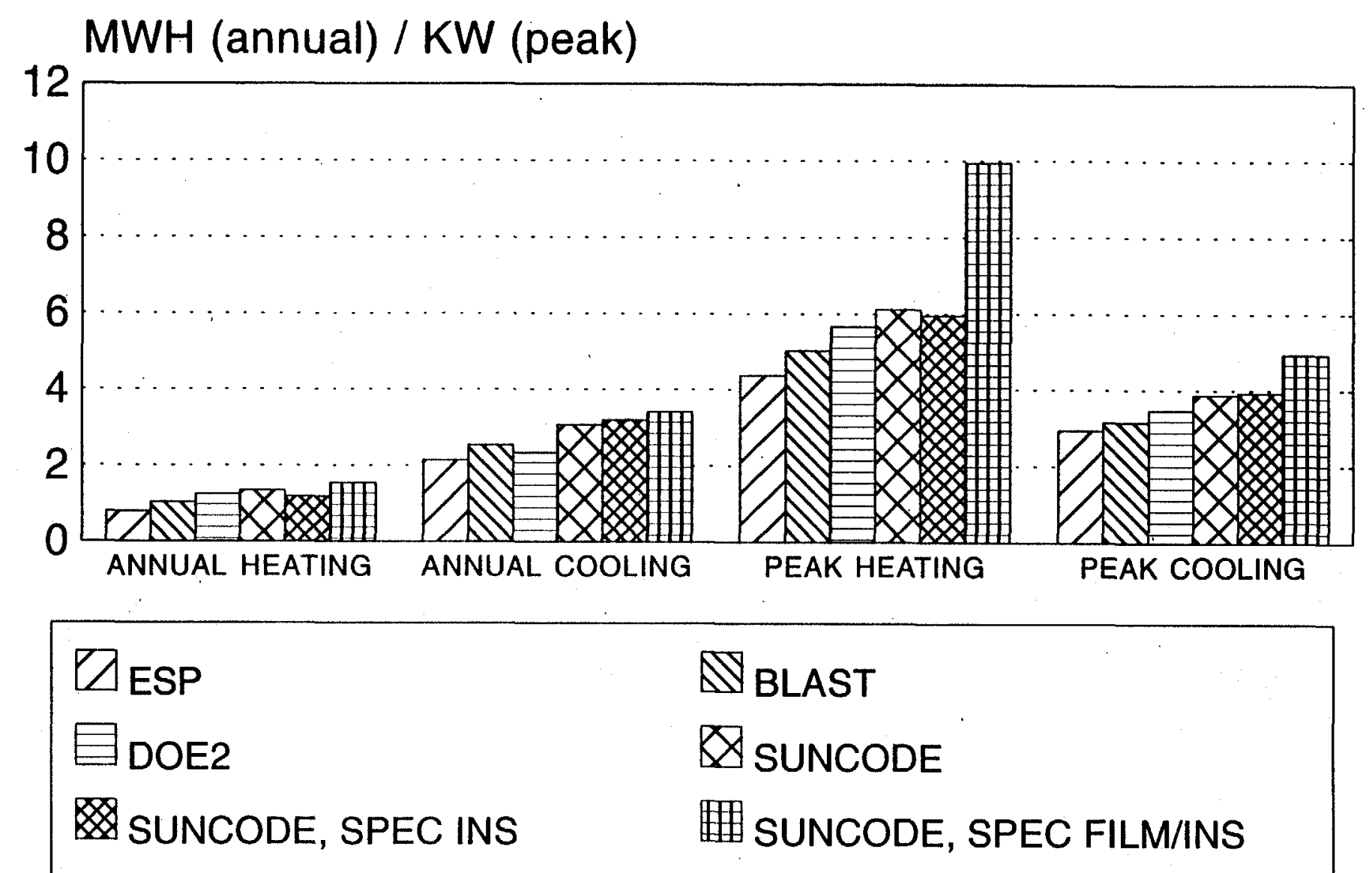

c:Ing3ironlsunfilm.ch3, 18 Mar 1993

Figure 2-15. SUNCODE interior film coefficient parametric study case 940: setback 


\subsubsection{Shading}

When we first ran shading in SUNCODE/SERIRES, there was much more solar energy being transmitted through shaded east/west windows than the other simulations showed (see Table 2-12).

Table 2-12. BESTEST East and West Shading Effectiveness Comparisons: January 1992 Outputs

\begin{tabular}{|c|c|c|c|}
\hline Simulation program & $\begin{array}{c}\text { E/W unshaded } \\
(620) \\
\left(\mathbf{k W h} / \mathrm{m}^{2}\right)\end{array}$ & $\begin{array}{c}\text { E/W shaded } \\
(630) \\
\left(\mathbf{k W h} / \mathbf{m}^{2}\right)\end{array}$ & $\begin{array}{c}E / W \\
\text { shaded/unshaded } \\
\text { (fraction) }\end{array}$ \\
\hline TRNSYS/BRE & 721 & 416 & 0.58 \\
\hline S3PAS & 638 & 419 & 0.66 \\
\hline TRNSYS-BEL & 894 & 495 & 0.55 \\
\hline TASE & 701 & 409 & 0.58 \\
\hline DOE2.1D & 735 & 481 & 0.65 \\
\hline SERIRES/BRE & 692 & 607 & 0.88 \\
\hline SERIRES/SUNCODE & 689 & 558 & 0.81 \\
\hline
\end{tabular}

Further examination uncovered a problem in the way SUNCODE deals with shadow overlap from both overhangs and fins. This problem resulted in the west side window being fully sunlit on January 21 , 1992, from 12 p.m. to 1 p.m. when it actually should have been fully shaded by either the fin or the overhang (SUNCODE assumes overhangs have finite width but infinite length in the horizontal plane [Kennedy et al. 1992; p. 1-5]). The problem was reported to Ecotope, Inc., and has been corrected (Kennedy 1992). Output presented in this report is from the corrected version.

In this particular case, there was not much effect from removing the bug because much of the sunlight incident on a west-facing window between 12 p.m. and 1 p.m. (solar time) is reflected due to the nearly parallel incidence angle.

In general, Table 2-12 shows a wide range of disagreement among the programs for the shading provided by an overhang and vertical fins on east- or west-facing windows. This is evident from Figure 2-10 (Section 2.4), which describes the ratio of annual shaded transmitted solar radiation to annual unshaded transmitted solar radiation. The amount of east/west shading provided by SERIRES (in both the SUNCODE and BRE versions) is similar to ESP but much less than for DOE2, TRNSYS, S3PAS, and TASE. According to Figure 2-9 (Section 2.4) (the diagnostic for east and west shading), there is also less annual load sensitivity to east and west shading for SERIRES and ESP, as well as for BLAST (which does not give incident solar radiation data in its output reports). This issue is worthy of further investigation, and may best be resolved by developing some analytic tests (based on analytical solutions) for generic shading cases.

\subsubsection{Building Operation}

Thermostat control. Thermostat control is based on the temperature of the central zone air node. (Kennedy et al. 1992, p. 6-1) As noted previously, using this node implies that the thermostat sees some radiative heat transfer with the walls, in addition to the zone air temperature. To compensate, the interior film coefficient was adjusted as described in Section 2.5.3.3. 
The documentation for defining schedules is in error. Schedules for SERIRES/SUNCODE are the same as for DOE2 in that all hour numbers correspond to an hour interval, with the ending time equal to the hour number (i.e., hour 14 is 1 p.m. to 2 p.m.). This problem was apparent from the initial free float temperature data for case 650 .

Ventilation control. SUNCODE/SERIRES requires thermostat control for ventilation. Thus, ventilation was modeled as infiltration and scheduled such that the maximum infiltration rate is the sum of BESTEST scheduled ventilation (13.14 air changes per hour $[\mathrm{ACH}]$ ) and continuous infiltration ( $0.5 \mathrm{ACH})$ (Kennedy et al. 1992, pp. 6-37 to 6-40). SERIRES automatically adjusts the density of air as a function of altitude.

\subsubsection{Intemal Radiation Distribution}

In SUNCODE/SERIRES, the user specifies the fraction of solar radiation absorbed by each wall and zone air, and that lost back out the window (cavity albedo). These fractions must add up to unity. The solar fractions for SERIRES/SUNCODE were calculated exactly as described in Section 1.4.10, Appendix F, and Section 1.4.12 (for the sunspace of case 960).

\subsubsection{Output}

SUNCODE is very flexible for hourly reporting. There were no problems with obtaining the hourly output required by BESTEST.

\subsubsection{Use of BESTEST Diagnostics and Error Trapping}

As noted above, cases 620 and 630 were used to indicate a problem with the way SUNCODE/SERIRES was handling overlapping shadows from both overhangs and fins.

The schedule documentation problem was apparent from observing an early version of the free-float temperature output for case 650 .

A cavity albedo algorithm comparison. Case 900 annual cooling load for SERIRES/SUNCODE is 0.6 MWh greater than the nearest program except for SERIRES-BRE, which is $0.25 \mathrm{MWh}$ greater than SERIRES/SUNCODE. From the diagnostic series results, SERIRES/SUNCODE and SERIRES-BRE annual cooling loads are more sensitive to cavity albedo (case 280 to case 270) than BLAST or TRNSYS by 0.34 to $0.46 \mathrm{MWh} / \mathrm{y}$. Although this is a relatively moderate difference, our curiosity about different cavity albedo algorithms led us to compare them for four of the programs, as noted below.

Cavity albedo at various interior shortwave absorptances was evaluated using different algorithms from DOE2, BLAST, and TRNSYS. For SUNCODE, the solution technique for solar fractions described in Section 1.4.10 and Appendix F was applied. The algorithms for DOE2 and BLAST are documented in their respective program reports. TRNSYS uses absorptance-weighted area ratios to distribute radiation throughout a space. For this purpose, all radiation that enters the zone is assumed to be diffuse, and radiation on the window that is neither reflected nor absorbed is lost (Klein et al. 1990, 4.8.8.1-18, 19). The resulting overall space reflectances are listed in Table 2-13.

Sensitivity tests were done using the cavity albedo algorithms from DOE2, BLAST, and TRNSYS to evaluate SOLAR LOST in SERIRES/SUNCODE for case 900. The results for annual cooling load are shown in Table 2-14. 
Table 2-13. Cavity Albedo for Various Methods and Interior Shortwave Absorptances

\begin{tabular}{|l|c|c|c|}
\hline Shortwave Absorptance $(\alpha)$ & $\alpha=0.1$ & $\alpha=0.6$ & $\alpha=0.9$ \\
\hline \hline SUNCODE (BESTEST) & 0.304 & 0.035 & 0.006 \\
\hline DOE2 & 0.409 & 0.030 & 0.005 \\
\hline BLAST & 0.274 & 0.041 & 0.018 \\
\hline TRNSYS & 0.296 & 0.071 & 0.049 \\
\hline
\end{tabular}

Table 2-14. SERIRES/SUNCODE Cooling Loads Versus Cavity Albedo Algorithm: Case 900

\begin{tabular}{|l|c|}
\hline Cavity albedo solution technique & $\begin{array}{l}\text { Annual cooling loads } \\
\text { for case } \mathbf{9 0 0} \text { (MWh) }\end{array}$ \\
\hline \hline SUNCODE (BESTEST) & 3.165 \\
\hline DOE2 & 3.197 \\
\hline BLAST & 3.128 \\
\hline TRNSYS & 2.944 \\
\hline
\end{tabular}

The algorithms from DOE2, BLAST, and BESTEST produce similar results; the cavity albedo algorithm used to calculate SOLAR LOST in SERIRES/SUNCODE is not causing the higher case 900 cooling loads in SERIRES/SUNCODE noted above. However, TRNSYS appears to be overpredicting cavity albedo, and its algorithm should be adjusted.

Because many of the programs (including SERIRES/SUNCODE) were not detailed enough to produce results for some of the A-series diagnostics, we were not able to isolate the source(s) of the difference in case 900 cooling loads. BESTEST represents a fairly coarse filter which has been successful at trapping major errors, but which may not detect all minor problems.

In an additional sensitivity test with cases 270 and 280, the SOLAR LOST parameter was varied in SERIRES/SUNCODE according to the cavity albedo, using algorithms for BLAST and TRNSYS. These results are shown in Table $2-15$, along with the sensitivity results obtained directly from BLAST and TRNSYS.

Varying SOLAR LOST in SERIRES/SUNCODE for cases 280 and 270-using the BLAST and TRNSYS cavity albedo algorithms-results in a reduced sensitivity to cavity albedo of 0.4 to $0.5 \mathrm{MWh} / \mathrm{y}$, as shown in Table 2-15. This is a significant sensitivity difference and suggests that for determining cavity albedo, a more rigorous algorithm that incorporates view factors is justified.

Also, Table 2-15 shows the resulting small differences in sensitivity to varying interior shortwave absorptance when comparing output of SERIRES/SUNCODE using the BLAST or TRNSYS algorithms with output directly from BLAST and TRNSYS. This indicates the effect on the annual cooling load of other program-specific interactions. That is, the difference in sensitivities indicates the amount of background noise that is present in a test designed primarily to vary cavity albedo. 
Table 2-15. SERIRES/SUNCODE Annual Cooling Load Sensitivity Versus Cavity Albedo Algorithm: Case 280-270

\begin{tabular}{|l|c|}
\hline Program & $\begin{array}{c}\text { Sensitivity of annual cooling load to cavity } \\
\text { albedo algorithm (MWh) }\end{array}$ \\
\hline SUNCODE (BESTEST) & 3.120 \\
\hline BLAST & 2.775 \\
\hline SUNCODE using BLAST algorithm & 2.713 \\
\hline TRNSYS & 2.780 \\
\hline SUNCODE using TRNSYS algorithm & 2.646 \\
\hline
\end{tabular}

Correction of problems. The overlapped-shadows bug has been corrected in the latest version of SUNCODE.

A description of the schedule documentation problem and the interior film coefficient modification used to model a nonradiant thermostat was sent to Ecotope, Inc.

\subsubsection{Recommendations}

Per discussion of the interior film coefficient in Section 2.5.3.3, revise p. 2-9 of the SUNCODE manual to say something like, "Based on the use of mean radiant wall temperature as the air temperature, the radiant portion of the combined interior film coefficient should be extracted if the modeler desires a nonradiant thermostat." Another option to correct this problem is to revise the code to include a more detailed zone air node.

If a more detailed air node is included, it would also be useful to directly model infrared radiation exchange between surfaces within the zone.

The capability for explicitly modeling exterior infrared emissivity should be added.

The capability to model exterior surface convection coefficients hourly as a function of windspeed should be added.

Add one more decimal place for net wall area in the input file template. This can be significant with metric units, since $0.1 \mathrm{~m}^{2}=1 \mathrm{ft}^{2}$. 


\subsubsection{Pro Forma}

Program name (please include version number)

$\boldsymbol{\nabla}$ possible to use

$\square$ used in BESTEST

SERIRES/SUNCODE 5.7

Your name and organization

Joel Neymark, NREL

\section{Program status}

- Public domain

- Commercial

Other (please specify) The original SERIRES is public domain. The PC-version is commercially available from Ecotope, Seattle, WA

\section{Solution method}

Explicit finite difference

$\square$ Implicit finite difference

$\square$ Weighting factors

$\square$ Response factor

$\square$ Other (please specify)

Timing convention for meteorological data: sampling interval

- Fixed within code (please specify interval) 1 hour

User-specified

Timing convention for meteorological data: period covered by first record

E Fixed within code (please specify period or time which meteorological record covers) $0: 00-1: 00$ User-specified

Meteorological data reconstruction scheme

- Climate assumed stepwise constant over sampling interval

$\square$ Linear interpolation used over climate sampling interval

Other (please specify)

\section{Output timing conventions}

$\square$ Produces spot predictions at the end of each timestep

$\square$ Produces spot output at end of each hour

- Produces average outputs for each hour (please specify period to which value relates) 
Treatment of zone air

- Single temperature (i.e., good mixing assumed)

$\square$ Stratified model

Simplified distribution model

Full CFD model

Other (please specify)

Heaters (dynamics)

- No dynamics assumed (output is instantaneous)

$\square$ Simple first order dynamics

Detailed modeling of heat source dynamics

Heaters (output characteristics)

- Purely convective

$\square$ Radiative/Convective split fixed within code

Radiative/Convective split specified by user

Detailed modeling of heat source output

See note above.

Control temperature

$\square$ Air temperature

- Combination of air and radiant temperatures fixed within the code

$\square$ User-specified combination of air and radiant temperatures

$\square$ User-specified construction surface temperatures

$\square$ User-specified temperatures within construction

Other (please specify)

\section{Control laws}

Perfect control

$\square$ On/Off thermostatic control

On/Off thermostatic control with deadband

$\square$ On/Off thermostatic control with accelerator heater

$\square$ Proportional control

More comprehensive control laws (please specify)

\section{Heat transfer within zones}

- Radiation and convection combined

Radiation and convection treated separately

\section{Convective heat transfer within zones}

Coefficients fixed within code

Coefficients specified by user

$\square$ Coefficients calculated by code as a function of surface orientation

$\square$ Coefficients calculated by code as a function of temperature difference

Coefficients calculated by code as a function of surface finishes

ㅁ. Other (please specify) 
Longwave radiative heat transfer within zones

- Constant linearized coefficients

$\square$ Linearized coefficients based on viewfactors

Linearized coefficients based on surface emissivities

Non-linear treatment of radiation heat exchange

Other (please specify) Not treated separately, is part of combined film coefficient.

Number of nodes placed within each layer of walls and slabs

$\square$ Not applicable for this solution method

$\square$ Fixed number of nodes per layer (please specify)

User-specified number of nodes per layer

Other (please specify

Airgaps within walls and slabs

$\square$ Resistance fixed within code

User-specified constant resistance

Resistance calculated within code as a function of orientation

Radiation and convection treated separately across airgaps

Treated as additional zones

Other (please specify)

Windows (heat loss)

- Fixed resistance used for window element

$\square$ Dynamic treatment of window heat loss using same scheme as for opaque elements

Other (please specify)

\section{Airgaps within windows}

$\square$ Resistance fixed within code

User-specified constant resistance

$\square$ Resistance calculated within code as a function of orientation

$\square$ Radiation and convection treated separately across airgaps

$\square$ Airgaps treated as additional zones

Other (please specify) Air gaps are not disaggregated from the general glazing properties.

Windows (transmission of direct shortwave radiation)

$\square$ Fixed transmission used

$\square$ ASHRAE solar heat coefficients used

Calculated by code as a function of incidence angle

$\square$ Calculated by code from user-specified function of incidence angle

Other (please specify)

Windows (transmission of diffuse radiation)

Diffuse radiation treated as direct from fixed altitude (please specify) $60^{\circ}$ angle of incidence

$\square$ Other (please specify) 
Distribution of solar radiation within zones

$\square$ Fixed within the code

- Constant user-specified distribution

$\square$ Calculated once by code and used throughout (please describe algorithm)

Calculated as a function of solar position (please describe algorithm)

Heat transfer between external surfaces and surrounding environment

- Radiation and convection combined

$\square$ Radiation and convection treated separately

\section{External convection}

$\square$ Coefficients fixed within code

User-specified constant coefficients

Calculated within code as a function of orientation

Calculated within code as a function of surface finish

Calculated within code as a function of wind speed

$\square$ Calculated within code as a function of wind speed and direction

Other (please specify)

\section{External radiative heat transfer}

- Assumed to be to ambient air temperature

$\square$ Assumed to be to sky temperature read from met file

$\square$ Based on calculated sky temperature (please specify algorithm and requirements)

Includes view factor of surrounding obstruction. Calculation evaluates view to sky dome, does not include fins and overhangs or other surfaces defined for the building.

Diffuse sky model

- Isotropic

Other (please specify model used) 


\subsubsection{SERIRES-1.2}

(British Version)

Building Research Establishment (BRE)

United Kingdom

May 1993 


\subsubsection{Introduction}

The IEA21 Subtask $\mathrm{C}$ benchmark test cases are described in Part I of BESTEST. They were run with SERIRES version 1.2 on a Sun $3 / 80$. Some points arose in applying the required input data and running SERIRES, and these are described in the next sections.

\subsubsection{Building Specification}

Size and shape. These are as defined in Part I of BESTEST.

Boundary conditions. For all cases except 990 , the floor insulation was defined directly as a resistance in SERIRES 1.2. In case 990, the specification gave no details for the dry earth layer apart from its physical properties. For SERIRES 1.2, the ground conditions were modeled following the recommendations of the Applicability Study 1 Research Note 2 by K.J. Lomas of January 1989; (Lomas 1989); this suggests that the earth can be modeled as a layer of $1.3 \mathrm{~m}$ in contact with the ground. Case 990 was found to be sensitive to the ground temperature; various values were used, and the output results are described in Section 2.5.4.7. The choice made was a schedule of monthly values based on the monthly average external air temperatures, with a 3-month time lag. The exception was where average air temperatures were below zero; here the ground temperature was taken as zero, the lower limit of SERIRES. Table 2-16 gives the ground temperature profile chosen.

Table 2-16. Monthly Ground Temperatures for SERIRES 1.2

\begin{tabular}{|c|c|}
\hline Month & Temp $\left({ }^{\circ} \mathrm{C}\right)$ \\
\hline \hline January & 9.5 \\
\hline February & 3.5 \\
\hline March & 0.0 \\
\hline April & 0.0 \\
\hline May & 0.0 \\
\hline June & 3.6 \\
\hline July & 9.3 \\
\hline August & 14.0 \\
\hline September & 18.2 \\
\hline October & 22.7 \\
\hline November & 21.2 \\
\hline December & 16.8 \\
\hline
\end{tabular}

The internal air temperature for case 990 at the start of the calculational period is affected by the long initialization period required for the slow response of the earth conditions. Research Report 8 (Lomas 1991) proposes that this initialization period can be compensated for by making the starting air 
temperature a weighted average of the external temperature and the design-heated temperature, the weighting factor being dependent on the construction, heating schedules and ventilation. Trials with starting air temperatures of $18.3^{\circ} \mathrm{C}$ (the SERIRES 1.2 default) and $20^{\circ} \mathrm{C}$ gave different results only for the first month, producing heating and cooling requirements that differed by less than $3 \%$. Assuming that the dominant external temperature is that of the ground at $10^{\circ} \mathrm{C}$, and the design temperature of the heated interior is $20^{\circ} \mathrm{C}$, the initial temperature of $18.3^{\circ} \mathrm{C}$ was felt to be satisfactory.

Exterior surface coefficients were defined as in the specification. Internal surface coefficients for horizontal surfaces were set to 8.29 for 0.9 emissivity and 3.73 for 0.1 emissivity, as there was no scheduling for winter and summer conditions.

For all cases except 990 , the internal solar coefficients were taken as defined in the specification. It should be noted that, since the fractions supplied to each surface and lost back through the window add up to 1 , the specification assumes there is no solar heat transfer directly to the zone air.

For case 990, with a different size of window, the solar fraction lost was taken proportionally, as 0.032 . Ceiling and floor coefficients were taken as for case 900 , but for the vertical walls, fractions were divided between the parts above and below the ground level (see Table 2-17).

Table 2-17. SERIRES 1.2 Interior Solar Distribution

Fractions for Case 990

\begin{tabular}{|l|c|}
\hline Interior Surface & $\begin{array}{c}\text { Solar Distribution } \\
\text { Fraction }\end{array}$ \\
\hline \hline Floor & 0.642 \\
\hline Ceiling & 0.168 \\
\hline Each east-west wall & 0.019 \\
\hline North wall & 0.0265 \\
\hline Below ground & 0.0935 \\
\hline South wall above ground & all glass \\
\hline
\end{tabular}

\subsubsection{Construction}

Walls, roof, floor. In SERIRES 1.2, it is necessary to define the number of nodes within each layer of a construction used for calculating the heat and temperature flows. The size of the working timestep depends on the node numbers. In these case studies, the numbers of nodes were chosen so as to reduce the timestep size to manageable proportions with as little loss of accuracy as possible. They resulted in heavyweight cases having 30 steps per hour and lightweight cases having 47 steps per hour.

The number of nodes used for various construction layers are:

3 nodes-floor timber, concrete block and slab (case 990 only, earth layer)

2 nodes-plasterboard, roof decking

1 node-all insulation, exterior wood for walls, glass.

Glazing. Opaque windows were taken as three-layer constructions of glass-air-glass, with the air being modeled as a resistance of $0.1588 \mathrm{~K} / \mathrm{m}^{2} \mathrm{~W}$, and the glass properties as defined in the BESTEST revised specification. Transparent windows are taken as two sheets of glass with a space of unknown resistance 
between them. SERIRES requires the total air-air U-value with the extinction coefficient and refractive index of the glass, and derives all other quantities from these.

\subsubsection{Shading}

The SERIRES 1.2 manual does not set out clearly. how side fins and overhangs should be defined with regard to the edge of any shaded surface. There is no problem with overhangs for the current case studies, since the overhang is set at the surface edge. However, several test runs with side fins revealed some strange results that suggest an error in the code. As a result, it was decided in the case of shaded eastwest windows to split the walls into three parts, with the side fins on the boundaries. Item \#2 in Figure 2-16 represents the segmented wall approach; item \#1 of Figure 2-16 shows how SERIRES 1.2 models overchange and fins if the wall is not split into three parts. This had an additional effect of ensuring that the overhang, which is assumed in SERIRES to stretch the full length of the surface it is shading, would shade only the window and not part of the adjoining wall surface.

\subsubsection{Building Operation}

Plant and control system. In addition to the heater and cooler maximum capacity (taken as specified as $1000 \mathrm{~kW}$ each), SERIRES 1.2 requires the cooler coil temperature. This was taken as the program default value of $12.8^{\circ} \mathrm{C}$, since it is only needed for latent load calculations.

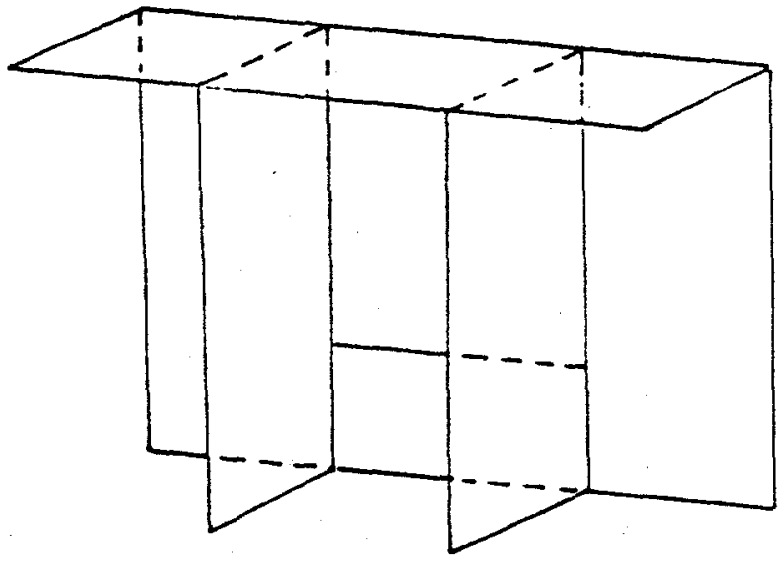

1. Single surface

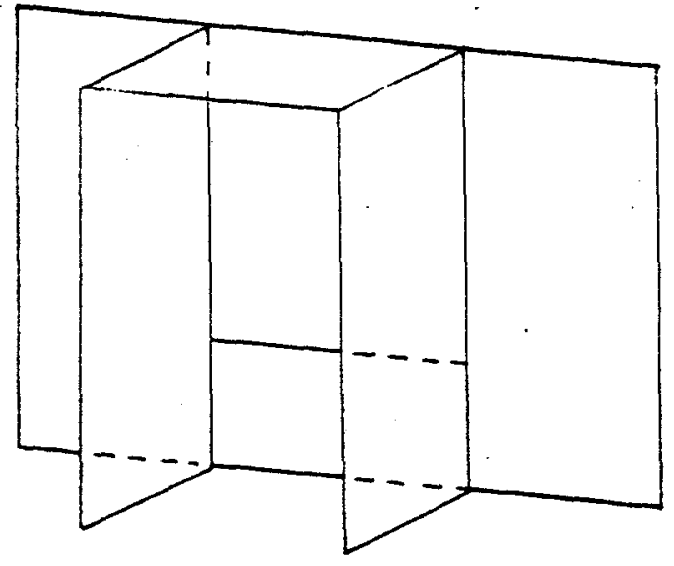

2. Three-part surface

Figure 2-16. East-West window shading schemes with SERIRES 1-2 
Ventilation. There are two ways of expressing ventilation: by scheduling the infiltration or by using forced ventilation. There are problems with forced ventilation. The lowest set point that SERIRES will accept is $0^{\circ} \mathrm{C}$. Hence, when the outside temperature is $-18^{\circ} \mathrm{C}$, if venting reduces the room temperature to freezing point, the control will switch it off. There also seems to be an error in the program. To avoid the cooler coming on while venting is in operation, its set point must be given a high value $\left(40^{\circ} \mathrm{C}\right)$. It is then scheduled to $27^{\circ} \mathrm{C}$ in the daytime, when the venting is off, so in its turn the venting set point is given a value higher than the cooler $\left(30^{\circ} \mathrm{C}\right)$. Runs for January showed that the cooling system did not come in properly during the day, though a run done for July seemed correct. Hence, it was decided to schedule infiltration:

from 7:00 to $18: 00$ infiltration $=0.5 \mathrm{ac} / \mathrm{h}$

from $18: 00$ to $7: 00$ infiltration $=13.64 \mathrm{ac} / \mathrm{h}$.

The evening infiltration plus ventilation rate of $13.64 \mathrm{ac} / \mathrm{h}$ is derived from the vent fan capacity of $1703.16 \mathrm{~m}^{3} / \mathrm{h}$, corrected for altitude within SERIRES, and combining forced and natural ventilation.

\subsubsection{Location and Climate}

Climate data could be extracted from the file DRYCOLD.TMY without modification other than the multiplication of values by 10 to conform with SERIRES input units requirements.

\subsubsection{Output}

Sensitivity of results. Peak heating and cooling values have been found to depend on the power defined for the equipment. When the power is above a certain value (depending on the case being studied), the design air temperature can be achieved within one hour, and the peak load is the same for all power levels above this. Below the critical power value, it takes more than one hour to bring the air temperature to its design value, and the peak power is reduced. Case 940 was investigated, and the limiting power value was found to lie between 10 and $15 \mathrm{~kW}$ for this configuration (see Table 2-18).

Table 2-18. Case 940 Sensitivity to Equipment Capability

\begin{tabular}{|c|c|c|}
\hline $\begin{array}{c}\text { Heater power } \\
(\mathbf{k W})\end{array}$ & $\begin{array}{c}\text { Peak heating } \\
(\mathbf{k W})\end{array}$ & $\begin{array}{c}\text { Peak cooling } \\
(\mathbf{k W})\end{array}$ \\
\hline 1000.0 & 9.323 & 4.406 \\
\hline 20.0 & 9.323 & 4.406 \\
\hline 15.0 & 9.323 & 4.406 \\
\hline 10.0 & 9.002 & 4.406 \\
\hline
\end{tabular}

In studying the sensitivity to ground temperature in case 990 , three runs were done with constant ground temperatures of $7^{\circ} \mathrm{C}, 10^{\circ} \mathrm{C}$, and $13^{\circ} \mathrm{C}$. There were also two runs with ground temperatures varying monthly. The values were based on average monthly external air temperatures as described in Section 2.5.4.2; one had two months' time lag and the other three months' time lag. They gave the results shown in Table 2-19. 
Table 2-19. SERIRES 1.2 Ground Coupling Sensitivity Tests

\begin{tabular}{|l|c|c||}
\hline $\begin{array}{l}\text { Ground } \\
\text { temperature }\end{array}$ & $\begin{array}{c}\text { Annual heating } \\
\text { (MWh) }\end{array}$ & $\begin{array}{c}\text { Annual cooling } \\
\text { (MWh) }\end{array}$ \\
\hline \hline Constant $7^{\circ} \mathrm{C}$ & 4.423 & 0.043 \\
\hline Constant $10^{\circ} \mathrm{C}$ & 3.312 & 0.141 \\
\hline Constant $13^{\circ} \mathrm{C}$ & 2.390 & 0.342 \\
\hline 2 months' lag & 4.741 & 0.931 \\
\hline 3 months' lag & 4.324 & 0.714 \\
\hline
\end{tabular}

Comparison of results. It was felt useful to compare the SERIRES 1.2 results with those of the U.S. version, SERIRES/SUNCODE. There were two areas of discrepancy: one for solar radiation and the other for annual and peak cooling.

The two versions of the code use different models for incident solar radiation. SERIRES 1.2 uses Gruter's method for solar position and Hay's anisotropic sky model for diffuse insolation. This gives $14 \%$ less annual incident radiation for west-facing surfaces than SERIRES/SUNCODE, and $11 \%$ less for northfacing surfaces, while east-facing surfaces have $11 \%$ more. South-facing and horizontal surface values are very close, however. Without detailed investigation into the codes, it would be impossible to analyze the differences.

The second area of discrepancy, that of annual and peak cooling, was studied. There is also a lesser discrepancy in annual and peak heating. Cooling values were larger in the U.K. results, in almost all cases. This effect was found to be due mostly to the difference in interior surface coefficients used. The U.K runs used the values as defined in the specification, while the U.S. runs removed the radiative component. Insulation resistances were then adjusted to give the BESTEST construction the defined airto-air heat transmission coefficients.

Tests with SERIRES 1.2 using the U.S. modified coefficients and resistances produced closer values. For example, case 600 gave the values found in Table 2-20.

Table 2-20. SERIRES 1.2 Annual and Peak Load Sensitivity to Interior Surface Coefficient

\begin{tabular}{|l|c|c|c|}
\hline Output & $\begin{array}{c}\text { SERIRES 1.2 } \\
\text { as defined }\end{array}$ & $\begin{array}{c}\text { SERIRES 1.2 } \\
\text { adjusted }\end{array}$ & SUNCODE \\
\hline \hline Annual heating & 5.596 & 5.312 & $5.226(\mathrm{MWh})$ \\
\hline Annual cooling & 7.964 & 7.220 & $7.278(\mathrm{MWh})$ \\
\hline Peak heating & 4.307 & 4.289 & $4.258(\mathrm{~kW})$ \\
\hline Peak (date) & Jan. $42: 00$ & Jan. $42: 00$ & Jan. $42: 00$ \\
\hline Peak cooling & 7.551 & 6.855 & $6.827(\mathrm{~kW})$ \\
\hline Peak (date) & Oct. $1613: 00$ & Oct. $1614: 00$ & Oct. 16 14:00 \\
\hline
\end{tabular}


In view of the changes in results due to this difference in input parameters, this is an area for possible further study, and for consideration in specifying procedures that aid building energy simulation users with creating uniform models.

There are also some differences in free-float temperature results between the U.K. and U.S. versions of SERIRES. However, changing the surface coefficients and resistances produces almost no change to the U.K. results. The results for case 600 are shown in Table 2-21.

Table 2-21. SERIRES 1.2 Maximum and Minimum Zone Temperature Sensitivity to Interior Surface Coefficient

\begin{tabular}{||l|c|c|c|c||}
\hline \multirow{2}{*}{ Simulation Run } & \multicolumn{2}{|c|}{ Maximum } & \multicolumn{2}{c|}{ Minimum } \\
\cline { 2 - 5 } & Temperature $\left({ }^{\circ} \mathrm{C}\right)$ & Date & Temperature $\left({ }^{\circ} \mathrm{C}\right)$ & Date \\
\hline \hline $\begin{array}{l}\text { SERIRES } 1.2 \\
\text { as defined }\end{array}$ & 67.1 & Oct $1616: 00$ & -9.6 & Dec $724: 00$ \\
\hline $\begin{array}{l}\text { SERIRES } 1.2 \\
\text { adjusted }\end{array}$ & 67.69 & Oct $1616: 00$ & -9.69 & Dec $95: 00$ \\
\hline SUNCODE & 68.6 & Oct 16 15:00 & -18.0 & Jan 4 7:00 \\
\hline
\end{tabular}


2.5.5 ESP

De Montfort University

United Kingdom (U.K.)

August 1993 


\subsubsection{Introduction}

This report describes the modeling strategy used for the BESTEST simulations carried out with ESP-r at De Montfort University, Leicester (DMU) on behalf of the U.K. Building Research Establishment (BRE). Any assumptions that had to be made in addition to the building specifications of Part I and any modeling difficulties that occurred are noted. This report supersedes the BRE Support Contract Report 9b (Eppel and Lomas 1992).

The program version used initially was ESPsim v6.18a, supplied by the Energy Simulation Research Unit (ESRU) at Strathclyde University. A preconditioning time of 19 days and four time steps per hour were used throughout.

Concern was expressed about the ESP results at the IEA meeting in Portland, Oregon (Sept. 19, 1992). All the simulations were therefore repeated using ESP-r, the so-called reference version of ESP. The latest available versions of this suite of programs were used, consisting of the following modules; prj v8series, bps v8.1a. ish v1.2a. win v2.2a. clm v6.3b and res v4.7a.

\subsubsection{Building Specification}

Size and shape. No assumptions had to be made.

Boundary conditions. ESP requires the specification of an "Index of Exposure." An index of 6 was chosen, which corresponds to an unobstructed site:

For floor insulation, BESTEST specifies the minimum density and specific heat allowed by the program being tested. We used $\rho=10 \mathrm{kgm}^{-3}$ and $c=100 \mathrm{Jkg}^{-1} \mathrm{~K}^{-1}$ in all cases (except case 990) to get a lowcapacitance material. A 1-m thick layer of insulation effectively decoupled the floor of the test building from the ground (which had a constant temperature of $10^{\circ} \mathrm{C}$ ).

A somewhat different philosophy was adopted for the uninsulated floor in the ground-coupled case 990 , for which no simplifying boundary conditions were given in the specification. It was left to the modeler to use the program in as detailed a fashion as possible. The complicated three-dimensional heat flow processes occurring in the ground beneath a building are not treated in a very detailed way in ESP. Onedimensional heat flow is assumed, connecting the floor construction to a monthly, varying, user-specified ground temperature. In a situation where the floor is not well-insulated, it is important to try and approximate the behavior of the real building. Work undertaken within the U.K. Applicability Study Project has gone some way in providing such an approximation. A practical approach is to specify a layer of earth of a certain thickness, say $1.3 \mathrm{~m}$, below the actual floor construction, and to connect the lower surface of the earth to a monthly varying deep-ground temperature. However, in a dynamic thermal program, this approach would lead to prohibitively long preconditioning times (typically in the order of one year or more). Research at DMU has shown that, by subdividing the earth layer into a thinner layer of "real earth" (about $0.3 \mathrm{~m}$ ) directly beneath the floor slab and a thicker layer of low-capacitance earth $\left(\rho=100 \mathrm{kgm}^{-3}, c=500 \mathrm{Jkg}^{-1} \mathrm{~K}^{-1}\right.$ ), it was possible to avoid the problem of excessive preconditioning times, while approximating the overall heat loss to the ground reasonably well.

In BESTEST, no monthly ground temperatures for the test site were given. Therefore, the American Society of Heating, Refrigerating and Air-Conditioning Engineers (ASHRAE) approach used by some other participants was employed. For below-grade walls, the ASHRAE method gives heat loss values and corresponding heat-flow path lengths through the soil for different depths below the ground surface, in steps of $0.3 \mathrm{~m}$. 
To simplify the input for ESP, and to avoid excessive heat-flow path lengths through the basement floor, an average path length through the sub-terrain parts of the walls was calculated; this path also accounted for the heat flow through the floor. The basement walls were then connected to monthly, varying average air temperatures for Denver with an assumed time lag of two months (i.e., the following 12 temperatures were used for January to December: $3.49^{\circ} \mathrm{C},-0.71^{\circ} \mathrm{C},-1.69^{\circ} \mathrm{C},-0.60^{\circ} \mathrm{C}, 3.56^{\circ} \mathrm{C}, 9.31^{\circ} \mathrm{C}, 14.04^{\circ} \mathrm{C}$, $18.16^{\circ} \mathrm{C}, 22.69^{\circ} \mathrm{C}, 21.16^{\circ} \mathrm{C}, 16.85^{\circ} \mathrm{C}$, and $9.49^{\circ} \mathrm{C}$ ).

\subsubsection{Construction}

Walls, roof, floor. No additional assumptions had to be made for wall or roof constructions. The boundary conditions of the floor, which influenced the construction details, were discussed in Section 2.5.5.2.

Glazing. Windows can be modeled in two ways in ESP. The TMC (transparent multi-layered construction) option was used here: windows are assigned a nodal scheme so that convective, conductive, and longwave radiative exchanges are handled separately and explicitly, with solar absorption treated in an exacting manner.

In the opaque window cases, the window surfaces were simply not declared transparent; i.e., they were modeled as walls consisting of two sheets of glass with an air gap in between. Like any other wall, the surfaces were assigned a nodal scheme so that convective, conductive, and longwave radiative exchanges were handled separately and explicitly. In the past, we observed that the TMC approach leads to lower heating and cooling load predictions than a U-value approach. We therefore conducted the following sensitivity study on case 200 (using ESPsim v6.18a):

Case 201

The windows were assigned a positive (variable) $\mathrm{U}$-value $\left(+3 \mathrm{Wm}^{-2} \mathrm{~K}^{-1}\right)$. If windows are defined in this way, then no nodes are used to represent the window layers. ESP subtracts the conventionally assumed external convective surface heat-transfer resistance $\left(0.04 \mathrm{~m}^{2} \mathrm{KW}^{-1}\right)$ from the air-to-air resistance (the inverse of the specified $U$-value). The reduced resistance is then corrected by adding the external convection resistance, which is calculated at every timestep-depending on wind speed and orientation.

Case 202

The windows were assigned a negative $\mathrm{U}$-value $\left(-3 \mathrm{Wm}^{-2} \mathrm{~K}^{-1}\right)$. In this case, the U-value is treated as being time invariant.

\section{Case 203}

The windows were modeled as doors with a $\mathrm{U}$-value of $3 \mathrm{Wm}^{-2} \mathrm{~K}^{-1}$.

The results of the study are described in Table $2-22$.

This confirmed and emphasized the results of an earlier sensitivity study we had undertaken, based on case 600 (case 601 positive U-value, case 602 negative U-value) (see Table 2-23). 
Table 2-22. Case 200: Window Type Sensitivity

\begin{tabular}{||c|c|c|c|c|c|c|c|c|c|c||}
\hline \hline & \multicolumn{2}{|c|}{ Annual Heating } & \multicolumn{2}{|c|}{ Annual Cooling } & \multicolumn{3}{|c|}{ Peak Heating } & \multicolumn{3}{c|}{ Peak Cooling } \\
\cline { 2 - 11 } Case & $\begin{array}{c}\text { Load } \\
(\mathrm{MWh})\end{array}$ & $\begin{array}{c}\text { Difference } \\
(\%)\end{array}$ & $\begin{array}{c}\text { Load } \\
(\mathrm{MWh})\end{array}$ & $\begin{array}{c}\text { Difference } \\
(\%)\end{array}$ & $\begin{array}{c}\text { Load } \\
(\mathrm{kW})\end{array}$ & Time & $\begin{array}{c}\text { Difference } \\
(\%)\end{array}$ & $\begin{array}{c}\text { Load } \\
(\mathrm{kW})\end{array}$ & $\begin{array}{c}\text { Difference } \\
(\%)\end{array}$ \\
\hline 200 & 5.238 & - & 0.572 & - & 2.648 & $4 \mathrm{Jan} 06 \mathrm{~h}$ & - & 0.866 & 11 Aug $14 \mathrm{~h}$ & - \\
\hline 201 & 6.860 & +31 & 0.658 & +15 & 3.179 & $4 \mathrm{Jan} 02 \mathrm{~h}$ & +20 & 1.129 & 16 Aug $17 \mathrm{~h}$ & +30 \\
\hline 202 & 7.284 & +39 & 0.684 & +20 & 3.365 & $4 \mathrm{Jan} 08 \mathrm{~h}$ & +27 & 1.183 & $26 \mathrm{Jul} 16 \mathrm{~h}$ & +36 \\
\hline 203 & 7.286 & +39 & 0.683 & +20 & 3.365 & $4 \mathrm{Jan} 08 \mathrm{~h}$ & +27 & 1.183 & $26 \mathrm{Jul} 16 \mathrm{~h}$ & +36 \\
\hline
\end{tabular}

Table 2-23. Case 600: Window Type Sensitivity

\begin{tabular}{|c|c|c|c|c|c|c|c|c|c|c|}
\hline \multirow[b]{2}{*}{$\begin{array}{l}\text { Case } \\
(\mathbf{k W})\end{array}$} & \multicolumn{2}{|c|}{ Annual Heating } & \multicolumn{2}{|c|}{ Annual Cooling } & \multicolumn{3}{|c|}{ Peak Heating } & \multicolumn{3}{|c|}{ Peak Cooling } \\
\hline & $\begin{array}{c}\text { Load } \\
\text { (MWh) }\end{array}$ & $\begin{array}{c}\text { Difference } \\
(\%)\end{array}$ & $\begin{array}{l}\text { Load } \\
(\mathbf{M W h})\end{array}$ & $\begin{array}{c}\text { Difference } \\
(\%)\end{array}$ & $\begin{array}{l}\text { Load } \\
(\mathbf{k W})\end{array}$ & Time & $\begin{array}{c}\text { Difference } \\
(\%)\end{array}$ & $\begin{array}{l}\text { Load } \\
(\mathrm{kW})\end{array}$ & Time & $\begin{array}{c}\text { Difference } \\
(\%)\end{array}$ \\
\hline 600 & 4.232 & - & 6.362 & - & 3.439 & $4 \mathrm{Jan} 06 \mathrm{~h}$ & - & 6.297 & 17 Oct $14 \mathrm{~h}$ & - \\
\hline 601 & 4.620 & +9 & 6.990 & +10 & 3.765 & $4 \mathrm{Jan} 02 \mathrm{~h}$ & +9 & 6.759 & 16 Oct $14 \mathrm{~h}$ & +7 \\
\hline 602 & 4.953 & +17 & 6.864 & +8 & 3.951 & 4 Jan $03 h$ & +15 & 6.752 & 16 Oct $14 \mathrm{~h}$ & +7 \\
\hline
\end{tabular}

A separate sensitivity study was undertaken for case 195 to investigate the influence of the external longwave emissivity value. This case had neither a transparent nor an opaque window; i.e., the south wall was of uniform, lightweight construction, with an external longwave emissivity of 0.1 . For comparison, case 196 was devised with an emissivity of 0.9 (Table 2-24).

Table 2-24. Case 195: Sensitivity to External Language Emissivity

\begin{tabular}{|c|c|c|c|c|c|c|c|c|c|c|}
\hline \multicolumn{1}{|c|}{} & \multicolumn{2}{|c|}{ Annual Heating } & \multicolumn{2}{|c|}{ Annual Cooling } & \multicolumn{3}{c|}{ Peak Heating } & \multicolumn{2}{c|}{ Peak Cooling } \\
\cline { 2 - 10 } Case & $\begin{array}{c}\text { Load } \\
(\mathrm{MWh})\end{array}$ & $\begin{array}{c}\text { Difference } \\
(\%)\end{array}$ & $\begin{array}{c}\text { Load } \\
(\mathrm{MWh})\end{array}$ & $\begin{array}{c}\text { Difference } \\
(\%)\end{array}$ & $\begin{array}{c}\text { Load } \\
(\mathrm{kW})\end{array}$ & $\begin{array}{c}\text { Difference } \\
(\%)\end{array}$ & $\begin{array}{c}\text { Load } \\
(\mathrm{kW})\end{array}$ & $\begin{array}{c}\text { Difference } \\
(\%)\end{array}$ \\
\hline \hline 195 & 4.153 & - & 0.417 & - & 2.004 & $4 \mathrm{Jan} 03 \mathrm{~h}$ & - & 0.655 & $26 \mathrm{Jul} 16 \mathrm{~h}$ & - \\
\hline 196 & 4.992 & +20 & 0.117 & -72 & 2.019 & $4 \mathrm{Jan} 03 \mathrm{~h}$ & +0.7 & 0.353 & $27 \mathrm{Jul} 16 \mathrm{~h}$ & -46 \\
\hline
\end{tabular}

\subsubsection{Building Operation}

Plant and control system. A $100 \%$ convective air system, with a thermostat that senses air temperature, was employed as specified. Ideal control was assumed.

A plant capacity sensitivity study was performed for case 940 . The results for all three cases (plant capacity $25 \mathrm{~kW}, 15 \mathrm{~kW}$, and $10 \mathrm{~kW}$ ) were identical to the original case .940 results.

Ventilation. Since ESP does not automatically correct for the reduced density of air at higher altitude, the altitude correction given in the specification was used to produce infiltration rates for the test location of $0.41 \mathrm{ACH}$ (all cases where $0.5 \mathrm{ACH}$ was specified) or $0.82 \mathrm{ACH}$ (case 230). In the cases with 
ventilation ( 650 and 950 ), the infiltration rate was increased by $10.8 \mathrm{ACH}$ to give a total air change rate of $11.21 \mathrm{ACH}$, which is equivalent to a total air change rate of $13.64 \mathrm{ACH}$ at the altitude of $1609 \mathrm{~m}$.

Casual gains. These were assumed to be sensible.

\subsubsection{Shading}

The program module "ish" was used to calculate hourly varying shading patterns on the external facades and window for the cases with shading devices (the patterns are calculated for one day per month).

\subsubsection{Internal Radiation Distribution}

Shortwave. The program module 'ish' was used to calculate hourly varying internal solar distribution patterns for both the unshaded and the shaded cases. As noted in Section 2.5.5.5, these patterns are calculated for one day per month.

Longwave. Files that accurately specify the intersurface view factors, were generated with the module ESPvwf and used in the initial simulations. This information is used to improve the accuracy of the longwave exchange calculations. In the absence of such information, ESP generates approximate view factors on the basis of simple area-weighting techniques. A sensitivity study was undertaken to determine the influence on the results. (No view factor file was specified in case 603.) In a building with simple geometry (such as BESTEST), the effect is negligible, as shown in Table 2-25. No view-factor files were used for the reruns with ESP-r.

Table 2-25. Case 600: View Factor Sensitivity

\begin{tabular}{|c|c|c|c|c|c|c|c|c|c|c|}
\hline \multicolumn{1}{|c|}{} & \multicolumn{2}{|c|}{ Annual Heating } & \multicolumn{2}{c|}{ Annual Cooling } & \multicolumn{3}{c|}{ Peak Heating } & \multicolumn{3}{c|}{ Peak Cooling } \\
\cline { 2 - 9 } & $\begin{array}{c}\text { Load } \\
(\mathbf{M W h})\end{array}$ & $\begin{array}{c}\text { Difference } \\
(\%)\end{array}$ & $\begin{array}{c}\text { Load } \\
(\mathrm{MWh})\end{array}$ & $\begin{array}{c}\text { Difference } \\
(\%)\end{array}$ & $\begin{array}{c}\text { Load } \\
(\mathrm{kW})\end{array}$ & Time & $\begin{array}{c}\text { Difference } \\
(\%)\end{array}$ & $\begin{array}{c}\text { Load } \\
(\mathrm{kW})\end{array}$ & $\begin{array}{c}\text { Difference } \\
(\%)\end{array}$ \\
\hline \hline 600 & 4.232 & - & 6.362 & - & 3.439 & 4 Jan $06 \mathrm{~h}$ & - & 6.297 & $\begin{array}{c}17 \text { Oct } \\
14 \mathrm{~h}\end{array}$ \\
\hline 603 & 4.219 & -0.3 & 6.386 & +0.3 & 3.434 & 4 Jan $06 \mathrm{~h}$ & -0.1 & 6.306 & $\begin{array}{c}17 \text { Oct } \\
14 \mathrm{~h}\end{array}$ \\
\hline
\end{tabular}

\subsubsection{Location and Climate}

In addition to or instead of the climate parameters contained in the climate file DRYCOLD.TMY, ESP requires diffuse horizontal radiation. This was calculated from the direct normal radiation, the global horizontal radiation, and the solar altitude using a small program written at DMU.

A problem arises because ESP expects the first record of the weather data to be a spot value taken at 01:00. However, the file DRYCOLD.TMY was assumed to contain data centered on the half hour (i.e., starting with the period 00:00 to 01:00), and the diffuse horizontal radiation values were calculated accordingly. As a result, the direct normal radiation values in the ESP climate file correspond exactly with the values in DRYCOLD.TMY, but an unavoidable time shift of one-half hour remains in the way ESP interprets the data. 


\subsubsection{Output}

ESP produces output in a binary file. The module "res". was used to obtain the required parameters. A problem was discovered when res was used to recover hourly input (averaged over four timesteps) from the annual results files. A time shift of 1 hour occurred, which was particularly noticeable in the low-mass case with ventilation (650). This problem is currently under investigation by the authors of ESP-r. For the purpose of this exercise, the problem was overcome by running short-period simulations consisting of 19 days for preconditioning, then three days centered around the day for which hourly output was required (January 4 or July 27 ). For these simulations, the problem did not occur.

The program TMPBIN (written by F. Parand) was used for sorting the hourly temperature outputs into bins of $1^{\circ} \mathrm{C}$ (free-floating case 900FF). The results were stored on a disk in the LOTUS-123 spreadsheet BESTOUT4.WK1, as specified.

\subsubsection{Use of BESTEST Diagnostics and Error Trapping}

Internal absorptivity modeling. The BESTEST diagnostics identified some of the results obtained with ESPsim v6.18a as being anomalous. This problem in v6.18's treatment of internal shortwave reflection occurred when the internal surface absorptivities were abnormally low, and the diagnostics therefore clearly highlighted a problem in this area (Table 2-26). This problem had actually been identified previously by the authors of ESP.

Whereas v6.18a computed the distribution and retransmission of the internally reflected component of shortwave flux on the basis of first reflections only, later versions employed a recursive algorithm to overcome this problem (DMU had continued to use v6.18a, which had otherwise proved to be reliable, because of involvement in another long-term project in which absorptivities were high, precluded frequent updating to newer versions).

Table 2-26. Example of Error Trapping through BESTEST Diagnostics

\begin{tabular}{|l|c|c|}
\hline & ESPsim v6.18a & All other programs \\
\hline \hline $\begin{array}{c}\text { Annual cooling difference }(\mathrm{kWh}) \\
\text { case 440-600 }\end{array}$ & 401 & 2261 to 2760 \\
\hline $\begin{array}{l}\text { Peak cooling difference }(\mathrm{kW}) \\
\text { case 440-600 }\end{array}$ & 0.291 & 1.541 to 1.936 \\
\hline $\begin{array}{c}\text { Annual cooling difference }(\mathrm{kWh}) \\
\text { case 280-270 }\end{array}$ & 700 & 2775 to 3236 \\
\hline $\begin{array}{c}\text { Peak cooling difference }(\mathrm{kW}) \\
\text { case 280-270 }\end{array}$ & 0.496 & 1.819 to 2.208 \\
\hline
\end{tabular}

${ }^{a}$ Except DOE-2 for which no case 440 results were reported, and TASE, which also produced anomalous results

This example demonstrates the capability of the BESTEST diagnostics to pinpoint specific model shortcomings. As mentioned earlier, all simulations were consequently rerun with the latest available version of ESP-r.

Surface heat transfer coefficients. Another problem was that ESP produced consistently lower annual heating predictions than the other programs. The contributions of the authors of ESP (the ESRU group) to the investigation of this issue are gratefully acknowledged. 
The problem was traced to the heat transfer coefficients. ESP computes hourly varying values. The BESTEST specification stated that constant combined convective and radiative film coefficients should not be used if the program can calculate surface radiation and convection in a more detailed, or physically correct manner. The variable values calculated by ESP in its default mode were therefore used. The specification did, however, contain suggested time-invariant values for use in programs that require these as inputs (Table 2-27).

Table 2-27. Time-Invariant Wall Surface Coefficients Suggested in the BESTEST Specification $\left(\mathrm{Wm}^{-2} \mathrm{~K}^{-1}\right)$

\begin{tabular}{|c|c|c|c|}
\hline \multicolumn{2}{|c|}{ Inside } & \multicolumn{2}{c|}{ Outside } \\
\hline Convective & Radiative & Convective & Radiative \\
\hline 3.16 & 5.13 & 24.67 & 4.63 \\
\hline
\end{tabular}

The ESRU group compared the convective and radiative heat transfer coefficients for an internal and external surface, as predicted by ESP-r, with the suggested fixed values. While emphasizing that these ESP-r data will vary considerably over time (depending on temperature differences, wind vectors, and the like). We present a brief one day (summer and winter) summary for an external wall as provided by ESRU (Table 2-28).

From these data, the following conclusions might be drawn (although different weather sequences on other days might well produce different trends):

- The ESP-r internal surface radiation coefficients (variation $4.7 \mathrm{Wm}^{-2} \mathrm{~K}^{-1}$ to $6.0 \mathrm{Wm}^{-2} \mathrm{~K}^{-1}$ ) are close to the suggested time-invariant value $\left(5.13 \mathrm{Wm}^{-2} \mathrm{~K}^{-1}\right)$.

- The ESP-r internal surface convection coefficients are always lower than the time-invariant values-in some instances significantly so (i.e., between $13 \%$ and $84 \%$ ).

- The ESP-r external surface convection coefficients are almost always lower than the time-invariant value $\left(24.67 \mathrm{Wm}^{-2} \mathrm{~K}^{-1}\right) \longrightarrow$ on occasions, by $89 \%$.

It was concluded, therefore, that it is likely that ESP-r is operating with significantly different surface heattransfer regimes than programs that use the fixed values.

To test this hypothesis, case 600 was rerun with the suggested time-invariant values imposed. The results are recorded in Table 2-29.

It may be concluded from these data that:

- The heating predictions are now within the range of the other programs (so presumably the surface heat transfer coefficients are markedly different and surface convection is a dominant flowpath).

- The cooling predictions are virtually unaltered (presumably cooling is driven by solar gain rather than surface convection at external surfaces).

- As yet, ESRU have not attempted to explore the issues further. However, they offered the following general observations: 
Table 2-28. Example of Hourly Varying ESP-r Surface Coefficients

\begin{tabular}{|c|c|c|c|c|c|c|c|c|}
\hline \multirow{3}{*}{ Time } & \multicolumn{4}{|c|}{ Summer } & \multicolumn{4}{|c|}{ Winter } \\
\hline & \multicolumn{2}{|c|}{ Inside } & \multicolumn{2}{|c|}{ Outside } & \multicolumn{2}{|c|}{ Inside } & \multicolumn{2}{|c|}{ Outside } \\
\hline & Conv. & Rad. & Conv. & Rad. & Conv. & Rad. & Conv. & Rad. \\
\hline $1: 00$ & 1.05 & 5.1 & 9.38 & -9 & 2.44 & 4.7 & 4.96 & 6. \\
\hline $2: 00$ & 0.68 & 5.1 & 7.61 & -11 & 2.46 & 4.7 & 5.85 & 6. \\
\hline 3:00 & 0.65 & 5.4 & 6.43 & -19 & 2.48 & 4.8 & 4.38 & $\dot{9}$. \\
\hline 4:00 & 0.74 & 5.4 & 5.85 & -6 & 2.48 & 4.8 & 5.88 & 9. \\
\hline 5:00 & 0.69 & 5.4 & 4.30 & -24 & 2.47 & 4.9 & 8.19 & 7. \\
\hline $6: 00$ & 0.84 & 5.4 & 7.61 & -7 & 2.48 & 4.9 & 5.50 & 9. \\
\hline $7: 00$ & 0.73 & 5.4 & 12.56 & -14 & 2.48 & 5.0 & 5.88 & 1. \\
\hline $8: 00$ & 0.51 & 5.5 & 10.44 & -63 & 2.48 & 5.0 & 4.30 & 3. \\
\hline 9:00 & 0.64 & 5.6 & 9.38 & 21 & 2.43 & 5.0 & 3.91 & 4. \\
\hline 10:00 & 1.55 & 5.8 & 4.47 & 11 & 2.07 & 5.1 & 9.98 & 3. \\
\hline 11:00 & 2.24 & 5.8 & 5.24 & 8 & 0.76 & 5.3 & 5.85 & 6. \\
\hline $12: 00$ & 2.51 & 5.9 & 4.09 & 10 & 1.79 & 5.4 & 2.80 & 4. \\
\hline 13:00 & 2.60 & 5.9 & 4.76 & 11 & 2.55 & 5.5 & 4.44 & 3. \\
\hline 14:00 & 2.66 & 6.0 & 4.91 & 10 & 2.74 & 5.5 & 5.24 & 4. \\
\hline 15:00 & 2.62 & 6.0 & 3.85 & 10 & 2.51 & 5.6 & 3.91 & 7. \\
\hline 16:00 & 2.49 & 6.0 & 3.95 & 69 & 2.76 & 5.7 & 2.80 & 5. \\
\hline $17: 00$ & 2.34 & 6.0 & 2.80 & -28 & 2.03 & 5.8 & 4.15 & 5. \\
\hline 18:00 & 2.13 & 5.8 & 38.20 & -37 & 2.36 & 6.0 & 2.80 & 14. \\
\hline 19:00 & 1.97 & 5.7 & 22.83 & -1 & 0.69 & 5.9 & 7.25 & 10. \\
\hline 20:00 & 1.79 & 5.5 & 14.20 & -17 & 1.69 & 5.8 & 4.75 & 6. \\
\hline 21:00 & 1.45 & 5.5 & 5.85 & -4 & 2.65 & 5.7 & 7.61 & 12. \\
\hline $22: 00$ & 1.07 & 5.4 & 8.78 & -10 & 2.41 & 5.5 & 8.78 & 8. \\
\hline 23:00 & 0.73 & 5.4 & 7.07 & 93 & 2.30 & 5.3 & 8.32 & 10. \\
\hline 24:00 & 0.91 & 5.1 & 8.78 & -1 & 2.47 & 5.0 & 4.75 & 15. \\
\hline
\end{tabular}


Table 2-29. Comparison of Case 600 Results Using Fixed and Variable Surface Coefficients

\begin{tabular}{|l|c|c|}
\hline & $\begin{array}{c}\text { Annual Heating } \\
(\mathrm{kWh})\end{array}$ & $\begin{array}{c}\text { Annual Cooling } \\
(\mathrm{kWh})\end{array}$ \\
\hline \hline Variable coefficients $^{\mathrm{a}}$ & 4232 & 6362 \\
\hline Fixed coefficients $^{\mathrm{b}}$ & 5230 & 6393 \\
\hline Range of other programs & 4733 to 5709 & 6433 to 7964 \\
\hline
\end{tabular}

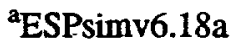

${ }^{b}$ ESP-r

- For the case of buoyancy-driven convection at internal surfaces, we (ESRU) would reaffirm our acceptance of the Alamdari and Hammond correlations which have been recently corroborated by research undertaken at British Gas. These correlations will produce convection coefficients which are significantly lower than the often quoted guide values (and the fixed BESTEST values). Of course, in real buildings, local mechanical effects and heat plumes will act to increase surface convection so that the guide values may be more appropriate. It is for this reason that ESP-r allows users to impose coefficients on a simulation.

- ESP-r uses "2.8+3.0*V" to evaluate the external surface convection coefficient (where $V$ is the surface resolved local air speed). For the quoted case of an annual wind speed of $4.02 \mathrm{~m} / \mathrm{s}$ this will give rise to a value considerably less than the suggested one, which we (ESRU) consider to be high. In any event, the hour-by-hour wind speeds will cover a wide range, giving rise to a spread in instantaneous coefficient values; this spread will be of importance in dynamic models.

- The issue then is "what are appropriate values for the surface heat transfer coefficients for range setting purposes?"

\subsubsection{Inclusion of ESP-R for Range Setting}

It is acknowledged that ESP- $r$, in its default mode, produces predictions of annual heating energy consumption, which are, for many cases, lower than those predicted by most of the other participating programs. It is felt that this is because ESP-r tends to model thermal processes with greater rigor than many other programs (TMS windows and variable heat transfer coefficients, for example). In this sense, ESP- $r$ is truly representative of state-of-the-art thermal simulation. It is felt, therefore, that the results produced by ESP-r in its default mode should be used for range setting in BESTEST.

Smaller ranges could have been obtained if the simulations had been carried out using fixed coefficients in ESP-r. However, the smaller ranges would perhaps be artificially narrow, when the BESTEST benchmarks are used to test other (particularly commercial) programs. In such programs, the user does not necessarily have the option of choosing parameters, such as heat transfer coefficients, and is even less likely to be able to interfere with the code.

It is still a matter of debate as to whether the default surface coefficient algorithms in ESP-r are appropriate for real buildings (or, indeed, for test rooms). However, this is an issue that requires further research and debate, but these uncertainties do not undermine the substance of the foregoing argument. 


\subsubsection{Pro Forma}

Program name (please include version number)

Q possible to use

$\square$ used in BESTEST

ESP-r Version 8 Series (modules bpsv8.1a, res v4.7a, ish v1.2a, win v2.2a

Your name and organization

Herbert Eppel, De Montfort University, Leicester, UK

\section{Program status}

$\square$ Public domain

$\square$ Commercial

- Other (please specify) freely available for research

Solution method

- Explicit finite difference

- Implicit finite difference

$\square$ Weighting factors

$\square$ Response factor

Other (please specify)

Timing convention for meteorological data: sampling interval

- Fixed within code (please specify interval) hourly

$\square$ User-specified

Timing convention for meteorological data: period covered by first record

- Fixed within code (please specify period or time which meteorological record covers) 01:00 (average between 00:30 and 01:30

User-specified

Meteorological data reconstruction scheme

¿ Climate assumed stepwise constant over sampling interval

- Linear interpolation used over climate sampling interval (default)

$\square$ Other (please specify)

\section{Output timing conventions}

Produces spot predictions at the end of each timestep

$\square$ Produces spot output at end of each hour

- Produces average outputs for each hour (please specify period to which value relates) average across timestep, e.g. for hourly simulations outputs are 00:30, 01:30 etc. Also possible to average over several timesteps, e.g., in BESTEST 15 minute timesteps were used, results produced were averaged over 4 timesteps. 
Treatment of zone air

Single temperature (i.e., good mixing assumed)

$\square$ Stratified model

$\square$ Simplified distribution model

$\square$ Full CFD model

$\square$ Other (please specify)

\section{Heaters (dynamics)}

- No dynamics assumed (output is instantaneous)

$\square$ Simple first order dynamics

Detailed modeling of heat source dynamics

\section{Heaters (output characteristics)}

\ Purely convective

$\square$ Radiative/Convective split fixed within code

- Radiative/Convective split specified by user

Detailed modeling of heat source output .

\section{Control temperature}

- Air temperature

$\square$ Combination of air and radiant temperatures fixed within the code.

User-specified combination of air and radiant temperatures

User-specified construction surface temperatures

$\checkmark$ User-specified temperatures within construction

$\square$ Other (please specify)
Control laws
- Perfect control
On/Off thermostatic control
On/Off thermostatic control with deadband
$\square$ On/Off thermostatic control with accelerator heater
Q Proportional control
$\square$ More comprehensive control laws (please specify)

Heat transfer within zones

$\square$ Radiation and convection combined

- Radiation and convection treated separately

\section{Convective heat transfer within zones}

$\square$ Coefficients fixed within code

\ Coefficients specified by user

- Coefficients calculated by code as a function of surface orientation

- Coefficients calculated by code as a function of temperature difference

$\square$ Coefficients calculated by code as a function of surface finishes

$\square$ Other (please specify) 
Longwave radiative heat transfer within zones

$\square$ Constant linearized coefficients

- Linearized coefficients based on viewfactors

- Linearized coefficients based on surface emissivities

$\square$ Non-linear treatment of radiation heat exchange

$\square$ Other (please specify)

Number of nodes placed within each layer of walls and slabs

Not applicable for this solution method

- Fixed number of nodes per layer (please specify) $\underline{3}$

$\boldsymbol{\nabla}$ User-specified number of nodes per layer effectively by subdividing layers

Other (please specify

Airgaps within walls and slabs

$\square$ Resistance fixed within code

User-specified constant resistance for different orientations

$\square$ Resistance calculated within code as a function of orientation

$\square$ Radiation and convection treated separately across airgaps

Treated as additional zones=possible

Other (please specify)

\section{Windows (heat loss)}

Fixed resistance used for window element

- Dynamic treatment of window heat loss using same scheme as for opaque elements

$\square$ Other (please specify)

\section{Airgaps within windows}

$\square$ Resistance fixed within code

- User-specified constant resistance

$\square$ Resistance calculated within code as a function of orientation

$\square$ Radiation and convection treated separately across airgaps

Q Airgaps treated as additional zones_-possible

$\square$ Other (please specify)

Windows (transmission of direct shortwave radiation)

$\square$ Fixed transmission used

$\square$ ASHRAE solar heat coefficients used

- Calculated by code as a function of incidence angle

$\square$ Calculated by code from user-specified function of incidence angle

$\square$ Other (please specify)

\section{Windows (transmission of diffuse radiation)}

- Diffuse radiation treated as direct from fixed incidence angle (please specify) $\underline{51^{\circ}}$

Other (please specify) 
Distribution of solar radiation within zones

$\square$ Fixed within the code

Constant user-specified distribution

$\square$ Calculated once by code and used throughout (please describe algorithm)

- Calculated as a function of solar position (please describe algorithm) Ray tracing distribution calculated on hourly basis for one day per month.

Heat transfer between external surfaces and surrounding environment

Radiation and convection combined

- Radiation and convection treated separately

\section{External convection}

Coefficients fixed within code

User-specified constant coefficients

- Calculated within code as a function of orientation

$\square$ Calculated within code as a function of surface finish

$\square$ Calculated within code as a function of wind speed

- Calculated within code as a function of wind speed and direction

$\square$ Other (please specify)

\section{External radiative heat transfer}

$\square$ Assumed to be to ambient air temperature

- Assumed to be to sky temperature read from met file

- Based on calculated sky temperature (please specify algorithm and requirements) Berdahl \& Martin: temperature, humidity, direct and diffuse radiation

- Includes view factor of surrounding obstruction sky/ground/building viewfactors

\section{Diffuse sky model}

Isotropic

- Other (please specify model used) Klucher (default), also available: Perez, Muneer 


$$
\text { 2-84 }
$$




\subsubsection{S3PAS}

Universidad de Sevilla

Spain

September 1992 


\subsubsection{Introduction}

This report describes the modeling assumptions and difficulties in the BESTEST exercise performed with the S3PAS building simulation code.

\subsubsection{Building Specification}

Size and shape. These are as specified in Part $\mathbf{I}$.

Boundary conditions. S3PAS uses constant user-defined convective surface coefficients, and calculates the radiant exchanges coefficients by itself. The convective coefficients assumed for the BESTEST exercise are

- Interior coefficient: $3.16 \mathrm{~W} / \mathrm{m}^{2} \mathrm{~K}$

- Exterior coefficient for walls: $24.67 \mathrm{~W} / \mathrm{m}^{2} \mathrm{~K}$

- Exterior coefficient for windows: $16.37 \mathrm{~W} / \mathrm{m}^{2} \mathrm{~K}$.

Though S3PAS can consider the outside longwave radiant exchange with the sky, we have not calculated any effective sky temperature from the original meteorological file. The sky temperature has been assumed equal to the ambient dry bulb temperature in this exercise. This assumption for outside surfaces is equivalent to using a combined convective-radiant coefficient.

\subsubsection{Construction}

Walls, roof. The Z-transfer functions with an hourly time step are used to model the transient behavior of these multilayered plane elements.

Floor. S3PAS deals with the ground-coupled surfaces by using a hybrid method that combines (a) steadystate bidimensional conductances for the average annual excitations, (b) bidimensional harmonic response for the relevant outdoor cycles, and (c) unidimensional Z-transfer functions for indoor excitations (Alvarez et al. 1989; Rodriguez and Alvarez 1989).

Glazing. Since windows, doors and other movable elements are modeled by S3PAS with the same equations, the input data for these elements are similar. All these elements are assumed noninertial elements (they behave in steady state for each time step), and are composed of several multilayered panes (assumed isothermal) separated by air or any other fixed thermal resistance.

For each layer of each pane, S3PAS requires either the basic optical constants (index of refraction and absorption coefficient of the semitransparent materials) or the normal optical properties, and whether or not the optical properties of the layer depends on the incident angle.

From this basic information, S3PAS calculates the optical properties of the window as a function of the incident angle, and a least square fit gives those properties in the form of a fifth order polynomial in $\cos$ (theta) (where theta is the angle of incidence).

For the separation between panes, S3PAS requires the thermal resistance (if that is not an air layer). In case of an air gap, S3PAS calculates the thermal resistance from the air thickness and the emissivities of the bounding surfaces.

For the BESTEST window, two panes separated by a non-air resistance of $0.1648 \$ \mathrm{~m}^{2} \mathrm{~K} / \mathrm{W}$ has been assumed (this value matches exactly the total thermal resistance of the window specified). 
The optical constants supplied for each pane are

- Index of refraction: 1.526

- (Absorption coefficient) $\times$ (Thickness): 0.062 .

\subsubsection{Shading}

There is no problem in the definition process of the shading devices. The shading planes are defined for each window. The shading of the opaque wall is not possible with the facade solar protections because they shade only the corresponding window for which they are defined and used.

\subsubsection{Building Operation}

Plant and control system. S3PAS can assume a perfect convective conditioning system, which acts as a heating or cooling system depending on whether it maintains the room in the lower or in the upper set point.

Casual gains. The radiant part is distributed uniformly along the interior surfaces. The convective part is released instantaneously in the zone air.

Ventilation. S3PAS takes into account the altitude correction of the air densities; therefore, the air flow rate correction is not necessary.

\subsubsection{Location and Climate.}

From the climate file DRYCOLD.TMY we have constructed a meteorological file readable by S3PAS.

Concerning radiation data, S3PAS needs the horizontal values (direct and diffuse). The time situation that S3PAS gives to the meteorological values matches exactly with that in the meteorological file DRYCOLD.TMY (values at hour between 00.00 and 01.00 are placed at 00:30). 


\subsubsection{TRNSYS}

Vrije Universiteit Brussel (VUB)

Belgium

and

Building Research Establishment (BRE)

United Kingdom

June 1993 


\subsubsection{Introduction}

This report describes the work done by Peter Verstraete of VUB, Belgium, and Foroutan Parand of BRE, U.K., in the BESTEST exercise of the IEA Solar Task 12B/Annex 21C. The BESTEST test cases were carried out with TRNSYS. The input decks for the several test cases were created following the specifications issued by Ron Judkoff (Judkoff 1993). Any assumptions that have been made in addition to these specifications are mentioned in this report. Modeling problems that occurred during the exercise are also noted in the report. Also some additional information on the main assumptions inherent to TRNSYS that is thought to be of importance in the analysis of the results and comparison with other programs, is included.

Input decks were prepared and run by both authors separately. Differences in results were found, due to

- A bug in the BID pre-processor of the TRNSYS 12.2 version used by the VUB. This bug is further described in Section 2.5.7.8. Both authors agreed to carry out further work in this exercise with TRNSYS 13.1.

- Differences or errors in the input decks, such as:

- Modification for altitude carried out twice (on both air density and infiltration value)

- Exchange of the radiant and convective components of the internal gains were swapped

- Definition of layer roof deck

- Initial value for the zone humidity ratio

- Defining of azimuth for east-oriented surfaces $\left(-90^{\circ} \mathrm{C}\right.$ versus $\left.270^{\circ} \mathrm{C}\right)$.

The first error had a major influence on the results (for case 600 , approximately $5 \%$ on annual heating and $2 \%$ on annual cooling). The following two errors had only a small impact on the results. The other differences had no effect on the results.

The TRNSYS results were compared with the results obtained by the other participating programs, with the help of the diagnostic flow diagrams included in the BESTEST specifications. Detected differences are discussed in Section 2.5.7.9.

It should be noted that, by combining their modeling efforts, the authors introduced a quality assurance procedure that has lead to a higher confidence in the obtained results.

\subsubsection{Weather and Location}

The DRYCOLD weather data was used without any change. It was assumed that the weather data was measured at the site of the building; therefore, the shift in local time-compared to solar time-was assumed to be zero, and the longitude information was not used.

\subsubsection{Building Specification}

Geometry. All dimensions, orientations, and shapes used were specified in the BESTEST specifications, with one exception. This exception was the modeling of the two south windows that were lumped together and modeled as a single window with an area of $12 \mathrm{~m}^{2}$. This is thought to have no effect on the results, as TRNSYS does not consider the location of windows and simply uses the area of the windows. 
Construction. No changes were made, but note that TRNSYS assumes all internal surface emittances are equal to 1 . This was rectified by applying an appropriate factor to the SIGMA value (Stefan-Boltzmann constant). This is discussed further in this report.

Ground coupling. This was modeled with no changes from those given in the specifications. However, it was not possible to run the case 990 , as the TRNSYS BID program was unable to calculate correct transfer function coefficients for the floor. This is discussed further in Section 2.5.7.7.

Infiltration. The ambient air density is corrected for the altitude. TRNSYS is then able to correct the infiltration values automatically.

Casual gains. No change from the specifications was necessary.

Exterior combined radiative and convective surface coefficients. TRNSYS uses a combined external surface coefficient. TRNSYS has a feature called "equation" which allowed the use of a variable wind speed dependent external surface coefficient. Equations given in the specifications were used in calculating these coefficients. It is important to note that cases with low emissivity were modeled implicitly, by reducing the combined surface coefficients as suggested in the specifications.

Interior convective surface coefficients. TRNSYS requires constant convective coefficients for internal surfaces. These were calculated from the given combined surface coefficients by deducting the given radiative portion.

High-conductance wall. The high-conductance wall is modeled as a resistance. This was decided for maintaining compatibility with the transparent window cases, since windows in TRNSYS are modeled as a resistance and not as a construction made of glass layers and a cavity.

Transparent window. The properties are discussed below.

Thermal properties. In TRNSYS, windows are thermally modeled as a resistance. However, it requires the glass-to-glass window resistance, internal convective, and external combined coefficients. The glass-toglass resistance was calculated from the given $U$-value and the combined internal and external surface coefficients. The actual glass-to-glass resistance used was $0.168 \mathrm{Km}^{2} / \mathrm{W}$. The internal convective coefficient was calculated by deducting the radiative portion of internal combined surface coefficient, as given in the specifications for surfaces with an emissivity of 0.9 . The value calculated and used, therefore, was $3.16 \mathrm{~W} / \mathrm{m}^{2} \mathrm{~K}$. As the emissivity of the glass given by the specifications is 0.84 , this value implies a slight error. No attempt was made to calculate the correct value of the radiant portion for window.

Optical properties. TRNSYS has a type 35 module which can be used to calculate the transmittance of the global (direct + diffuse) solar radiation. This calculates an effective transmittance. This module uses thickness, the extinction coefficient, and the refractive index to calculate the beam transmittance. The output of this module was used as input to type 56, TRNSYS' multizone building module, in all calculations.

The values obtained for beam transmittance from TRNSYS, from a program written by F. Parand, and from the ENERGY2 Program written by M. Holmes of Over Arrup (See IEA21RN 292/92) are given in Table 2-30 (angles of incidence below 30 degrees are not for TRNSYS, as they were not used in the test run made). 
Table 2-30. Incidence-Angle-Dependent Direct-Beam Transmittance for Double-Pane Glazing Using Various Methods

\begin{tabular}{|c|c|c|c|c|}
\hline $\begin{array}{c}\text { Angle } \\
(\text { Degree })\end{array}$ & $\begin{array}{c}\text { TRNSYS } \\
(\%)\end{array}$ & $\begin{array}{c}\text { Specification } \\
(\%)\end{array}$ & $\begin{array}{c}\text { FP program } \\
(\%)\end{array}$ & $\begin{array}{c}\text { MH program } \\
(\%)\end{array}$ \\
\hline 0 & - & 74.74 & 74.6 & 74.4 \\
\hline 10 & - & 74.68 & 74.5 & 74.4 \\
\hline 20 & - & 74.46 & 74.3 & 74.1 \\
\hline 30 & 73.9 & 73.99 & 73.6 & 73.5 \\
\hline 40 & 72.8 & 72.98 & 72.1 & 72.1 \\
\hline 50 & 70.5 & 70.73 & 65.1 & 68.9 \\
\hline 60 & 64.7 & 65.25 & 60.4 & 61.8 \\
\hline 70 & 50.7 & 51.67 & 45.1 & 47.2 \\
\hline 80 & 23.5 & 26.30 & 21.5 & 22.7 \\
\hline
\end{tabular}

${ }^{\text {a}}$ Program written by F. Parand

${ }^{b}$ Program written by $M$. Holmes

The differences between the specification and TRNSYS are small for angles below 60 degrees, which are the prevalent angles for the cases with south windows throughout the year. However, at higher incidence angle it appears that the specification predicts higher transmittances than TRNSYS, and much higher transmittances than the other two programs. This merits further investigation.

The TRNSYS BID program requires glazing reflectance for outgoing rays reflected from internal surfaces, and average absorptance for both incoming and outgoing rays. Since no guidance was given in the specifications, both inputs were calculated (see Section 2.5.7.9).

Window overhang. No changes to the shape or dimension of overhangs were necessary. However, since the windows on the south side were modeled as a single window, a small but negligible error may occur.

Interior solar distribution. TRNSYS assumes a uniform area and absorptivity weighted distribution of transmitted solar radiation to all surfaces, including windows. It should be noted that the interior solar distribution calculated by TRNSYS differs from the distribution given in the specifications, which has an influence on the heating and cooling results (for case $600-$ on annual heating approximately $0.7 \%$, on annual cooling approximately $1.5 \%$; for case $900-$ on annual heating approximately $2.6 \%$, on annual cooling approximately $2.3 \%$ ).

Mechanical system. No changes were made from those of the specifications.

\subsubsection{Initial Conditions and Timestep}

No preconditioning period was used. The initial temperatures were assumed to be $20^{\circ} \mathrm{C}$ for cases with a mechanical system and $3.3^{\circ} \mathrm{C}$ for free-floating cases. For some test cases, the choice of the timestep is of major importance. This is discussed in further detail in Section 2.5.7.9. 


\subsubsection{Runs with Low-Emittance}

Runs with external low-emittance were carried out implicitly. That, is the radiative part in the given equations for combined surface coefficients was adjusted according to specifications.

For runs with internal low-emittance, the user-given value of the Stefan-Boltzmann was reduced by a factor of 0.1 to obtain the required effect of having internal surface emittances of 0.1 .

\subsubsection{Main Modeling Assumptions}

Sky diffuse model. TRNSYS 13.1 allows the user to select one of the four following sky models:

- ISOTROPIC model

- PEREZ model

- HAY \& Davies model

- $\quad$ REINDL model.

The Hay \& Davies model was selected, which is close to the sky model used in SERIRES (another program participating in the BESTEST).

Shading. TRNSYS applies shading to the total incident solar radiation, which includes both direct and diffuse solar radiation.

Internal longwave exchange. TRNSYS uses a star equivalent node for all surfaces including windows to calculate internal radiant exchange.

\subsubsection{Problems Encountered during Implementation of BESTEST Cases}

The main problem encountered was the inability of TRNSYS to run case 990 . This is explained below.

The TRNSYS BID program was unable to handle thick, dense layers of soil. As shown in Table 2-31, the results fluctuated widely when different thicknesses were used. Because of this, results were not included.

Table 2-31. TRNSYS Case 990 Sensitivity to Soil Thickness

\begin{tabular}{|c|c|c|}
\hline $\begin{array}{c}\text { Soil thickness } \\
(\mathbf{m})\end{array}$ & $\begin{array}{c}\text { Annual heating } \\
(\mathbf{k W h})\end{array}$ & $\begin{array}{c}\text { Annual cooling } \\
(\mathbf{k W h})\end{array}$ \\
\hline 0.50 & 6680 & 1.4 \\
\hline 0.60 & 5400 & 7.1 \\
\hline 0.65 & 5570 & 5.9 \\
\hline 0.70 & 2800 & 1880 \\
\hline 0.80 & 15900 & 0.0 \\
\hline 0.90 & 29800 & 0.0 \\
\hline$>1.0$ & Error (overflow) & Error (overflow) \\
\hline
\end{tabular}


This problem was found to be inherent in the TRNSYS BID program, which calculates the transfer function coefficients. For heavyweight and thick layers, the method used is not able to find the correct roots for the transfer function coefficients. Since the BID program does not check the results of its calculations, the user may be led to believe that the calculated transfer function coefficients are correct. There are tests that can be applied to find out whether the calculated transfer function coefficients are correct or not. These have not been applied yet, but they will be done for all the results at a later time.

\subsubsection{Comparison between Various TRNSYS Versions}

General. In earlier runs of the BESTEST test cases with TRNSYS 12.2, some problems were experienced with the version that the VUB obtained from Wisconsin. These problems were further investigated. As a result, a bug was detected in the BID pre-processor.

Programs used. The BESTEST test cases are run with three different TRNSYS versions:

- TRNSYS 12.2 with BID pre-processor dated April 7, 1988 ; received from Solar Energy Laboratory, University of Wisconsin (further referred to as TRNSYS $12.2 \mathrm{v} 1$ and BID $12.2 \mathrm{v} 1$ )

- TRNSYS 12.2 with BID pre-processor dated July 20, 1989 ; received from TRNSYS-club, University of Liège (further referred to as TRNSYS $12.2 \mathrm{v} 2$ and BID $12.2 \mathrm{v} 2$ )

- TRNSYS 13.1 and BID 13.1.

Problem. Results obtained with. TRNSYS 13.1 and TRNSYS $12.2 \mathrm{v} 2$ are similar, but results from TRNSYS 12.2 v1 are different and not realistic (see Figures 2-17 to 2-22).

Reason. The BID pre-processor translates the BID input deck into two files, later used by type 56 during a TRNSYS simulation. One of these files contains the transfer function coefficients for each wall modeled in the BID input deck. Hard copies of this file generated by BID 12.2 v1 and BID 12.2 v2 (equal to the file generated by BID 13.1) are included in Tables 2-32 and 2-33. Comparing both files leads to the following conclusions:

coefficient $A(B I D 12.2$ v1) = coefficient C (BID 12.2 v2)

coefficient $C(B I D 12.2$ v1) = coefficient A (BID 12.2 v2)

Also, the following check revealed that the problem is caused by a mistake made by BID 12.2 v1 and not by TRNSYS $12.2 \mathrm{v} 1$ :

BID 12.2 v2 + TRNSYS 12.2 v1 = results similar to results TRNSYS 13.1 .

One can conclude that the transfer function coefficients generated by BID $12.2 \mathrm{v} 1$ are wrongly stored in the file, due to a bug in the program. 


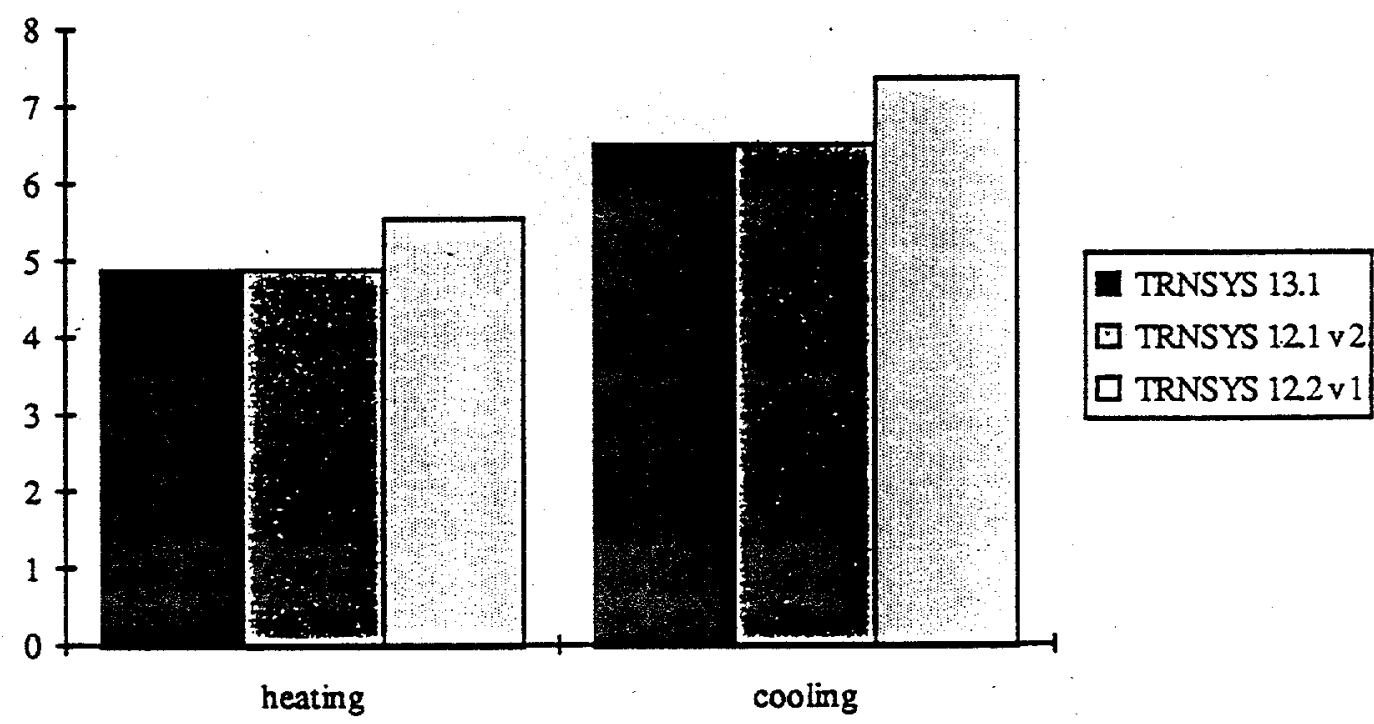

Figure 2-17. Annual heating and cooling: case 600



TRNSYS 13.1

$\square$ TRNSYS $12.2 \times 2$

$\square$ TRNSYS $122 \mathrm{VI}$

Figure 2-18. Annual heating and cooling: case 900 




Figure 2-19. Peak heating and cooling: case 600

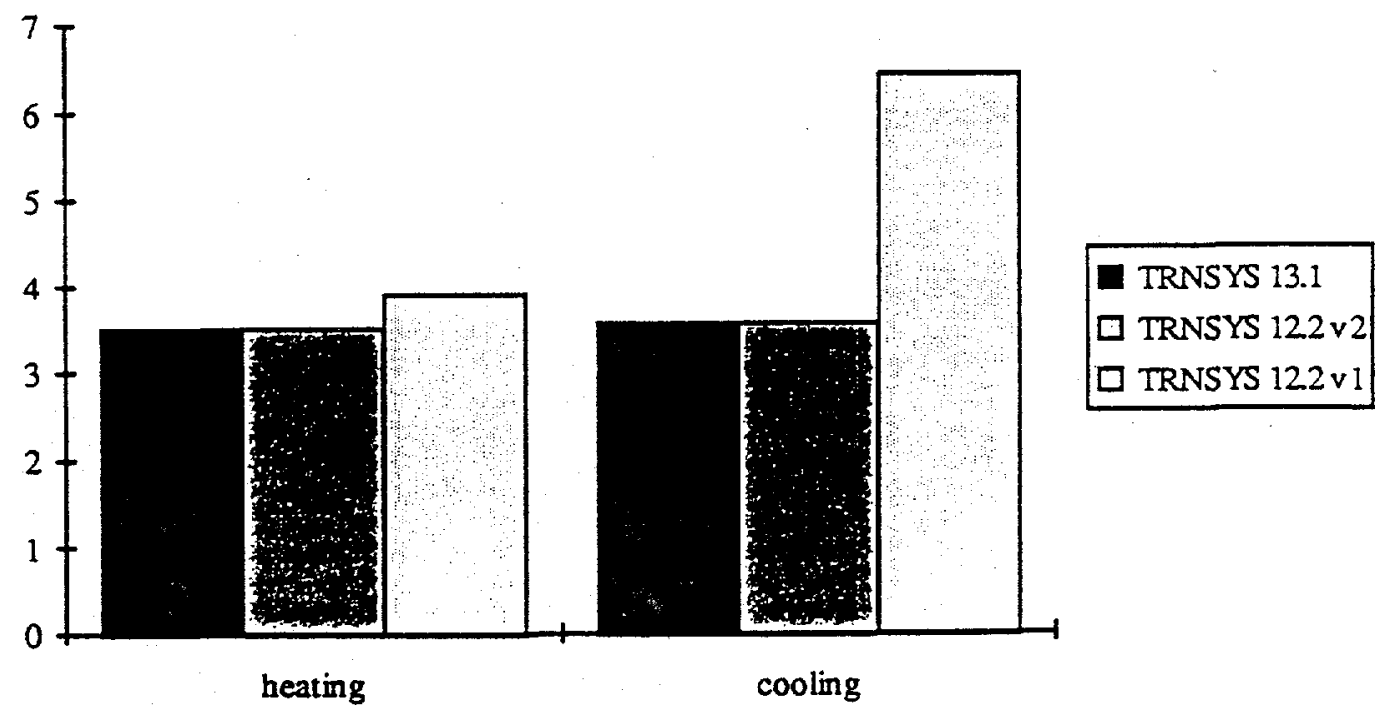

Figure 2-20. Peak heating and cooling: case 900 


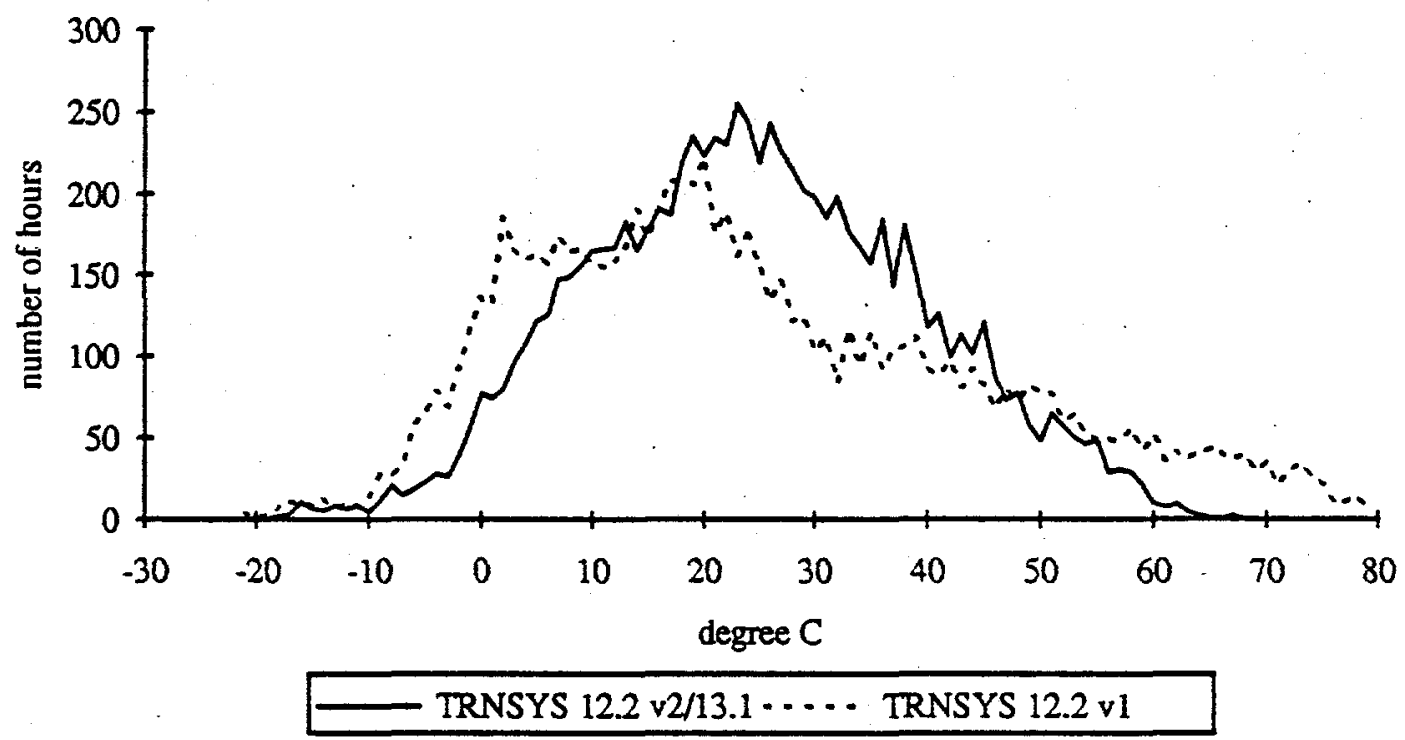

Figure 2-21. Annual hourly temperature frequency: case 600FF

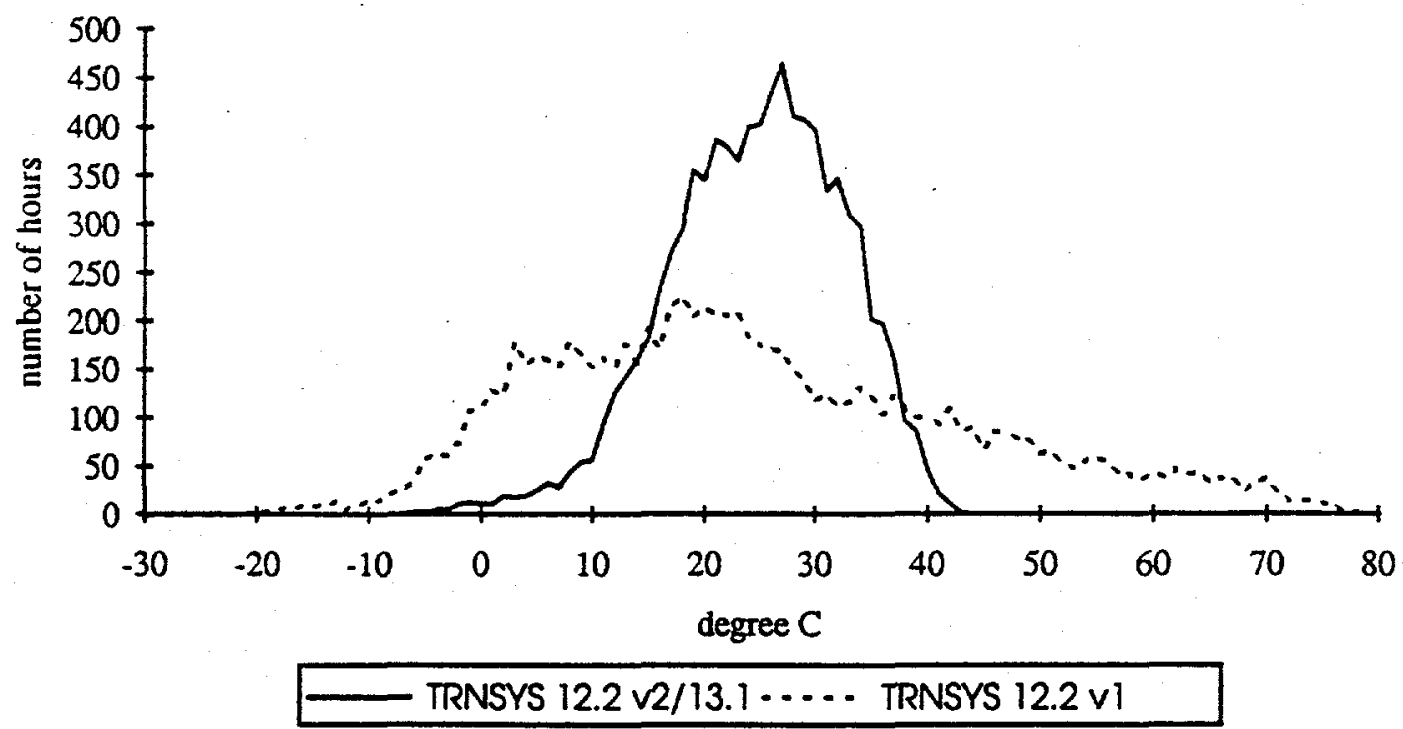

Figure 2-22. Annual hourly temperature frequency: case 900FF 
Table 2-32. Transfer Function Coefficient File Generated by BID 12.2 v1

\begin{tabular}{|c|c|c|c|c|c|}
\hline \multirow[t]{2}{*}{ Coefficient } & \multicolumn{5}{|c|}{ File } \\
\hline & $\begin{array}{l}3 \\
6.0000 \mathrm{E}-01 \\
1.1376 \mathrm{E}+01 \\
-2.0010 \mathrm{E}+03 \\
1 \\
1\end{array}$ & $\begin{array}{l}13 \\
0.0000 \mathrm{E}+00 \\
1.1376 \mathrm{E}+01 \\
0.0000 \mathrm{E}+00 \\
5 \\
3\end{array}$ & $\begin{array}{l}9 \\
6.0000 \mathrm{E}-01 \\
1.1376 \mathrm{E}+01 \\
-2.0020 \mathrm{E}+03 \\
9 \\
6\end{array}$ & $\begin{array}{c}0.5000 \\
\\
14 \\
10\end{array}$ & . \\
\hline $\mathbf{A}$ & $\begin{array}{c}2.07617 \mathrm{E}+01 \\
-3.21223 \mathrm{E}+01 \\
6.95320 \mathrm{E}-01\end{array}$ & $\begin{array}{c}-1.87654 \mathrm{E}+01 \\
2.04748 \mathrm{E}+00 \\
-1.81375 \mathrm{E} .03\end{array}$ & $\begin{array}{r}1.05272 \mathrm{E}-02 \\
-1.10309 \mathrm{E}-05 \\
3.51485 \mathrm{E}-08\end{array}$ & $\begin{array}{r}-2.72890 \mathrm{E}-08 \\
1.75671 \mathrm{E}+01\end{array}$ & $\begin{array}{r}3.01778 E+01 \\
-1.71110 E+01\end{array}$ \\
\hline B & $\begin{array}{l}1.23693 \mathrm{E}+00 \\
5.71980 \mathrm{E}-02 \\
5.41898 \mathrm{E}-02 \\
\end{array}$ & $\begin{array}{l}7.67889 \mathrm{E}-01 \\
1.23153 \mathrm{E}-03 \\
9.87793 \mathrm{E}-05 \\
\end{array}$ & $\begin{array}{l}2.02747 \mathrm{E}-03 \\
2.43995 \mathrm{E}-09 \\
1.06625 \mathrm{E}-09\end{array}$ & $\begin{array}{l}3.61215 \mathrm{E} .09 \\
3.37234 \mathrm{E}-01\end{array}$ & $\begin{array}{l}4.45990 \mathrm{E}-02 \\
7.58110 \mathrm{E}-01\end{array}$ \\
\hline $\mathrm{C}$ & $\begin{array}{c}1.07349 \mathrm{E}+01 \\
-4.00006 \mathrm{E}-02 \\
2.76501 \mathrm{E}-01\end{array}$ & $\begin{array}{r}-8.74983 \mathrm{E}-06 \\
3.05110 \mathrm{E}-06 \\
-5.13713 \mathrm{E}-04\end{array}$ & $\begin{array}{r}2.17869 \mathrm{E}-02 \\
-4.31239 \mathrm{E}-12 \\
3.79588 \mathrm{E}-08\end{array}$ & $\begin{array}{r}-3.05305 \mathrm{E}-08 \\
1.87016 \mathrm{E}+01\end{array}$ & $\begin{array}{c}1.43026 \mathrm{E} .01 \\
-1.78279 \mathrm{E}+01\end{array}$ \\
\hline $\mathrm{D}$ & $\begin{array}{l}1.00000 \mathrm{E}+00 \\
1.00000 \mathrm{E}+00\end{array}$ & $\begin{array}{l}-2.54849 \mathrm{E}-03 \\
-4.42817 \mathrm{E}-02\end{array}$ & $\begin{array}{l}1.00000 \mathrm{E}+00 \\
1.42433 \mathrm{E}-04\end{array}$ & $\begin{array}{l}-2.77268 E-01 \\
-1.09499 E-08\end{array}$ & $2.84691 \mathrm{E}-06$ \\
\hline
\end{tabular}

Note: Observe the switching between coefficients $A$ and $C$ between Table 2-32 and Table 2-33.

Table 2-33. Transfer Function Coefficient File Generated by BID 12.2 v2

\begin{tabular}{|c|c|c|c|c|c|}
\hline \multirow[t]{2}{*}{ Coefficient } & \multicolumn{5}{|c|}{ File } \\
\hline & $\begin{array}{l}3 \\
6.0000 \mathrm{E}-01 \\
1.1376 \mathrm{E}+01 \\
-2.0010 \mathrm{E}+03 \\
1 \\
1\end{array}$ & $\begin{array}{l}13 \\
0.0000 \mathrm{E}+00 \\
1.1376 \mathrm{E}+01 \\
0.0000 \mathrm{E}+00 \\
5 \\
3\end{array}$ & $\begin{array}{l}9 \\
6.0000 \mathrm{E}-01 \\
1.1376 \mathrm{E}+01 \\
-2.0020 \mathrm{E}+03 \\
9 \\
6\end{array}$ & $\begin{array}{l}0.50000 \\
\\
14 \\
10\end{array}$ & \\
\hline A & $\begin{array}{c}1.07349 \mathrm{E}+01 \\
-4.00006 \mathrm{E}-02 \\
2.76501 \mathrm{E}-01\end{array}$ & $\begin{array}{r}-8.74983 E+00 \\
3.05110 E-06 \\
-5.13713 E+04\end{array}$ & $\begin{array}{r}2.17869 \mathrm{E}-02 \\
-4.31239 \mathrm{E}-12 \\
3.79588 \mathrm{E}-08\end{array}$ & $\begin{array}{c}-3.05305 \mathrm{E}-08 \\
1.87016 \mathrm{E}+01\end{array}$ & $\begin{array}{c}1.43026 \mathrm{E}-01 \\
-1.78279 E+01\end{array}$ \\
\hline B & $\begin{array}{l}1.23693 E+00 \\
5.71980 E-02 \\
5.41898 E-02\end{array}$ & $\begin{array}{l}7.67889 \mathrm{E}-01 \\
1.23153 \mathrm{E}-03 \\
9.87793 \mathrm{E}-05\end{array}$ & $\begin{array}{l}2.02747 \mathrm{E}-03 \\
2.43995 \mathrm{E}-09 \\
1.06625 \mathrm{E}-09\end{array}$ & $\begin{array}{l}3.61215 \mathrm{E}-09 \\
3.37234 \mathrm{E}-01\end{array}$ & $\begin{array}{l}4.45990 \mathrm{E}-02 \\
7.58110 \mathrm{E}-01\end{array}$ \\
\hline C & $\begin{array}{r}2.07617 \mathrm{E}+01 \\
-3.21223 \mathrm{E}+01 \\
6.95320 \mathrm{E}-01\end{array}$ & $\begin{array}{r}-1.87654 E+01 \\
2.04748 E+00 \\
-1.81375 E-03\end{array}$ & $\begin{array}{r}1.05272 \mathrm{E}-02 \\
-1.10309 \mathrm{E}-05 \\
3.51485 \mathrm{E}-08\end{array}$ & $\begin{array}{c}-2.72890 \mathrm{E}-08 \\
1.75651 \mathrm{E}+01\end{array}$ & $\begin{array}{r}3.01778 \mathrm{E}+01 \\
-1.71110 \mathrm{E}+01\end{array}$ \\
\hline D & $\begin{array}{l}1.00000 \mathrm{E}+00 \\
1.00000 \mathrm{E}+00\end{array}$ & $\begin{array}{l}-2.54849 \mathrm{E}-03 \\
-4.42817 \mathrm{E}-02\end{array}$ & $\begin{array}{l}1.00000 \mathrm{E}+00 \\
1.42433 \mathrm{E}-04\end{array}$ & $\begin{array}{l}-2.77268 \mathrm{E}-01 \\
-1.09499 \mathrm{E}-08\end{array}$ & $2.84691 \mathrm{E}-06$ \\
\hline
\end{tabular}

Note: Observe the switching between coefficients $A$ and $C$ between Table 2-32 and Table 2-33. 
Comparison source code BID 12.2 v1 versus BID 12.2 v2. By comparing both BID source codes, several differences were detected. They are listed in Table 2-34.

Table 2-34. TRNSYS BID Source Code Comparison

\begin{tabular}{|c|c|c|}
\hline Line number & BID 12.2 v1 & $\begin{array}{c}\text { BID } 12.2 \mathrm{v} 2 \\
\text { (correct version) }\end{array}$ \\
\hline 456 & $\begin{array}{l}\text { CALL FILL (NDUM,3,1,5,NV, } \\
\text { DCOOL (NODE-1,NHEAT), } \\
\text { 108T,ERROR) }\end{array}$ & $\begin{array}{l}\text { CALL FILL (NDUM,3,1,5,NV, } \\
\text { DCOOL(NODE-1,NCOOL), } \\
\text { IOUT,ERROR) }\end{array}$ \\
\hline $\begin{array}{l}1415 \\
1416 \\
1417 \\
1418\end{array}$ & $\begin{array}{l}\text { TH(NL)=DLAY }(1, \text { NLTYPE }) \\
\text { CON(NL)=DLAY }(2, N L T Y P E) \\
\text { SH(NL)=DLAY }(3, N L T Y P E) \\
\text { DEN(NL)=DLAY }(4, N L T Y P E)\end{array}$ & $\begin{array}{l}\text { TH(N)=DLAY }(1, \text { NLTYPE }) \\
\text { CON(N)=DLAY }(2, N L T Y P E) \\
\text { SH(N)=DLAY }(3, N L T Y P E) \\
\text { DEN(N)=DLAY }(4, N L T Y P E)\end{array}$ \\
\hline $\begin{array}{l}1419 \\
1420 \\
2137\end{array}$ & $\begin{array}{l}\text { RES(NL)=DLAY(5,NLTYPE) } \\
\text { IF(RES(NL).LT.1.E-06) } \\
\text { RESIS=.FALSE. } \\
\text { DELTA=INT(FLOAT(NTABL } \\
\text { E-1)*AMOD(FLOAT } \\
\text { (STRING)*THETA,1.)+0.1)+1 }\end{array}$ & $\begin{array}{l}\text { RES(N)=DLAY(5,NLTYPE) } \\
\text { IF(RES(N).LT.1.E-06)RESIS= } \\
\text {.FALSE. } \\
\text { DELTA=INT(FLOAT(NTABLE-1)* } \\
\text { AMOD(FLOAT(STRING)*THETA, } \\
\text { 1.))+1 }\end{array}$ \\
\hline 2150 & $\mathrm{NEXT}=\mathrm{NEXT}+\mathrm{DELTA}$ & $\begin{array}{l}\text { NEXT=MOD(NEXT+DELTA-1, } \\
\text { NTABLE)+1 }\end{array}$ \\
\hline
\end{tabular}

Conclusion. Users of TRNSYS 12.2 should check the source code of the BID pre-processor and, if necessary, carry out corrections (See Table 2-34). This check will ensure that a correct transfer function coefficient file is created by BID, which is used later during TRNSYS simulations with. the type 56 module (multizone building module). Or switch to a version update.

\subsubsection{BESTEST Diagnostic Flow Diagrams and Error Detection}

Detected differences. The TRNSYS results (March 1993 run) were compared with the results obtained by the other participating programs, using the diagnostic flow diagrams included in the BESTEST specifications. The following differences were detected :

- For all test cases with windows-lower annual cooling and peak cooling

- For case 960 -minimum temperature in sunspace $4.2^{\circ} \mathrm{C}$ lower than nearest

- For delta case 640-600-peak heating more than $0.5 \mathrm{~kW}$ lower than nearest (possible setback problem)

- For delta case 940-640_-sensitivity in opposite direction (possible mass/setback interaction problem)

- For delta case 960-900-annual heating more than 0.5 MWh higher than nearest (possible mass/interzone heat transfer problem).

A number of sensitivity studies were carried out to identify the reason(s) for some of the differences (see following sections). 
Solar loss. In the March 1993 BESTEST run, the following values were used for glazing reflectance for outgoing solar radiation and average absorptance for both incoming and outgoing solar radiation:

$$
\begin{aligned}
& \rho=0.1511 \\
& \alpha=0.1191 .
\end{aligned}
$$

For cases 600 and 900 , TRNSYS calculated a solar loss of $8.3 \%$, which is more than double the value given in the specifications $(3.5 \%)$. Table $2-35$ shows the impact of the solar loss on the heating and cooling results.

Table 2-35. TRNSYS Sensitivity to Cavity Albedo, Cases 600 and 900

\begin{tabular}{|l|c|c|c|c|c|c||}
\hline & \multicolumn{3}{|c|}{ Annual heating loads (MWh) } & \multicolumn{3}{c|}{ Annual cooling loads (MWh) } \\
\hline Case & $\begin{array}{c}\text { March 1993 } \\
\text { run }\end{array}$ & $\begin{array}{c}\text { Corrected } \\
\text { solar loss }\end{array}$ & $\begin{array}{c}\text { Difference } \\
(\%)\end{array}$ & $\begin{array}{c}\text { March 1993 } \\
\text { run }\end{array}$ & $\begin{array}{c}\text { Corrected } \\
\text { solar loss }\end{array}$ & $\begin{array}{c}\text { Difference } \\
(\%)\end{array}$ \\
\hline \hline 600 & 4.811 & 4.777 & -0.71 & 5.958 & 6.387 & 7.20 \\
\hline 900 & 1.768 & 1.649 & -6.73 & 2.210 & 2.476 & 12.04 \\
\hline & \multicolumn{2}{|c|}{ Peak heating loads (kW) } & Peak cooling loads (kW) \\
\hline Case & $\begin{array}{c}\text { March 1993 } \\
\text { run }\end{array}$ & $\begin{array}{c}\text { Corrected } \\
\text { solar loss }\end{array}$ & $\begin{array}{c}\text { Difference } \\
(\%)\end{array}$ & $\begin{array}{c}\text { March 1993 } \\
\text { run }\end{array}$ & $\begin{array}{c}\text { Corrected } \\
\text { solar loss }\end{array}$ & $\begin{array}{c}\text { Difference } \\
(\%)\end{array}$ \\
\hline \hline 600 & 3.931 & 3.931 & 0.00 & 6.083 & 6.378 & 4.85 \\
\hline 900 & 3.522 & 3.508 & -0.40 & 3.347 & 3.558 & 6.30 \\
\hline
\end{tabular}

Based on these results, it was decided to correct the solar loss in all the BESTEST test cases by modifying the reflectance for outgoing solar radiation to $\rho=0.5872$.

Analytical conduction tests. A validation procedure for heat conduction through opaque walls was used to validate the conduction solution technique implemented in TRNSYS. The procedure is described in a CEN WG6/TC89 document (Thermal Performance of Buildings. Internal temperature in summer of a room without mechanical cooling - general criteria and calculation procedures. CEN, doc. January 1994, CEN/TC89 n. 244 E.) and is summarized in Section 2.5.7 Attachment 1. In this procedure, five external wall constructions are tested (tests 1 to 5). Attachment 2 summarizes the TRNSYS results for the validation procedure.

For the heavyweight structure (test 1), 24 hours after the excitation the error (the difference between TRNSYS results and those of the analytical test) was about $2^{\circ} \mathrm{C}$. Similarly, for the lightweight structure (test 2), the error was up to $2^{\circ} \mathrm{C}$ for hours 1 and 6 . However, for normal constructions (test 5), the error is less than $0.2^{\circ} \mathrm{C}$, which is acceptable. As a result of this investigation, one can conclude that TRNSYS has an intrinsic problem in its conduction solution technique that causes only small errors, unless the structure is either too heavyweight or too lightweight.

Timestep. Sensitivity studies showed that a correct choice of the timestep is important, especially in the nighttime setback cases 640 and 940 . This is summarized in Table 2-36 (1 h in March 1993 run versus $0.5 \mathrm{~h})$. 
Table 2-36. TRNSYS Sensitivity to Timestep

\begin{tabular}{||l|c|c|c|c|c|c||}
\hline & \multicolumn{3}{|c|}{ Annual heating loads (MWh) } & \multicolumn{3}{c|}{ Annual cooling loads (MWh) } \\
\hline Case & $\begin{array}{c}\text { March 1993 } \\
\text { run }\end{array}$ & $\begin{array}{c}\text { Timestep } \\
\mathbf{0 . 5} \mathbf{~ h}\end{array}$ & $\begin{array}{c}\text { Difference } \\
(\%)\end{array}$ & $\begin{array}{c}\text { March 1993 } \\
\text { run }\end{array}$ & $\begin{array}{c}\text { Timestep } \\
\mathbf{0 . 5} \mathbf{~ h}\end{array}$ & $\begin{array}{c}\text { Difference } \\
(\%)\end{array}$ \\
\hline \hline 600 & 4.811 & 4.905 & 1.95 & 5.958 & 6.059 & 1.70 \\
640 & 2.837 & 3.084 & 8.71 & 5.636 & 5.824 & 3.34 \\
900 & 1.768 & 1.773 & 0.28 & 2.210 & 2.217 & 0.32 \\
940 & 1.126 & 1.176 & 4.44 & 2.114 & 2.127 & 0.61 \\
\hline $640-600$ & -1.9074 & -1.821 & -7.75 & -0.322 & -0.235 & -27.02 \\
$940-900$ & -0.642 & -0.597 & -7.01 & -0.096 & -0.090 & -6.25 \\
$940-640$ & -1.711 & -1.908 & 11.51 & -3.522 & -3.697 & 4.97 \\
\hline & \multicolumn{2}{|c|}{ Peak heating loads (kW) } & \multicolumn{2}{c|}{ Peak cooling loads (kW) } \\
\hline & March 1993 & Timestep & Difference & March 1993 & Timestep & Difference \\
Case & run & $\mathbf{0 . 5} \mathbf{~ h}$ & $\mathbf{( \% )}$ & run & $\mathbf{0 . 5 ~ h}$ & $(\%)$ \\
\hline \hline 600 & 3.931 & 3.931 & 0.00 & 6.083 & 6.186 & 1.70 \\
640 & 4.964 & 5.731 & 15.45 & 6.003 & 6.139 & 2.26 \\
900 & 3.522 & 3.531 & 0.26 & 3.347 & 3.556 & 0.26 \\
940 & 5.236 & 5.136 & -1.91 & 3.347 & 3.356 & 0.26 \\
\hline $640-600$ & 1.033 & 1.800 & 74.25 & -0.080 & -0.047 & -40.97 \\
$940-900$ & -1.714 & 1.605 & -6.36 & 0.0 & 0.0 & \\
$940-640$ & 0.272 & -0.595 & -318.5 & -3.388 & -3.513 & -3.69 \\
\hline
\end{tabular}

Sunspace case. The effect of correcting the solar loss for this case is shown in Table 2-37.

This modification in the input decks had only a small impact on the annual heating results for delta case 960-900.

The BID pre-processor could not calculate correct transfer function coefficients when a smaller timestep $(0.5 \mathrm{~h}$ instead of $1 \mathrm{~h})$ was used. This problem is under further investigation.

Further checking of the input files did not reveal other input mistakes or modeling errors.

\subsubsection{Conclusions}

All the BESTEST test cases were run again after correcting the solar losses and using a smaller timestep of $0.5 \mathrm{~h}$ (with the exception of case 960 and 990). TRNSYS was unable to run case 990 because of the high-capacity thick layer of soil. For case 960 , only the solar losses were corrected; the simulation run was carried out with a timestep of $1 \mathrm{~h}$. Problems experienced with cases 960 and 990 are probably caused by the conduction solution technique used in TRNSYS. For normal constructions this technique only causes small errors, unless the construction is either too heavyweight or too lightweight. This topic needs further investigation.

A main difference in the TRNSYS input data from those given in the specifications-that have some effect-is the solar transmittance through the window. The transmittance of the window given in the specifications were higher than those calculated by TRNSYS. Large discrepancies were observed for 
Table 2-37. TRNSYS Sensitivity to Cavity Albedo, Cases 900 and 960

\begin{tabular}{|c|c|c|c|c|c|c|}
\hline & \multicolumn{3}{|c|}{ Annual heating loads (MWh) } & \multicolumn{3}{|c|}{ Annual cooling loads (MWh) } \\
\hline Case & $\begin{array}{l}\text { March } 1993 \\
\text { run }\end{array}$ & $\begin{array}{l}\text { Corrected } \\
\text { solar loss }\end{array}$ & $\begin{array}{c}\text { Difference } \\
(\%)\end{array}$ & $\begin{array}{l}\text { March } 1993 \\
\text { run }\end{array}$ & $\begin{array}{l}\text { Corrected } \\
\text { solar loss }\end{array}$ & $\begin{array}{c}\text { Difference } \\
(\%)\end{array}$ \\
\hline $\begin{array}{l}900 \\
960 \\
960-900\end{array}$ & $\begin{array}{l}1.768 \\
3.498 \\
1.730\end{array}$ & $\begin{array}{l}1.649 \\
3.373 \\
1.724\end{array}$ & $\begin{array}{l}-6.73 \\
-3.57 \\
-0.35\end{array}$ & $\begin{array}{r}2.210 \\
0.387 \\
-1.823\end{array}$ & $\begin{array}{r}2.476 \\
0.441 \\
-2.065\end{array}$ & $\begin{array}{r}12.04 \\
6.17 \\
13.27\end{array}$ \\
\hline & \multicolumn{3}{|c|}{ Peak heating loads (kW) } & \multicolumn{3}{|c|}{ Peak cooling loads (kW) } \\
\hline $\begin{array}{l}900 \\
960 \\
960-900\end{array}$ & $\begin{array}{c}3.522 \\
2.535 \\
-0.805\end{array}$ & $\begin{array}{c}3.508 \\
2.522 \\
-0.798\end{array}$ & $\begin{array}{l}-0.40 \\
-0.51 \\
-0.87\end{array}$ & $\begin{array}{r}3.347 \\
1.062 \\
-2.656\end{array}$ & $\begin{array}{r}3.558 \\
1.378 \\
-2.745\end{array}$ & $\begin{array}{r}6.30 \\
29.76 \\
3.35\end{array}$ \\
\hline \multicolumn{7}{|c|}{ Temperature in sunspace for case $960\left({ }^{\circ} \mathrm{C}\right)$} \\
\hline & \multicolumn{3}{|c|}{ March 1993 run } & \multicolumn{3}{|c|}{ Corrected solar loss } \\
\hline $\begin{array}{l}\text { Mean } \\
\text { Maximum } \\
\text { Minimum }\end{array}$ & & $\begin{array}{l}27.41 \\
51.80 \\
-3.55\end{array}$ & & & & $\begin{array}{l}28.96 \\
55.34 \\
-2.82\end{array}$ \\
\hline
\end{tabular}

values calculated by several algorithms for the transmittance of the window. It is suggested that a theoretically sound and usable method be identified and documented in BESTEST specifications.

BESTEST clearly proved its usefulness by detecting a bug in early releases of TRNSYS 12.2 and by detecting input deck mistakes and modeling errors.

Users of TRNSYS 12.2 should check the source code of the BID pre-processor and, if necessary, carry out corrections (see Section 2.5.7.8). This check will ensure that a correct transfer function coefficient file is created by BID. However, it is advisable to switch to the latest version update. 


\subsubsection{Attachment 1}

\section{Summary of Validation Procedure Proposed by CENWG6/TC89 ${ }^{1}$}

Heat conduction through opaque walls requires the evaluation of the indoor temperature of a room of different external walls at several time intervals (specified below). The procedure includes the following:

1. Characteristics of the room

- internal dimensions $=1 \times 1 \times 1 \mathrm{~m}$.

- emissivities of each internal and external surface $=0$

- internal convective heat transfer coefficient of each wall $=2.7 \mathrm{~W} / \mathrm{m}^{2} \mathrm{~K}$.

- external convective heat transfer coefficient of each wall $=14.5 \mathrm{~W} / \mathrm{m}^{2} \mathrm{~K}$.

- shortwave radiation exchanges at inside and outside $=0$

- longwave radiation exchanges at inside and outside $=0$

- thermal capacity of the internal air is assumed to be 0

- boundary conditions-variation of the outdoor air temperature (Figure 2-23)

2. Data to be calculated

The internal air temperature will be determined at hours $1,2,6,12,24$, and 120 .

3. Tests

Tests will be done for the walls, as described in Table 2-38.

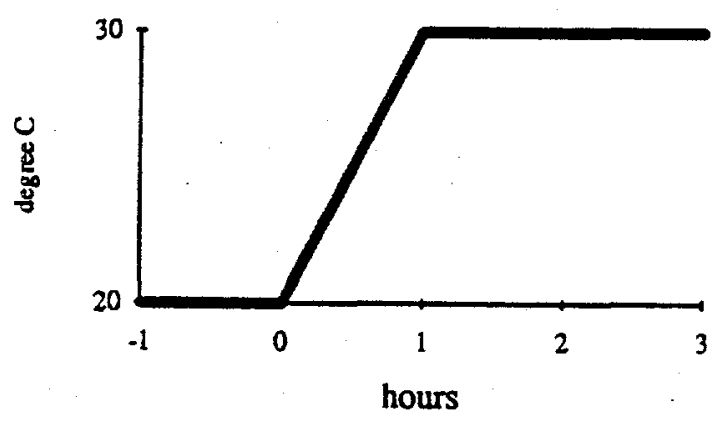

Figure 2-23. Variation of outdoor air temperature

${ }^{1}$ Thermal Performance of Buildings. Internal temperature in summer of a room without mechanical cooling-general criteria and calculation procedures. CEN, doc. January 1994, CEN/TC89 n. 244 E. 
Table 2-38. Wall Conduction Validation Test Matrix

\begin{tabular}{|c|c|c|c|c|}
\hline Test & $\mathbf{d}(\mathbf{m})$ & $\lambda(\mathbf{W} / \mathbf{m K})$ & $\rho\left(\mathbf{k g} / \mathbf{m}^{\mathbf{3}}\right)$ & $\mathbf{c}(\mathbf{J} / \mathbf{k g K})$ \\
\hline \hline 1 & 0.20 & 1.2 & 2000 & 1.0 \\
\hline 2 & 0.10 & 0.04 & 50 & 1.0 \\
\hline 3 & 0.005 & 0.14 & 800 & 1.5 \\
\hline & 0.20 & 1.2 & 2000 & 1.0 \\
$4^{\mathrm{a}}$ & 0.10 & 0.04 & 50 & 1.0 \\
& 0.005 & 0.14 & 800 & 1.5 \\
\hline & 0.005 & 0.14 & 800 & 1.5 \\
$5^{\mathrm{a}}$ & 0.10 & 0.04 & 50 & 1.0 \\
& 0.20 & 1.2 & 2000 & 1.0 \\
\hline
\end{tabular}

${ }^{a}$ From outside to inside 


\subsubsection{Attachment 2}

TRNSYS Results Obtained with the Validation Procedure

Table 2-39. Comparison of Indoor Air Temperatures $\left({ }^{\circ} \mathrm{C}\right)$

\begin{tabular}{|c|c|c|c|c|c|c|c|}
\hline \multirow[b]{2}{*}{ Test } & & \multicolumn{6}{|c|}{ Time (h) } \\
\hline & & 1 & 2 & 6 & 12 & 24 & 120 \\
\hline Test 1 & $\begin{array}{l}\text { TRNSYS } \\
\text { analytical }^{\mathrm{a}}\end{array}$ & $\begin{array}{l}20.01 \\
20.01\end{array}$ & $\begin{array}{l}20.06 \\
20.13\end{array}$ & $\begin{array}{l}21.76 \\
21.19\end{array}$ & $\begin{array}{l}24.52 \\
24.54\end{array}$ & $\begin{array}{l}27.61 \\
29.54\end{array}$ & $\begin{array}{l}30.00 \\
30.00\end{array}$ \\
\hline Test 2 & $\begin{array}{l}\text { TRNSYS } \\
\text { analytical }^{\mathrm{a}}\end{array}$ & $\begin{array}{l}20.78 \\
22.05\end{array}$ & $\begin{array}{l}24.10 \\
25.40\end{array}$ & $\begin{array}{l}29.44 \\
29.54\end{array}$ & $\begin{array}{l}29.98 \\
29.99\end{array}$ & $\begin{array}{l}30.00 \\
30.00\end{array}$ & $\begin{array}{l}30.00 \\
30.00\end{array}$ \\
\hline Test 3 & $\begin{array}{l}\text { TRNSYS } \\
\text { analytical }^{\mathrm{a}}\end{array}$ & $\begin{array}{l}25.98 \\
28.71\end{array}$ & $\begin{array}{l}29.81 \\
29.85\end{array}$ & $\begin{array}{l}30.00 \\
30.00\end{array}$ & $\begin{array}{l}30.00 \\
30.00\end{array}$ & $\begin{array}{l}30.00 \\
30.00\end{array}$ & $\begin{array}{l}30.00 \\
30.00\end{array}$ \\
\hline Test 4 & $\begin{array}{l}\text { TRNSYS } \\
\text { analytical }^{\mathrm{a}}\end{array}$ & $\begin{array}{l}20.03 \\
20.00\end{array}$ & $\begin{array}{l}20.03 \\
20.00\end{array}$ & $\begin{array}{l}20.38 \\
20.45\end{array}$ & $\begin{array}{l}22.22 \\
22.33\end{array}$ & $\begin{array}{l}26.01 \\
26.03\end{array}$ & $\begin{array}{l}30.00 \\
29.99\end{array}$ \\
\hline Test 5 & $\begin{array}{l}\text { TRNSYS } \\
\text { analytical }^{\text {a }}\end{array}$ & $\begin{array}{l}20.12 \\
20.00\end{array}$ & $\begin{array}{l}20.12 \\
20.00\end{array}$ & $\begin{array}{l}20.18 \\
20.07\end{array}$ & $\begin{array}{l}20.37 \\
20.25\end{array}$ & $\begin{array}{l}20.75 \\
20.64\end{array}$ & $\begin{array}{l}23.34 \\
23.21\end{array}$ \\
\hline
\end{tabular}

${ }^{a}$ Analytical results as given in document Thermal Performance of Buildings. Internal temperature in summer of a room without mechanical cooling-general criteria and calculation procedures. CEN, doc. January 1994, CEN/TC89 n. $244 \mathrm{E}$. 


\subsubsection{Pro Forma}

Program name (please include version number)

possible to use

used in BESTEST

TRNSYS 13.1

Your name and organization

Peter Verstraete-VUB

Program status

$\square$ Public domain

Commercial

Other (please specify)

Solution method

$\square \quad$ Explicit finite difference

$\square$ Implicit finite difference

$\square \quad$ Weighting factors

Response factor

- Other (please specify) Transfer function method, with use of Laplace and Z-transform theory

Timing convention for meteorological data: sampling interval

Fixed within code (please specify interval)

User-specified

Timing convention for meteorological data: period covered by first record

$\square \quad$ Fixed within code (please specify period or time which meteorological record covers)

- User-specified

Meteorological data reconstruction scheme

$\square$ Climate assumed stepwise constant over sampling interval

- Linear interpolation used over climate sampling interval except for solar radiation, see "other"

- Other (please specify) Interpolation of solar radiation data using the ratio of extraterrestrial radiation over timestep to extraterrestrial radiation over period which corresponds to data.

\section{Output timing conventions}

$\square$ Produces spot predictions at the end of each timestep

$\square$ Produces spot output at end of each hour

$\square$ Produces average outputs for each hour (please specify period to which value relates)

Produces average outputs for each timestep 


\section{Treatment of zone air}

- Single temperature (i.e., good mixing assumed)

$\square \quad$ Stratified model

$\square$ Simplified distribution model

$\square$ Full CFD model

$\square$ Other (please specify)

\section{Heaters (dynamies)}

- No dynamics assumed (output is instantaneous)

$\square$ Simple first order dynamics

$\square$ Detailed modeling of heat source dynamics

\section{Heaters (output characteristics)}

- Purely convective

$\square$ Radiative/Convective split fixed within code

$\square$ Radiative/Convective split specified by user

Detailed modeling of heat source output

\section{Control temperature}

a Air temperature

$\square$ Combination of air and radiant temperatures fixed within the code

$\square$ User-specified combination of air and radiant temperatures

$\square$ User-specified construction surface temperatures

$\square$ User-specified temperatures within construction

$\square$ Other (please specify)

\section{Control laws}

- Perfect control

On/Off thermostatic control

On/Off thermostatic control with deadband

$\square$ On/Off thermostatic control with accelerator heater

Proportional control

$\square$ More comprehensive control laws (please specify)

\section{Heat transfer within zones}

$\square \quad$ Radiation and convection combined

- Radiation and convection treated separately

\section{Convective heat transfer within zones}

$\square$ Coefficients fixed within code

- Coefficients specified by user

$\square$ Coefficients calculated by code as a function of surface orientation

$\square$ Coefficients calculated by code as a function of temperature difference

$\square$. Coefficients calculated by code as a function of surface finishes

Other (please specify) 
Longwave radiative heat transfer within zones

- Constant linearized coefficients Boltzmann etc. and approx. average surface temp. are user specified inputs.

$\square$ Linearized coefficients based on viewfactors

$\square$ Linearized coefficients based on surface emissivities

$\square$ Non-linear treatment of radiation heat exchange

$\square \quad$ Other (please specify)

Number of nodes placed within each layer of walls and slabs

Not applicable for this solution method

- Fixed number of nodes per layer (please specify)

$\square$ User-specified number of nodes per layer

$\square$ Other (please specify

Airgaps within walls and slabs

$\square$ Resistance fixed within code

User-specified constant resistance

$\square$ Resistance calculated within code as a function of orientation

$\square$ Radiation and convection treated separately across airgaps

$\square \quad$ Treated as additional zones

$\square \quad$ Other (please specify)

Windows (heat loss)

- Fixed resistance used for window element user specified

$\square$ Dynamic treatment of window heat loss using same scheme as for opaque elements

$\square \quad$ Other (please specify)

\section{Airgaps within windows}

$\square$ Resistance fixed within code

U User-specified constant resistance

$\square$ Resistance calculated within code as a function of orientation

$\square$ Radiation and convection treated separately across airgaps

$\square$ Airgaps treated as additional zones

$\square \quad$ Other (please specify)

Windows (transmission of direct shortwave radiation)

$\square \quad$ Fixed transmission used

$\square$ ASHRAE solar heat coefficients used

- Calculated by code as a function of incidence angle

$\square$ Calculated by code from user-specified function of incidence angle

$\square$ Other (please specify)

Windows (transmission of diffuse radiation)

$\square$. Diffuse radiation treated as direct from fixed altitude (please specify)

- Other (please specify) Diffuse radiation is part of total incident radiation 
Distribution of solar radiation within zones

Fixed within the code

$\square$ Constant user-specified distribution

a Calculated once by code and used throughout (please describe algorithm) Use of absorptance weighted area ratios

$\square$ Calculated as a function of solar position (please describe algorithm)

Heat transfer between external surfaces and surrounding environment

- Radiation and convection combined

$\square$ Radiation and convection treated separately

\section{External convection}

$\square$ Coefficients fixed within code

$\square$ User-specified constant coefficients

$\square$ Calculated within code as a function of orientation

$\square$ Calculated within code as a function of surface finish

$\square$ Calculated within code as a function of wind speed

$\square$ Calculated within code as a function of wind speed and direction

- Other (please specify) Algorithm specified in input deck (function of wind speed)

\section{External radiative heat transfer}

Assumed to be to ambient air temperature

$\square \quad$ Assumed to be to sky temperature read from met file

$\square$ Based on calculated sky temperature (please specify algorithm and requirements)

$\square$ Includes view factor of surrounding obstruction

\section{Diffuse sky model}

$\square \quad$ Isotropic

- Other (please specify model used) Hay and Davis (BESTESTS), Reindl (Empirical) 


\subsubsection{TASE}

Tampere University, Finland

July 1993 


\subsubsection{Introduction}

This report describes the modeling strategy used for the BESTEST carried out at Tampere University of Technology with the TASE program. Any modeling assumptions that had to be made in addition to the building specification issued by Ron Judkoff are noted.

\subsubsection{The Background of the TASE Program}

The first version of TASE was made at the Technical Research Centre of Finland in 1975 and sponsored by the Finnish government. Since 1986, TASE has been redeveloped at Tampere University of Technology. It has been used in many Finnish energy analysis investigations.

The basis of the solution method of TASE is a matrix equation of heat balances. There are separate heat balance equations for indoor air and every surface of the room. The heat balance for indoor air includes convective heat fluxes to all surfaces of the room and all convective heat sources in the room (e.g., heating, cooling, people, equipment, and light loads.) Each surface heat balance equation describes the net heat flux at the inside surface. This is a function of radiative heat transfer between inside surfaces, convective heat transfer to indoor air and transient heat conduction through the wall. The transient heat conduction is calculated using the transfer factors of Mitalas and Arsenault (Mitalas and Arsenault 1971). In each timestep, the solution of the heat balance matrix equation gives simultaneous exact values of room air temperature and inside surface temperature. The heat fluxes and energies are then calculated using those temperatures. There are no weighting factors.

The TASE program has been made so that the user can easily change input data during the calculation. Many of the input data are organized in independent timetables so the user can easily describe complicated combinations of loads. There is the option to create many special output files that include only one variable (e.g., room temperature, heating load, surface temperature, or surface heat flux). Under redevelopment since 1986, many new calculation models have been added which have improved the calculating results; they have also been used in this study. Examples of improved features are variable convective and radiative inside surface heat transfer coefficients, variable window thermal transmittance (U-value), and transient conduction from a slab to the ground.

\subsubsection{Simulation of the Base Building}

The building was described for the TASE program as defined in Part I. Every surface was undivided, and calculated temperature and heat flux of the surface was the average value of the whole surface. Similarly, the room air temperature was the average value of the whole room space. The thermostat control temperature was the dry air temperature.

The convective heat transfer between room air and inside surfaces was calculated using variable convective heat transfer coefficients. The convective heat transfer coefficients were functions of temperature differences between room air and various inside surfaces, and the surface type. Walls, ceilings, floors, and windows have separate correlations (Alamdari and Hammond 1983); these are graphed in Figure 2-24.

The radiative heat transfer between inside surfaces was calculated using variable radiative heat transfer coefficients and view factors. The radiative heat transfer coefficients were calculated using the formula

$$
h_{\mathrm{r}}=4 \varepsilon \sigma \mathrm{T}^{3} \text {, }
$$




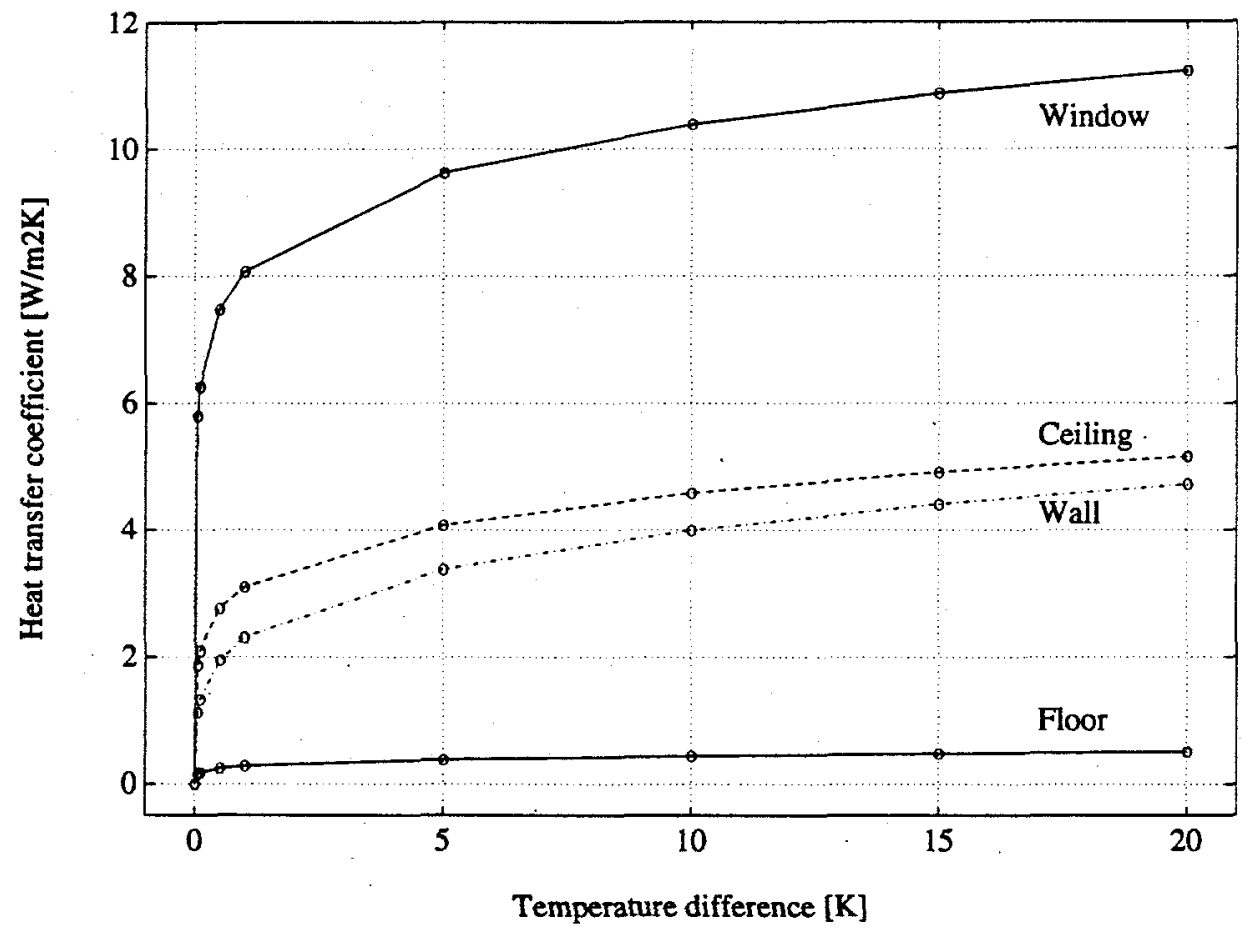

Figure 2-24. Variable convective heat-transfer coefficients

where:

$$
\begin{aligned}
& \varepsilon=\text { effective emissivity } \\
& \sigma=\text { Stefan-Boltzmann constant } \\
& T=\text { the mean value of the surface temperatures. }
\end{aligned}
$$

The effective emissivity has been constant over the entire calculation period. The transient heat conduction in the walls, ceiling, and floor was calculated using the transfer factors. Window heat conduction is modeled as steady state conduction, where window U-value varies as a function of inside window surface temperature and outdoor temperature. The varying window U-value accounts for convective and radiative heat transfer within the window.

The convective and radiative heat transfer for all outside surfaces was calculated using the BESTEST constant total heat transfer coefficients. The effect of Denver's high altitude on the density of outdoor air was taken into account by using the BESTEST adjustment factors.

The diffuse solar radiation to an inclined surface code of TASE needed two additional terms of weather data that have not been included in the given weather data file. The first term was total reflected solar radiation from the ground. This missing term was calculated by multiplying the sum of the direct and diffuse solar radiation with the reflectivity of ground. The other term was the relative cloud cover, which was estimated from the ratio of diffuse radiation to direct beam radiation. 
The transmitted solar radiation through the window was calculated using angle-dependent window transmittance. Interior solar distribution is a one-time calculation within TASE. All solar radiation is assumed to initially hit the floor. Radiation that is not absorbed by the floor is distributed to other surfaces according to shortwave absorptances and view factors.

The energy consumption was calculated using one-hour timesteps for the entire calculation period. The pre-calculation time was 275 days. All time was local time with no daylight savings.

\subsubsection{Simulation of Modified Cases}

The high conductance wall was modeled as a wall whose transfer factors had no thermal capacity. This was a better way in TASE to model an opaque window than using a window with zero transmittance.

In cases 310,630, and 930 (which include vertical east and west shadings), the east and west walls have been divided into three vertical parts. This was the only way to describe the vertical shading, which is in the middle of the wall.

The sunspace, case 960, was modeled with two rooms. The sun zones and back zones were ordinary heavy and light constructions, respectively, with the common wall as a separate construction.

Ground coupling, case 990 , was modeled by dividing the walls horizontally into two parts. The upper part was in contact with the outdoor air, and the lower part in contact with the soil. The nonmasonry layers were taken away from the floor and the sub-grade portions of the walls. The effect of the soil resistance was taken into account in the total outside heat transfer coefficient of the floor and the sub-grade portions of the walls. The thermal capacity of soil was neglected from the calculation of heat loss of below-grade walls. The floor was modeled using a three-dimensional heat conduction model (Hagentoft 1988). Belowgrade surfaces were modeled as walls that include an interior layer of masonry and an exterior layer of soil, where the exterior of the soil layer is exposed to the varying air temperature.

\subsubsection{Notices of Simulation and Results}

In the March 1993 version of BESTEST (Judkoff 1993) there were some errors in the TASE results. The real error in the code of TASE was in the shading module of the sidefins. The rest of the errors were due to users' mistakes.

The present results can not be directly compared to older ones because the inside surface heat transfer coefficients and window transmission coefficients (U-values) are now modeled in the more detailed way. This more-detailed modeling gives greater energy consumptions and peak loads than simpler ways. With constant heat transfer coefficients for the inside surfaces and constant window transmission coefficients, the energy consumptions and peak loads were very close to previous values.

The sidefins were problematic. If the sidefins shaded only a window, but not the wall around them, the energy consumption and peak loads were very close to the results of the other programs. Now it seems that the sidefins shade too much. 


\subsubsection{Pro Forma}

Program name (please include version number)

$\triangle$ possible to use

used in BESTEST

TASE version 3.0

Your name and organization

Tapio Haapala, Tampere University of Technology

Program status

$\square$ Public domain

$\square$ Commercial

Other (please specify) Only for scientific use

\section{Solution method}

$\square$ Explicit finite difference

$\square$ Implicit finite difference

$\square$ Weighting factors

Response factor

$\square$ Other (please specify)

Timing convention for meteorological data: sampling interval

$\square$ Fixed within code (please specify interval)

User-specified

Timing convention for meteorological data: period covered by first record

$\square$ Fixed within code (please specify period or time which meteorological record covers)

User-specified

Meteorological data reconstruction scheme

- Climate assumed stepwise constant over sampling interval

$\square$ Linear interpolation used over climate sampling interval

$\square$ Other (please specify)

\section{Output timing conventions}

$\square$ Produces spot predictions at the end of each timestep

- Produces spot output at end of each hour

$\square$ Produces average outputs for each hour (please specify period to which value relates) 
Treatment of zone air

Single temperature (i.e., good mixing assumed)

Stratified model

Simplified distribution model

Full CFD model

Other (please specify)

Heaters (dynamics)

$\square$ No dynamics assumed (output is instantaneous)

Simple first order dynamics

Detailed modeling of heat source dynamics

Heaters (output characteristics)

$\square$ Purely convective

$\square$ Radiative/Convective split fixed within code

$\square$ Radiative/Convective split specified by user

Detailed modeling of heat source output

\section{Control temperature}

Air temperature

$\square$ Combination of air and radiant temperatures fixed within the code

$\square$ User-specified combination of air and radiant temperatures

$\square$ User-specified construction surface temperatures

$\square$ User-specified temperatures within construction

Other (please specify)

\section{Control laws}

$\square$ Perfect control

On/Off thermostatic control

On/Off thermostatic control with deadband

On/Off thermostatic control with accelerator heater

Proportional control

$\square$ More comprehensive control laws (please specify)

Heat transfer within zones

$\square$ Radiation and convection combined

Radiation and convection treated separately

Convective heat transfer within zones

Coefficients fixed within code

$\Delta$ Coefficients specified by user

Coefficients calculated by code as a function of surface orientation

- Coefficients calculated by code as a function of temperature difference

Coefficients calculated by code as a function of surface finishes

Other (please specify) 


\section{Longwave radiative heat transfer within zones}

$\square$ Constant linearized coefficients

$\square$ Linearized coefficients based on viewfactors

$\square$ Linearized coefficients based on surface emissivities

- Non-linear treatment of radiation heat exchange

Other (please specify)

Number of nodes placed within each layer of walls and slabs

Not applicable for this solution method

$\square$ Fixed number of nodes per layer (please specify)

User-specified number of nodes per layer

$\square$ Other (please specify

\section{Airgaps within walls and slabs}

$\square$ Resistance fixed within code

User-specified constant resistance

$\square$ Resistance calculated within code as a function of orientation

$\square$ Radiation and convection treated separately across airgaps

$\Delta$ Treated as additional zones

Other (please specify)

\section{Windows (heat loss)}

$\square$ Fixed resistance used for window element

$\square$ Dynamic treatment of window heat loss using same scheme as for opaque elements

Other (please specify) U-value of windows are function of temperature difference

\section{Airgaps within windows}

$\square$ Resistance fixed within code

User-specified constant resistance

$\square$ Resistance calculated within code as a function of orientation

- Resistance calculated within code as a function of temperature difference

$\square$ Radiation and convection treated separately across airgaps

$\square$ Airgaps treated as additional zones

Other (please specify)

Windows (transmission of direct shortwave radiation)

$\square$ Fixed transmission used

ASHRAE solar heat coefficients used

$\square$ Calculated by code as a function of incidence angle

Calculated by code from user-specified function of incidence angle

$\square$ Other (please specify)

\section{Windows (transmission of diffuse radiation)}

Diffuse radiation treated as direct from fixed altitude (please specify) user-specified

$\square$ Other (please specify) 


\section{Distribution of solar radiation within zones}

$\square$ Fixed within the code

$\square$ Constant user-specified distribution

Calculated once by code and used throughout (please describe algorithm)

$\square$ Calculated as a function of solar position (please describe algorithm) Solar distribution is calculated by matrix equation of reflection coefficients of inside surfaces.

Heat transfer between external surfaces and surrounding environment

Radiation and convection combined

$\square$ Radiation and convection treated separately

\section{External convection}

$\square$ Coefficients fixed within code

User-specified constant coefficients

$\square$ Calculated within code as a function of orientation

$\square$ Calculated within code as a function of surface finish

$\square$ Calculated within code as a function of wind speed

$\square$ Calculated within code as a function of wind speed and direction

$\square$ Other (please specify)

External radiative heat transfer

$\square$ Assumed to be to ambient air temperature

$\square$ Assumed to be to sky temperature read from met file

Based on calculated sky temperature (please specify algorithm and requirements) See 2.5.8 Attachment 1

$\square$ Includes view factor of surrounding obstruction

\section{Diffuse sky model}

$\square$ Isotropic

Other (please specify model used) See 2.5.8 Attachment 2 


\subsubsection{Attachment 1}

(From Kalema 1992, p. 31)

The effective exterior temperature for exterior walls $\mathrm{T}_{\mathrm{oi}}^{*}$ includes the effects of shortwave and longwave radiation. E.g., in the TASE program the following equation is used where the second term on the right side takes into account the absorption of shortwave radiation and the third term the long-wave sky radiation, in which the cloud cover and view factor to surroundings are accounted for (Aittomäki and Kalema 1976):

$$
\mathrm{T}_{\mathrm{oi}}^{*}=\mathrm{T}_{\mathrm{o}}+\frac{\alpha_{\mathrm{oi}} \mathrm{J}_{\mathrm{oi}}}{\mathrm{h}_{\mathrm{o}}}+\left(1-0.89 \mathrm{~S}_{\mathrm{c}}\right)\left(1-\mathrm{F}_{\mathrm{oi}, \mathrm{s}}\right) \frac{\mathrm{h}_{\mathrm{ro}}}{\mathrm{h}_{\mathrm{o}}}\left(0.1 \mathrm{~T}_{\mathrm{o}}-4.8^{\circ} \mathrm{C}\right),
$$

where:

$\mathrm{T}_{\mathrm{o}} \quad=$ exterior air temperature

$\alpha_{o i}=$ absorption coefficient for shortwave radiation

$I_{\mathrm{oi}}=$ total shortwave radiation

$h_{0}=$ total heat transfer coefficient

$\mathrm{S}_{\mathrm{c}} \quad=$ relative cloud cover

$\mathrm{F}_{\mathrm{oi}, \mathrm{s}}=$ view factor from exterior wall to surroundings

$h_{\mathrm{ro}}=$ radiative heat transfer coefficient. 


\subsubsection{Attachment 2}

(From Kalema 1992, pp. 72-73)

The Finnish Meteorological Institute has verified one isotropic, one anisotropic, and one mixed model for calculating diffuse solar radiation (Tammelin et al. 1987). The verification showed that the isotropic model, which was developed by Kondratjev (Kondratjev 1977), was the best and gave "extremely good results" when compared with measurements in the calculation of mean solar radiation. This model was incorporated into the TASE program. The diffuse solar radiation to an inclined surface $\left(\mathrm{I}_{\mathrm{d \alpha}}\right)$ according to Kondratjev (Kondratjev 1977), is obtained from the equation:

$$
I_{d \alpha}=I_{d H} \cos ^{2}\left(\frac{\alpha}{2}\right)+I_{d p}\left[1-\cos ^{2}\left(\frac{\alpha}{2}\right)\right],
$$

where:

$I_{\mathrm{dH}}=$ diffuse solar radiation to horizontal surface

$I_{d p} \quad=$ reflected diffuse solar radiation from the ground

$\alpha=$ angle of inclination of exterior surface with horizontal surface (for a vertical surface $\alpha=90^{\circ}$ ).

If the reflected solar radiation from the ground $\left(I_{\alpha \rho}\right)$ is not given in the weather data, it can be calculated (assuming the reflection to be diffuse) from the equation:

$$
I_{\alpha p}=\rho_{g}\left(I_{d H}+I_{D H}\right)
$$

where:

$\rho_{\mathrm{g}} \quad=\quad$ reflection coefficient of ground

$I_{D H}=$ direct solar radiation to horizontal surface. 


\subsubsection{DEROB-LTH}

Lund Institute of Technology

Sweden

November 1993 


\subsubsection{Introduction}

The program DEROB-LTH has been tested with the BESTEST constructed by IEA group 12B/21C. Almost all cases were tested. The results are summarized in Section 2.5.9.7.

\subsubsection{DEROB-LTH}

DEROB-LTH, which is an acronym for Dynamic Energy Response of Buildings, is a family of six modules that calculate energy consumption for heating, cooling, and ventilation. The program was originally developed at the Numerical Simulation Laboratory, School of Architecture, University of Texas, Austin, Texas. Since 1985 the DEROB modules have been further developed to suit the local needs at the Department of Building Science at Lund Institute of Technology, Lund, Sweden.

DEROB uses an RC network that is solved with the Crank-Nicholson method (with a fixed timestep of one hour). The matrixes are solved with the Newton-Raphson method. DEROB can simulate buildings with arbitrary geometries; it also interprets the presence of shading devices.

\subsubsection{Model of the Building}

The building was basically modeled as the BESTEST specification. The most important assumptions and exceptions are listed below.

Outside film coefficient. There was no separation between convective and radiative heat transfer on the outside surfaces. The overall heat transfer coefficient was set to $21 \mathrm{~W} / \mathrm{m}^{2} \mathrm{~K}$ for $\varepsilon=0.9$ and $16.9 \mathrm{~W} / \mathrm{m}^{2} \mathrm{~K}$ for $\varepsilon=0.1$. These values were the prescribed values for the windows. The values for the walls were higher. DEROB has the same heat transfer coefficient for the whole outer surface.

Inside film coefficient. The inside film coefficient is separated in a radiative and convective part in DEROB. The coefficient $\varepsilon$ was the same for all inner surfaces. The convective part is calculated from the temperature difference and the inclination of the surface.

Infiltration. The airchanges per hour were corrected for the altitude: 0.41 instead of 0.5 ach and 0.82 instead of 1.0 ach.

Internal generated heat. The internal heat cannot be separated in a convective and radiative part in DEROB. All energy is delivered to the air node, i.e., purely convective. Because of this, the internal energy was lowered from 200 to $180 \mathrm{~W}$. When the radiation energy reaches the wall, only a fraction of the energy is transported by convection to the air. This fraction depends on the temperatures and the construction of the wall. The calculation was made for the specified wall, with the temperatures $9.7^{\circ} \mathrm{C}$ on the outside and $20^{\circ} \mathrm{C}$ on the inside.

High conductance wall. The high conductance wall was modeled as a wall with the same resistance and capacity as the window.

Shortwave absorption. The shortwave absorption was specified for each surface.

Transparent window. The transparent window was thermally modeled as one resistance. The direct shortwave transmission was calculated from incident angle, shading, and number of panes. The transmission of the diffuse radiation was $80 \%$ of the transmission of direct radiation at normal incidence. The diffuse shortwave radiation was not affected by shading. To calculate the direct shortwave transmission, a grid of 50 cells for each wall and 100 cells for the floor was used. 
Heating and cooling. The heating and cooling was delivered directly to the air node, i.e., purely convective.

\subsubsection{Problems During the Tests}

Problems that occurred during the test are described below:

- The outside film coefficient was originally $15 \mathrm{~W} / \mathrm{m}^{2} \mathrm{~K}$ in DEROB. For case 600 , the heating increased by $0.25 \mathrm{MWh}$ and the cooling decreased by $0.5 \mathrm{MWh}$ when the outside film coefficient was increased from 15 to $21 \mathrm{~W} / \mathrm{m}^{2} \mathrm{~K}$.

- The internal generated heat was reduced from 200 to $180 \mathrm{~W}$. This increased the heat required for case 600 by $0.08 \mathrm{MWh}$ and decreased the cooling required by $0.07 \mathrm{MWh}$.

- The calculation of the shortwave solar transmission was rewritten in DEROB during the BESTEST simulation period. With BESTEST, an error in the new code was found and corrected.

- To be able to change the longwave emissivity on the inside, the source code of the program had to be changed. The emissivity was originally set to 0.9 for all surfaces.

- The density of the insulation under the floor was first set to $50 \mathrm{~kg} / \mathrm{m}^{3}$. The value was later corrected to $0.1 \mathrm{~kg} / \mathrm{m}^{3}$. The heat required for case 600 increased by $0.22 \mathrm{MWh}$ and the cooling required was increased by $0.25 \mathrm{MWh}$.

\subsubsection{Results of the BESTEST Comparison}

The general results were that DEROB calculated a low annual heating and cooling load and a low peak cooling load compared to the average of the other programs-not extremely low but almost always on the low side. The peak heating was generally much closer to the other programs.

Low-mass qualification test. The low-mass qualification test indicated a potential problem with night setback calculation, east/west shortwave transmission, and shading. The setback seemed less of a problem for the heavy case. Other studies have shown that, when the temperature setting changes with large steps, the peak and (partly) the annual heating and cooling load are very sensitive to the choice of convective heat transfer coefficient on the inner surface. This might be the reason for the setback problems.

The fact that DEROB calculates the solar position at the end instead of in the middle of each hour is probably the reason for the problems with the east and west shortwave transmission.

The difficulty with the shading probably arises from the fact that diffuse radiation is not shaded in DEROB.

Low-mass primitive diagnostic tests. The tests clearly showed that the longwave radiation on the inside was smaller for DEROB than for the other programs, except for ESP. The longwave radiation is calculated in detail in DEROB; this could be the reason for this difference.

The absorptance of shortwave radiation on the inside was low. This could be explained by the fact that DEROB permits shortwave radiation to be reflected out through the window.

The east- and west-window shortwave transmission seemed less of a problem here. Only the peak cooling was significantly different. The difference with shading was the same as above. 
Low-mass realistic diagnostic tests. The tests indicated about the same as the low-mass primitive tests.

High-mass qualification tests. The tests indicated a possible problem with mass interaction. The difference between low- and high-mass cases was generally lower than the difference in the other programs. The difference between sunspace and no sunspace was low.

High-mass diagnostic tests. These showed nothing new.

Solar transmission. The annual incident solar radiation was average. The annual transmitted solar radiation was average, except on the west windows where the transmission was among the higher values.

Hourly values. Hourly values of insolation and temperature suggested a problem in DEROB with the time assumptions, particularly the calculation of the position of the sun.

Free-float temperatures. The free-float temperatures were similar to the average temperatures. The minimum temperatures were generally rather low for DEROB.

\subsubsection{Summary}

As stated above, DEROB calculated a low annual heating and cooling load and a low peak cooling load compared to the average of the other programs. The BESTEST qualification tests and diagnostic tests suggested some problems in DEROB that will be investigated.

- The diffuse radiation should perhaps be shaded.

- It is possible that the timestep is too long for the low-mass cases.

- The results would probably be better if the calculation of the solar position were done in the middle of each hour, especially for low solar positions.

- The setback cases showed some problems. The reason for this might be the choice of the inner convective heat transfer coefficient.

\subsubsection{BESTEST Results for DEROB-LTH}


Table 2-40. DEROB-LTH Annual and Peak Heating and Cooling Load Results

\begin{tabular}{|c|c|c|c|c|}
\hline Case & $\begin{array}{c}\text { Annual Heating } \\
\text { (MWh) }\end{array}$ & $\begin{array}{c}\text { Annual Cooling } \\
\text { (MWh) } \\
\end{array}$ & $\begin{array}{c}\text { Peak Heating } \\
(\mathbf{k W h} / \mathbf{h})\end{array}$ & $\begin{array}{c}\text { Peak Cooling } \\
(\mathbf{k W h} / \mathbf{h})\end{array}$ \\
\hline 600 & 4.506 & 6.203 & 3.960 & 5.830 \\
\hline 610 & 4.685 & 4.785 & 3.960 & 5.702 \\
\hline 620 & 4.920 & 4.022 & 3.960 & 4.520 \\
\hline 630 & 5.224 & 3.041 & 3.962 & 4.188 \\
\hline 640 & 3.064 & 6.260 & 5.230 & 5.910 \\
\hline 650 & 0.000 & 5.460 & 0.000 & 5.860 \\
\hline 900 & 1.766 & 2.619 & 3.541 & 3.447 \\
\hline 910 & 1.958 & $1.480^{\circ}$ & 3.544 & 2.474 \\
\hline 920 & 3.700 & 2.495 & 3.746 & 3.168 \\
\hline 930 & 4.300 & 1.867 & 3.775 & 2.720 \\
\hline 940 & $1.289^{\circ}$ & 2.560 & 5.023 & 3.447 \\
\hline 950 & 0.000 & 0.608 & 0.000 & 3.063 \\
\hline 960 & 2.575 & 0.773 & 2.712 & 1.213 \\
\hline 195 & 4.570 & 0.400 & 2.177 & 0.699 \\
\hline 200 & 6.385 & 0.559 & 3.162 & 0.977 \\
\hline 210 & 6.542 & 0.535 & 3.214 & 0.969 \\
\hline 215 & 6.790 & 0.626 & 3.323 & 1.085 \\
\hline 220 & 6.984 & 0.602 & 3.389 & 1.078 \\
\hline 230 & 10.487 & 0.892 & 4.954 & 1.592 \\
\hline 240 & 5.800 & 0.995 & 3.209 & 1.258 \\
\hline 250 & 5.214 & 2.531 & 3.371 & 2.252 \\
\hline 270 & 4.674 & 8.478 & 3.370 & 6.538 \\
\hline 280 & 4.894 & 5.039 & 3.372 & 4.138 \\
\hline 290 & 4.702 & 6.739 & 3.370 & 6.509 \\
\hline 300 & 4.866 & 5.504 & 3.372 & 4.497 \\
\hline 310 & 5.145 & 4.271 & 3.373 & 4.179 \\
\hline 320 & 4.236 & 5.966 & 3.369 & 5.879 \\
\hline
\end{tabular}


Table 2-40. DEROB-LTH Annual and Peak Heating and Cooling Load Results (Concluded)

\begin{tabular}{|c|c|c|c|c||}
\hline Case & $\begin{array}{c}\text { Annual Heating } \\
(\mathbf{M W h})\end{array}$ & $\begin{array}{c}\text { Annual Cooling } \\
(\mathbf{M W h})\end{array}$ & $\begin{array}{c}\text { Peak Heating } \\
(\mathbf{k W h} / \mathbf{h})\end{array}$ & $\begin{array}{c}\text { Peak Cooling } \\
(\mathbf{k W h} / \mathbf{h})\end{array}$ \\
\hline 395 & 4.581 & 0.019 & 2.194 & 0.330 \\
\hline 400 & 6.921 & 0.039 & 3.390 & 0.500 \\
\hline 410 & 8.667 & 0.057 & 4.172 & 0.625 \\
\hline 420 & 7.456 & 0.148 & 3.990 & 0.821 \\
\hline 430 & 6.196 & 0.631 & 3.965 & 1.487 \\
\hline 440 & 4.871 & 3.671 & 3.961 & 3.935 \\
\hline 800 & 5.732 & 0.245 & 3.858 & 0.884 \\
\hline 810 & 2.706 & 1.230 & 3.657 & 2.400 \\
\hline
\end{tabular}

Table 2-41. DEROB-LTH Low-Mass Qualification Tests

\begin{tabular}{|l|c|c|c|c||}
\hline \multicolumn{1}{|c|}{ Case } & $\begin{array}{c}\text { Annual Heating } \\
(\mathbf{M W h})\end{array}$ & $\begin{array}{c}\text { Annual Cooling } \\
(\mathbf{M W h})\end{array}$ & $\begin{array}{c}\text { Peak Heating } \\
(\mathbf{k W h} / \mathbf{h})\end{array}$ & $\begin{array}{c}\text { Peak Cooling } \\
(\mathbf{k W h} / \mathbf{h})\end{array}$ \\
\hline 600 & 4.506 & 6.203 & 3.960 & 5.830 \\
\hline $610-600$ & 0.179 & -1.418 & 0.000 & -0.128 \\
\hline $620-600$ & 0.414 & -2.181 & 0.000 & -1.310 \\
\hline $630-620$ & 0.304 & -0.981 & 0.002 & -0.332 \\
\hline $640-600$ & -1.442 & 0.057 & 1.270 & 0.080 \\
\hline $650-600$ & -4.506 & -0.743 & -3.960 & 0.030 \\
\hline
\end{tabular}


Table 2-42. DEROB-LTH Low-Mass Primitive Diagnostic Tests

\begin{tabular}{||l|c|c|c|c||}
\hline \multicolumn{1}{|c|}{ Case } & $\begin{array}{c}\text { Annual Heating } \\
\text { (MWh) }\end{array}$ & $\begin{array}{c}\text { Annual Cooling } \\
\text { (MWh) }\end{array}$ & $\begin{array}{c}\text { Peak Heating } \\
\text { (kWh/h) }\end{array}$ & $\begin{array}{c}\text { Peak Cooling } \\
\text { (kWh/h) }\end{array}$ \\
\hline \hline 195 & 4.570 & 0.400 & 2.177 & 0.699 \\
\hline $200-195$ & 1.815 & 0.159 & 0.985 & 0.278 \\
\hline $210-200$ & 0.157 & -0.024 & 0.052 & -0.008 \\
\hline $220-215$ & 0.194 & -0.024 & 0.066 & -0.007 \\
\hline $215-200$ & 0.405 & 0.067 & 0.161 & 0.108 \\
\hline $220-210$ & 0.442 & 0.067 & 0.175 & 0.109 \\
\hline $230-220$ & 3.503 & 0.290 & 1.565 & 0.514 \\
\hline $240-220$ & -1.184 & 0.393 & -0.180 & 0.180 \\
\hline $250-220$ & -1.770 & 1.929 & -0.018 & 1.174 \\
\hline $270-220$ & -2.310 & 7.876 & -0.019 & 5.460 \\
\hline $280-270$ & 0.220 & -3.439 & 0.002 & -2.400 \\
\hline $320-270$ & -0.438 & -2.512 & -0.001 & -0.659 \\
\hline $290-270$ & 0.028 & -1.739 & 0.000 & -0.029 \\
\hline $300-270$ & 0.192 & -2.974 & 0.002 & -2.041 \\
\hline $310-300$ & 0.279 & -1.233 & 0.001 & -0.318 \\
\hline
\end{tabular}

Table 2-43. DEROB-LTH Low-Mass Realistic Diagnostic Tests

\begin{tabular}{|l|c|c|c|c|}
\hline \multicolumn{1}{|c|}{ Case } & $\begin{array}{c}\text { Annual Heating } \\
(\mathbf{M W h})\end{array}$ & $\begin{array}{c}\text { Annual Cooling } \\
(\mathbf{M W h})\end{array}$ & $\begin{array}{c}\text { Peak Heating } \\
(\mathbf{k W h} / \mathbf{h})\end{array}$ & $\begin{array}{c}\text { Peak Cooling } \\
\text { (kWh/h) }\end{array}$ \\
\hline \hline $400-395$ & 2.340 & 0.020 & 1.196 & 0.170 \\
\hline $410-400$ & 1.746 & 0.018 & 0.782 & 0.125 \\
\hline $420-410$ & -1.211 & 0.091 & -0.182 & 0.196 \\
\hline $430-420$ & -1.260 & 0.483 & -0.025 & 0.666 \\
\hline $600-430$ & -1.690 & 5.572 & -0.005 & 4.343 \\
\hline $440-600$ & 0.365 & -2.532 & 0.001 & -1.895 \\
\hline
\end{tabular}


Table 2-44. DEROB-LTH High-Mass Qualification Tests

\begin{tabular}{||l|c|c|c|c|}
\hline \multicolumn{1}{|c|}{ Case } & $\begin{array}{c}\text { Annual Heating } \\
(\mathbf{M W h})\end{array}$ & $\begin{array}{c}\text { Annual Cooling } \\
(\mathbf{M W h})\end{array}$ & $\begin{array}{c}\text { Peak Heating } \\
(\mathbf{k W h} / \mathbf{h})\end{array}$ & $\begin{array}{c}\text { Peak Cooling } \\
(\mathbf{k W h} / \mathbf{h})\end{array}$ \\
\hline \hline $900-600$ & -2.740 & -3.584 & -0.419 & -2.383 \\
\hline $910-900$ & 0.192 & -1.139 & 0.003 & -0.973 \\
\hline $920-900$ & 1.934 & -0.124 & 0.205 & -0.279 \\
\hline $930-920$ & 0.600 & -0.628 & 0.029 & -0.448 \\
\hline $940-900$ & -0.477 & -0.059 & 1.482 & 0.000 \\
\hline $950-900$ & -1.766 & -2.011 & -3.541 & -0.384 \\
\hline $960-900$ & 0.809 & -1.846 & -0.829 & -2.234 \\
\hline
\end{tabular}

Table 2-45. DEROB-LTH High-Mass Diagnostic Tests

\begin{tabular}{||l|c|c|c|c|}
\hline \multicolumn{1}{|c|}{ Case } & $\begin{array}{c}\text { Annual Heating } \\
(\mathbf{M W h})\end{array}$ & $\begin{array}{c}\text { Annual Cooling } \\
(\mathbf{M W h})\end{array}$ & $\begin{array}{c}\text { Peak Heating } \\
(\mathbf{k W h} / \mathbf{h})\end{array}$ & $\begin{array}{c}\text { Peak Cooling } \\
\text { (kWh/h) }\end{array}$ \\
\hline \hline $800-430$ & -0.464 & -0.386 & -0.107 & -0.603 \\
\hline $900-800$ & -3.966 & 2.374 & -0.317 & 2.563 \\
\hline $910-610$ & -2.727 & -3.305 & -0.416 & -3.228 \\
\hline $920-620$ & -1.220 & -1.527 & -0.214 & -1.352 \\
\hline $930-630$ & -0.924 & -1.174 & -0.187 & -1.468 \\
\hline $940-640$ & -1.775 & -3.700 & -0.207 & -2.463 \\
\hline $950-650$ & 0.000 & -4.852 & 0.000 & -2.797 \\
\hline
\end{tabular}

Table 2-46. DEROB-LTH Free-Float Temperature Output

\begin{tabular}{||l|c|c|l|l|l||}
\hline \multicolumn{1}{|c|}{ Case } & Average $\left({ }^{\circ} \mathrm{C}\right)$ & Min $\left({ }^{\circ} \mathrm{C}\right)$ & Date/Hour & $\begin{array}{c}\text { Max } \\
\left({ }^{\circ} \mathrm{C}\right)\end{array}$ & \multicolumn{1}{c|}{ Date/Hour } \\
\hline \hline $600 \mathrm{FF}$ & 25.3 & -18.2 & Jan 04 07:00 & 68 & Oct 06 14:00 \\
\hline $900 \mathrm{FF}$ & 25.3 & -5.2 & Jan 04 08:00 & 45.1 & Sep 02 15:00 \\
\hline $650 \mathrm{FF}$ & 19.8 & -23.1 & Jan 04 02:00 & 67.1 & Oct 16 14:00 \\
\hline $950 \mathrm{FF}$ & 14.4 & -20.2 & Jan 04 07:00 & 38.8 & Sep 02 15:00 \\
\hline 960 & 27.2 & -0.1 & Jan 04 08:00 & 49.3 & Sep 02 15:00 \\
\hline
\end{tabular}


Table 2-47. DEROB-LTH Annual Incident and Transmitted Solar Radiation

\begin{tabular}{|c|c|c|c|c|}
\hline \multicolumn{5}{|c|}{$\begin{array}{l}\text { Annual Incident Solar Radiation } \\
\mathrm{kWh} / \mathrm{m}^{2} \text { (Diffuse + Direct) }\end{array}$} \\
\hline North & East & West & South & Horizontal \\
\hline 447 & 954 & 1079 & 1460 & 1812 \\
\hline \multicolumn{5}{|c|}{$\begin{array}{l}\text { Annual Transmitted Solar Radiation } \\
\mathbf{k W h} / \mathbf{m}^{2} \text { (Diffuse + Direct) }\end{array}$} \\
\hline West & South & West Shaded & South Shaded & \\
\hline 745 & 984 & 599 & 823 & \\
\hline
\end{tabular}




\subsubsection{CLIM2000}

Electricité de France France

October 1993 


\subsubsection{Introduction}

The work presented falls within the framework of Annex 21C ("Model Evaluation and Improvement") of the International Energy Agency. We describe the BESTEST validation exercise in which we participated.

The work consists of (1) modeling a set of configurations under CLIM2000 environmental conditions whose complexity ranges from simple/primitive to complex/realistic, and (2) comparing the results to those derived from eight advanced building thermics codes considered state of the art in the United States and Europe.

Such an exercise is not an experimental validation because the comparison does not involve a measured physical phenomenon; rather, the comparison is with other numeric codes which, depending on their degree of sophistication, give only an estimation of the actual facts. This comparative method, although unable to assess computational validity, does detect numeric bugs and major modeling problems that detract from software credibility.

The test cases proposed enable us to study the response of a building with a plain configuration (rectangular cell without partitioning walls) on which particular internal and external excitation scenarios are applied. These cases are grouped into two different families:

- Qualification cases (cases 600 to 650 and 900 to 950) represent relatively realistic light and heavy buildings which include the modeling of:

- windows for different orientations

- outside horizontal and vertical shading devices for glazing

- control systems

- ventilation systems

- earth coupling effects.

- Diagnostic cases (cases 195 to 320) represent plain configurations or theoretical cases (to minimize complex couplings), where only one parameter is varied at a time. Results can be compared to a sensitivity analysis and enable one to study separately the physical phenomena such as conduction and convection.

We were not able to process all the proposed test cases. For example, the existing version of CLIM2000 could not always comply with modeling hypotheses (e.g., shading devices and particular distribution of the solar flux inside a cavity). Also, numeric problems sometimes occurred when carrying out the tests because of a particular assembly.

\subsubsection{Description of Cases-Modeling Hypotheses}

\section{External conditions}

All cases model a rectangular cell exposed to natural climatic conditions. The meteorological data used are statistical; they represent the month considered most typical of the weather at a particular measuring station for that month from 1953 to 1975.

The solar fluxes supplied are the horizontal global flux and the normal direct flux (sensor's plane perpendicular to the incident ray). To meet CLIM2000 requirements, the horizontal direct flux was computed according to the formula: 


$$
\mathrm{I}_{\mathrm{DH}}=\mathrm{I}_{\mathrm{DN}} \sin (\mathrm{h}),
$$

where:

$\mathrm{I}_{\mathrm{DH}}=$ horizontal direct flux

$\mathrm{I}_{\mathrm{DN}}=$ normal direct flux

$\mathrm{h}=$ solar altitude angle

The meteorological file gave no information about the sky temperature, so we applied the correlation:

$$
T_{\text {amb }}-T_{\text {sky }}=20 \mathrm{~K} \text {. }
$$

\section{Opaque partitions}

- The partition composition and geometrical and thermophysical variables are recorded in the User's Manual (Part I).

- The values of radiation coefficients are given as a function of partition emissivity; those of convection coefficients vary with the surface condition and were computed for mean wind velocities of $4.02 \mathrm{~m} / \mathrm{s}$.

- For internal partitions, convection and radiation exchange coefficients are aggregated, whereas these two phenomena are distinct for external surfaces. Under CLIM2000 environmental conditions, this involves acquiring a single parameter-the convection exchange coefficient-which accounts for the radiation as the case may be.

- Case numbers 200 to 250 include an opaque glazing with the following characteristics:

- no solar transmission

- an external convection coefficient and thermophysical parameters identical to those of a standard glazing

- same emissivity and absorptance as for the supporting wall.

- We opted for a glass-air-glass three-layer-type modeling.

Table 2-48. Interior (Global) and Exterior (Convection) Exchange Coefficients for the Different Partitions

\begin{tabular}{|c|c|c|c|c|c|c|c|c|c|c||}
\hline$\varepsilon$ & \multicolumn{2}{|c|}{ Exterior Wall } & \multicolumn{2}{|c|}{ Floor } & \multicolumn{2}{c|}{ Ceiling } & \multicolumn{2}{c|}{ Opaque Glazing } & \multicolumn{2}{c|}{ Double Glazing } \\
\hline \hline & $\mathbf{h}_{\mathrm{i}}$ & $\mathrm{h}_{e}$ & $\mathrm{~h}_{\mathrm{i}}$ & $\mathrm{h}_{e}$ & $\mathrm{~h}_{\mathrm{i}}$ & $\mathrm{h}_{e}$ & $\mathrm{~h}_{i}$ & $\mathrm{~h}_{e}$ & $\mathrm{~h}_{i}$ & $\mathrm{~h}_{e}$ \\
\hline 0.1 & 3.73 & 24.67 & 4.7 & $10^{-4}$ & 1.57 & 24.67 & 3.73 & 16.37 & & \\
\hline 0.9 & 8.29 & 24.67 & 9.26 & $10^{-4}$ & 6.13 & 24.67 & 8.29 & 16.37 & 8.29 & 16.37 \\
\hline
\end{tabular}




\section{Double glazing}

The solar transmission coefficient and absorption coefficient given by the IEA are direct flux coefficients (which are a function of angle of incidence). For diffuse flux, we used direct flux parameters corresponding to a $60^{\circ}$ incidence angle.

\section{Infiltration}

The air renewal computation in CLIM2000 is based on a density of air equivalent to that at sea level and consequently does not take altitude into account. The site is at $1609 \mathrm{~m}$, and the flux values are corrected by applying a multiplication factor of 0.822 , as discussed in Part I, Appendix B.

\section{Internal gains}

The source of heat has a nominal power of $200 \mathrm{~W}$, with $40 \%$ transmitted by convection to atmospheric air, and the remaining portion exchanged by radiation. The model chosen requires that internal gains be applied directly to the air node as purely convective gains.

\section{Distribution of the solar flux inside the cell}

The whole solar flux transmitted by the glazing is first directed toward the flow that absorbs it partly (depending on the absorption coefficient); the remaining portion is reflected diffusely toward the other walls (via configuration factors) which themselves partly absorb and reflect the solar radiation. The User's Manual (Part I) supplies the fractions of flux absorbed for each wall. Hypotheses made by CLIM2000 assume that the flux transmitted is totally absorbed by the floor and redirected toward the air node via the overall exchange coefficient. Consequently, the other walls do not absorb the flux transmitted in short wavelengths.

\section{The mechanical systems}

The systems are supposed to be perfect emitters, i.e., inertia-free with a purely convective transfer of power. Their nominal power is infinite $(7000 \mathrm{~kW})$.

- Hot and cold control-two protocols have been studied:

- 20,20: if $\mathrm{T}_{\text {int }}<20^{\circ} \mathrm{C}$ heating, and if $\mathrm{T}_{\text {int }}>20^{\circ} \mathrm{C}$ cooling

- 20,27: if $T_{\text {int }}<20^{\circ} \mathrm{C}$ heating, and if $T_{\text {int }}>27^{\circ} \mathrm{C}$ cooling.

Proportional-type controllers were used for both protocols by introducing as the central range the smallest software-admissible value $\left(0.1^{\circ} \mathrm{C}\right)$.

- Ventilation:

- Heating is always off

- Ventilation is off from $7 \mathrm{~h}$ to $18 \mathrm{~h}$

- Cooling is on if $\mathrm{T}_{\text {int }}>27^{\circ} \mathrm{C}$

- Ventilation is on and cooling is off from $18 \mathrm{~h}$ to $7 \mathrm{~h}$.

The ventilation rate is corrected, similar to infiltration, as a function of the site altitude. 


\subsubsection{Results of Testing}

Series 600 study:

1. Consumption

The results for annual heating and cooling consumption for CLIM2000 (Figures 2-25 through 2-28) show

- overestimated heating consumptions and peak demands

- cooling consumptions comparable with those of other reference codes, though the peak demand is overestimated.

In other respects, the hourly consumption curves for the 4th of January (Figures 2-29 and 2-30) agree fairly well with the reference results and make one suppose that there are no major problems regarding the thermal dynamics.

Minimum free-float temperatures from cases 600FF and 900FF (Figure 2-31) tend to be at the low end of the reference results, especially in the high-mass case (900FF) where the temperature is about $1^{\circ} \mathrm{C}$ less than the next lowest result. This result, combined with the overconsumption noted above, indicates that the disagreement may be linked not only to poor modeling of the thermostat but also to low solar inputs, poor acknowledgement of internal inputs, too much thermostat infiltration, and/or high conduction losses.

\section{Acknowledgement of the sun}

Flux impinging on opaque walls- when studying the global incident fluxes on the five walls (Figure 2-32) we notice that:

- the yearly flux for the horizontal wall is below that of the meteorological file used (i.e., an underestimation of $8.36 \mathrm{kWh} / \mathrm{m}^{2}$ or $0.6 \%$ ) owing to two problems linked, respectively, to a poor reading of the meteorological file and to a problem in computing solar functions.

- with regard to the south wall, the flux disagrees slightly with the reference results. This underestimation may be due to the slightly underestimated horizontal flux.

However, if we analyze the variation in fluxes that impinge on the south and west walls on particular days (5 March and 7 July, Figures 2-33 through 2-36), the CLIM2000 results agree with the reference results.

Flux transmitted by south and west glazings-Figures 2-37 and 2-38 also show that the yearly flux transmitted by the glazing and the transmission coefficient are comparable with those of the other codes.

Thus, it seems that the acknowledgement of solar inputs are not responsible for too low a temperature level. We have not interpreted the results of diagnostic cases (by referring to the flow diagrams in Section 1.7 of the User's Manual to identify the other sources of error).

The diagnostic case results are shown in Figures 2-39 through 2-50.

These studies could demonstrate that:

- the conduction, the external convection for a glazed surface, and the absorption of solar flux by external opaque walls are properly modeled. In addition, these cases allowed the heating and cooling 
temperature control to be tested at a single operating point at $20^{\circ} \mathrm{C}$ (where using a $0.1^{\circ} \mathrm{C}$ range for proportional control for CLIM2000 is satisfactory).

- the annual heating load sensitivity to IR exchange (Figures 2-47 through 2-50, case 210-200) is higher than for the other programs and probably is due to a low sky-temperature assumption. It may be advisable to review the above sky-temperature hypothesis.

- the infiltration (Figures $2-47$ through $2-50$, case $230-220$ ) has been slightly overestimated $(+1.5 \%)$.

- the heating consumption is just slightly more sensitive to a variation in internal gains than the other programs (not shown in the figures), because internal gains are assumed to be fully convective.

Other graphs comparing CLIM2000 with the reference results are modeled in Figures 2-51 through 2-60.

\subsubsection{Conclusion}

This exercise is fully adapted to the working method selected to validate our models. This method consists of the following items:

(a) check the basic theory

(b) check the proper numeric operation

(c) compare software

(d) check analytical results

(e) do sensitivity analysis of parameters

(f) validate experimental results.

BESTEST gives a fairly reliable answer to items (b) and (c) and provides a partial answer to item (e). 


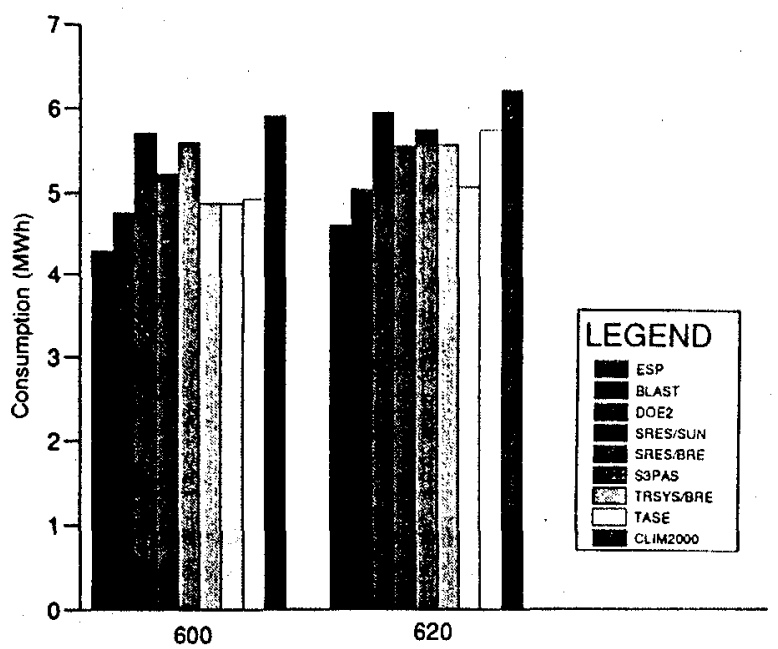

Figure 2-25. Annual heating consumption: low-mass (light) bullding

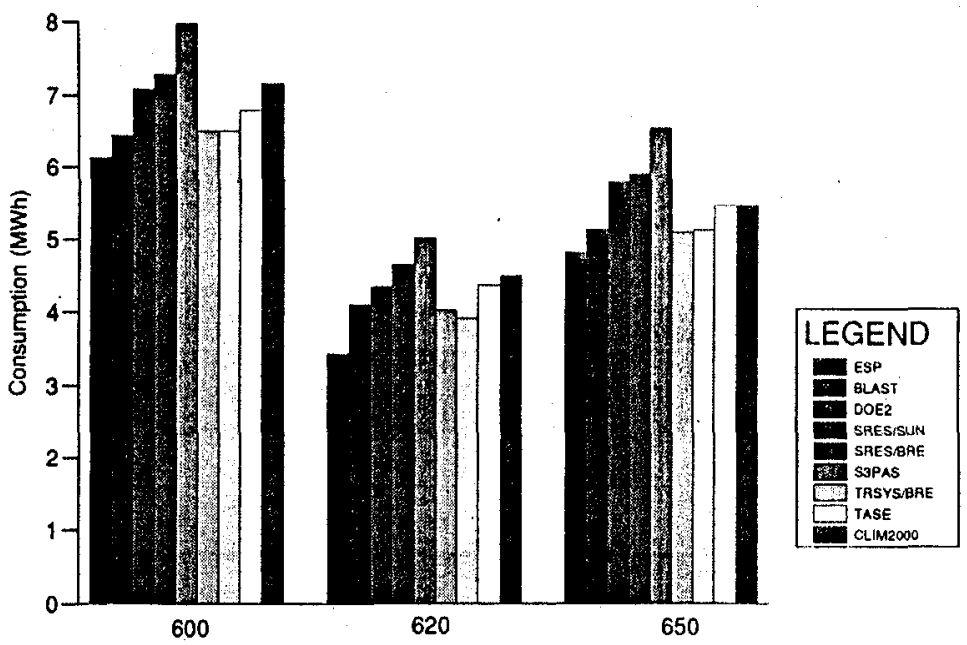

Figure 2-27. Annual cooling consumption: low-mass building

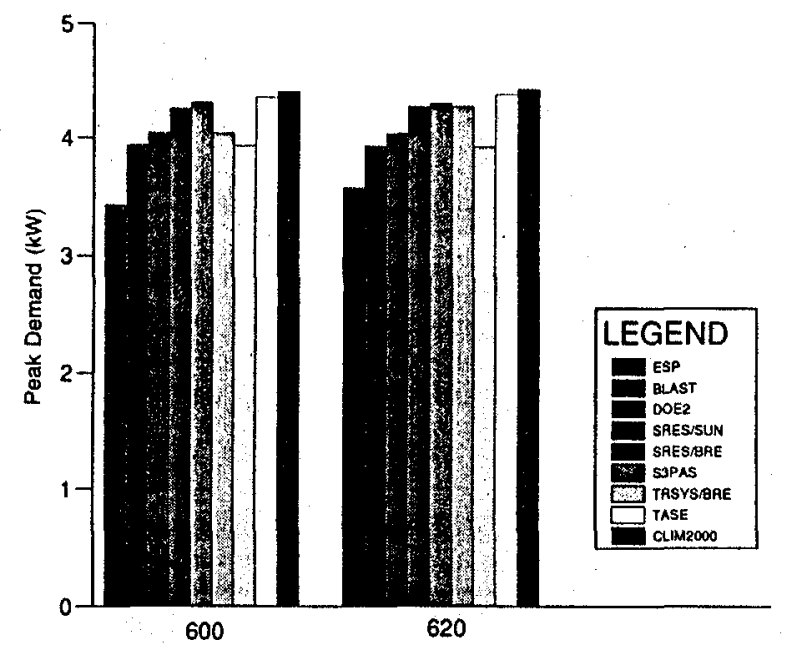

Figure 2-26. Peak heating demand: low-mass building

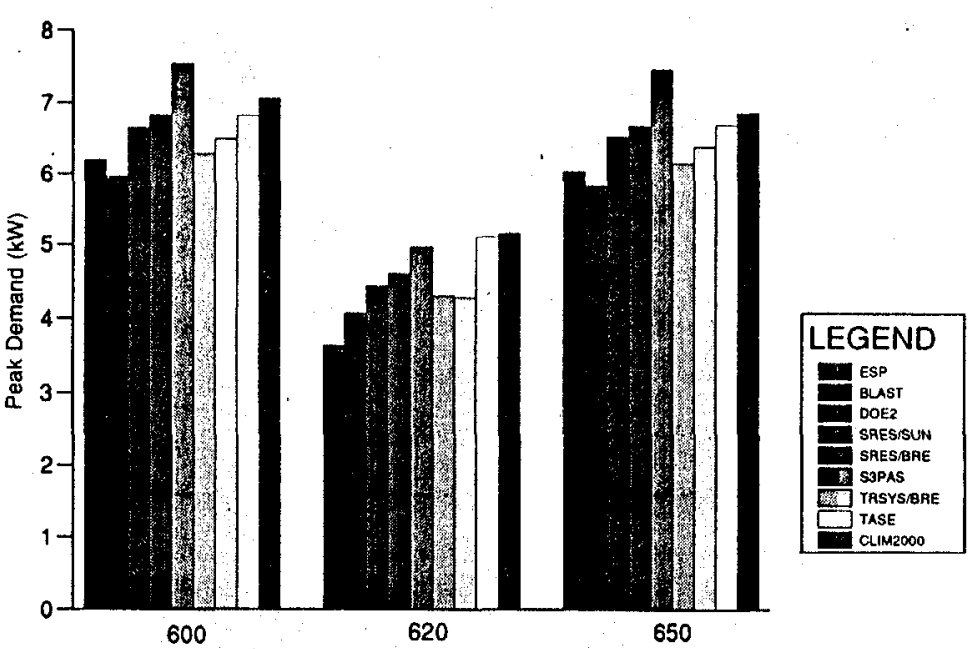

Figure 2-28. Peak cooling demand: low-mass building 


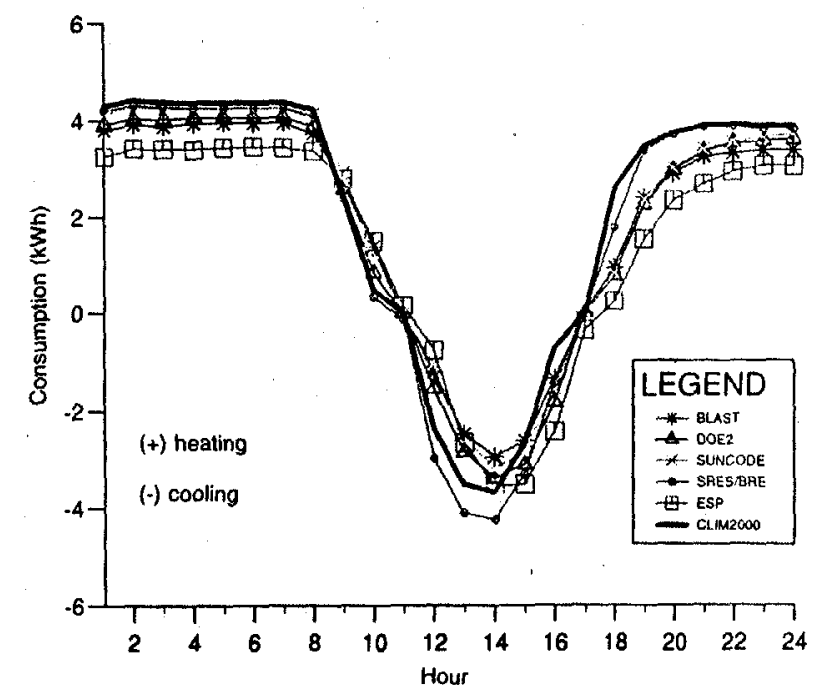

Figure 2-29. Heating and cooling consumptions, January 4: case 600

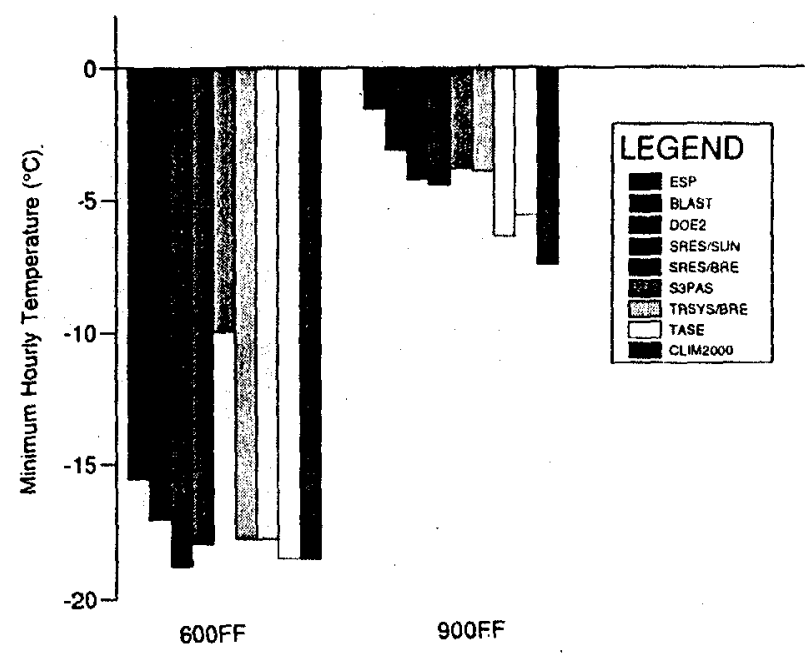

Figure 2-31. Minimum hourly temperatures: free-float case



Figure 2-30. Heating and cooling consumptions, January 4: case 900

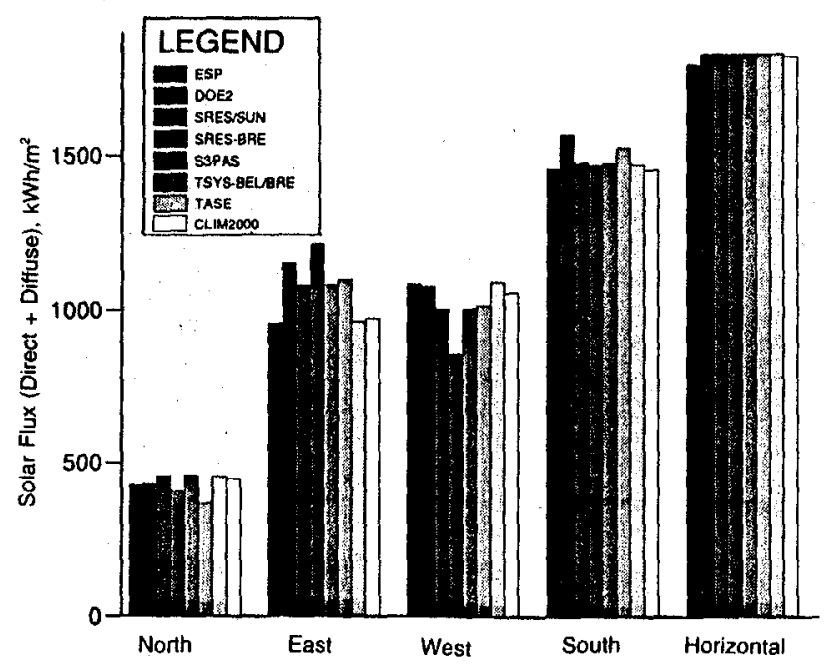

Figure 2-32. Annual solar flux incident on the five walls 


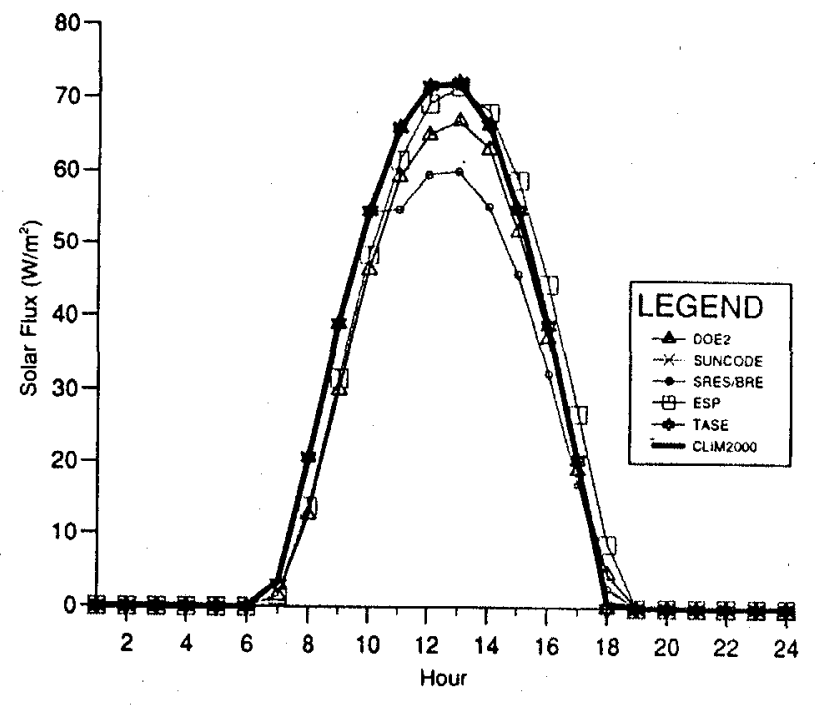

Figure 2-33. Global flux incident on south wall, March 5

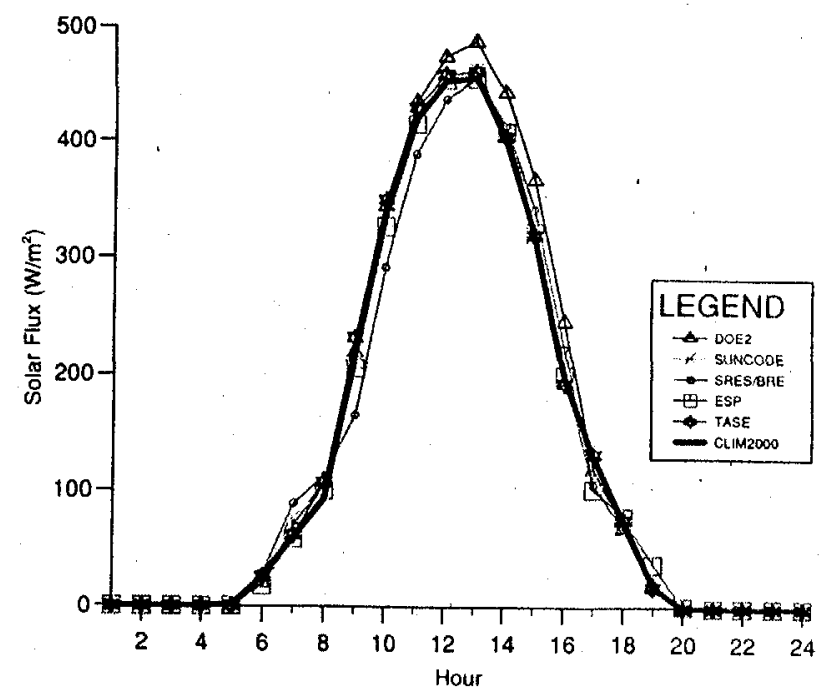

Figure 2-35. Global flux incident on south wall, July 27



Figure 2-34. Global flux incident on west wall, March 5

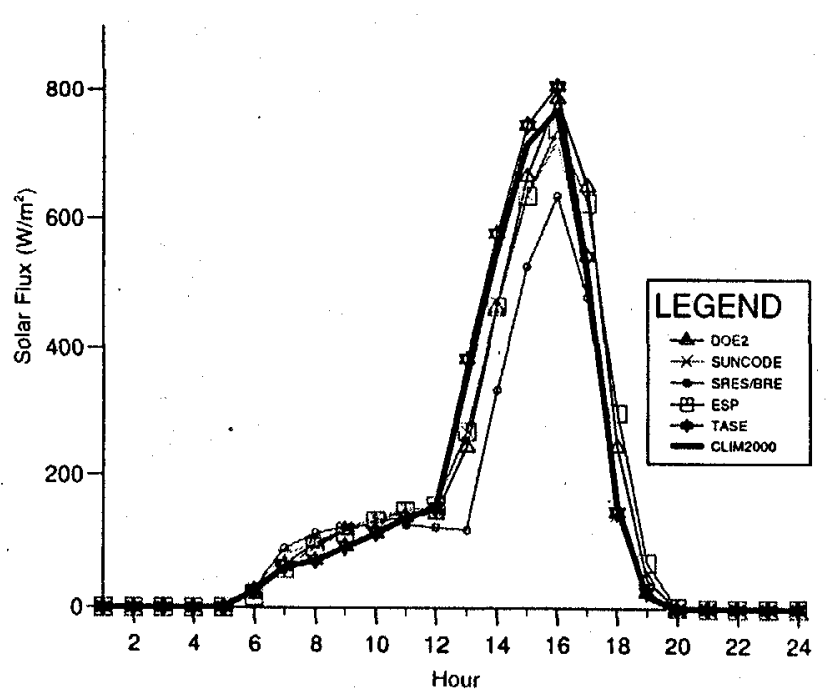

Figure 2-36. Global flux incident on west wall, July 27 


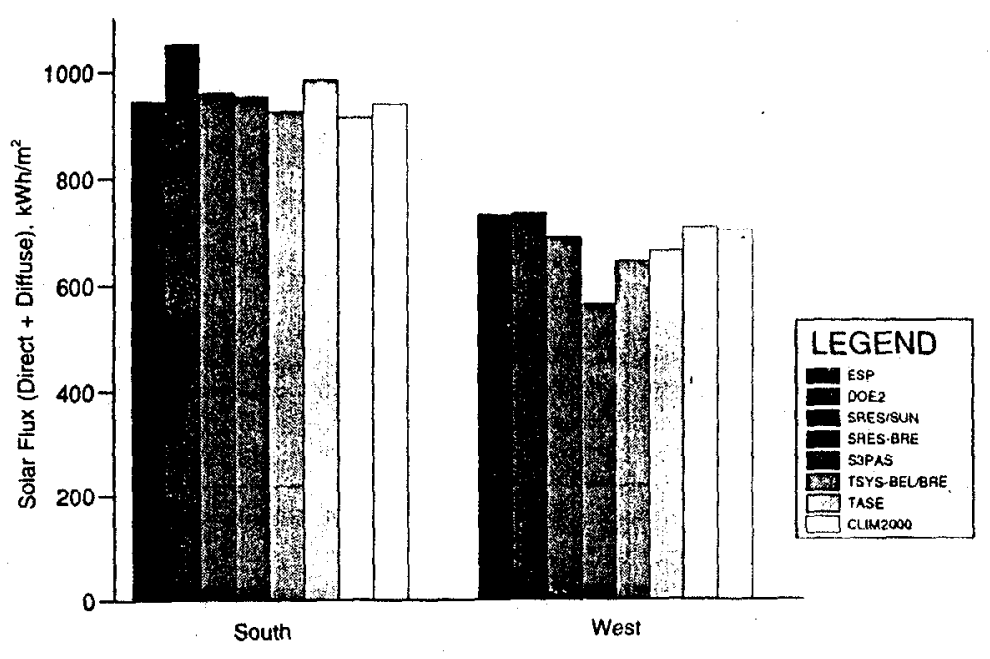

Figure 2-37. Annual solar flux transmitted by south and $\frac{\tilde{I}}{E}$ west windows

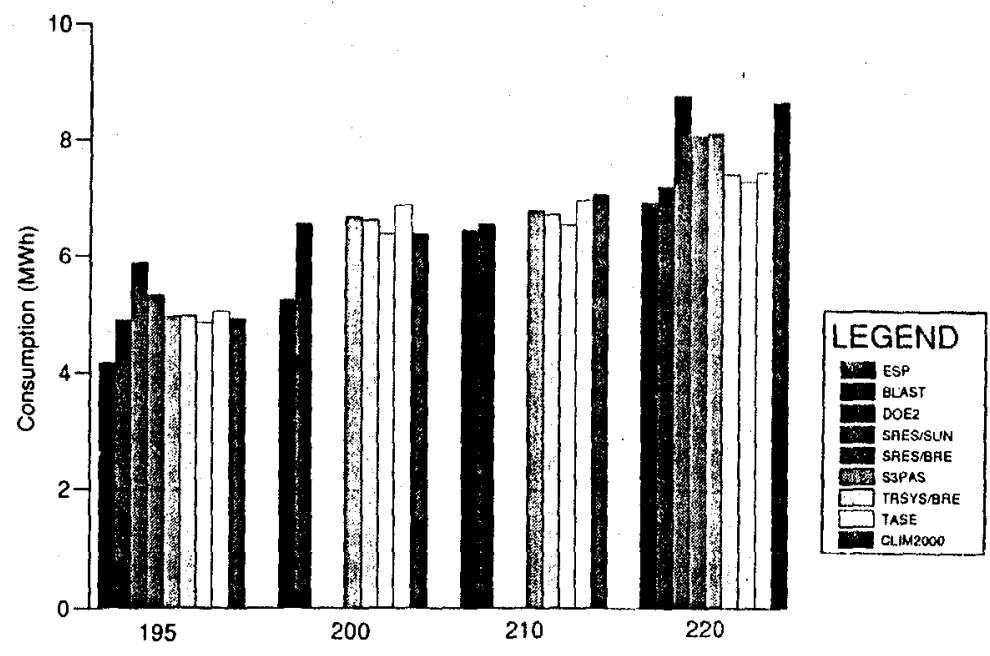

Figure 2-39. Annual heating consumption: elementary cases (195 through 220)

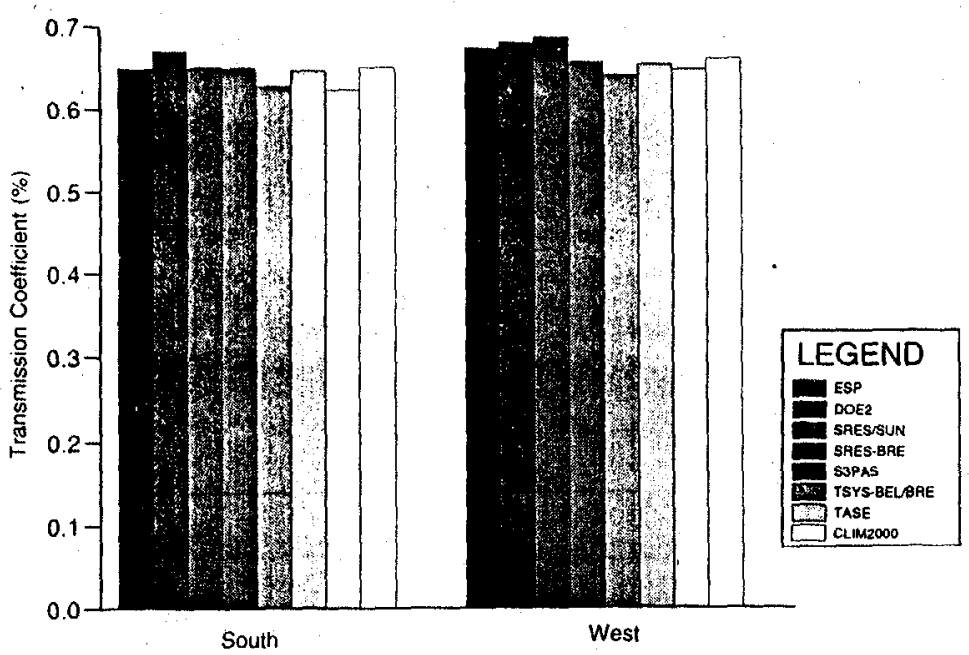

Figure 2-38 Transmission coefficient of windows (annual transmitted flux/annual incident flux)

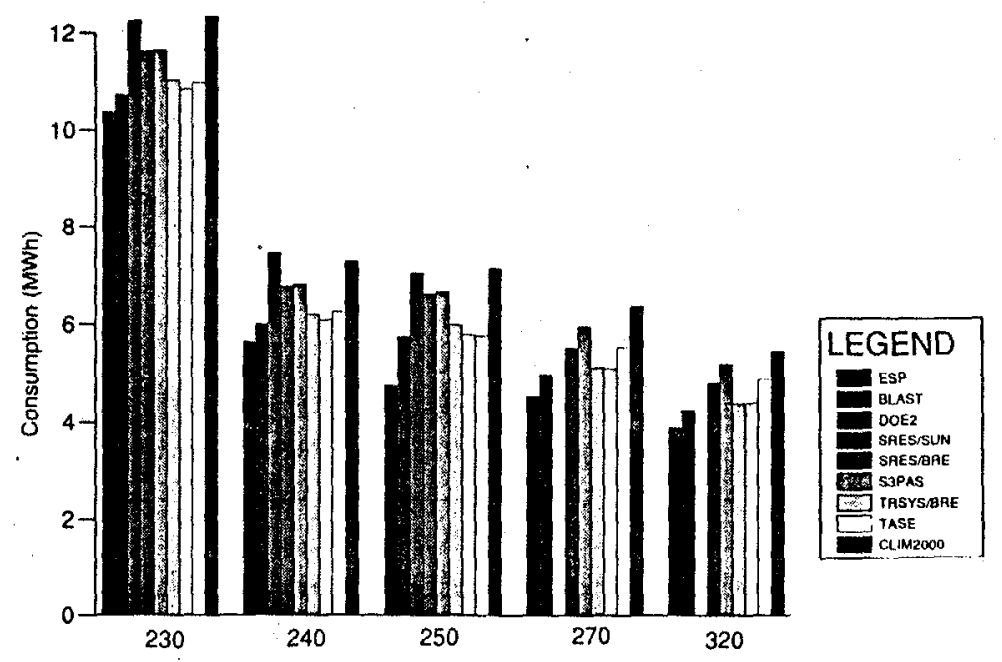

Figure 2-40. Annual heating consumption: elementary cases (230 through 320) 


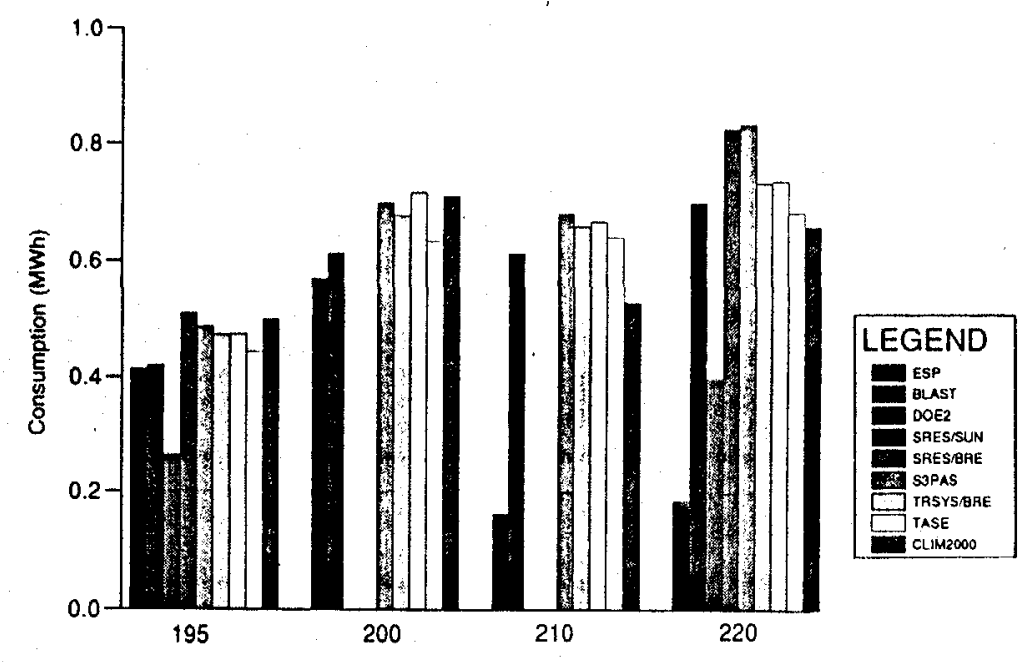

Figure 2-41. Annual cooling consumption: elementary cases (195 through 220)

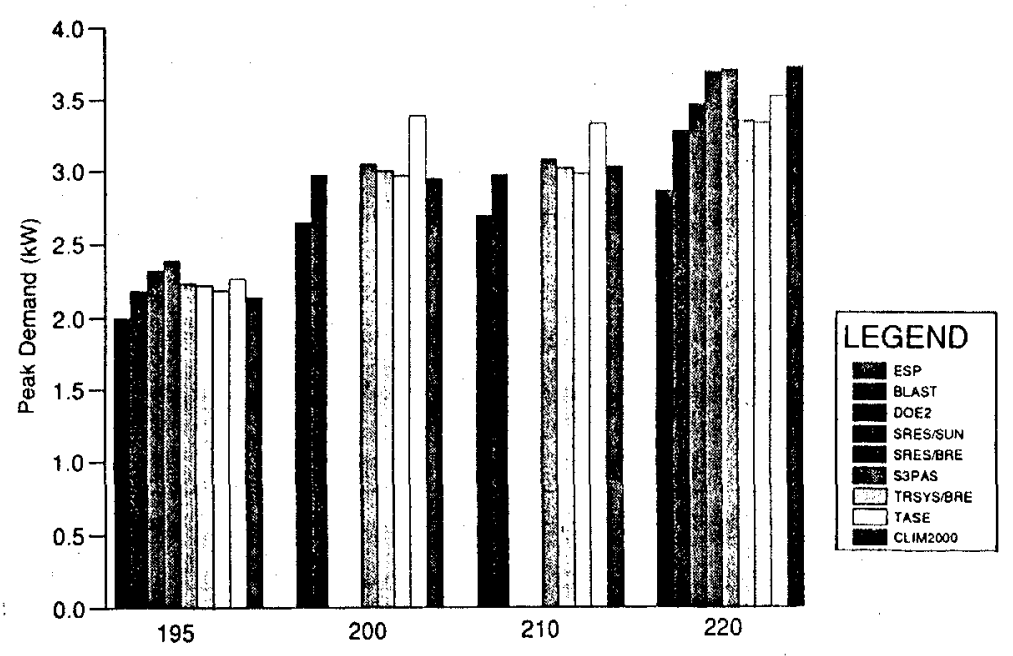

Figure 2-43. Peak heating demand: elementary cases (195 through 220)

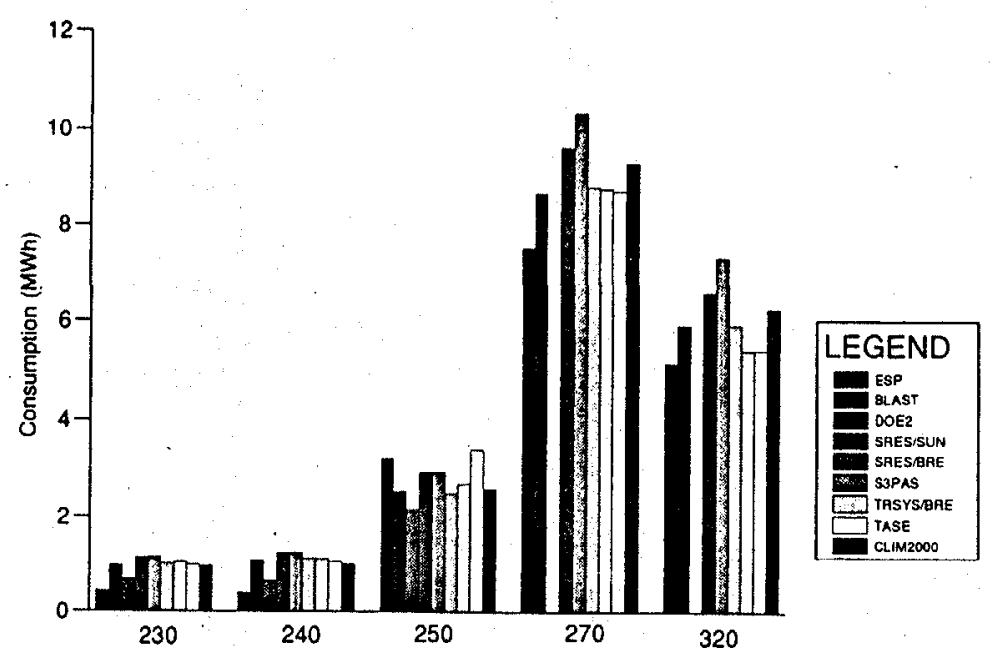

Figure 2-42. Annual cooling consumption: elementary cases (230 through 320)

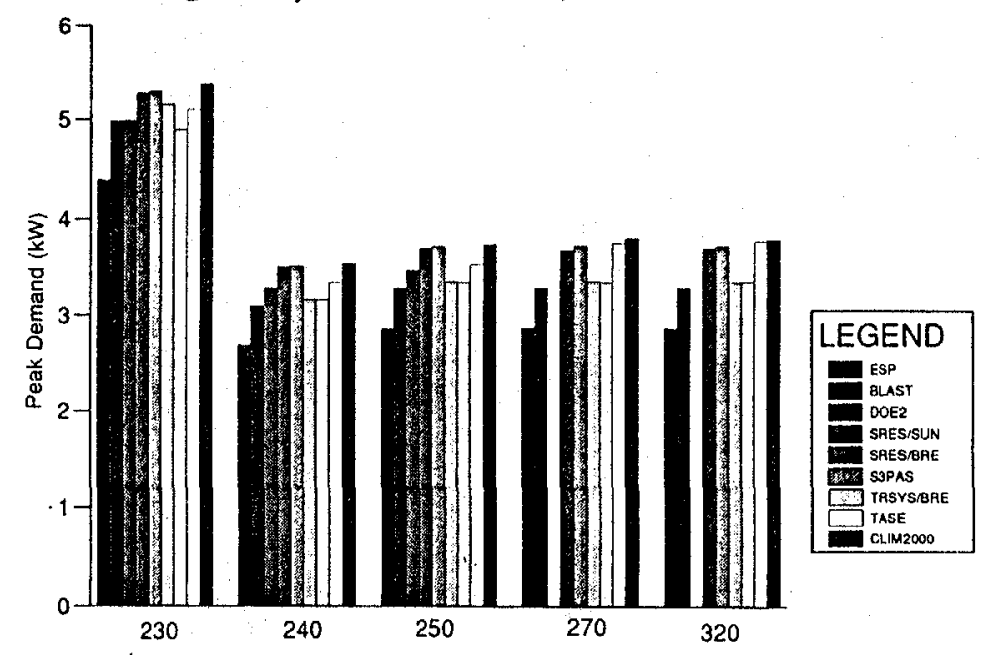

Figure 2-44. Peak heating demand: elementary cases (230 through 320 ) 


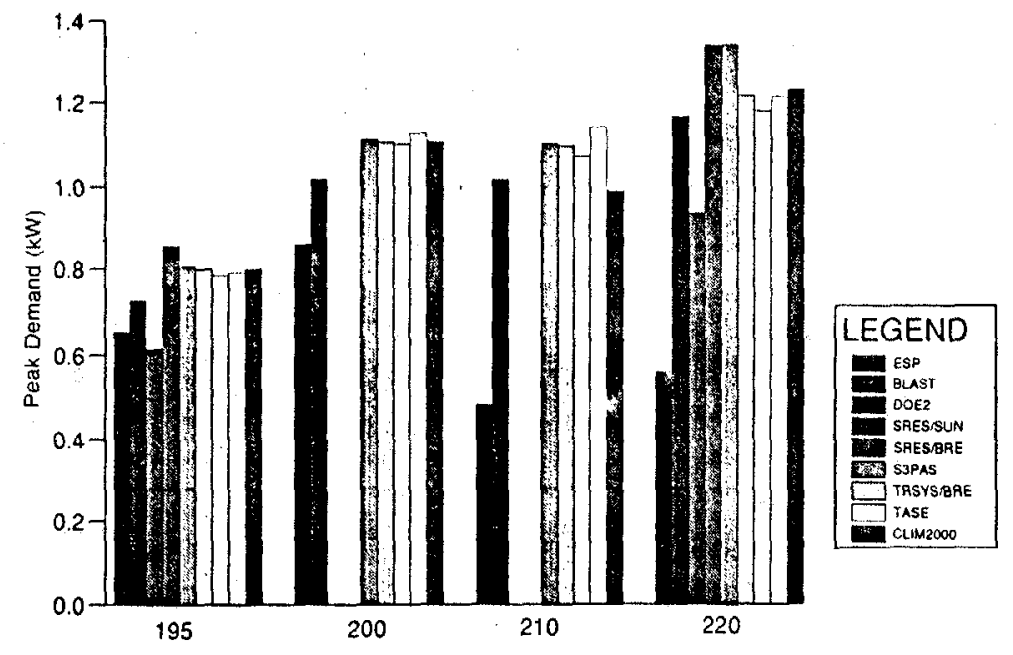

Figure 2-45. Peak cooling demand: elementary $\frac{N}{\stackrel{N}{N}}$ rases (195 through 220)

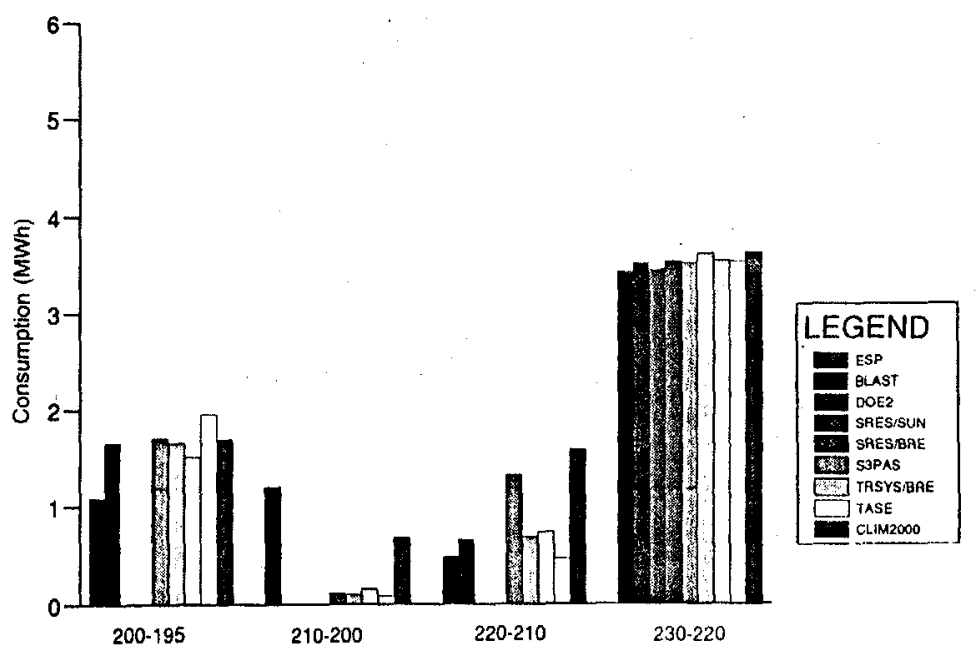

Figure 2-47. Annual heating consumption: series A1 through A6

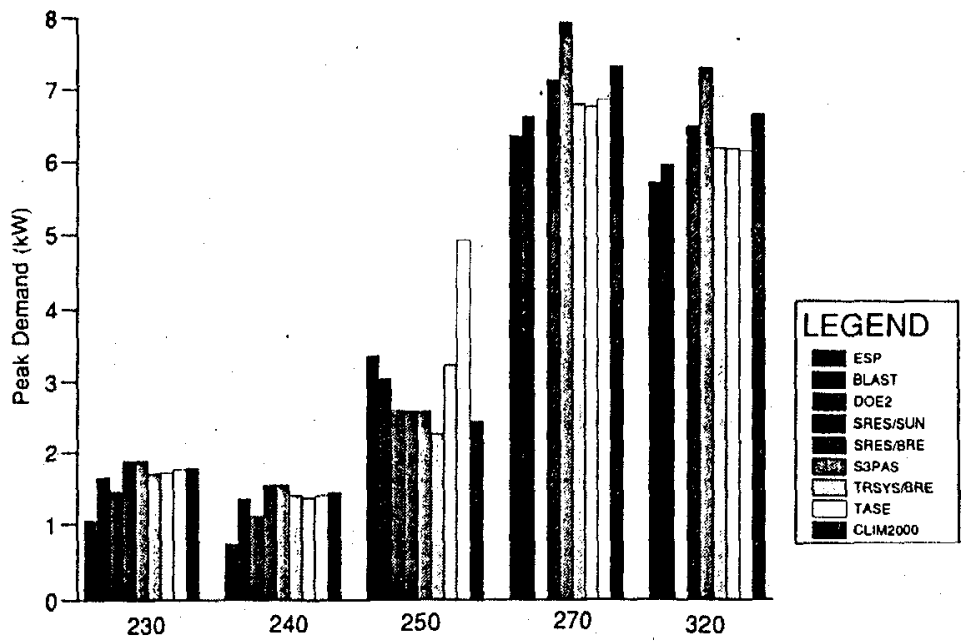

Figure 2-46. Peak cooling demand: elementary cases (230 through 320)

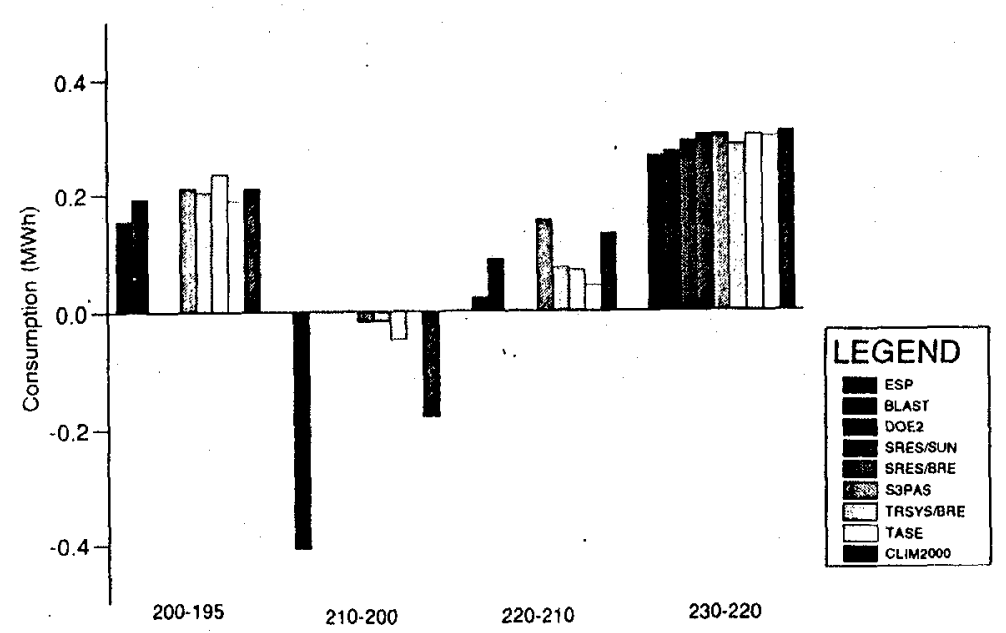

Figure 2-48. Annual cooling consumption: series A1 through $A 6$ 


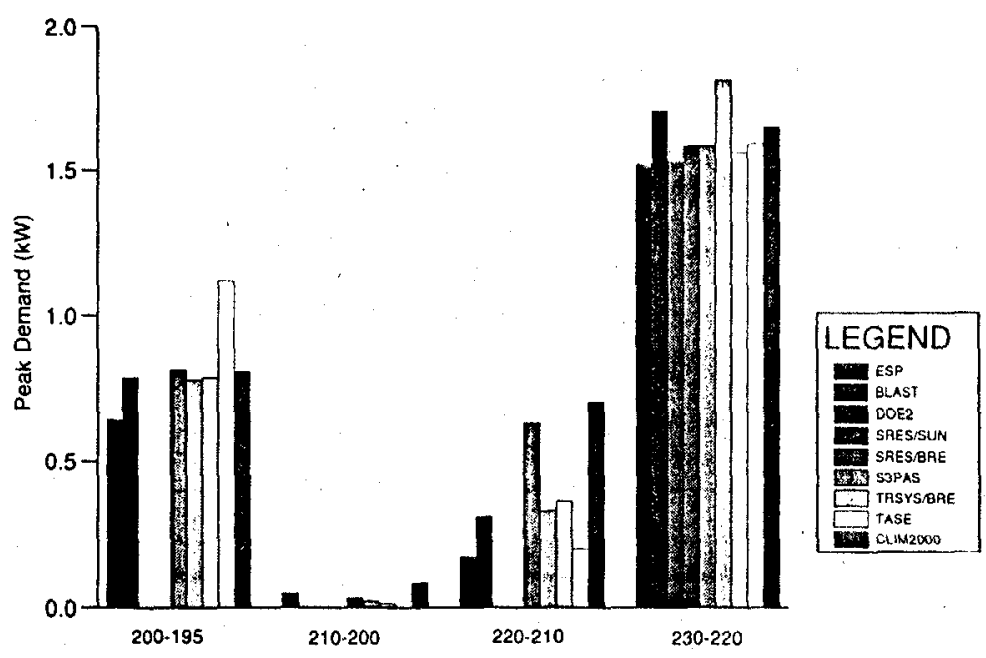

Figure 2-49. Peak heating demand: series A1 through A6

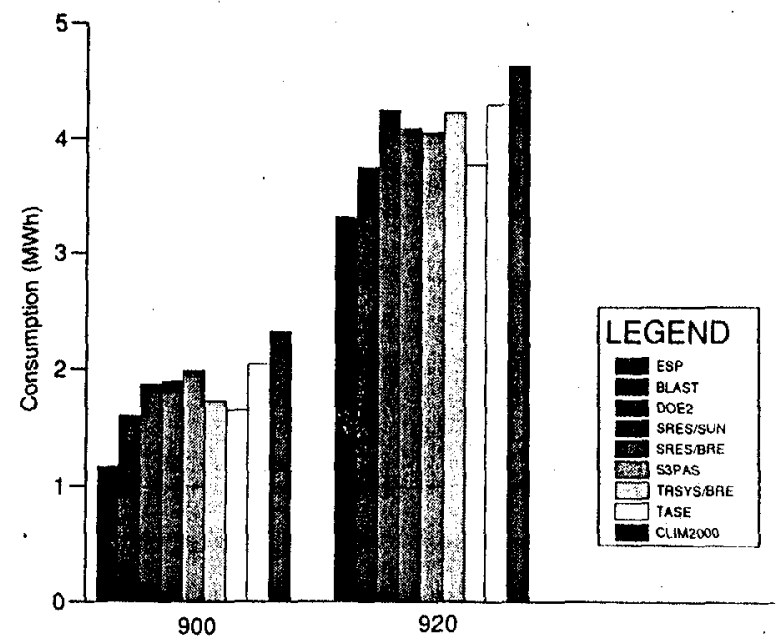

Figure 2-51. Annual heating consumption: high-mass (heavy) building

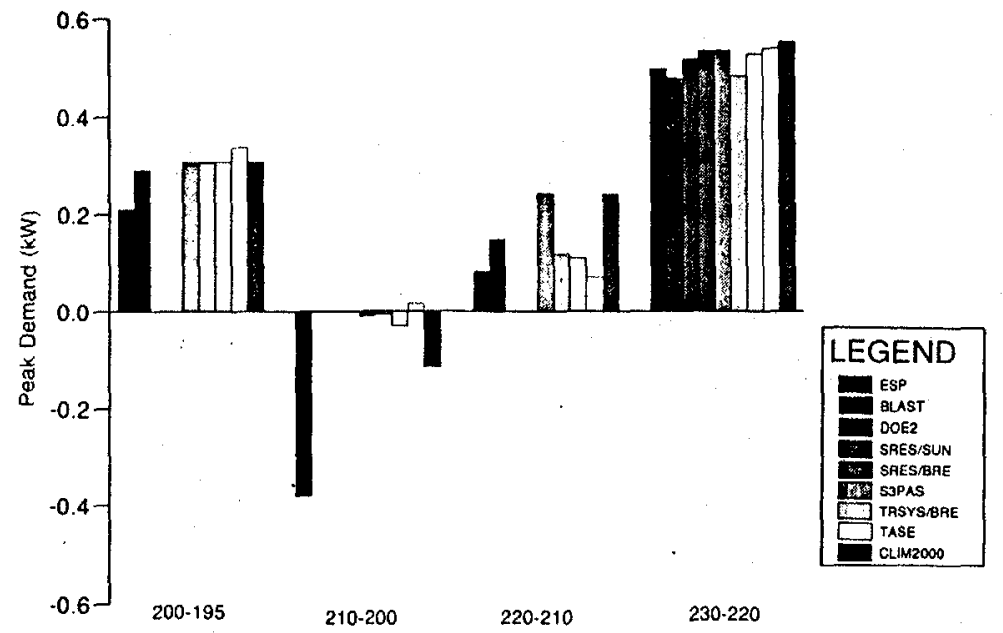

Figure 2-50. Peak cooling demand: series A1 through A6

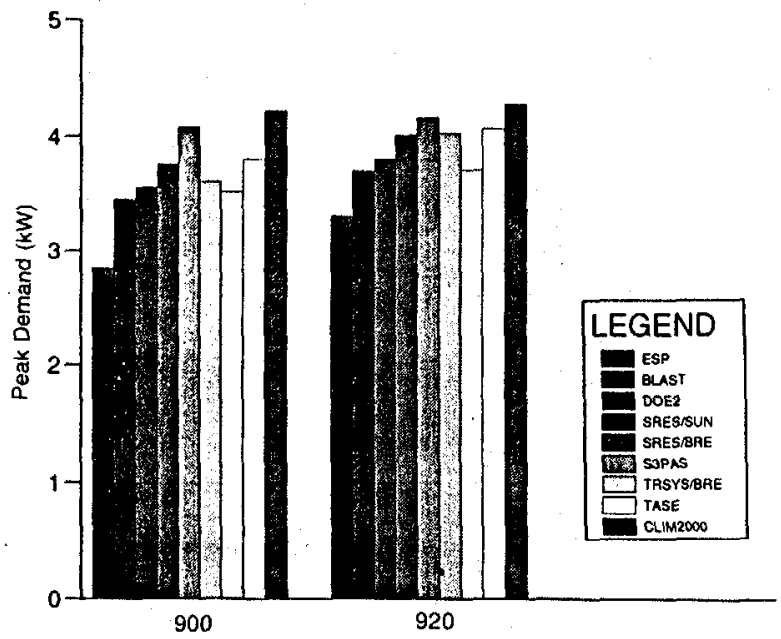

Figure 2-52. Peak heating demand: high-mass building 


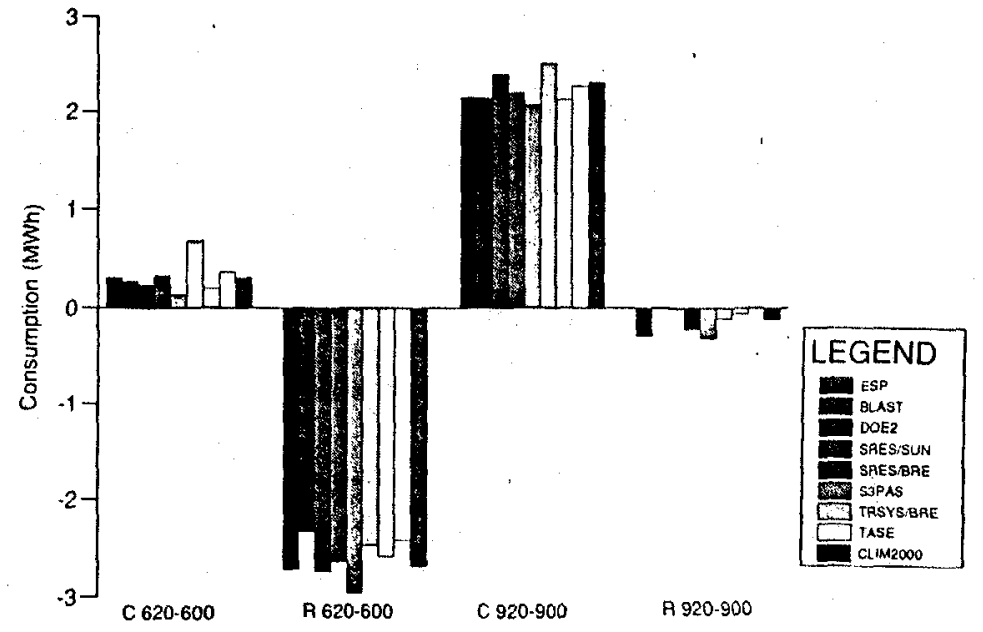

Figure 2-53. Annual heating and cooling consumptions: influence of window orientation

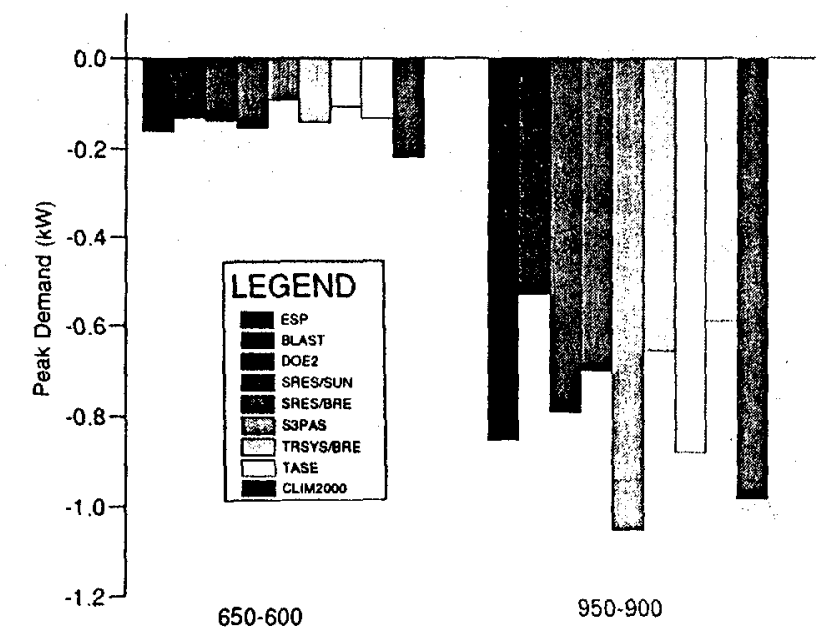

Figure 2-55. Peak heating demand: influence of ventilation

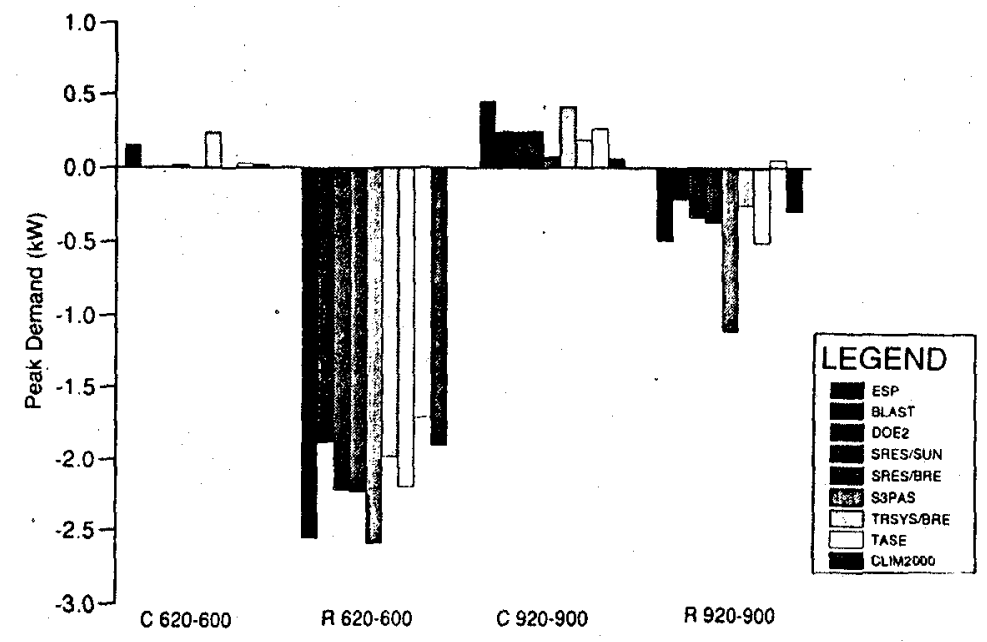

Figure 2-54. Peak heating and cooling demands: influence of window orientation

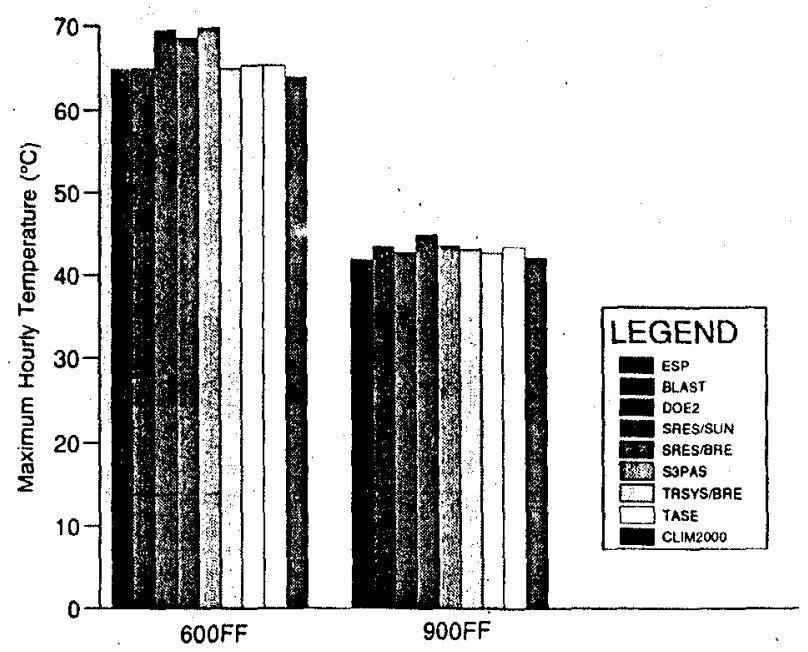

Figure 2-56. Maximal hourly temperatures: free-float case 


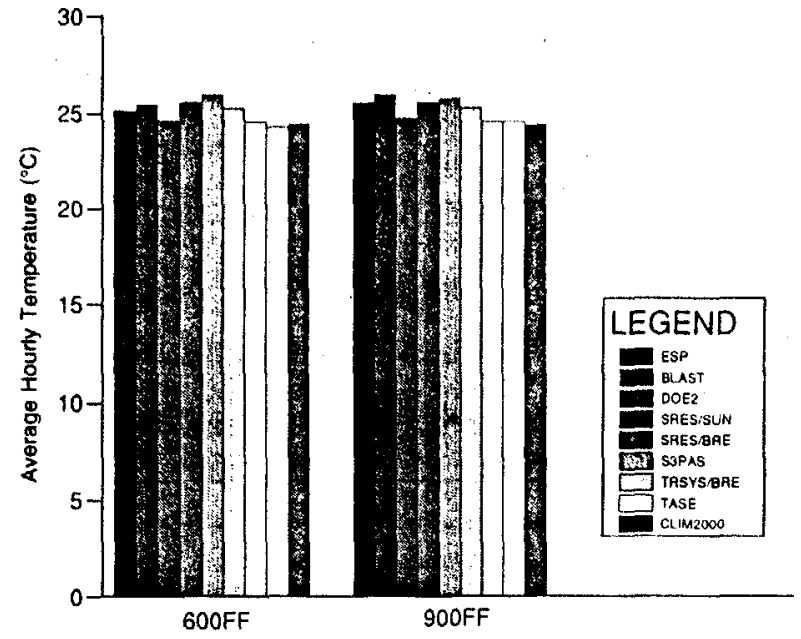

Figure 2-57. Average hourly temperatures: free-float case

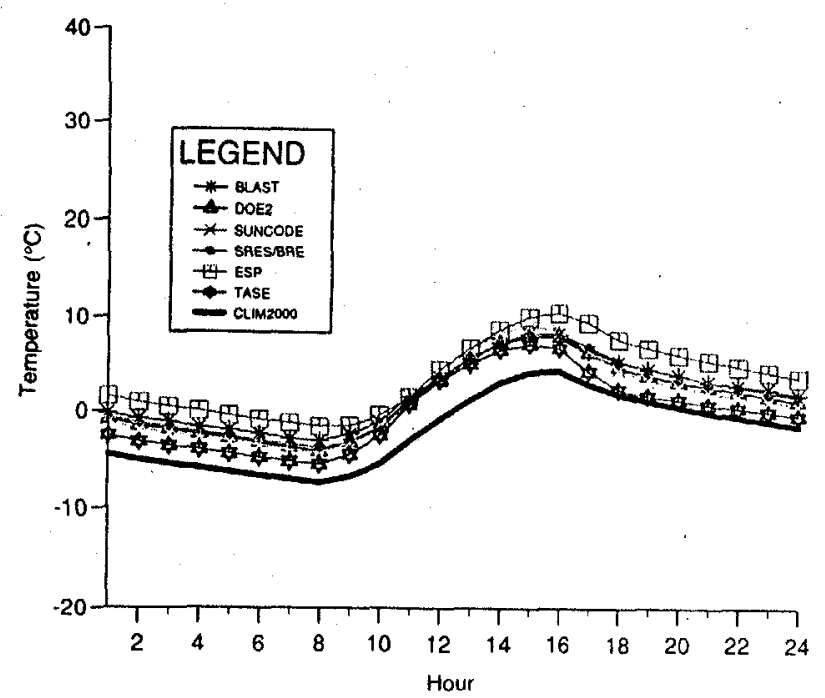

Figure 2-59. Interior temperature change, January 4, case 900FF



Figure 2-58. Interior temperature change, January 4, case 600FF

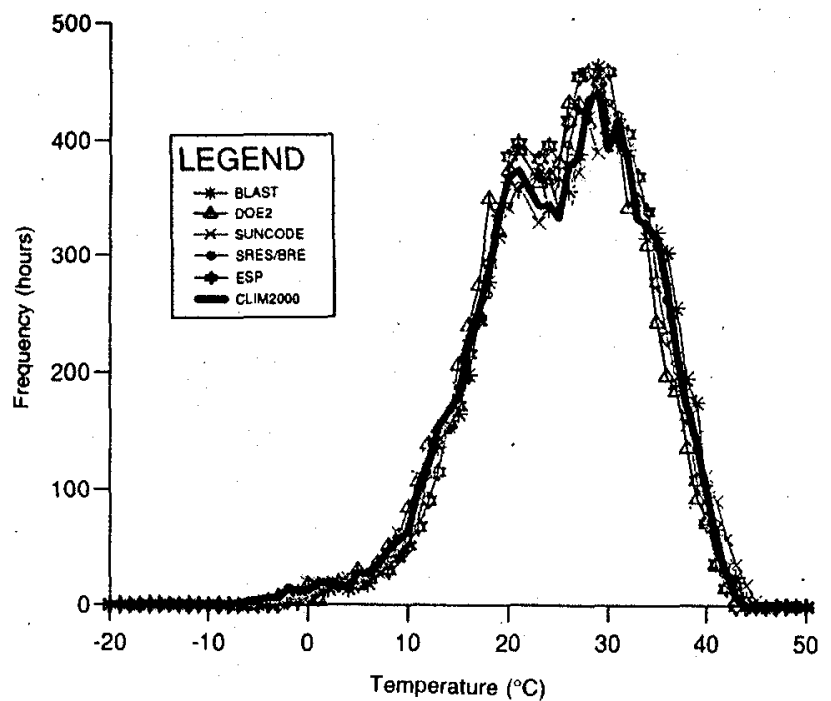

Figure 2-60. Frequency of hourly temperatures: case 900FF 


\subsection{Interpretation of Results}

The final results from the reference programs are presented in Part III in tabular and graphic form. Maximum and minimum reference ranges have been superimposed on some of the graphs. Ranges were not set for the diagnostic cases because we expect that diagnostics will be performed by specialists for whom such a simplification will not be necessary. As previously stated, the reference ranges do not represent truth. They do represent the best current state-of-the-art in whole building energy simulation predictions. There is no truth standard in this type of exercise. For any given case, a program that yields values in the middle of the range should not be perceived as better or worse than a program that yields values at the borders of the range. The ranges represent algorithmic differences in the current-state-of-theart. Programs that fall outside the range are producing results different from the current state-of-the-art as defined by our group of international experts. Investigating the source(s) of the difference(s) is worthwhile, but the existence of a difference does not necessarily mean a program is faulty. Our collective experience in this task has indicated that when programs show major disagreement with a range, we often find a bug, or a questionable algorithm.

The results show a considerable amount of disagreement among the programs for many of the cases and output types. The reference ranges reflect this disagreement.

There is too much output data to comment specifically on each case. However, some trends are apparent, as evidenced in Table 2-49 which shows the average percent spread and the absolute difference between the maximum and minimum reference range values for the low-and high-mass annual and peak load results. The percent spread for each case is taken as $100(\max -\min ) /((\max +\min ) / 2)$.

The absolute difference is simply ( $\max -\min$ ). The resulting values are averaged across all applicable cases for a given output type and thermal capacitance category.

Table 2-49 indicates less disagreement among the programs in the calculation of peak loads (17\% to $35 \%$ ) than in the calculation of annual loads (28\% to $66 \%$ ). There is considerably more disagreement among the programs for the calculation of annual cooling loads (37\% to 66\%) than for the calculation of annual heating loads ( $28 \%$ to $39 \%$ ). Also, there is generally more disagreement for the high-mass cases ( $27 \%$ to $60 \%$ ) than for the low-mass cases (17\% to $37 \%)$.

Table 2-49. BESTEST Reference Results Summary

\begin{tabular}{|l|c|c|}
\hline Case type & $\begin{array}{c}\text { Mean absolute } \\
\text { difference between } \\
\text { reference range } \\
\text { maximum and minimum }\end{array}$ & $\begin{array}{c}\text { Mean \% difference } \\
\text { (Reference range) }\end{array}$ \\
\hline \hline Low-mass annual heating (600 series) & $1.3 \mathrm{MWh}$ & 28 \\
\hline Low-mass annual cooling (600 series) & $1.7 \mathrm{MWh}$ & 37 \\
\hline Low-mass peak heating (600 series) & $1.0 \mathrm{~kW}$ & 23 \\
\hline Low-mass peak cooling (600 series) & $0.9 \mathrm{~kW}$ & 17 \\
\hline High-mass annual heating (900 series) & $0.9 \mathrm{MWh}$ & 39 \\
\hline High-mass annual cooling (900 series) & $1.0 \mathrm{MWh}$ & 66 \\
\hline High-mass peak heating (900 series) & $1.0 \mathrm{~kW}$ & 27 \\
\hline High-mass peak cooling (900 series) & $0.8 \mathrm{~kW}$ & 35 \\
\hline
\end{tabular}


There was no obvious pattern across cases. However, disagreements were particularly large in the peak heating predictions for the thermostat setback cases (640 and 940) and in the annual cooling predictions for the east- and west-shading device cases (630 and 930).

There were no general trends apparent in the diagnostic cases. Some of the 200 series cases could only be explicitly modeled by a single program (ESP). Such cases will not have much diagnostic value until the capability to explicitly model them becomes more common among the state-of-the-art programs. For the rest of the diagnostic cases, some effects were calculated with very close agreement among the programs, such as the effect of a known infiltration rate (case 410-400) and the effect of a known internal heat-gain rate (case 420-410). Other more complex effects showed considerable disagreement because of the variety of algorithms used to model them in the programs. The results from the "insulated box" (case 395) showed a surprisingly large amount of disagreement (approximately $1 \mathrm{MWh}$ or $20 \%$ for annual heating), although most of this difference was due to a single program. Despite the magnitude of disagreement among the reference programs, the diagnostic procedures proved very effective at filtering out bugs, faulty algorithms, and input errors.

These results are fairly consistent with those from previous studies in which it was concluded that disagreement among programs increases when the diffusion of sensible heat in solid media becomes dominated by other, more complex transfer mechanisms such as: exterior and interior infrared radiation; surface convection; and distribution, transmission, and absorption of solar radiation (Judkoff 1988a).

The importance of the interior surface heat transfer coefficients is often underestimated because of the steady state argument that they are only a very small portion of the overall resistance through the exterior wall. However, under transient conditions these coefficients also play an important role in

- linking the capacitance of the building to the thermostat control node

- determining how responsive the thermostat is to radiation and convection

- determining how heat from mechanical or solar sources is distributed, and how quickly the thermostat is affected

- affecting surface temperature, especially on solar receiving surfaces.

The amount of disagreement exhibited in this study was greater than that shown in a previous IEA study (Bloomfield 1989). This was expected because the cases for this study were designed to be more strongly solar driven than those in the previous study. Also, in this study modelers were instructed to use the most detailed level of modeling available in their program. In the previous study, modelers were instructed to use a "common denominator" level of modeling when possible. The amount of disagreement in this study was also consistent with that found in an empirical validation exercise conducted by our Experts Group (Lomas et al. 1994).

Wider reference ranges are observed in this study because many state-of-the-art building energy simulation programs allow several levels of modeling sophistication. Improved computer hardware has encouraged the inclusion of more detailed algorithmic options. Unfortunately, little conclusive data exists to determine which option best represents reality. 


\subsubsection{Test Cases for Future Work}

In the course of this work it became apparent that some additional test cases might be useful for improved error trapping and diagnostics with BESTEST. In future work, we suggest that some extensions to the test suite be considered.

In the diagnostic cases involving infrared radiation and exterior solar absorptance, there is a trade-off between how clean a case can be, and the strength of excitation of the mechanism being tested. For example, the cleanest test of the effect of interior infrared emissivity is one in which both exterior infrared. emissivity and exterior shortwave absorptivity are disabled. However, such a case provides only a weak test of the algorithms associated with interior infrared radiation exchange because the excitation from solar radiation has been minimized. Setting the exterior solar absorptance to 0.9 provides a much stronger excitation, but also introduces noise because different programs can use different algorithms for distributing incident solar radiation on exterior surfaces of the building. We have not yet had the opportunity to test these trade-offs because so few of the programs are capable of explicitly modeling infrared radiation.

Two additional cases are worth investigating to more completely test radiation models. These cases allow the models related to infrared radiation and exterior shortwave absorptance to be checked by both a "cleanest test" and a "strongest excitation test." We designate these new cases with the numbers 205 and 218. Case 218 would be the same as case 250 but with exterior infrared emissivity off $\left(\varepsilon_{\text {ext }}=0.1\right)$. Cases 250 and 218 would then test exterior infrared radiative heat transfer with exterior shortwave absorptance on $\left(\alpha_{\text {ext }}=0.9\right)$ and interior infrared emissivity on $\left(\varepsilon_{\text {int }}=0.9\right)$. This new case would allow testing of the interaction between exterior infrared radiative heat transfer and incident solar radiation. The advantage of testing exterior infrared radiative heat transfer with $\alpha_{\text {ext }}$ on, is that the additional solar radiation absorbed by the exterior wall produces greater excitation of the exterior surface temperature. This magnifies the amount of infrared radiative heat transfer between the wall and ambient during the daytime. Additionally, since both cases 250 and 218 have $\varepsilon_{\text {int }}$ on, zone heating and cooling are more closely coupled to the walls and opaque windows. Thus, the space conditioning loads are more sensitive to changes in exterior surface material properties. The disadvantage of testing exterior infrared radiative heat transfer with $\alpha_{\text {ext }}$ and $\varepsilon_{\text {int }}$ on is that, with more energy flowing through various heat transfer paths, the overall output noise level is raised so that the effect of varying $\varepsilon_{\text {ext }}$ could be obscured. Finally, since $\varepsilon_{\text {int }}$ is on, exterior infrared radiative heat transfer can be tested in programs that allow varying $\varepsilon_{\text {ext }}$, but not varying $\varepsilon_{\text {int }}$

Cases 218 and 215 test exterior shortwave absorptance with $\varepsilon_{\text {ext }}$ off and $\varepsilon_{\text {int }}$ on. The advantage of this configuration is that infrared radiative losses from exterior wall surfaces to ambient are minimized, while the zone-space conditioning system is more closely coupled to the exterior walls and opaque windows. The disadvantage of having $\varepsilon_{\text {int }}$ on is the increased noise level in the load outputs, as noted above.

Case 205 would be the same as case 200 but with $\alpha_{\text {ext }}=0.9$. Cases 218 and 205 would test interior infrared radiative heat transfer with $\alpha_{\text {ext }}$ on and $\varepsilon_{\text {ext }}$ off. The advantage of this configuration is maximized excitation of the heating and cooling system from solar gains. Cases 205 and 200 would test exterior shortwave absorptance with $\varepsilon_{\text {ext }}$ off and $\varepsilon_{\text {int }}$ off. This is the cleanest possible embodiment of the test, but provides a weak connection to the thermostat control node-resulting in lower building loads.

Table 2-50 shows all possible diagnostic combinations that test the algorithms for exterior solar absorptance and infrared radiation. 
Table 2-50. Radiation Diagnostics

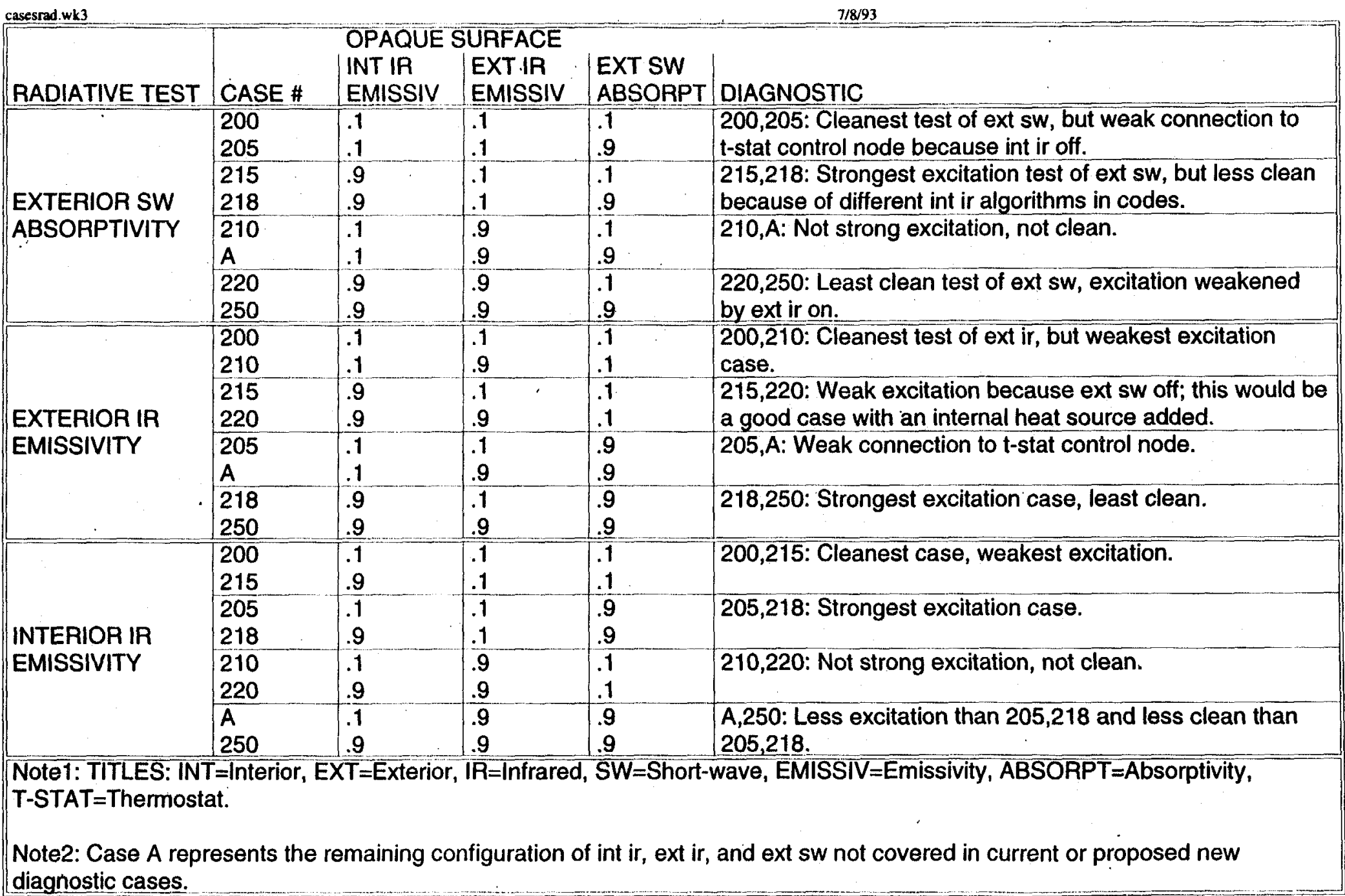


A very clean and powerful test for exterior infrared radiation could be created by adding a relatively large and constant internal heat source to diagnostic cases 200 and 210 . This would provide adequate excitation without increasing the noise level.

Two other cases would also be helpful to serve as relatively realistic base cases for the low- and high-mass qualification series. We designate these new cases with the numbers 425 and 795 . Case 425 would be the same as case 600 except that the window is replaced by a normally insulated low-mass wall. Cases 600 and 425 would provide a means for directly checking sensitivity to transparent glazings versus an unglazed wall for low-mass construction. Case 425 results would be displayed with the 600 series results and with the south window (delta) results in the BESTEST qualification plots.

Case 795 would be the same as case 900 except that the window is replaced by a normally insulated highmass wall. Cases 900 and 795 would provide a means for directly checking sensitivity to transparent glazings versus an unglazed wall for high-mass construction. Case 795 results would be displayed with the 900 series results and with the south window (delta) results in the BESTEST qualification plots.

Table 2-51 shows the characteristics of the new cases. 
Table 2-51. BESTEST Case Descriptions Proposed New Cases

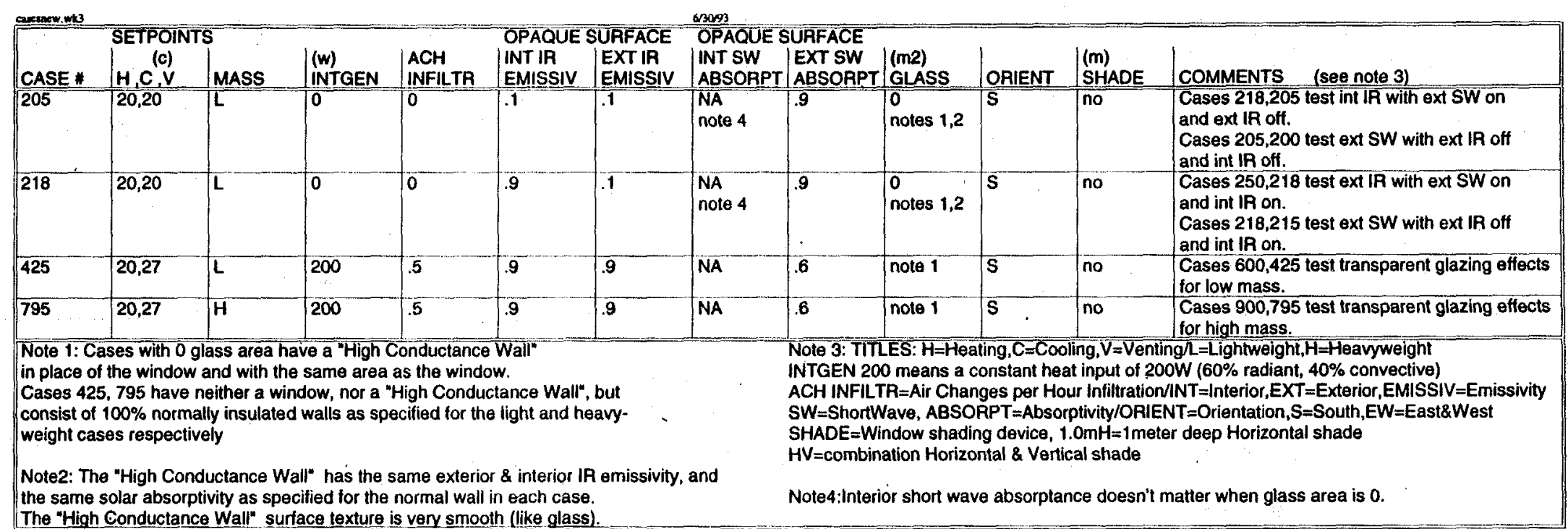




\subsection{Conclusions and Recommendations}

\subsubsection{Conclusions}

A method has been developed for systematically comparing whole-building energy software and determining the algorithms responsible for prediction differences. The method has a variety of uses that include:

- Comparing several building energy simulation programs to determine the amount of disagreement among them

- Diagnosing the algorithmic sources of prediction differences among several building energy simulation programs

- Comparing the predictions from other building energy programs to the reference results presented in this report

- Checking a program against a previous version of itself after internal code modifications to ensure that only the intended changes actually resulted

- Checking a program against itself after a single algorithmic change to understand the sensitivity between algorithms.

The method gives building energy software developers and users the ability to test a program for reasonableness of results and to determine if a program is appropriate for a particular application.

BESTEST tests a program over a broad range of parametric interactions and for a number of different output types, thus minimizing the concealment of algorithmic problems by compensating errors. The procedure does not by itself comprise a complete validation methodology, which would consist of empirical, analytical, and comparative techniques. It does allow a given program to be compared with a number of so-called state-of-the-art programs. These state-of-the-art programs have undergone some "validation" tests, but cannot be considered fully validated. Therefore "failing" a test does not necessarily indicate a faulty program, but it does indicate a difference that should be investigated and understood. Our collective experience in this study indicates that when a program shows major disagreement with the reference programs, a bug, questionable algorithm, or documentation problem is often found.

The procedure has been field tested using a number of national building energy simulation programs from the United States and Europe. These same programs were used to generate reference data which can be used as a basis for testing other programs that did not participate in the exercise.

The method has proven-effective at isolating the sources of predictive differences. The diagnostic procedures revealed bugs, faulty algorithms, limitations, and input errors in every one of the building energy computer programs, among the best in the world, tested in this study including BLAST, CLIM2000, DEROB, DOE2, ESP, SERIRES, S3PAS, SUNCODE, TASE, and TRNSYS. Notable examples were:

- Isolation and correction of a bug in the transfer function (BID) module of TRNSYS version 12.2

- Isolation and correction of an error in the algorithm calculating absorptance of solar energy on interior surfaces in ESPsimv 6.18a 
- Isolation and correction of an error in the algorithm calculating absorptance of solar energy on exterior surfaces labelled as doors in DOE2.1D Version 14

- Isolation of a documentation problem related to the detailed algorithm that calculates exterior surface infrared radiation exchange in BLAST3.0 level 193 v.1

- Identification of input errors (subsequently corrected) in almost all the programs even for these simple buildings, emphasizing the need for the quality assurance procedures for program users developed in IEA BCS Annex 21C.

Performance of the BESTEST resulted in quality improvements to all eight of the building energy simulation programs used in this study. These programs were selected by participants as representing the best of the national programs from Belgium, Finland, France, Italy, Spain, Sweden, the United Kingdom, and the United States.

The majority of errors found during the project stemmed from incorrect code implementation. Some of these bugs may well have been present for many years. The fact that they have just now been uncovered shows the power of BESTEST and also suggests that validation is not given a high enough priority by code developers. It is only after coding bugs have been eliminated that the assumptions and approximations in the algorithms can be evaluated and improved where necessary.

Checking a building energy simulation program with BESTEST requires about 2 to 5 days for an experienced user. The major programs have taken many years to produce. BESTEST provides a very cost effective way of evaluating them.

The field trials revealed much disagreement among the reference programs even after all known problems were repaired. The differences ranged from approximately $20 \%$ for prediction of peak loads in cases with low thermal capacitance to about $66 \%$ for prediction of annual cooling loads in the high thermal capacitance cases. There was less disagreement in the calculation of peak loads (17\%-35\%) than in the calculation of annual loads $(28 \%-66 \%)$. There was considerably more disagreement for the calculation of annual cooling loads (37\%-66\%) than for the calculation of annual heating loads (28\%-39\%). Also, there was more disagreement for cases with high thermal capacitance $(27 \%-66 \%)$ than for those with low thermal capacitance (17\%-37\%). Even the most detailed of these programs still contain many simplifying assumptions, and legitimate differences in the choice of algorithms which can lead to significant energy prediction differences in certain cases.

The amount of disagreement exhibited in this study was greater than that found in a previous IEA SHC Task 8 study (Bloomfield 1989). This was expected because the cases for this study were designed to be more strongly solar "driven" than those in the previous study. Also, in this study modelers were instructed to use the most detailed level of modeling available in their program. In the previous study modelers were instructed to use a "common denominator" level of modeling when possible. The amount of disagreement in this study was consistent with that found in the Empirical Validation exercise also conducted under the IEA 12B/21C joint working group (Lomas et al. 1994).

In general, the current generation of programs appear most reliable when modeling diffusion of sensible heat in solid media assuming one-dimensional heat transfer and constant properties. Prediction inaccuracy and intermodel disagreement increase as solar excitations become stronger, and the solid conduction heattransfer mode becomes dominated by other more complex energy transfer mechanisms. The predominant sources of disagreement in the prediction of building fabric response to the external and internal environment appear to be in those algorithms related to the calculation of: 
- Interior and exterior surface convection and infrared radiation exchange

- Interior and exterior solar radiation distribution including shading effects

- Ground heat transfer.

Algorithms that we have not yet tested, but which we believe may contribute to major predictive uncertainties, are:

- 2- and 3-dimensional conduction

- Interzone and intrazone natural convection, and stratification

- Latent loads, moisture migration, and moisture adsorption and desorption

- Variation of thermal properties due to temperature and moisture content.

A need therefore exists to develop validated algorithms for these effects.

The value of the BESTEST methodology is to some extent independent of the particular computer programs used to generate the reference ranges. We expect that reference ranges will be periodically updated as the state-of-the-art programs improve. There is also room within the BESTEST structure to add new test cases when required. BESTEST currently emphasizes those algorithms related to energy flows and energy storage in the architectural fabric of the building. In future work, we hope to add test cases that emphasize the special modeling issues associated with more complex building types and HVAC systems.

\subsubsection{Recommendations}

The IEA 12B/21C experts, a group consisting of both model developers and model users, unanimously recommend that no building energy simulation program be used until, at a minimum, it has been checked with the BESTEST procedure. We hope that as this procedure becomes better known, developers will automatically run the tests as part of their normal in-house quality control efforts. Developers should also include the test input and output files with their respective software packages to be used as part of the standard benchmarking process by the model user.

There is clearly a need for further development of these models, combined with a substantial program of testing and validation. Such an effort should contain all the elements of an overall validation methodology; including:

- Analytical Verification

- Empirical Validation

- Comparative Testing and Diagnostics.

Future work should therefore encompass

- Production of a standard set of analytical tests

- Development of a set of comparative tests that emphasize the modeling issues important in large commercial buildings, such as zoning and HVAC systems 
- Development of a sequentially ordered series of high quality data sets for empirical validation.

Continued support of model development and validation activities is essential because buildings are not amenable to classical controlled, repeatable experiments. The energy, comfort, and lighting performance of buildings depends on the interactions between a large number of transfer mechanisms, components, and systems. Simulation is the only practical way to bring a systems integration problem of this magnitude within the grasp of designers. Radically reducing the energy intensity of buildings through better design is possible with the use of simulation tools. However, widespread use of building energy simulation programs will not occur unless the design and engineering communities have confidence in these programs. Confidence can best be encouraged by combining a rigorous development and validation effort with friendly user interfaces, to minimize human error and effort.

Detailed building energy simulation programs represent the ultimate repository for our collective formal knowledge of the physics governing the energy, comfort, and lighting performance of buildings. They are the technical foundation on which we rely to properly inform the design-related and policy-related decision-making process. Inaccuracies in these programs can severely limit our ability to make intelligent decisions related to

- Building energy code generation and compliance

- Prediction of energy savings from, and allocation of resources for, utility demand-side management programs

- Allocation of resources for building energy reseaarch based on the prediction of energy savings potential

- Design of energy-efficient buildings.

Development and validation of whole-building energy simulation programs is one of the most important activities meriting the support of national energy research programs. The IEA Executive Committees for Solar Heating and Cooling and for Buildings and Community Systems should diligently consider what sort of future collaborations would best support this essential research area. 


\section{Part II References}

Aittomäki, A. and T. Kalema. (1976). TASE-A Computer Program for Energy Analysis of Buildings. Technical Research Centre of Finland, Espoo, Finland.

Alamdari, F. and G. Hammond. (1983). "Improved Data Correlations for Buoyance-Driven Convection in Rooms." Building Services Engineering Research \& Technology; Vol. 4, No. 3, pp. 106-112.

Alvarez, S., E.A. Rodriguez, and J. Coronado. (1989). "Thermal Modeling of Earth-Contact Surfaces." Proceedings of the Sixth International PLEA Conference: July 27-31, 1988, Porto, Portugal. New York: Pergamon Press; pp. 415-420.

ASHRAE Handbook Fundamentals. (1977). Atlanta, GA: American Society of Heating, Refrigerating, and Air-Conditioning Engineers.

ASHRAE Handbook Fundamentals. (1981). Atlanta, GA: American Society of Heating, Refrigerating, and Air-Conditioning Engineers.

ASHRAE Handbook Fundamentals. (1989). Atlanta, GA: American Society of Heating, Refrigerating, and Air-Conditioning Engineers.

BLAST 3.0 User's Manual. (April 1986). BLAST Support Office. Urbana, IL: University of Illinois.

BLAST Support Office. (December 1991 and June 1992). Personal communication. Department of Mechanical and Industrial Engineering, University of Illinois, Urbana, IL.

BLAST User Reference, Volume 1. (1991). BLAST Support Office. Urbana, IL: University of Illinois.

BLAST User Reference, Volume 2. (1991). BLAST Support Office. Urbana, IL: University of Illinois.

Bloomfield, D., ed. (November 1989). Design Tool Evaluation: Benchmark Cases. IEA T8B4. Solar Heating and Cooling Program, Task VIII: Passive and Hybrid Solar Low-Energy Buildings. Building Research Establishment. Garston, UK: International Energy Agency.

Chorpening, B. (February 1995). Letters and e-mail to Ron Judkoff. BLAST Support Office, University of Illinois, Urbana, IL.

DOE-2 Engineer's Manual (Version 2.1A). (November 1981). D. York, C. Cappiello, eds. Berkeley, CA: Lawrence Berkeley Laboratory.

DOE-2 Reference Manual (Version 2.1A) Part 1. (May 1981). D. York, C. Cappiello, eds. Berkeley, CA: Lawrence Berkeley Laboratory.

DOE-2 Supplement (Version 2.1D). (June 1989). Berkeley, CA: Lawrence Berkeley Laboratory.

Duffie, J.A. and W.A. Beckman. (1974). Solar Energy Thermal Processes. New York, NY: John Wiley \& Sons. 
Eppel, H. and K. Lomas. (November 1992). Building Energy Simulation Test (BESTEST) Simulations with ESP. BRE Support Contract Report No. 9b, IEARN328/93. De Montfort University, Leicester, United Kingdom: Building Research Establishment.

Haberl, J. and G. Yuill. (1993). ASHRAE TC-4.7/SPC-140 Working Document. Atlanta, GA: American Society of Heating, Refrigerating, and Air-Conditioning Engineers.

Hagentoft, C.E. (1988). Heat Loss to the Ground from a Building Slab on the Ground and Cellar. TVBH-1004. Lund Institute of Technology, Lund, Sweden.

Hirsch, J. (1992-1993). Personal communication, Camarillo, CA.

Hittle, D. (March 1993). Personal communication. Department of Mechanical Engineering, Colorado State University, Boulder, CO.

Jensen, S.O. (1993). Empirical Whole Model Validation Case Study: the PASSYS Reference Wall (draft). IEA 21RN347/93. Technical University of Denmark. Copenhagen, Denmark: International Energy Agency.

Judkoff, R. (1988a). Validation of Building Energy Analysis Simulation Programs at the Solar Energy Research Institute (now NREL). Energy and Buildings, Vol. 10, No. 3, p. 235. Lausanne, Switzerland: Elsevier Sequoia.

Judkoff, R. (March 1988b). Letter to Dave Bloomfield.

Judkoff, R. (March 18, 1993). Building Energy Simulation Test and Diagnostic Method (draft revision). Golden, CO: National Renewable Energy Laboratory.

Judkoff, R., S. Barakat, D. Bloomfield, B. Poel, R. Stricker, P. van Haaster, and D. Wortman. (1988). International Energy Agency Design Tool Evaluation Procedure. SERUTP-254-3371, Golden, CO: Solar Energy Research Institute (now NREL).

Judkoff, R., D. Wortman, C. Christensen, R. O'Doherty, D. Simms, and M. Hannifan. (1980). A Comparative Study of Four Passive Building Energy Simulations: DOE-2.1, BLAST, SUNCAT-2.4, DEROB-III. SERI/TP-721-837. Golden, CO: National Renewable Energy Laboratory (formerly SERI).

Judkoff, R., D. Wortman, and R. O'Doherty. (1981). A Comparative Study of Four Building Energy Simulations: Phase II. SERI/TP-721-1326. Golden, CO: National Renewable Energy Laboratory (formerly SERI).

Judkoff, R. et al. (1983), A Methodology for Validating Building Energy Analysis Simulations. SERI/TR-254-1508. Golden, CO: Solar Energy Research Institute (now NREL).

Kalema, T. (1992). Thermal Analysis of Buildings-Verification and Further Development of the TASE Program. Publication 87. Tampere University of Technology. Tampere, Finland.

Kennedy, M. (June 1991). Earth Contact: Assumptions, Calculations, and Coefficient Tables. Work performed by Ecotope, Inc., Seattle, WA. Portland, OR: Bonneville Power Administration.

Kennedy, M. (January 1992). Various personal communications. Ecotope, Inc., Seattle, WA. 
Kennedy, M., L. Palmiter, and T. Wheeling. (1992). SUNCODE-PC Building Load Simulation Program. Available from Ecotope, Inc., 2812 E. Madison, Seattle, WA 98112, (206) 322-3753.

Klein, S.A. et al. (September 1990). TRNSYS: A Transient System Simulation Program. Madison, WI: Solar Energy Lab, University of Wisconsin.

Kondratjev, K. (1977). Radiation Regime of Inclined Surfaces. Technical Note 152. Geneva, Switzerland: World Meteorological Organization.

Kreith, F. and M. Bohn. (1993). Principles of Heat Transfer. Fifth edition. St. Paul, MN: West Publishing Company.

Lomas, K. (January 1989). Description and Results of Round 1 Simulations. Applicability Study 1, Research Report 2, Leicester Polytechnic, Leicester, UK.

Lomas, K. (October 1991). Observations on the Validation of Simple Thermal Models. Research Report 8. Leicester Polytechnic, Leicester, UK.

Lomas, K., H. Eppel, C. Martin, and D. Bloomfield. (1994). Empirical Validation of Thermal Building Simulation Programs Using Test Room Data, Volume 1: Final Report. De Montfort University, Leicester, United Kingdom: Building Research Establishment.

Martin, C. (1991). Detailed Model Comparisons: An Empirical Validation Exercise Using SERI-RES. EMC Contractor Report to ETSU. United Kingdom. ETSU 1197-I.

Mitalas, G. and J. Arsenault. (1971). Fortran IV Program to Calculate Z-Transfer Functions for the Calculation of Transient Heat Transfer through Walls and Roofs. National Bureau of Standards Building Science Series 39: Use of Computer for Environmental Engineering Related to Buildings, pp. 633-668. Washington, D.C.: National Bureau of Standards.

Rodriguez, E.A. and S. Alvarez. (1989). "Heat Transfer Analysis of Ground-Coupled Structures." Thermal Performance of the Exterior Envelopes of Buildings IV: Proceedings of the ASHRAEJDOE/ BTECC/CIBSE Conferences: December 4-7, 1989, Orlando, Florida. Atlanta, GA: American Society of Heating, Refrigerating and Air-Conditioning Engineers; pp. 791-799.

Tammelin, B., M. Pietarinen, and A. Peltomaa. (1987). On the Global Radiation Incident on Variously Orientated Surfaces on the South Coast of Finland. Meteorological Publication No. 5. Helsinki, Finland: Finnish Meteorological Institute.

Walton, G. (November 1981). Passive Solar Extension of the Building Loads Analysis and System Thermodynamics (BLAST) Program. Champaign, IL: Department of the Army, Construction Engineering Research Laboratory.

Walton, G. (March 1983). Thermal Analysis Research Program Reference Manual (TARP). NBSIR 83-2655. Washington, D.C.: National Bureau of Standards. (Note that this software is based on BLAST and the manual has a high level of technical detail. Since the BLAST Support Office does not supply an engineer's manual, the TARP manual is used as a substitute.) A report of this document can be obtained through the BLAST Support Office, Department of Mechanical and Industrial Engineering, University of Illinois, Urbana, IL. 
Winkelmann, F. (December 1991 to February 1993). Personal communication. Lawrence Berkeley Laboratory, Berkeley, CA.

Wortman, D., R. O'Doherty, and R. Judkoff. (1981). The Implementation of an Analytical Verification Technique on Three Building Energy Analysis Codes. SERI/TP-721-1008. Golden, CO: National Renewable Energy Laboratory (formerly SERI). 


\subsection{Final Results from Reference Programs: Tables and Graphs}

The final results from the reference programs are presented here in tabular and graphic form. Horizontal bands representing the reference ranges are superimposed on the heating and cooling energy results for the qualification cases ( 600 and 900 series). The band widths were set according to the principles described in Section 2.2. Several pages have been left blank intentionally so that related graphs are on facing pages.

Generally, the results show a considerable amount of disagreement for many of the cases and output types. Ranges were not set for the diagnostic cases because we expect that diagnostics will be performed by model developers, scientists, or other specialists for whom the simplification represented by the ranges would not be necessary. 


\begin{tabular}{|c|c|c|c|c|c|c|c|c|c|c|c|c|}
\hline \multicolumn{13}{|c|}{ LADS } \\
\hline \multicolumn{13}{|c|}{ ANNUAL HEATING [MWH] } \\
\hline CASE & $\begin{array}{c}\text { ESP } \\
\text { UK-DMU }\end{array}$ & $\begin{array}{l}\text { BLAST } \\
\text { US/IT }\end{array}$ & $\begin{array}{l}\text { DOE2 } \\
\text { USA }\end{array}$ & $\begin{array}{c}\text { SRES/SUN } \\
\text { USA }\end{array}$ & $\begin{array}{l}\text { SERIRES } \\
\text { UK-BRE }\end{array}$ & $\begin{array}{l}\text { S3PAS } \\
\text { SPAIN }\end{array}$ & $\begin{array}{l}\text { TRNSYS } \\
\text { BELUK }\end{array}$ & $\begin{array}{l}\text { TASE } \\
\text { FINLAND }\end{array}$ & $\begin{array}{c}\text { RANGE } \\
\text { MIN }\end{array}$ & $\begin{array}{l}\text { RANGE } \\
\text { MAX }\end{array}$ & $\begin{array}{l}\text { ALLCODE } \\
\text { MAXMIN }\end{array}$ & $\begin{array}{c}\text { ALLCODE } \\
\text { MEAN }\end{array}$ \\
\hline 600 & 4.296 & 4.773 & 5.709 & 5.226 & 5.596 & 4.882 & 4.872 & 5.362 & 4.296 & 5.709 & 1.329 & 5.090 \\
\hline 610 & 4.355 & 4.806 & 5.786 & 5.280 & 5.620 & 4.971 & 4.970 & 5.383 & 4.355 & 5.786 & 1.329 & 5.146 \\
\hline 620 & 4.613 & 5.049 & 5.944 & 5.554 & 5.734 & 5.564 & 5.073 & 5.728 & 4.613 & 5.944 & 1.289 & 5.407 \\
\hline 630 & 5.050 & 5.359 & 6.469 & 5.883 & 6.001 & 6.095 & 5.624 & 7.018 & 5.050 & 6.469 & 1.390 & 5.937 \\
\hline 640 & 2.751 & 2.888 & 3.543 & 3.255 & 3.803 & 3.065 & 3.043 & 3.309 & 2.751 & 3.803 & 1.382 & 3.207 \\
\hline 650 & 0.000 & 0.000 & 0.000 & 0.000 & 0.000 & 0.000 & 0.000 & 0.000 & & & ERR & 0.000 \\
\hline 900 & 1.170 & 1.610 & 1.872 & 1.897 & 1.988 & 1.730 & 1.655 & 2.041 & 1.170 & 2.041 & 1.744 & 1.745 \\
\hline 910 & 1.575 & 1.862 & 2.254 & 2.174 & 2.282 & 2.063 & 2.097 & 2.220 & 1.575 & 2.282 & 1.449 & 2.066 \\
\hline 920 & 3.313 & 3.752 & 4.255 & 4.093 & 4.058 & 4.235 & 3.776 & 4.300 & 3.313 & 4.300 & 1.298 & 3.973 \\
\hline 930 & 4.143 & 4.347 & 5.335 & 4.755 & 4.728 & 5.168 & 4.740 & 6.306 & 4.143 & 5.335 & 1.522 & 4.940 \\
\hline 940 & 0.793 & 1.021 & 1.239 & 1.231 & 1.411 & 1.179 & 1.080 & 1.323 & 0.793 & 1.411 & 1.779 & 1.160 \\
\hline 950 & 0.000 & 0.000 & 0.000 & 0.000 & 0.000 & 0.000 & 0.000 & 0.000 & & & ERR & 0.000 \\
\hline 960 & 2.311 & 2.664 & 2.928 & 2.884 & 2.851 & 2.943 & 3.373 & 2.816 & 2.311 & 3.373 & 1.460 & 2.846 \\
\hline 990 & 2.222 & 3.448 & 3.425 & 2.972 & 4.324 & 4.301 & & 3.813 & & & 1.946 & 3.501 \\
\hline 195 & 4.167 & 4.895 & 5.871 & 5.324 & 4.968 & 4.973 & 4.871 & 4.921 & & & 1.409 & 4.999 \\
\hline 200 & 5.252 & 6.559 & & & 6.683 & 6.636 & 6.395 & 6.882 & & & 1.310 & 6.401 \\
\hline 210 & 6.456 & 6.559 & & & 6.794 & 6.735 & 6.554 & 6.967 & & & 1.079 & 6.678 \\
\hline 215 & 5.547 & 7.215 & & & 7.943 & 7.281 & 7.130 & 7.319 & & & 1.432 & 7.073 \\
\hline 220 & 6.944 & 7.215 & 8.787 & 8.102 & 8.127 & 7.422 & 7.297 & 7.437 & & & 1.265 & 7.666 \\
\hline 230 & 10.376 & 10.740 & 12.243 & 11.633 & 11.649 & 11.037 & 10.840 & 10.964 & & & 1.180 & 11.185 \\
\hline 240 & 5.649 & 6.009 & 7.448 & 6.769 & 6.786 & 6.194 & 6.076 & 6.234 & & & 1.318 & 6.396 \\
\hline 250 & 4.751 & 5.739 & 7.024 & 6.608 & 6.653 & 5.974 & 5.764 & 5.738 & & & 1.478 & 6.031 \\
\hline 270 & 4.510 & 4.930 & & 5.482 & 5.920 & 5.072 & 5.047 & 5.489 & & & 1.313 & 5.207 \\
\hline 280 & 4.675 & 5.125 & & 5.937 & 6.148 & 5.363 & 5.279 & 5.841 & & & 1.315 & 5.481 \\
\hline 290 & 4.577 & 4.959 & & 5.539 & 5.942 & 5.160 & 5.132 & 5.509 & & & 1.298 & 5.260 \\
\hline 300 & 4.761 & 5.077 & & 5.689 & 5.964 & 5.662 & 5.124 & 5.786 & & & 1.253 & 5.438 \\
\hline 310 & 5.221 & 5.327 & & 5.937 & 6.165 & 6.154 & 5.610 & 7.135 & & & 1.367 & 5.936 \\
\hline 320 & 3.859 & 4.209 & & 4.764 & 5.141 & 4.343 & 4.348 & 4.840 & & & 1.332 & 4.501 \\
\hline 395 & 4.984 & 4.799 & 5.835 & 5.199 & 5.201 & 4.967 & 4.855 & 4.839 & & & 1.216 & 5.085 \\
\hline 400 & 6.900 & 7.075 & 8.770 & 7.966 & 7.973 & 7.287 & 7.166 & 7.326 & & & 1.271 & 7.558 \\
\hline 410 & 8.596 & 8.873 & 10.506 & 9.726 & 9.734 & 9.019 & 8.936 & 9.085 & & & 1.222 & 9.309 \\
\hline 420 & 7.298 & 7.610 & 9.151 & 8.365 & 8.373 & 7.774 & 7.697 & 7.863 & & & 1.254 & 8.016 \\
\hline 430 & 5.429 & 6.488 & 7.827 & 7.178 & 7.186 & 6.662 & 6.500 & 6.510 & & & 1.442 & 6.723 \\
\hline 440 & 4.449 & 4.987 & & 5.652 & 5.811 & 5.152 & 5.098 & 5.642 & & & 1.306 & 5.256 \\
\hline 800 & 4.868 & $5: 953$ & 7.228 & 6.611 & 6.600 & 6.161 & 5.940 & 5.861 & & & 1.485 & 6.153 \\
\hline 810 & 1.839 & 2.446 & & 3.004 & 2.828 & 2.722 & 2.567 & 2.962 & & & 1.633 & 2.624 \\
\hline \multicolumn{13}{|c|}{ ANNUAL COOLING [MWH] } \\
\hline & ESP & BLAST & DOE2 & SRES/SUN & SERIRES & S3PAS & TANSYS & TASE & RANGE & RANGE & ALLCODE & ALLCODE \\
\hline CASE\# & UK-DMU & USIIT & USA & USA & UK-BRE & SPAIN & BEUUK & FINLAND & MiN & MAX & MAX/MIN i & MEAN \\
\hline 600 & 6.137 & 6.433 & 7.079 & 7.278 & 7.964 & 6.492 & 6.492 & 6.778 & 6.137 & 7.964 & 1.298 & $6 . \overline{832}$ \\
\hline 610 & 3.915 & 4.851 & 4.852 & 5.448 & 5.778 & 4.764 & 4.601 & 5.506 & 3.915 & 5.778 & 1.476 & 4.964 \\
\hline 620 & 3.417 & 4.092 & 4.334 & 4.633 & 5.004 & 4.011 & 3.901 & 4.351 & 3.417 & 5.004 & 1.464 & 4,218 \\
\hline 630 & 2.129 & 3.108 & 2.489 & 3.493 & 3.701 & 2.489 & 2.416 & 1.721 & 2.129 & 3.701 & 2.150 & 2.693 \\
\hline 640 & 5.952 & 6.183 & 6.759 & 7.026 & 7.811 & 6.247 & 6.246 & 6.508 & & & 1.312 & 6.592 \\
\hline 650 & 4.816 & 5.140 & 5.795 & 5.894 & 6.545 & 5.088 & 5.119 & 5.456 & 4.816 & 6.545 & 1.359 & 5.482 \\
\hline 900 & 2.132 & 2.600 & 2.455 & 3.165 & 3.415 & 2.572 & 2.485 & 2.599 & 2.132 & 3.415 & 1.602 & 2.678 \\
\hline 910 & 0.821 & 1.533 & 0.976 & 1.872 & 1.854 & 1.428 & 1.326 & 1.767 & 0.821 & 1.872 & 2.280 & 1.447 \\
\hline 920 & 1.840 & 2.616 & 2.440 & 2.949 & 3.092 & 2.457 & 2.418 & 2.613 & 1.840 & 3.092 & 1.680 & 2.552 \\
\hline 930 & 1.039 & 1.934 & 1.266 & 2.173 & 2.238 & 1.439 & $1.416 i$ & 0.894 & 1.039 & 2.238 & 2.503 & 1.550 \\
\hline 940 & 2.079 & 2.536 & 2.340 & 3.036 & 3.241 & 2.489 & 2.383 ! & 2.516 & & & 1.559 & 2.578 \\
\hline 950 & 0.387 & 0.526 & 0.538 & 0.921 & 0.589 & 0.551 & 0.561 & 0.771 & 0.387 & 0.921 & 2.380 & 0.605 \\
\hline 960 & 0.488 & 0.666 & 0.428 & 0.803 & $0.718 !$ & 0.643 & 0.411 & 0.786 & 0.411 & $0.803 i$ & 1.952 & $0.618:$ \\
\hline 990 & 1.001 & 1.640 & 1.841 & 1.387 & 0.714 & 0.616 ! & & 1.388 & & & 2.989 & 1.227 \\
\hline 195 & 0.414 & $0 . \overline{421}$ & 0.264 & 0.510 & 0.488 & 0.474 & 0.474 & 0.443 & & & 1.932 & 0.436 \\
\hline 200 & 0.570 & 0.613 & & & 0.699 & 0.677 & $0.716 !$ & 0.633 & & & 1.255 & 0.651 \\
\hline 210 & 0.162 & 0.613 & & & 0.681 & 0.661 & 0.668 & 0.641 & & & 4.204 & 0.571 \\
\hline 215 & 0.639 & 0.701 & & & 0.853 & 0.749 & 0.765 & 0.671 & & & 1.335 & 0.730 \\
\hline 220 & 0.186 & 0.701 & 0.399 & 0.827 & 0.835 & 0.734 & 0.737 & 0.683 & & & 4.489 & 0.638 \\
\hline 230 & 0.454 & 0.976 & 0.692 & 1.131 & 1.139 & 1,020 & 1.040 & 0.985 & & & 2.509 & 0.930 \\
\hline 240 & 0.415 & 1.072 & 0.660 & 1.239 & 1.246 & 1.108 & 1.114 & 1.045 & . & & 3.002 & 0.987 \\
\hline 250 & 3.213 & 2.545 & 2.177 & 2.924 & 2.931 & 2.486 & 2.684 & 3.380 & & & 1.553 & 2.793 \\
\hline 270 & 7.528 & 8.670 & & 9.631 & 10.350 & 8.795 & 8.764 & 8.714 & & & 1.375 & 8.922 \\
\hline 280 & 4.873 & 5.895 & & 6.511 & 7.114 & 5.805 & 5.761 & 6.257 & & & 1.460 & 6.031 \\
\hline 290 & 5.204 & 7.011 & & 7.721 & B.089 & 6.903 & 6.699 & 7.431 & & & 1.554 & 7.008 \\
\hline 300 & 4.302 & 5.836 & & 6.525 & 7.100 & 5.849 & 5.721 & 5.781 & & & 1.650 & 5.873 \\
\hline 310 & 2.732 & 4.570 & & 5.136 & 5.471 & 3.875 & 3.727 & 2.471 & & & 2.214 & 3.997 \\
\hline 320 & 5.061 & 5.906 & & 6.576 & 7.304 & 5.914 & 5.956 & 5.663 & & & 1.443 & 6.054 \\
\hline 395 & 0.000 & 0.011 & 0.000 & 0.016 & 0.014 & 0.010 & 0.010 & 0.011 & & & ERF & 0.009 \\
\hline 400 & 0.000 & 0.040 & 0.002 & 0.061 & 0.058 & 0.042 & 0.045 & 0.044 & & & ERP & 0.036 \\
\hline 1410 & 0.000 & 0.059 & 0.010 & 0.084 & 0.084 & 0.063 & 0.067 & 0.065 & & & ERR & 0.054 \\
\hline 420 & 0.011 & 0.147 & 0.051 & 0.189 & 0.188 & 0.154 & 0.158 & 0.143 & & & 17.182 & 0.130 \\
\hline 430 & 0.542 & 0.617 & 0.422 & 0.704 & 0.684 & 0.563 & 0.617 & 0.875 & & & 2.073 & 0.628 \\
\hline 440 & 3.967 & 4.172 & & 4.674 & 5.204 & 3.992 & 3.975 & 4.684 & & & 1.312 & 4.381 \\
\hline 800 & 0.113 & 0.224 & $0 . \overline{055}$ & 0.272 & 0.222 & 0.195 & 0.207 & 0.325 & & & 5.909 & 0.202 \\
\hline 810 & 1.052 & 1.405 & & 1.711 & 1.708 & 1.307 & 1.191 & 1.624 & & & 1.626 & 1.428 \\
\hline
\end{tabular}




\begin{tabular}{|c|c|c|c|c|c|c|c|c|c|c|c|c|c|c|c|c|c|c|c|c|c|c|c|}
\hline \multirow[t]{2}{*}{$\begin{array}{l}\text { CODENA } \\
\text { COUNTA } \\
\text { CASE }\end{array}$} & \multicolumn{3}{|c|}{$\begin{array}{l}\text { ESP } \\
\text { IY: UK-DMU } \\
\text { KW DATE HR }\end{array}$} & \multicolumn{2}{|c|}{$\begin{array}{l}\text { OLAST } \\
\text { USAITALY }\end{array}$} & \multicolumn{2}{|l|}{$\begin{array}{l}\text { DOE2 } \\
\text { USA } \\
\text { DATE }\end{array}$} & \multicolumn{2}{|c|}{$\begin{array}{l}\text { SAESSUN } \\
\text { USA } \\
\text { W DATE HR }\end{array}$} & \multicolumn{3}{|c|}{$\begin{array}{l}\text { SERIAES } \\
\text { UK-BRE } \\
\text { W DATE HR }\end{array}$} & \multicolumn{2}{|c|}{$\begin{array}{l}\text { S3PAS } \\
\text { SPAIN } \\
\text { KW DATE HA }\end{array}$} & \multicolumn{3}{|c|}{$\begin{array}{l}\text { TANSYS } \\
\text { BEL/UK } \\
\text { W DATE HR }\end{array}$} & \multicolumn{2}{|c|}{$\begin{array}{l}\text { TASE } \\
\text { FINLAND } \\
\text { KW DATE HR }\end{array}$} & $\begin{array}{c}\text { RANGE } \\
\text { MIN } \\
\end{array}$ & $\begin{array}{l}\text { RANGE } \\
\text { MAX }\end{array}$ & $\begin{array}{l}\text { ALLCODE } \\
\text { MAXIMIN }\end{array}$ & $\begin{array}{c}\text { ALLCOOE } \\
\text { MEAN }\end{array}$ \\
\hline & 3.437 & 04Jan & & 3.940 JAN 04 & 5 & 4.045 JAN 04 & $=$ & 4.258 JAN O4 & 2 & 4.307 & $\operatorname{San}-04$ & 2 & 4.037 JAN 04 & 2 & 3.931 & Jan-04 & 6 & 4.354 JAN 04 & 2 & \begin{tabular}{|l|}
3.437 \\
\end{tabular} & 4.354 & $\begin{array}{l}1.267 \\
\end{array}$ & $\begin{array}{r}4.0386 \\
\end{array}$ \\
\hline 610 & 3.437 & 04-Jan & 5 & 3.941 JAN 04 & 5 & 4.034 JAN 04 & 5 & 4.258 JAN O4 & 2 & 4.306 & Jan-04 & 2 & 4.037 JAN 04 & 2 & 3.922 & Jan-04 & 6 & 4.354 JAN 04 & 2 & 3.437 & 4.354 & 1.267 & 4.0362 \\
\hline 620 & 3.591 & 04Jan & 6 & 3.941 JAN 04 & 5 & 4.046 JAN 04 & 5 & 4.277 JAN 04 & 2 & 4.306 & Jan-04 & 2 & 4.277 JAN 04 & 2 & 3.922 & Jan-04 & 6 & 4.379 JAN 04 & 2 & 3.591 & 4.379 & 1.219 & 4.0924 \\
\hline $\begin{array}{l}630 \\
640 \\
650\end{array}$ & $\begin{array}{l}3.592 \\
5.232 \\
0.000\end{array}$ & $\begin{array}{l}\text { O4-Jan } \\
\text { 04-Jan }\end{array}$ & $\begin{array}{l}7 \\
7\end{array}$ & $\begin{array}{l}\text { 3.941 JAN 04 } \\
5.486 \text { JAN 04 } \\
0.000\end{array}$ & $\begin{array}{l}5 \\
8\end{array}$ & $\begin{array}{l}4.025 \text { JAN } 04 \\
5.943 \text { JAN } 04 \\
0.000\end{array}$ & $\begin{array}{l}5 \\
8\end{array}$ & $\begin{array}{l}4.280 \text { JAN } 04 \\
6.530 \text { JAN } 04 \\
0.000\end{array}$ & $\begin{array}{l}2 \\
8\end{array}$ & $\begin{array}{l}4.306 \\
8.078 \\
0.000\end{array}$ & $\begin{array}{l}\text { Jan-04 } \\
\operatorname{Jan}-04\end{array}$ & $\begin{array}{l}2 \\
8\end{array}$ & $\begin{array}{l}4.278 \text { JAN 04 } \\
6.347 \text { JAN } 04 \\
0.000\end{array}$ & $\begin{array}{l}2 \\
8\end{array}$ & $\begin{array}{l}3.922 \\
5.722 \\
0.000\end{array}$ & $\begin{array}{l}\text { Jan-04 } \\
\text { Jan-04 }\end{array}$ & $\begin{array}{l}6 \\
8 \\
8\end{array}$ & $\begin{array}{l}4.379 \text { JAN } 04 \\
6.954 \text { JAN } 04 \\
0.000\end{array}$ & $\begin{array}{l}2 \\
8\end{array}$ & $\begin{array}{l}3.592 \\
5.232\end{array}$ & $\begin{array}{l}4.278 \\
6.954\end{array}$ & $\begin{array}{r}1.219 \\
1.544 \\
\text { ERR }\end{array}$ & $\begin{array}{l}4.0904 \\
6.2865 \\
0.0000\end{array}$ \\
\hline 900 & 2.850 & 04-Jan & 7 & 3.453 JAN 04 & 7 & 3.557 JAN 04 & 7 & 3.760 JAN 04 & 7 & 4.081 & $\operatorname{san-04}$ & 7 & 3.608 JAN 04 & 8 & 3.517 & $\operatorname{Jan}-04$ & 7 & 3.797 JAN 04 & 7 & 2.850 & 3.797 & 1.432 & 3.5778 \\
\hline 910 & 2.858 & 04-Jan & 7 & 3.456 JAN 04 & 7 & 3.564 JAN 04 & 7 & 3.764 JAN 04 & 7 & 4.083 & Jan-04 & 7 & 3.618 JAN 04 & 8 & 3.536 & Jan-04 & 7 & 3.801 JAN 04 & 7.) & 2.858 & 3.801 & 1.429 & 3.5850 \\
\hline 920 & 3.308 & 04-Jan & & 3.703 JAN 04 & 7 & 3.805 JAN 04 & 7 & 4.013 JAN 04 & 7 & 4.156 & Jan-04 & 7 & 4.029 JAN O4 & 7 & 3.708 & Jan-04 & 7 & 4.061 JAN 04 & 7 & 3.308 & 4.061 & 1.256 & 3.8479 \\
\hline 930 & 3.355 & 04-Jan & 7 & 3.732 JAN 04 & 7 & 3.832 JAN 04 & 7 & 4.042 JAN 04 & 7 & 4.165 & Jan-04 & 7 & 4.064 JAN 04 & 7 & 3.744 & Jan-04 & 7 & 4.188 JAN 04 & B & 3.355 & 4. & 1.248 & 3.8903 \\
\hline $\begin{array}{l}940 \\
950\end{array}$ & $\begin{array}{l}3.980 \\
0.000\end{array}$ & O4Jan & 7 & $\begin{array}{l}5.028 \text { JAN } 04 \\
0.000\end{array}$ & 8) & $\begin{array}{l}5.665 \text { JAN } 04 \\
0.000\end{array}$ & 8 & $\begin{array}{l}\text { 6.116 JAN } 04 \\
0.000\end{array}$ & 8) & $\begin{array}{l}9.923 \\
0.000\end{array}$ & Jan-04 & 8 & $\begin{array}{l}6.117 \text { JAN } 04 \\
0.000\end{array}$ & 8 & $\begin{array}{l}5.122 \\
0.000\end{array}$ & Jan-03 & 9 & $\begin{array}{l}6.428 \text { JAN } 04 \\
0.000\end{array}$ & B & 3.980 & 6.428 & $\begin{array}{r}2.493 \\
\text { ERR }\end{array}$ & $\begin{array}{l}6.0474 \\
0.0000\end{array}$ \\
\hline $\begin{array}{l}960 \\
990\end{array}$ & $\begin{array}{l}2.410 \\
2.769 \\
\end{array}$ & $\begin{array}{l}\text { 04Jan } \\
\text { O6-Feb }\end{array}$ & $\begin{array}{l}7 \\
2 \\
\end{array}$ & $\begin{array}{l}2.751 \text { JAN } 04 \\
3.734 \text { JAN 04 }\end{array}$ & $\begin{array}{l}8 \\
7\end{array}$ & $\begin{array}{l}2.727 \text { JAN } 04 \\
3.427 \text { JAN } 04\end{array}$ & $\begin{array}{l}8 \\
7 \\
\end{array}$ & $\begin{array}{l}2.863 \text { JAN } 04 \\
3.681 \text { JAN } 04\end{array}$ & $\begin{array}{l}8 \\
7\end{array}$ & $\begin{array}{l}2.896 \\
3.738\end{array}$ & $\begin{array}{l}\text { Jan-04 } \\
\text { Feb-06 }\end{array}$ & $\begin{array}{l}8 \\
2\end{array}$ & $\begin{array}{l}2.852 \text { JAN } 04 \\
3.799 \text { JAN } 04\end{array}$ & $\begin{array}{l}8 \\
8\end{array}$ & 2.522 & Jan-04 & 8 & $\begin{array}{l}2.779 \text { JAN } 04 \\
4.296 \text { JAN } 04\end{array}$ & 8 & 2.410 & 2.896 & $\begin{array}{l}1.202 \\
1.372\end{array}$ & $\begin{array}{l}2.7250 \\
3.5247\end{array}$ \\
\hline 195 & 2.004 & O4 Jan & 2 & 2.186 JAN 04 & 8 & 2.320 JAN 04 & 3 & 2.385 JAN 04 & 3 & 2.235 & $\operatorname{Jan}-04$ & 3 & 2.221 JAN 04 & 4 & 2.186 & $\operatorname{Jan}-04$ & 3 & 2.263 JAN 04 & 3 & & & 1.190 & $\frac{v}{2.2249}$ \\
\hline 200 & 2.651 & O4Jan & 5 & 2.973 JAN 04 & 5 & & & & & 3.047 & $\operatorname{Jan}-04$ & 3 & 2.999 JAN 04 & 2 & 2.969 & Jan-04 & 5 & 3.382 JAN 04 & 2 & & & 1.276 & 3.0036 \\
\hline 210 & 2.701 & 04 Jan & 5 & 2.973 JAN 04 & 5 & & & & & 3.077 & $\operatorname{Jan}-04$ & 3 & 3.020 JAN 04 & 2 & 2.981 & Jan-04 & 5 & 3.325 JAN 04 & 2 & & & 1.231 & \\
\hline 215 & 2.787 & 04-Jan & 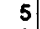 & 3.280 JAN 04 & 5 & & & & & 3.650 & Jan-04 & 2 & 3.307 JAN 04 & 6 & 3.294 & Jan-04 & 6 & 3.458 & B & & & 1.310 & \\
\hline 220 & 2.867 & 04-Jan & 5 & 3.280 JAN 04 & 5 & 3.465 JAN 04 & 5 & 3.695 JAN 04 & 2 & 3.709 & Jan-04 & 2 & 3.348 JAN 04 & 8 & 3.336 & Jan-04 & 6 & $3.520 \mathrm{JA}$ & 2 & & & 1.294 & 3.4025 \\
\hline 230 & 4.396 & 04-Jan & 5 & 4.984 JAN 04 & 2 & 4.994 JAN 04 & 2 & 5.279 JAN 04 & 2 & 5.293 & Jan-04 & 2 & 5.159 JAN O4 & 2 & 4.892 & Jan-04 & 6 & 5.107 JAN 04 & 2 & & & 1.207 & 5.0117 \\
\hline 240 & 2.605 & 04-Jan & 5 & 3.100 JAN 04 & 5 & 3.282 JAN 04 & 5 & 3.495 JAN 04 & 2 & 3.509 & Jan-04 & 2 & 3.159 JAN 04 & 8 & 3.153 & Jan-04 & 6 & 3.333 & B & & & 1.307 & 3.2145 \\
\hline 250 & 2.866 & 04Jan & 5 & 3.279 JAN 04 & 5 & 3.465 JAN 04 & 5 & 3.695 JAN 04 & 2 & 3.709 & Jan-04 & 2 & 3.341 JAN 04 & 6 & 3.336 & Jan-04 & 6 & $3.525 \mathrm{~J}$ & 2 & & & 1.294 & 3. \\
\hline 270 & 2.863 & 04Jan & 5 & 3.277 JAN 04 & 5 & & & 3.670 JAN 04 & 2 & 3.714 & Jan-04 & 2 & 3.340 JAN 04 & 6 & 3.336 & Jan-04 & 6 & 3.738 JAN 04 & 2 & & & 1.306 & 3.4197 \\
\hline 280 & 2.864 & O4van & 5 & 3.278 JAN 04 & 5 & & & 3.685 JAN 04 & 2 & 3.714 & Jan-04 & 2 & 3.341 JAN 04 & 6 & 3.336 & Jan-04 & 6 & 3.759 JAN 04 & 2 & & & 1.313 & 3.4253 \\
\hline 290 & 2.863 & 04-Jan & 5 & 3.277 JAN 04 & 5 & & & 3.670 JAN 04 & 2 & 3.714 & Jan & & 3.340 JAN 04 & 6 & 3.328 & & 6 & $3.738 \mathrm{~J}$ & 2 & & & 1.306 & $\mathbf{3 . 4 1 8 5}$ \\
\hline 300 & 3.014 & 04Jan & 6 & 3.276 JAN 04 & 5 & & & 3.685 JAN 04 & 2 & 3.714 & Jan-04 & 2 & 3.599 JAN 04 & 5 & 3.328 & Jan-04 & 6 & $3.770 \mathrm{JAI}$ & 2 & & & 1.251 & 3. \\
\hline 310 & 3.015 & 04-Jan & 6 & 3.277 JAN 04 & 5 & & & 3.672 JAN 04 & 2 & 3.714 & Jan-04 & 2 & 3.599 JAN 04 & 5 & 3.328 & Jan-04 & 6 & $3.771 \mathrm{JA}$ & 2 & & & 1.251 & 3.4823 \\
\hline 320 & 2.861 & 04-Jan & $\underline{5}$ & 3.275 JAN 04 & 5 & & & $3.66 \backslash$ JAN 04 & 2 & 3.714 & Jan-04 & 2 & 3.340 JAN 04 & 6 & 3.336 & Jan-04 & 6 & & 3 & & & 1.305 & 3.4174 \\
\hline 395 & 2.062 & 04d Jan & 7 & 2.209 JAN 04 & 8 & 2.328 JAN 04 & 3 & 2.385 JAN 04 & 3 & 2.391 & & 3 & 2.263 JAN 04 & 4 & 2.221 & Jan-04 & 8 & $2.270 \mathrm{JAN} 04$ & 3 & & & 1.160 & 2.2661 \\
\hline 400 & 2.867 & 04-Jan & 5 & 3.280 JAN 04 & 5 & 3.476 JAN 04 & 5 & 3.695 JAN 04 & 2 & 3.709 & $\operatorname{Jan}-04$ & 2 & 3.342 JAN 04 & 8 & 3.336 & Jan-04 & 6 & 3.520 JAN O4 & 2 & & & 1.294 & 31 \\
\hline 410 & 3.625 & 04-Jan & 5 & 4.124 JAN 04 & 5 & 4.233 JAN 04 & 5 & 4.487 JAN 04 & 2 & 4.501 & Jan-04 & 0 & 4.227 JAN 04 & 2 & 4.114 & Jan-04 & 6 & 4.314 JAN 04 & 2 & & & 1.242 & \\
\hline 420 & 3.443 & 04Jan & 5 & 3.944 JAN 04 & 5 & 4.050 JAN 04 & 5 & 4.287 JAN 04 & 2 & 4.301 & Jan-04 & & 4.044 JAN 04 & 2. & 3.931 & & 6 & 4.126 JAN 04 & 2 & & & 1.249 & 4.0157 \\
\hline 430 & 3.442 & 04-Jan & 5 & 3.944 JAN 04 & 5 & 4.050 JAN 04 & 5 & 4.287 JAN 04 & 2 & 4.301 & Jan-04 & & 4.044 JAN 04 & 1 & 3.931 & Jan-04 & 6 & 4.137 JAN 04 & 2 & & & 1.250 & 4.0169 \\
\hline 440 & 3.439 & O4Jan & 5) & 3.942 JAN 04 & 5 & & & 4.277 JAN 04 & 01 & 4.306 & Jan-04 & & 4.041 JAN 04 & 1 & 3.931 & Jan-04 & $\mathrm{f}$ & 4.376 JAN 04 & 2 & & & 1.272 & 4.0445 \\
\hline 800 & 3.227 & 4Jan & 5 & 3.793 JAN 04 & 7 & 3.909 JAN 04 & 7 & $4.138 \mathrm{JAN} 04$ & $\overline{2}$ & & & & $3.902 \mathrm{JAN} 04$ & & 3.786 & Jan-04 & 7 & & & & & & 3.8603 \\
\hline 810 & 2.979 & & & 356 & 7 & & & 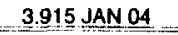 & & 4.11 & & & 3.709 JAN 04 & & 3.606 & Jan-04 & 7 & 3.963 JAN O4 & & & & 1.381 & 3.6932 \\
\hline
\end{tabular}




\begin{tabular}{|c|c|c|c|c|c|c|c|c|c|c|c|c|c|c|c|c|c|c|c|c|c|c|}
\hline \multirow{3}{*}{$\begin{array}{l}\text { CODENAM } \\
\text { COUNTRY: } \\
\text { CASEY }\end{array}$} & \multirow{3}{*}{\multicolumn{2}{|c|}{$\begin{array}{l}\text { ESP } \\
\text { UK-DMU } \\
\text { KW DATE HA }\end{array}$}} & \multirow{2}{*}{\multicolumn{2}{|c|}{$\begin{array}{l}\text { BLAST } \\
\text { USAITALY }\end{array}$}} & \multirow{2}{*}{\multicolumn{2}{|c|}{ DOE2 }} & \multicolumn{2}{|c|}{ SAESTSUN } & \multirow{2}{*}{\multicolumn{3}{|c|}{ SEAIAES }} & \multirow{2}{*}{\multicolumn{2}{|c|}{ S3PAS }} & \multirow{2}{*}{\multicolumn{3}{|c|}{$\begin{array}{l}\text { TANSYS } \\
\text { BEL UKK }\end{array}$}} & \multirow{2}{*}{\multicolumn{2}{|c|}{ TASEE }} & \multirow{3}{*}{$\begin{array}{l}\text { RANGE } \\
\text { MIN }\end{array}$} & \multirow{3}{*}{ RANGE } & \multirow{3}{*}{$\begin{array}{l}\text { ALLCODE } \\
\text { MAX/MIN }\end{array}$} & \multirow{3}{*}{ ALLCODE } \\
\hline & & & & & & & USA & & & & & & & & & & & & & & & \\
\hline & & & KW DATE & HA & KW DATE & $\mathrm{HA}$ & KW DATE & $\mathrm{HR}$ & Kw & DATE & $\mathrm{HA}$ & KW DATE & $\mathrm{HA}$ & $k w$ & DATE & & KW DATE & HR & & & & \\
\hline 600 & 6.194 & $17-0 \mathrm{ct} 13$ & 5.965 OCT 16 & 14 & 6.656 OCT 16 & 13 & 6.827 OCT 16 & 14 & 7.551 & $0 c t-16$ & & 6.286 NOV 25 & -6 & 6.496 & Oct-16 & 14 & $6.8120 C \overline{1} 17$ & 14 & 5.965 & 6.812 & & 6.5971 \\
\hline 610 & 5.669 & 25-Nov 13 & 5.824 NOV 25 & 14 & 6.064 JAN 13 & 14 & 6.371 NOV 25 & 14 & 7.215 & Nov-25 & 13 & 6.170 NOV 25 & -6 & 5.675 & Nov-25 & 14 & 6.146 OCT 17 & 14 & 5.669 & 6.146 & 1.273 & 6.1418 \\
\hline 620 & 3.634 & 26-Jul 16 & 4.075 JUL 26 & 17 & $4.430 \mathrm{JUL} 26$ & 17 & 4.593 JUL 26 & 17 & 4.959 & Jul-02 & 10 & 4.297 JUL 26 & -4 & 4.275 & Jul-26 & 17 & $5.096 \mathrm{JUL} 26$ & 16 & 3.634 & 5.096 & 1.402 & 4.4199 \\
\hline 630 & 3.072 & 26-Jul 16 & 3.704 JUL 26 & 17 & 3.588 JUL 26 & 17 & 4.116 JUL 26 & 17 & 4.400 & Jul-02 & 9 & 3.665 JUL 26 & -3 & 3.608 & Jul-26 & 17 & 3.546 JUN 30 & 17 & 3.072 & 3.704 & 1.432 & 3.7124 \\
\hline 640 & 6.161 & 17.0 ct 13 & $5.8920 \mathrm{CT} 16$ & 14 & 6.576 OCT 16 & 14 & $6.77600 \mathrm{Cr} 16$ & 14 & 7.537 & Oct-16 & 13 & 6.250 NOV 25 & -6 & 6.442 & Oct-16 & 14 & $6.7710 \mathrm{CT} 17$ & 14 & & & 1.279 & 6.5506 \\
\hline 650 & 6.031 & $17.0 \mathrm{ct} 13$ & 5.831 ocr 16 & 14 & 6.516 OCT 16 & 14 & $6.671 \mathrm{OCI} 16$ & 14 & 7.458 & Oct-16. & 13 & 6.143 NOV 25 & -6 & 6.378 & Oct-17 & 14 & 6.679 OCT 17 & 14 & 5.831 & 6.679 & 1.279 & 6.4633 \\
\hline 900 & 2.888 & $17-0 \mathrm{ct} 14$ & 3.15500 T 06 & 15 & 3.450 OCT 17 & 14 & $3.87100 T 17$ & 14 & 4.901 & OCt-17 & 14 & 3.334 OCT 17 & -3 & 3.567 & Oct-17 & 15 & 3.457 OCT 17 & 15 & 2.888 & 3.567 & 1.697 & 3.5788 \\
\hline 910 & 1.896 & $17-0 \mathrm{ct}$ is & 2.500 OCT 21 & 15 & 2.336 OCT 17 & 15 & 3.277 OCT 17 & 15 & 3.973 & Oct-17 & 15 & 2.786 OCT 17 & -2 & 2.792 & Oct-17 & 15 & 3.147 OCT 17 & 15 & 1.896 & 3.147 & 2.095 & 2.8383 \\
\hline 920 & 2.385 & 26-Jul 16 & 2.933 JUL 26 & 17 & 3.109 JUL 26 & 17 & $3.487 \mathrm{JUL} 26$ & 17 & 3.777 & Jul-26 & 17 & 3.071 JUL 26 & -2 & 3.050 & Jul-26 & 17 & $3.505 \mathrm{JUL} 26$ & 17 & 2.385 & 3.505 & 1.584 & 3.1646 \\
\hline 930 & 1.873 & 26-Jul 17 & 2.546 JUL 26 & 17 & 2.388 JUL 26 & 18 & 3.080 JUL 26 & 17 & 3.203 & Jul-26 & 17 & 2.486 JUL 26 & .2 & 2.498 & Jul-26 & 17 & $2.304 \mathrm{JUN} 30$ & 17 & 1.873 & 2.546 & 1.710 & 2.5473 \\
\hline 940 & 2.888 & 17 -oct is & 3.155 OCr 06 & 15 & 3.45800 or 17 & 14 & 3.871 OCT 17 & 14 & 4.901 & Oct-17 & 14 & 3.334 OCT 17 & .3 & 3.567 & Oct-17 & 15 & 3.457 OCT 17 & 15 & & & 1.697 & 3.5788 \\
\hline 950 & 2.033 & 02-Sep 14 & 2.621 SEP O2 & 15 & 2.664 SEP 2 & 15 & 3.170 SEP 02 & 14 & 3.848 & Sep-02 & 15 & 2.677 SEP 02 & -2 & 2.686 & Sep-02 & 15 & 2.867 SEP 02 & 14 & 2.033 & 2.867 & 1.893 & 2.8208 \\
\hline 960 & 0.953 & 16-Aug 16 & 1.144 JUL 26 & 16 & $1.057 \mathrm{JUL} 26$ & 16 & 1.370 JUL 26 & 16 & 1.306 & Jul-26 & 16 & 1.179 JUL 26 & 16 & 1.378 & Jut-26 & 16 & & 16 & 0.953 & 1.403 & 1.472 & 1.2238 \\
\hline 000 & 2.422 & 17-0at is & $2.912 \mathrm{~S}$ & 14 & 3.436 OCT 17 & 13 & 2.819 SEP 02 & 14 & 3.525 & Oct-17 & 10 & 1.859 NOV 25 & 14 & & & & & & & & 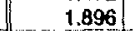 & \\
\hline 195 & 0.651 & $26-J u l ~ 15$ & 0.728 JUL 26 & 16 & 0.616 JUL 27 & 15 & $0.853 \mathrm{JUL} .26$ & $\frac{16}{16}$ & 0.806 & Jul-26 & 16 & 0.799 JUL 26 & -1 & 0.791 & Jul-26 & 16 & 0.790 JUL 26 & 16 & & & 1.385 & 0.7543 \\
\hline 200 & 0.863 & 16-Aug 14 & 1.017 JUL 26 & 15 & & & & & 1.111 & Jut-26 & 15 & 1.105 JUL 26 & -1 & 1.101 & Jut-26 & 16 & 1.126 JUL 26 & 15 & & & 1.305 & 1.0538 \\
\hline 210 & 0.476 & 16-Aug 16 & 1.017 JUL 26 & 15 & & & & & 1.101 & Jul-26 & & 1.097 JUL 26 & 0 & 1.068 & Jul-26 & 16 & 1.142 JUL 26 & 15 & & & 2.399 & 0.9835 \\
\hline 215 & 1.007 & 11-Aug is & 1.166 JUL 26 & 15 & & & & & 1.347 & Jul-26 & 15 & 1.216 JUL 26 & .1 & 1.184 & Jul-26 & 16 & 1.192 JUL 26 & 15 & & & 1.338 & 1.1853 \\
\hline 220 & 0.560 & 27-Jul 15 & 1.166 JUL. 26 & 15 & 0.937 JUL 27 & 14 & 1.340 JUL 26 & 15 & 1.342 & Jut-26 & 15 & 1.215 JUL 26 & -1 & 1.179 & Jul-26 & 16 & 1.213 JUL 26 & 15 & & & 2.396 & 1.1190 \\
\hline 230 & 1.059 & 27.Jul 15 & 1.646 JUL 26 & 15 & 1.455 JUL 27 & 14 & $1.875 \mathrm{JUL} 26$ & 15 & 1.878 & Jul-26 & 15 & 1.700 JUL 26 & .1 & 1.708 & Jul-26 & 16 & 1.749 JUL 26 & 15 & & & 1.773 & 1.6337 \\
\hline 240 & 0.739 & 27 Jul 15 & 1.347 JUL 26 & 15 & 1.119 JUL 27 & 14 & 1.540 JUL 26 & 15 & 1.542 & Jut-26 & 15 & 1.398 JUL 26 & .1 & 1.361 & Jut-26. & 16 & 1.397 JUL 26 & 15 & & & 2.087 & 1.3054 \\
\hline 250 & 3.360 & 05-Sep 12 & 3.036 SEP 05 & 12 & 2.605 SEP 5 & 11 & 2.590 AUG 26 & 14 & 2.582 & Aug-11 & 12 & 2.258 AUG 26 & -3 & 3.228 & Sep-05 & 13 & 4.912 SEP 05 & 12 & & & 2.175 & 3.0713 \\
\hline 270 & 6.356 & 25-Nov 13 & 6.641 NOV 25 & 14 & & & 7.163 OCT 16 & 14 & 7.967 & Nov-25 & 13 & 6.819 NOV 25 & -6 & 6.764 & Oct-17 & 14 & 6.867 OCT 16 & 14 & & & 1.253 & 6.9396 \\
\hline 280 & 4.444 & $17-0$ ct 13 & 4.631 NoV 25 & 13 & & & $5.220 \propto C T 16$ & 14 & 5.759 & Oct 16 & & 4.630 NOV 25 & -4 & 4.786 & Oct-16 & 14 & $5.2360 \mathrm{CT} 16$ & 14 & & & 1.296 & 4.9580 \\
\hline 290 & 6.269 & 13-Jan 13 & 6.555 NOV 25 & 14 & & & 6.910 NOV 25 & 14 & 7.793 & Dec-23 & 13 & 6.700 NOV 25 & -6 & 6.203 & Nov-25 & 14 & 6.621 NOV 25 & 14 & & & 1.256 & 6.7215 \\
\hline 300 & 3.404 & 26-vul te & 4.093 JUL 26 & 17 & & & $4.642 \mathrm{JUL} 26$ & i7) & 5.072 & Jul-02 & 10 & 4.336 JUL 26 & -3 & 4.278 & Jut-26 & 17) & 4.929 JUL 26 & 17 & & & 1.490 & 4.3934 \\
\hline 310 & 2.848 & 26-Jul te & 3.749 JUN 30 & 17 & & & 4.186 JUL 26 & 17 & 4.666 & Jul-02 & 9 & 3.669 JUL. 26 & -3 & 3.589 & Jut-26 & $i$ & 3.425 JUN 30 & 17 & & & 1.638 & 3.7331 \\
\hline 320 & 5.701 & 25 -Nov 13 & 5.946 NOV 25 & 14 & & & 6.484 OCT 16 & 14 & 7.332 & Nov-25 & & 6.183 NOV 25 & 6 & 6.178 & Oct-17 & 14 & 6.141 OCT 16 & 14 & & & 1.286 & 6.2807 \\
\hline 395 & 0.000 & & 0.362 JUL 26 & 18 & 0.000 & & $0.394 \mathrm{JUL} 26$ & 17 & 0.421 & Jul-26 & 5 & $0.356 \mathrm{JUL} 26$ & 18 & 0.363 & Jul-26 & 18 & 0.345 JUL 26 & 18 & & & ERA & 0.2801 \\
\hline 400 & 0.000 & & 0.581 JUL 26 & 17 & 0.265 JUL 27 & 17 & 0.666 JUL 26 & 16 & 0.712 & Jul-26 & 15 & 0.612 JUL 26 & 17 & 0.613 & Jul-26 & 17 & 0.572 JUL 26 & 17 & & & ERA & 0.5027 \\
\hline 410 & 0.035 & 27-Jul 16 & 0.699 JUL 20 & 17 & 0.413 JUL 27 & 17 & 0.814 JUL 26 & 15 & 0.863 & Jul-26 & 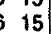 & 0.724 JUL 26 & -0 & 0.743 & Jul-26 & 17 & 0.710 JUL 26 & 17 & & & 24.657 & 0.6251 \\
\hline 420 & 0.258 & 27-Jul 15 & 0.923 JUL 26 & 15 & $0.631 \mathrm{JUL} 27$ & 15 & 1.047 JUL 26 & 15 & 1.078 & Jul-26 & 15 & 0.938 JUL 26 & -0 & 0.938 & Jut-26 & 16 & 0.921 JUL 26 & 15 & & & 4.178 & 0.8417 \\
\hline 430 & 1.493 & 16-Aug 14 & 1.772 AUG 26 & 14 & $1.427 \mathrm{AUG} 16$ & 14 & 1.762 JUL 26 & 15 & 1.779 & Aug-11 & 13 & 1.575 JUL 26 & -1 & 1.798 & Sep-05 & & 2.578 SEP 05 & 12 & & & 1.807 & 1.7730 \\
\hline 440 & 4.546 & 17-oct 13 & 4.424 OCT 16 & 14 & & & 5.053 OCT 16 & 14 & 5.615 & Oct-16 & & 4.465 OCT 16 & -5 & 4.686 & oct-16 & 14 & 5.278 OCT 17 & 14 & & & 1.269 & 4.8667 \\
\hline 800 & 0.585 & $27-$ Jul 14 & 0.967 AUG 16 & 14 & $0.743 \mathrm{JUL} 28$ & 14 & $1.352 \mathrm{JUL} 27$ & 14 & 1.382 & Jul-27 & 14 & 1.028 JUL 27 & -1 & 0.983 & Aug-16 & 14 & $1.35 B$ SEP 05 & 12 & & & 2.362 & 1.0497 \\
\hline 810 & 1.852 & $02-\operatorname{Sep} 1$ & 2.357 AUG 26 & 14 & & & 2.991 SEP 02 & 14 & .3 .624 & Sep-02 & 14 & 2.432 SEP 02 & .2 & 2.344 & Sep-02 & $\because 1$ & 2.862 SEP 02 & 14 & & & $\uparrow .957$ & 2.6374 \\
\hline
\end{tabular}




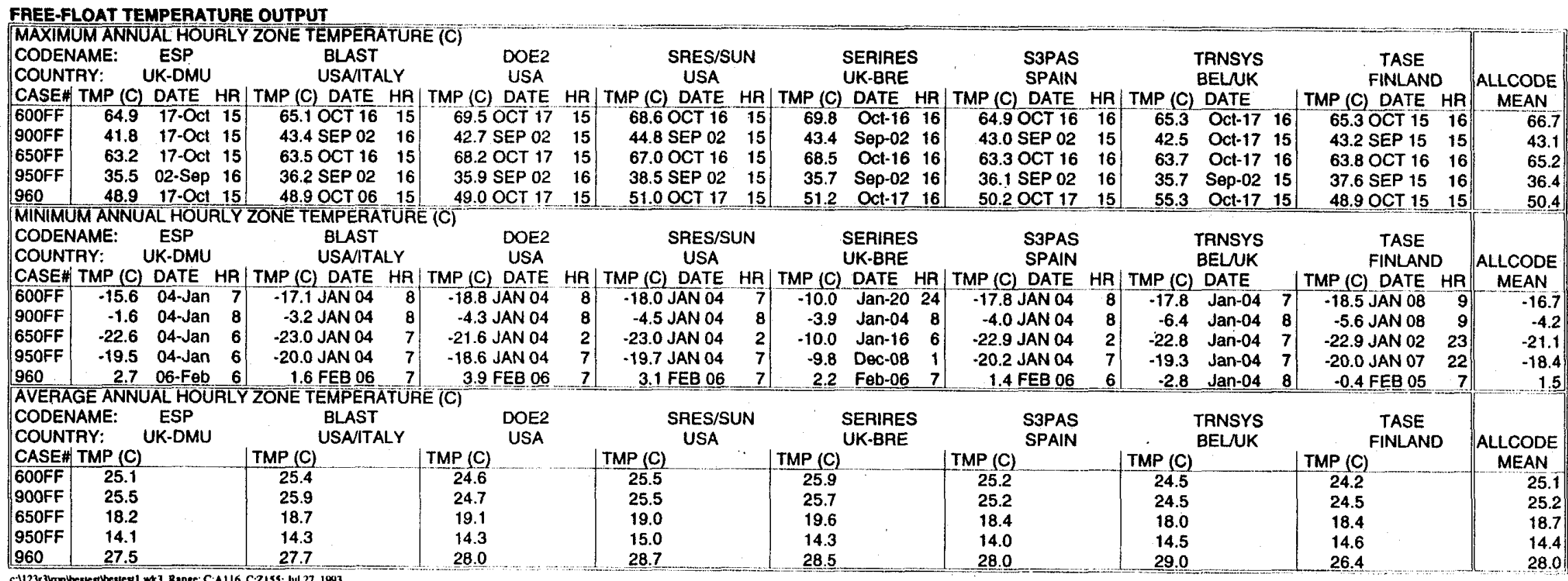


LOW MASS QUALIFICATON TESTS

\begin{tabular}{|c|c|c|c|c|c|c|c|c|c|c|c|c|}
\hline \multicolumn{13}{|c|}{ ING [MWr } \\
\hline CASES & $\begin{array}{c}\text { ESP } \\
\text { UK-DMU }\end{array}$ & $\begin{array}{l}\text { BLAST } \\
\text { US/TT }\end{array}$ & $\begin{array}{l}\text { DOE2 } \\
\text { USA }\end{array}$ & $\begin{array}{c}\text { SRES/SUN } \\
\text { USA }\end{array}$ & $\begin{array}{l}\text { SERIRES } \\
\text { UK-BAE }\end{array}$ & $\begin{array}{l}\text { S3PAS } \\
\text { SPAIN }\end{array}$ & $\begin{array}{l}\text { TRNSYS } \\
\text { BEUUK }\end{array}$ & $\begin{array}{l}\text { TASE } \\
\text { FINLAND }\end{array}$ & $\begin{array}{l}\text { RANGE } \\
\text { MIN }\end{array}$ & $\begin{array}{l}\text { RANGE } \\
\text { MAX }\end{array}$ & $\begin{array}{l}\text { ALLCODE } \\
\text { MAXMIN }\end{array}$ & $\begin{array}{l}\text { ALLCODE } \\
\text { MEAN }\end{array}$ \\
\hline $610-600$ & 0.059 & 0.033 & 0.077 & 0.054 & 0.024 & 0.089 & 0.098 & 0.021 & 0.021 & 0.098 & 4.667 & 0.057 \\
\hline $620-600$ & 0.317 & 0.276 & 0.235 & & 0.138 & 0.682 & 0.201 & 0.366 & 0.138 & 0.682 & 4.942 & 0.318 \\
\hline $630-620$ & 0.437 & 310 & 0.5 & & 0.267 & 0. & 0. & 1.290 & 0.267 & 0.551 & 4. & 0.530 \\
\hline $640-600$ & -1.545 & & & & & & & & & & & \\
\hline \multicolumn{13}{|c|}{ ANNUAL COOLING [MWH] } \\
\hline CASES & $\begin{array}{c}\text { ESP } \\
\text { UK-DMU }\end{array}$ & $\begin{array}{l}\text { BLAST } \\
\text { USIT }\end{array}$ & $\begin{array}{l}\text { DOE2 } \\
\text { USA }\end{array}$ & $\begin{array}{c}\text { SRES/SUN } \\
\text { USA }\end{array}$ & $\begin{array}{l}\text { SERIRES } \\
\text { UK-BRE }\end{array}$ & $\begin{array}{l}\text { S3PAS } \\
\text { SPAIN }\end{array}$ & $\begin{array}{l}\text { TRNSYS } \\
\text { BELUK }\end{array}$ & $\begin{array}{l}\text { TASE } \\
\text { FINLAND }\end{array}$ & $\begin{array}{c}\text { RANGE } \\
\text { MIN }\end{array}$ & $\begin{array}{l}\text { RANGE } \\
\text { MAX }\end{array}$ & MAL & $\begin{array}{c}\text { ALLCODE } \\
\text { MEAN }\end{array}$ \\
\hline $620-600$ & -2.720 & -2.341 & -2.745 & -2.645 & -2.960 & -2.481 & -2.591 & -2.427 & -2.960 & -2.341 & 0.791 & -2.614 \\
\hline $630-620$ & -1.288 & -0.984 & -1.845 & -1.140 & -1.303 & -1.522 & -1.485 & -2.630 & -1.845 & -0.984 & 0.374 & -1.525 \\
\hline $640-600$ & -0.185 & -0.250 & -0.320 & -0.252 & -0.153 & -0.245 & -0.246 & -0.270 & & & 0.478 & -0.240 \\
\hline $650-600$ & -1.321 & 1000 & -1284 & & 1 & & & -1.322 & -1. & -1.284 & & -1.350 \\
\hline \multicolumn{13}{|c|}{ PEAK HEATING (KW) } \\
\hline & $\begin{array}{c}\text { ESP } \\
\text { UK-DMU }\end{array}$ & $\begin{array}{l}\text { BLAST } \\
\text { USIIT }\end{array}$ & $\begin{array}{l}\text { DOE2 } \\
\text { USA }\end{array}$ & $\begin{array}{c}\text { SRES/SUN } \\
\text { USA }\end{array}$ & $\begin{array}{l}\text { SERIRES } \\
\text { UK-BRE }\end{array}$ & $\begin{array}{l}\text { S3PAS } \\
\text { SPAIN }\end{array}$ & $\begin{array}{l}\text { TRNSYS } \\
\text { BELUK }\end{array}$ & $\begin{array}{c}\text { TASE } \\
\text { FINLAND }\end{array}$ & $\begin{array}{c}\text { RANGE } \\
\text { MIN }\end{array}$ & $\begin{array}{l}\text { RANGE } \\
\text { MAX }\end{array}$ & $\begin{array}{l}\text { ALLCODE } \\
\text { MAX/MIN }\end{array}$ & $\begin{array}{c}\text { ALLCODE } \\
\text { MEAN }\end{array}$ \\
\hline $610-600$ & 0.000 & 0.001 & -0.011 & 0.000 & -0.001 & 0.000 & -0.008 & 0.000 & -0.011 & 0.000 & - & -0.002 \\
\hline 600 & 0.154 & 0.001 & 0.001 & 19 & -0.001 & 40 & 08 & 0.025 & -0 & 40 & - & 054 \\
\hline $640-600$ & 1.795 & 446 & 1.898 & 72 & 3.771 & & & 600 & & & 139 & 248 \\
\hline \multicolumn{13}{|c|}{ PEAK COOLING [KW] } \\
\hline & $\begin{array}{c}\text { ESP } \\
\text { UK-DMU }\end{array}$ & $\begin{array}{l}\text { BLAST } \\
\text { USIIT }\end{array}$ & $\begin{array}{c}\text { DOE2 } \\
\text { USA }\end{array}$ & $\begin{array}{c}\text { SRES/SUN } \\
\text { USA }\end{array}$ & $\begin{array}{l}\text { SERIRES } \\
\text { UK-BRE }\end{array}$ & $\begin{array}{l}\text { S3PAS } \\
\text { SPAIN }\end{array}$ & $\begin{array}{l}\text { TRNSYS } \\
\text { BELUK }\end{array}$ & $\begin{array}{c}\text { TASE } \\
\text { FINLAND }\end{array}$ & $\begin{array}{l}\text { RANGE } \\
\text { MIN }\end{array}$ & $\begin{array}{l}\text { RANGE } \\
\text { MAX }\end{array}$ & $\begin{array}{l}\text { ALLCODE } \\
\text { MAXMMIN }\end{array}$ & $\begin{array}{c}\text { ALLCODE } \\
\text { MEAN }\end{array}$ \\
\hline $610-600$ & 0.525 & -0.141 & -0.592 & -0.456 & -0.336 & -0.116 & -0.811 & -0.666 & -0.811 & -0.116 & 0.143 & -0.455 \\
\hline $620-600$ & -2.560 & -1.890 & -2.226 & -2.234 & -2.592 & -1.989 & -2.211 & -1.716 & -2.560 & -1.716 & 0.662 & -2.177 \\
\hline $630-620$ & -0.562 & -0.371 & -0.842 & -0.477 & -0.559 & -0.632 & -0.667 & -1.550 & -0.842 & -0.371 & 0.239 & -0.707 \\
\hline $640-600$ & -0.033 & -0.073 & -0.080 & -0.051 & -0.014 & -0.036 & -0.044 & -0.041 & & & 0.175 & -0.047 \\
\hline 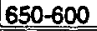 & -0.163 & -0.134 & -0.140 & -0.156 & -0.093 & -0.143 & -0.108 & -0.133 & -0.163 & -0.108 & 0.571 & -0.134 \\
\hline
\end{tabular}

HIGH MASS QUALIFICATION TESTS



Nore: In the Mar/Min column " $"$ " indicates opponite sensitivities. When this occurs the magnitude of the value loses meaning.

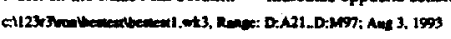


LOW MASS PRIMITIVE DIAGNOSTIC TESTS

\begin{tabular}{|c|c|c|c|c|c|c|c|c|c|c|}
\hline \multicolumn{11}{|c|}{ ANNUAL HEATING [MWH] } \\
\hline CASES & $\begin{array}{c}\text { ESP } \\
\text { UK-DMU }\end{array}$ & $\begin{array}{l}\text { BLAST } \\
\text { USIIT }\end{array}$ & $\begin{array}{c}\text { DOE2 } \\
\text { USA }\end{array}$ & $\begin{array}{c}\text { SRES/SUN } \\
\text { USA }\end{array}$ & $\begin{array}{c}\text { SERIRES } \\
\text { UK-BRE }\end{array}$ & $\begin{array}{l}\text { S3PAS } \\
\text { SPAIN }\end{array}$ & $\begin{array}{l}\text { TRNSYS } \\
\text { BELUK }\end{array}$ & $\begin{array}{l}\text { TASE } \\
\text { FINLAND }\end{array}$ & $\begin{array}{l}\text { ALLCODE } \\
\text { MAXMMIN }\end{array}$ & $\begin{array}{l}\text { ALLCODE } \\
\text { MEAN }\end{array}$ \\
\hline $200-195$ & 1.085 & 1.664 & & & 1.715 & 1.663 & 1.524 & 1.961 & 1.807 & 1.602 \\
\hline $210-200$ & 1.204 & 0.000 & & & 0.111 & 0.099 & 0.159 & 0.085 & ERR & 0.276 \\
\hline $220-215$ & 1.397 & 0.000 & & & 0.184 & 0.141 & 0.167 & 0.118 & ERR & 0.334 \\
\hline $215-200$ & 0.295 & 0.656 & & & 1.260 & 0.645 & 0.735 & 0.437 & 4.271 & 0.671 \\
\hline $220-210$ & 0.488 & 0.656 & & & 1.333 & 0.687 & 0.743 & 0.470 & 2.836 & 0.730 \\
\hline $230-220$ & 3.432 & 3.525 & 3.456 & 3.531 & 3.522 & 3.615 & 3.543 & 3.527 & 1.053 & 3.519 \\
\hline $240-220$ & -1.295 & -1.206 & -1.339 & -1.333 & -1.341 & -1.228 & -1.221 & -1.203 & 0.897 & -1.271 \\
\hline $250-220$ & -2.193 & -1.476 & -1.763 & -1.494 & -1.474 & -1.448 & -1.533 & -1.699 & 0.660 & -1.635 \\
\hline $270-220$ & -2.434 & -2.285 & & -2.620 & -2.207 & -2.350 & -2.250 & -1.948 & 0.744 & -2.299 \\
\hline $280-270$ & 0.165 & 0.195 & & 0.455 & 0.228 & 0.291 & 0.232 & 0.352 & 2.758 & 0.274 \\
\hline $320-270$ & -0.651 & -0.721 & & -0.718 & -0.779 & -0.729 & -0.699 & -0.649 & 0.833 & -0.707 \\
\hline $290-270$ & 0.067 & 0.029 & & 0.057 & 0.022 & 0.088 & 0.085 & 0.020 & .4 .400 & 0.053 \\
\hline $300-270$ & 0.251 & 0.147 & & 0.207 & 0.044 & 0.590 & 0.077 & 0.297 & 13.409 & 0.230 \\
\hline $310-300$ & 0.460 & 0.250 & & 0.248 & 0.201 & 0.492 & 0.486 & 1.349 & 6.711 & 0.498 \\
\hline \multicolumn{11}{|c|}{ ANNUAL COOLING [MWH] } \\
\hline CASES & $\begin{array}{c}\text { ESP } \\
\text { UK-DMU }\end{array}$ & $\begin{array}{l}\text { BLAST } \\
\text { US/IT }\end{array}$ & $\begin{array}{l}\text { DOE2 } \\
\text { USA }\end{array}$ & $\begin{array}{c}\text { SRES/SUN } \\
\text { USA }\end{array}$ & $\begin{array}{l}\text { SERIRES } \\
\text { UK-BRE }\end{array}$ & $\begin{array}{l}\text { S3PAS } \\
\text { SPAIN }\end{array}$ & $\begin{array}{l}\text { TRNSYS } \\
\text { BELUK }\end{array}$ & $\begin{array}{l}\text { TASE } \\
\text { FINLAND }\end{array}$ & $\begin{array}{l}\text { ALLCODE } \\
\text { MAXMMIN }\end{array}$ & $\begin{array}{c}\text { ALLCODE } \\
\text { MEAN }\end{array}$ \\
\hline $200-195$ & 0.156 & 0.192 & & & 0.211 & 0.203 & 0.241 & 0.190 & 1.546 & 0.199 \\
\hline $210-200$ & -0.408 & 0.000 & & & -0.018 & -0.016 & -0.048 & 0.008 & - & -0.080 \\
\hline $220-215$ & -0.453 & 0.000 & & & -0.018 & -0.015 & -0.028 & 0.012 & - & -0.084 \\
\hline $215-200$ & 0.069 & 0.088 & & & 0.154 & 0.072 & 0.050 & 0.038 & 4.053 & 0.078 \\
\hline $220-210$ & 0.024 & 0.088 & & & 0.154 & 0.073 & 0.069 & 0.042 & 6.417 & 0.075 \\
\hline $230-220$ & 0.268 & 0.275 & 0.293 & 0.304 & 0.304 & 0.286 & 0.303 & 0.302 & 1.134 & 0.292 \\
\hline $240-220$ & 0.229 & 0.371 & 0.261 & 0.412 & 0.411 & 0.374 & 0.377 & 0.362 & 1.799 & 0.350 \\
\hline $250-220$ & 3.027 & 1.844 & 1.778 & 2.097 & 2.096 & 1.752 & 1.947 & 2.697 & 1.728 & 2.155 \\
\hline $270-220$ & 7.342 & 7.969 & & 8.804 & 9.515 & 8.061 & 8.027 & 8.031 & 1.296 & 8.250 \\
\hline $280-270$ & -2.655 & -2.775 & & -3.120 & -3.236 & -2.990 & -3.003 & -2.457 & 0.759 & -2.891 \\
\hline $320-270$ & -2.467 & -2.764 & & -3.055 & -3.046 & -2.881 & -2.808 & -3.051 & 0.808 & -2.867 \\
\hline $290-270$ & -2.324 & -1.659 & & -1.910 & -2.261 & -1.892 & -2.065 & -1.283 & 0.552 & -1.913 \\
\hline $300-270$ & -3.226 & -2.834 & & -3.106 & -3.250 & -2.946 & -3.043 & -2.933 & 0.872 & -3.048 \\
\hline $310-300$ & -1.570 & -1.266 & & -1.389 & -1.629 & -1.974 & -1.994 & -3.310 & 0.382 & -1.876 \\
\hline \multicolumn{11}{|c|}{ PEAK HEATING [KW] } \\
\hline CASES & $\begin{array}{c}\text { ESP } \\
\text { UK-DMU }\end{array}$ & $\begin{array}{l}\text { BLAST } \\
\text { US } / T \text { T }\end{array}$ & $\begin{array}{l}\text { DOE2 } \\
\text { USA }\end{array}$ & $\begin{array}{c}\text { SRES/SUN } \\
\text { USA }\end{array}$ & $\begin{array}{c}\text { SERIRES } \\
\text { UK-BRE }\end{array}$ & $\begin{array}{l}\text { S3PAS } \\
\text { SPAIN }\end{array}$ & $\begin{array}{l}\text { TRNSYS } \\
\text { BELUK }\end{array}$ & $\begin{array}{c}\text { TASE } \\
\text { FINLAND }\end{array}$ & $\begin{array}{l}\text { ALLCODE } \\
\text { MAXMIN }\end{array}$ & $\begin{array}{l}\text { ALLCODE } \\
\text { MEAN }\end{array}$ \\
\hline $200-195$ & 0.647 & 0.787 & & & 0.812 & 0.778 & 0.784 & 1.119 & 1.730 & 0.821 \\
\hline $210-200$ & 0.050 & 0.000 & & & 0.030 & 0.021 & 0.011 & -0.057 & & 0.009 \\
\hline $220-215$ & 0.080 & 0.000 & & & 0.059 & 0.041 & 0.042 & 0.062 & ERR & 0.047 \\
\hline $215-200$ & 0.136 & 0.307 & & & 0.603 & 0.308 & 0.325 & 0.076 & 7.934 & 0.293 \\
\hline $220-210$ & 0.166 & 0.307 & & & 0.632 & 0.328 & 0.356 & 0.195 & 3.807 & 0.331 \\
\hline $230-220$ & 1.519 & 1.704 & 1.529 & 1.584 & 1.584 & 1.811 & 1.556 & 1.587 & 1.192 & 1.609 \\
\hline $240-220$ & -0.182 & -0.180 & -0.183 & -0.200 & -0.200 & -0.189 & -0.183 & -0.187 & 0.900 & -0.188 \\
\hline $250-220$ & -0.001 & -0.001 & 0.000 & 0.000 & 0.000 & -0.007 & 0.000 & 0.005 & 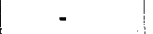 & -0.001 \\
\hline $270-220$ & -0.004 & -0.003 & & -0.025 & 0.005 & -0.008 & 0.000 & 0.218 & - & 0.026 \\
\hline $280-270$ & 0.001 & 0.001 & & 0.015 & 0.000 & 0.001 & 0.000 & 0.021 & ERR & 0.006 \\
\hline $320-270$ & -0.002 & -0.002 & & -0.009 & 0.000 & 0.000 & 0.000 & -0.003 & 0.000 & -0.002 \\
\hline $290-270$ & 0.000 & 0.000 & & 0.000 & 0.000 & 0.000 & -0.008 & 0.000 & 0.000 & -0.001 \\
\hline $300-270$ & 0.151 & -0.001 & & 0.015 & 0.000 & 0.259 & -0.008 & 0.032 & - & 0.064 \\
\hline $310-300$ & 0.001 & 0.001 & & -0.013 & 0.000 & 0.000 & 0.000 & 0.001 &  & -0.001 \\
\hline \multicolumn{11}{|c|}{ PEAK COOLING [KW] } \\
\hline & ESP & BLAST & DOE2 & SRES/SUN & SERIRES & & TRNSYS & TASE & ALLC & ALLCODE \\
\hline CASES & UK-DMU & US/IT & & & UK-BRE & & & AND & MIN & \\
\hline $200-195$ & 0.212 & 0.289 & & & 0.305 & 0.306 & 0.309 & 0.336 & 1.585 & 0.293 \\
\hline $210-200$ & -0.387 & 0.000 & & & -0.010 & -0.008 & -0.033 & 0.016 & - & -0.070 \\
\hline $220-215$ & -0.447 & 0.000 & & & -0.005 & -0.001 & -0.005 & 0.021 & - & -0.073 \\
\hline $215-200$ & 0.144 & 0.149 & & . & 0.236 & 0.111 & 0.083 & 0.066 & 3.576 & 0.132 \\
\hline $220-210$ & 0.084 & 0.149 & & & 0.241 & 0.118 & 0.111 & 0.071 & 3.394 & 0.129 \\
\hline $230-220$ & 0.499 & 0.480 & 0.518 & 0.535 & 0.536 & 0.485 & 0.529 & 0.536 & 1.117 & 0.515 \\
\hline $240-220$ & 0.179 & 0.181 & 0.182 & 0.200 & 0.200 & 0.183 & 0.183 & 0.184 & 1.117 & 0.186 \\
\hline $250-220$ & 2.800 & 1.870 & 1.668 & 1.250 & 1.240 & 1.043 & 2.049 & 3.699 & 3.547 & 1.952 \\
\hline $270-220$ & 5.796 & 5.475 & & 5.823 & 6.625 & 5.604 & 5.585 & 5.654 & 1.210 & 5.795 \\
\hline $280-270$ & -1.912 & -2.010 & & -1.943 & -2.208 & -2.189 & -1.978 & -1.631 & 0.739 & -1.982 \\
\hline $320-270$ & -0.655 & -0.695 & & -0.679 & -0.635 & -0.636 & -0.586 & -0.726 & 0.807 & -0.659 \\
\hline $290-270$ & -0.087 & -0.086 & & -0.253 & -0.174 & -0.119 & -0.561 & -0.246 & 0.153 & -0.218 \\
\hline $300-270$ & -2.952 & -2.548 & & -2.521 & -2.895 & -2.483 & -2.486 & -1.938 & 0.657 & -2.546 \\
\hline $310-300$ & -0.556 & -0.344 & & -0.456 & -0.406 & -0.667 & -0.689 & -1.504 & 0.229 & -0.660 \\
\hline
\end{tabular}

Note: In the Max/Min columa " " indicates opposite sensitivities. When this occurs the magnitude of the value loses meaning

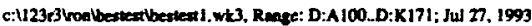


LOW MASS REALISTIC DIACNOSTIC TESTS

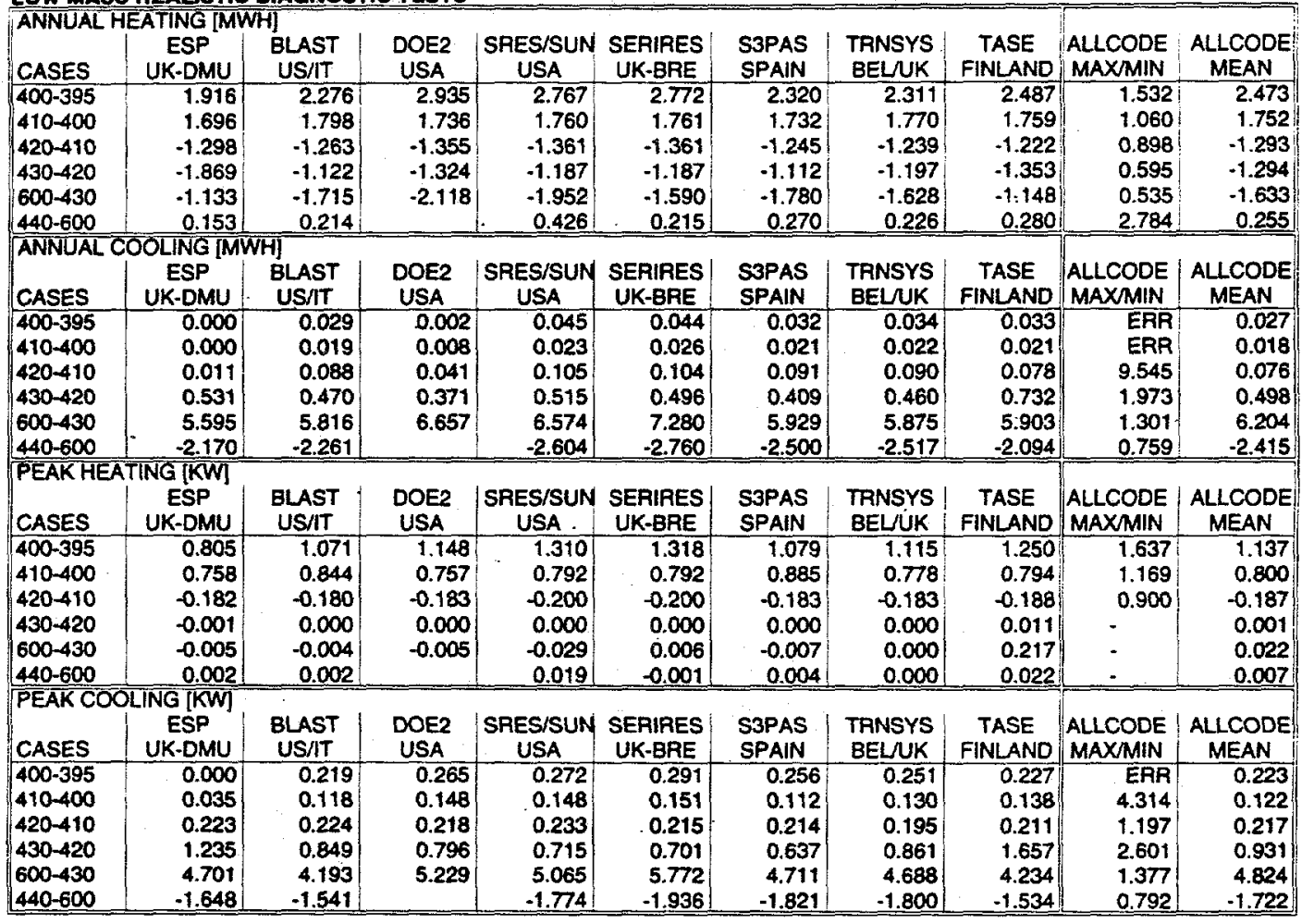

HIGH MASS DIAGNOSTIC TESTS

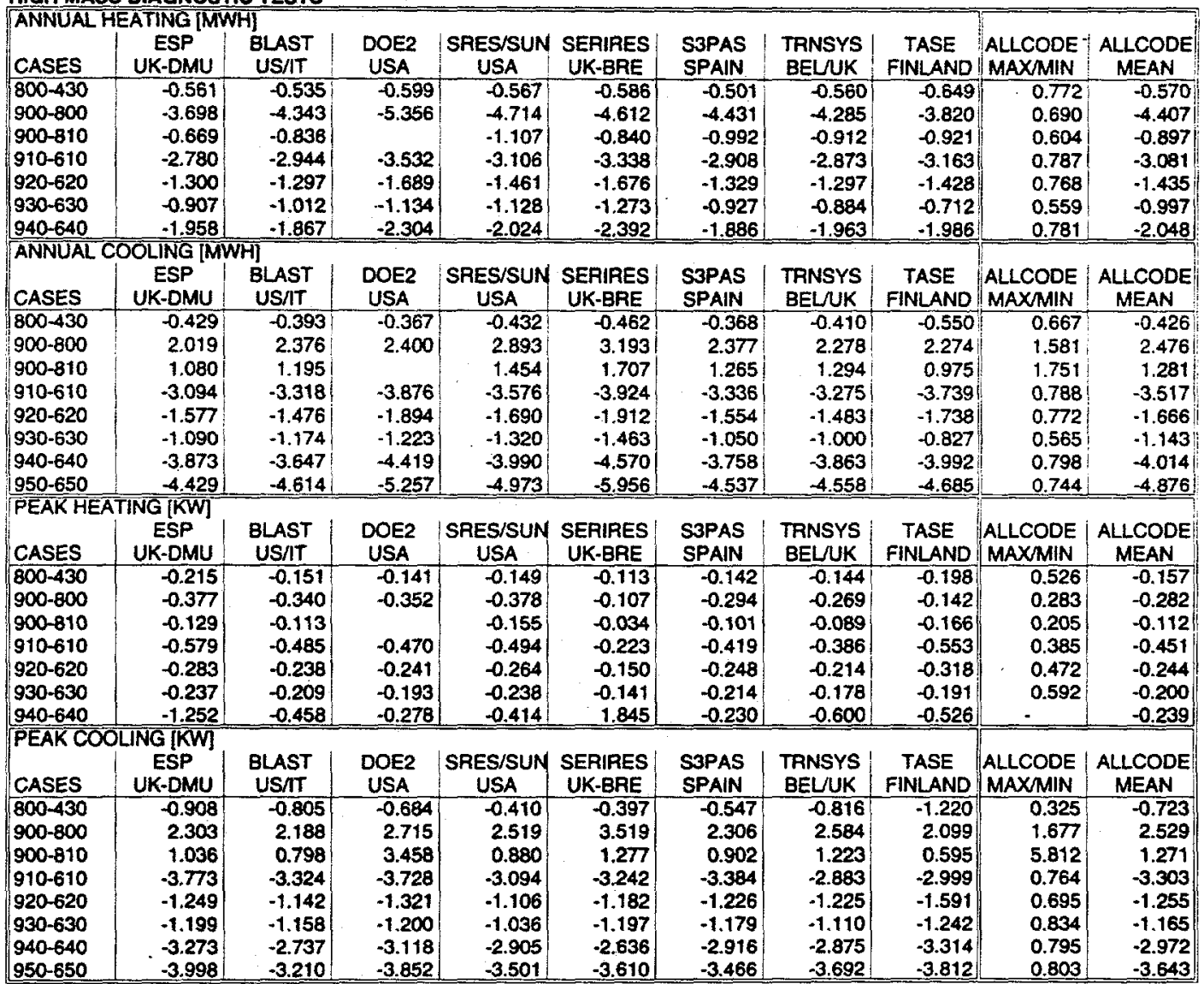

Note: in the Max/Min colurm "o" indicates opposite sensitivities. When this wocurs the magnitude of the value loses meaning.

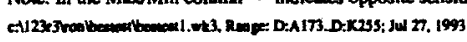




\begin{tabular}{|c|c|c|c|c|c|c|c|c|c|c|}
\hline \multicolumn{11}{|c|}{$\begin{array}{l}\text { ANNUAL TRANSMISSIVITY COEFFICIENT OF WINDOWS } \\
\text { (ANNUAL UNSHADED TRANSMITTED SOLRAD)/(ANNUAL UNSHADED INCIDENT SOLRAD) }\end{array}$} \\
\hline $\begin{array}{l}\text { CODENAME: } \\
\text { COUNTRY: } \\
\text { CASE\# }\end{array}$ & $\begin{array}{l}\text { ESP } \\
\text { UK-DMU }\end{array}$ & $\begin{array}{l}\text { BLAST } \\
\text { US/IT }\end{array}$ & $\begin{array}{l}\text { DOE2.1D } \\
\text { USA }\end{array}$ & $\begin{array}{c}\text { SUNCODE } \\
\text { USA }\end{array}$ & $\underset{\text { UK }}{\text { SERIRES }}$ & $\begin{array}{l}\text { S3PAS } \\
\text { SPAIN }\end{array}$ & $\begin{array}{l}\text { TRNSYS } \\
\text { BELUK }\end{array}$ & $\begin{array}{c}\text { TASE } \\
\text { FINLAND }\end{array}$ & $\begin{array}{l}\text { ALLCODE } \\
\text { MAX/MIN }\end{array}$ & $\begin{array}{l}\text { ALLCODE } \\
\text { MEAN }\end{array}$ \\
\hline 920WEST & 0.674 & & 0.681 & 0.687 & 0.657 & 0.641 & 0.654 & 0.648 & 1.072 & 0.663 \\
\hline 900SOUTH & 0.650 & & 0.671 & 0.652 & 0.650 & 0.628 & 0.647 & 0.623 & 1.078 & 0.646 \\
\hline
\end{tabular}

\begin{tabular}{|c|c|c|c|c|c|c|c|c|c|c|}
\hline \multicolumn{9}{|c|}{$\begin{array}{l}\text { ANNUAL SHADING COEFFICIENT OF WINDOW SHADING DEVICES: OVERHANGS \& FINS } \\
\text { (1-(ANNUAL SHADED TRANSMITTED SOLRAD)/(ANNUAL UNSHADED TRANSMITTED SOLRAD)) }\end{array}$} & \multirow[b]{2}{*}{$\begin{array}{l}\text { ALLCODE } \\
\text { MAX/MIN }\end{array}$} & \multirow[b]{2}{*}{$\begin{array}{l}\text { ALLCODE } \\
\text { MEAN. }\end{array}$} \\
\hline $\begin{array}{l}\text { CODENAME: } \\
\text { COUNTRY: } \\
\text { CASE\# }\end{array}$ & $\begin{array}{l}\text { ESP } \\
\text { UK-DMU }\end{array}$ & $\begin{array}{l}\text { BLAST } \\
\text { US/IT }\end{array}$ & $\begin{array}{l}\text { DOE2.1D } \\
\text { USA }\end{array}$ & $\begin{array}{l}\text { SUNCODE } \\
\text { USA }\end{array}$ & $\begin{array}{l}\text { SERIRES } \\
\text { UK }\end{array}$ & $\begin{array}{l}\text { S3PAS } \\
\text { SPAIN }\end{array}$ & $\begin{array}{l}\text { TRNSYS } \\
\text { BELUK }\end{array}$ & $\begin{array}{c}\text { TASE } \\
\text { FINLAND }\end{array}$ & & \\
\hline $930 / 920 \mathrm{~W}$ & 0.182 & & 0.346 & 0.196 & 0.216 & 0.329 & 0.339 & 0336 & 1002 & 0277 \\
\hline $910 / 900 \mathrm{~S}$ & 0.170 & & 0.209 & 0.165 & 0.188 & 0.183 & 0.205 & 0.115 & $\begin{array}{l}1.90< \\
1.822\end{array}$ & 0.177 \\
\hline
\end{tabular}


This page intentionally left blank 


\section{BESTEST QUALIFICATION ANNUAL INCIDENT SOLAR RADIATION}

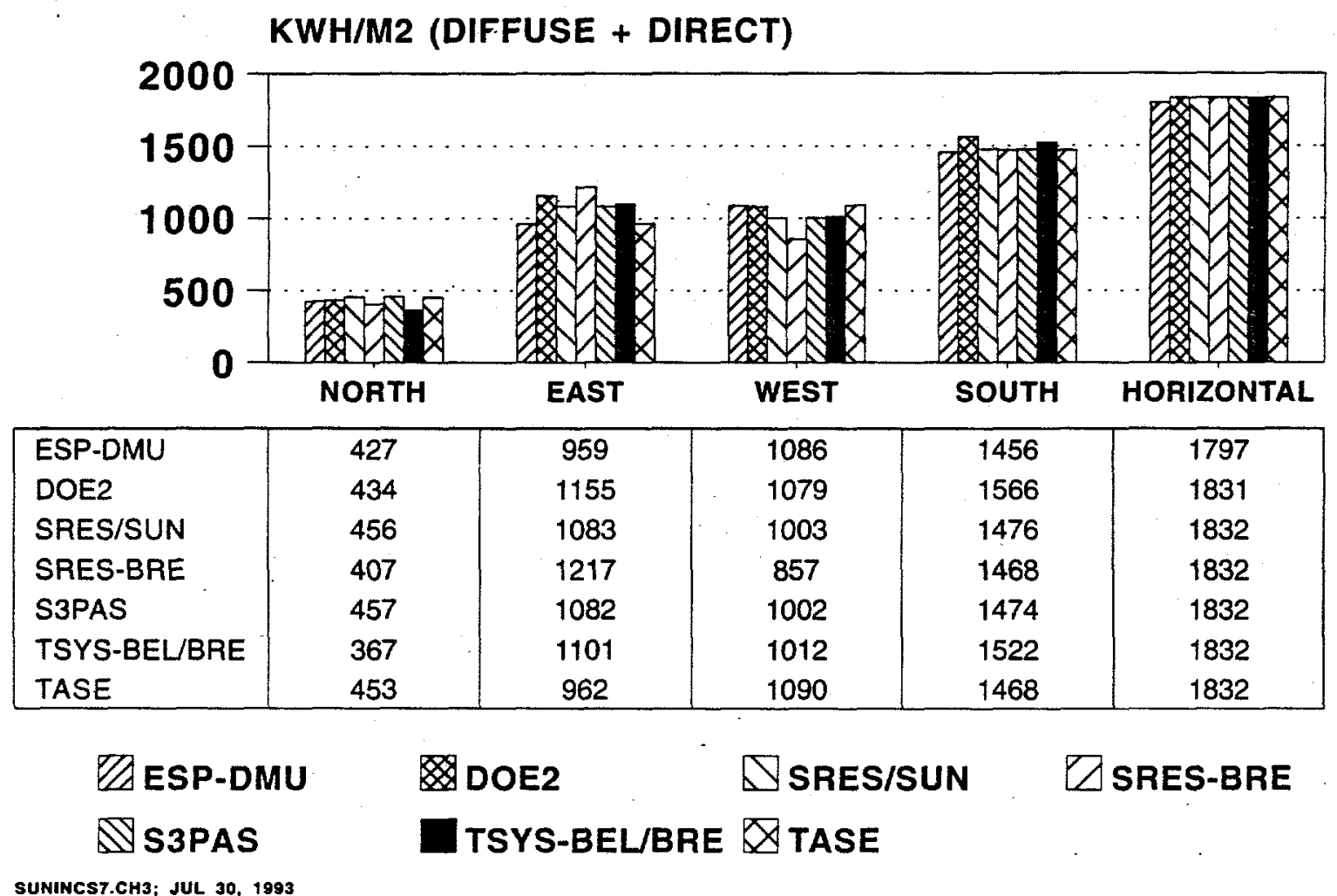




\section{BESTEST QUALIFICATION ANNUAL TRANSMITTED SOLRAD UNSHADED}



\begin{tabular}{|l|c|c|}
\hline ESP-DMU & 732 & 946 \\
DOE2 & 735 & 1051 \\
SRES/SUN & 689 & 962 \\
SRES-BRE & 563 & 954 \\
S3PAS & 642 & 926 \\
TSYS-BEL/BRE & 662 & 984 \\
TASE & 706 & 914 \\
\hline
\end{tabular}
ZESP-DMU
DOE2
$\triangle$ SRES/SUN
$\triangle$ SRES-BRE
SS3PAS
TSYS-BEL/BRE TASE

SUNTRS7.CH3; JUL 22, 1993

\section{BESTEST QUALIFICATION ANNUAL TRANSMITTED SOLRAD SHADED}

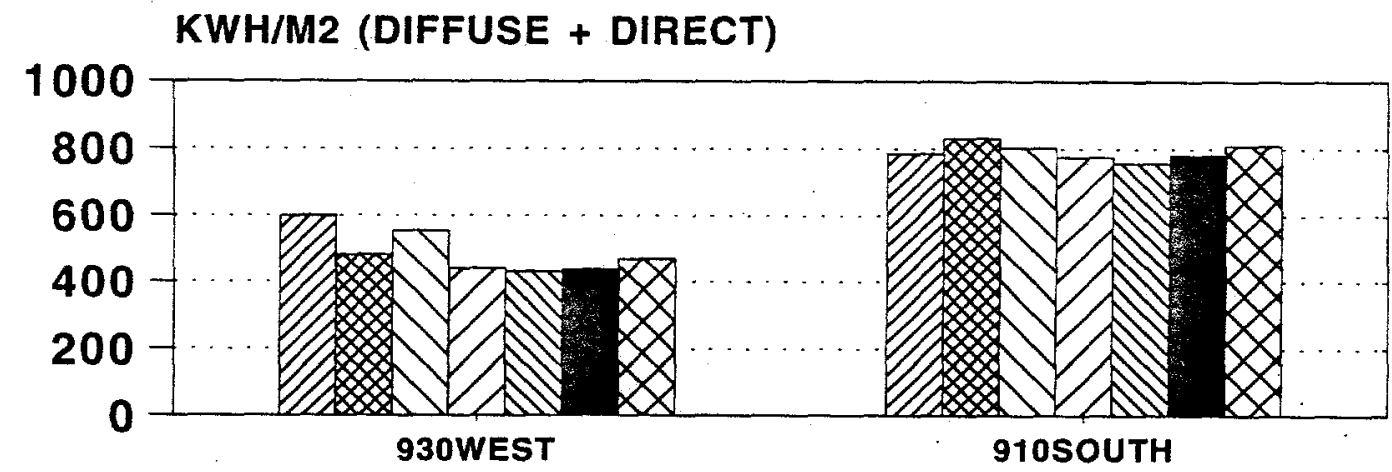

\begin{tabular}{|l|l|l|}
\hline ESP-DMU & 599 & 785 \\
DOE2 & 481 & 831 \\
SRES/SUN & 554 & 803 \\
SRES-BRE & 441 & 775 \\
S3PAS & 431 & 757 \\
TSYS-BELBRE & 438 & 782 \\
TASE & 469 & 809 \\
\hline
\end{tabular}

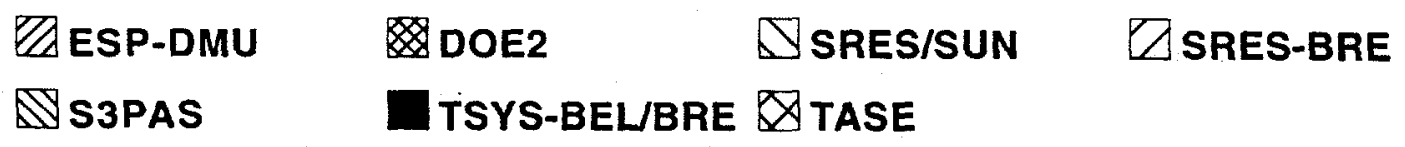




\section{BESTEST QUALIFICATION ANNUAL TRANSMISSIVITY COEFFICIENT OF WINDOWS (UNSHADED TRANSMITTED)/(INCIDENT SOLRAD)}

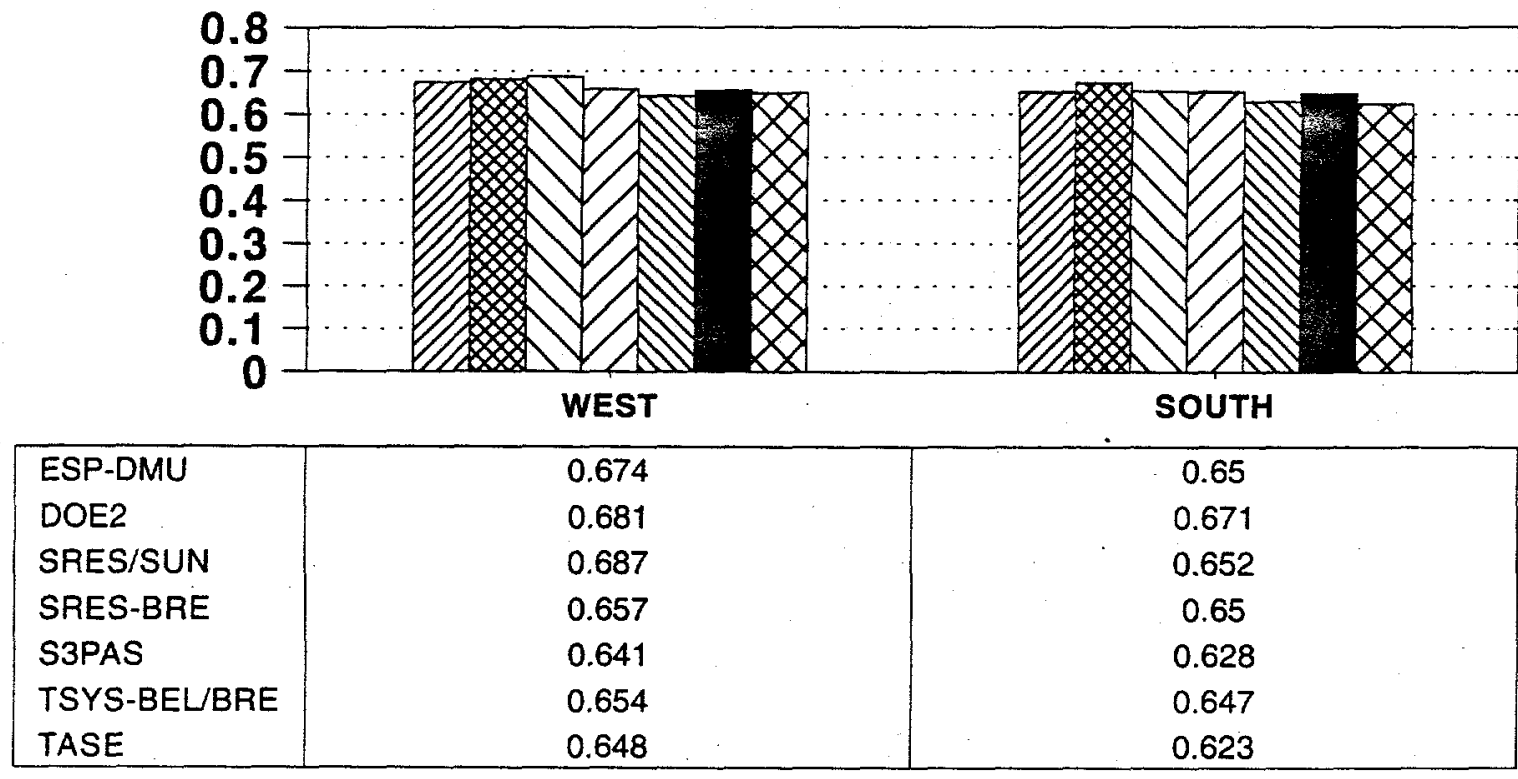

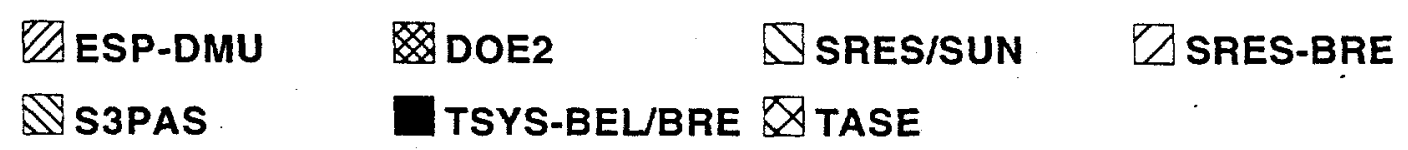

ATCO7.CH3; JUL 22, 1993

BESTEST QUALIFICATION

ANNUAL OVERHANG AND FIN SHADING COEFFICIENTS (1-(SHADED)/(UNSHADED)) TRANSMITTED SOLRAD

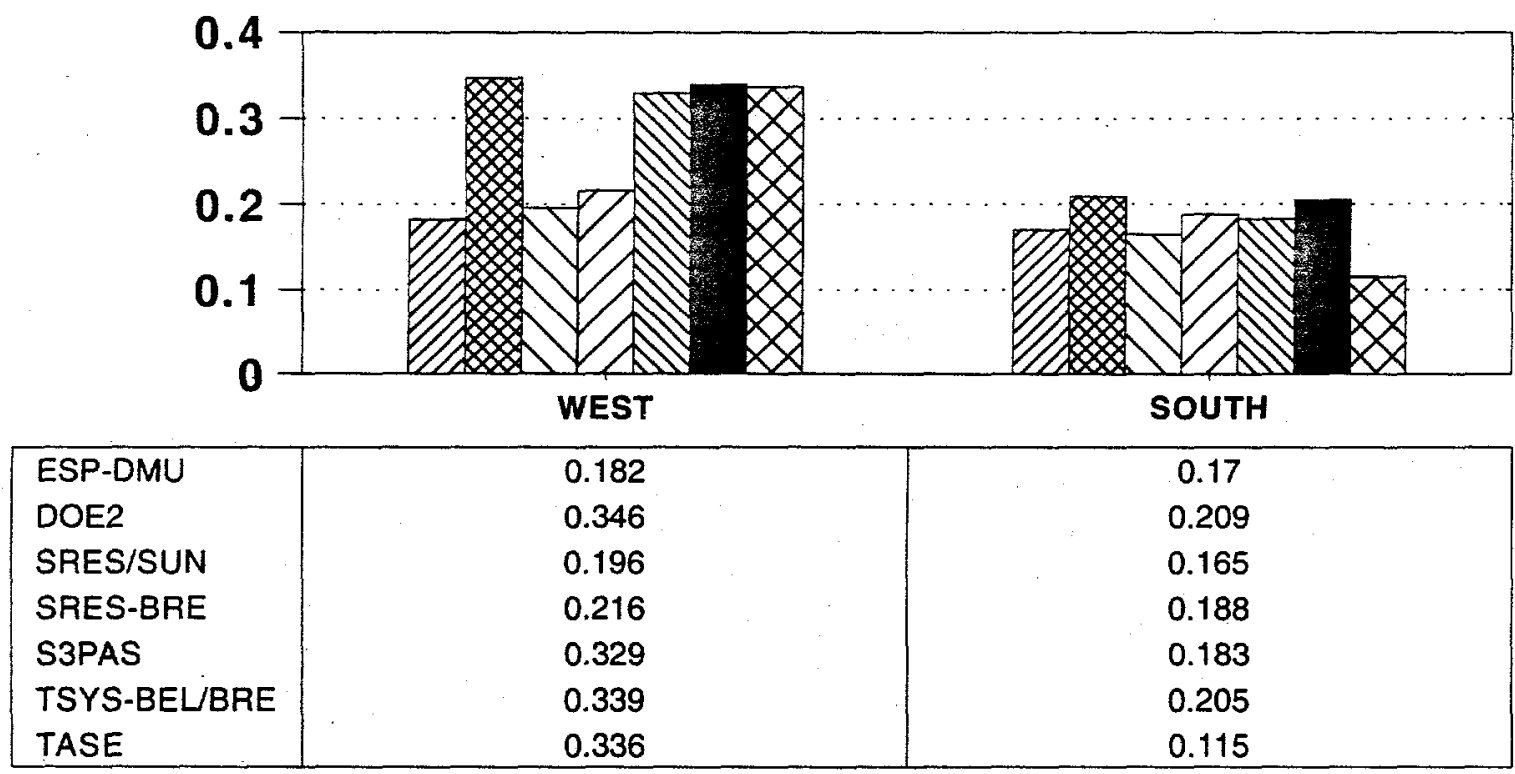
ZESP-DMU
DOE2
QSRES/SUN
$\triangle$ SRES-BRE
SSPAS
TSYS-BEL/BRE $\otimes$ TASE 


\section{BESTEST QUALIFICATION LOW MASS ANNUAL HEATING}



\section{BESTEST QUALIFICATION LOW MASS PEAK HEATING}

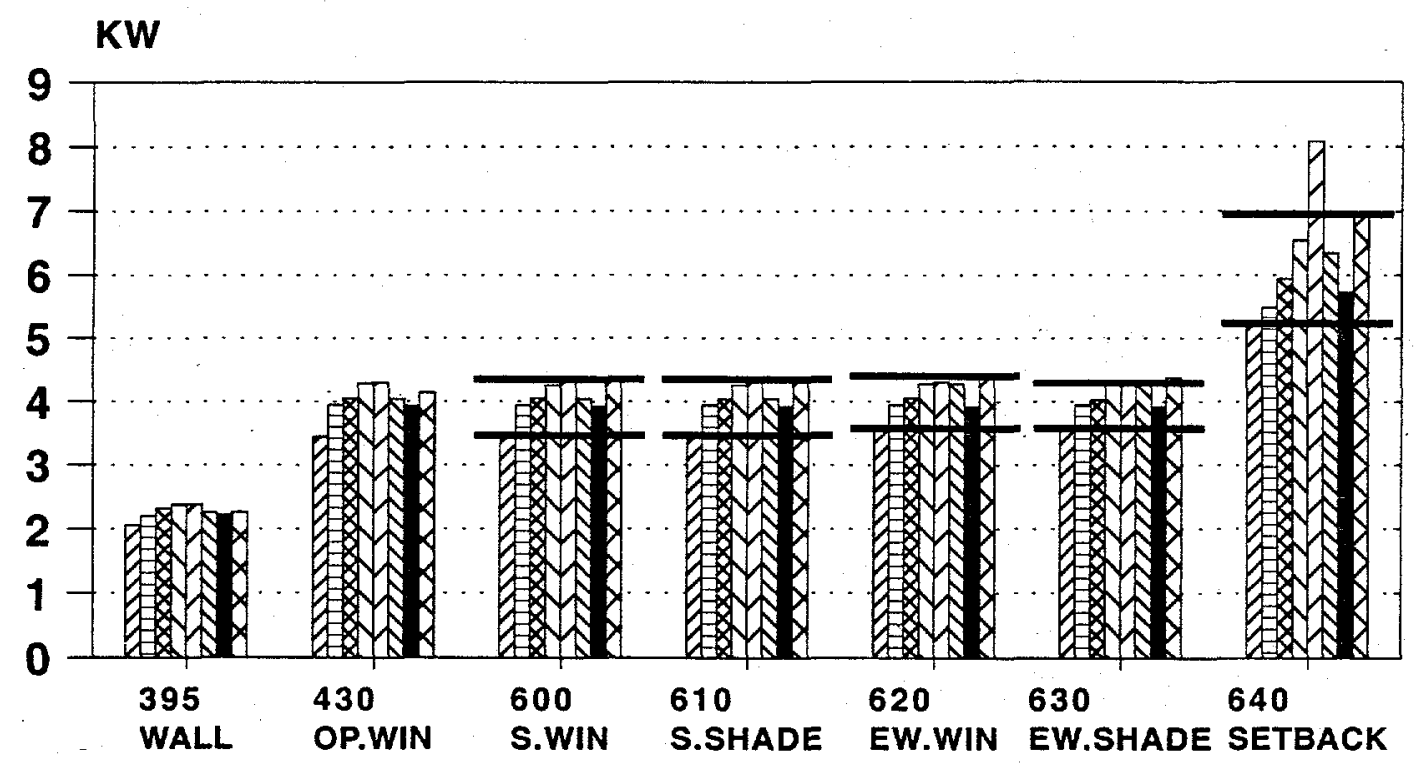

$\square$ ESP-DMU DLAST-USIT DOE2 DSRESISUN



PHLQ7.CH3; JUL 29, 1993

\section{BESTEST QUALIFICATION LOW MASS PEAK COOLING}

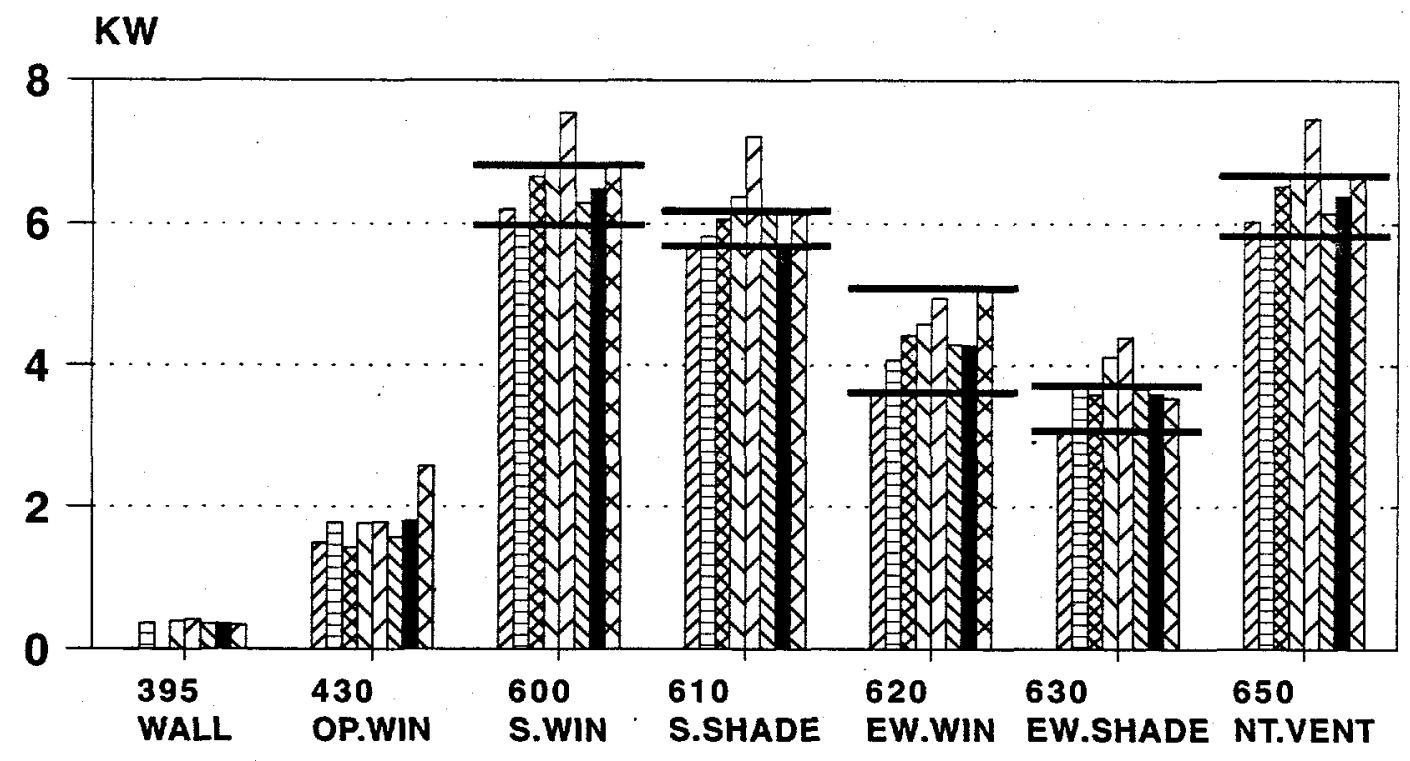

ZESP-DMU 目BLAST-USITT DOE2 $\triangle$ SRES/SUN

$\triangle$ SRES-BRE $\$$ S3PAS $\square$ TSYS-BEL/BRE $\otimes$ TASE 


\section{BESTEST QUALIFICATION HIGH MASS ANNUAL HEATING}

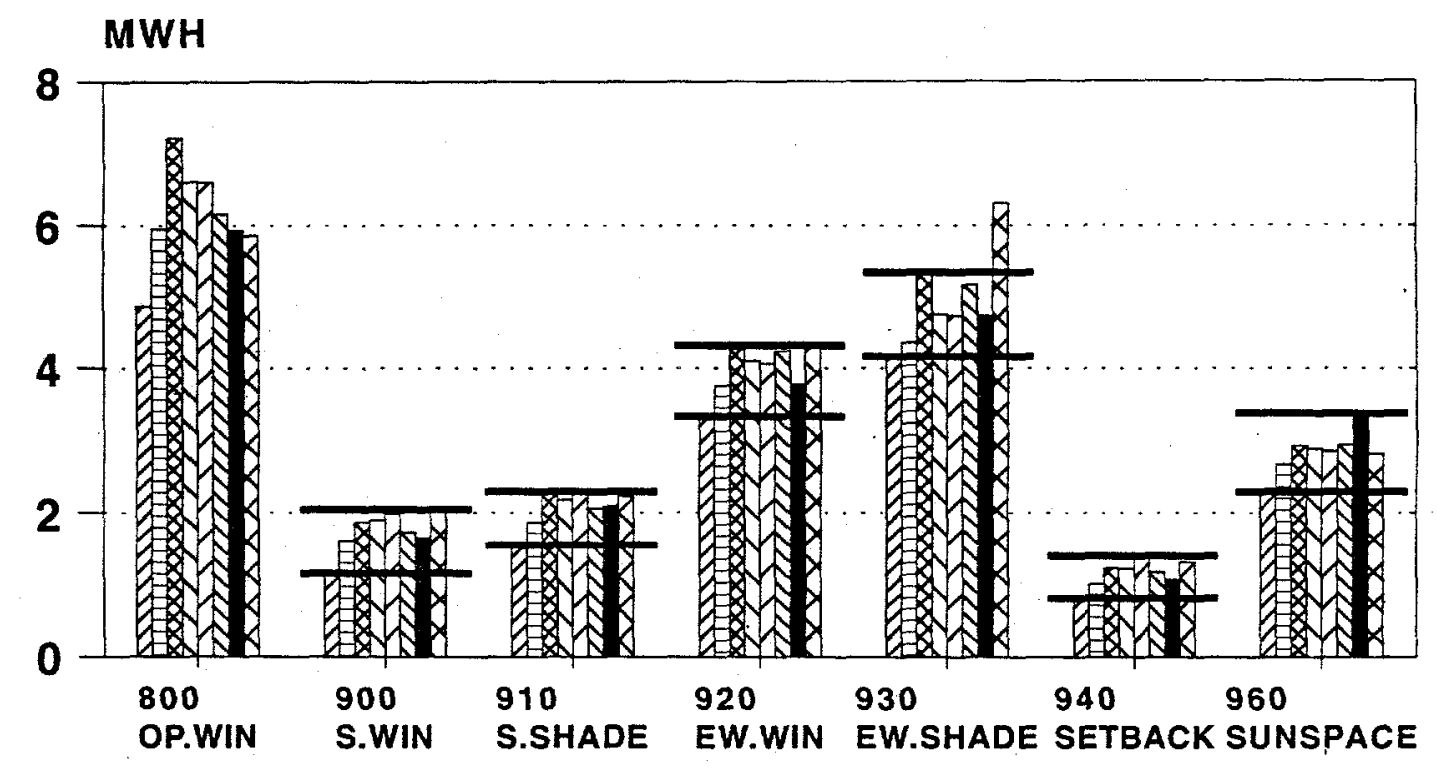
ZESP.DMU
目BLAST-US/IT DOE2
$\triangle$ SRESISUN
$\triangle$ SRES-BRE $\mathbb{Q}$ S3PAS
DTSYS-BEL/BRE $\mathbb{X}$ TASE

АHMO7.CH3; JUL 29. 1993

\section{BESTEST QUALIFICATION HIGH MASS ANNUAL COOLING}






\section{BESTEST QUALIFICATION HIGH MASS PEAK HEATING}



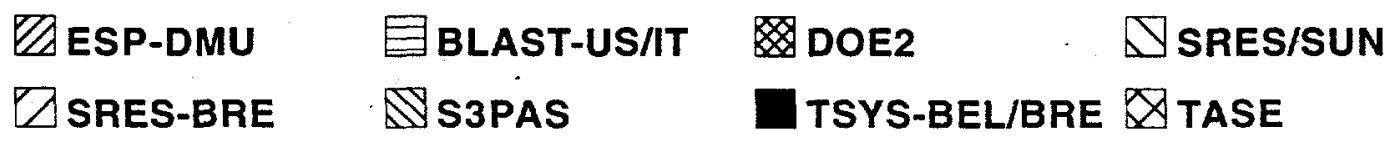

PHMO7.CH3; JUL 29, 1993

\section{BESTEST QUALIFICATION HIGH MASS PEAK COOLING}


ZESP-DMU
目BLAST-US/IT
DOE2
$\triangle$ SRESISUN
$\square$ SRES-BRE NS3PAS
TSYS-BEL/BRE $\mathbb{X}$ TASE 


\section{BESTEST QUALIFICATION MAXIMUM HOURLY ANNUAL TEMPERATURE FREE-FLOAT CASES}

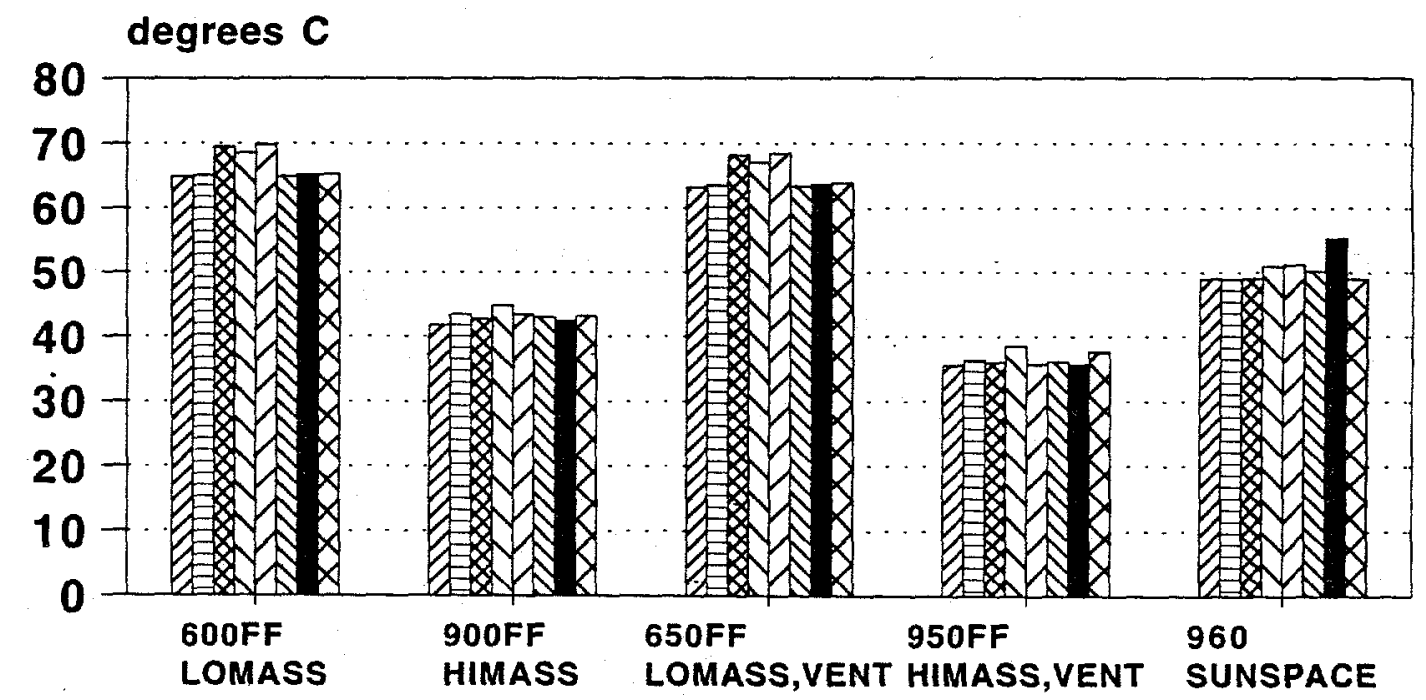
Q $\triangle$ ESP-DMU
目BLAST-US/IT DOE2
$\triangle$ SRES/SUN

¿SRES-BRE $\$$ S3PAS

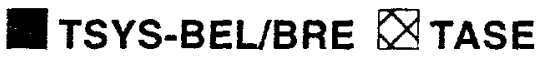

TMAXFFO7.CH3; JUL 22, 1993

\section{BESTEST QUALIFICATION \\ MINIMUM HOURLY ANNUAL TEMPERATURE FREE-FLOAT CASES}


ZESP-DMU
目BLAST-US/IT
DOE2
$\triangle$ SRES/SUN
DSRES-BRE \$SBPAS
TSYS-BEL/BRE $\otimes$ TASE 


\section{BESTEST QUALIFICATION AVERAGE HOURLY ANNUAL TEMPERATURE FREE-FLOAT CASES}

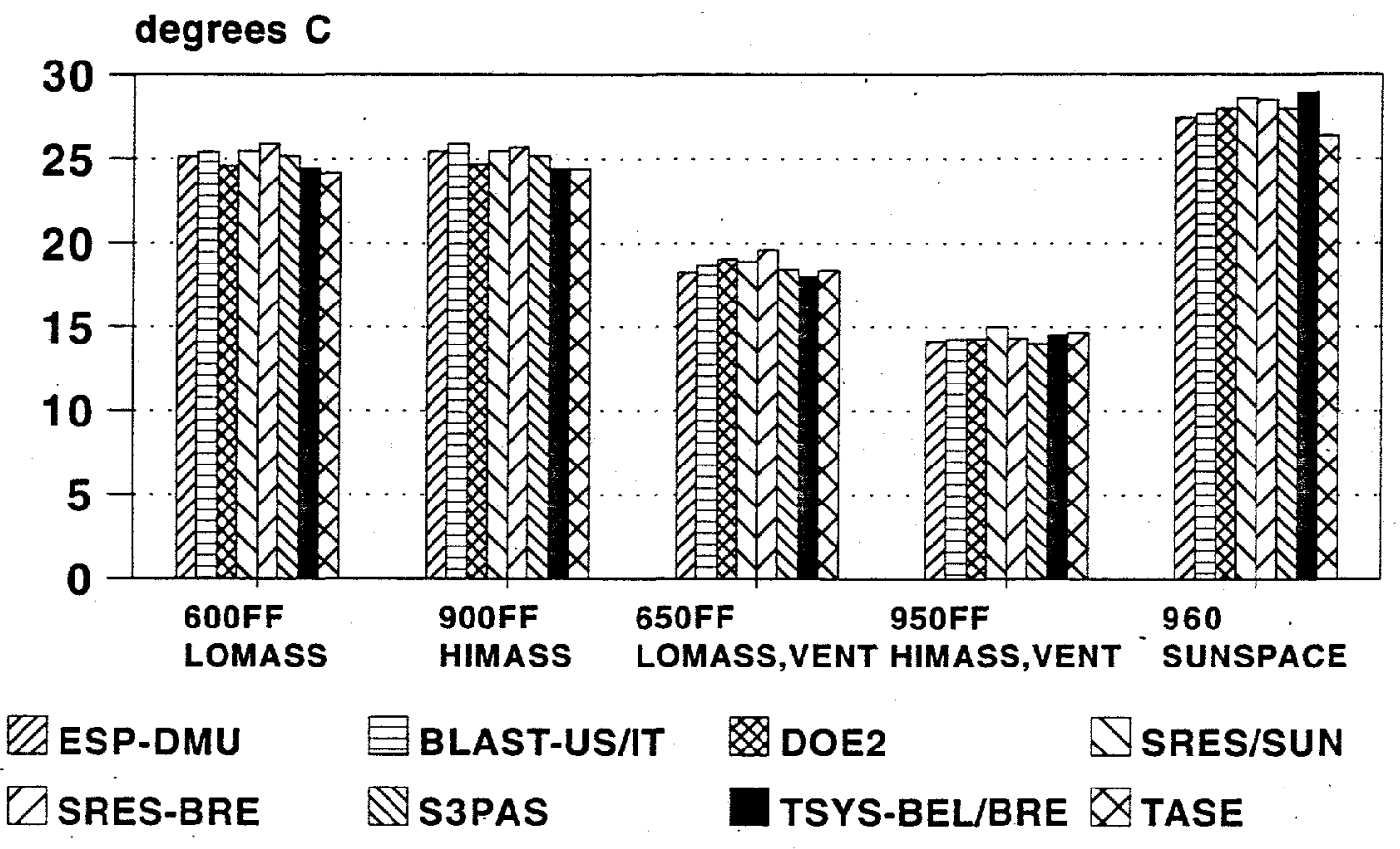

TAYGFFQ7,CH3; JUL 22, 1993 
This page intentionally left blank 


\section{BESTEST QUALIFICATION SOUTH WINDOW SHADING (DELTA) ANNUAL HEATING AND COOLING}

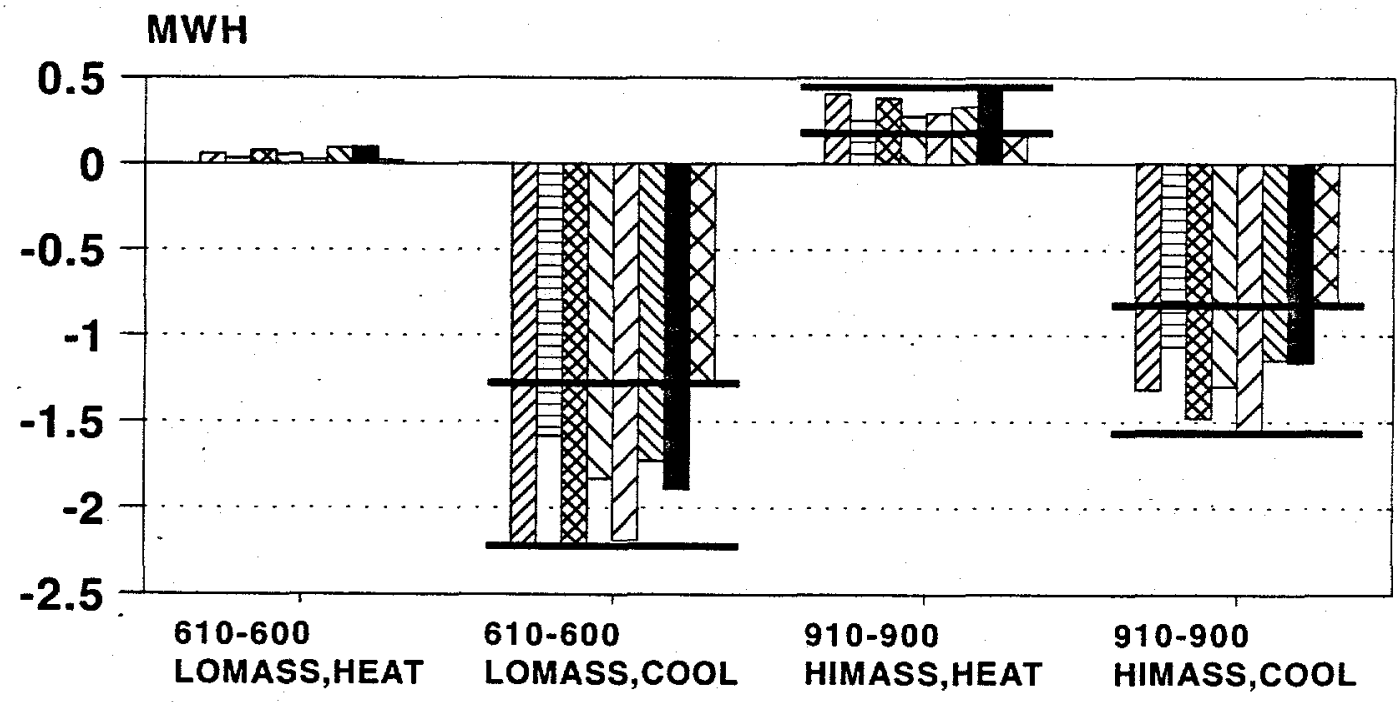

ZESP-DMU 目BLAST-USIT DOE2 DSRESISUN

$\triangle$ SRES-BRE $\$$ S3PAS DASSO7.CH3; JUL 29, 1993

\section{BESTEST QUALIFICATION SOUTH WINDOW SHADING (DELTA) PEAK HEATING AND COOLING}

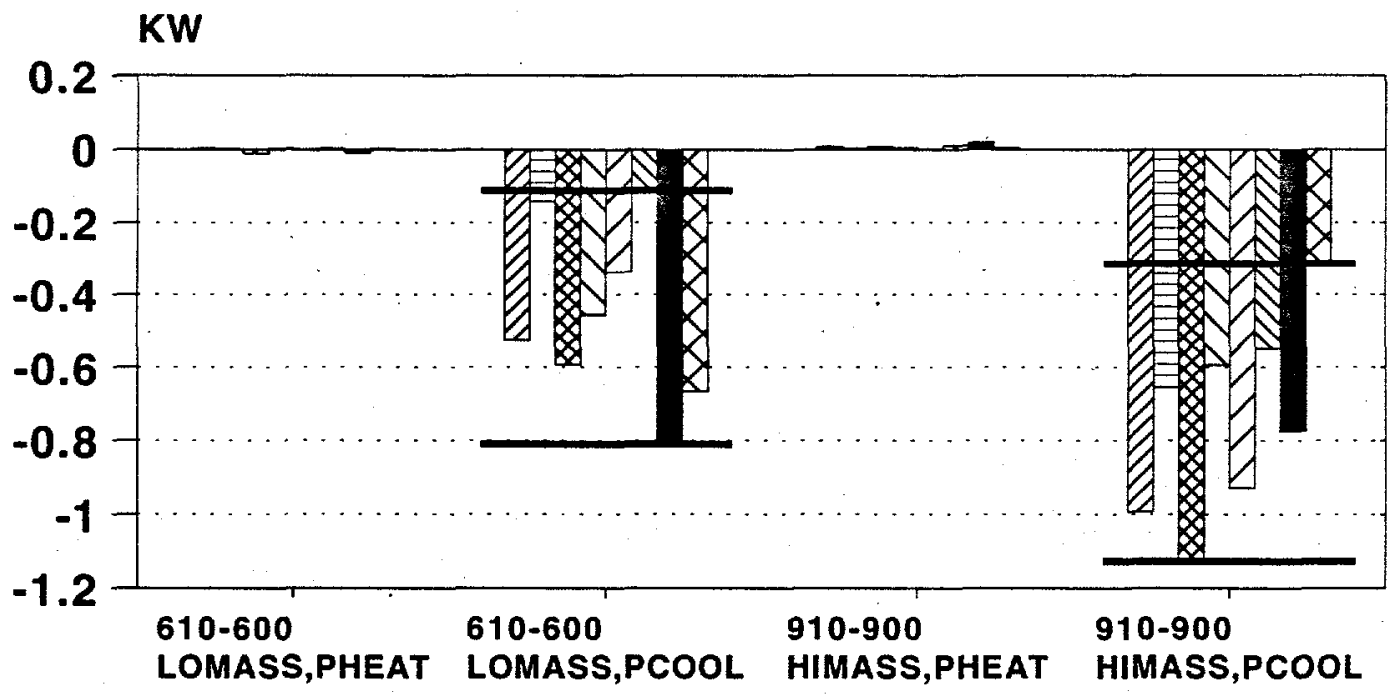
QESP-DMU
目BLAST-US/IT
DOE2
$\triangle$ SRESISUN
$\triangle$ SRES-BRE
Ss3PAS
TSYS-BEL/BRE $\otimes$ TASE 


\section{BESTEST QUALIFICATION EAST \& WEST WINDOW (DELTA) ANNUAL HEATING AND COOLING}

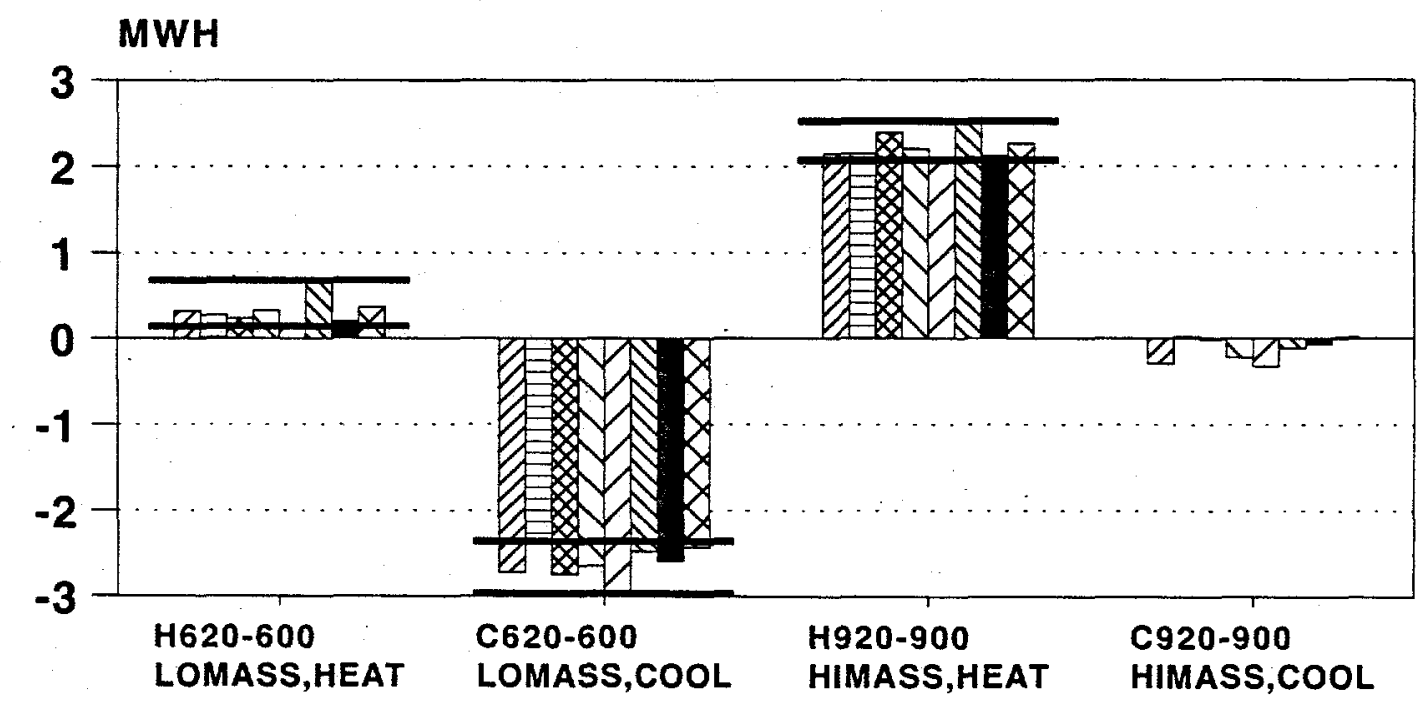

QESP-LP DOEL DST-US/IT DSRESISUN

DSRES-BRE $\$$ STPAS

\section{BESTEST QUALIFICATION EAST \& WEST WINDOW (DELTA) PEAK HEATING AND COOLING}

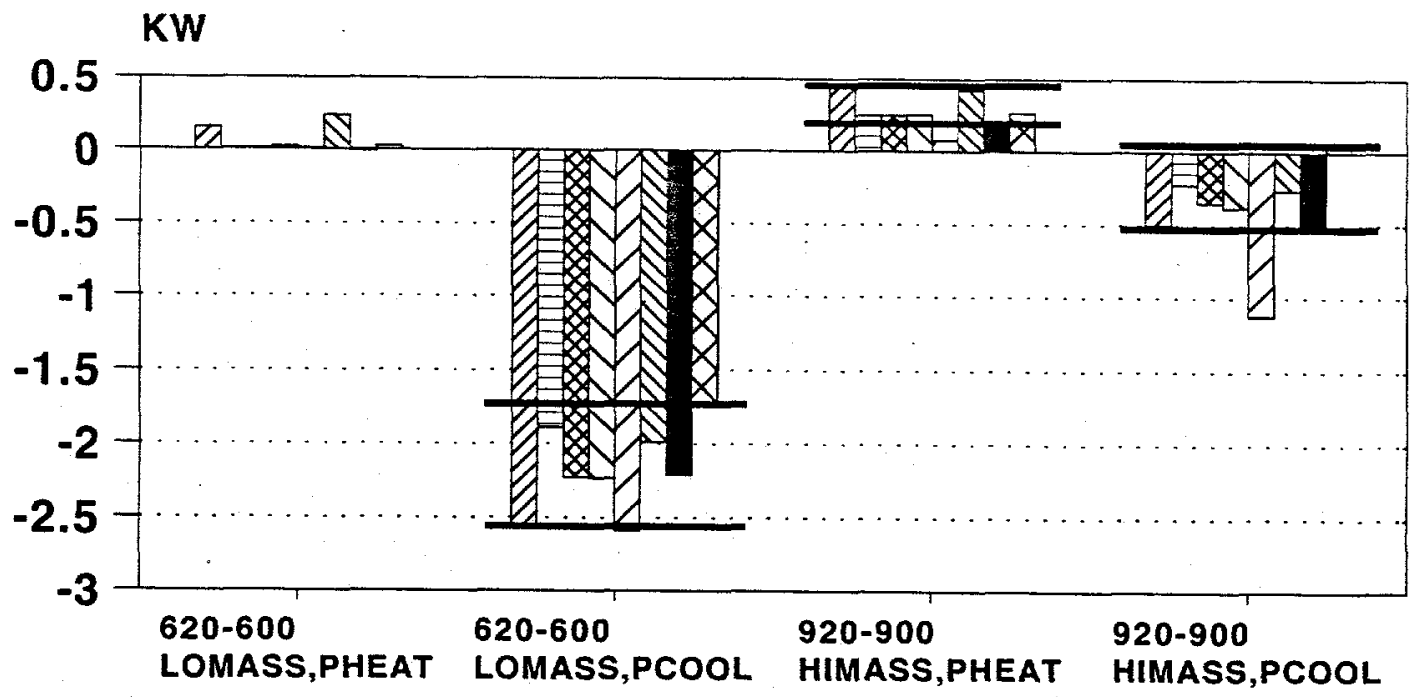

שESP-DMU 目BLAST-US/IT DOE2

$\triangle$ SRES/SUN

$\triangle$ SRES-BRE NS3PAS 


\section{BESTEST QUALIFICATION EAST \& WEST SHADED WINDOW (DELTA) ANNUAL HEATING AND COOLING}

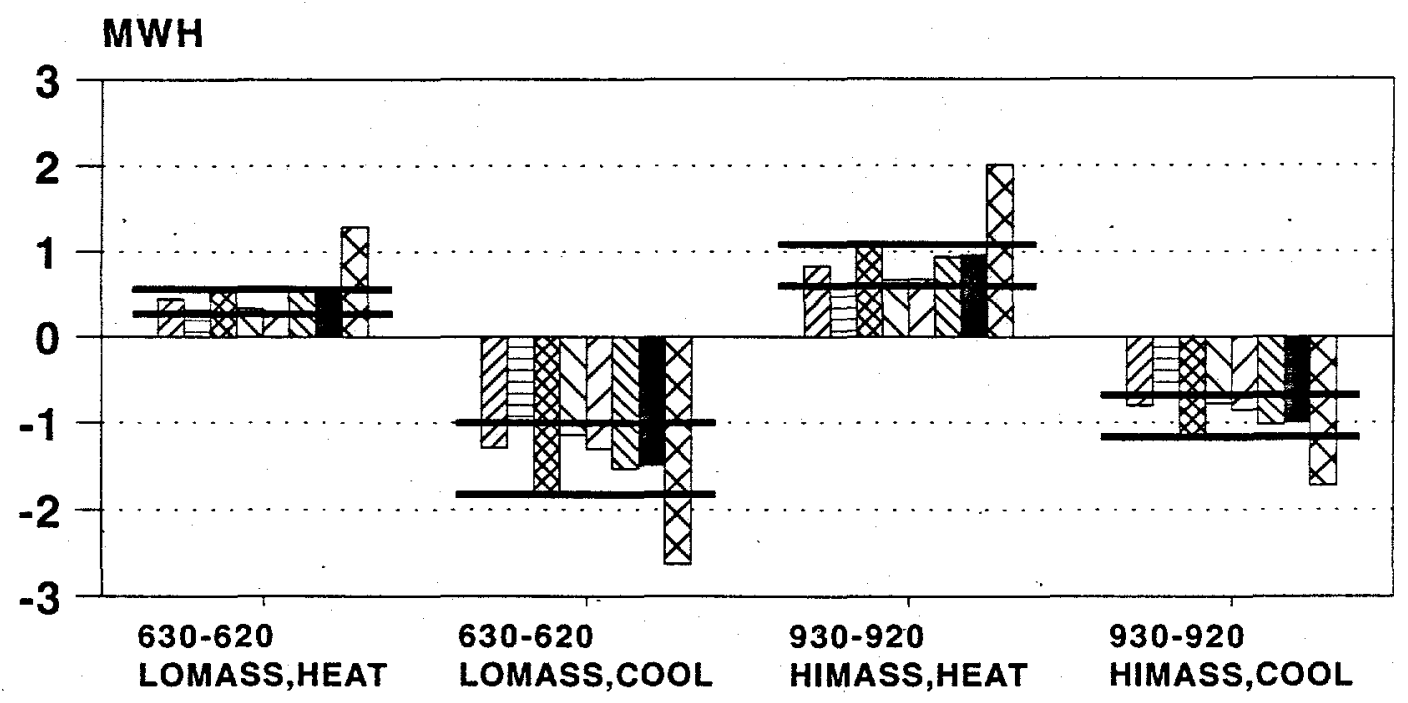

ZESP-LP $⿴ 囗 十$ BLAST-US/IT DOE2 DSRES/SUN

$\triangle$ SRES-BRE $\mathrm{NS}$ SPASASYS-BEL/BRE

\section{BESTEST QUALIFICATION EAST \& WEST SHADED WINDOW (DELTA) PEAK HEATING AND COOLING}

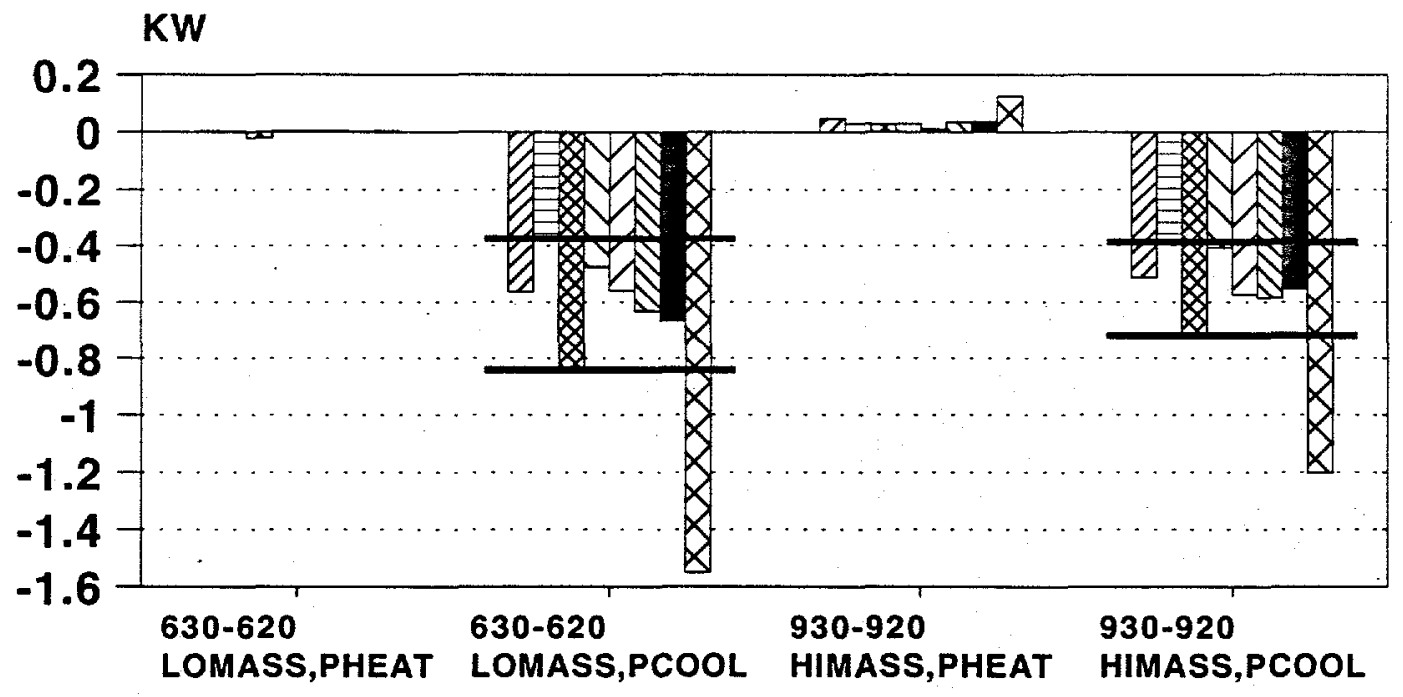
ZESP-DMU
目BLAST-US/IT
DOE2
$\triangle$ SRES/SUN

$\triangle$ SRES-BRE $\mathbb{Q}$ S3PAS

DTSYS-BEL/BRE 8 TASE 


\section{BESTEST QUALIFICATION THERMOSTAT SETBACK (DELTA) ANNUAL HEATING}

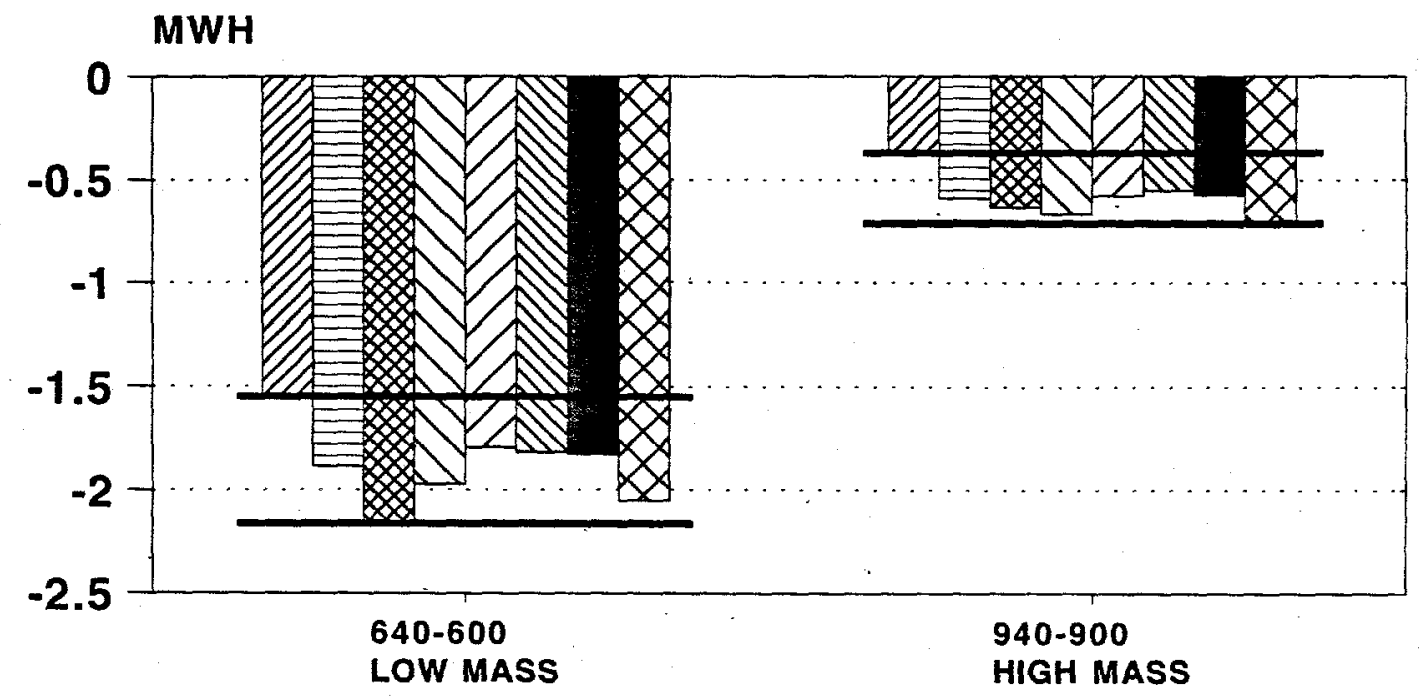

ZESP-DMU DLAST-US/IT DOE2

$\triangle$ SRES-BRE $\$$ S3PAS DAsBa7.CH3; JUL 29, 1993

\section{BESTEST QUALIFICATION THERMOSTAT SETBACK (DELTA) PEAK HEATING}

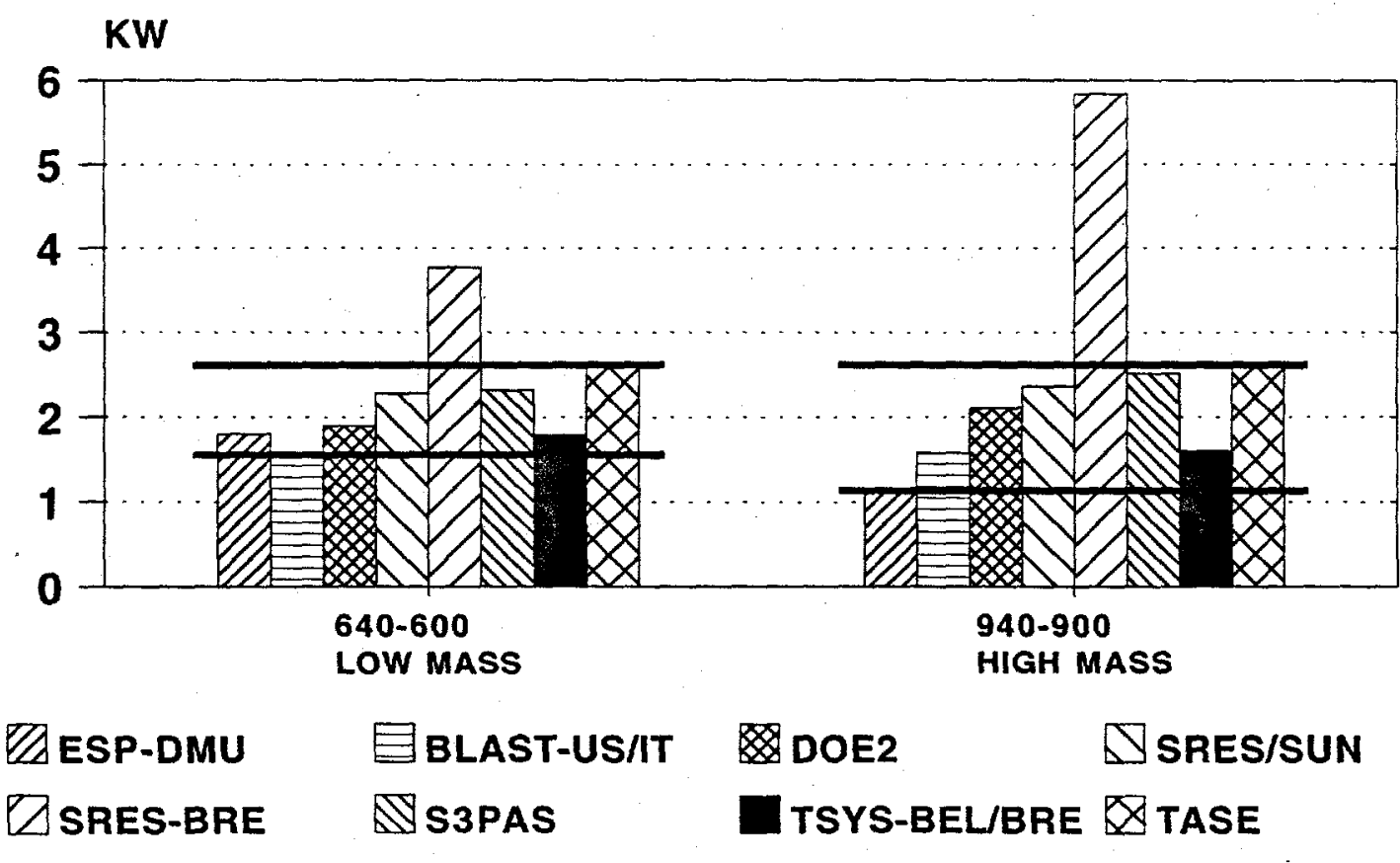




\section{BESTEST QUALIFICATION VENT COOLING (DELTA) ANNUAL COOLING}

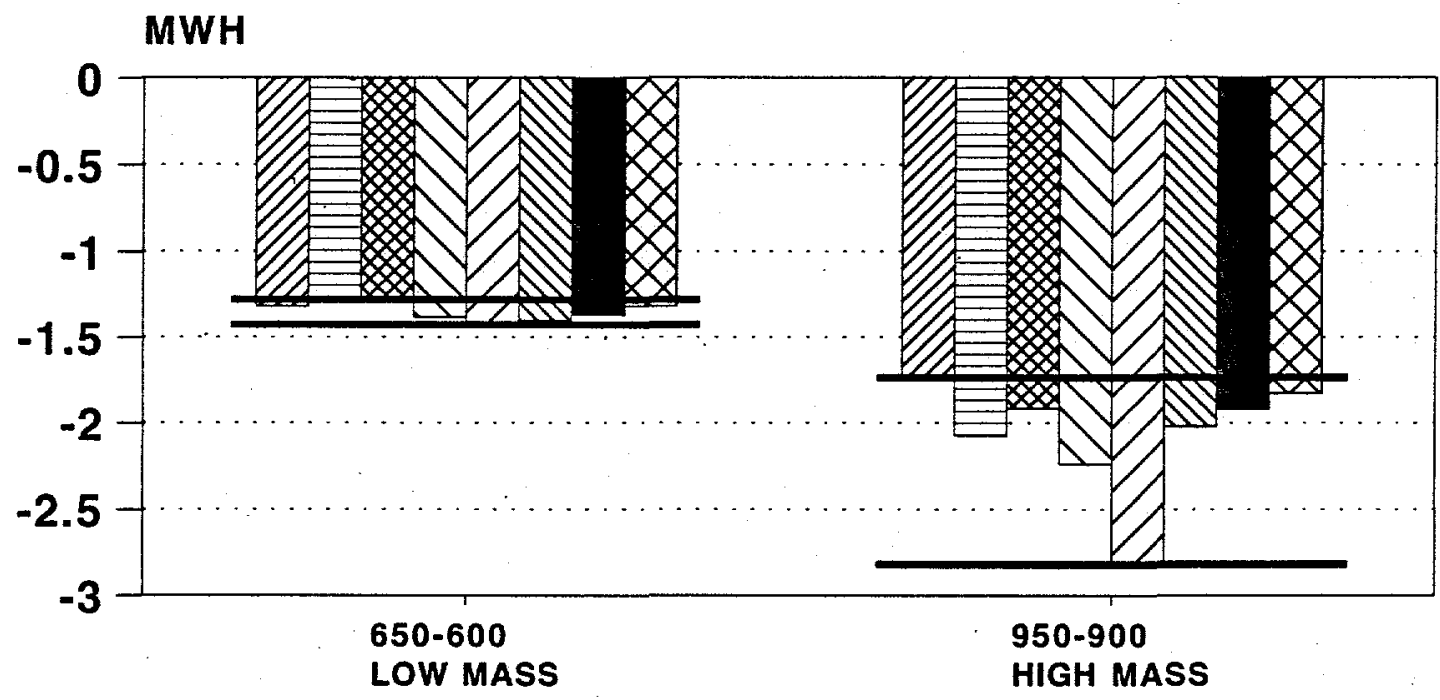

ZESP-DMU 目BLAST-US/IT DOE2 $\nabla$ SRES/SUN

$\triangle$ SRES-BRE $\$$ S3PAS $\square$ TSYS-BEL/BRE $\bigotimes$ TASE DAVQ7.CH3; JUL 29, 1993

\section{BESTEST QUALIFICATION VENT COOLING (DELTA) PEAK COOLING}

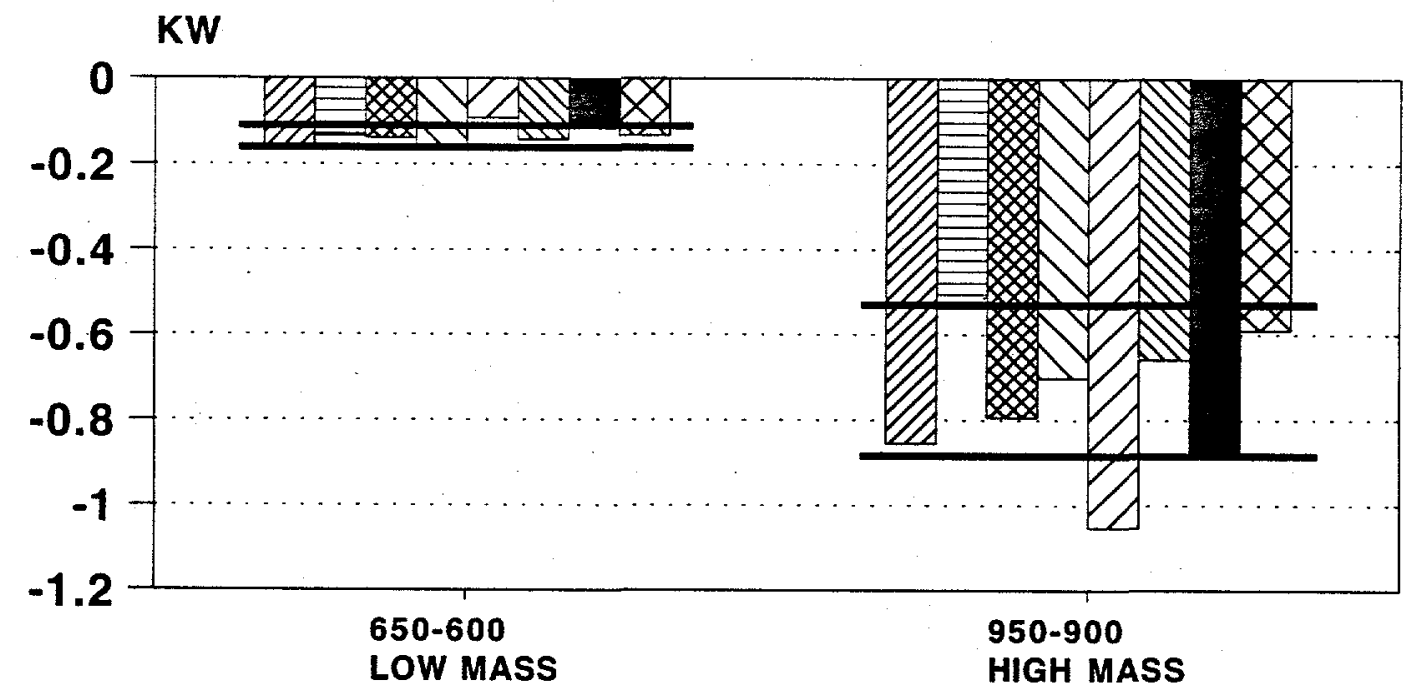
ZESP-DMU
目BLAST-US/IT
DOE2
$\triangle$ SRES/SUN
$\triangle$ SRES-BRE $\mathbb{Q}$ S3PAS
DTSYS-BEL/BRE $\otimes$ TASE 


\section{BESTEST QUALIFICATION SUNSPACE (DELTA) ANNUAL HEATING AND COOLING}

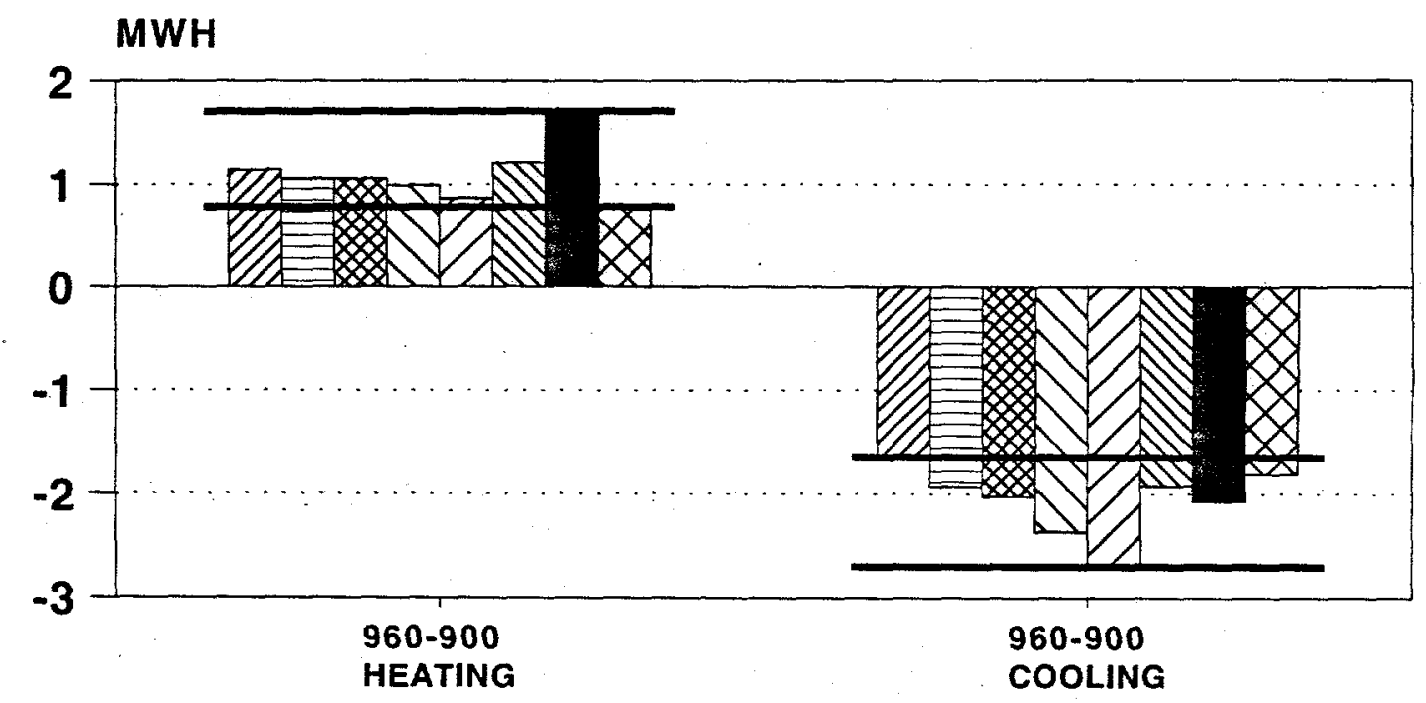

ZESP-DMU 目BLAST-US/IT DOE2 $\nabla$ SRESISUN

$\triangle$ SRES-BRE $\$$ S3PAS DAST.CH3; AUG 2, 1993

\section{BESTEST QUALIFICATION SUNSPACE (DELTA) PEAK HEATING AND COOLING}

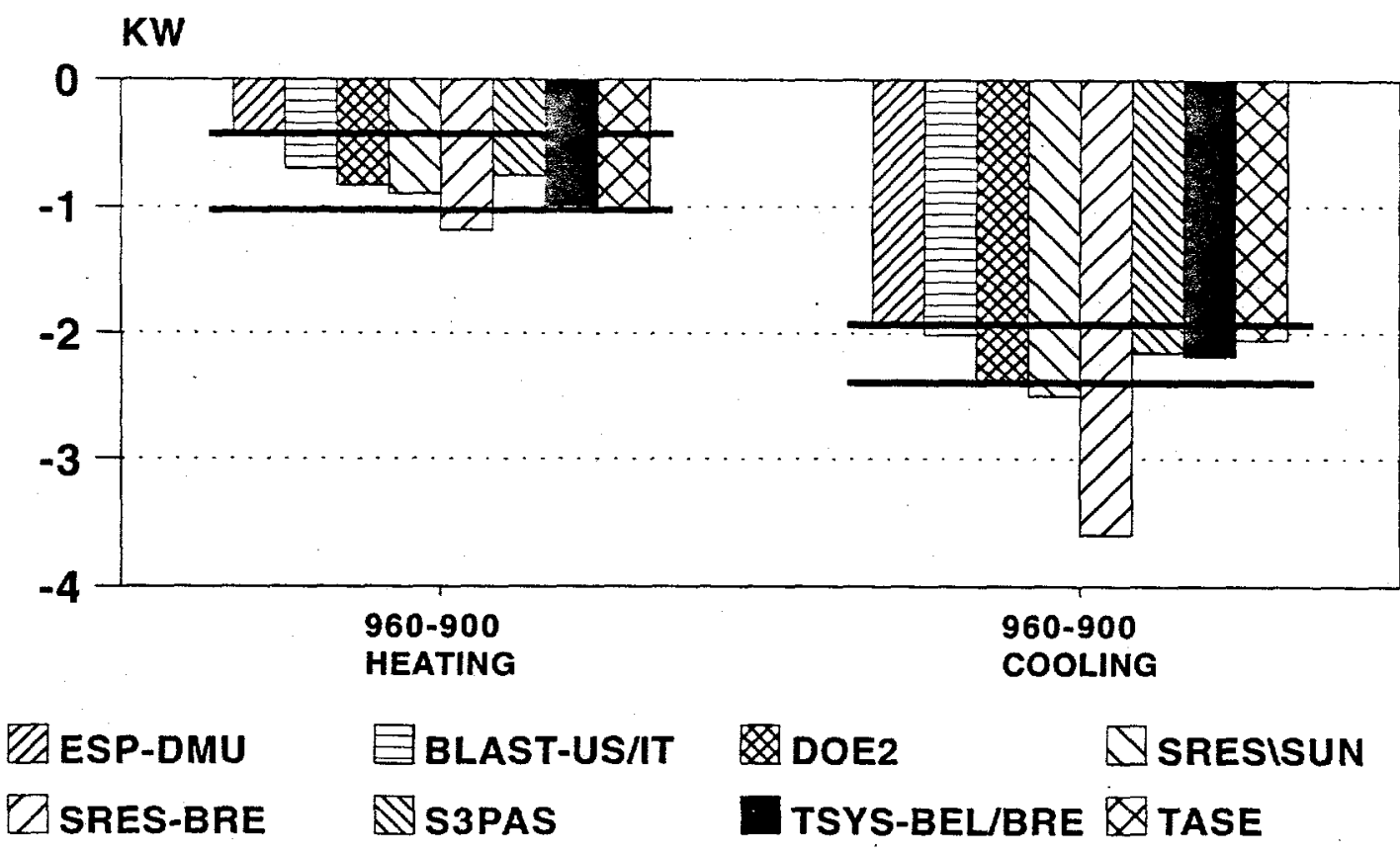


This page intentionally left blank 


\section{GROUND COUPLING ANNUAL HEATING AND COOLING}

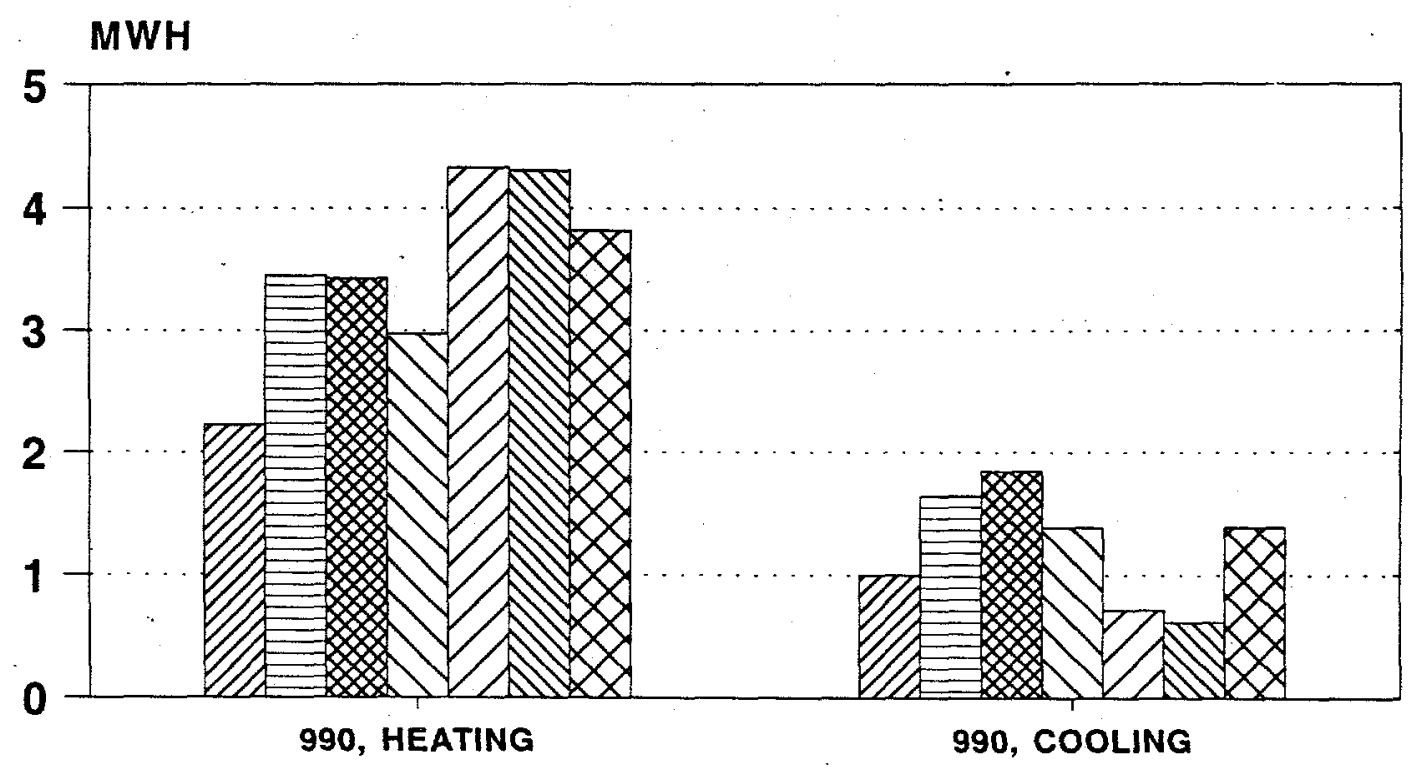

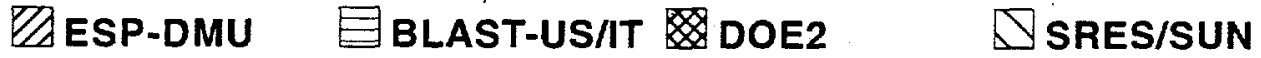

$\triangle$ SRES-BRE $\triangle$ S3PAS $\$ TASE

990A7.CH3; JUL 30. 1993

\section{GROUND COUPLING PEAK HEATING AND COOLING}



QESP-DMU 目BLAST-US/IT DOE2 $\triangle$ SRES-BRE $\$$ S3PAS 


\section{BESTEST \\ GROUND COUPLING (DELTA) ANNUAL HEATING AND COOLING}

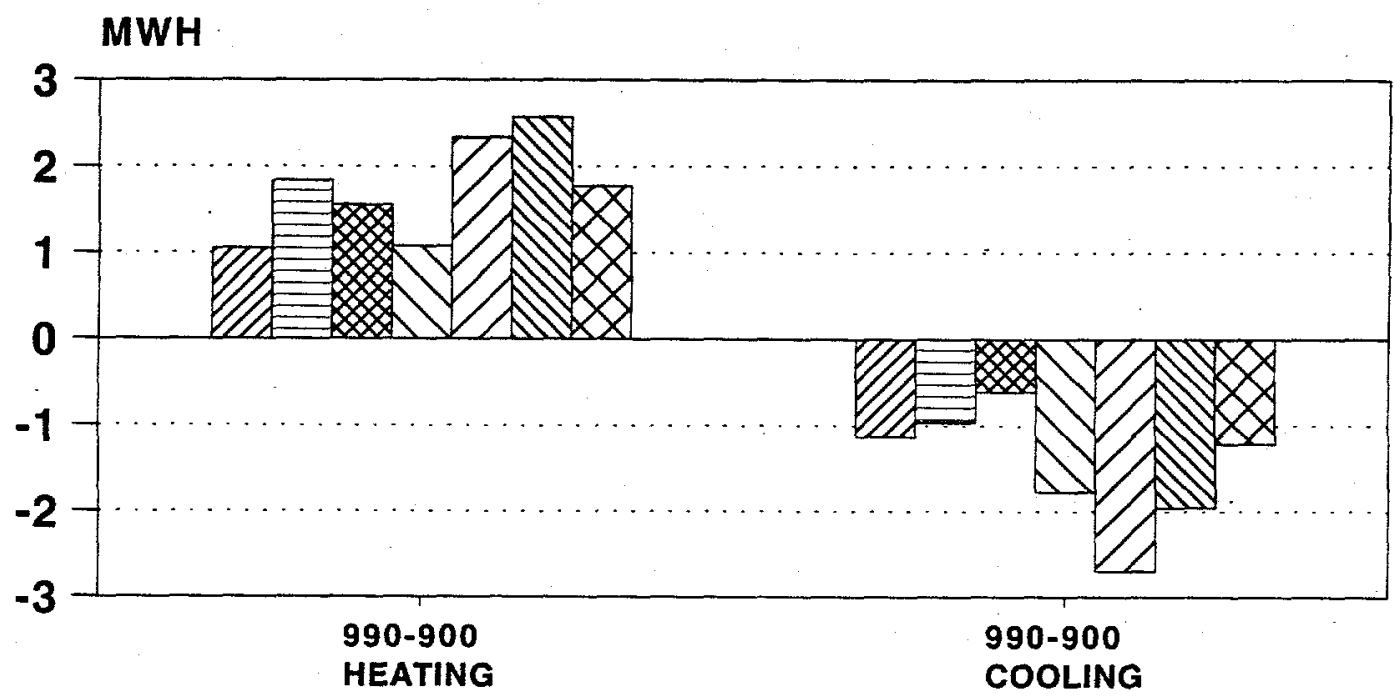

『ESP-DMU 目BLAST-US/TT DOE2 : DSRES/SUN

$\square$ SRES-BRE $\triangle$ STPAS

\section{BESTEST \\ GROUND COUPLING (DELTA) PEAK HEATING AND COOLING}

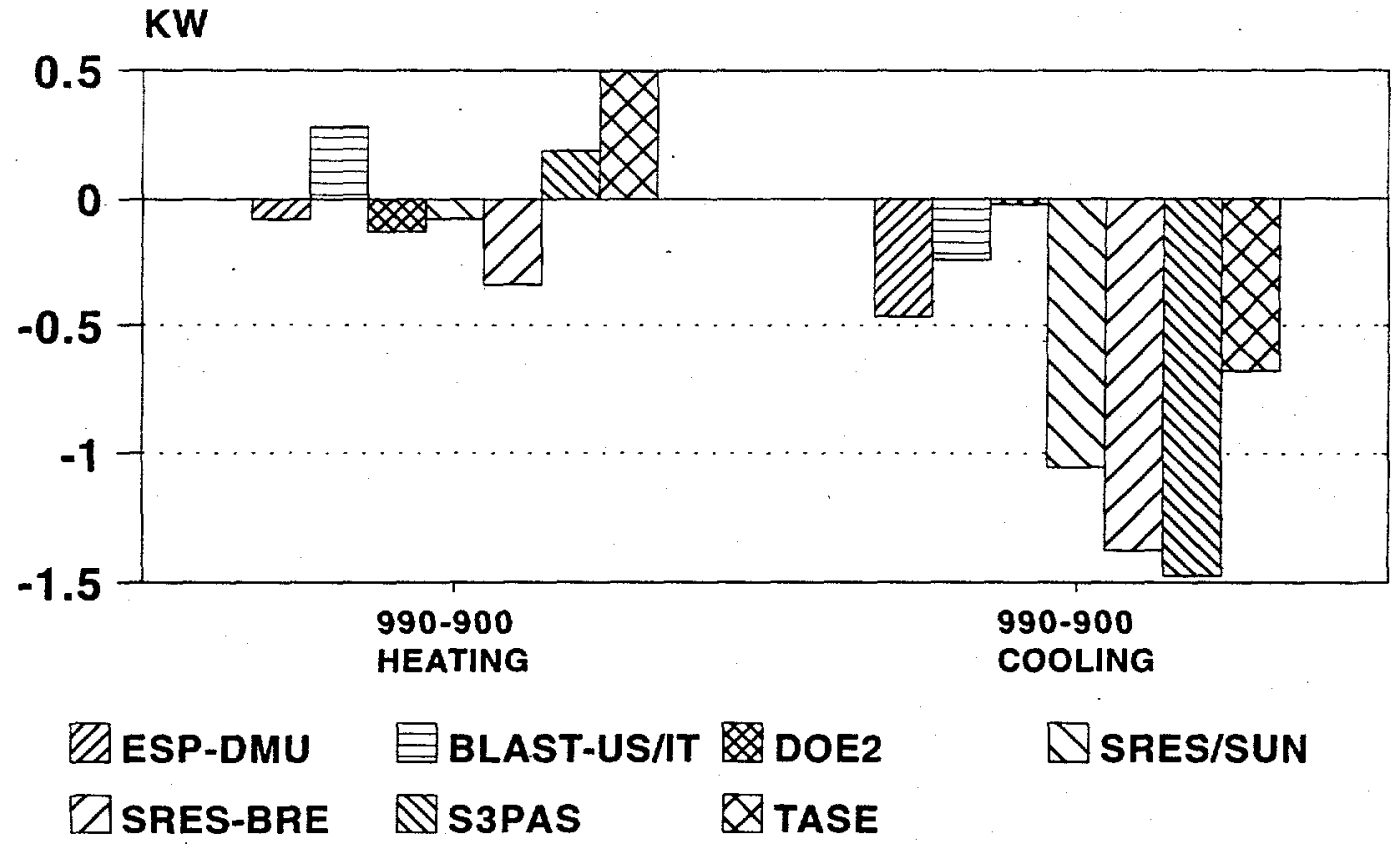


BESTEST QUALIFICATION AND DIAGNOSTICS

\section{MASS EFFECT (DELTA) \\ ANNUAL HEATING AND COOLING}

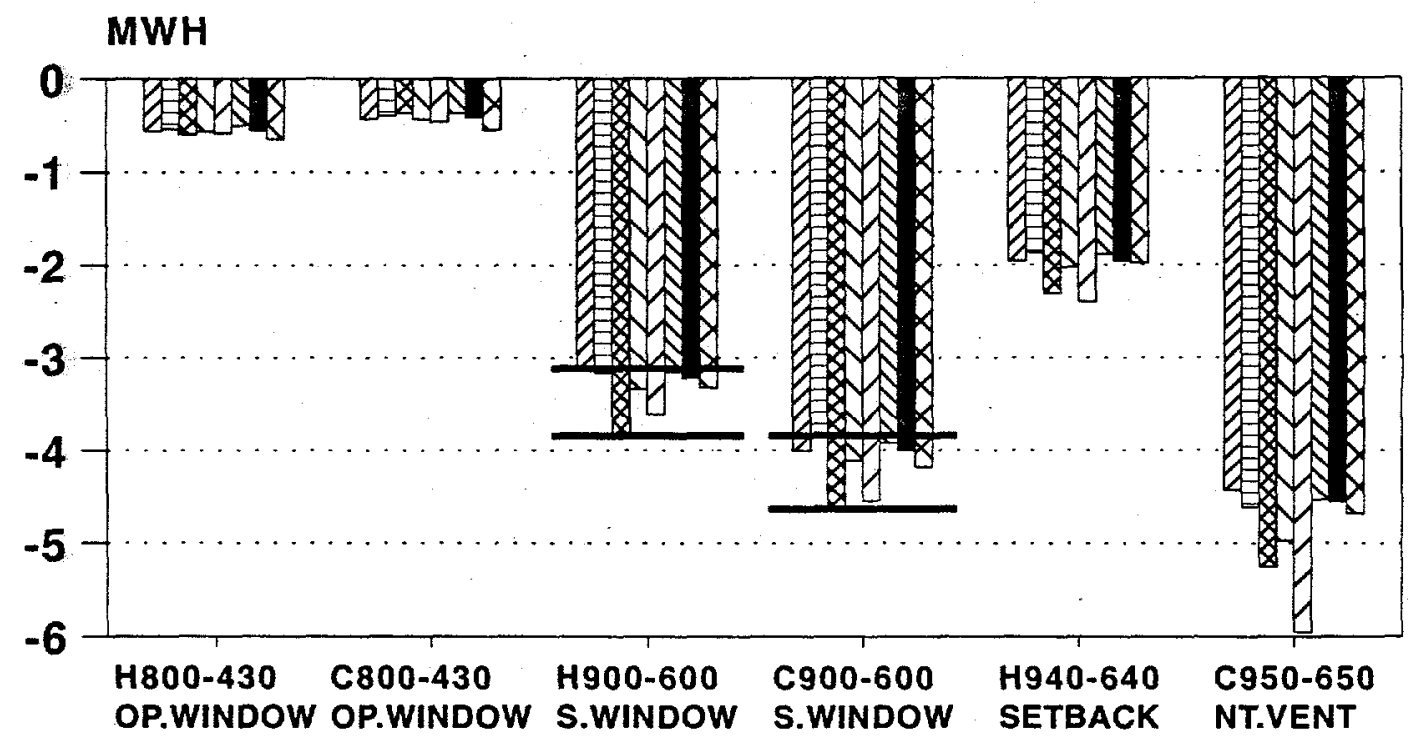

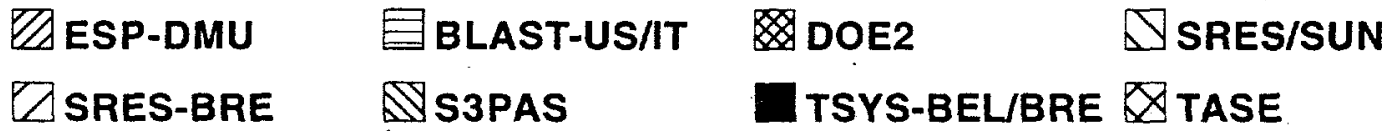

DAMX7.CH3; JAN 21, 1094

\section{BESTEST QUALIFICATION AND DIAGNOSTICS MASS EFFECT (DELTA) PEAK HEATING AND COOLING}

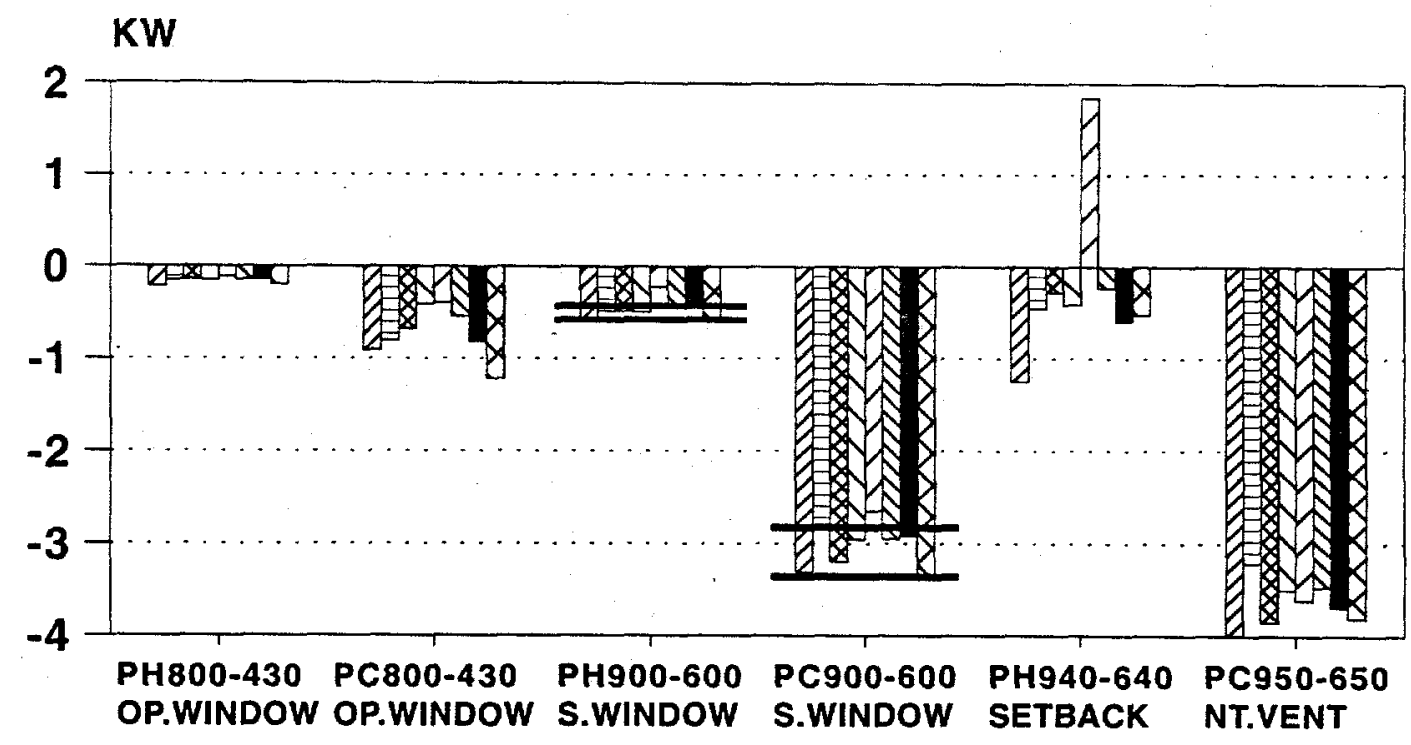
שESP-DMU
目BLAST-US/IT
DOE2
$\triangle$ SRES/SUN
$\triangle$ SRES-BRE
Ns3PAs
TSYS-BEL/BRE $\bigotimes$ TASE 


\section{BESTEST DIAGNOSTICS SOUTH WINDOW (DELTA) ANNUAL HEATING AND COOLING}

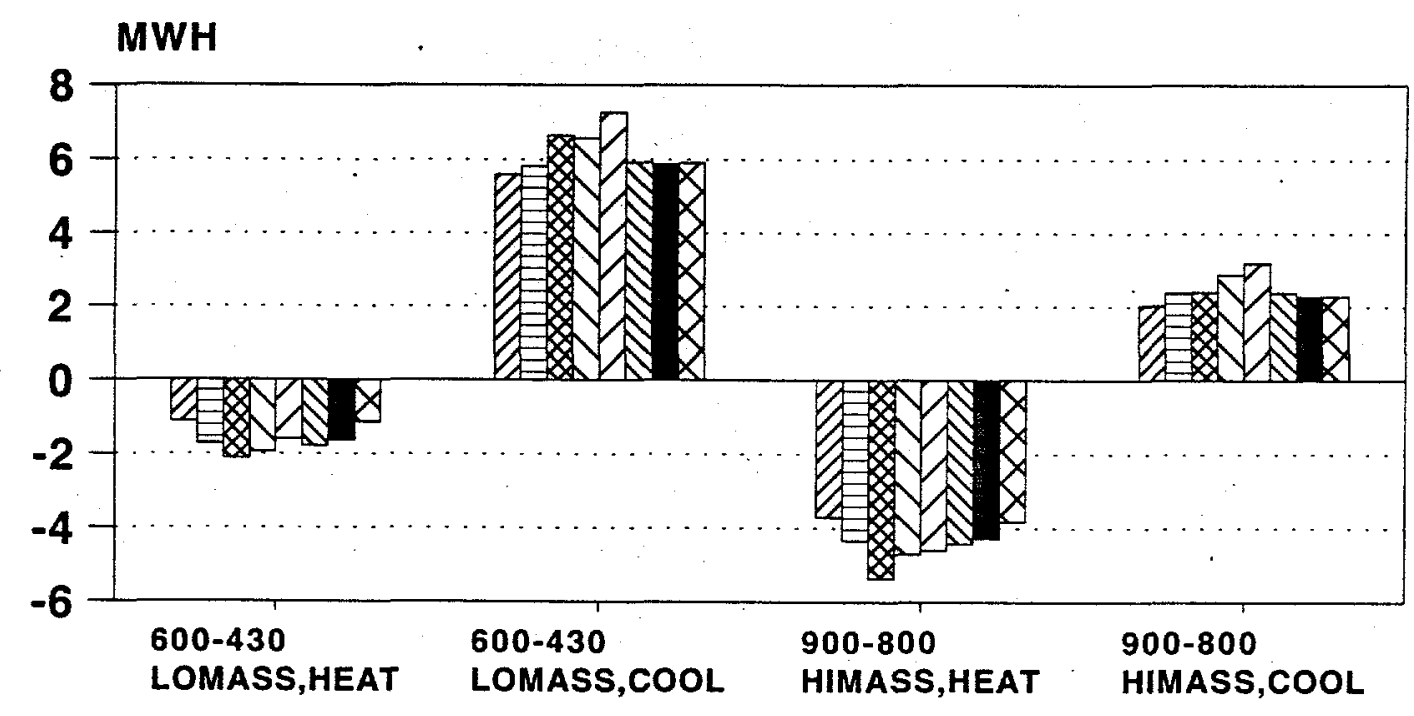

ZESP-DMU 目BLAST-US/TT DOE2 DSRESISUN

$\triangle$ SRES-BRE $\triangle$ S3PAS

\section{BESTEST DIAGNOSTICS SOUTH WINDOW (DELTA) PEAK HEATING AND COOLING}

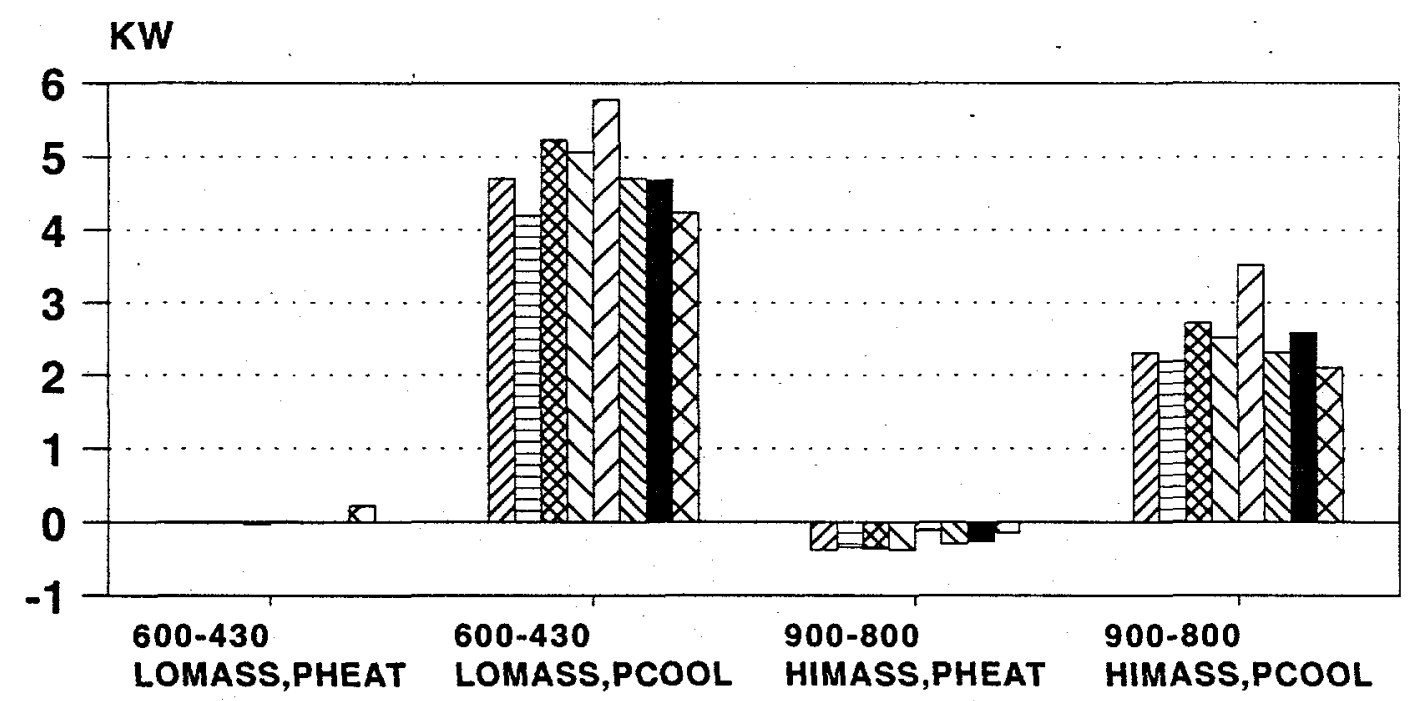

ZIESP-DMU 目BLAST-US/TT DOE2

$\triangle$ SRES-BRE $\$$ STPAS 


\section{BESTEST DIAGNOSTICS \\ LOW MASS ANNUAL HEATING (A) PRIMITIVE CASES (195 TO 250)}

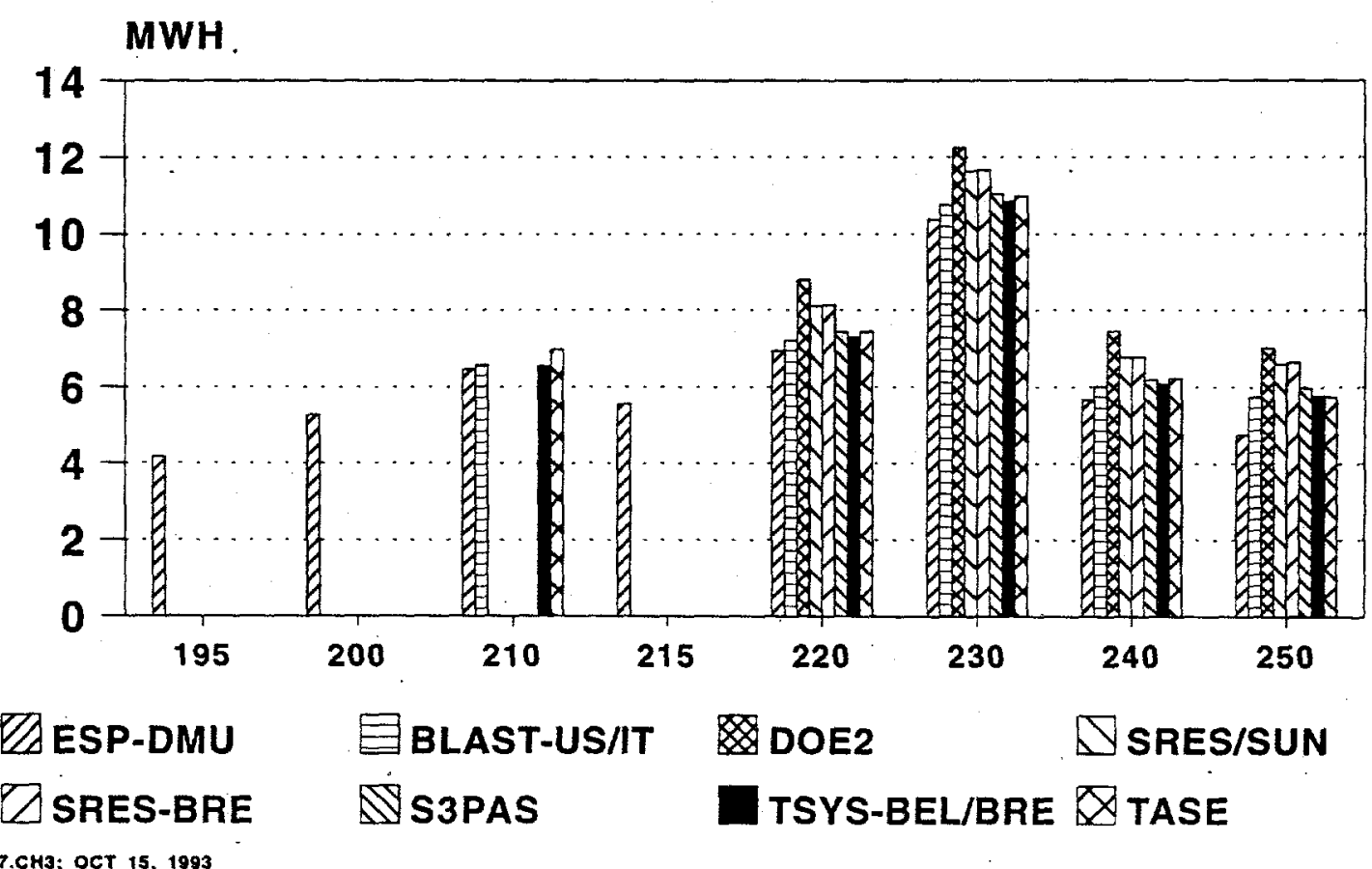

AHLXA1-7.CH3; OCT 15, 1993

\section{BESTEST DIAGNOSTICS LOW MASS ANNUAL COOLING (A) PRIMITIVE CASES (195 TO 250)}

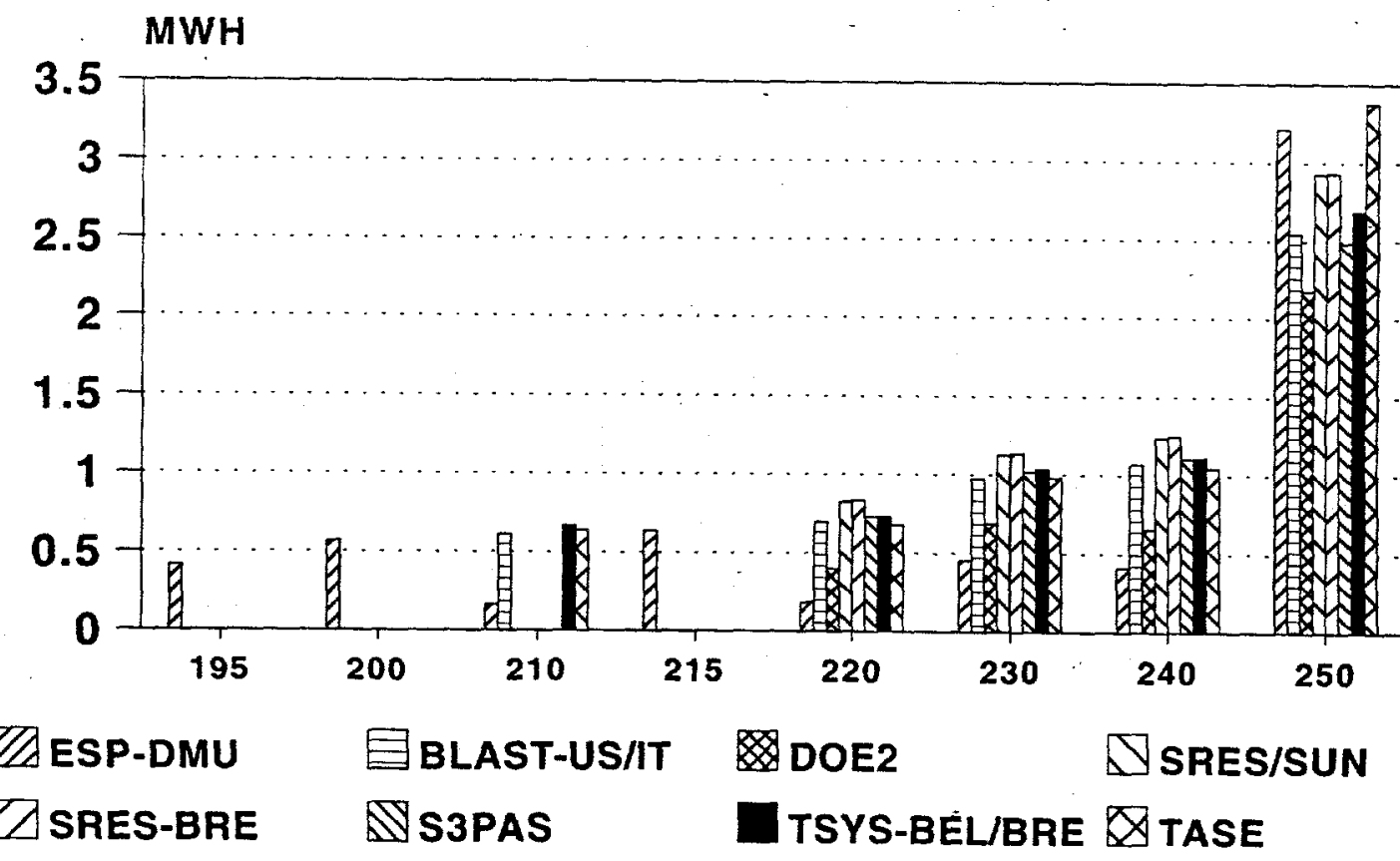




\section{BESTEST DIAGNOSTICS LOW MASS PEAK HEATING (A) PRIMITIVE CASES (195 TO 250)}

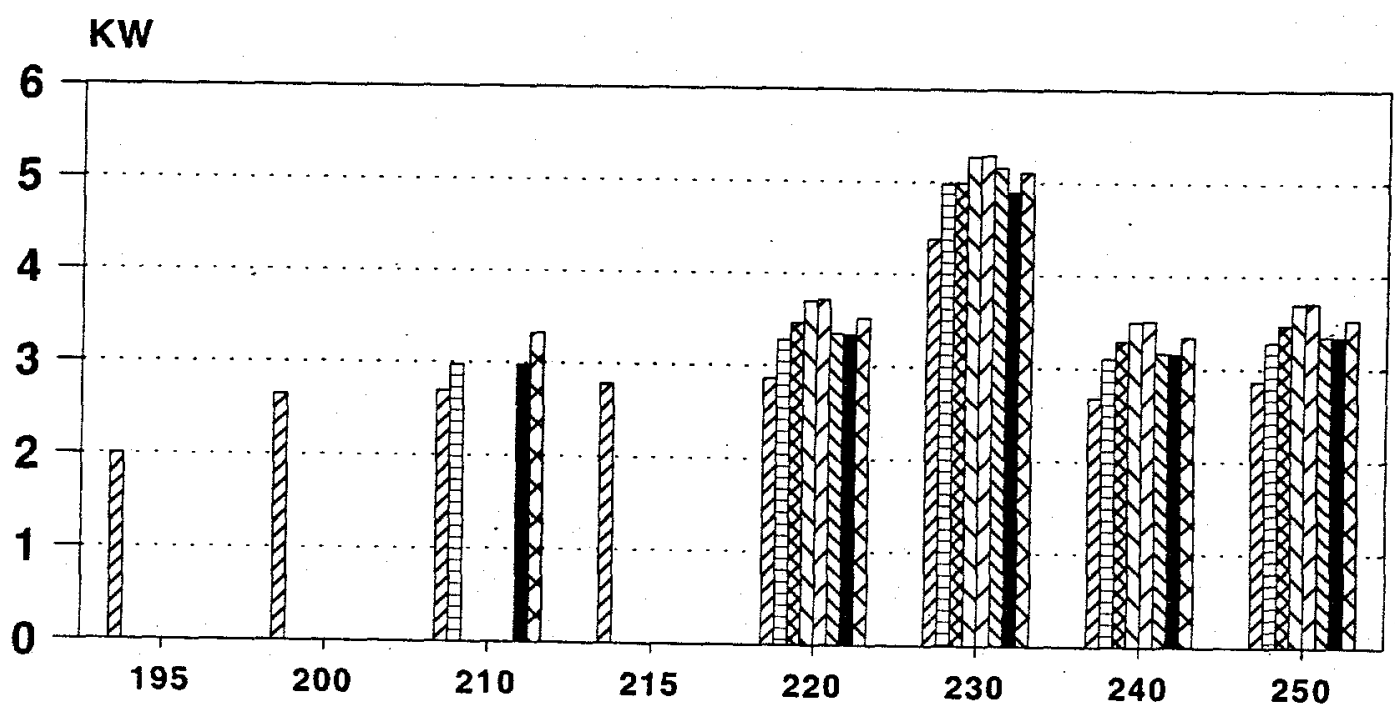

VESP-DMU 圈BLAST-US/IT DOE2 DSRESISUN

$\square$ SRES-BRE $\quad$ STSPSS-BEL/BRE $\triangle$ TASE

\section{BESTEST DIAGNOSTICS LOW MASS PEAK COOLING (A) PRIMITIVE CASES (195 TO 250)}

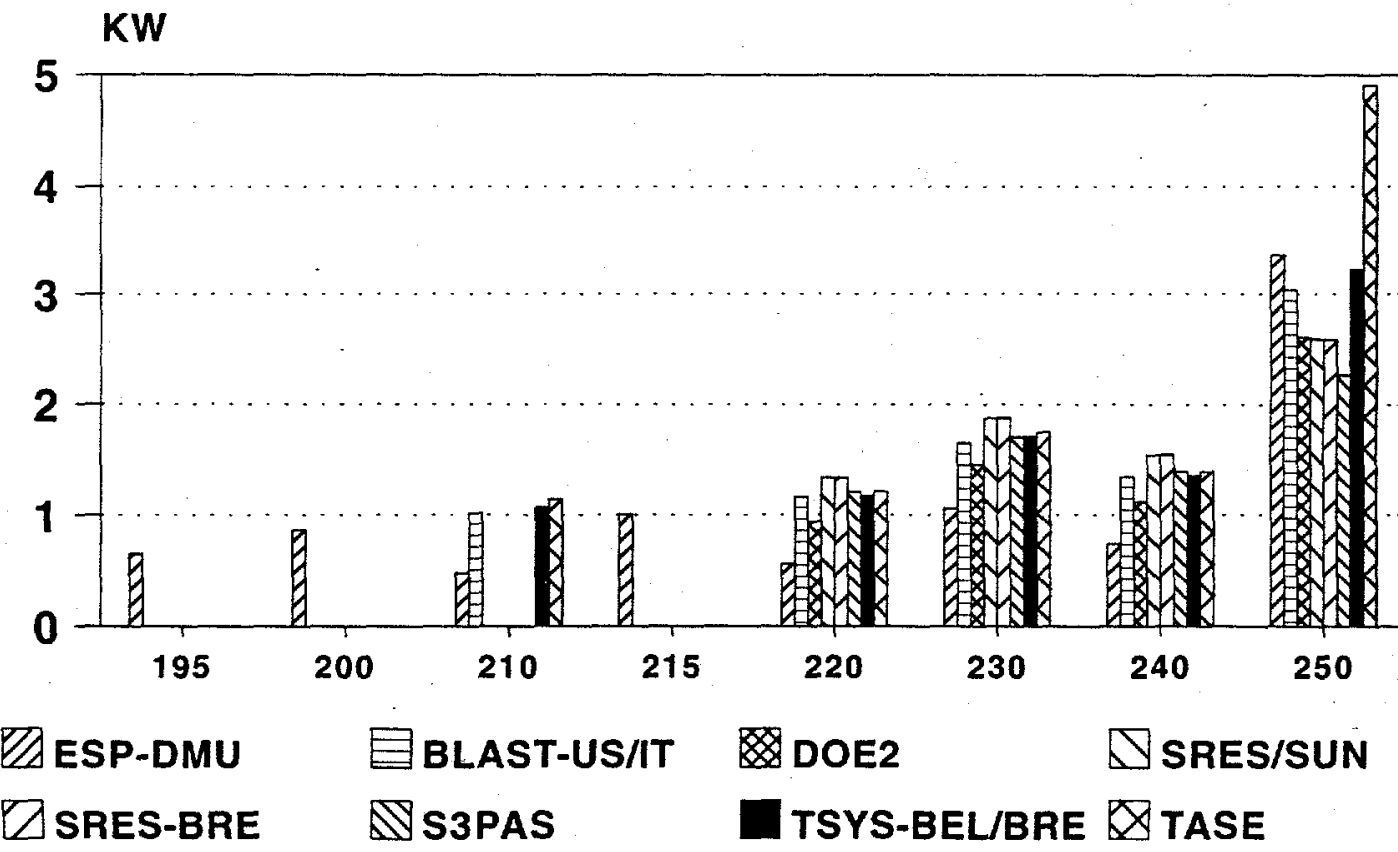




\section{BESTEST DIAGNOSTICS \\ LOW MASS ANNUAL HEATING (A) PRIMITIVE CASES (270 TO 320)}

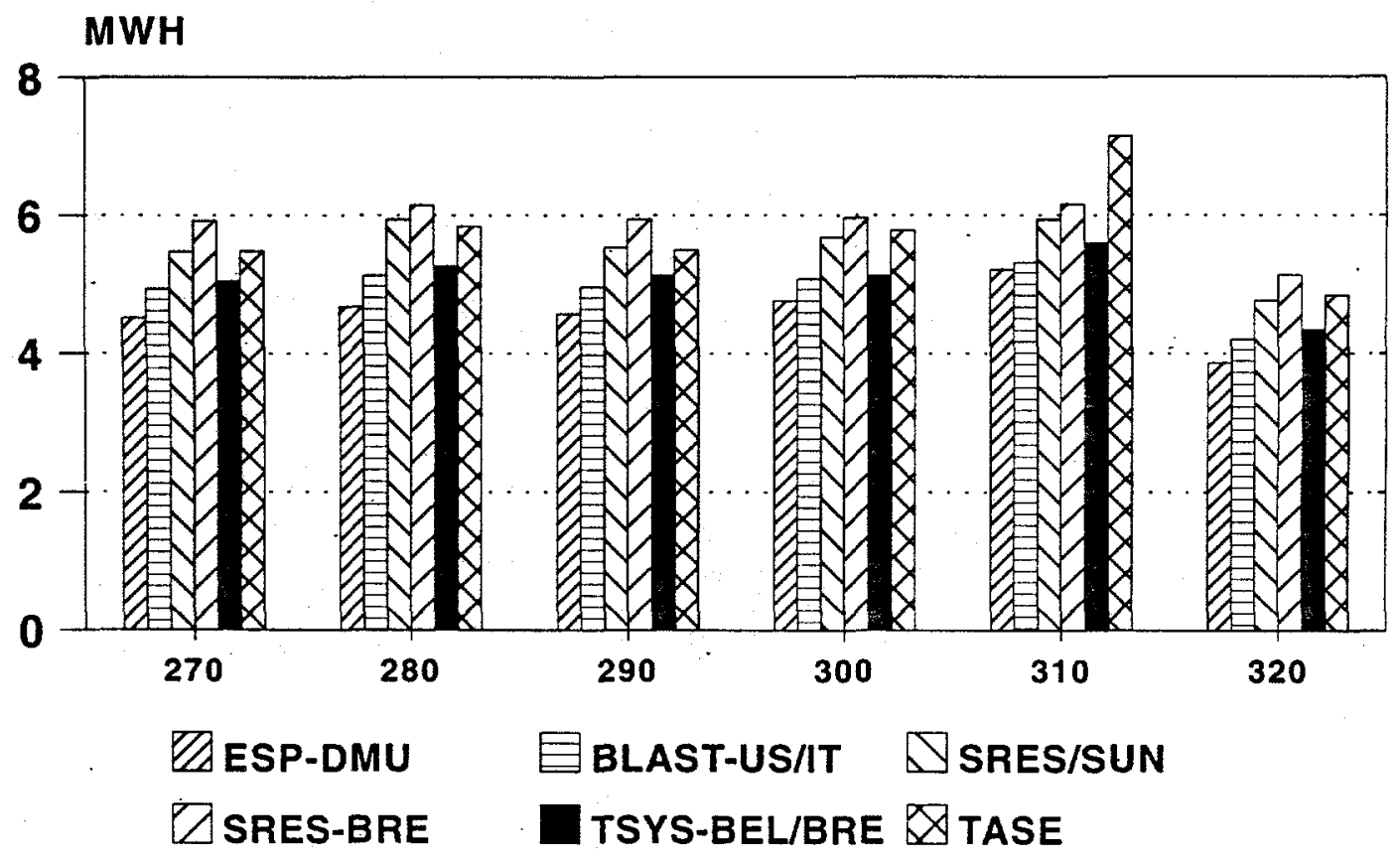

AHLXA2-7.CH3; JUL 23, 1993

\section{BESTEST DIAGNOSTICS LOW MASS ANNUAL COOLING (A) PRIMITIVE CASES (270 TO 320)}

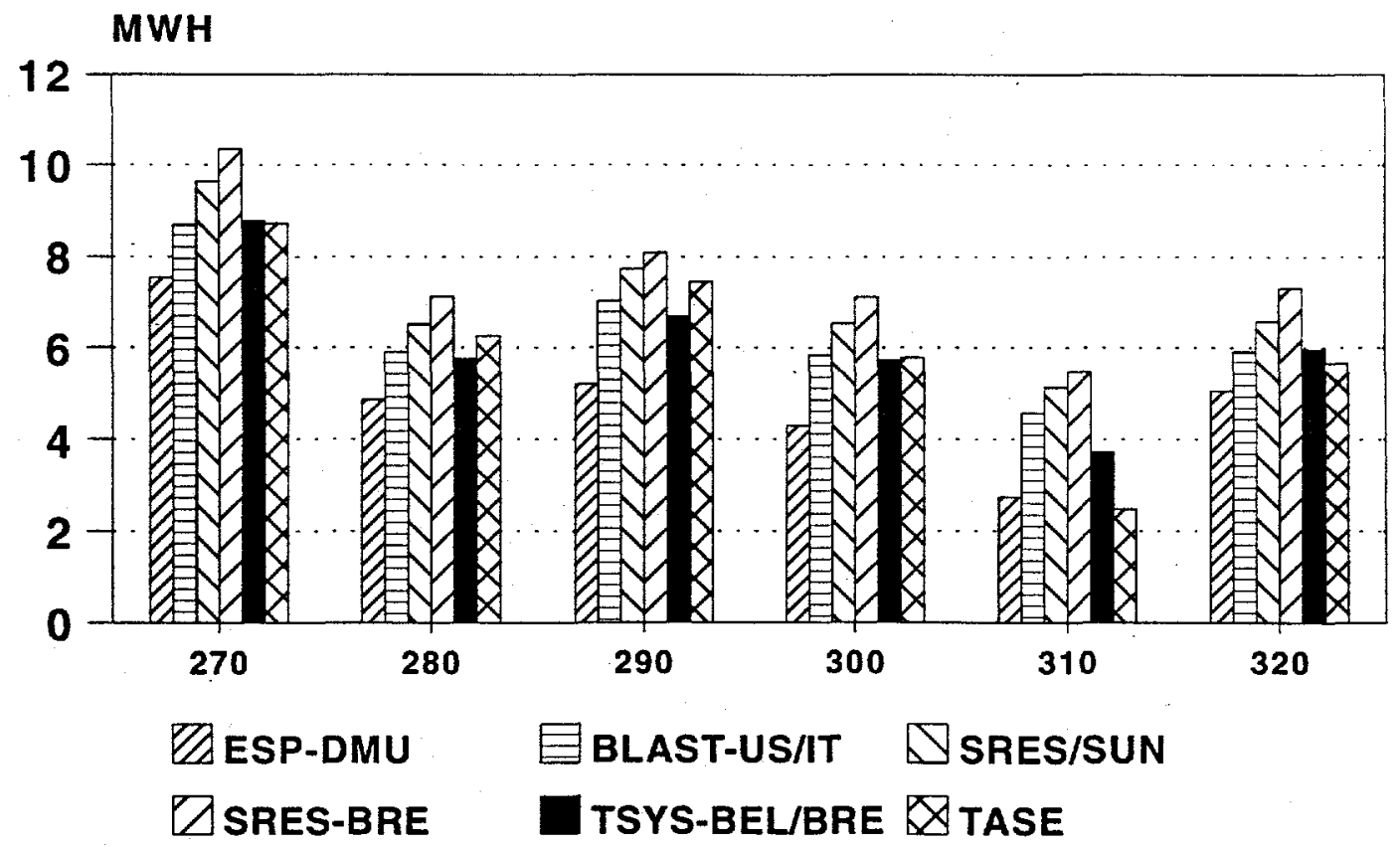




\section{BESTEST DIAGNOSTICS LOW MASS PEAK HEATING (A) PRIMITIVE CASES (270 TO 320)}

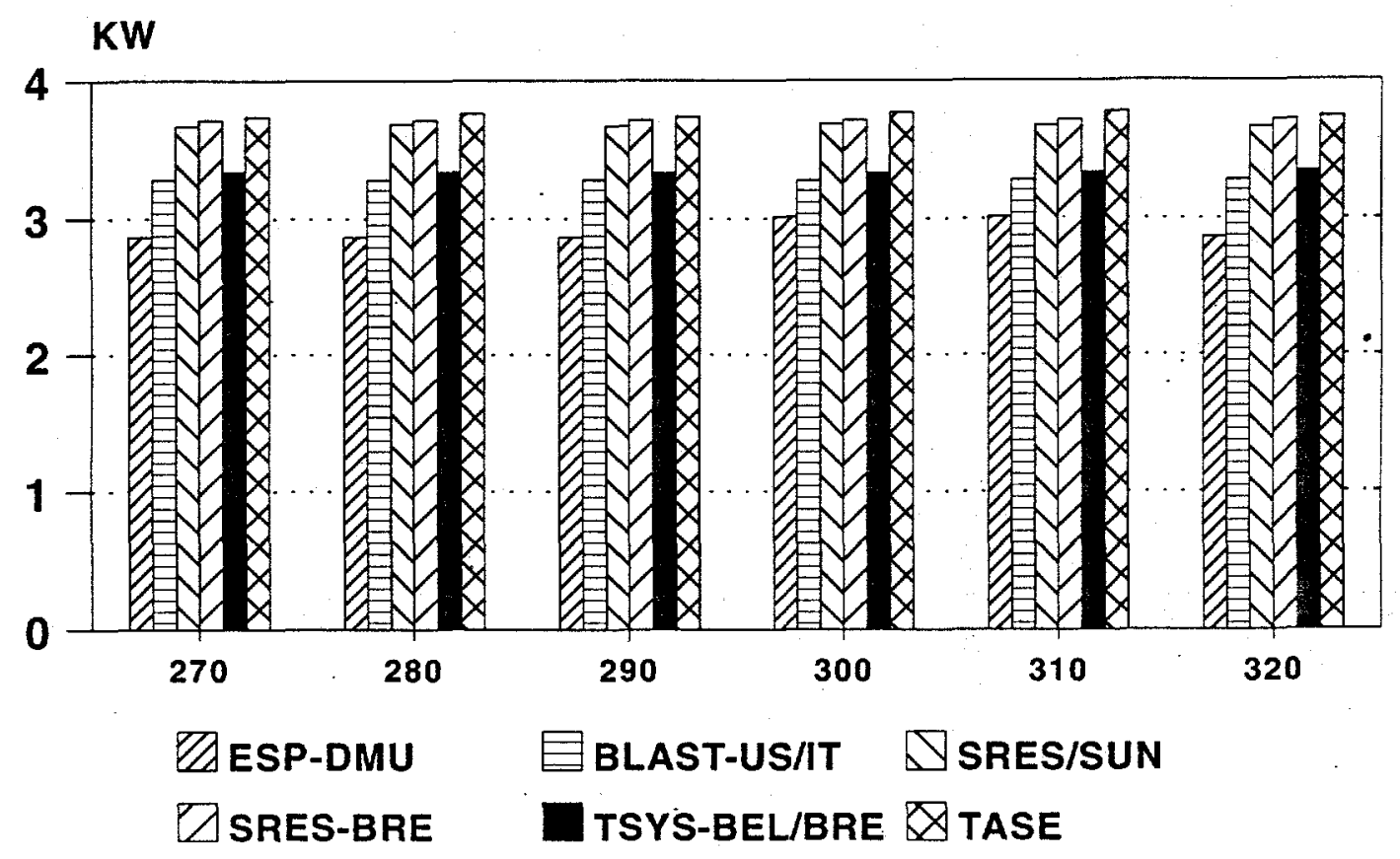

PHLXA2-7.CH3; JUL 23, 1993

\section{BESTEST DIAGNOSTICS LOW MASS PEAK COOLING (A) PRIMITIVE CASES (270 TO 320)}

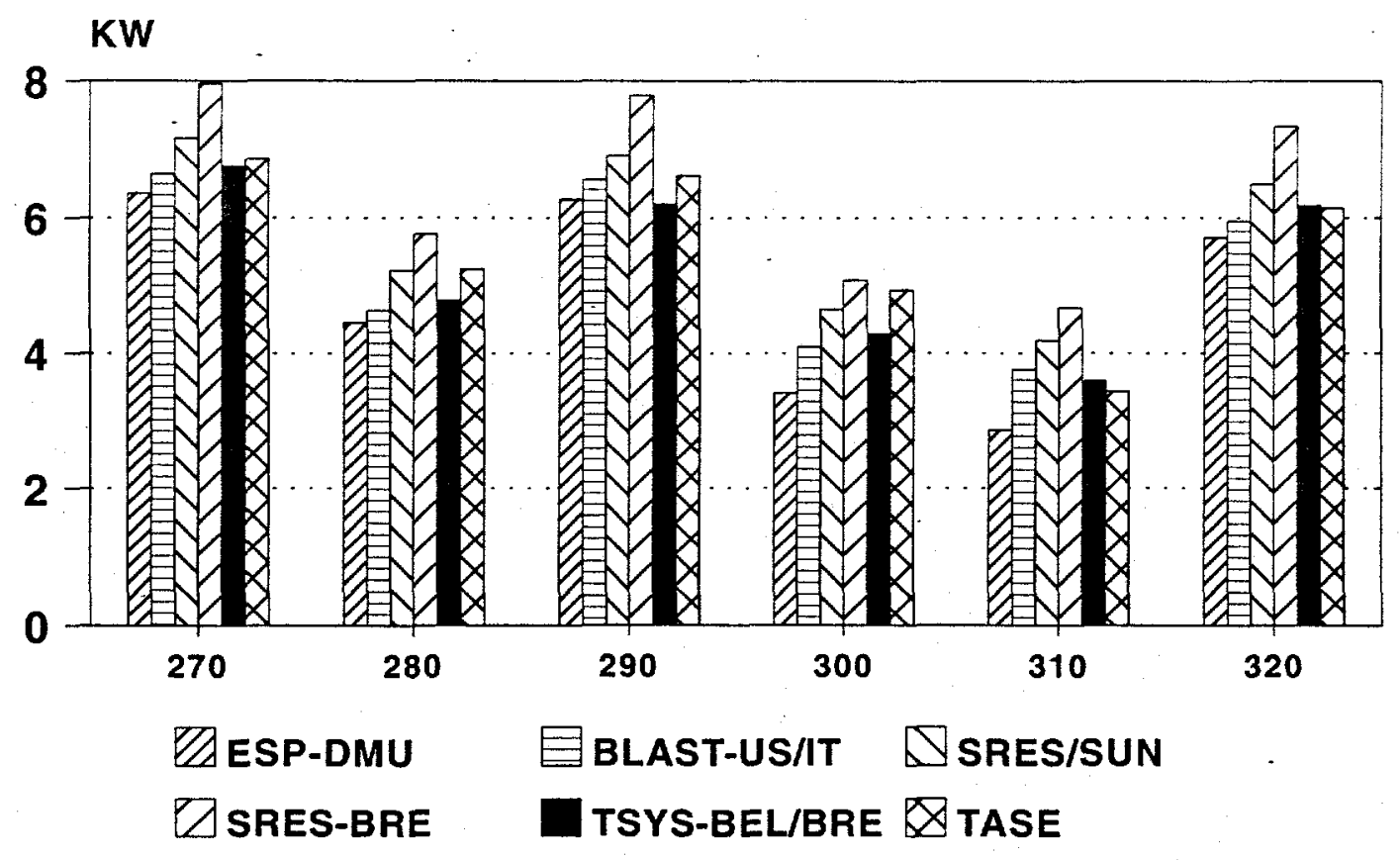




\section{BESTEST DIAGNOSTICS SERIES A1 TO A4 (DELTA) ANNUAL HEATING AND COOLING}

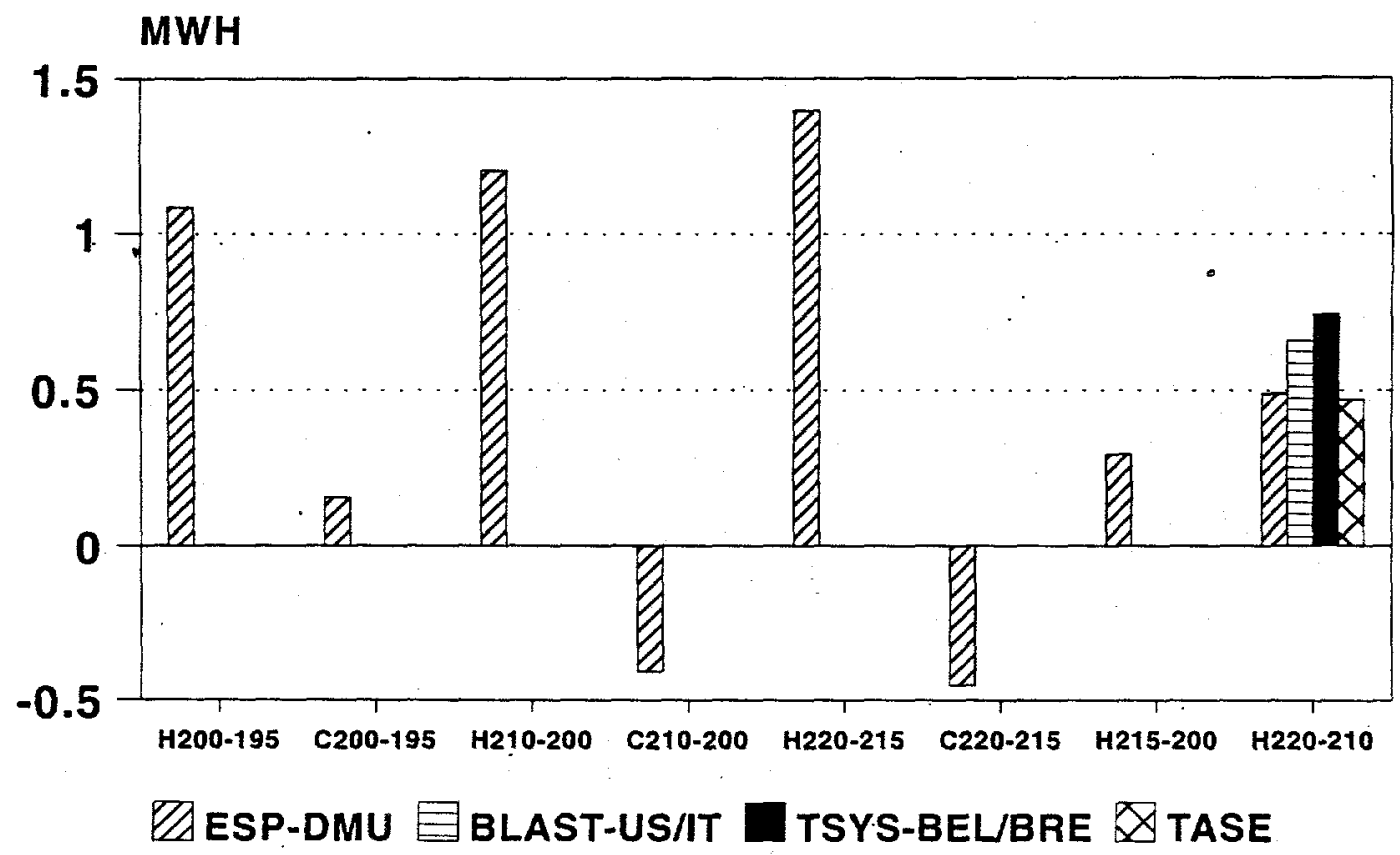

DAA1-7.CH3; OCT 15, 1993

\section{BESTEST DIAGNOSTICS SERIES A1 TO A4 (DELTA) PEAK HEATING AND COOLING}

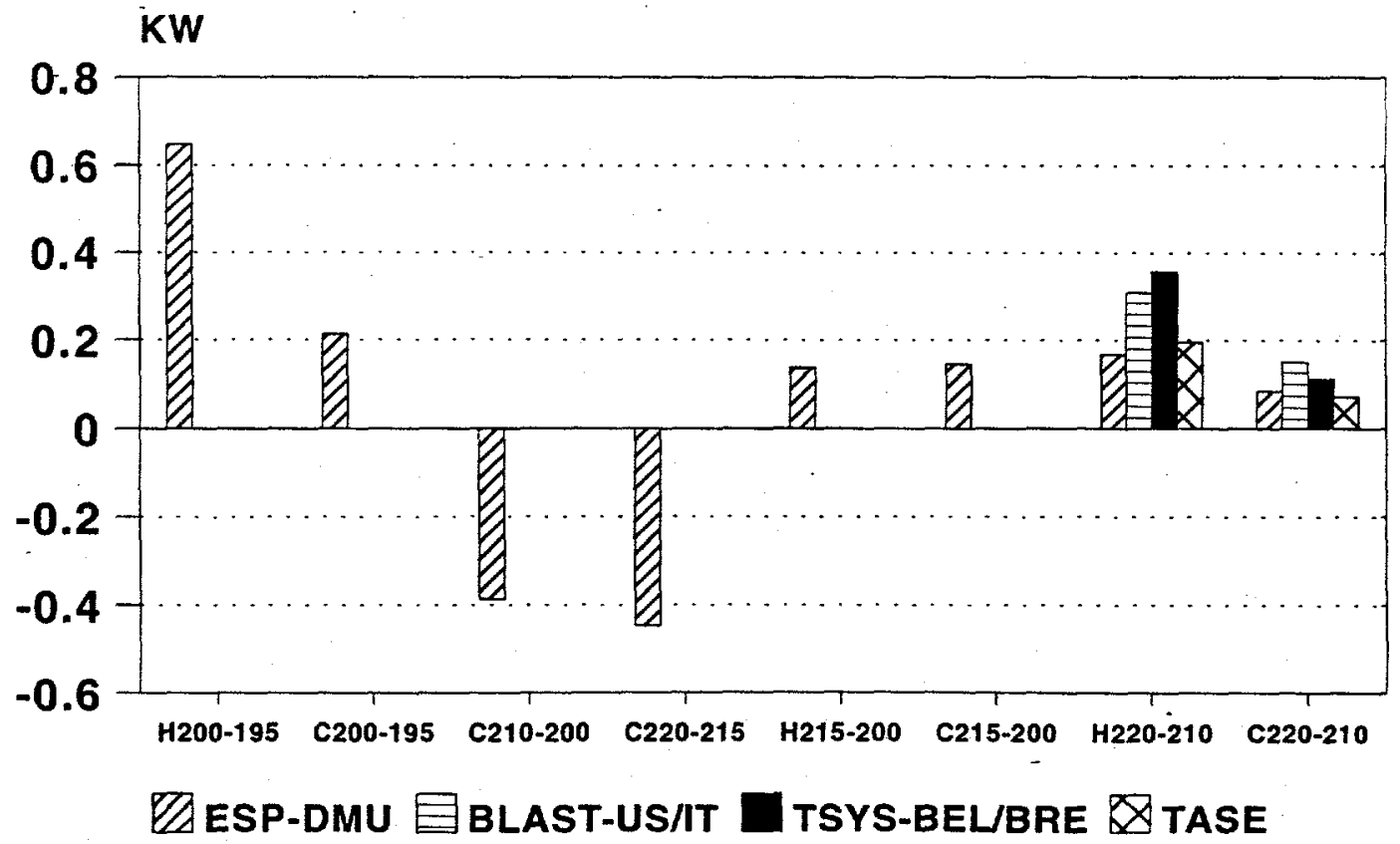




\section{BESTEST DIAGNOSTICS SERIES A6 TO A9 (DELTA) ANNUAL HEATING AND COOLING}

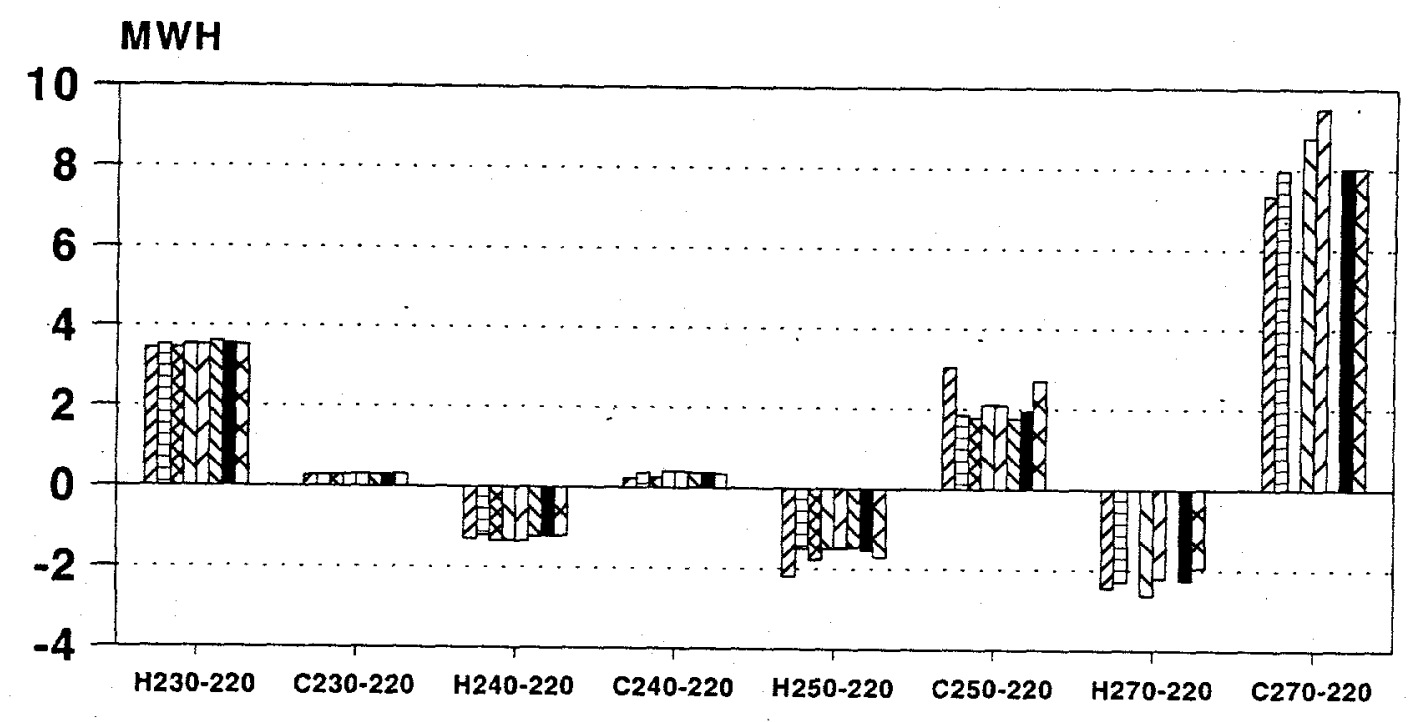

ZESP-DMU 目BLAST-USIIT DOE2 $\triangle$ SRESISUN

$\triangle$ SRES-BRE $\$$ S3PAS $\quad \square$ TSYS-BEL/BRE

\section{BESTEST DIAGNOSTICS SERIES A6 TO A9 (DELTA) PEAK HEATING AND COOLING}

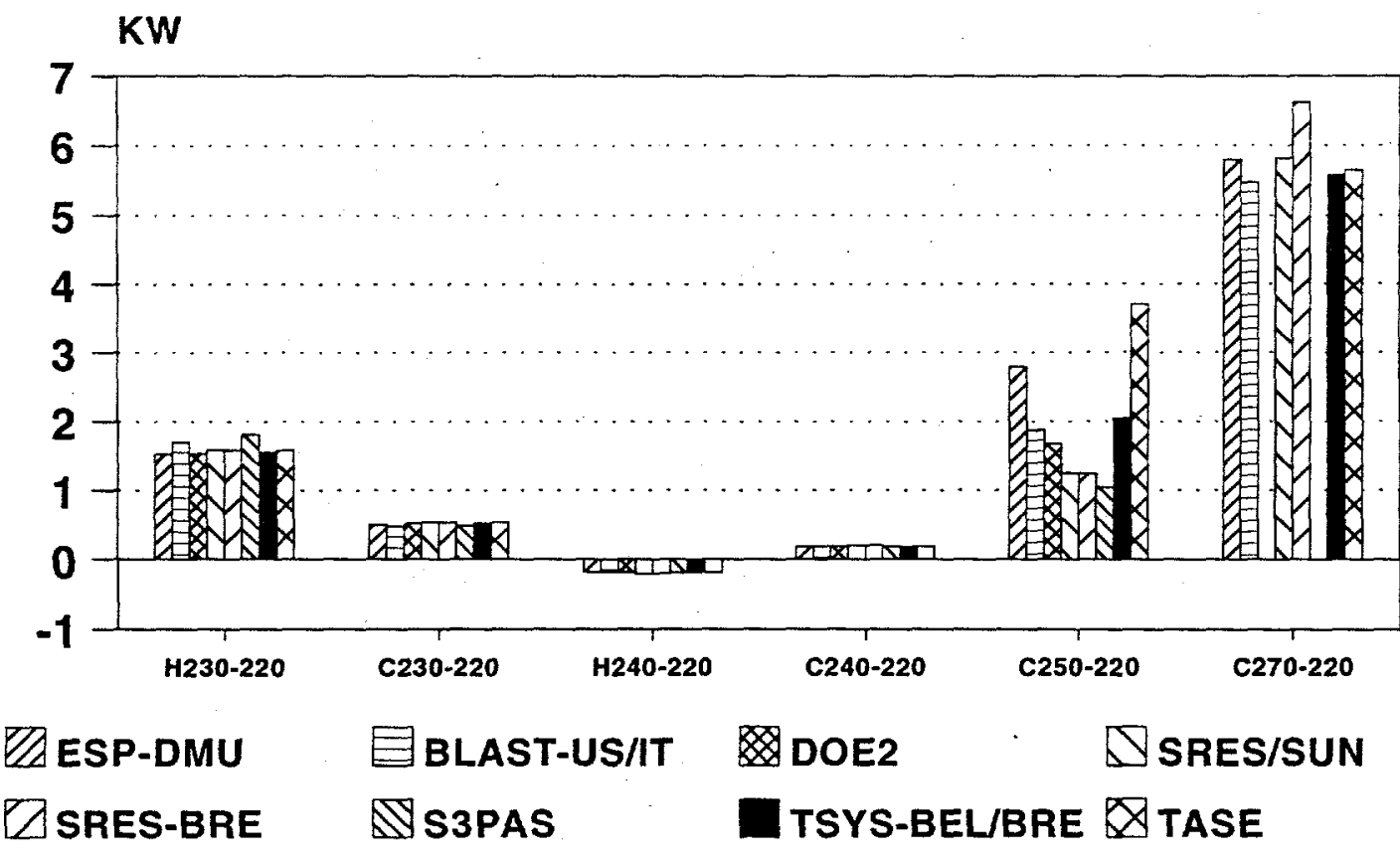




\section{BESTEST DIAGNOSTICS SERIES A10 TO A14 (DELTA) ANNUAL HEATING AND COOLING}

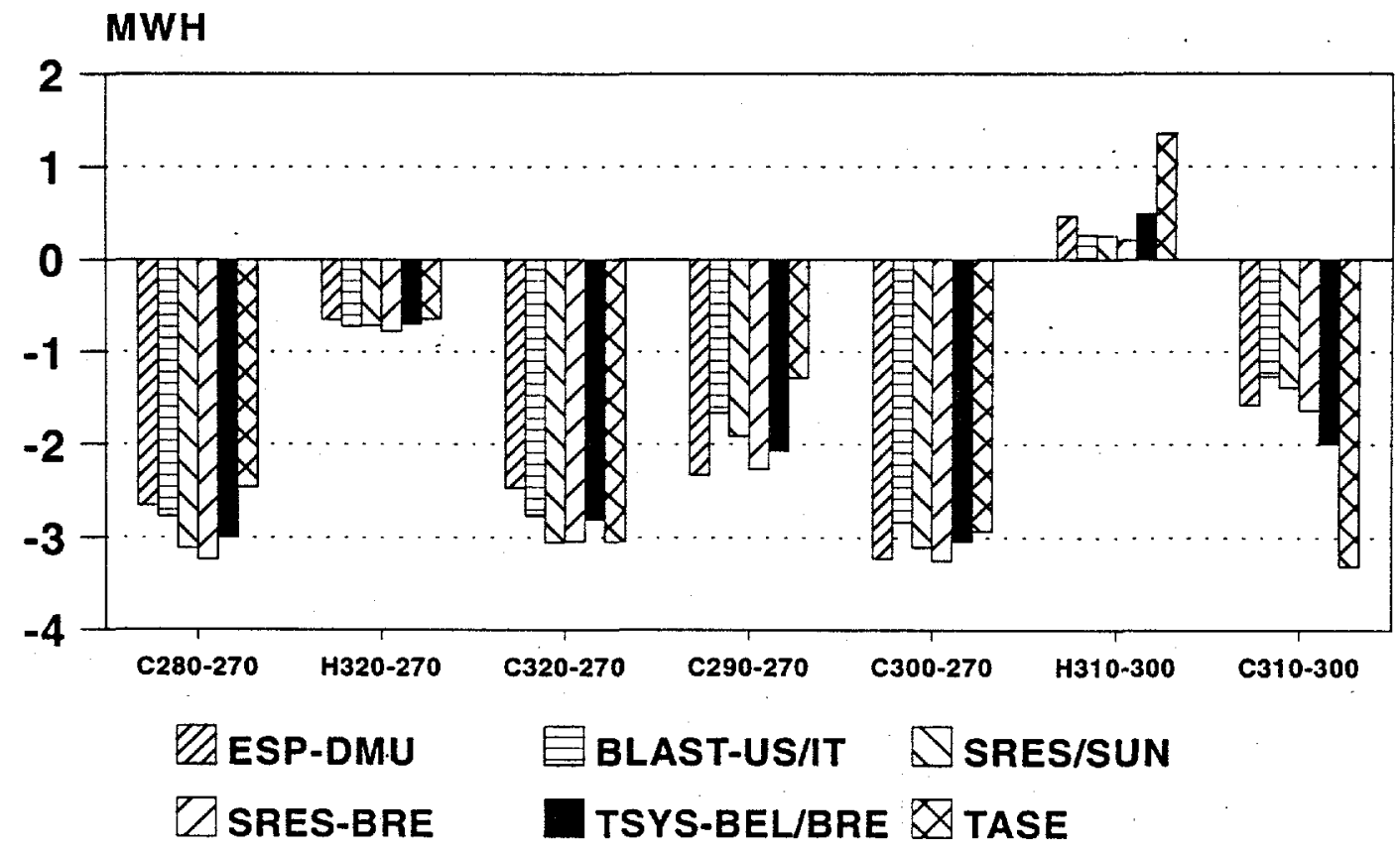

DAA3-7.CH3; JUL 26, 1993

\section{BESTEST DIAGNOSTICS SERIES A10 TO A14 (DELTA) PEAK COOLING}

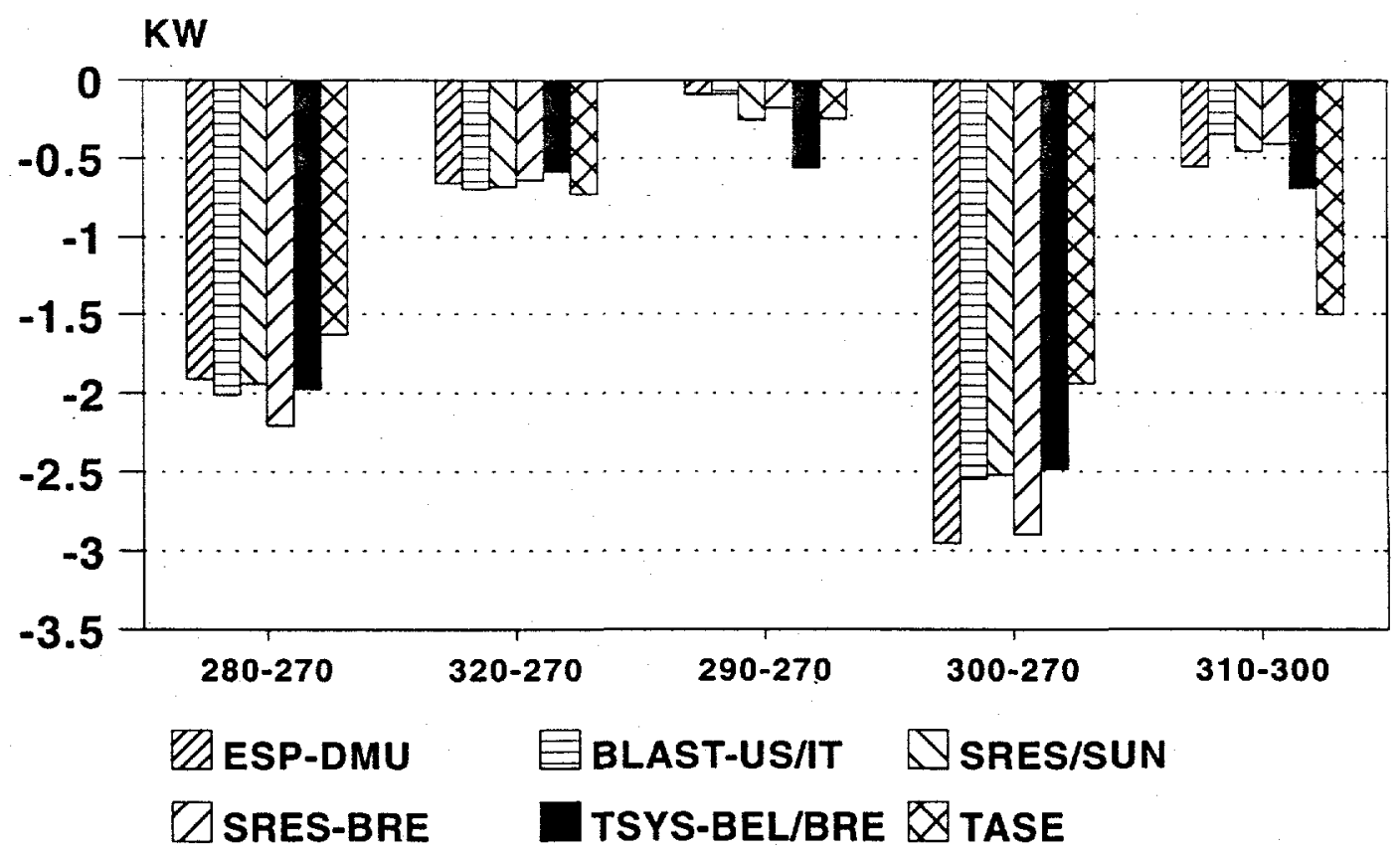


This page intentionally left blank 


\section{BESTEST DIAGNOSTICS ANNUAL HEATING (B) REALISTIC CASES}

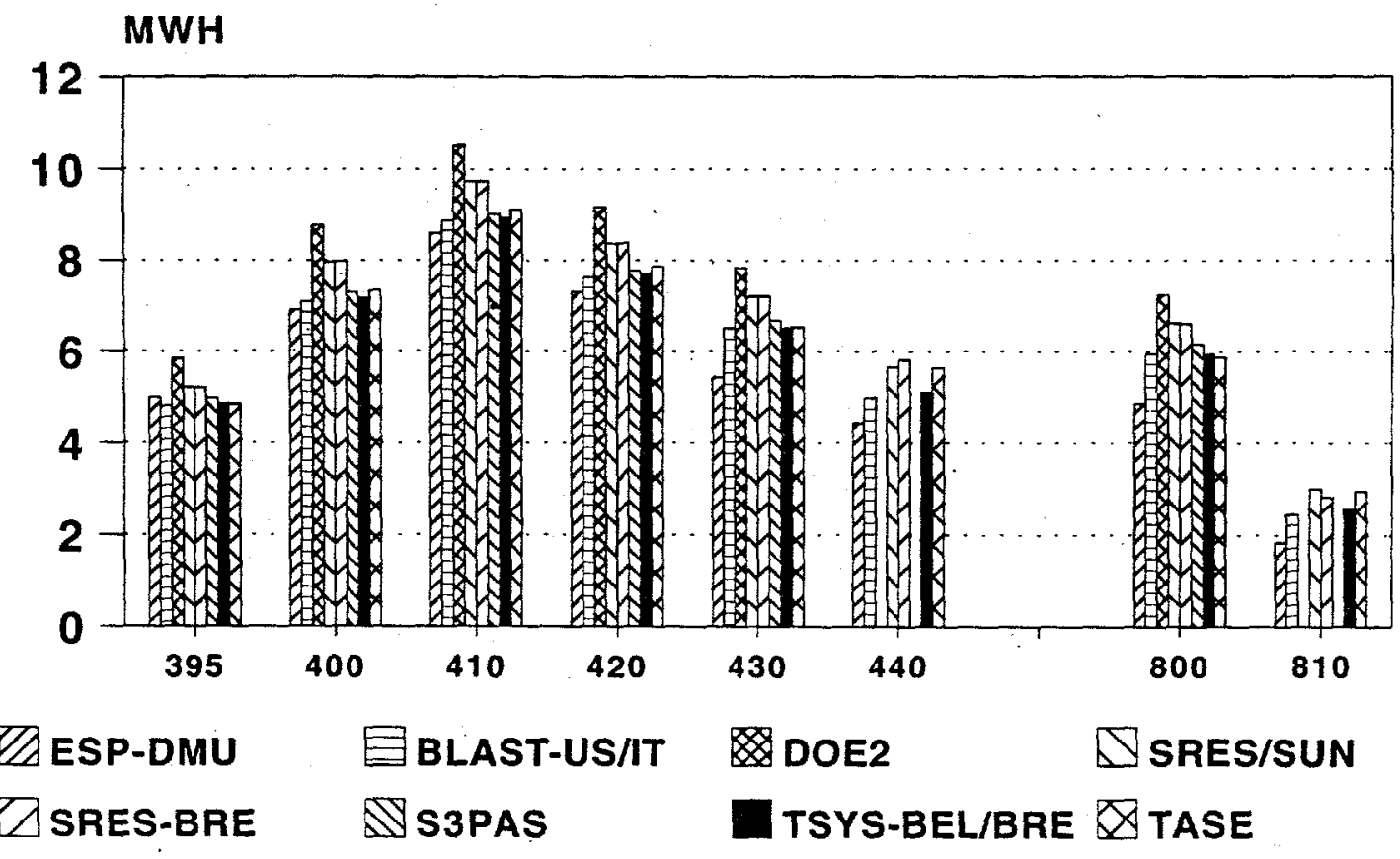

AHLXB-7.CH3: JUL 23, 1993

\section{BESTEST DIAGNOSTICS ANNUAL COOLING (B) REALISTIC CASES}

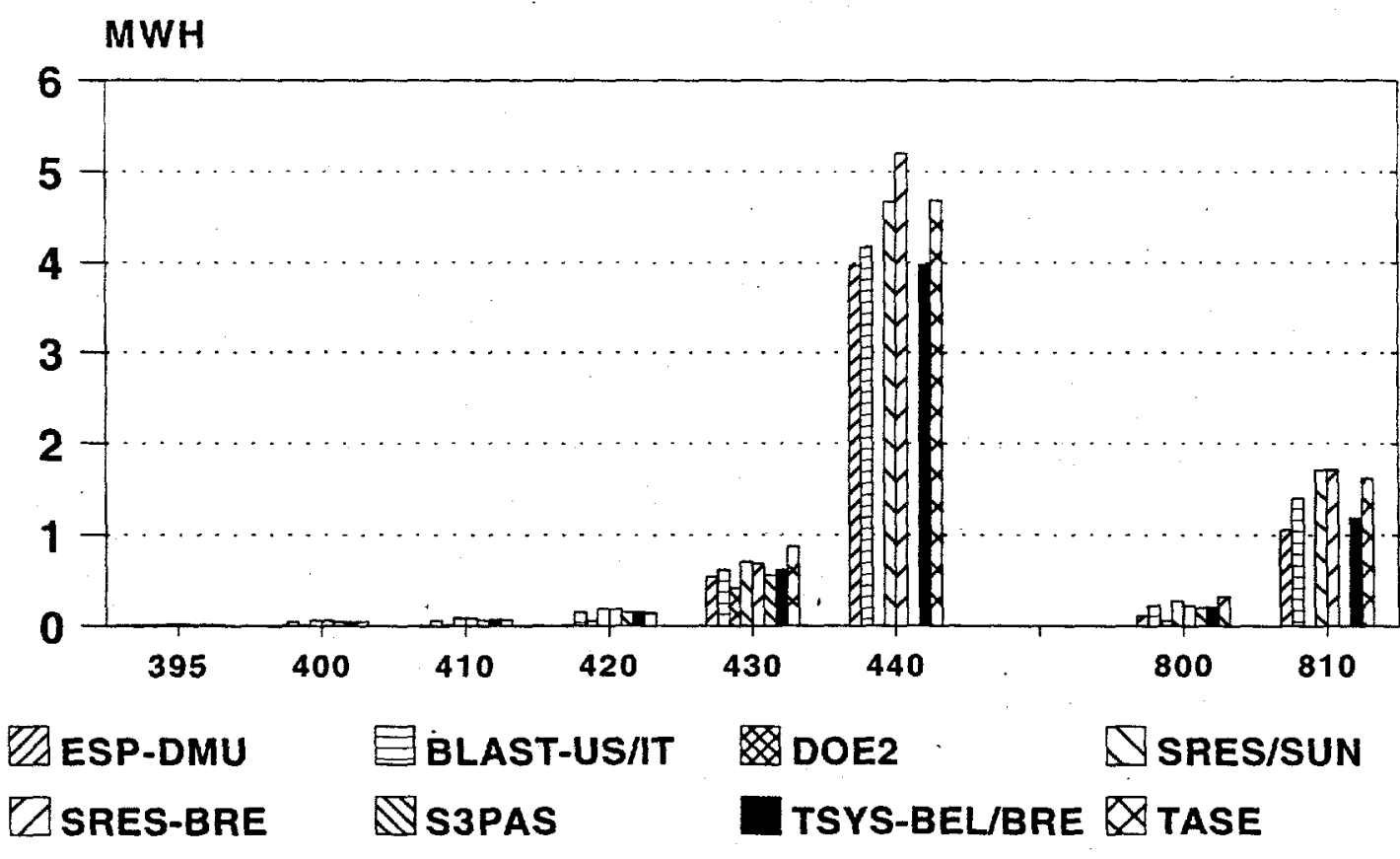




\section{BESTEST DIAGNOSTICS PEAK HEATING (B) REALISTIC CASES}

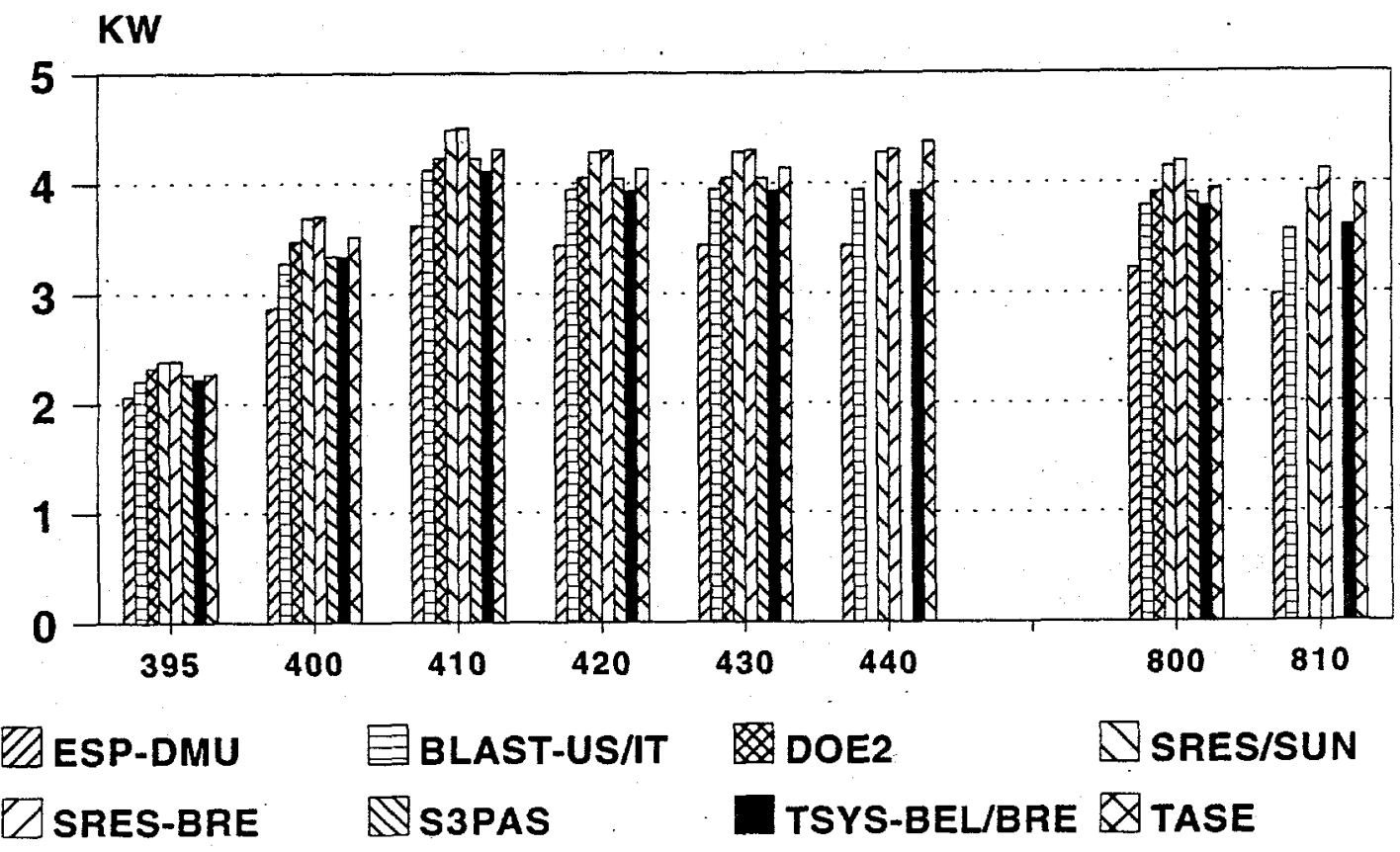

PHLXB-7.CH3; JUL 23, 1993

\section{BESTEST DIAGNOSTICS PEAK COOLING (B) REALISTIC CASES}

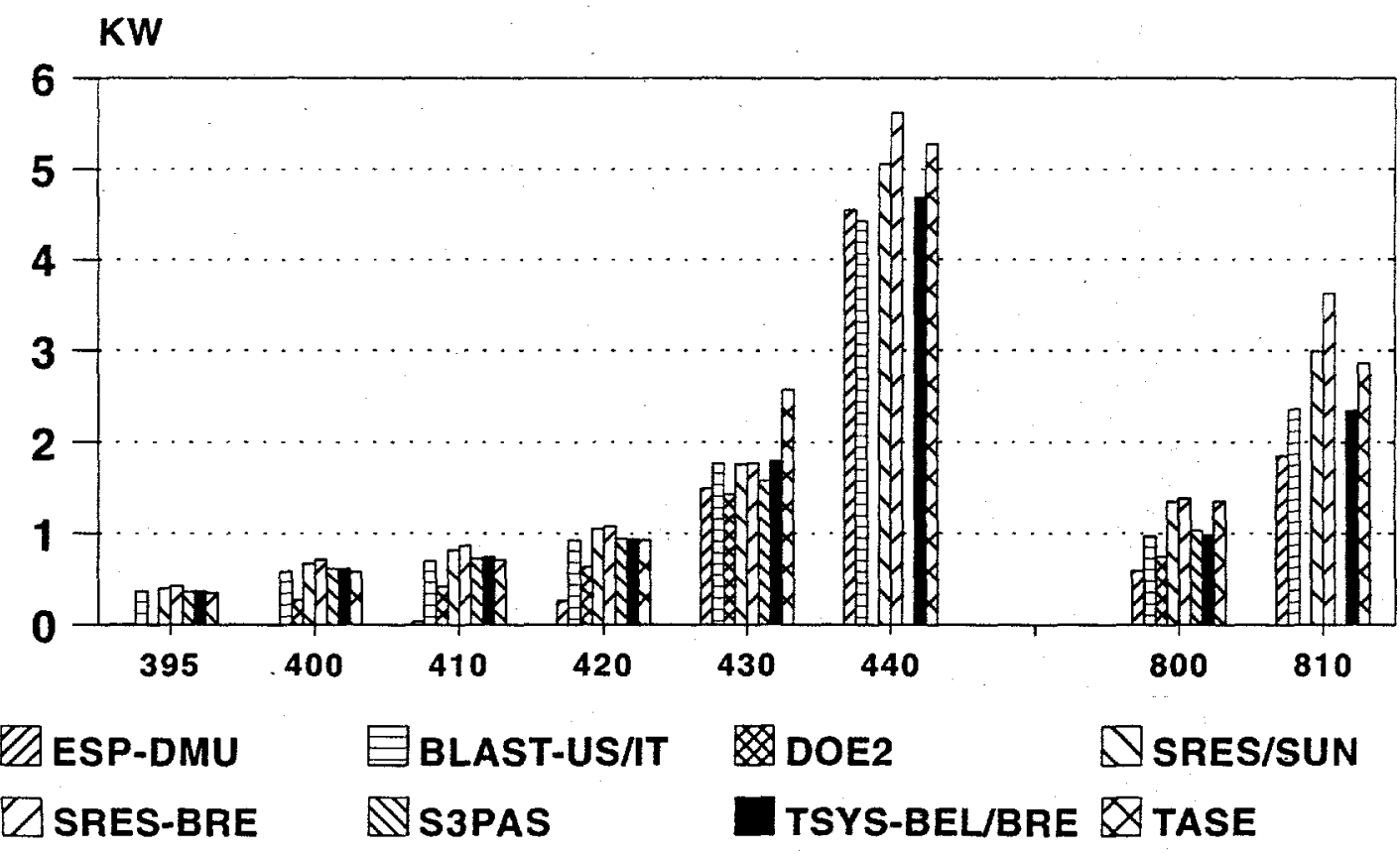




\section{BESTEST DIAGNOSTICS SERIES B (DELTA) \\ ANNUAL HEATING AND COOLING}

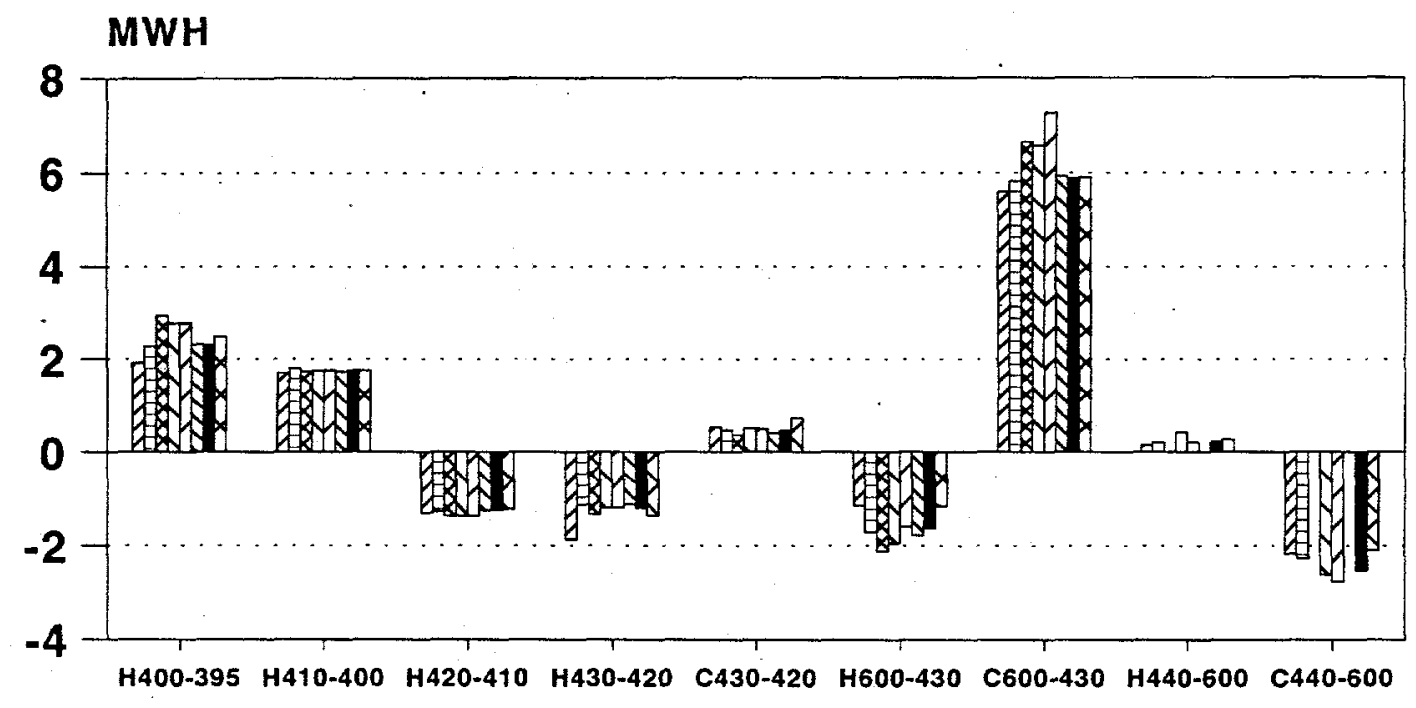
民ESP-DMU
$\bigoplus$ BLAST-US/IT
DOE2
$\triangle$ SRES/SUN
$\triangle$ SRES-BRE
S3PAS
TSYS-BEL/BRE $\$ TASE

DAB-7.CH3; JUL 25, 1993

\section{BESTEST DIAGNOSTICS SERIES B (DELTA) PEAK HEATING AND COOLING}




This page intentionally left blank 


\section{BESTEST CASE 900FF ANNUAL HOURLY TEMPERATURE FREQUENCY}

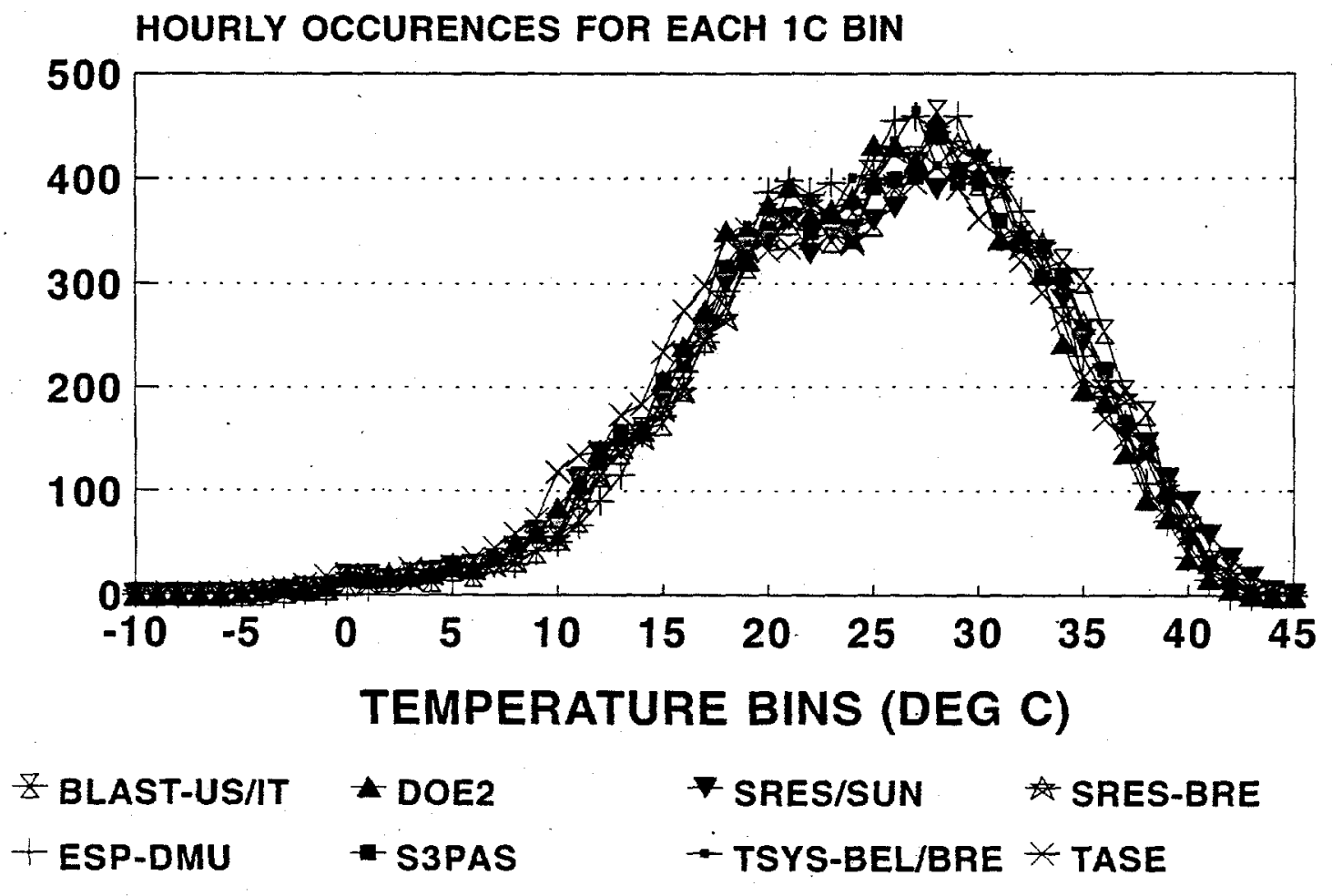

FF900-7.CH3; JUL 22, 1993 


\section{BESTEST CASE 900FF \\ CLOUDY \& CLEAR DAY HOURLY INCIDENT SOLAR SOUTH FACING SURFACE}

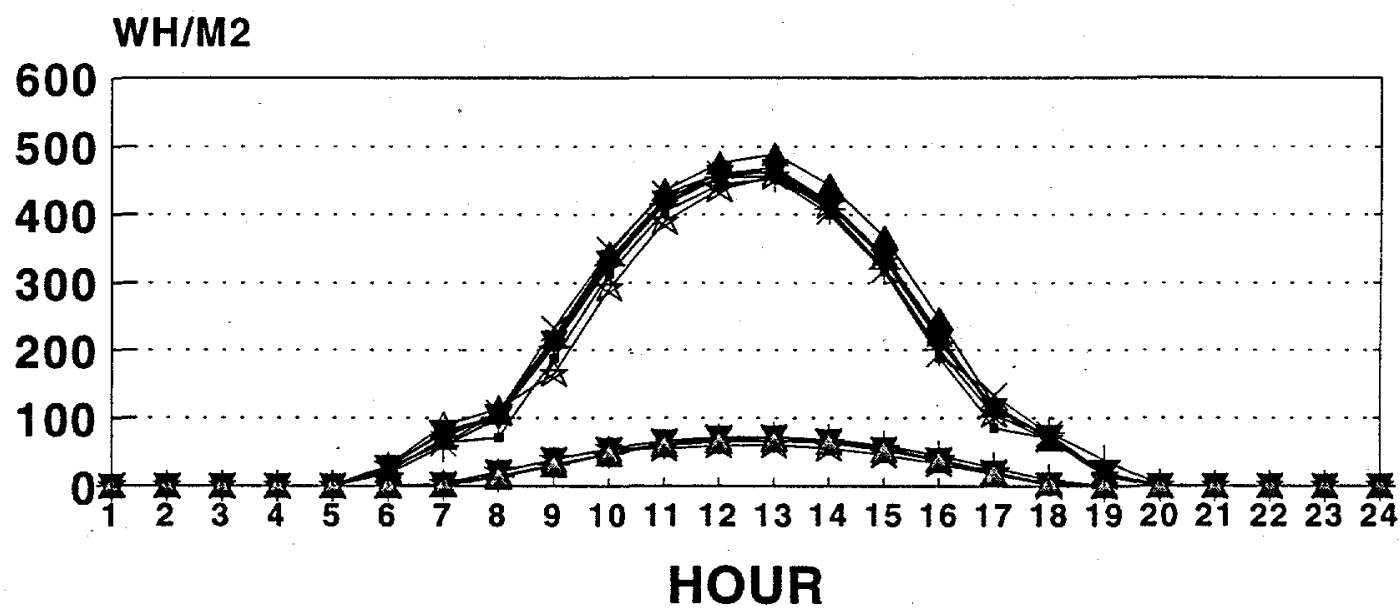

^ DOE2, CLDY

- S3PAS, CLDY

$\checkmark$ SRESSUN, CLR

- TRNSYS, CLR

HISST.CH3; JUL 22, 1993

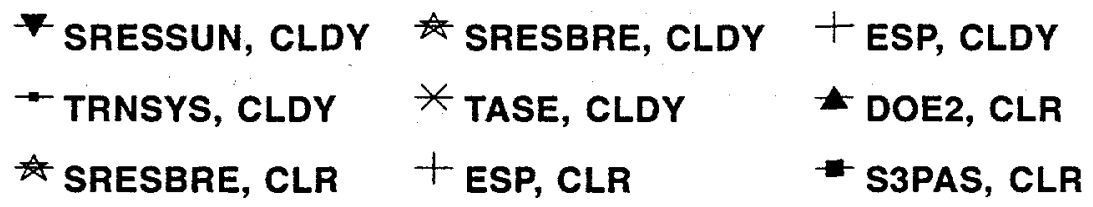

* tase, clr

\section{BESTEST CASE 900FF \\ CLOUDY \& CLEAR DAY HOURLY INCIDENT SOLAR WEST FACING SURFACE}



$$
\begin{aligned}
& \text { * DOE2, CLDY } \quad \text { SRESSUN, CLDY * SRESBRE, CLDY + ESP, CLDY } \\
& \text { - S3PAS, CLDY - TRNSYS, CLDY * TASE, CLDY } \quad \text { DOE2, CLR } \\
& \text { * SRESSUN, CLR * SRESBRE, CLR + ESP, CLR - S3PAS, CLR } \\
& \rightarrow \text { TRNSYS, CLR } \quad * \text { TASE, ClR }
\end{aligned}
$$


BESTEST HOURLY FREE FLOAT TEMPERATURES CLEAR COLD DAY, CASES $600 \& 900$

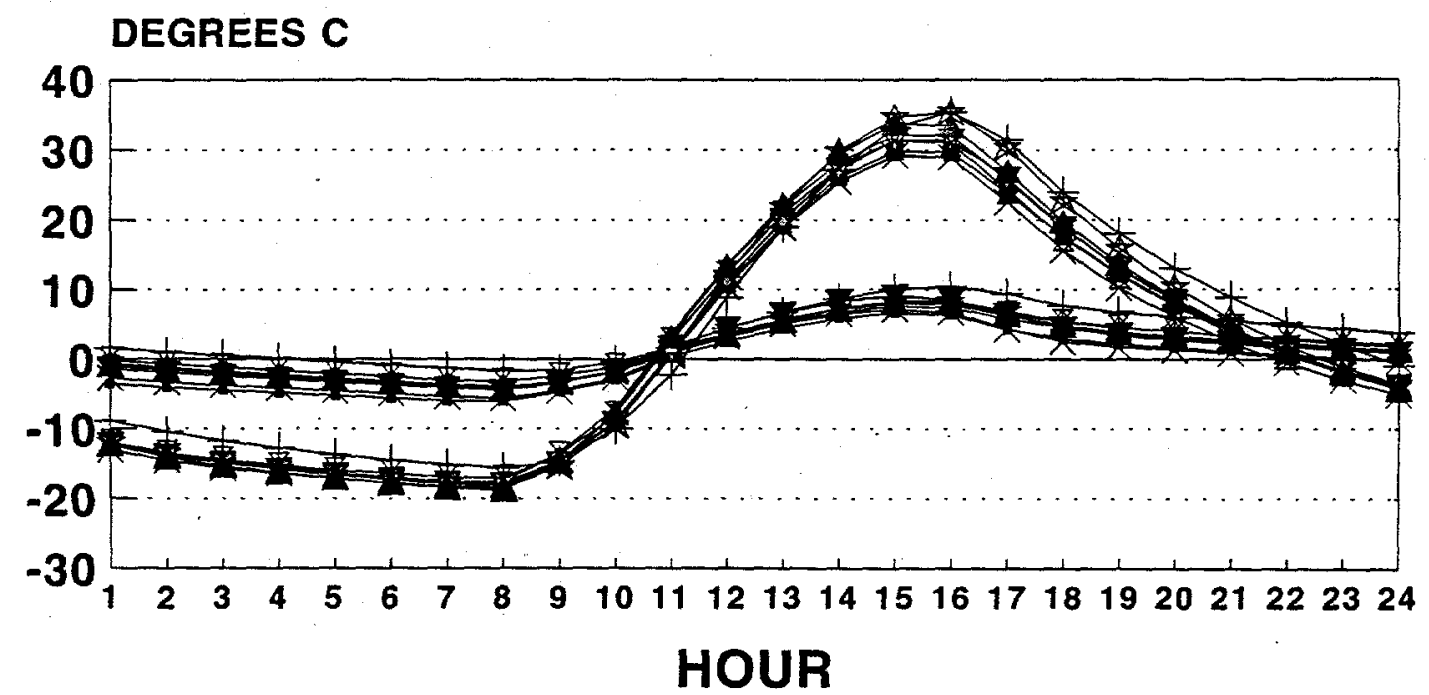
8 BLAST, 600 DOE2, 600
+ ESP, 600
- S3PAS, 600
* SRESSUN, 600 SRESBRE, 600
\& BLAST, 900
$\triangle$ DOE2, 900
- TRNSYS, 600 * TASE, 600
+ ESP, 900
- S3PAS, 900
- SRESSUN, 900 SRESBRE, 900
$\rightarrow$ TRNSYS, $900 *$ TASE, 900

G900WIN7.CH3; SUL 22, 1993

\section{BESTEST HOURLY FREE FLOAT TEMPERATURES CLEAR HOT DAY, CASES 650 \& 950}

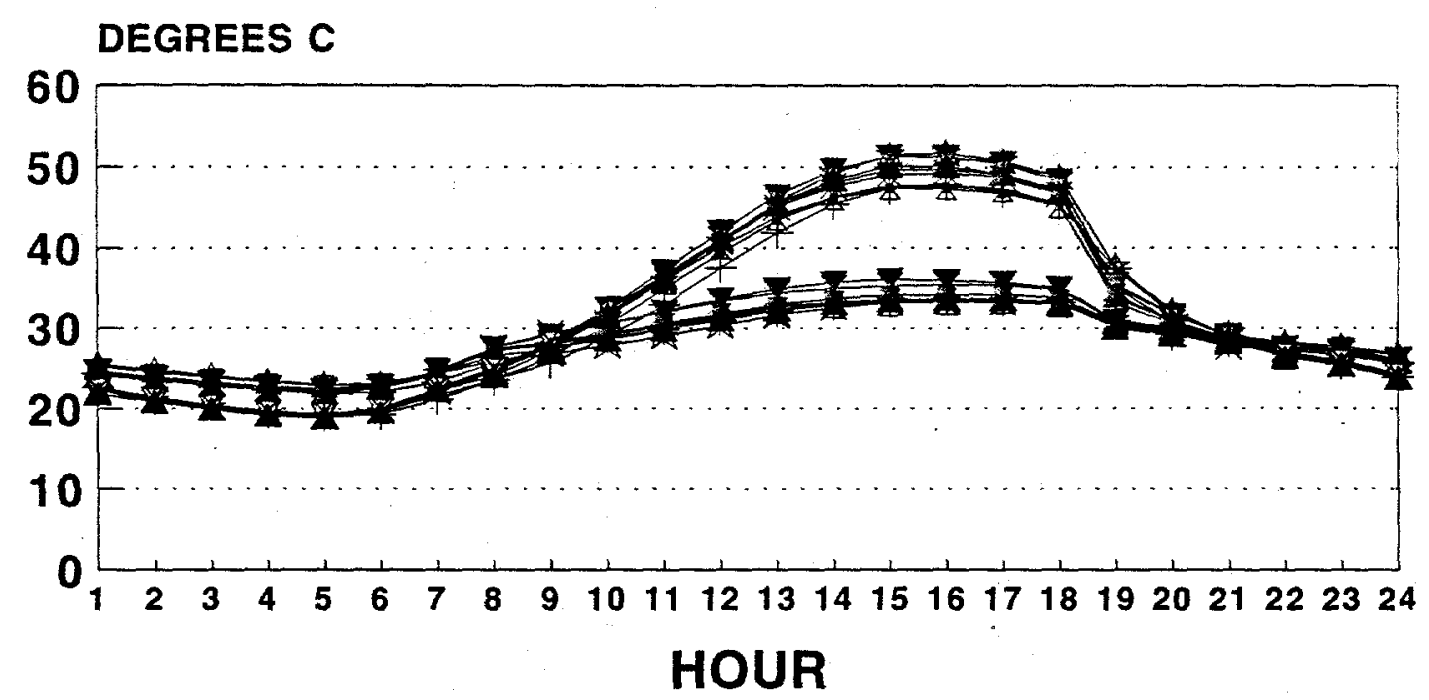
\& BLAST, 650 DOE2, 650
+ ESP, 650
- S3PAS, 650
Z BLAST, 950
$\star$ DOE2, 950
+ ESP, 950
- S3PAS, 950

7 SRESSUN, 650 SRESBRE, 650

- TRNSYS, 650 * TASE, 650

$\checkmark$ SRESSUN, 950 SRESBRE, 950

- TRNSYS, 950 * TASE, 950 


\section{BESTEST HOURLY LOADS \\ CLEAR COLD DAY, CASE 600 HEATING (+), COOLING $(-)$}

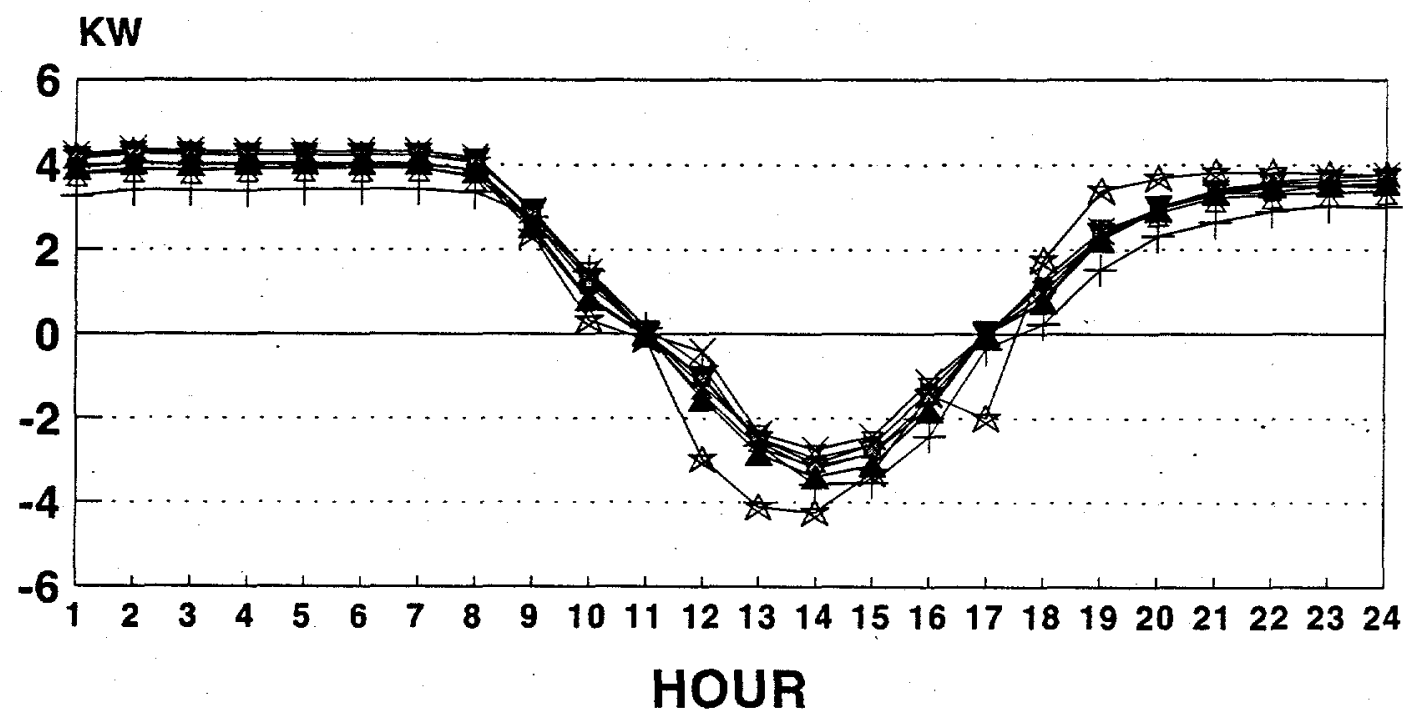

$\begin{array}{lll}\text { \& BLAST-US/IT } & \text {-DOE2 } & \text { - SRES/SUN } \\ + \text { ESP-DMU } & \text { - S3PAS } & \text { - TSYS-BEL/BRE }\end{array}$

HHCL6-7.CH3; JUL 23, 1993

NOTE: HOUR 18 OF S3PAS 600 DATA WAS OUT OF RANGE, AN INTERPOLATED VALUE WAS USED.

\section{BESTEST HOURLY LOADS CLEAR COLD DAY, CASE 900 HEATING (+), COOLING (-)}

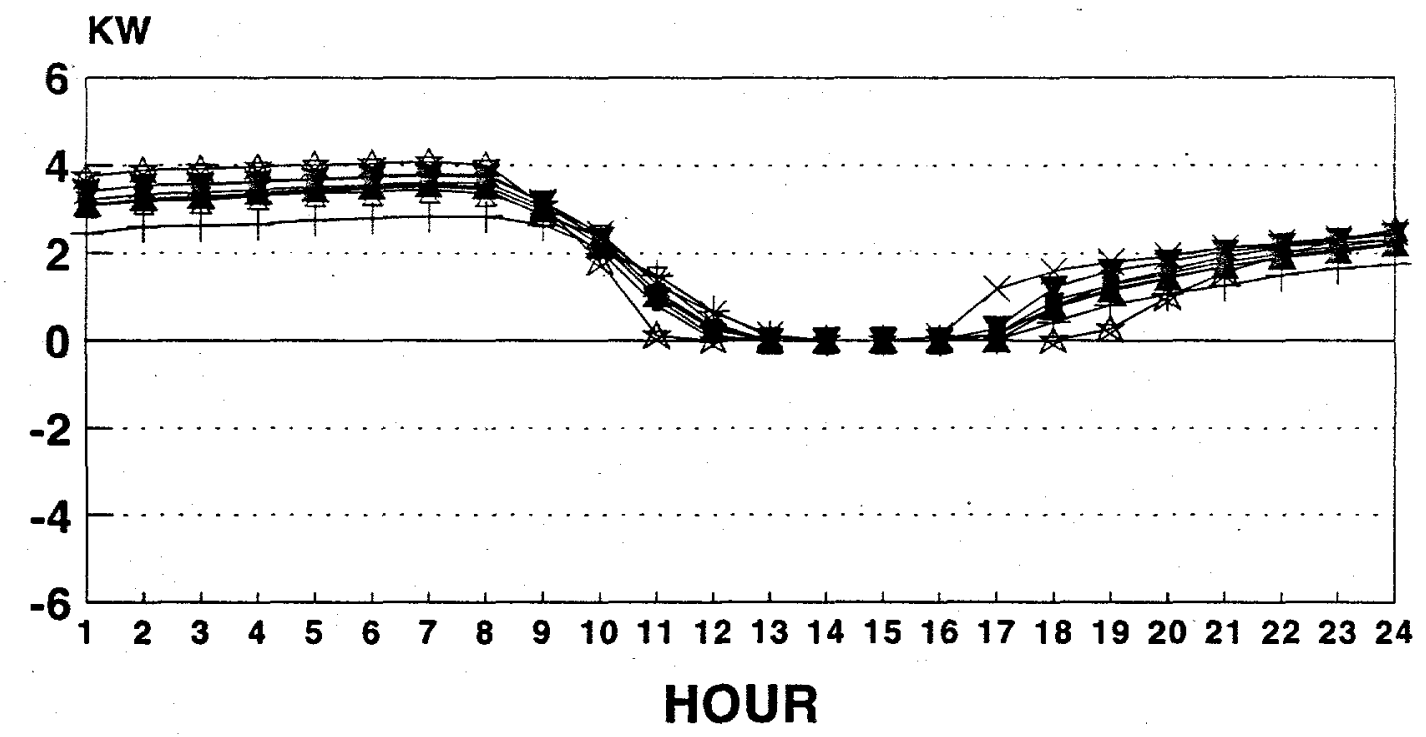
\& BLAST-US/IT \DOE2
† SRESISUN \# SRES-BRE
+ ESP-DMU
- S3PAS
- TSYS-BEL/BRE * TASE 
Public reporting burden for this collection of information is estimated to average 1 hour per response, including the time for reviewing instructions, searching existing data sources, gathering and maintaining the data needed, and completing and reviewing the collection of information. Send comments regarding this burden estimate or any other aspect of this collection of information, including suggestions for reducing this burden, to Washington Headquarters Services, Directorate for information Operations and Reports, 1215 Jefferson Davis Highway, Suite 1204, Arlington, VA 22202-4302, and to the Office of Management and Budget; Paperwork Reduction Project (0704-0188), Washington, DC 20503.
1. AGENCY USE ONLY (Leave blank)
2. REPORT DATE
February 1995
3. REPORT TYPE AND DATES COVERED
IEA Final Report

4. TITLE AND SUBTITLE

International Energy Agency Building Energy Simulation Test (BESTEST) and Diagnostic Method
5. FUNDING NUMBERS

(TA) BE51.4001

6. AUTHOR(S)

Authors are R. Judkoff and J. Neymark (NREL).

Contributors include A. Mazza and V. Bocchio (Politecnico di Torino, Italy), P. Dalicieux

(Electricite de France), P. Wallenten (University of Lund, Sweden), H. Eppel and K. Lomas (De Montfort University, U.K.), S. Hammond, F. Parand (Building Research Establishment, U.K.), S. Alvarez and E. Rodriguez (Universidad de Sevilla, Spain), S. Kataja, T. Kalema, and T. Haapala (Tampere University, Finland), P. Verstraete and R. Van De Perre (Vrije Universiteit, Belgium)

7. PERFORMING ORGANIZATION NAME(S) AND ADDRESS(ES)

8. PERFORMING ORGANIZATION REPORT NUMBER

National Renewable Energy Laboratory

1617 Cole Boulevard

DE94000280

Golden, Colorado 80401-3393

9. SPONSORING/MONITORING AGENCY NAME(S) AND ADDRESS(ES)

National Renewable Energy Laboratory

1617 Cole Boulevard

International Energy Agency

2 , rue Andre Pascal

F-75775 Paris Cedex 16, France

Goiden, Colorado 80401-3393

10. SPONSOFING/MONITORING AGENCY REPORT NUMBER

NRELTP-472-6231

11. SUPPLEMENTARY NOTES

This proiect is a cooperative project between EA Sotat Heating and Cooling Task 12 and IEA Energy Conservation in Buildings and Community Systems Annex 21

12a. DISTRIBUTION/AVAILABILITY STATEMENT National Technical Information Service

U.S. Department of Commerce

5285 Port Royal Road

Springfield, Virginia 22161

13. ABSTRACT

The BESTEST project developed a procedire to systematically test whole-building energy simulation programs and to diagnose the sources of predictive disagreemert. Field tilals of the method were conducted with "reterence" programs representing the best stateof-the-art detailed simulation capability avaluble in the United States and Europe. The method consists of a series of carefully specified test-case buildings that grngress systematically from extremely simpie to relatively reatstic. Output values for the cases-annual loads, maximum and minimum, temperatures, and peak loads, and sorme houty data-are compared and used with diagnostic logic to determine the joarithms fesponsible for predictive differences. The more tealistic casss, although geometrically simple, test the ability of the progfams to rodel such combined effects as thermal mass, direct-solar-gair windows, window-shading devices, internally generated heat intiltratich, sunspaces, earth coupling, and dead-band and setback thermostat control. The more

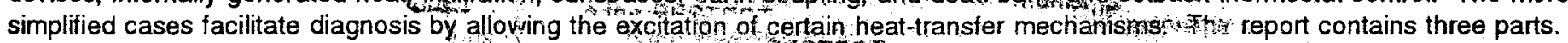
Part $I$ is a user's manual with instructions of apolying the BESTES procedure. Part II describes the development, field-testing, and production of data for the procedure. Part III presents reference programs' output in tables and graphs. A diskette contains weather data, some utility programs for formatting output data, and all reference data in a common spreadsheet format.

\section{SUBJECT TERMS}

BESTEST, building energy software, whole-building energy simulation programs, diagnostic methodology, user's manual

\begin{tabular}{l|l|l} 
17. SECURITY CLASSIFICATION & $\begin{array}{l}\text { 18. SECURITY CLASSIFICATION } \\
\text { OF THIS PAGE }\end{array}$ & $\begin{array}{l}\text { 19. SECURITY CLASSIFICATION } \\
\text { OF ABSTRACT }\end{array}$
\end{tabular}

\section{NUMBER OF PAGES 296}

16. PRICE CODE

20. LIMITATION OF ABSTRACT

Standard Form 298 (Rev. 2-89)

Prescribed by ANSI Std. Z39-18 